\title{
STATE OF THE CLIMATE IN 2013
}

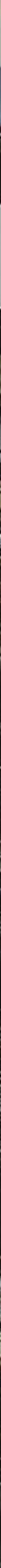




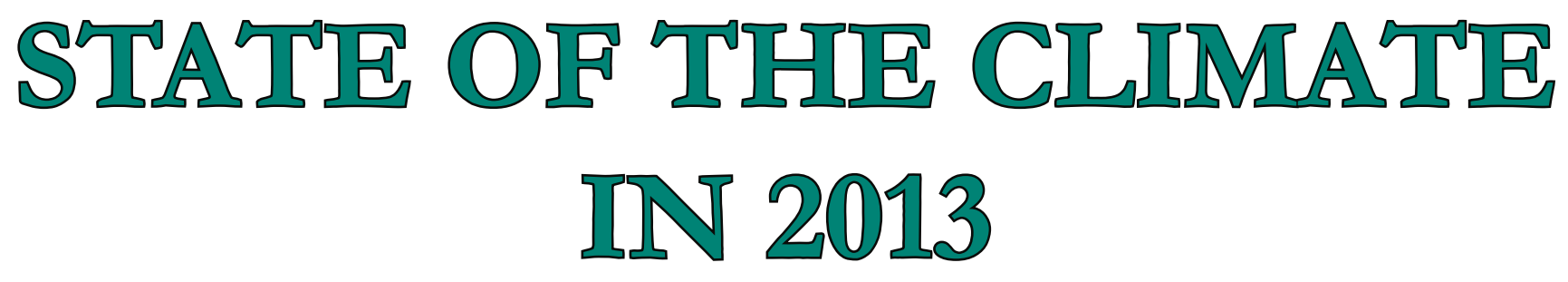

Editors

Jessica Blunden Derek S. Arndt

Howard J. Diamond

A. Johannes Dolman

Ryan L. Fogt

Margarita C. Gregg

Dale F. Hurst

\section{Chapter Editors}

Martin O. Jeffries

Michele L. Newlin Jared Rennie James A. Renwick Jacqueline A. Richter-Menge

Ahira Sánchez-Lugo
Ted A. Scambos

Wassila M. Thiaw

Peter W. Thorne Scott J. Weaver

Kate M. Willett

\section{Technical Editor}

Mara Sprain 
COVER CREDITS:

Front: Dan Kitwood/Getty Images — Leyte, Philippines - November 21, 2013.

Back: NOAA Environmental Visualization Laboratory — Super Typhoon Haiyan - Suomi NPP (National Polar-orbiting Partnership) -VIIRS

How to cite this document:

Citing the complete report:

Blunden, J., and D. S. Arndt, Eds., 2014: State of the Climate in 20I3. Bull. Amer. Meteor. Soc., 95 (7), SI-S257.

Citing a chapter (example):

Willett, K. M., A. J. Dolman, D. F. Hurst, J. Rennie, and P. W. Thorne, Eds., 20I4: Global climate [in "State of the Climate in 20I3”]. Bull. Amer. Meteor. Soc., 95 (7), S5-S49.

Citing a section (example):

Willett, K. M., A. Simmons, and D. Berry, 2014: [Global climate] Surface humidity [in "State of the Climate in 2013”]. Bull. Amer. Meteor. Soc., 95 (7), S19-S20. 
Aaron-Morrison, Arlene P., Trinidad \& Tobago Meteorological Service, Piarco, Trinidad

Ackerman, Steven A., CIMSS, University of WisconsinMadison, Madison, WI

Albanil, Adelina, National Meteorological Service of Mexico, Mexico

Alfaro, Eric J., Center for Geophysical Research and School of Physics, University of Costa Rica, San José, Costa Rica

Allan, Rob, Met Office Hadley Centre, Exeter, United Kingdom

Alves, Lincoln M., Centro de Ciencias do Sistema Terrestre (CCST), Instituto Nacional de Pesquisas Espaciais (INPE), Cachoeira Paulista, Sao Paulo, Brazil

Amador, Jorge A., Center for Geophysical Research and School of Physics, University of Costa Rica, San José, Costa Rica

Ambenje, Peter, Kenya Meteorological Department (KMD), Nairobi, Kenya

Anderson, L., Department of Chemistry and Molecular Biology, University of Gothenburg, Gothenburg, Sweden

Andreassen, L. M., Section for Glaciers, Snow and Ice, Norwegian Water Resources and Energy Directorate, Oslo, Norway

Antonov, John, NOAA/NESDIS National Oceanographic Data Center, Silver Spring, MD; and University Corporation for Atmospheric Research, Boulder, CO

Arendt, A., Geophysical Institute, University of Alaska Fairbanks, Fairbanks, AK

Arévalo, Juan, Instituto Nacional de Meteorología e $\mathrm{Hi}$ drología de Venezuela (INAMEH), Caracas, Venezuela

Arndt, Derek S., NOAA/NESDIS National Climatic Data Center, Asheville, NC

Ashik, I., Arctic and Antarctic Research Institute, St. Petersburg, Russia

Atheru, Zachary, IGAD Climate Prediction and Applications Cetnre (ICPAC), Nairobi, Kenya

Augustine, John, NOAA/OAR Earth System Research Laboratory, Boulder, $\mathrm{CO}$

Baklanov, A., Research Department, World Meteorological Organization, Geneva, Switzerland

Banzon, Viva, NOAA/NESDIS National Climatic Data Center, Asheville, NC

Baringer, Molly O., NOAA/OAR Atlantic Oceanographic and Meteorological Laboratory, Miami, FL

Barreira, Sandra, Argentine Naval Hydrographic Service, Buenos Aires, Argentina

Barriopedro, David, Universidad Complutense de Madrid, Instituto de Geociencias, Madrid, Spain

Baxter, Stephen, NOAA/NWS Climate Prediction Center, College Park, MD

Bazo, Juan, Servicio Nacional de Meteorología e Hidrología de Perú (SENAMHI), Lima, Perú

Becker, Andreas, Global Precipitation Climatology Centre, Deutscher Wetterdienst, Offenbach, Germany

Behrenfeld, Michael J., Oregon State University, Corvallis, OR
Bell, Gerald D., NOAA/NWS Climate Prediction Center, College Park, MD

Benedetti, Angela, European Centre for Medium-Range Weather Forecasts, Reading, United Kingdom

Bernhard, Germar, Biospherical Instruments, San Diego, CA

Berrisford, Paul, NCAS Climate, European Centre for Medium-Range Weather Forcasts, Reading, United Kingdom

Berry, David I., National Oceanography Centre, Southampton, United Kingdom

Bhatt, U. S., Geophysical Institute, University of Alaska Fairbanks, Fairbanks, AK

Bidegain, Mario, Instituto Uruguayo de Meteorologia, Montevideo, Uruguay

Bindoff, Nathan, Antarctic Climate and Ecosystems Cooperative Research Centre, Hobart, Australia; and CSIRO Marine and Atmospheric Laboratories, Hobart, Australia

Bissolli, Peter, Deutscher Wetterdienst, WMO RA VI Regional Climate Centre Network, Offenbach, Germany

Blake, Eric S., NOAA/NWS National Hurricane Center, Miami, FL

Blenman, Rosalind C., Barbados Meteorological Services, Christ Church, Barbados

Blunden, Jessica, ERT, Inc., NOAA/NESDIS National Climatic Data Center, Asheville, NC

Bosilovich, Michael, Global Modelling and Assimilation Office, NASA Goddard Space Flight Center, Greenbelt, MD

Box, J. E., Geological Survey of Denmark and Greenland, Copenhagen, Denmark

Boyer, Tim, NOAA/NESDIS National Oceanographic Data Center, Silver Spring, MD

Braathen, Geir O., WMO Atmospheric Environment Research Division, Geneva, Switzerland

Bromwich, David H., Byrd Polar Research Center, The Ohio State University, Columbus, $\mathrm{OH}$

Brown, Glenroy, Meteorological Service, Jamaica, Kingston, Jamaica

Brown, L. C., Climate Research Division, Environment Canada, Toronto, Ontario, Canada

Brown, R., Climate Research Division, Environment Canada, Montreal, Quebec, Canada

Bruhwiler, Lori, NOAA/OAR, Earth System Research Laboratory, Global Monitoring Division, Boulder, CO

Bulygina, Olga N., Russian Institute for Hydrometeorological Information, Obninsk, Russia

Burgess, D., Geological Survey of Canada, Ottawa, Ontario, Canada

Butler, Mary, Department of Meteorology, Nassau, Bahamas

Calderón, Blanca, Center for Geophysical Research, University of Costa Rica, San José, Costa Rica

Camargo, Suzana J., Lamont-Doherty Earth Observatory, Columbia University, Palisades, NY

Campbell, Garret G., National Snow and Ice Data Center, University of Colorado, Boulder, CO

Campbell, Jayaka D., Department of Physics, The University of the West Indies, Mona, Jamaica 
Cappelen, John, Danish Meteorological Institute, Copenhagen, Denmark

Carrasco, Gualberto, Servicio Nacional de Meteorología e Hidrología de Bolivia (SENAMHI), La Paz, Bolivia

Chambers, Don P., College of Marine Science, University of South Florida, St. Petersburg, FL

Chang'a, L., Tanzania Meteorological Agency, Dar es Salaam, Tanzania

Chappell, Petra R., National Institute of Water and Atmospheric Research, Ltd., Auckland New Zealand

Christiansen, Hanne H., Geology Department, University Centre in Svalbard, UNIS, Norway; and Center for Permafrost, CENPERM, Department of Geosciences and Natural Resource Management, University of Copenhagen, Denmark

Christy, John R., University of Alabama in Huntsville, Huntsville, AL

Chung, D., Vienna University of Technology, Vienna, Austria

Ciais, Phillipe, LCSE, Gif sur l'Yvette, France

Clem, Kyle R., Department of Geography, Ohio University, Athens, $\mathrm{OH}$

Coelho, Caio A. S., CPTEC/INPE Center for Weather Forecasts and Climate Studies, Cachoeira Paulista, Brazil

Coldewey-Egbers, Melanie, DLR (German Aerospace Center) Oberpfaffenhofen, Wessling, Germany

Colwell, Steve, British Antarctic Survey, Cambridge, United Kingdom

Cooper, Owen R., Cooperative Institute for Research in Environmental Sciences, University of Colorado, Boulder, CO; and NOAA/OAR Earth System Research Laboratory, Boulder, CO

Coulibaly, K. Alama, National Meteorological Service / SODEXAM, Abidjan, Côte D'lvoire

Cox, C., Cooperative Institute for Research in Environmental Sciences, University of Colorado, Boulder, CO

Cross, J. N., NOAA/OAR Pacific Marine Environmental Laboratory, Seattle, WA; and Ocean Acidification Research Center, University of Alaska Fairbanks, Fairbanks, AK

Crouch, Jake, NOAA/NESDIS National Climatic Data Center, Asheville, NC

Cunningham, Stuart A., Scottish Marine Institute Oban, Argyll, United Kingdom

Dahlback, A., Department of Physics, University of Oslo, Norway

Davis, Sean M., Cooperative Institute for Research in Environmental Sciences, University of Colorado, Boulder, CO; and NOAA/OAR Earth System Research Laboratory, Boulder, CO

de Jeu, Rochard A. M., Department of Earth Sciences, VU University Amsterdam, Amsterdam, Netherlands

Dekaa, Francis S., Nigerian Meteorological Agency, Abuja, Nigeria

Derksen, Chris, Climate Research Division, Environment Canada, Toronto, Ontario, Canada

Diamond, Howard J., NOAA/NESDIS National Climatic Data Center, Silver Spring, MD
Dlugokencky, Ed J., NOAA/OAR Earth System Research Laboratory, Boulder, CO

Dohan, Kathleen, Earth and Space Research, Seattle, WA

Dolman, A. Johannes, Department of Earth Sciences, VU University Amsterdam, Amsterdam, Netherlands

Domingues, Catia M., Antarctic Climate and Ecosystems Cooperative Research Centre, Hobart, Australia

Donat, Markus, Climate Change Research Centre, University of New South Wales, Sydney, Australia

Dong, Shenfu, NOAA/OAR Atlantic Oceanographic and Meteorological Laboratory, Miami, FL; and Cooperative Institute for Marine and Atmospheric Science, Miami, FL

Dorigo, Wouter A., Vienna University of Technology, Vienna, Austria

Drozdov, D. S., Earth Cryosphere Institute, Tyumen, Russia

Duguay, Claude, Interdisciplinary Centre on Climate Change and Department of Geography \& Environmental Management, University of Waterloo, Waterloo, Ontario, Canada

Dunn, Robert J. H., Met Office Hadley Centre, Exeter, United Kingdom

Durán-Quesada, Ana M., Center for Geophysical Research and School of Physics, University of Costa Rica, San José, Costa Rica

Dutton, Geoff S., Cooperative Institute for Research in Environmental Sciences, University of Colorado, Boulder, CO; and NOAA/OAR Earth System Research Laboratory, Boulder, $\mathrm{CO}$

Ebrahim, Awatif, Egyptian Meteorological Authority, Cairo, Egypt

Elkins, James W., NOAA/OAR Earth System Research Laboratory, Boulder, CO

Espinoza, Jhan C., Instituto Geofisico del Peru, Lima, Peru

Euscátegui, Christian, Instituto de Hidrología de Meteorología y Estudios Ambientales de Colombia (IDEAM), Bogotá, Colombia

Evans, W., NOAA/OAR Pacific Marine Environmental Laboratory, Seattle, WA; and Ocean Acidification Research Center, University of Alaska Fairbanks, Fairbanks, AK

Evans III, Thomas E., NOAA/NWS Central Pacific Hurricane Center, Honolulu, $\mathrm{HI}$

Famigliette, James S., Department of Earth System Science, University of California, Irvine, CA

Fauchereau, Nicolas C., National Institute of Water and Atmospheric Research, Ltd., Auckland, New Zealand; and Oceanography Department, University of Cape Town, Rondebosh, South Africa

Feely, Richard A., NOAA/OAR Pacific Marine Environmental Laboratory, Seattle, WA

Fenimore, Chris, NOAA/NESDIS National Climatic Data Center, Asheville, NC

Fettweis, X., Department of Geography, University of Liege, Liege, Belgium

Fioletov, Vitali E., Environment Canada, Toronto, Ontario, Canada

Flanner, M. G., Department of Atmospheric, Oceanic, and Space Sciences, University of Michigan, Ann Arbor, MI 
Flemming, Johannes, European Centre for Medium-Range Weather Forecasts, Reading, United Kingdom

Fogarty, Chris T., Environment Canada, Canadian Hurricane Centre, Dartmouth, Nova Scotia, Canada

Fogt, Ryan L., Department of Geography, Ohio University, Athens, $\mathrm{OH}$

Folland, Chris K., Met Office Hadley Centre, Exeter, United Kingdom and Department of Earth Sciences, Gothenburg University, Sweden

Foster, Michael J., CIMSS University of Wisconsin-Madison, Madison, WI

Frajka-Williams, Eleanor, National Oceanography Centre, Southampton, United Kingdom

Francis, Jennifer, Institute of Marine and Coastal Sciences, Rutgers University, NJ

Franz, Bryan A., NASA Goddard Space Flight Center, Greenbelt, MD

Frith, Stacey M., NASA Goddard Space Flight Center, Greenbelt, MD

Frolov, I., Arctic and Antarctic Research Institute, St. Petersburg, Russia

Ganter, Catherine, Australian Bureau of Meteorology, Melbourne, Australia

Garzoli, Silvia, NOAA/OAR Atlantic Oceanographic and Meteorological Laboratory, Miami, FL; and Cooperative Institute for Marine and Atmospheric Science, Miami, FL

Geai, M-L., Department of Earth and Atmospheric Sciences, University of Alberta, Edmonton, Alberta, Canada

Gerland, S., Norwegian Polar Institute, Fram Centre, Tromsø, Norway

Gitau, Wilson, Department of Meteorology, University of Nairobi, Nairobi, Kenya

Gleason, Karin L., NOAA/NESDIS National Climatic Data Center, Asheville, NC

Gobron, Nadine, European Commission Joint Research Centre, ISPRA, Italy

Goldenberg, Stanley B., NOAA/OAR Atlantic Oceanographic and Meteorological Laboratory, Miami, FL

Goni, Gustavo, NOAA/OAR Atlantic Oceanographic and Meteorological Laboratory, Miami, FL

Gonzalez, Idelmis T., Climate Center, Institute of Meteorology of Cuba, Cuba

Good, Simon A., Met Office Hadley Centre, Exeter, United Kingdom

Gottschalck, Jonathan, NOAA/NWS Climate Prediction Center, College Park, MD

Gregg, Margarita C., NOAA/NESDIS National Oceanographic Data Center, Silver Spring, MD

Grooß, Jnes-Uwe, Forschungszentrum Jülich, Jülich, Germany

Guard, Charles P. “Chip”, NOAA/NWS Weather Forecast Office, Guam

Gugliemin, Mauro, Department of Theoretical and Applied Sciences, Insubria University, Varese, Italy

Gupta, Shashi K., Science Systems Applications, Inc., Hampton, VA
Ha, H. K., Korea Polar Research Institute, Incheon, Republic of Korea

Hahn, S., Vienna University of Technology, Vienna, Austria

Hall, Bradley D., NOAA/OAR Earth System Research Laboratory, Boulder, $\mathrm{CO}$

Halpert, Michael S., NOAA/NWS Climate Prediction Center, College Park, MD

Hamlington, Ben, Colorado Center for Astrodynamics Research, University of Colorado, Boulder, CO

Hanna, E., Department of Geography, University of Sheffield, Sheffield, United Kingdom

Hanssen-Bauer, I., Norwegian Meteorological Institute, Blindern, Oslo, Norway

Harada, Yayoi, Climate Prediction Division, Japan Meteorological Agnecy, Tokyo, Japan

Haran, Terry, National Snow and Ice Data Center, University of Colorado, Boulder, CO

Heidinger, Andrew K., NOAA/NESDIS University of Wisconsin-Madison, Madison, WI

Heikkilä, Anu, Finnish Meteorological Institute, Helsinki, Finland

Heim, Jr., Richard R., NOAA/NESDIS National Climatic Data Center, Asheville, NC

Hendricks, S., Alfred Wegener Institute, Bremerhaven, Germany

Herber, A., Alfred Wegener Institute, Bremerhaven, Germany

Hidalgo, Hugo G., Center for Geophysical Research and School of Physics, University of Costa Rica, San José, Costa Rica

Hilburn, Kyle, Remote Sensing Systems, Santa Rosa, CA

Ho, Shu-oeng (Ben), UCAR COSMIC, Boulder, CO

Hobbs, Will R., ARC Centre of Excellence for Climate System Science, University of Tasmania, Hobart, Australia

Hovhannisyan, Diana, Armenian State Hydrometeorological and Monitoring Service, Yerevan, Armenia

Hu, Zeng-Zhen, NOAA/NWS Climate Prediction Center, College Park, MD

Hurst, Dale F., Cooperative Institute for Research in Environmental Sciences, University of Colorado, Boulder, CO; and NOAA/OAR Earth System Research Laboratory, Boulder, $\mathrm{CO}$

Ingvaldsen, R., Institute of Marine Research, Bergen, Norway Inness, Antje, European Centre for Medium-Range Weather Forecasts, Reading, United Kingdom

James, I. A., Nigerian Meteorological Agency, Abuja, Nigeria

Jeffries, Martin O., Office of Naval Research, Arlington, VA; and, prior to 24 March 2014, U.S. Arctic Research Commission, Arlington, VA and University of Alaska Fairbanks, Fairbanks, AK

Jensen, T. S., Geological Survey of Denmark and Greenland, Copenhagen, Denmark

Jin, Xiangze, Woods Hole Oceanographic Institution, Woods Hole, MA

Johns, William E., Rosenstiel School of Marine and Atmospheric Science, Miami, FL 
Johnsen, Bjorn, Norwegian Radiation Protection Authority, Østerås, Norway

Johnson, Bryan, NOAA/OAR Earth System Research Laboratory, Boulder, CO; and University of Colorado, Boulder, $\mathrm{CO}$

Johnson, Gregory C., NOAA/OAR Pacific Marine Environmental Laboratory, Seattle, WA

Jones, Luke T., European Centre for Medium-Range Weather Forecasts, Reading, United Kingdom

Jumaux, Guillaume, Météo France, Réunion

Kabidi, Khadija, Direction de la Météorologie Nationale Maroc, Rabat, Morocco

Kaiser, Johannes W., Kings College London, London, United Kingdom; European Centre for Medium-Range Weather Forecasts, Reading, United Kingdom; and Max-Planck Institute for Chemistry, Mainz, Germany

Kang, Kyun-Kuk, Interdisciplinary Centre on Climate Change and Department of Geography \& Environmental Management, University of Waterloo, Waterloo, Ontario, Canada

Kanzow, Torsten O., Helmholtz-Centre for Ocean Research Kiel (GEOMAR), Kiel, Germany

Kao, Hsun-Ying, Earth \& Space Research, Seattle, WA

Keller, Linda M., Department of Atmospheric and Oceanic Sciences, University of Wisconsin-Madison, Madison, WI

Kendon, Michael, Met Office Hadley Centre, Exeter, United Kingdom

Kennedy, John J., Met Office Hadley Centre, Exeter, United Kingdom

Key, Jeff, NOAA/NESDIS Center for Satellite Applications and Research, Madison, WI

Khatiwala, Samar, Lamont-Doherty Earth Observatory, Columbia Unisversity, Palisades, NY

Kheyrollah Pour, H., Interdisciplinary Centre on Climate Change and Department of Geography \& Environmental Management, University of Waterloo, Waterloo, Ontario, Canada

Kholodov, A. L., Geophysical Institute, University of Alaska Fairbanks, Fairbanks, AK

Khoshkam, Mahbobeh, Islamic Republic of Iranian Meteorological Organization (IRIMO), Iran

Kijazi, Agnes, Tanzania Meteorological Agency, Dar es Salaam, Tanzania

Kikuchi, T., Japan Agency for Marine-Earth Science and Technology, Tokyo, Japan

Kim, B.-M., Korea Polar Research Institute, Incheon, Republic of Korea

Kim, Hyuanjun, Institute of Industrial Science, The University of Tokyo, Tokyo, Japan

Kim, S.-J., Korea Polar Research Institute, Incheon, Republic of Korea

Kim, T. W., Korea Polar Research Institute, Incheon, Republic of Korea

Kimberlain, Todd B., NOAA/NWS National Hurricane Center, Miami, FL

Klotzbach, Philip, Department of Atmospheric Science, Colorado State University, Fort Collins, CO
Knaff, John A., NOAA/NESDIS Center for Satellite Applications and Research, Fort Collins, $\mathrm{CO}$

Kohler, J., Norwegian Polar Institute, Tromsø, Norway

Korshunova, Natalia N., All-Russian Research Institute of Hydrometeorological Information - World Data Center, Obninsk, Russia

Koskela, Tapani, Finnish Meteorological Institute, Helsinki, Finland

Kramarova, Natalya, Science Systems and Applications, Inc., NASA Goddard Space Flight Center, Greenbelt, MD

Kratz, David P., NASA Langley Research Center, Hampton, VA

Krishfield, R., Woods Hole Oceanographic Institution, Woods Hole, MA

Kruger, Andries, South African Weather Service, Pretoria, South Africa

Kruk, Michael C., ERT Inc., NOAA/NESDIS National Climatic Data Center, Asheville, NC

Kumar, Arun, NOAA/NWS Climate Prediction Center, College Park, MD

Kupiainen, K., Finnish Environment Institute, Helsinki, Finland

Lagerloef, Gary S. E., Earth \& Space Research, Seattle, WA

Lakkala, Kaisa, Finnish Meteorological Institute, Arctic Research Centre, Sodankylä, Finland

Lander, Mark A., University of Guam, Mangilao, Guam

Landsea, Chris W., NOAA/NWS National Hurricane Center, Miami, FL

Lankhorst, Matthias, Scripps Institution of Oceanography, University of California, San Diego, La Jolla, CA

Lantz, Kathy O., Cooperative Institute for Research in Environmental Sciences, University of Colorado, Boulder, CO; and NOAA/OAR Earth System Research Laboratory, Boulder, $\mathrm{CO}$

Laurila, T., Finnish Meteorological Institute, Helsinki, Finland

Law, K. S., LATMOS-IPSL, UPMC University of Paris, Paris, France

Lazzara, Matthew A., Space Science and Engineering Center, University of Wisconsin-Madison, Madison, WI

Leuliette, Eric, NOAA/NESDIS Laboratory for Satellite Altimetry, Silver Spring, MD

Levira, Pamela, Tanzania Meteorological Agency, Dar es Salaam, Tanzania

L'Heureux, Michelle, NOAA/NWS Climate Prediction Center, College Park, MD

Lieser, Jan, Antarctic Climate and Ecosystems Cooperative Research Centre (ACE CRC), University of Tasmania, Hobart, Tasmania, Australia

Lin, I-I, National Taiwan University, Taipei, Taiwan

Liu, Hongxing, Department of Geography, University of Cincinnati, Cincinnati, $\mathrm{OH}$

Liu, Y. Y., University of New South Wales, Sydney, Australia

Liu, Yinghui, Cooperative Institute for Meteorological Satellite Studies, University of Wisconsin, Madison, WI

Lobato-Sánchez, Rene, National Meteorological Service of Mexico, Mexico 
Locarnini, Ricardo, NOAA/NESDIS National Oceanographic Data Center, Silver Spring, MD

Loeb, Norman G., NASA Langley Research Center, Hampton VA

Loeng, H., Institute of Marine Research, Bergen, Norway

Long, Craig S., NOAA/NWS National Center for Environmental Prediction, College Park, MD

Lorrey, Andrew M., National Institute of Water and Atmospheric Research, Ltd., Auckland, New Zealand

Loyola, Diego, DLR (German Aerospace Center) Oberpfaffenhofen, Wessling, Germany

Luhunga, P., Tanzania Meteorological Agency, Dar es Salaam, Tanzania

Lumpkin, Rick, NOAA/OAR Atlantic Oceanographic and Meteorological Laboratory, Miami, FL

Luo, Jing-Jia, Centre for Australian Weather and Climate Research, Melbourne, Australia

Luojus, K., Finnish Meteorological Institute, Helsinki, Finland

Lyman, John M., NOAA/OAR Pacific Marine Environmental Laboratory, Seattle, WA; and Joint Institute for Marine and Atmospheric Research, University of Hawaii, Honolulu, $\mathrm{HI}$

Macara, Gregor R., National Institute of Water and Atmospheric Research, Ltd., Auckland, New Zealand

Maddux, Brent C., AOS/CIMSS University of WisconsinMadison, Madison, WI

Malkova, G. V., Earth Cryosphere Institute, Tyumen, Russia

Manney, Gloria, NorthWest Research Associates, Socorro, NM; and New Mexico Institute of Mining and Technology, Socorro, NM

Marcellin-Honore', Vernie, Dominica Meteorological Service, Dominica

Marchenko, S. S., Geophysical Institute, University of Alaska Fairbanks, Fairbanks, AK

Marengo, José A., Centro de Ciencias do Sistema Terrestre (CCST), Instituto Nacional de Pesquisas Espaciais (INPE), Cachoeira Paulista, Sao Paulo, Brazil

Marotzke, Jochem, Max-Planck-Institut für Meteorologie, Hamburg, Germany

Marra, John J., NOAA/NESDIS National Climatic Data Center, Honolulu, HI

Martínez-Güingla, Rodney, Centro Internacional para la Investigación del Fenómeno El Niño (CIIFEN), Guayaquil, Ecuador

Massom, Robert A., Australian Antarctic Division and Antarctic Climate and Ecosystems Cooperative Research Centre (ACE CRC), University of Tasmania, Hobart, Tasmania, Australia

Mathis, Jeremy T., NOAA/OAR Pacific Marine Environmental Laboratory, Seattle, WA; and Ocean Acidification Research Center, University of Alaska Fairbanks, Fairbanks, AK

McBride, Charlotte, South African Weather Service, Pretoria, South Africa

McCarthy, Gerard, National Oceanography Centre, Southampton, United Kingdom
McGree, Simon, Australian Bureau of Meteorology, Melbourne, Australia

Mclnnes, Kathleen, Centre for Australian Climate and Weather Research, Australia

McLean, Natalie, Department of Physics, The University of the West Indies, Mona, Jamaica

McVicar, Tim, CSIRO Land and Water, Canberra, Australia

Mears, Carl A., Remote Sensing Systems, Santa Rosa, CA

Meier, W., NASA Goddard Space Flight Center, Greenbelt, MD

Meinen, Christopher S., NOAA/OAR Atlantic Oceanographic and Meteorological Laboratory, Miami, FL

Menéndez, Melisa, Environmental Hydraulic Institute, Universidad de Cantabria, Santander, Spain

Merrifield, Mark A., Joint Institute Marine and Atmospheric Research, University of Hawaii, Honolulu, $\mathrm{HI}$

Mitchum, Gary T., College of Marine Science, University of South Florida, St. Petersburg, FL

Montzka, Stephen A., NOAA/OAR Earth System Research Laboratory, Boulder, CO

Morcrette, Jean-Jacques, European Centre for MediumRange Weather Forecasts, Reading, United Kingdom

Mote, Thomas, Department of Geography, University of Georgia, Athens, GA

Mühle, Jens, Scripps Institution of Oceanography, University of California, San Diego, La Jolla, CA

Mullan, A. Brett, National Institute of Water and Atmospheric Research, Ltd., Wellington, New Zealand

Müller, Rolf, Forschungszentrum Jülich, Jülich, Germany

Nash, Eric R., Science Systems and Applications, Inc., NASA Goddard Space Flight Center, Greenbelt, MD

Nerem, R. Steven, Colorado Center for Astrodynamics Research, University of Colorado, Boulder, $\mathrm{CO}$

Newlin, Michele L., NOAA/NESDIS National Oceanographic Data Center, Silver Spring, MD

Newman, Paul A., Laboratory for Atmospheres, NASA Goddard Space Flight Center, Greenbelt, MD

Ng'ongolo, H., Tanzania Meteorological Agency, Dar es Salaam, Tanzania

Nicolaus, M., Alfred Wegener Institute, Bremerhaven, Germany

Nieto, Juan J., Centro Internacional para la Investigación del Fenómeno El Niño (CIIFEN), Guayaquil, Ecuador

Nishino, S., Japan Agency for Marine-Earth Science and Technology, Tokyo, Japan

Nitsche, Helga, Climate Monitoring Satellite Application Facility, Deutscher Wetterdienst, Offenbach, Germany

Noetzli, Jeannette, Deptartment of Geography, University of Zurich, Switzerland

Oberman, N. G., MIRECO Mining Company, Syktyvkar, Russia

Obregón, Andre, Deutscher Wetterdienst, WMO RA VI Regional Climate Centre Network, Offenbach, Germany

Ogallo, Laban A., IGAD Climate Prediction and Applications Cetnre (ICPAC), Nairobi, Kenya 
Ohno, Hiroshi, Tokyo Climate Center, Climate Prediction Division, Japan Meteorological Agency, Tokyo, Japan

Oki, Taikan, Institute of Industrial Science, The University of Tokyo, Tokyo, Japan

Oludhe, Christopher S., Department of Meteorology, University of Nairobi, Nairobi, Kenya

Overland, James, NOAA/OAR Pacific Marine Environmental Laboratory, Seattle, WA

Oyunjargal, Lamjav, Institute of Meteorology and Hydrology, National Agency for Meteorology, Hydrology and Environmental Monitoring, Ulaanbaatar, Mongolia

Parinussa, Robert M., Department of Earth Sciences, VU University Amsterdam, Amsterdam, Netherlands

Park, E-Hyung, Korea Meteorological Administration, Republic of Korea

Parker, David, Met Office Hadley Centre, Exeter, United Kingdom

Pasch, Richard J., NOAA/NWS National Hurricane Center, Miami, FL

Pascual-Ramirez, Reynaldo, National Meteorological Service of Mexico, Mexico

Paulik, C., Vienna University of Technology, Vienna, Austria

Pelto, Mauri S., Nichols College, Dudley, MA

Penalba, Olga C., Departamento Ciencias de la Atmósfera y los Océanos, Facultad de Ciencias Exactas y Naturales, Universidad de Buenos Aires, Argentina

Peng, Liang, UCAR COSMIC, Boulder, CO

Perovich, Don, ERDC - Cold Regions Research and Engineering Laboratory, Hanover, $\mathrm{NH}$; and Thayer School of Engineering, Dartmouth College, Hanover, NH

Pezza, Alexandre B., Melbourne University, Melbourne, Australia

Phillips, David, Environment Canada, Toronto, Ontario, Canada

Pickart, R., Woods Hole Oceanographic Institution, Woods Hole, MA

Pinty, Bernard, JRC, European Comission, Brussels, Belgium

Pitts, Michael C., NASA Langley Research Center, Hampton, VA

Polyakov, I., International Arctic Research Center, University of Alaska Fairbanks, Fairbanks, AK

Pope, Allen, National Snow and Ice Data Center, University of Colorado, Boulder, CO

Porter, Avalon O., Cayman Islands National Weather Service, Grand Cayman, Cayman Islands

Quegan, Shaun, University of Sheffield, Sheffield, United Kingdom

Quinn, P. K., NOAA/OAR Pacific Marine Environmental Laboratory, Seattle, WA

Rabe, B., Alfred Wegener Institute, Bremerhaven, Germany

Rahimzadeh, Fatemeh, Atmospheric Science and Meteorological Research Center, Tehran, Iran

Rajeevan, Madhavan, National Atmospheric Research Laboratory, Gadanki, India

Rakotomavo, Zo, Direction Générale de la Météorologie, Antananarivo, Madagascar

Rayner, Darren, National Oceanography Centre, Southampton, United Kingdom
Rayner, Nick A., Met Office Hadley Centre, Exeter, United Kingdom

Razuvaev, Vyacheslav N., All-Russian Research Institute of Hydrometeorological Information, Obninsk, Russia

Ready, Steve, New Zealand Meteorological Service, Ltd., Wellington, New Zealand

Reagan, James, NOAA/NESDIS National Oceanographic Data Center, Silver Spring, MD

Reid, Phillip, Australian Bureau of Meteorology and CAWRC, Hobart, Tasmania, Australia

Reimer, C., Vienna University of Technology, Vienna, Austria

Rémy, Samuel, European Centre for Medium-Range Weather Forecasts, Reading, United Kingdom

Rennermalm, A. K., Department of Geography, Rutgers University, New Brunswick, NJ

Rennie, Jared, Cooperative Institute for Climate and Satellites, NC State University, Asheville, NC

Renwick, James A., Victoria University of Wellington, New Zealand

Revadekar, Jayashree V., Indian Institute of Tropical Meteorology, Pune, India

Richter-Menge, Jacqueline, ERDC - Cold Regions Research and Engineering Laboratory, Hanover, $\mathrm{NH}$; and Thayer School of Engineering, Dartmouth College, Hanover, NH

Rivera, Ingrid L., Center for Geophysical Research, University of Costa Rica, San José, Costa Rica

Robinson, David A., Department of Geography, Rutgers University, Piscataway, NJ

Rodell, Matthew, Hydrological Sciences Laboratory, NASA Goddard Space Flight Center, Greenbelt, MD

Romanovsky, Vladimir E., Geophysical Institute, University of Alaska Fairbanks, Fairbanks, AK

Ronchail, Josyane, University of Paris, Paris, France

Rosenlof, Karen H., NOAA/OAR Earth System Research Laboratory, Boulder, $\mathrm{CO}$

Sabine, Christopher L., NOAA/OAR Pacific Marine Environmental Laboratory, Seattle, WA

Sánchez-Lugo, Ahira, NOAA/NESDIS National Climatic Data Center, Asheville, NC

Santee, Michelle L., NASA Jet Propulsion Laboratory, Pasadena, CA

Santoro, M., Gamma Remote Sensing, Gümligen, Switzerland

Sawaengphokhai, P., Science Systems Applications, Inc., Hampton, VA

Sayouri, Amal, Direction de la Météorologie Nationale Maroc, Rabat, Morocco

Scambos, Ted A., National Snow and Ice Data Center, University of Colorado, Boulder, $\mathrm{CO}$

Schauer, U., Alfred Wegener Institute, Bremerhaven, Germany

Schemm, Jae, NOAA/NWS Climate Prediction Center, College Park, MD

Schlosser, P., Lamont-Doherty Earth Observatory of Columbia University, Palisades, NY

Schmale, J., Institute for Advanced Sustainability Studies, Potsdam, Germany 
Schmid, Claudia, NOAA/OAR Atlantic Oceanographic and Meteorological Laboratory, Miami, FL

Schreck, Carl J., Cooperative Institute for Climate and Satellites, North Carolina State University, Asheville, NC

Send, Uwe, Scripps Institution of Oceanography, University of California, San Diego, La Jolla, CA

Sensoy, Serhat, Turkish State Meteorological Service, Kalaba, Ankara, Turkey

Setzer, Alberto, National Institute for Space Research, São Jose dos Compos-SP, Brazil

Sharma, S., Environment Canada, Toronto, Ontario, Canada

Sharp, Martin, Department of Earth and Atmospheric Science, University of Alberta, Edmonton, Alberta, Canada

Shiklomanov, Nicolai I., Department of Geography, George Washington University, Washington, DC

Shu, Song, Department of Geography, University of Cincinnati, Cincinnati, $\mathrm{OH}$

Siegel, David A., University of California, Santa Barbara, Santa Barbara, CA

Sima, Fatou, Division of Meteorology, Department of Water Resources, Banjul, The Gambia

Simmons, Adrian, European Centre for Medium-Range Weather Forcasts, Reading, United Kingdom

Smeed, David A., National Oceanography Centre, Southampton, United Kingdom

Smethie, W. M., Lamont-Doherty Earth Observatory of Columbia University, Palisades, NY

Smith, Cathy, NOAA/OAR Earth System Research Laboratory, Boulder CO; and Cooperative Institute for Research in Environmental Sciences, Boulder, CO

Smith, L. C., Department of Geography, University of California Los Angeles, Los Angeles, CA

Smith, Sharon L., Geological Survey of Canada, Natural Resources Canada, Ottawa, Ontario, Canada

Smith, Thomas M., NOAA/NESDIS Center for Satellite Applications and Research, College Park, MD; and Cooperative Institute for Climate and Satellites, University of Maryland, College Park, MD

Sokolov, V., Arctic and Antarctic Research Institute, St. Petersburg, Russia

Spence, Jacqueline M., Meteorological Service, Jamaica, Kingston, Jamaica

Srivastava, A. K., India Meteorological Department, Pune, India

Stackhouse Jr., Paul W., NASA Langley Research Center, Hampton, VA

Stammerjohn, Sharon, Institute of Arctic and Alpine Research, University of Colorado, Boulder, CO

Steele, M., Applied Physics Laboratory, University of Washington, Seattle, WA

Steinbrecht, Wolfgang, Deutscher Wetterdienst, Hohenpeissenberg, Germany

Stella, Jose L., Servicio Meteorologico Nacional, Argentina

Stengel, M., Deutscher Wetterdienst, Offenbach, Germany

Stephenson, Tannecia S., Department of Physics, The University of the West Indies, Mona, Jamaica
Stohl, A., NILU - Norwegian Institute for Air Research, Kjeller, Norway

Stone, R., NOAA/OAR Earth System Research Laboratory, Boulder, CO; and Cooperative Institute for Research in Environmental Sciences, University of Colorado, Boulder, CO

Streletskiy, D. A., Department of Geography, George Washington University, Washington, DC

Svendby, T., Norwegian Institute for Air Research, Kjeller, Norway

Sweet, William, NOAA/NOS Center for Operational Oceanographic Products and Services, Silver Spring, MD

Takahashi, Taro, Lamont-Doherty Earth Observatory, Columbia Unisversity, Palisades, NY

Tanaka, Shotaro, Tokyo Climate Center, Climate Prediction Division, Japan Meteorological Agency, Tokyo, Japan

Tang, Q., Institute of Geographic Sciences and Natural Resources Research, Chinese Academy of Sciences, Beijing, China

Taylor, Michael A., Department of Physics, The University of the West Indies, Mona, Jamaica

Tedesco, Marco, National Science Foundation, Arlington, VA; and City College of New York, New York, NY

Thiaw, Wassila M., NOAA/NWS Climate Prediction Center, College Park, MD

Thompson, Philip, Joint Institute Marine and Atmospheric Research, University of Hawaii, Honolulu, HI

Thorne, Peter W., Nansen Environmental and Remote Sensing Center, Bergen, Norway

Timmermans, Mary-Louise, Yale University, New Haven, CT

Tobin, Isabelle, Laboratoire des Sciences du Climat et de l'Environnement (LSCE), CEA-CNR-UVSQ, Gif-sur-Yvette, France

Tobin, Skie, Australian Bureau of Meteorology, Melbourne, Australia

Toole, J., Woods Hole Oceanographic Institution, Woods Hole, MA

Trachte, Katja, Laboratory for Climatology and Remote Sensing, Philipps-Universität, Marburg, Germany

Trewin, Blair C., Australian Bureau of Meteorology, Melbourne, Australia

Trigo, Ricardo, Instituto Dom Luiz, Universidade de Lisboa, Campo Grande, Lisboa, Portugal

Trotman, Adrian R., Caribbean Institute for Meteorology and Hydrology, Bridgetown, Barbados

Tschudi, M., Aerospace Engineering Sciences, University of Colorado, Boulder, CO

van de Wal, Roderik S. W., Institute for Marine and Atmospheric Research Utrecht, Utrecht University, Netherlands

van $\operatorname{der}$ A, Ronald J., KNMI (Royal Netherlands Meteorological Institute), DeBilt, Netherlands

van der Werf, Guido R., Department of Earth Sciences, VU University Amsterdam, Amsterdam, Netherlands

Vautard, Robert, Laboratoire des Sciences du Climat et de l'Environnement (LSCE), CEA-CNR-UVSQ, Gif-surYvette, France 
Vavrus, S., Center for Climatic Research, University of Wisconsin-Madison, Madison, WI

Vazquez, J. L., National Meteorological Service of Mexico, Mexico

Vega, Carla, Center for Geophysical Research, University of Costa Rica, San José, Costa Rica

Vestreng, V., Norwegian Pollution Control Authority, Oslo, Norway

Vincent, Lucie A., Environment Canada, Toronto, Ontario, Canada

Volkov, Denis, NOAA/OAR Atlantic Oceanographic and Meteorological Laboratory, Miami, FL; and Cooperative Institute for Marine and Atmospheric Science, Miami, FL

von Salzen, K., Canadian Centre for Climate Modelling and Analysis, University of Victoria, Victoria, British Columbia, Canada

Vose, Russell S., NOAA/NESDIS National Climatic Data Center, Asheville, NC

Wagner, Wolfgang W., Vienna University of Technology, Vienna, Austria

Wahr, John, Department of Physics and CIRES, University of Colorado, Boulder, $\mathrm{CO}$

Walden, V., Department of Civil and Environmental Engineering, Washington State University, Pullman, WA

Walsh, J., International Arctic Research Center, University of Alaska Fairbanks, Fairbanks, AK

Wang, Bin, University of Hawaii, SOEST, Department of Meteorology, and IPRC, Honolulu, HI

Wang, Chunzai, NOAA/OAR Atlantic Oceanographic and Meteorological Laboratory, Miami, FL

Wang, Guojie, College of Hydrometeorology, Nanjing University of Information Science \& Technology, Nanjing, China

Wang, Junhong, State University of New York, Albany, NY

Wang, Lei, Department of Geography and Anthropology, Louisiana State University, Baton Rouge, LA

Wang, M., Joint Institute for the Study of the Atmosphere and Ocean, University of Washington, Seattle, WA

Wang, Sheng-Hung, Byrd Polar Research Center, The Ohio State University, Columbus, $\mathrm{OH}$

Wang, Shujie, Department of Geography, University of Cincinnati, Cincinnati, $\mathrm{OH}$

Wanninkhof, Rik, NOAA/OAR Atlantic Oceanographic and Meteorological Laboratory, Miami, FL

Weaver, Scott J., NOAA/NWS Climate Prediction Center, College Park, MD

Weber, Mark, Institute of Environmental Physics, University of Bremen, Bremen, Germany

Werdell, P. Jeremy, NASA Goddard Space Flight Center, Greenbelt, MD

Whitewood, Robert, Environment Canada, Toronto, Ontario, Canada

Wilber, Anne C., Science Systems Applications, Inc., Hampton, VA

Wild, Jeannette D., Innovim, NOAA/NWS Climate Prediction Center, College Park, MD
Willett, Kate M., Met Office Hadley Centre, Exeter, United Kingdom

Williams, W., Institute of Ocean Sciences, Sidney, British Columbia, Canada

Willis, Joshua K., Jet Propulsion Laboratory, California Institute of Technology, Pasadena, CA

Wolken, G., Alaska Division of Geological and Geophysical Surveys, Fairbanks, AK

Wong, Takmeng, NASA Langley Research Center, Hampton, VA

Woodgate, R., Applied Physics Laboratory, University of Washington, Seattle, WA

Worthy, D., Environment Canada, Climate Research Division, Toronto, Ontario, Canada

Wouters, B., University of Colorado Boulder, Boulder, CO

Xue, Yan, NOAA/NWS Climate Prediction Center, College Park, MD

Yamada, Ryuji, Tokyo Climate Center, Climate Prediction Division, Japan Meteorological Agency, Tokyo, Japan

Yamamoto-Kawai, M., Tokyo University of Marine Science and Technology, Tokyo, Japan

Yin, Xungang, ERT Inc., NOAA/NESDIS National Climatic Data Center, Asheville, NC

Yoshimatsu, Kazuyoshi, Tokyo Climate Center, Climate Prediction Division, Japan Meteorological Agency, Tokyo, Japan

Yu, Lisan, Woods Hole Oceanographic Institution, Woods Hole, MA

Zambrano, Eduardo, Centro Internacional para la Investigación del Fenómeno El Niño (CIIFEN), Guayaquil, Ecuador

Zhang, Peiqun, Beijing Climate Center, Beijing, China

Zhao, Lin, Cold and Arid Regions Environmental and Engineering Research Institute, Lanzhou, China

Ziemke, Jerry, NASA Goddard Space Flight Center, Greenbelt, MD

Zimmermann, S., Institute of Ocean Sciences, Sidney, British Columbia, Canada

\section{EDITORIAL AND PRODUCTION TEAM}

Love-Brotak, S. Elizabeth, Graphics Production, NOAA/ NESDIS National Climatic Data Center, Asheville, NC

Sprain, Mara, Technical Editor, LAC Group, NOAA/NESDIS National Climatic Data Center, Asheville, NC

Veasey, Sara W., Lead Graphics Production, NOAA/NESDIS National Climatic Data Center, Asheville, NC

Griffin, Jessicca, Graphics Support, CICS-NC, Asheville, NC

Misch, Deborah J., Graphics Support, Jamison Professional Services, NOAA/NESDIS National Climatic Data Center, Asheville, NC

Riddle, Deborah B., Graphics Support, NOAA/NESDIS National Climatic Data Center, Asheville, NC 


\section{TABLE OF CONTENTS}

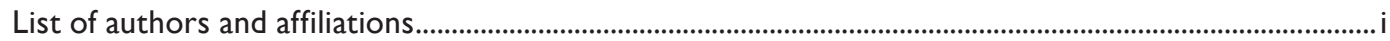

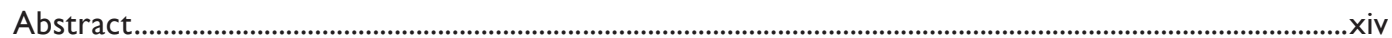

I. INTRODUCTION

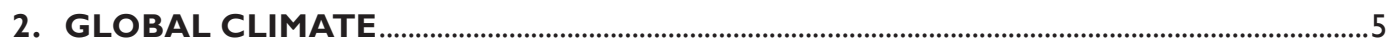

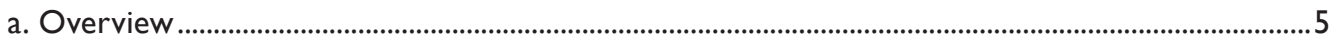

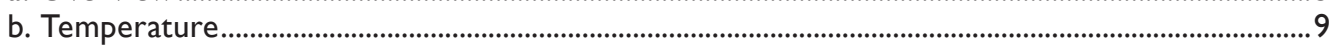

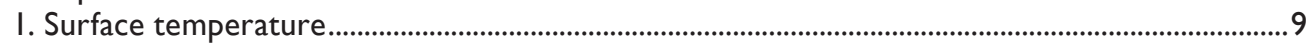

2. Lower tropospheric temperature................................................................................................... 10

SIDEBAR 2.I: TEMPERATURE EXTREME INDICES IN 2013 ………………........................................................ 12

3. Lower stratospheric temperature ……………………………………………….................... 14

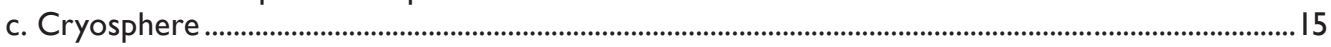

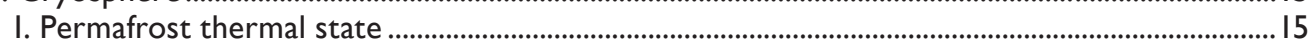

2. Northern Hemisphere continental snow cover extent................................................................... 17

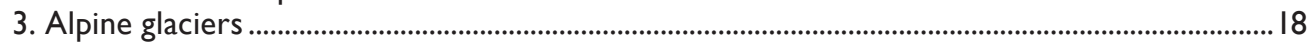

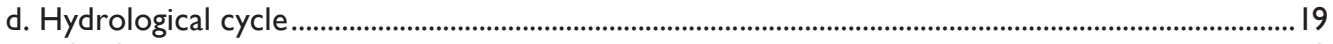

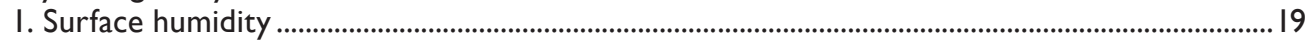

2. Total column water vapor .................................................................................................... 20

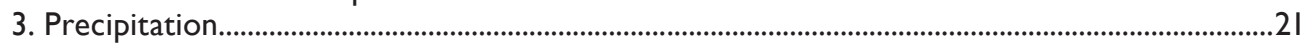

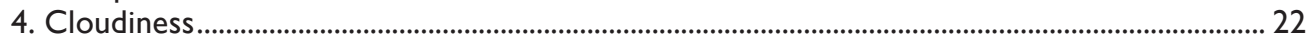

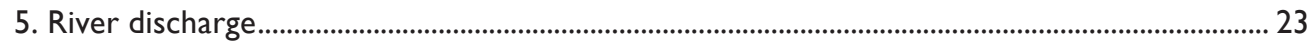

6. Groundwater and terrestrial water storage..................................................................................2

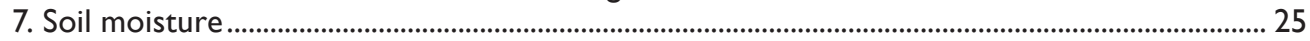

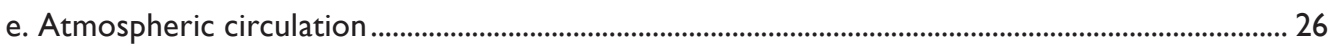

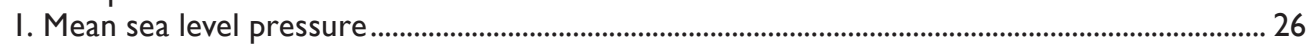

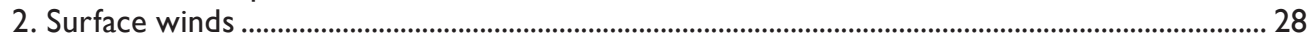

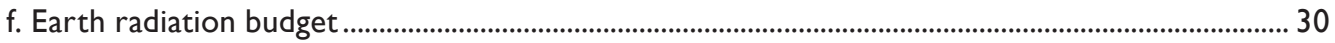

I. Earth radiation budget at top-of-atmosphere …………................................................................ 30

2. Mauna Loa clear-sky atmospheric solar transmission....................................................................... 32

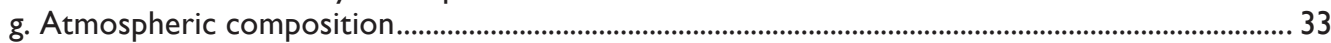

I. Long-lived greenhouse gases ...................................................................................................... 33

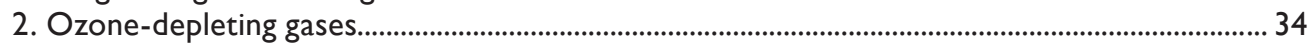

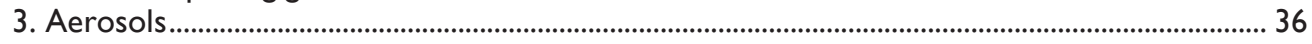

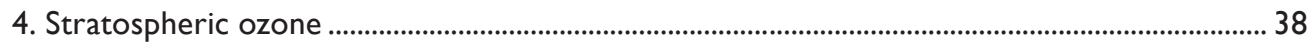

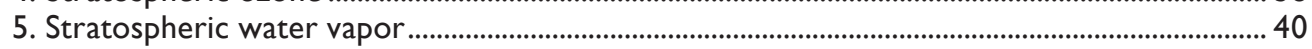

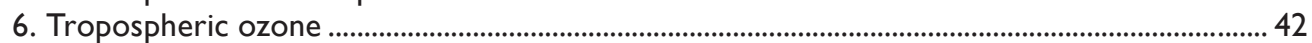

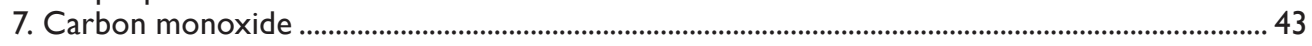

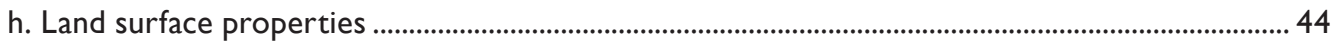

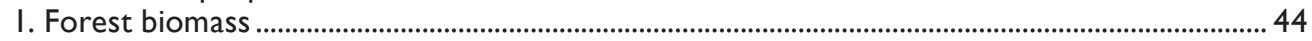

2. Land surface albedo dynamics .................................................................................................... 45

3. Terrestrial vegetation dynamics ........................................................................................ 46

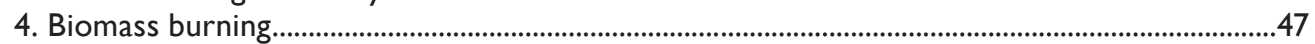

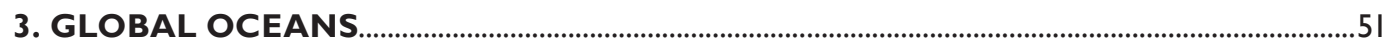

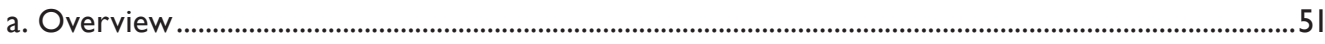

b. Sea surface temperatures ......................................................................................................

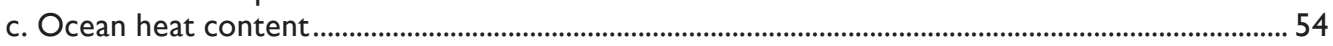

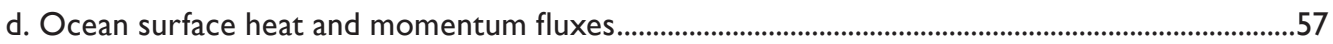

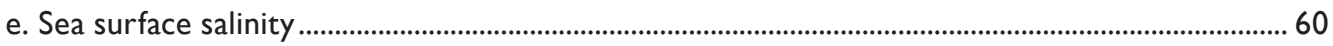

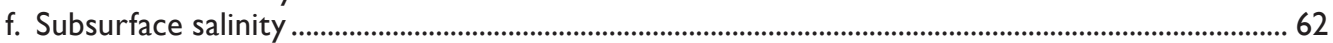

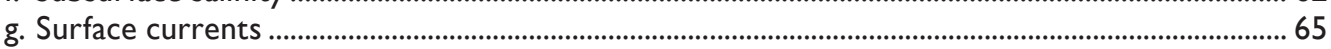

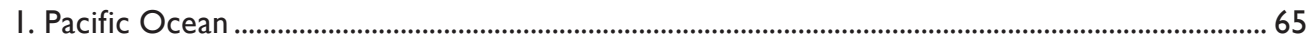

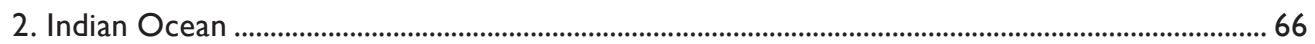


3. Atlantic Ocean

h. Meridional overturning circulation observations in the North Atlantic Ocean .............................67

i. Meridional oceanic heat transport in the Atlantic ......................................................................................69

j. Sea level variability and change ................................................................................................................

k. Global ocean carbon cycle.................................................................................................................... 73

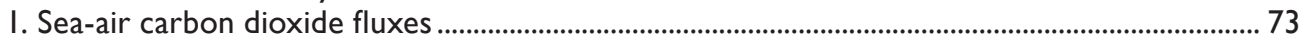

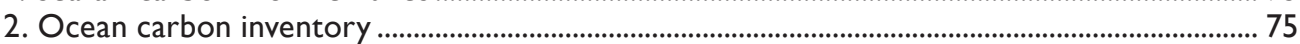

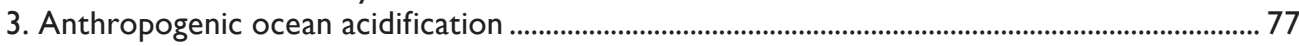

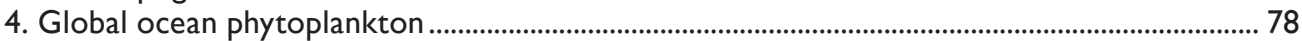

4. THE TROPICS

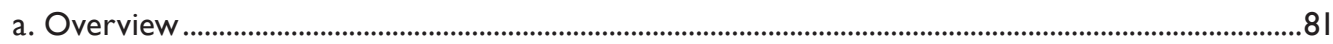

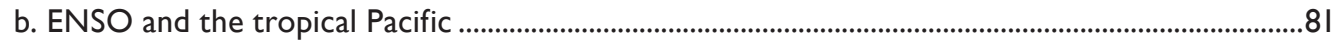

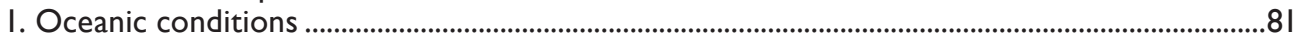

2. Atmospheric circulation ................................................................................................................... 82

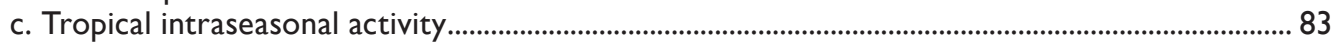

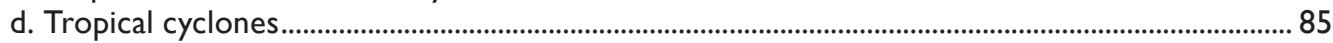

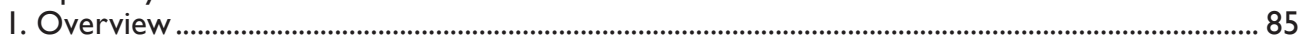

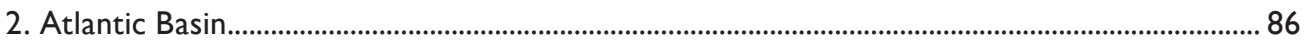

3. Eastern North Pacific and Central North Pacific Basins............................................................... 90

4. Western North Pacific Basin .......................................................................................................... 92

5. North Indian Ocean ..................................................................................................................... 94

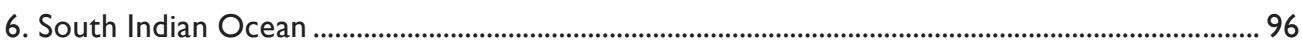

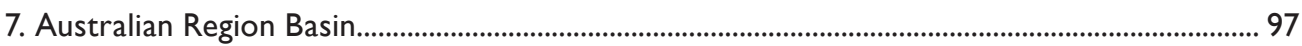

8. Southwest Pacific Basin .................................................................................................................. 98

e. Tropical cyclone heat potential ....................................................................................................... 99

f. Global monsoon summary …………………………........................................................................ I0I

g. Intertropical convergence zones......................................................................................................... 103

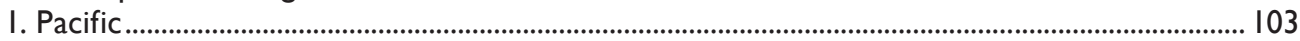

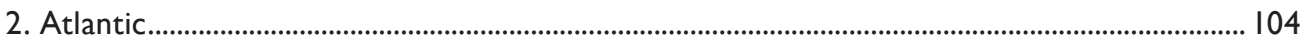

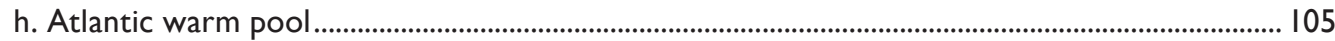

SIDEBAR 4.I: THE 20I3 ATLANTIC HURRICANE SEASON: BLIP OR FLIP? .......................................................... 106

i. Indian Ocean dipole ............................................................................................................................. 109

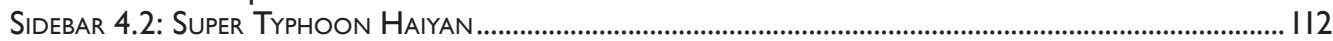

5. THE ARCTIC

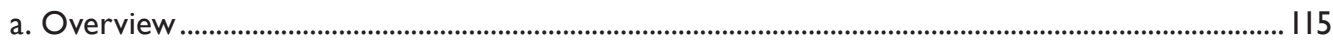

b. The lower atmosphere: air temperature, clouds and surface radiation ....................................... 115

I. Mean annual surface air temperature ........................................................................................... 115

2. Seasonal and regional surface air temperature variability......................................................... 116

3. Cloud cover and surface radiation budget................................................................................... 117

SIDEBAR 5.I: RAPID ARCTIC WARMING AND MIDLATITUDE WEATHER PATTERNS: ARE THEY CONNECTED?.......... II 8

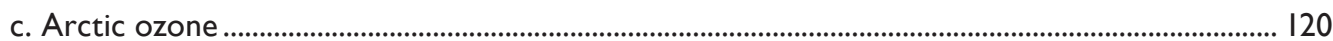

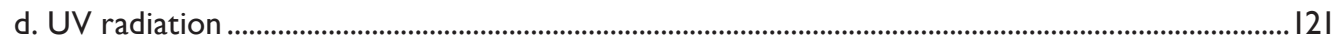

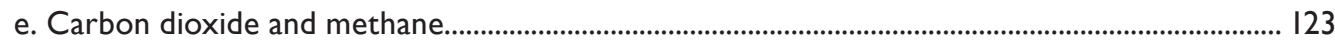

Sidebar 5.2: RadiATIVE ForCING BY BLACK CARBON IN THE ARCTIC ........................................................ 124

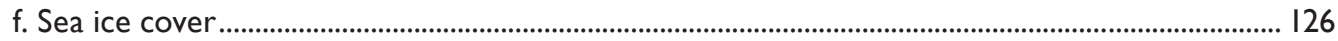

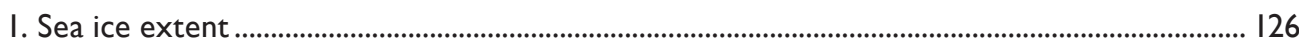

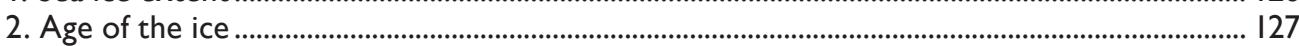

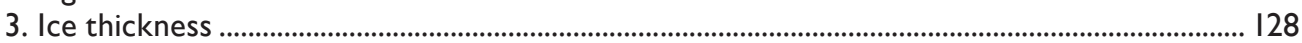

g. Ocean temperature and salinity ...................................................................................................... 128

I. Summer sea surface temperature ................................................................................................ 128

2. Upper ocean salinity ...................................................................................................................... 129

3. Freshwater content ......................................................................................................................... 129

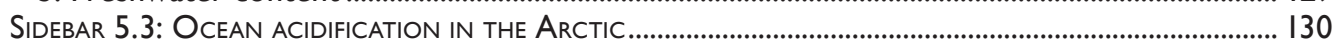

4. Pacific Water layer .................................................................................................................... $|3|$

5. Atlantic Water layer .................................................................................................................. 132 


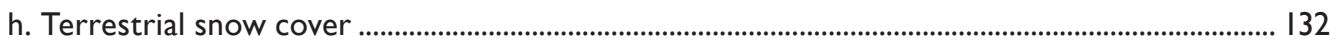

I. Snow cover extent ..................................................................................................................... 132

2. Snow cover duration ................................................................................................................... 132

3. Snow depth .............................................................................................................................. 132

4. Snow water equivalent.............................................................................................................. 132

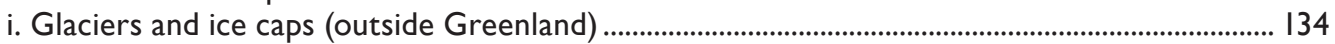

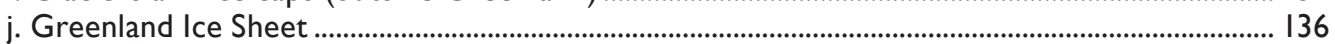

I. Satellite observations of surface melting and albedo................................................................... 136

2. Surface mass balance and river discharge............................................................................... 136

3. Surface air temperature observations ........................................................................................ 137

4. Satellite observations of ice mass and marine-terminating glaciers............................................ 137

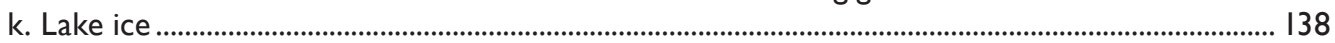

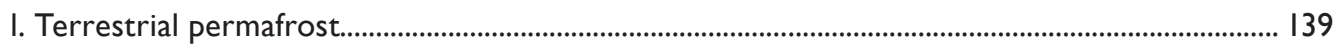

I. Permafrost temperature.............................................................................................................. 139

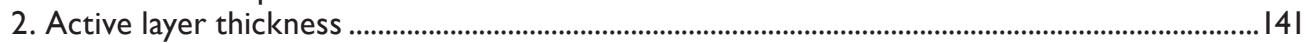

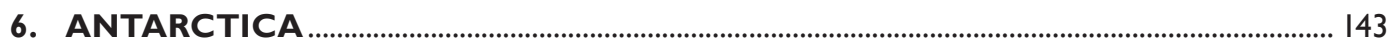

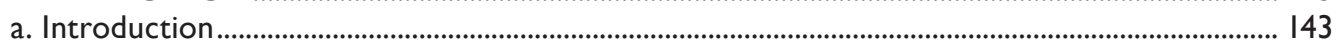

b. Atmospheric circulation ...................................................................................................................... 143

c. Surface manned and automatic weather station observations ....................................................... 145

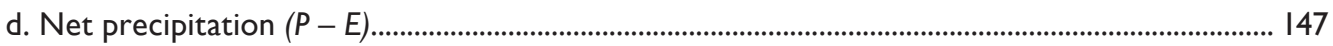

e. 2012/13 Seasonal melt extent and duration ............................................................................... 149

f. Sea ice extent, concentration, and duration.............................................................................. 150

g. Ozone depletion ............................................................................................................................... 152

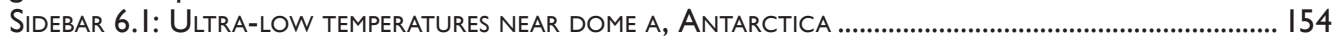

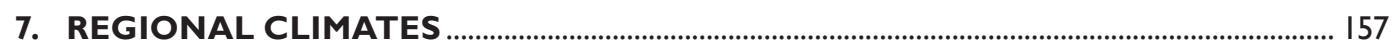

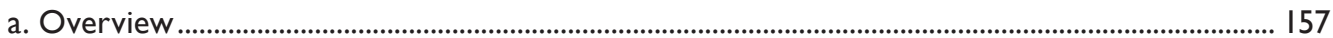

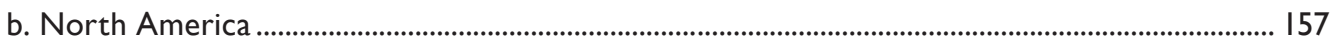

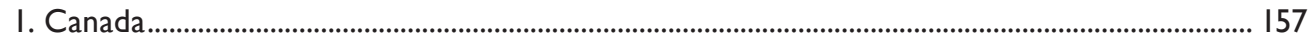

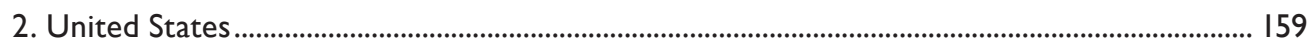

Sidebar 7.I: TRENDS IN SURFACE RADIATION OVER THE UNITED STATES SINCE THE MID-1990s ...........................161

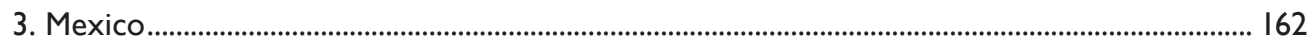

c. Central America and the Caribbean ............................................................................................ 164

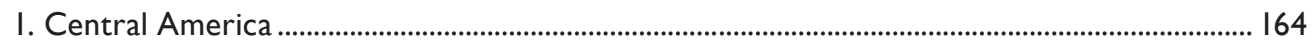

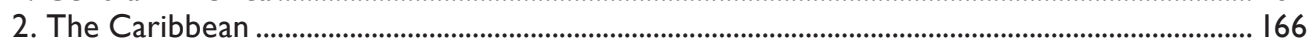

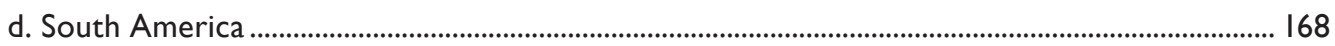

I. Northern South America and the tropical Andes..................................................................... 169

2. Tropical South America east of the Andes .................................................................................. 170

3. Southern South America................................................................................................................ 172

Sidebar 7.2: Extreme heat wave over Central southern South America during DeCember 2013 .... 173

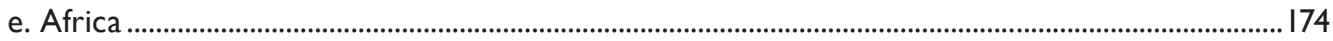

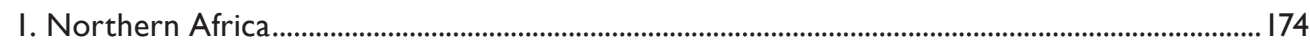

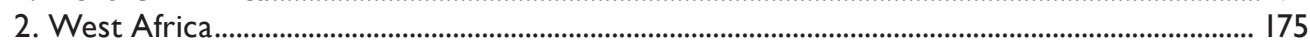

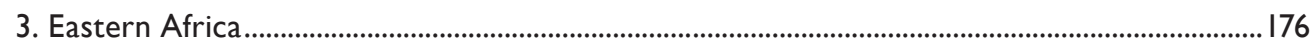

4. Southern Africa...................................................................................................................... 178

5. Western Indian Ocean countries................................................................................................. 180

f. Europe and the Middle East....................................................................................................... $|8|$

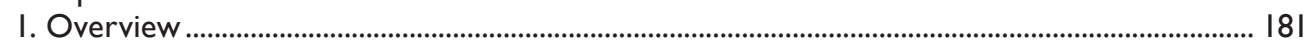

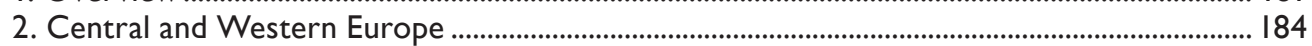

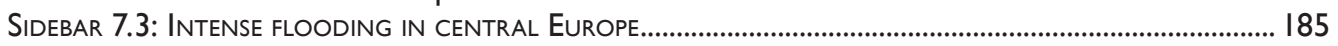

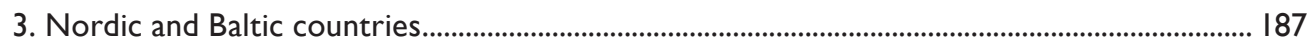

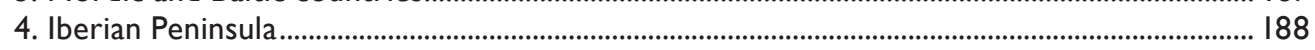

5. Mediterranean, Italy, and Balkan States ..................................................................................... 189

6. Eastern Europe ............................................................................................................................. 190

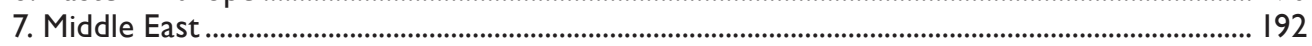




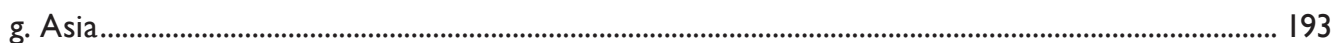

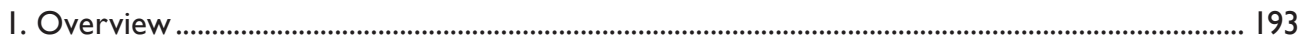

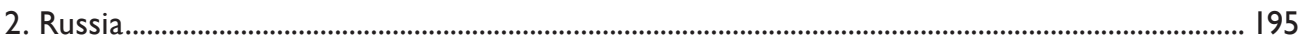

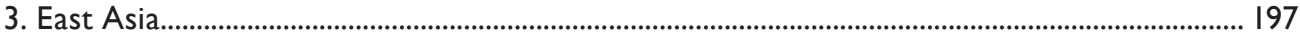

Sidebar 7.4: Extreme conditions in East Asia IN Summer 2013......................................................... 199

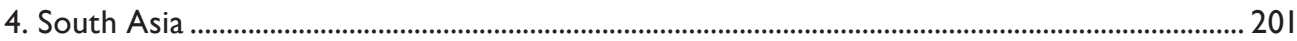

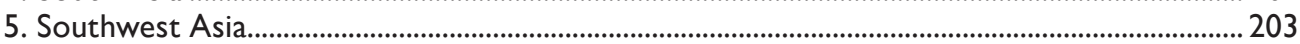

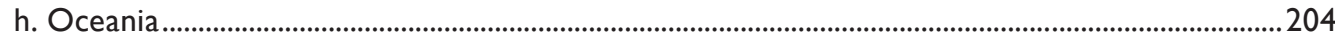

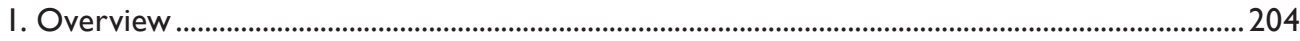

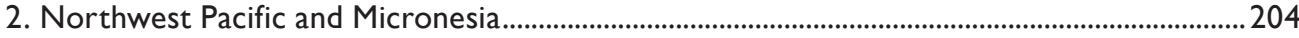

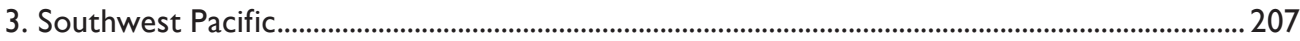

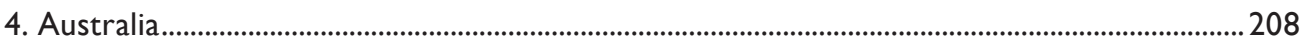

Sidebar 7.5: A YeAR Of PERSISTENT AND WIDESPREAD heAT fOR AUSTRALIA ................................................2II

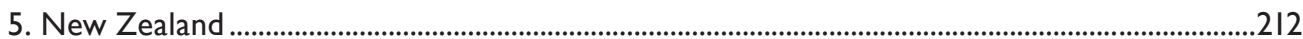

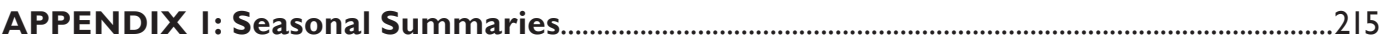

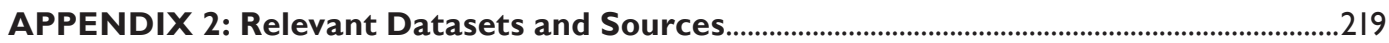

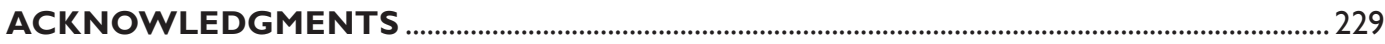

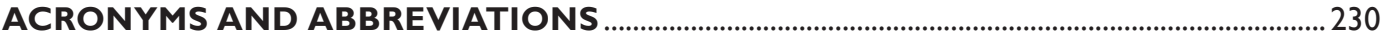

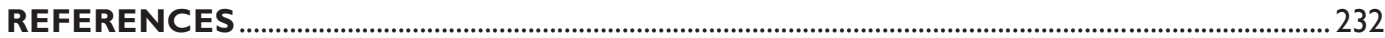




\section{ABSTRACT—J. BLUNDEN AND D. S. ARNDT}

In 2013 , the vast majority of the monitored climate variables reported here maintained trends established in recent decades. ENSO was in a neutral state during the entire year, remaining mostly on the cool side of neutral with modest impacts on regional weather patterns around the world. This follows several years dominated by the effects of either La Niña or El Niño events.

According to several independent analyses, 2013 was again among the 10 warmest years on record at the global scale, both at the Earth's surface and through the troposphere. Some regions in the Southern Hemisphere had record or near-record high temperatures for the year. Australia observed its hottest year on record, while Argentina and New Zealand reported their second and third hottest years, respectively. In Antarctica, Amundsen-Scott South Pole Station reported its highest annual temperature since records began in 1957. At the opposite pole, the Arctic observed its seventh warmest year since records began in the early 20th century. At 20-m depth, record high temperatures were measured at some permafrost stations on the North Slope of Alaska and in the Brooks Range. In the Northern Hemisphere extratropics, anomalous meridional atmospheric circulation occurred throughout much of the year, leading to marked regional extremes of both temperature and precipitation. Cold temperature anomalies during winter across Eurasia were followed by warm spring temperature anomalies, which were linked to a new record low Eurasian snow cover extent in May.

Minimum sea ice extent in the Arctic was the sixth lowest since satellite observations began in 1979. Including 2013 , all seven lowest extents on record have occurred in the past seven years. Antarctica, on the other hand, had above-average sea ice extent throughout 2013, with 116 days of new daily high extent records, including a new daily maximum sea ice area of 19.57 million $\mathrm{km}^{2}$ reached on I October.

ENSO-neutral conditions in the eastern central Pacific Ocean and a negative Pacific decadal oscillation pattern in the North Pacific had the largest impacts on the global sea surface temperature in 2013 . The North Pacific reached a historic high temperature in 2013 and on balance the globally-averaged sea surface temperature was among the 10 highest on record. Overall, the salt content in nearsurface ocean waters increased while in intermediate waters it decreased. Global mean sea level continued to rise during 2013, on pace with a trend of $3.2 \mathrm{~mm} \mathrm{yr}^{-1}$ over the past two decades. A portion of this trend $(0.5 \mathrm{~mm}$ $\left.\mathrm{yr}^{-1}\right)$ has been attributed to natural variability associated with the Pacific decadal oscillation as well as to ongoing contributions from the melting of glaciers and ice sheets and ocean warming.

Global tropical cyclone frequency during 2013 was slightly above average with a total of 94 storms, although the North Atlantic Basin had its quietest hurricane season since 1994. In the Western North Pacific Basin, Super Typhoon Haiyan, the deadliest tropical cyclone of 2013, had I-minute sustained winds estimated to be $170 \mathrm{kt}$ $\left(87.5 \mathrm{~m} \mathrm{~s}^{-1}\right)$ on 7 November, the highest wind speed ever assigned to a tropical cyclone. High storm surge was also associated with Haiyan as it made landfall over the central Philippines, an area where sea level is currently at historic highs, increasing by $200 \mathrm{~mm}$ since 1970 .

In the atmosphere, carbon dioxide, methane, and nitrous oxide all continued to increase in 2013. As in previous years, each of these major greenhouse gases once again reached historic high concentrations. In the Arctic, carbon dioxide and methane increased at the same rate as the global increase. These increases are likely due to export from lower latitudes rather than a consequence of increases in Arctic sources, such as thawing permafrost. At Mauna Loa, Hawaii, for the first time since measurements began in 1958, the daily average mixing ratio of carbon dioxide exceeded 400 ppm on 9 May.

The state of these variables, along with dozens of others, and the 2013 climate conditions of regions around the world are discussed in further detail in this 24th edition of the State of the Climate series. 
I. INTRODUCTION-D. S. Arndt, J. Blunden, and K. M. Willett

We are pleased to present and be part of this 24 th edition of the annual State of the Climate series, which began as NOAA's Climate Assessment, and now completes its 19th consecutive edition associated with the Bulletin of the American Meteorological Society (BAMS).

By fate of the calendar and the synching of multiyear schedules, this is one of several comprehensive reports on the climate system to be released in 2014, following some components of the Fifth Assessment Report of the Intergovernmental Panel on Climate Change, and the United States' National Climate Assessment, and others. This State of the Climate series is unique compared to these larger assessments for its strict focus on the state of the physical climate system, and our capacity to observe it. It consciously defers the attribution of specific events to other studies.

In some ways this effort can be viewed as the "annual physical" of the climate system. Like any annual physical, diagnoses are more robust when based upon data from multiple independent tests, e.g., today's measurements are richer and more meaningful when they are considered in context with past observations; and changes are best detected and monitored when done on a regular basis.

The chapter and section editors are the heart of this series, and have the challenging role of balancing the desire for more and broader content, while constructing the most concise report possible. Global-scale incoming solar radiation is new in this report, as is surface humidity over land areas. Some atmospheric composition sections have been reworked, including the addition of a tropospheric ozone section, following its introduction as a sidebar last year. The Tropics chapter has been refreshed, including new tropical cyclone basin definitions and a global monsoon analysis.

For most of 2013, it appeared that extreme heat and drought in Australia, reminiscent of the United States' experience in 2012, would be the singular and foremost climate story of the year. However, November saw the development, intensification, and catastrophic landfall of Super Typhoon Haiyan. Although Haiyan's meteorological life cycle is measured in weeks, its impact on humanity within and beyond the region will be measured in generations. In a physical climate sense, the seas over which it evolved have undergone changes on the scales of climate variability and change. SSTs were record warm in much the region, and the region's sea level rise has outpaced the global average in recent years. For these reasons, it was most appropriate for the front and back covers of this report to reflect its importance as a meteorological, climatological, and human event.

On the topic of the intersection of climate and humanity, we thank and recognize our authors throughout the world who organize the data and create the content of this report. We are proud of the ever-increasing international participation in this series. Many of our authors, and the institutions they represent, must deal with disruptions in the course of their work. Despite the demise of observing systems, and in the face of budgetary pressures, and even civil unrest, their contributions make this report and our profession more whole. We are fortunate to share this space as we share our climate system itself-with so many fine colleagues.

An overview of findings is presented in the Abstract, Plate 1.1, and Fig. 1.1. Chapter 2 features globalscale climate variables; Chapter 3 highlights the global oceans; and Chapter 4 covers tropical climate phenomena including tropical cyclones. The Arctic and Antarctic respond differently through time and are reported in separate chapters (5 and 6, respectively). Chapter 7 provides a regional perspective authored largely by local government climate specialists. Sidebars included in each chapter are intended to provide background information on a significant climate event from 2013, a developing technology, or emerging dataset germane to the chapter's content. A list of relevant datasets and their sources for all chapters is provided as an Appendix. 


\section{ESSENTIAL CLIMATE VARIABLES — K. M. WILLET, J. BLUNDEN,}

AND D. S. ARNDT

Time series of major climate indicators are again presented in this introductory chapter. Many of these indicators are essential climate variables (ECVs), originally defined in GCOS 2003 and updated again by GCOS in 2010.

The following ECVs, included in this edition, are considered "fully monitored", in that they are observed and analyzed across much of the world, with a sufficiently long-term dataset that has peerreviewed documentation:

- Atmospheric Surface: air temperature, precipitation, air pressure, water vapor, wind speed and direction.

- Atmospheric Upper Air: earth radiation budget, temperature, water vapor.

- Atmospheric Composition: carbon dioxide, methane, other long-lived gases, ozone.

- Ocean Surface: temperature, salinity, sea level, sea ice, current, ocean color, phytoplankton.

- Ocean Subsurface: temperature, salinity.

- Terrestrial: snow cover, albedo.
ECVs in this edition that are considered "partially monitored", meeting some but not all of the above requirements, include:

- Atmospheric Upper Air: cloud properties.

- Atmospheric Composition: aerosols and their precursors.

- Ocean Surface: carbon dioxide, ocean acidity.

- Ocean Subsurface: current, carbon.

- Terrestrial: soil moisture, permafrost, glaciers and ice caps, river discharge, groundwater, ice sheets, fraction of absorbed photosynthetically- active radiation, biomass, fire disturbance.

ECVs that are expected to be added in the future include:

- Atmospheric Surface: surface radiation budget.

- Atmospheric Upper Air: wind speed and direction.

- Ocean Surface: sea state.

- Ocean Subsurface: nutrients, ocean tracers, ocean acidity, oxygen.

- Terrestrial: water use, land cover, lakes, leaf area index, soil carbon.

PLATE I.I. Global (or representative) average time series for many of the essential climate variables presented in this report. Anomalies are shown relative to the base period in parentheses although original base periods may differ. Square brackets are the respective numbers of reanalyses, satellites, and in situ in that order. (a) N. Hemisphere lower stratospheric ozone (March) $[0,5,1]$; (b) S. Hemisphere lower stratospheric ozone (October) $[0,5,1]$; (c) Apparent transmission (Mauna Loa) [0,0,I]; (d) Lower stratospheric temperature [3,3,4]; (e) Lower tropospheric temperature [3,2,4]; (f) Surface temperature [4,0,4]; (g) Arctic sea ice extent (max and min (dashed)) [0,0,2]; (h) Antarctic sea ice extent (max and $\min$ (dashed)) [0,0,2]; (i) Glacier cumulative mean specific balance $[0,0,1]$; (j) $N$. Hemisphere snow cover extent $[0,1,0]$; (k) Lower stratospheric water vapor $[0,1,0]$; (I) Cloudiness [I,6, I]; (m) Total column water vapor over land [0, I, 2]; (n) Total column water vapor over ocean [0,2,0]; (o) Specific humidity over land [3,0,4]; (p) Specific humidity over ocean [3, I,3]; (q) Relative humidity over land [2,0,4]; (r) Relative humidity over ocean [2,0,2]; (s) Precipitation over land [0,0,3]; (t) Precipitation over ocean [0,3,0]; (u) Ocean heat content $(0-700 \mathrm{~m})$ [0,0,4]; (v) Sea level rise [0, I,0]; (w) Lower tropospheric ozone [0,I,0]; (x) Land wind speed [0,0,2]; (y) Ocean wind speed [4, I,2]; (z) Biomass burning [0,2,0]; (aa) Soil moisture $[0,1,0] ;(a b)$ Terrestrial groundwater storage $[0,1,0] ;(a c)$ FAPAR $[0,1,0] ;(a d)$ Land surface albedo in visible and infrared (dashed) $[0,2,0]$. 


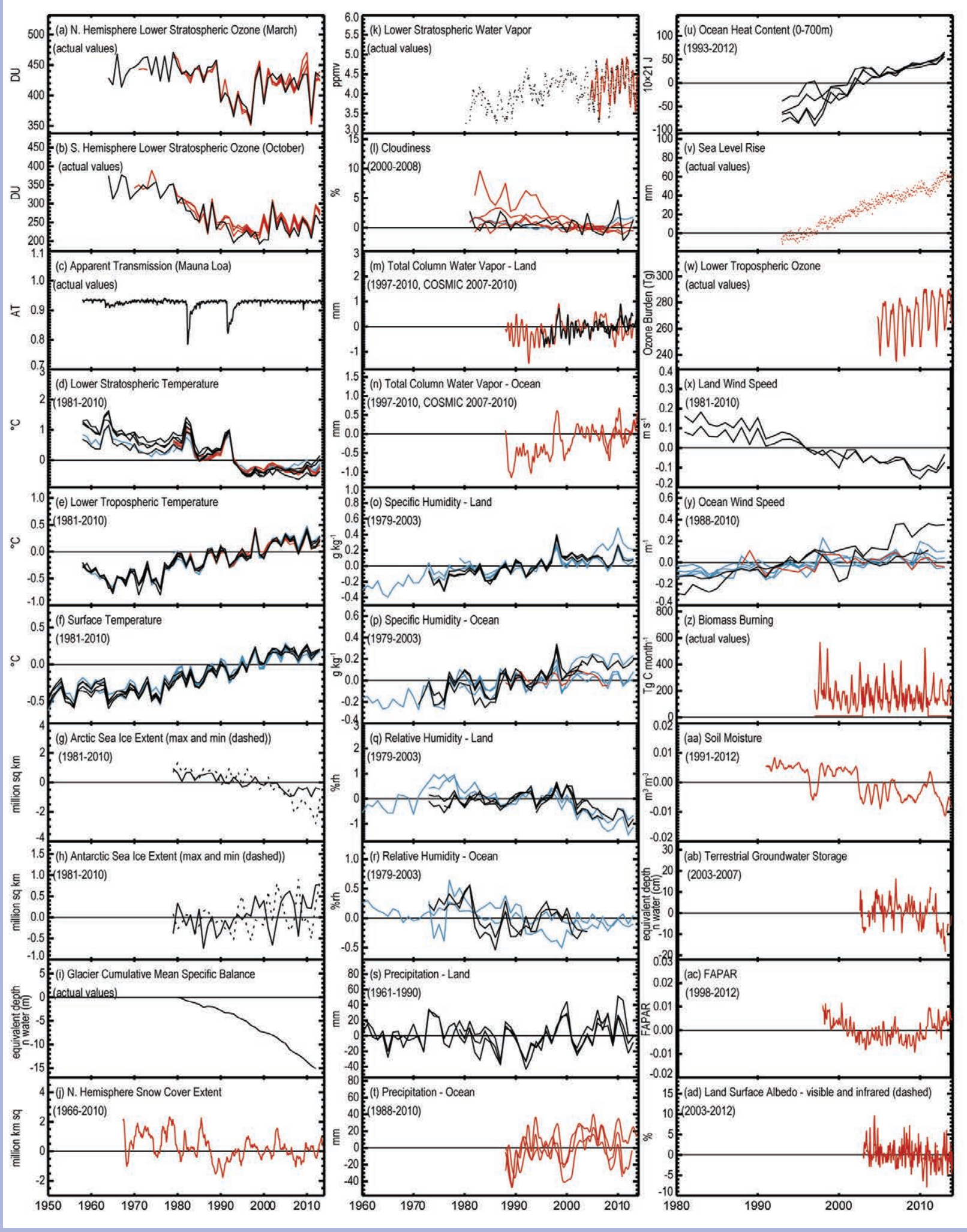




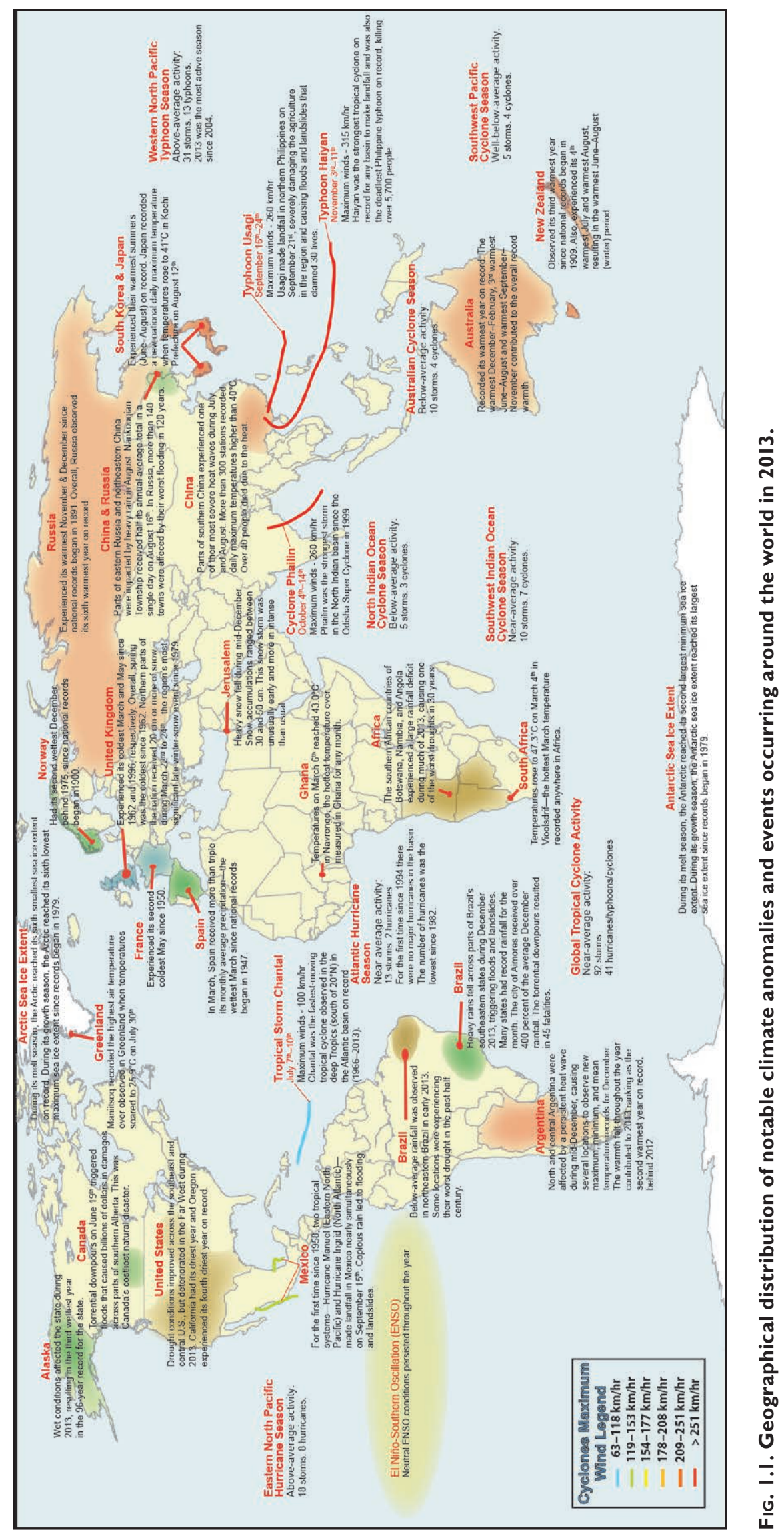


2. GLOBAL CLIMATE-K. M. Willett, A. J. Dolman, D. F. Hurst, J. Rennie, and P. W. Thorne, Eds.

a. Overview -P. W. Thorne, A. J. Dolman, D. F. Hurst, J. Rennie, and K. M. Willett

After several years strongly influenced by either La Niña or El Niño events, 2013 was the first full year without either of these phenomena present. Without the typical large-scale dynamical teleconnections driven by variability within the El Niño-Southern Oscillation (ENSO), 2013 was dominated by patterns of regional extremes of temperature and especially the hydrological cycle. Regional variations were particularly notable in the Northern Hemisphere extratropics where anomalously meridional atmospheric circulation occurred throughout much of the year, leading to marked regionally coherent extremes of heat/cold and dry/wet.

This year, an analysis of temperature extremes since 1950 is introduced in Sidebar 2.1, since societal impacts are more often related to extreme events than changes in the mean climate. The year 2013 ranked within the top 10 years for the frequency of warm days and bottom 10 years for the frequency of cool days. The global average maximum temperature index which tracks extreme daytime heat was also within the top 10 highest years, largely driven by the record-warm summer in Australia.

New sections include an updated solar transmission record with a view to subsequent global analyses. New data products have also been introduced. The JRA-55 reanalysis now extends back to 1958, providing a second long-term reanalysis for comparison. The HadISDH surface humidity product now includes land relative humidity and concurs with previous indications of declining relative humidity over land since 2000. Conversely, it was not possible to update total column water vapor from both groundbased GPS and radiosondes this year.

Globally, 2013 was again one of the 10 warmest years on record, both at the surface and in the troposphere, according to the large range of available estimates; however, there is uncertainty in the precise rankings of any given year.

Long-lived greenhouse gases carbon dioxide $\left(\mathrm{CO}_{2}\right)$, methane $\left(\mathrm{CH}_{4}\right)$, and nitrous oxide $\left(\mathrm{N}_{2} \mathrm{O}\right)$ continued to increase in the atmosphere during 2013. On 9 May, for the first time since $\mathrm{CO}_{2}$ measurements began in 1958 at Mauna Loa, Hawaii, the daily average mole fraction exceeded 400 parts per million (ppm). The global abundance of tropospheric ozone, a greenhouse gas and pollutant, also continued to grow but the root causes have not yet been identified. Global atmospheric burdens of ozone-depleting chlorofluorocarbons (CFCs) continued to decline while those of their replacements increased. Stratospheric ozone levels remain well below the pre-1980 benchmark of ozone layer "recovery". Stratospheric water vapor abundance declined in 2013 after a 6-7 year period of increase that followed the rapid drop in 2000. Aerosol optical depth and carbon monoxide (CO) column measurements by satellites continue to demonstrate the importance of boreal and tropical biomass fires as global sources.

Early indications from the limited available sample of global glaciers are that 2013 was the 24th consecutive year of net glacier loss globally. Snow cover continued to decline in the Northern Hemisphere, as did soil moisture, albeit less strongly due to the absence of a strong ENSO signal. Noticeable also were declines in the Fraction of Absorbed Photosynthetically Active Radiation (FAPAR) over north east Brazil (also a region of a dry soil anomaly) and Siberia. Global fire activity was relatively low during 2013, but regionally strong fire activity caused severe air pollution problems in some regions, including Siberia and Sumatra.

Where available, time series and anomaly maps of the variables described in this chapter are shown in Plates 1.1 and 2.1, respectively. Most anomalies are referenced against a standard 1981-2010 climatology which covers the period of many satellite observations and all reanalysis products. Many sections refer to online figures that can be found here: http://dx.doi.org/10.1175/2014BAMSStateoftheClimate.2. 
(a)

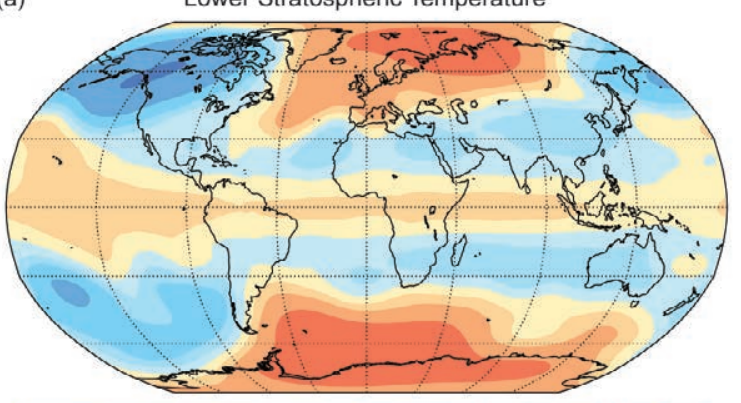

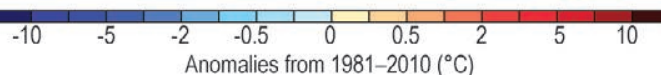

(b)
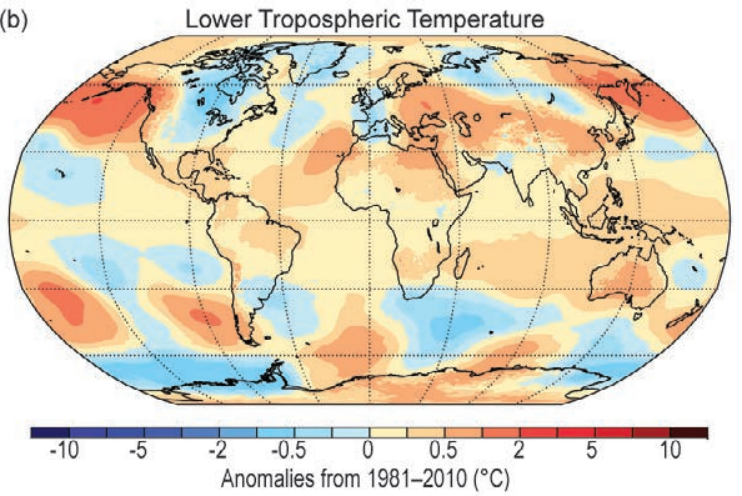

(c)
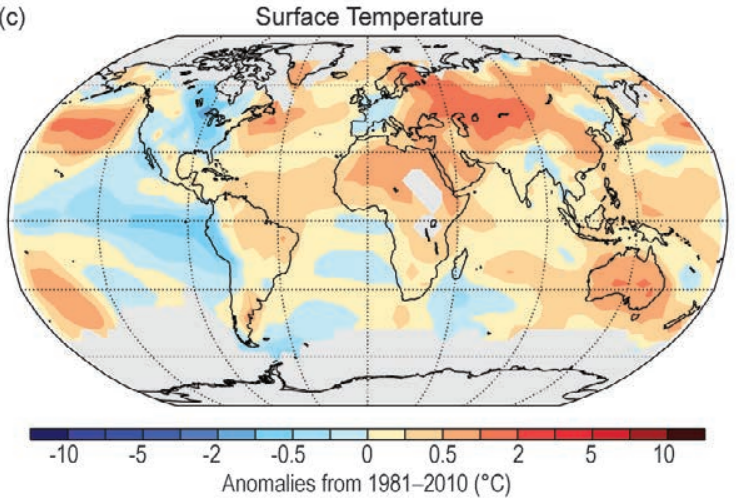

(d)
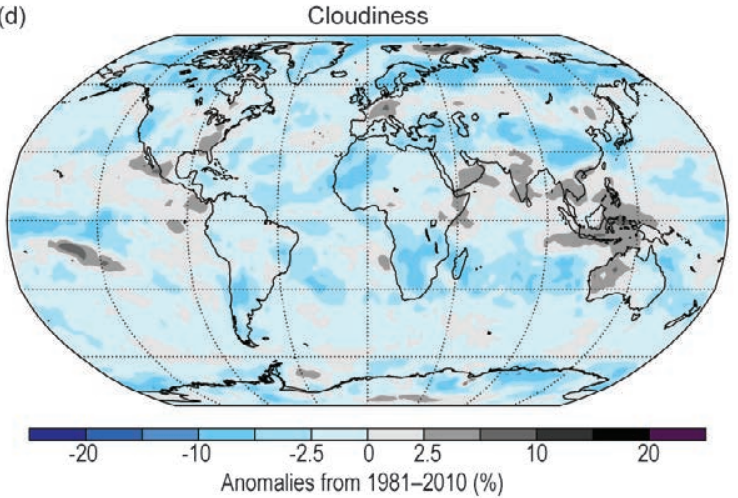

(e)
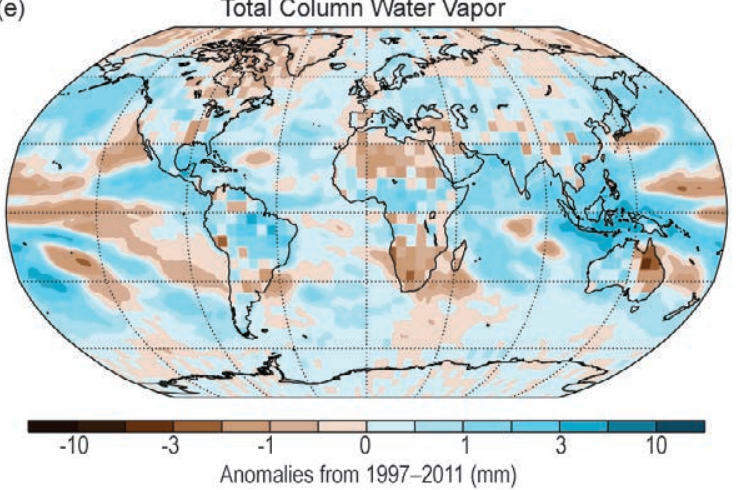

(f)
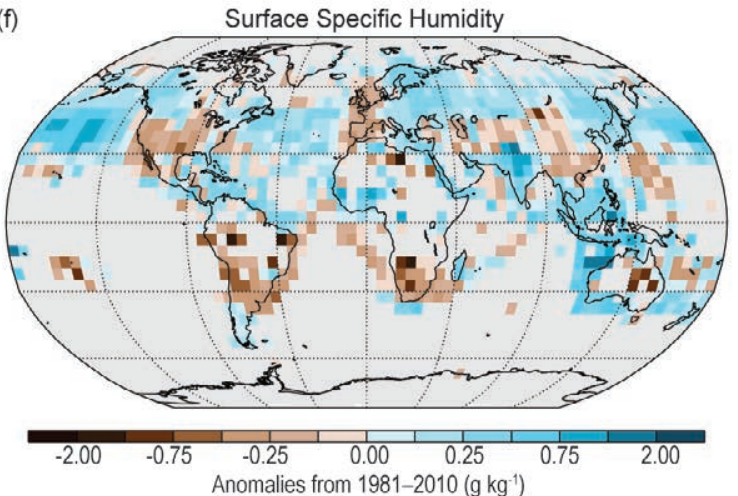

(g)
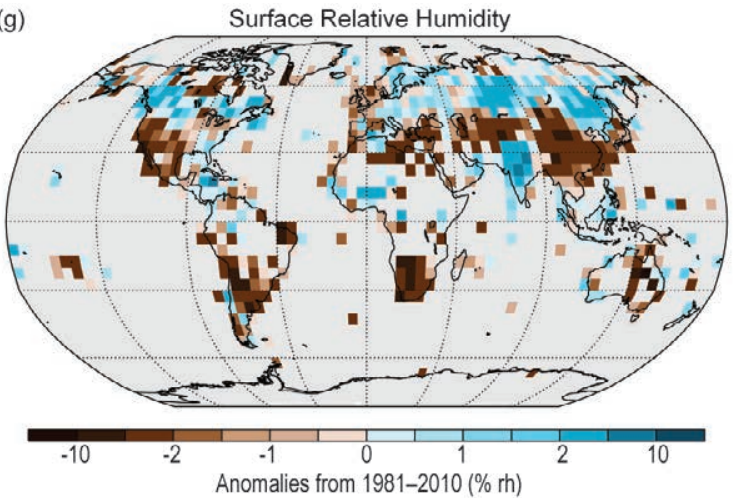

(h)

Precipitation

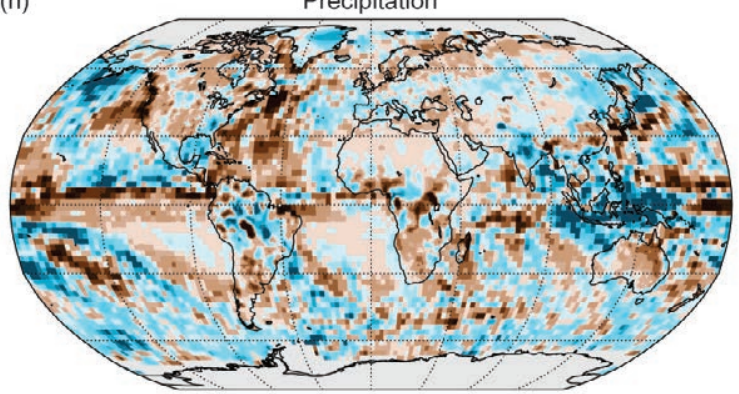

$\begin{array}{ccccccc}-500 & -300 & -100 & 0 & 100 & 300 & 500 \\ & & \text { Anomalies from } 1988-2010(\mathrm{~mm}) & \end{array}$ 

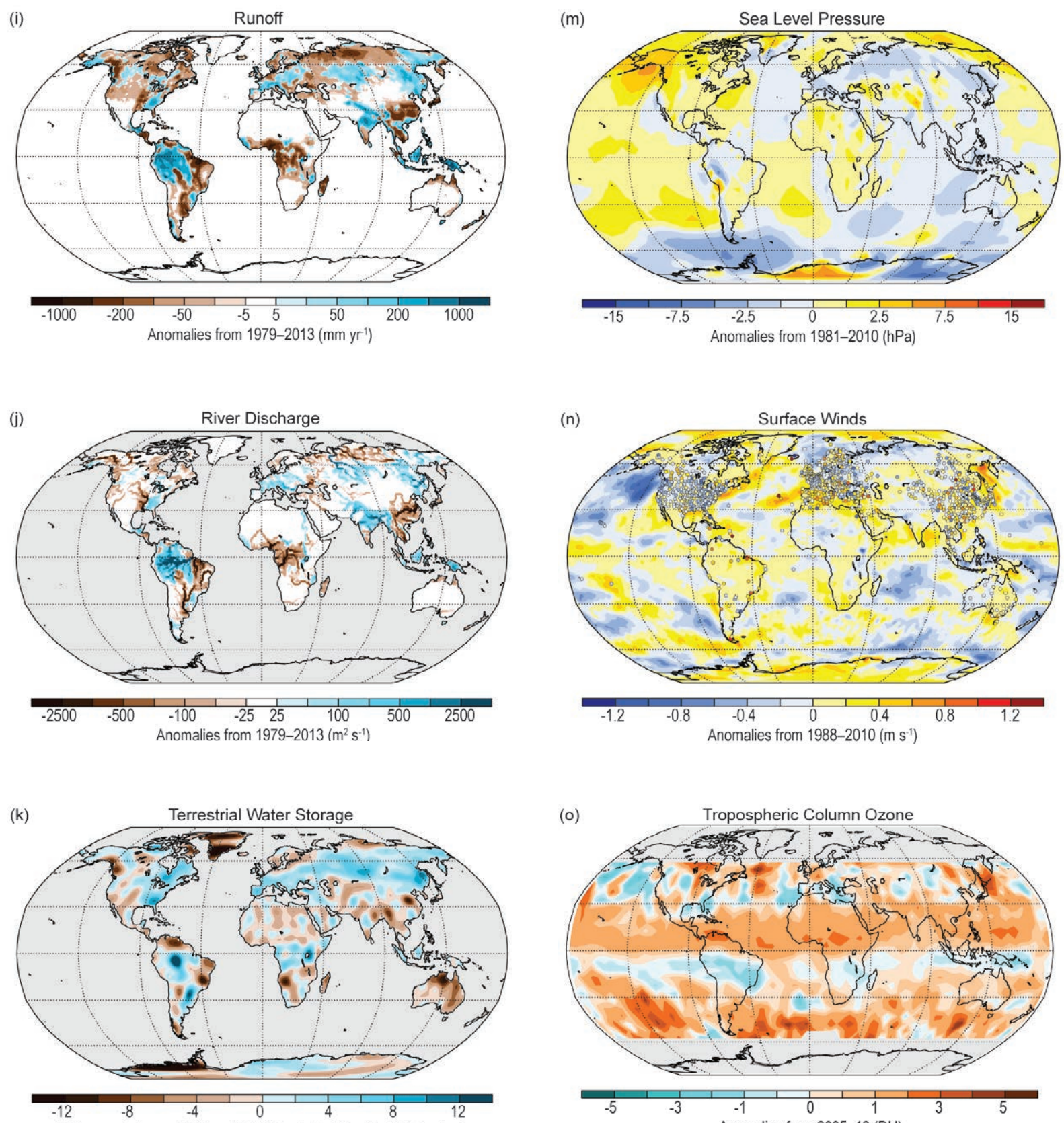

Difference between 2013 and 2012 Equivalent Depth of Water (cm)
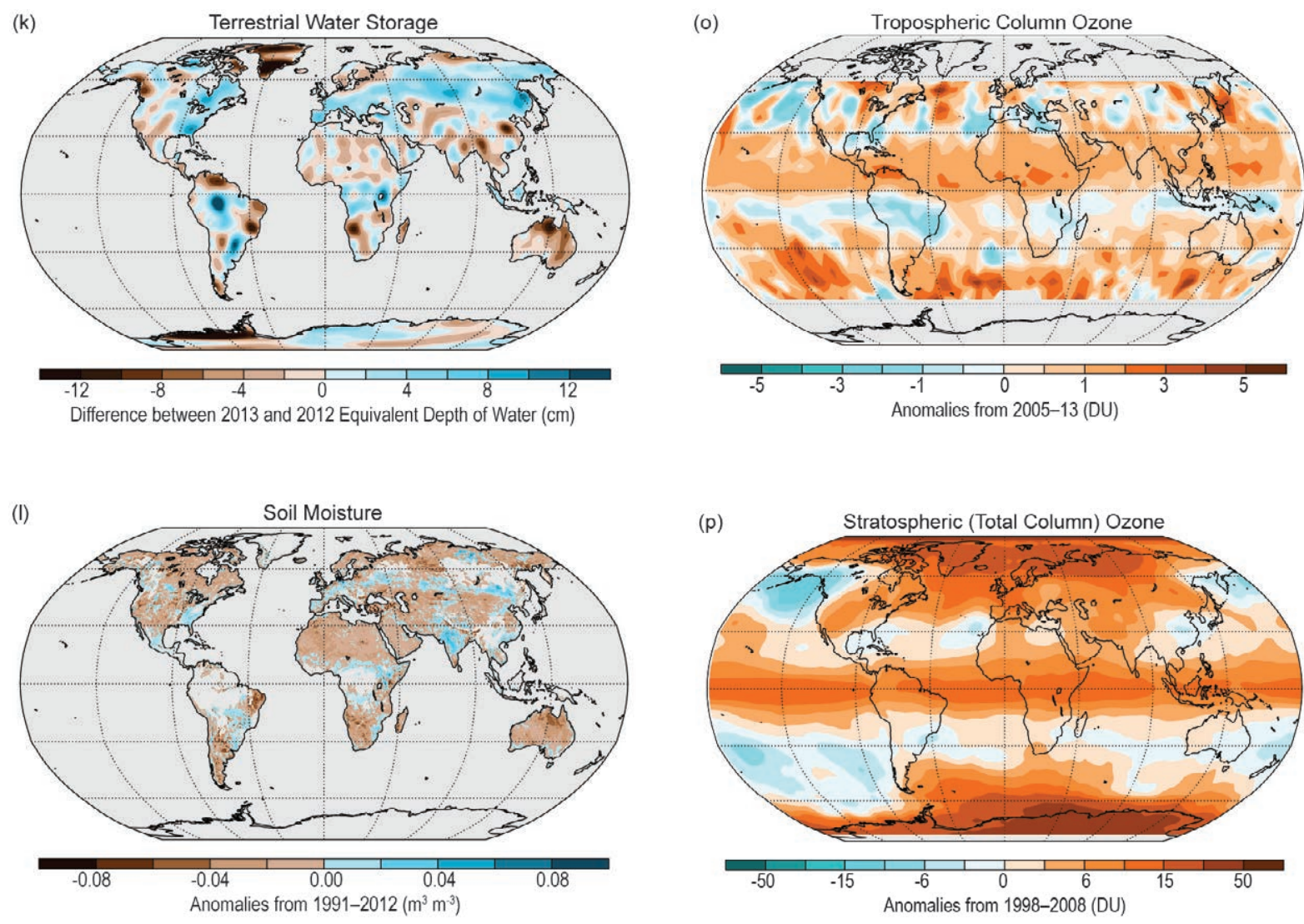

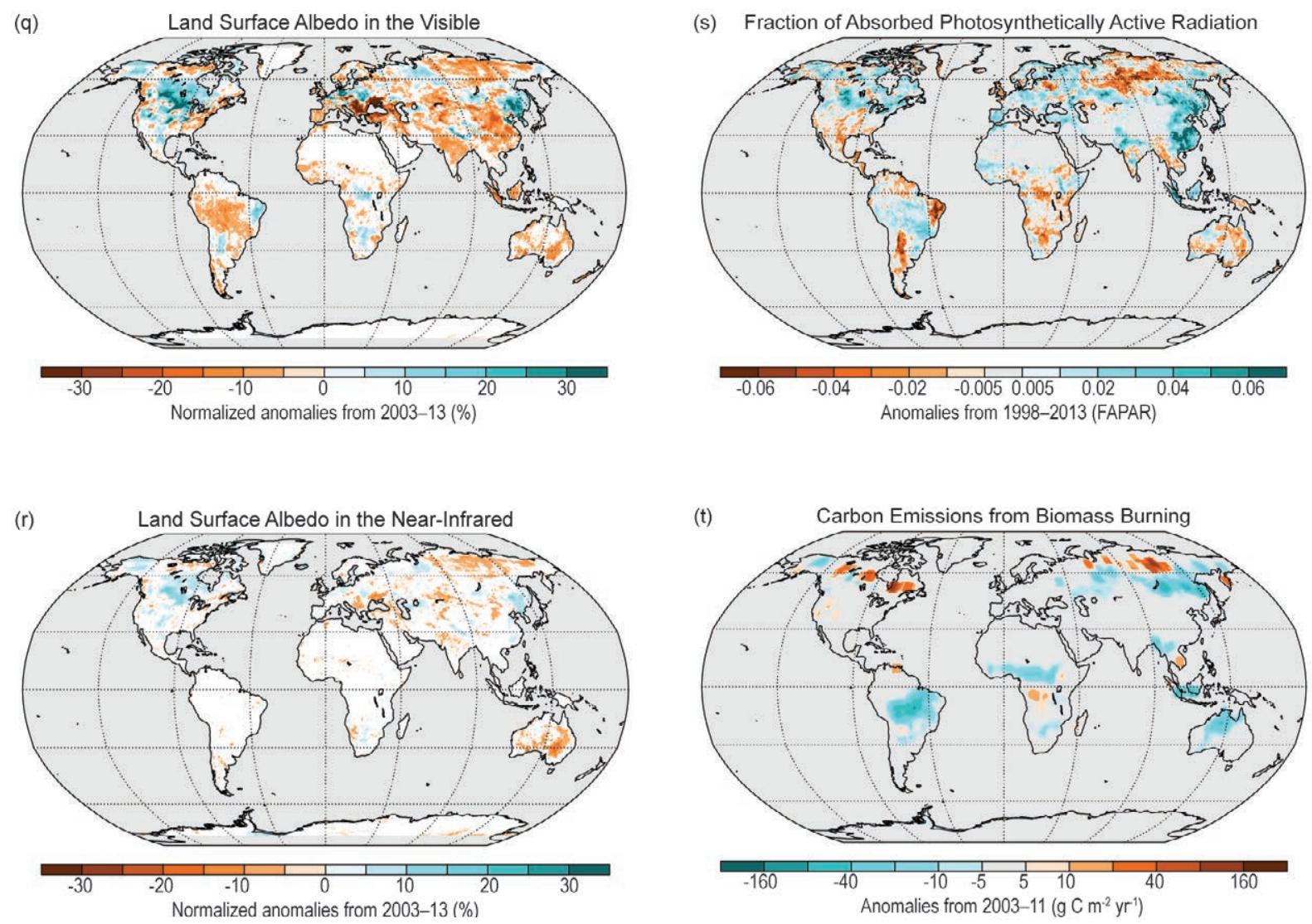

PLATE 2.I. Annually-averaged global spatial anomaly maps for many of the ECVs presented in this chapter.

(a) ERA-Interim 2013 anomalies of lower stratospheric temperature.

(b) ERA-Interim 2013 anomalies of lower tropospheric temperature.

(c) NOAA NCDC 2013 anomalies of surface temperature.

(d) PATMOS-x 2013 anomalies of cloudiness.

(e) SSMIS and WindSat (oceans) and COSMIC (land) 2013 anomalies of total column water vapor.

(f) Blended NOCSv2.0 (oceans) and HadISDH (land) 2013 anomalies of surface specific humidity.

(g) HadISDH (land) 2013 anomalies of surface relative humidity.

(h) GHCNMv2 (land) and RSS (ocean) 2013 anomalies of precipitation.

(i) ELSE system 2013 annual anomalies of runoff.

(j) ELSE system 2013 annual anomalies of river discharge.

(k) GRACE 2013 difference from 2012 anomalies of terrestrial water storage.

(I) ESA CCI ECV SM 2013 anomalies of soil moisture.

(m) HadSLP2r 2013 anomalies of sea level pressure.

(n) WindSat and SSMIS FI7 satellite (ocean) and ISD-Lite (land points) and ERA-Interim (land grids and poles) 2013 anomalies of land surface wind speed.

(o) OMI/MLS 2013 anomalies of tropospheric column ozone.

(p) GOME-2 2013 anomalies (using GOME, SCIAMACHY, GOME-2 for the climatology) of stratospheric (total column) ozone.

(q) MODIS White Sky broadband 2013 anomalies for surface albedo in the visible domain.

(r) MODIS White Sky broadband 2013 anomalies for surface albedo in the near-infrared domain.

(s) SeaWiFS/MERIS/MODIS TIP 2013 anomalies of the Fraction of Absorbed Photosynthetically Active Radiation (FAPAR).

(t) MACC 2013 anomalies in biomass burning. 
Table 2.I. Temperature anomalies $\left({ }^{\circ} \mathrm{C}\right)$ and uncertainties (where available) for 2013 with respect to the $1981-2010$ base period. For ERA-Interim, the values shown are the analyzed 2-m temperature anomalies. Note that the land values computed for HadCRUT.4.2.0.0 used the CRUTEM-4.2.0.0 data set, the ocean values were computed using the HadSST.3.I.0.0 data set, and the global land and ocean values used the HadCRUT4.2.0.0 data set. Uncertainty ranges are represented in terms of a $95 \%$ confidence interval, with the exception of JMA which has a $90 \%$ confidence interval.

\begin{tabular}{|c|c|c|c|c|c|}
\hline Global & NASA-GISS & HadCRUT & $\begin{array}{c}\text { NOAA- } \\
\text { NCDC }\end{array}$ & JMA & $\begin{array}{c}\text { ERA- } \\
\text { Interim }\end{array}$ \\
\hline Land & $+0.38 \pm 0.10$ & $+0.32 \pm 0.17$ & $+0.38 \pm 0.19$ & +0.34 & +0.42 \\
\hline Ocean & $+0.13 \pm 0.10$ & $+0.17 \pm 0.07$ & $+0.14 \pm 0.03$ & +0.14 & +0.08 \\
\hline $\begin{array}{c}\text { Land \& } \\
\text { Ocean }\end{array}$ & $+0.21 \pm 0.05$ & $+0.20 \pm 0.10$ & $+0.21 \pm 0.09$ & $+0.20 \pm 0.12$ & +0.18 \\
\hline
\end{tabular}

b. Temperature

I) Surface temperature-A. SánchezLugo, J. J. Kennedy, and P. Berrisford

The year 2013 was the warmest since 2010 and among the 10 warmest years since records began in the mid- to late 1800s. According to four independent observational analyses (NASA-GISS, Hansen et al. 2010; HadCRUT4, Morice et al. 2012; NOAA-NCDC, Smith et al. 2008; JMA, Ishihara 2006), the 2013 globally-averaged surface temperature was $0.20^{\circ}-0.21^{\circ} \mathrm{C}$ (Table 2.1) above the 1981-2010 average and ranked from second to sixth warmest, depending on the dataset considered.

Each of the four independent teams analyzes air temperatures from weather stations over land and sea surface temperatures (SST) observed from ships and buoys and then merges the land and SST datasets to form a global analysis. While their methods differ, leading to minor differences in anomalies and ranks, all four analyses are in close agreement (Fig. 2.1). The main difference between the four datasets is how each methodology treats areas with little to no data (see Kennedy et al. 2010 for additional details). Recent research (Cowtan and Way 2014) suggests that the current method used to estimate global temperatures for HadCRUT4 might have led to a slight underestimation of global temperatures in recent years.

Global average temperatures are also estimated using reanalyses, which blend model and observational data together.
Surface temperatures from reanalyses are the result of in situ and satellite, surface and upper-air, current and prior observations that are propagated by the model. Although errors arise both from data handling and the model, surface temperatures from reanalyses are consistent with observations in regions of good observational

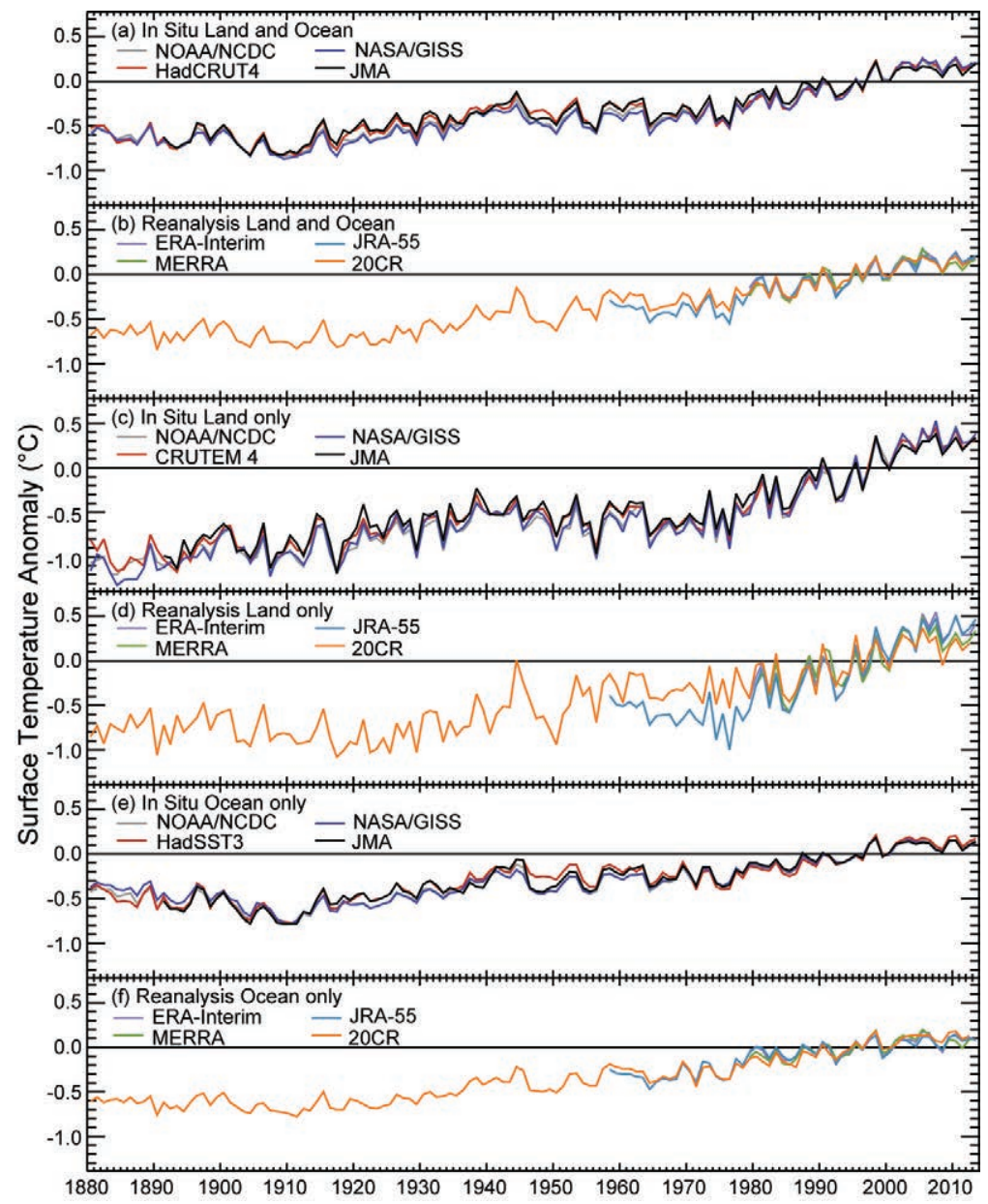

FIG. 2.I. Global average surface temperature annual anomalies ( ${ }^{\circ} \mathrm{C}, 198 \mathrm{I}-2010$ base period). In situ datasets for the globe: as listed in the text. In situ dataset for land only: NOAA/NCDC (see text); CRUTEM4 (Jones et al. 20I2); NASA/GISS (see text); and JMA (see text). In situ datasets for ocean surface only: NOAA/NCDC; HadSST3 (Kennedy et al. 20I la,b); ERSST (Smith et al. 2008); and JMA. Reanalysis datasets: ERA-Interim (Dee et al. 20II); MERRA (Rienecker et al. 20II, provided by M. Bosilovich); JRA-55 (Ebita et al. 20II, provided by Y. Harada); and 20CR (Compo et al. 20II, provided by C. Smith). 
coverage at the surface, due in part to the large volumes of assimilated observations (a total of more than 40 billion to date in ERA-Interim). In ERA-Interim (Dee et al. 2011), the 2013 globally-averaged analyzed 2-m temperature was $0.18^{\circ} \mathrm{C}$ above the $1981-2010$ average (Table 2.1) and ranked as the fourth warmest year in the record, which began in 1979.

Unlike 2011 and 2012 when La Niña conditions were present, neutral ENSO conditions prevailed throughout 2013. The presence of neutral ENSO conditions during 2013 contributed to a global average temperature slightly higher than the two previous years (Fig. 2.1), for all datasets. Typically, the presence of a La Niña tends to have a cooling influence on global temperatures.

Overall, the observational datasets indicate that the annual 2013 surface temperatures were warmer than average across most of the world's land and ocean surfaces (Plate 2.1c; Online Fig. S2.1), with cooler-than-average conditions across central Canada, the central and eastern parts of United States, the equatorial Pacific Ocean, and along the Pacific coast of South America. The globally-averaged annual temperature over land was $0.32^{\circ}-0.38^{\circ} \mathrm{C}$ above the $1981-2010$ average-between the third and sixth warmest land temperature on record, depending on the dataset. The globally-averaged annual temperature over the ocean was $0.13^{\circ}-0.17^{\circ} \mathrm{C}$ above average-between the fourth and eighth warmest sea surface temperature on record.

ERA-Interim also shows warmer-than-average conditions over many regions of the world (Fig. 2.2). The globally-averaged analyzed $2-\mathrm{m}$ temperature over land was $0.42^{\circ} \mathrm{C}$ above average, making 2013 the fourth warmest year in the 35-year period of record. Over ocean it was $0.08^{\circ} \mathrm{C}$ above average-the ninth warmest year.

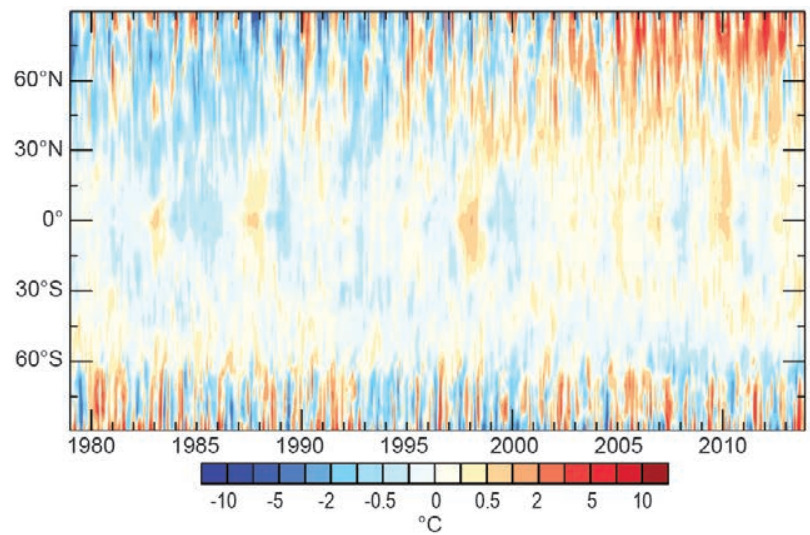

FIG. 2.2. ERA-Interim monthly mean anomalies $\left({ }^{\circ} \mathrm{C}\right.$; 198I-20I0 base period) of surface temperature by latitude.
2) LOWER TROPOSPHERIC TEMPERATURE-J. Christy

The 2013 annual, globally-averaged temperature of the lower troposphere (the bulk atmosphere below $10-\mathrm{km}$ altitude or roughly the lower $70 \%$ by mass) was approximately $+0.2^{\circ} \mathrm{C}$ above the $1981-2010$ average. This placed 2013 between the fourth and ninth warmest of the past 35 years depending on dataset and about $0.2^{\circ} \mathrm{C}$ cooler than the warmest year, 1998 (Fig. 2.3).

Direct measurement of the lower-atmospheric bulk temperature utilizes radiosonde datasets with available data since 1958 and satellites since late 1978 . Radiosondes are balloon-borne instrument packages that monitor the temperature of the air as the balloon ascends. Satellites monitor the intensity of upwelling microwave emissions of atmospheric oxygen that are proportional to temperature. Temperature variations in the troposphere are relatively large-scale when averaged over a month or year due to mixing by atmospheric circulation. Hence, fewer spatial points (i.e., radiosondes) are needed to create a reasonable estimate of the global average compared to the more inhomogeneous surface. However, as at the surface, the instrumentation on both radiosondes and satellites has changed through the years and adjustments to the data are required to produce homogeneous time series for climate analysis. The different choices made in homogenizing the raw series lead to slightly different results (termed "structural uncertainty" below.)

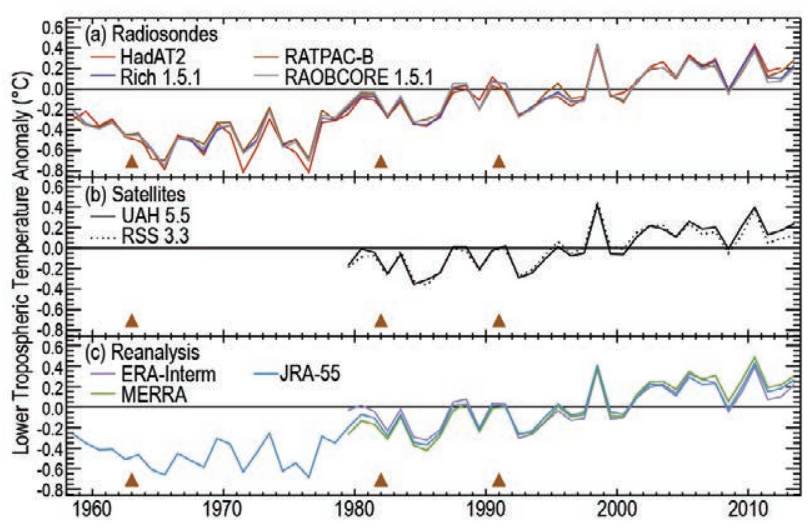

Fig. 2.3. Global average lower tropospheric temperature annual anomalies $\left({ }^{\circ} \mathrm{C} ; 198 \mathrm{I}-2010\right.$ base period) for the MSU 2LT equivalent layer. Radiosondes: HadAT2 (Thorne et al. 2005; 465 day, 384 night stations), RATPAC (Free et al. 2005; 85 stations), RAOBCORE (Haimberger et al. 20I2; II84 stations), and RICHobs (Haimberger et al. 20 I2; II84 stations). Satellites: UAHv5.5 (Christy et al. 20II) and RSSv3.3 (Mears and Wentz 2009). Reanalyses: as described in Fig. 2.I. Major volcanic eruptions, which cause 2-3 year cooling episodes, are indicated by triangles in 1963, 1982, and 1991. 
The global temperature anomaly at any point in time is closely tied to the phase of ENSO. Although 2013 was an ENSO-neutral year, lower tropospheric temperatures show some indication of a warm ENSO phase at the end of 2012, which warmed tropical temperatures in the first part of the year (see Fig. 2.23; section 2e1). The rest of the year was neutral, with tropical temperatures staying near the 30 -year average. Monthly departures from the global average were most positive in January, June, September, and October and least positive in April and May.

Regionally, warm anomalies extended from northeast Asia through the North Pacific, as well as from North Africa to western Russia. Australia experienced its warmest annual anomaly in the upper air record. Antarctica, along with the South Pacific, was also warmer than average. Smaller areas of cooler-than-average temperatures prevailed in central North America, Hawaiian region, eastern Asia, and scattered areas in the Southern Hemisphere oceans (Plate 2.1b).

The long-term global trend based on radiosondes [starting in 1958 (excluding HadAT2)] is $+0.15^{\circ} \mathrm{C}$ decade $^{-1}$ and both radiosondes and satellites (starting in 1979) is $+0.13 \pm 0.02^{\circ} \mathrm{C}$ decade $^{-1}$ (Table 2.2). The range represents the variation among the different datasets and serves as an estimate of structural uncertainty in Fig. 2.3. When taking into account the magnitude of the year-to-year variations, there is a statistical confidence range of $\pm 0.06^{\circ} \mathrm{C} \mathrm{decade}{ }^{-1}$, so the trends are still significantly positive. Major volcanic events in 1963, 1982, and 1991 led to periods of cooler temperatures that affected the early and middle part of the tropospheric record, especially in the satellite era, enhancing the upward trend to some extent. A number of smaller eruptions have occurred since 2000 which may also have moderated the temperature slightly (see section 2f2).

Given basic lapse-rate theory (Christy 2013) tropospheric trends are expected to exceed those at the surface by about 1.2 (1.4) for the globe (tropics). Over the satellite era trends in observations indicate a troposphere-to-surface ratio close to or slightly less than 1.0 for both global and tropical domains (Table 2.2). Over the longer radiosonde era the observed results are nearer theoretically-expected values.

In addition to radiosonde and satellite estimates, four reanalyses products are also shown (Fig. 2.3). There is reasonable agreement in the interannual variability and long-term trend between the reanaly-
Table 2.2. Trend values $\left({ }^{\circ} \mathrm{C}\right.$ decade- $)$ of the tropospheric datasets utilized in this report with surface values as indicated.

\begin{tabular}{|c|c|c|}
\hline & $1979-2013$ & $1958-2013$ \\
\hline & Globe & Globe \\
\hline RATPAC-B & +0.139 & +0.146 \\
\hline RICHvI.5 & +0.142 & +0.147 \\
\hline RAOBCOREvI. 5 & +0.121 & +0.143 \\
\hline UAHv5.6 LT & +0.138 & $x$ \\
\hline RSSv3.3 LT & +0.126 & $x$ \\
\hline $\begin{array}{c}\text { Slope of Avg. LT } \\
\text { Series }\end{array}$ & +0.133 & +0.145 \\
\hline NCDC Surface & +0.149 & +0.129 \\
\hline HadCRUT4 Surface & +0.155 & +0.123 \\
\hline & $20^{\circ} \mathrm{S}-20^{\circ} \mathrm{N}$ & $20^{\circ} \mathrm{S}-20^{\circ} \mathrm{N}$ \\
\hline RATPAC-B & +0.082 & +0.128 \\
\hline $\mathrm{RICHvI.5}$ & +0.130 & +0.128 \\
\hline RAOBCOREvI.5 & +0.087 & +0.149 \\
\hline UAHv5.5 LT & +0.069 & $x$ \\
\hline RSSv3.3 LT & +0.108 & $x$ \\
\hline $\begin{array}{c}\text { Slope of Avg. LT } \\
\text { Series }\end{array}$ & +0.095 & +0.134 \\
\hline NCDC Surface & +0.110 & +0.116 \\
\hline HadCRUT4 Surface & +0.110 & +0.100 \\
\hline
\end{tabular}

ses and observation products. ERA-Interim shows good agreement with satellite estimates and is used here to provide the spatial depictions (Plate 2.1b; Fig. 2.4).

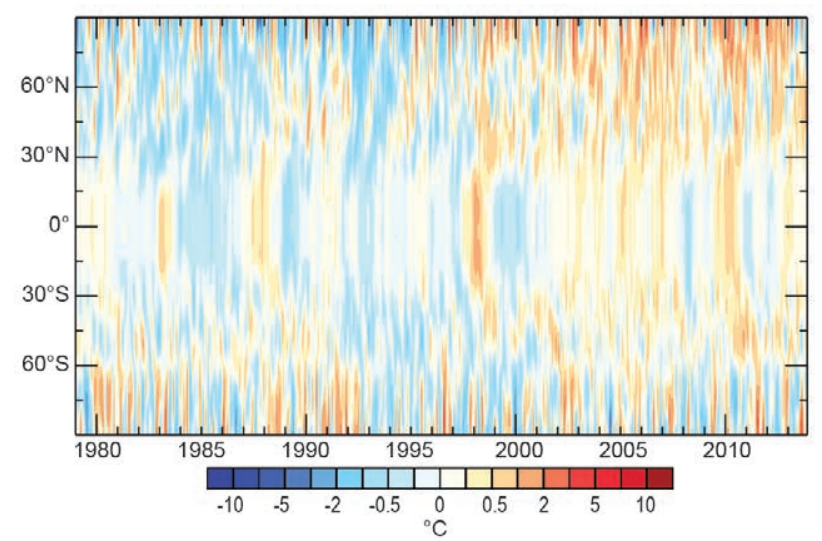

FIG. 2.4. ERA-Interim monthly mean anomalies $\left({ }^{\circ} \mathrm{C}\right.$; 1981-2010 base period) of lower tropospheric temperature MSU channel 2LT equivalent by latitude. 
While monthly and annual means of essential climate variables (ECVs) are fundamental to monitoring climate change, it is more often the climate extremes that noticeably impact society, infrastructure, and ecosystems. Several datasets for globally monitoring longterm changes in extremes have recently been developed. For temperature and precipitation, the most widely observed climate variables, these global datasets consist of a set of 27 indices recommended by the Expert Team on Climate Change Detection and Indices (ETCCDI; Zhang et al. 20II). These indices are calculated on a monthly or annual basis from observations of daily maximum and minimum temperatures, and precipitation totals, and have been gridded to form global land-based datasets [e.g., HadEX2 on a $3.75^{\circ}$ $\times 2.5^{\circ}$ grid (Donat et al. 2013a) and GHCNDEX on $2.5^{\circ} \times 2.5^{\circ}$
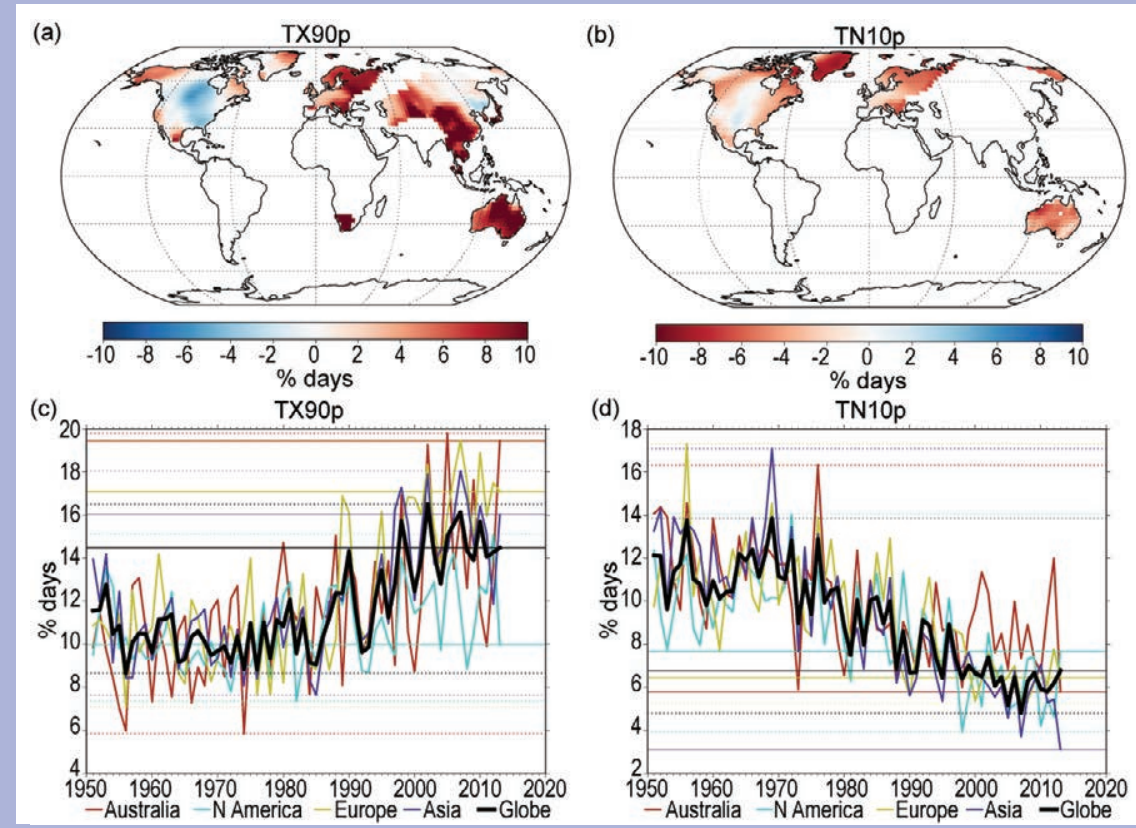

(b)

FIG. SB2.I. GHCNDEX TX90p and TNI0p anomaly map and time series relative to the 196I-90 base reference period. The (a) TX90p (warm days) and (b) TNIOp (cool nights) annual anomalies for 2013 (\% days). Note change in direction of color scale (red indicates warmer than normal, blue cooler than normal). The (c) TX90p and (d) TNI0p area-average time series for Australia, N. America, Europe, Asia, and the globe. Dotted horizontal lines show the record maximum and minimum values. The solid horizontal lines show the value for 2013 . Only grid boxes which have data for $90 \%$ of the years since 1950 are included when calculating the global average.

(Donat et al. 20I3b)]. Currently, these datasets provide the most comprehensive picture of extremes globally over the last century. For assessing 2013 in terms of extremes indices GHCNDEX was used, as this monitoring product is updated regularly from the Global Historical Climate

Network-Daily (GHCND) database, which is updated daily with near-real-time updates and weekly with period of record updates (Durre et al. 2010).

A selection of temperature extremes indices which represent the frequency of days (and nights) in the highest

Table SB2.I. Climate extremes indices discussed in this sidebar. For a more complete discussion of the suite of ETCCDI indices see Zhang et al. (2011).

\begin{tabular}{|c|c|c|c|}
\hline Index & Name & Definition & Unit \\
\hline TXI0p & Cool days & $\begin{array}{c}\text { Share of days when } \\
\text { Tmax }<10 \text { th percentile }\end{array}$ & $\begin{array}{c}\% \text { of } \\
\text { days }\end{array}$ \\
\hline TNI0p & Cool nights & $\begin{array}{c}\text { Share of days when } \\
\text { Tmin }<10 \text { th percentile }\end{array}$ & $\begin{array}{c}\% \text { of } \\
\text { days }\end{array}$ \\
\hline TX90p & Warm days & $\begin{array}{c}\text { Share of days when } \\
\text { Tmax }>90 \text { th percentile }\end{array}$ & $\begin{array}{c}\% \text { of } \\
\text { days }\end{array}$ \\
\hline TN90p & $\begin{array}{c}\text { Warm } \\
\text { nights }\end{array}$ & $\begin{array}{c}\text { Share of days when } \\
\text { Tmin }>90 \text { th percentile }\end{array}$ & $\begin{array}{c}\% \text { of } \\
\text { days }\end{array}$ \\
\hline TXx & $\begin{array}{c}\text { Hottest } \\
\text { day }\end{array}$ & $\begin{array}{c}\text { Warmest daily maximum } \\
\text { temperature }\end{array}$ & ${ }^{\circ} \mathrm{C}$ \\
\hline
\end{tabular}
and lowest deciles of the local temperature distributions is discussed here (see Table SB2.I). These are calculated relative to percentiles of the 1961-90 average and represent rather moderate measures of extreme temperatures, but allow the easy comparison of extreme events across different climate zones. The coverage of GHCNDEX for 2013 is restricted to North America, Europe, parts of Asia, and Australia (Fig. SB2.I), as station data from other regions were not yet updated in the GHCND archive at the time of this analysis. 
The TXx index, which measures the annual maximum of daily Tmax, reached a record value in 2013 for the global average of $35.7^{\circ} \mathrm{C}$ (Fig. SB2.2). This followed a previous record value in 2012 of $35.5^{\circ} \mathrm{C}$. The record of 2012 was driven by high TXx values in North America, Europe, and Asia whereas the record of 2013 was mainly driven by the very high TXx in Australia. Note that there is considerable uncertainty in these rankings given the limited spatial coverage in this analysis.

In general, 2013 saw above-average warm day frequencies and below-average cool night frequencies (Fig. SB2.Ia,b). More warm days than average occurred over large parts of Europe, central and east Asia, and Australia, while fewer warm days than average were observed over central North America. Regional and global average time series of these statistics suggest that the increase in warm day frequency and decrease in cool night frequency is part of a long-term trend (Fig.

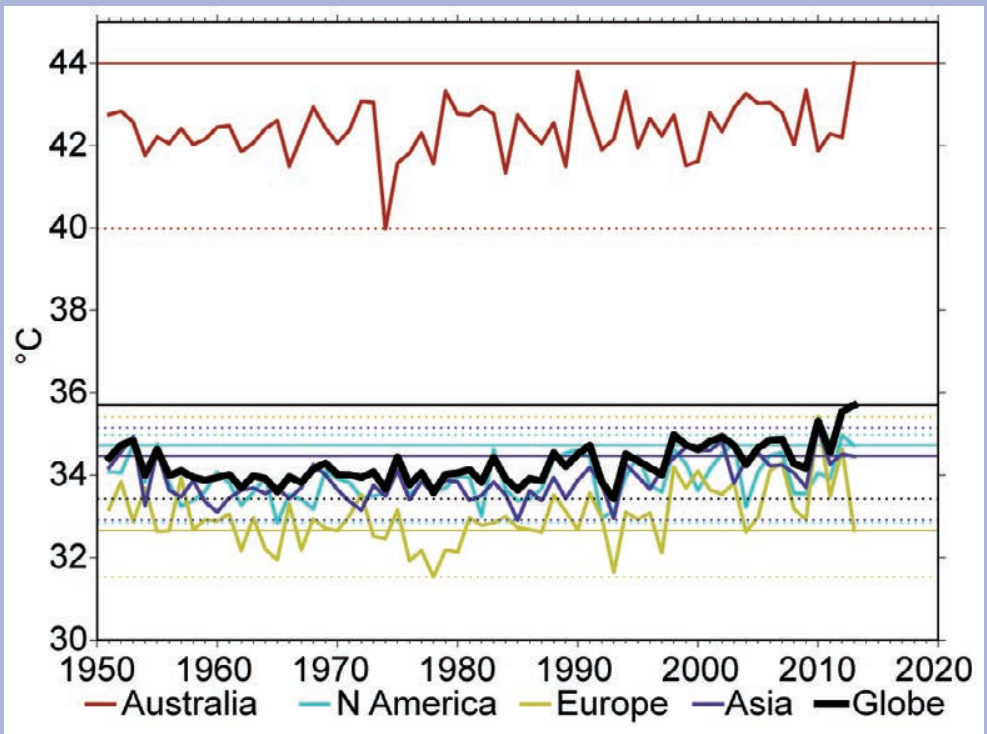

FIG. SB2.2. The GHCNDEX annual maximum maximum-temperature (TXX) time series $\left({ }^{\circ} \mathrm{C}\right)$ averaged over for Australia, N. America, Europe, Asia, and the globe (as represented by those regions). Dotted horizontal lines show the record maximum and minimum values. The solid horizontal lines show the value for 2013 . Only grid boxes which have data for $90 \%$ of the years since 1950 are included when calculating the global average.

SB2.Ic,d). Note that the "global" average is in

fact the average of land area grids with close to complete coverage (i.e., $\geq 90 \%$ of years during 1951-2013 are available) only. Globally, 2013 had the sixth highest number of warm days on record, and the eighth lowest number of cool nights, indicating that in terms of temperature extremes 2013 was among the top 10 of warmest years observed. North America had relatively few warm days, and the highest number of cool nights since 2002, which ties into the relatively wet and mild year experienced by the contiguous United States (see section 7b2). Europe and Asia had more warm days than average, and the number of cool nights was the lowest on record in Asia.

The annual average anomalies may mask individual cooler or warmer months. Monthly anomalies (Online Figs. SB2.I, SB2.2) have clear signatures from particularly hot or cold periods. These monthly maps clearly show, for example, the heat wave in southern China during July and August of 2013. The cold spring in northern Europe (March and into April) is shown in both more-thanaverage cold days (and nights) and fewer warm days in March. Similarly, the warm December in Europe and the cold start to the winter in North America are visible as is the warmth in Europe during July. However, this warm summer was not as extreme as those in 2010 or 2003.
Australia, with its all-time warmest month (January 20I3), warmest summer (20I2/I3), and warmest calendar year on record, had the second highest frequency of warm days on record, lower only than 2005. Unsurprisingly, 2013 had the fewest cool nights on record. The TXx index was unprecedented in many parts of Australia and even on a nationwide average reached the highest value on record of $44^{\circ} \mathrm{C}$ in 2013 (Fig. SB2.2). Across the country, a total of 44 stations with more than 30 years of data set all-time Tmax records, and a further 15 set January records (BoM 2013).

The global and regional time series of warm days and nights and cool days and nights (Fig. SB2.I and Online Figs. SB2.I-SB2.5) display a general long-term tendency towards warmer conditions, as indicated by increasing numbers of warm extremes (TX90p, TN90p) and decreasing numbers of cool extremes (TNIOp, TXIOp). According to several extreme temperature indices, 2013 was among the warmest years globally and in most subregions (apart from North America which displayed cold anomalies), and this is consistent with the general observed warming trends. As global temperatures increase, more warm extremes and fewer cold extremes are expected to occur (Donat et al. 20I3a; Sillmann et al. 20I3). 
3) LOWER STRATOSPHERIC TEMPERATURE-C. S. Long and J. Christy

The global-average temperature in the lower stratosphere for 2013 was slightly below the 1981-2010 climatology (Fig. 2.5). All the various measurement systems (radiosonde, satellite, reanalysis) determined that 2013 was warmer than 2012 and continued a near-neutral to very gradual warming trend from 1995 to present. The annually-averaged temperature anomaly was positive in most regions poleward of the midlatitudes and in the equatorial zone (see Plate 2.1a; Online Fig. S2.2). The subtropics and lower midlatitudes were cooler than the climatology, with a region of negative temperature anomalies extending from central Canada to Alaska in the Northern Hemisphere, as well as southern South America to New Zealand in the Southern Hemisphere. Between these two features were positive temperature anomalies over the eastern Pacific Ocean. These annual features were results of strong monthly departures. The northern polar region experienced positive temperature anomalies in January and February resulting from a stratospheric warming in early January. The central Canada to Alaska negative temperature anomalies arose from below-average temperatures in this region during November and December. The southern polar positive temperature anomalies resulted from above-average polar temperatures during September-December (see Online Fig. S2.7). These warm temperatures resulted in a smaller-than-average ozone hole for 2013 (sections 2g4, 6g). The Southern Hemispheric polar circulation was displaced off the South Pole for much of 2013, resulting in negative temperature anomalies from the southern South America to New Zealand region during August-December. The tropical temperature anomalies transitioned from slightly negative in the early months of the year to positive by the end of the year (see Online Figs. S2.3-S2.7), as a result of the quasi-biennial oscillation winds transitioning from descending easterlies to descending westerlies throughout the year.

Historically, the radiosondes (RAOBCORE, Haimberger et al. 2012; RICH, Haimberger et al. 2012; HadAT2, Thorne et al. 2005; and RATPAC, Free et al. 2005) and later on the satellites (RSS, Mears and Wentz 2009; STAR, Zhou and Wang 2010; and UAH, Christy et al. 2011) show a cooling trend from the 1960s through the mid-1990s (Fig. 2.5). Both measuring systems indicate a change in that cooling trend around 1995. Since then there has been a near-neutral or warming trend, depending upon the data product.

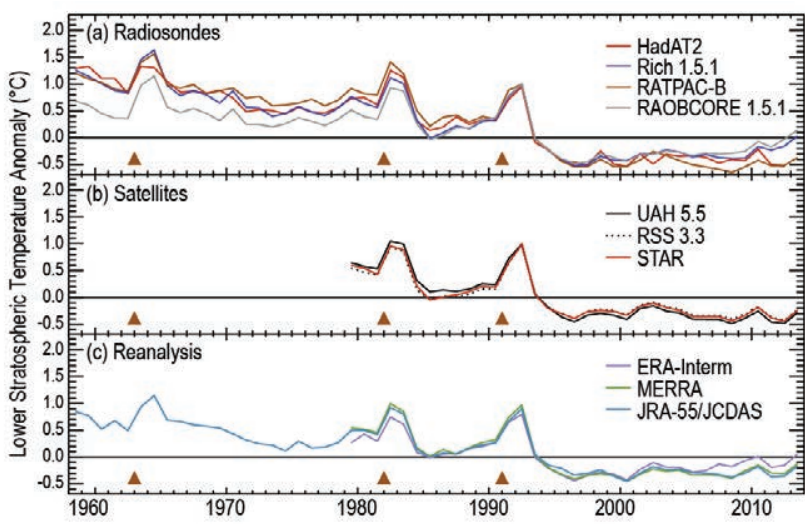

FIG. 2.5. Global average lower stratospheric temperature annual anomalies ( ${ }^{\circ} \mathrm{C}$; 198I-2010 base period) for the MSU channel 4 equivalent layer. Radiosondes, satellites, and reanalyses are as shown in Fig. 2.I plus (satellite) STAR (Zhou and Wang 20I0). Major volcanic eruptions, which cause 2-3 year warming episodes, are indicated by triangles in 1963, 1982, and 1991.

In prior reports, a linear trend from 1979 to present was determined, because long period time series are necessary for robust assessment of long-term trends. However, it is clear that using one linear trend to characterize the entire period does not accurately describe the behavior since 1995. Four of the most recent meteorological reanalyses (MERRA, Rienecker et al. 2011; ERA-Interim, Dee et al. 2011; JRA-55, Ebita et al. 2011; NCEP-CFSR, Saha et al. 2010) show general agreement with the radiosonde and satellite temperature anomalies. Table 2.3 shows the trends of the various estimates for 1958-95 (radiosonde only), 1979-95, 1995-2013, and 1979-2013. These periods reflect the cooling trend through 1995 and the neutral-to-warming trend from 1995 to present.

More detail about the tropical lower stratospheric trends is obtained if the zonal trends are examined. Figure 2.6 shows the zonal trends for the cooling 1979-95 period and the neutral-to-warming trend from 1995-present. The equatorial region exhibits the smallest trends (both warming and cooling) while the polar latitudes exhibit the greatest trends. The increasing size of the ozone hole and its associated cooling in September-November is a strong contributing factor in the Southern Hemisphere 1979-95 cooling trend. The cooling in the Northern Hemisphere polar region in 1979-1995 can be attributed, to a large extent, to reducing occurrences of winter stratospheric warmings. From 1995 to present there have been more frequent stratospheric warmings and hence a general warming trend in the Northern Hemisphere polar latitudes (Pawson and Naujokat 1999; Manney et al. 2005; Butler and Polyani 2011). In the Southern 


\begin{tabular}{|c|c|c|c|c|}
\hline Data Set & $1958-1995$ & 1979-1995 & $1995-2013$ & $1979-2013$ \\
\hline & ${ }^{\circ} \mathrm{C}$ decade- ${ }^{-1}$ & ${ }^{\circ} \mathrm{C}$ decade- & ${ }^{\circ} \mathrm{C}$ decade- -1 & ${ }^{\circ} \mathrm{C}$ decade-1 \\
\hline \multicolumn{5}{|l|}{ Radiosonde } \\
\hline HadAT2 & -0.285 & -0.562 & $x^{*}$ & $x^{*}$ \\
\hline RAOBCORE & -0.126 & -0.304 & 0.123 & -0.300 \\
\hline $\mathrm{RICH}$ & -0.283 & -0.482 & 0.103 & -0.370 \\
\hline RATPAC & -0.253 & -0.612 & -0.040 & -0.486 \\
\hline \multicolumn{5}{|l|}{ Satellite } \\
\hline RSS & $x$ & -0.427 & -0.026 & -0.371 \\
\hline STAR & $x$ & -0.337 & -0.045 & -0.299 \\
\hline UAH & $\mathrm{x}$ & -0.365 & -0.059 & -0.320 \\
\hline \multicolumn{5}{|l|}{ Reanalysis } \\
\hline CFSR & $x$ & -0.648 & 0.109 & -0.383 \\
\hline ERA-I & $x$ & -0.183 & 0.193 & -0.144 \\
\hline JRA-55 & $x$ & -0.231 & -0.006 & -0.240 \\
\hline MERRA & $x$ & -0.306 & 0.134 & -0.253 \\
\hline
\end{tabular}

c. Cryosphere

I) Permafrost thermal STATE-J. Noetzli, H. H. Christiansen, M. Gugliemin, V. E. Romanovsky, N. I. Shiklomanov, S. L. Smith, and L. Zhao

The Global Terrestrial Network on Permafrost (GTNP) brings together long-term records on ground temperatures and active layer depths from permafrost regions worldwide in order to document the state and changes of permafrost on a global scale.

Arctic permafrost Hemisphere, there have recently been years with active wave activity during the winter/spring and consequently, warmer average polar temperatures (and smaller associated ozone holes). Between the two polar regions there has been a very slight warming trend.

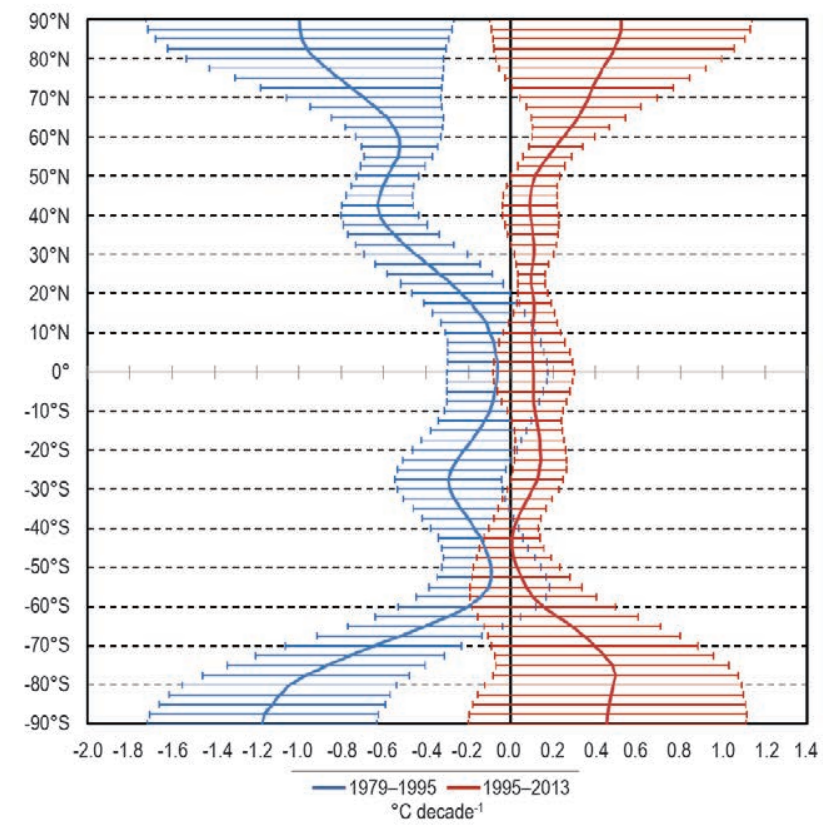

FIG. 2.6. MERRA zonal temperature trends and error bars ( ${ }^{\circ} \mathrm{C}$ decade-1, 198I-2010 base period) of MSU channel 4 equivalent layer for both the cooling period between 1979-95 and warming trend from 1995-present.

temperatures generally vary from $0^{\circ}$ to $-2.5^{\circ} \mathrm{C}$ within the discontinuous zone, with colder conditions in the continuous zone from $-3^{\circ} \mathrm{C}$ in high Arctic Svalbard (Christiansen et al. 2010; Fig. 2.7) to $-15^{\circ} \mathrm{C}$ elsewhere in the high Arctic (Romanovsky et al. 2010a). Permafrost has warmed over the past two to three decades, and generally continues to warm across the circumpolar north. Record-high temperatures were observed in 2012-13 in the Alaskan Arctic and the Canadian Archipelago (Romanovsky et al. 2013a,b; a detailed discussion of Arctic permafrost is provided in section 5l).

Permafrost in the European Alps is discontinuous or patchy and generally warm with temperatures between $0^{\circ}$ and $-3^{\circ} \mathrm{C}$ (Haeberli et al. 2010; PERMOS 2013; Fig. 2.7). However, on shaded slopes at high elevations permafrost can be as cold as in the high Arctic in Svalbard. So far the lowest borehole temperatures of $-5^{\circ} \mathrm{C}$ were measured in horizontal boreholes installed in 2008 in a near-vertical rock pillar in the French Mont Blanc Massif at $3800 \mathrm{~m}$ above sea level on the Aiguille du Midi (Magnin et al. 2014, manuscript submitted to The Cryosphere). In addition, measurements on the south and north face confirm large temperature differences of up to $6^{\circ} \mathrm{C}$ between steep north and south slopes of midlatitude mountains. This results in 3D temperature patterns and large lateral heat fluxes (Noetzli and Gruber 2009). Decadal records for European mountain permafrost show a warming trend at depths of $20 \mathrm{~m}$ and more for many but not all sites, especially in the past 

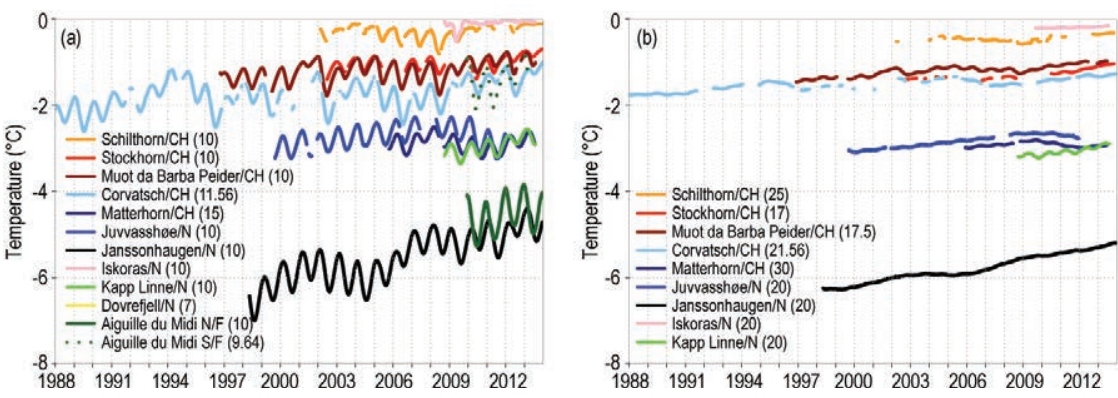

FIG. 2.7. Permafrost temperatures $\left({ }^{\circ} \mathrm{C}\right)$ in daily or monthly resolution measured at $10-\mathrm{m}$ (a) and 20-m (b) depth for selected boreholes in the European Alps, Scandinavia, and Svalbard showing seasonal (a) as well as long-term (b) variations of permafrost temperatures at depth. (Sources: Swiss sites: PERMOS; Norwegian sites: Norwegian Meteorological Institute and the Norwegian Permafrost Database, NORPERM; French site: EDYTEM/University of Savoie.)

five years; with smaller increases where permafrost is close to $0^{\circ} \mathrm{C}$ (Isaksen et al. 2007; PERMOS 2013) At temperatures close to the melting point phase change processes absorb a part of the energy transported from the atmosphere to the subsurface. That way latent heat can mask atmospheric warming in the underground. At 10-m depth seasonal variations are well displayed, which reveals warmer winters at warmer sites in recent years. Pronounced warming trends are observed in Scandinavia (Isaksen et al. 2011; Fig. 2.7), which are consistent with changes in air temperatures.

In the warm permafrost of the higher altitudes of central Asia, ground temperatures have increased by up to $0.5^{\circ} \mathrm{C}$ decade $^{-1}$ since the early 1990 s. Additional boreholes were recently installed in the QinghaiXizang Plateau (Zhao et al. 2011) and Mongolia (Sharkhuu and Sharkhuu 2012) as part of GTN-P. The average warming rate of permafrost in these regions was about $0.31^{\circ} \mathrm{C}$ decade $^{-1}$ from 1998 to 2010 (Zhao et al. 2011).

The latitudinal transect in maritime Antarctica ANTPAS (Antarctic Permafrost, Soils and Periglacial Environments) was upgraded in 2012 and 2013 with new boreholes near Palmer Station and at Signy Island. Permafrost temperature at $17-\mathrm{m}$ depth was $-1.3^{\circ} \mathrm{C}$ and active layer thickness (ALT) reached almost 4 $m$ in 2013. Farther south at Rothera station $\left(67^{\circ} \mathrm{S}\right)$, Guglielmin et al. (2014a) reported

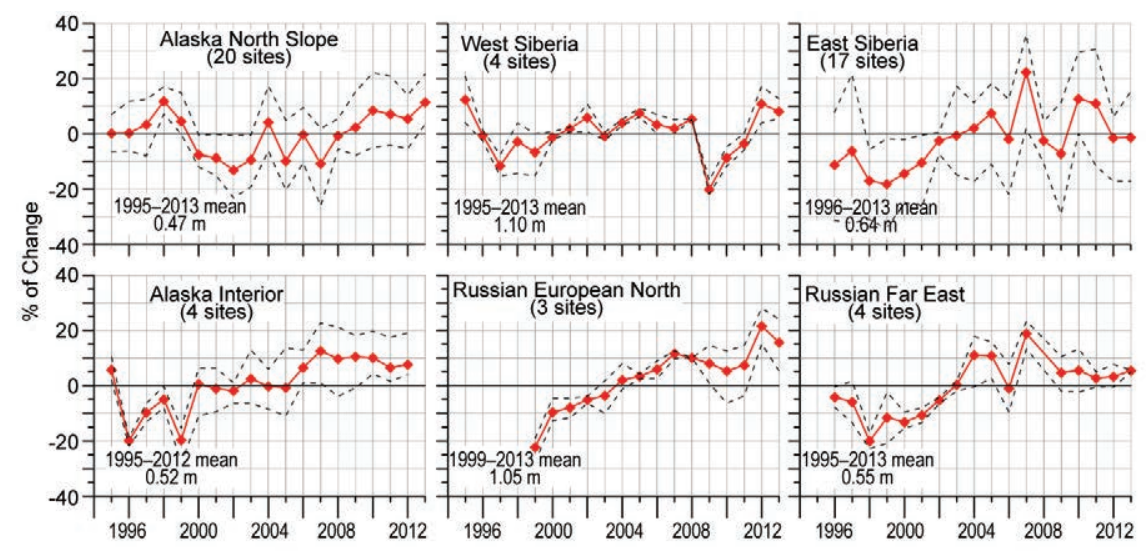

FIG. 2.8. Long-term active-layer change in six different Arctic regions as observed within the Circumpolar Active Layer Monitoring (CALM) project. The data are presented as annual percentage deviations from the mean value for the period of observations. Thaw depth observations from the end of the thawing season were used. Availability of at least ten years of continuous thaw depth observations through the 2013 thawing season was the only criterion for site selection. Solid red lines show mean values for the regions. Dashed black lines represent maximum and minimum values for the region. 
Land, continental Antarctica, observations by Guglielmin et al. (2014b) confirmed the thickening of the active layer since 1997 reported by Guglielmin and Cannone (2012), which mainly results from increasing solar radiation in austral summer.

\section{2) Northern Hemisphere Continental snow cover} EXTENT-D. Robinson

Annual snow cover extent (SCE) over Northern Hemisphere $(\mathrm{NH})$ lands averaged 25.5 million $\mathrm{km}^{2}$ in 2013. This is 0.3 million $\mathrm{km}^{2}$ more than the 44 year average, and ranks 2013 as having the 13th most extensive cover on record (Table 2.4). This evaluation includes the Greenland ice sheet. SCE in 2013 ranged from 49.2 million $\mathrm{km}^{2}$ in January to 2.9 million $\mathrm{km}^{2}$ in August. Monthly SCE is calculated at the Rutgers Global Snow Lab from daily SCE maps produced by meteorologists at the National Ice Center (a US joint NOAA, Navy, and Coast Guard facility), who rely primarily on optical satellite imagery to construct the maps.

Monthly mean anomalies varied considerably across the year in all regions (Fig. 2.9). The first four months of 2013 saw above-average snow cover extent over Eurasia (EU) and North America (NA). EU SCE observed its sixth snowiest January of the past 47 years. North American SCE exhibited the largest

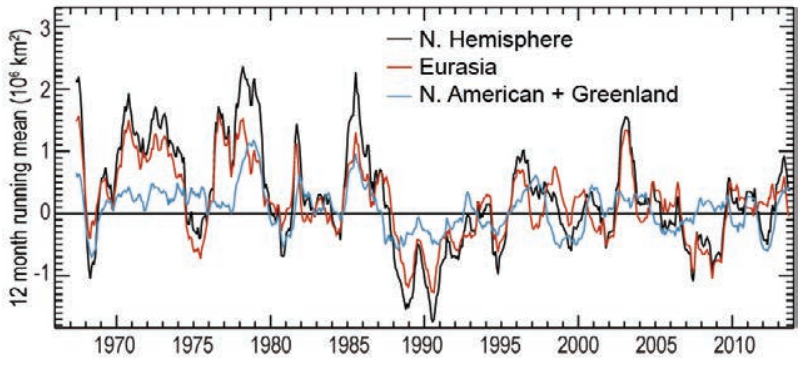

FIG. 2.9. Twelve-month running anomalies of monthly snow cover extent over $\mathbf{N}$. Hemisphere lands (including Greenland) as a whole and Eurasia and N. America separately between Nov 1966 and Dec 2013. Anomalies are calculated from NOAA snow maps. Mean hemispheric snow extent is $\mathbf{2 5 . 2}$ million $\mathbf{~ k m}^{2}$ for the full period of record. Monthly means for the period of record are used for nine missing months between 1968 and 1971 in order to create a continuous series of running means. Missing months fall between Jun and Oct; no winter months are missing.

positive anomalies in March (sixth largest for the month) and April (third largest for the month). As seen on multiple occasions over the past decade, May and June SCE were well below the long-term average. NH SCE plummeted from the ninth most extensive in April to the third least extensive coverage in May and second least in June.

Snow arrived early over the Northern Hemisphere continents during fall 2013. Hemispheric rankings were sixth and Table 2.4. Monthly and annual climatological information on Northern Hemisphere (N. Hem.) and continental snow extent between November 1966 and December 2013. Included are the numbers of years with data used in the calculations, means, standard deviations, 2013 values and rankings. Areas are in millions of square kilometers. 1968, 1969, and 197I have I, 5, and 3 missing months respectively, thus are not included in the annual (Ann) calculations. North America (N. Am.) includes Greenland. Ranks are from most extensive (I) to least (ranges from 44 to 48 depending on the month).

\begin{tabular}{|c|c|c|c|c|c|c|c|}
\hline & Years & Mean & Std. Dev. & 2013 & $\begin{array}{c}\text { N. Hem. } \\
\text { rank }\end{array}$ & $\begin{array}{c}\text { Eurasia } \\
\text { rank }\end{array}$ & $\begin{array}{c}\text { N. Am. } \\
\text { rank }\end{array}$ \\
\hline Jan & 47 & 47.1 & 1.6 & 49.2 & 5 & 6 & 13 \\
\hline Feb & 47 & 46.1 & 1.9 & 47.0 & 15 & 17 & 15 \\
\hline Mar & 47 & 40.7 & 1.8 & 41.7 & 14 & 21 & 6 \\
\hline Apr & 47 & 30.6 & 1.7 & 32.6 & 9 & 18 & 3 \\
\hline May & 47 & 19.4 & 1.9 & 16.3 & 45 & 47 & 29 \\
\hline Jun & 46 & 9.9 & 2.3 & 6.0 & 45 & 44 & 44 \\
\hline Jul & 44 & 4.1 & 1.2 & 3.0 & 37 & 40 & 26 \\
\hline Aug & 45 & 3.0 & 0.7 & 2.9 & 21 & 37 & 11 \\
\hline Sep & 45 & 5.3 & 0.9 & 6.5 & 6 & 7 & 8 \\
\hline Oct & 46 & 18.1 & 2.5 & 21.0 & 7 & 4 & 20 \\
\hline Nov & 48 & 33.9 & 2.0 & 34.8 & 16 & 31 & 3 \\
\hline Dec & 48 & 43.7 & 1.9 & 45.3 & 8 & 20 & 7 \\
\hline Ann & 44 & 25.2 & 0.9 & 25.5 & 13 & 21 & 7 \\
\hline
\end{tabular}
seventh most extensive in September and October, respectively. The advance of the seasonal snowpack continued at a rapid pace over North America in November (third most extensive) and December (seventh most expensive). However the SCE advance slowed considerably over Eurasia in November, the rank falling to 31 st most extensive, though it became above average (20th most extensive) in December.

Unlike the previous winter, contiguous United States SCE in early 2013 was above average. This included the fifth most extensive SCE for 
April, prior to a rapid melt that left May with the second least extensive SCE on record. Late in 2013, SCE developed quickly and ranked between 5 th and 12 th most extensive from October through December.

Maps depicting daily, weekly, and monthly conditions, daily and monthly anomalies, and monthly climatologies for the entire period of record may be viewed at the Rutgers Global Snow Lab website (http://snowcover.org). Monthly SCE for the NH, EU, NA, the contiguous United States, Alaska, and Canada are also posted, along with information on how to access weekly areas and the weekly and monthly gridded products.

\section{3) Alpine glaciers and ICE Sheets-M. Pelto}

The World Glacier Monitoring Service (WGMS) record of mass balance and terminus behavior (WGMS 2013) provides a global index for alpine glaciers. Glacier mass balance is the difference between accumulation and ablation. Mass balance was $-638 \mathrm{~mm}$ in 2012, negative for the 23rd consecutive year. Preliminary data for 2013 from Austria, Canada, Nepal, New Zealand, Norway, and United States indicate it is highly likely that 2013 will be the 24th consecutive year of negative annual balances.

Alpine glaciers have been studied as sensitive indicators of climate for more than a century, most commonly focusing on changes in terminus position and mass balance. The worldwide retreat of mountain glaciers is one of the clearest signals of ongoing climate change (Haeberli et al. 2000). The retreat is a reflection of strongly negative mass balances over the last 30 years (WGMS 2013).

The cumulative mass balance loss since 1980 is 14.9 $\mathrm{m}$ w.e. (meters in water equivalent), the equivalent of cutting a $16.5 \mathrm{~m}$ thick slice off the top of the average glacier (Fig. 2.10). The trend is remarkably consistent from region to region (WGMS 2013). WGMS mass balance results based on 30 reference glaciers with 30 years of record are not appreciably different, $-15.1 \mathrm{~m}$

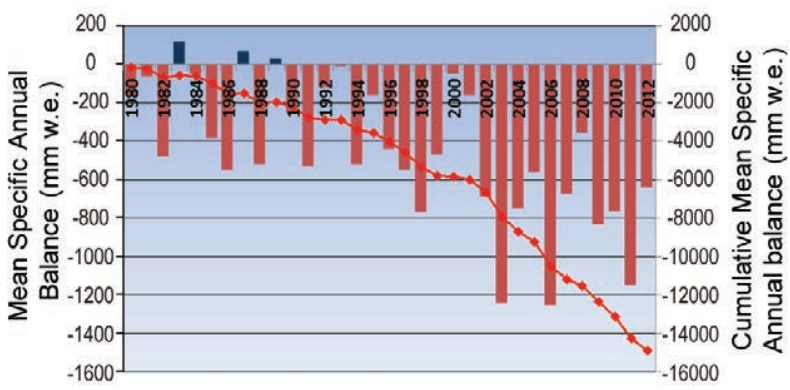

FIG. 2.10. Mean annual balance and cumulative annual balance for the 30 reference glaciers, 1980-2012. (Source: WGMS.) w.e. The decadal mean annual mass balance was -198 $\mathrm{mm}$ in the $1980 \mathrm{~s},-382 \mathrm{~mm}$ in the 1990s, and -740 $\mathrm{mm}$ for 2000s. The declining mass balance trend during a period of retreat indicates alpine glaciers are not approaching equilibrium and retreat will continue to be the dominant terminus response. The recent rapid retreat and prolonged negative balances have led to some glaciers disappearing and others fragmenting (Fig. 2.11; Pelto 2010; Carturan et al. 2013).

In 2013 the Austrian glacier inventory examined 96 glaciers: 93 were in retreat, 1 was advancing, and 2
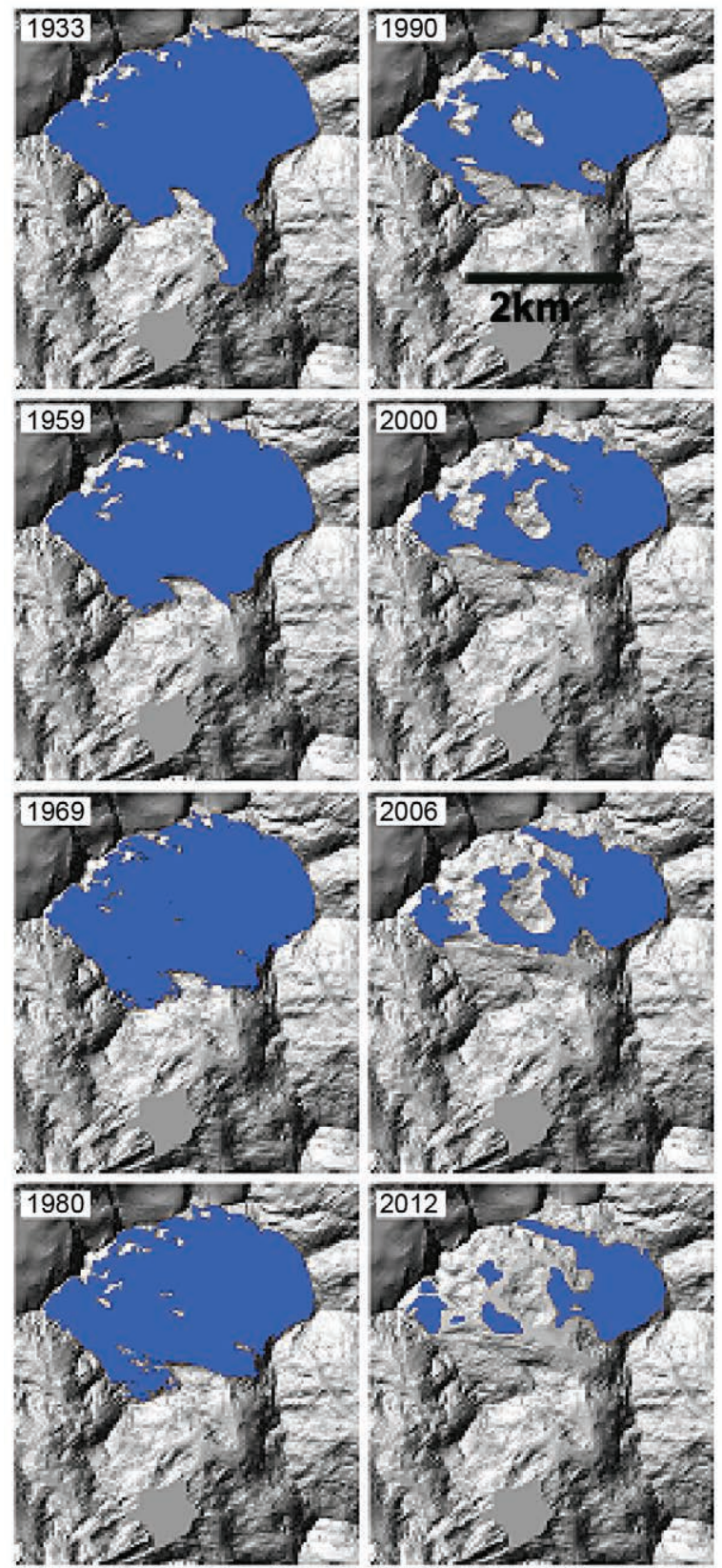

FIG. 2.II. Disintegration of Careser Glacier, Italy, 19332012; glacier in blue. (Source: Carturan et al. 2013.) 
were stationary, with an average terminus change of $-17 \mathrm{~m}$. Mass balance in 2013 was slightly negative on three glaciers with completed data. A 170-m increase in annual equilibrium line altitude on 43 glaciers in the Alps from 1984 to 2010 is driving the ongoing retreat (Rabatel et al. 2013).

In Norway terminus fluctuation data from 33 glaciers for 2013 with ongoing assessment indicate 26 retreating, 4 stable, and 3 advancing, with an average terminus change of $-12.5 \mathrm{~m}$ (Elverhoi 2013). Mass balance surveys with completed results are available for six glaciers; all have negative mass balances with an average loss exceeding $1 \mathrm{~m}$ w.e. (Andreassen 2013). Of the five outlet glaciers examined from 2002-13 all retreated; the mean retreat was $190 \mathrm{~m}$.

In the North Cascades, Washington, the 2013 winter accumulation season featured 93\% of average (1984-2013) snowpack. The melt season was exceptional with the average June-September temperature tied as the highest for the 1989-2013 period and also having the highest average minimum daily temperatures. This contributed to significant negative balances on all 10 glaciers observed, with an average of $-1 \mathrm{~m}$ w.e. (Pelto 2013). In British Columbia, end-of-summer snowlines were higher than normal and annual mass balance was significantly negative. In Alaska, all four glaciers with mass balance assessed had significant negative mass balances (Pelto 2013).

In New Zealand, the annual end-of-summer snowline survey on 50 glaciers found snowlines that were slightly above the elevation for glacier equilibrium. Heavy snow accumulation during October was offset by a warm, dry summer with high ablation (NIWA 2013).

In Nepal, the mass balances of Yala, Mera, and Pokalde Glaciers were near equilibrium. Accumulation was the highest of the last seven years, with particularly heavy snow from extratropical storm Phailin (ICIMOD 2013).

\section{d. Hydrological Cycle}

I) SuRfaCe HUmidiTY-K. Willett, A. Simmons, and D. Berry

Over land, specific humidity (q) for 2013 was just above the 1979-2003 average and slightly higher than in 2012, as shown by the in situ HadISDH and ERA-40/Interim (spatially matched to HadISDH) and JRA-55 reanalysis products (Fig. 2.12a,b). Over the ocean, specific humidity in 2013 was considerably above the average and slightly higher than 2012, as shown by the NOCSv2.0 in situ product masked to regions where data quality is sufficient (essentially the Northern Hemisphere; Fig. 2.12c). While agreement between and within both in situ and reanalyses product types is generally good over land, there is much less agreement over ocean (Fig. 2.12c,d), though the reanalyses show some similarity in interannual behavior to each other. The differences between the in situ data products and the reanalyses may be partially due to the significant difference in spatial coverage. In regions of poor data coverage the reanalyses still provide values, however, these are less constrained

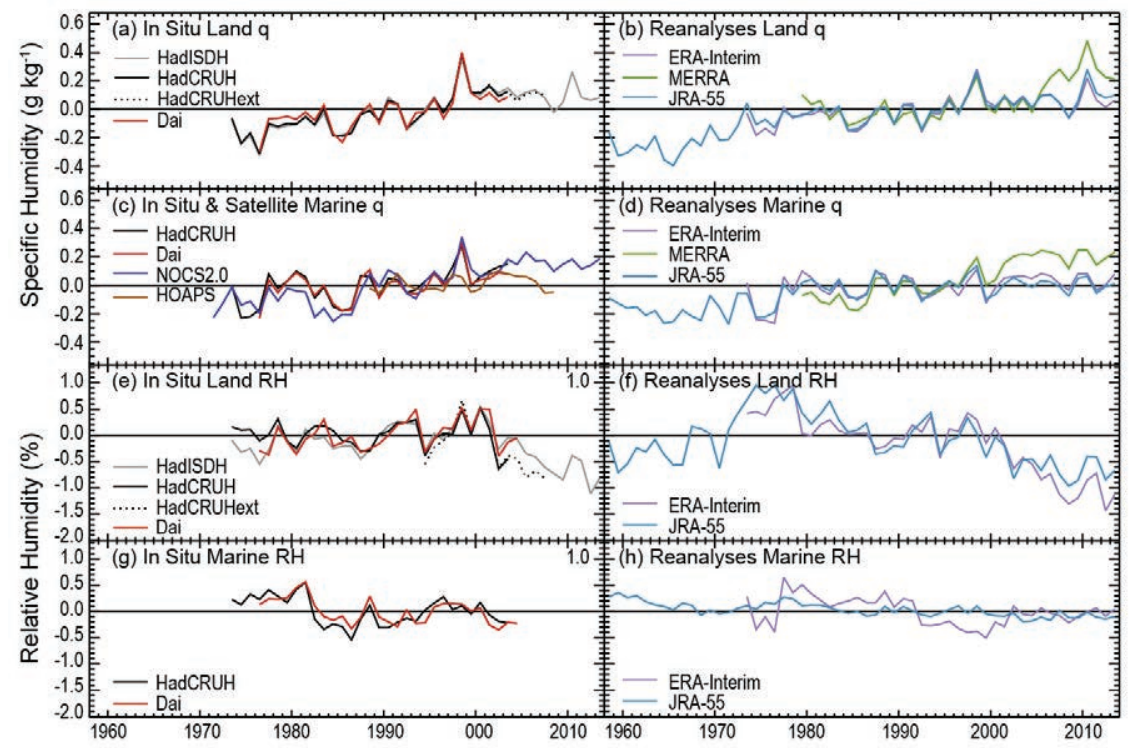

FIG. 2.12. Global average surface humidity annual anomalies (1979-2003 base period). For the in situ datasets $2-\mathrm{m}$ surface humidity is used over land and $\sim 10-\mathrm{m}$ over the oceans. For the reanalyses $2-\mathrm{m}$ humidity is used over the whole globe. For ERA-Interim ocean series only points over open sea are selected and background forecast values are used as opposed to analysis values because of unreliable use of ship data in producing the analysis. All data have been adjusted to have a mean of zero over the common period 1979-2003 to allow direct comparison, with HOAPS given a zero mean over the 1988-2003 period. ERA values over land are from ERA-40 prior to 1979 and ERA-Interim thereafter. (Sources: HadISDH (Willett et al. 2014, manuscript submitted to Climate Past); HadCRUH (Willett et al. 2008); Dai (Dai 2006); HadCRUHext (Simmons et al. 2010); NOCSv2.0 (Berry and Kent 2009, 20II); and reanalyses as described in Fig. 2.I. Data provided by authors, $A$. Dai, M. Bosilovich, and Y. Harada.) 
compared to well-sampled regions and the uncertainties are higher. The HOAPS satellite ocean humidity product shows good agreement with NOCSv2.0 in the early period, deteriorating from 1998 where the ENSO signal is not present in HOAPS.

Overall there was more water vapor than average in the near-surface atmosphere in 2013; the long-term behavior of all estimates suggests an increasing trend with more water vapor in the near-surface atmosphere now than in the 1970s.

Plate 2.1f (and Online Figs. S2.8, S2.9) shows the annual average $q$ anomalies over the globe for 2013 . The picture is mixed but coherent regional patterns emerge. The southern and central United States, western Europe, central and east Asia, central South America, southern Africa, and central eastern Australia were drier than the 1981-2010 average. These signals stretch across coastlines, showing good consistency between the independent HadISDH and NOCSv2.0 products, and are also in agreement with ERA-Interim (Online Fig. S2.9). Overall, there are more regions showing moister-than-average anomalies. The midlatitude northern Pacific and northern Atlantic, Southeast Asia, and most of the observed tropical Africa are areas of considerable moistening. Seasonal variability in these features is large (Online Fig. S2.10), with the dry anomalies predominant in the boreal winter (DJF) and spring (MAM).

Over land, relative humidity (RH) in 2013 was far below average although slightly higher than in 2012, as shown by the in situ only HadISDH and by the ERA-40/Interim and JRA-55 reanalyses (Fig. 2.12e,f). Over ocean, the only estimates for 2013 available are provided by reanalyses. These suggest no significant deviation from average and little variability in the record overall (Fig. 2.12g,h). There is generally greater variability both between and within the in situ and reanalyses estimates for RH. For the in situ record, this suggests high sensitivity to both methodological choice and station coverage which differs between the Dai, HadCRUH, and HadISDH datasets.

Overall, this means that although there is more water vapor in the near-surface atmosphere relative to the 1970s, the surface atmosphere over land is less saturated. This feature has really only become apparent since $\sim 2000$ but is clear in all estimates. The drivers of this are not yet fully understood but differences in the rate of warming between land and ocean have been suggested (Simmons et al. 2010) and land surface water availability may be a factor.

Plate 2.1g (and Online Fig. S2.11) shows the annual average RH anomalies over the globe for 2013. Be- low-average saturation is a predominant feature of the midlatitude land masses whereas the higher latitudes and tropics, especially India, are more humid than the long-term average. Anomalies are much larger over land than over the oceans, in agreement with ERA-Interim (Online Fig. S2.11). Seasonal variability in these features is large (Online Fig. S2.12), although the dry regions of central South America, southern Africa, and central eastern Australia, and humid regions of India persist year round.

The majority of products used here to show estimates of surface humidity are described in Willett et al. (2013). This year JRA-55 is shown, which extends the previous JRA-25/JCDAS back to 1958. JRA-55 improves on the JRA-25/JCDAS post-October 2011 record which previously suffered from a large discontinuity due to the absence of precipitable water retrievals from the microwave imagers used. HadISDH has been updated to HadISDH.2.0.0.2013p which now includes land $\mathrm{RH}$ in addition to land $q$ and different homogenisation methodology (Willett et al. 2014, manuscript submitted to Climate Past). There is negligible difference between the two versions for large scale averages of $q$.

\section{2) Total column water vapor-C. Mears, S. Ho, L. Peng, and J. Wang}

The map of total column water vapor (TCWV) anomalies for 2013 (Plate 2.1e) was made by combining data both from satellite-borne microwave radiometers over ocean (Wentz 1997; Wentz el al. 2007) and COSMIC GPS-RO over land (Ho et al. 2010a,b; Teng et al. 2013; Huang et al. 2013). Despite the lack of any significant ENSO event during 2013, La Niña-like dry anomalies persisted across the central Pacific. There were also pronounced dry anomalies in eastern Australia and both northern and southern Africa. There were pronounced wet anomalies in the eastern and western tropical Pacific, the South Pacific convergence zone, and the Amazon basin. Many of the same features were present in the 2013 precipitation anomalies (Plate $2.1 \mathrm{~h}$ ). The pattern in TCWV over the ocean is confirmed by COSMIC ocean measurements.

Over the ocean, the TCWV anomaly time series (Fig. 2.13a) from the microwave radiometers shows maxima in 1987-88, 1997-98, and 2009-10, associated with El Niño events, as well as a more subtle increasing trend corresponding with increasing global temperatures. A linear fit to this time series suggests that the total amount of vapor over the oceans has increased $\sim 3 \%$ since 1988. Minima are apparent in 


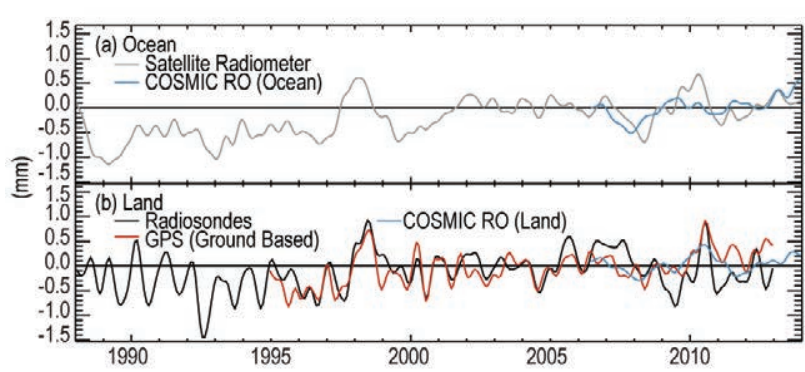

FIG. 2.13. Anomaly time series of total column water vapor $(\mathrm{mm})$. (a) Ocean time series from satellite-borne microwave radiometers and COSMIC, 2007-I 2 reference period. The time series have been smoothed to remove variability on time scales shorter than 6 months. (b) Land time series from radiosondes (Dai et al. 20II), ground-based GPS (Wang et al. 2007), and COSMIC. Except for COSMIC, the reference period is 1997-20II. The COSMIC land anomalies are calculated relative to a 2007-II COSMIC land climatology. The time series have been smoothed to remove variability on time scales shorter than 6 months.

Northern Hemisphere winters during the La Niña events of 1988-89, 1992-93, 1999-2000, 2007-08, and late 2010 to mid-2012. Global water vapor has increased since this last minimum. The ocean-only COSMIC data are in general agreement with the radiometer data, but show less of a peak in 2009-10. An increase since late 2010 is also shown in the COSMIC data over land (Fig. 2.13b). A Hövmoller plot derived from the satellite radiometers (Fig. 2.14) shows that the long-term increase in TCWV is occurring at all latitudes, with less variability outside the tropics.

3) Precipitation-R. S. Vose, K. Hilburn, $X$. Yin, M. Kruk, and A. Becker

Globally, precipitation over land surfaces was near the 1961-90 average in 2013 (Fig. 2.15a). This conclusion is based primarily on station records in the Global Historical Climatology Network (GHCN) Monthly version 2 (Peterson and Vose 1997), which was about $1 \mathrm{~mm}$ above normal, and the Global Precipitation Climatology Centre (GPCC) Monitoring Product version 4 (Becker et al. 2013), which was about $1 \mathrm{~mm}$ below normal. Historically, GHCN and GPCC have been similar on an annual basis, though GHCN has higher interannual variability due to its smaller network. Land data for a blended satellite-in situ product, the Global Precipitation Climatology Project version 2.1 (GPCP; Adler et al. 2003), sug-

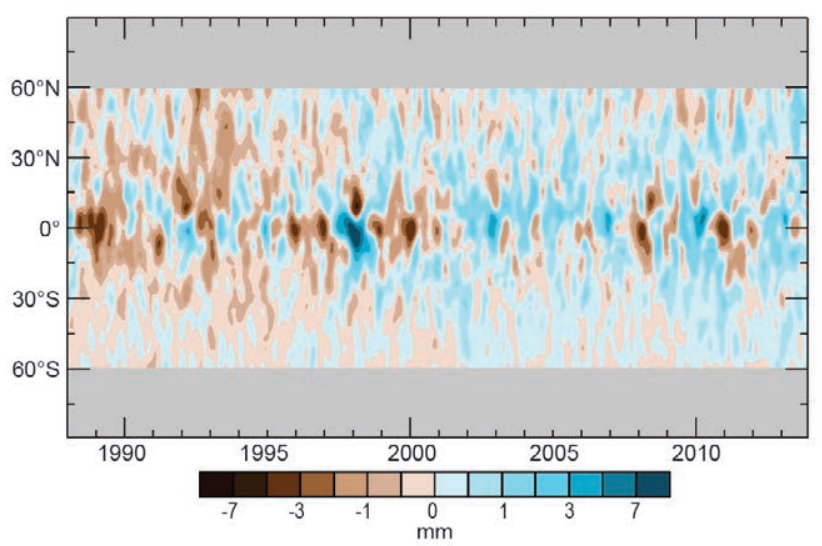

FIG. 2.I4. Time-latitude plot of TCWV anomalies (mm), 1997-2010 reference period. The data (SSM/I, SSMIS, AMSR-E, and WindSat) have been smoothed in the time direction to remove variability on time scales shorter than 4 months.

gest that 2013 may have been somewhat below average, though GPCP has generally been slightly drier than the other products in recent years.

Several coherent anomaly patterns were evident over land in 2013 (Plate 2.1h). For instance, below-average precipitation fell over much of North America, northern Eurasia, southern South America, sub-Saharan Africa, and Australia. In contrast, above-average precipitation fell over parts of southern Asia, the Amazon basin, the Maritime Continent, and Greenland (though the latter should be viewed cautiously because of the statistically in-filled estimates

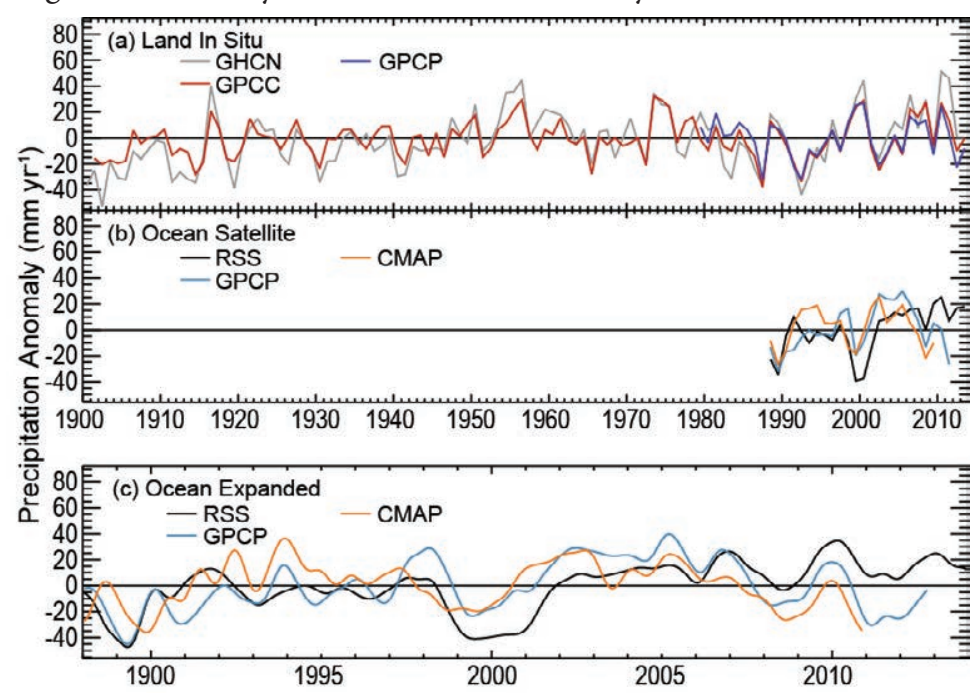

FIG. 2.I5. Globally-averaged precipitation anomalies (mm, I96I-90 base period over land, 1988-20I0 base period over ocean) for (a) three in situ datasets over land and (b), (c) three satellite-based datasets over ocean. Global ocean averages cover $60^{\circ} \mathrm{N}-60^{\circ} \mathrm{S}$ using a common definition of "ocean". Panel (c) shows low-pass filtered time series by convolution with a Gaussian distribution with 4-month width at half-peak power whereas panel (b) shows annual averages of this for comparison with land data. 
in that area). Relative to 2012, the dry conditions over central North America and eastern South America became somewhat less extreme. Meanwhile, much of the Sahel flipped from above- to below-normal rainfall.

Globally, precipitation over the oceans was above the 1988-2010 average in 2013 (Fig. 2.15b,c). This conclusion is based on intercalibrated passive microwave retrievals in the Remote Sensing Sytems (RSS; Hilburn and Wentz 2008) version 7 product, which was about $12 \mathrm{~mm}$ above normal. Ocean data for two other products, the GPCP blended satellite-in situ dataset and the Climate Prediction Center Merged Analysis of Precipitation (CMAP; Xie and Arkin 1997), are not yet available for 2013. Relative to terrestrial datasets, the ocean products are less similar globally, though some consistency is evident-e.g., the wettest recent year was 2010, 2011 was much drier, and ocean precipitation has increased since then. RSS has been wetter than GPCP, which has been wetter than CMAP.

Coherent anomaly patterns were evident over the ocean as well in 2013 (Plate 2.1h). For instance, there were dry anomalies in much of the Indian Ocean and the Arabian Sea. Wet anomalies extended southward from the Bay of Bengal, along Sumatra, and between Australia and Indonesia, covering the Timor and Arafura Seas. The wet anomalies extended northward through the Java and Banda Seas, as far north as the South China Sea, and as far east as the Caroline Islands. The North Pacific had wet anomalies from Japan to Alaska, and the South Pacific had wet anomalies along the South Pacific convergence zone. It was drier over the North Atlantic, especially along North America, extending as far south as the Caribbean Sea.

4) Cloudiness-M. Foster, S. A. Ackerman, A. K. Heidinger, B. C. Maddux, and M. Stengel

Global mean annual cloudiness anomalies from six satellite data records, a synoptic record, and a reanalysis product are shown in Fig. 2.16. The PATMOS-x (Pathfinder Atmospheres Extended) and MISR (Multiangle Imaging Spectroradiometer) records show mean global cloudiness remained static from 2012 to 2013 (within $0.1 \%$ ) while the Moderate Resolution Imaging Spectroradiometer (MODIS) showed a moderate increase of $0.4 \%$. ISCCP (International Satellite Cloud Climatology Project), HIRS (High Resolution Infrared Sounder), and CLARA-A1 (Cloud, ALbedo and RAdiation dataset) are also shown though they currently do not extend through 2013. CLARA-A1 is a

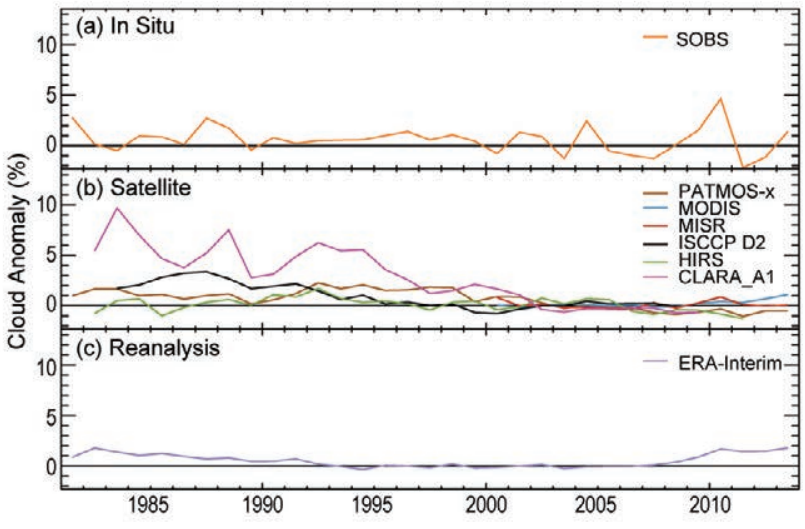

FIG. 2.16. Annual global cloudiness anomalies (\%) for $198 \mid-2013$. The anomaly is defined as the annual value minus the mean, derived between 2000 and 2009, a period common to all of the satellite records included in (b). Panel (a) SYNOP cloud cover provided by DWD. The satellite datasets included in (b) are: MODIS (Ackerman et al. 2008) and MISR (Di Girolamo et al. 2010 ) instruments, which are located on NASA's Terra satellite and span from 2000 to present (a MODIS instrument is also located on NASA's Aqua satellite and is included in the climatology from 2003); ISCCP D2 (Rossow and Schiffer 1999) data derived from the imaging radiometers on the operational weather satellites of several nations; HIRS (Wylie et al. 2005); CLARA-AI (Karlsson et al. 2013) from AVHRR data covering 1982-2009; and PATMOS-x (Heidinger et al. 2013), which is also derived from the AVHRR imager record but covers 198 I through present. Panel (c) ERAInterim (Dee et al. 20II).

EUMETSAT Satellite Application Facility on Climate Monitoring (CM-SAF) climate application product consisting of cloud, surface albedo, and radiative parameters. It covers 1982-2009 with plans for future reprocessing. The synoptic record, SYNOP, consists of manual cloud cover observations in oktas. For inclusion SYNOP sites must have available observations for at least 75\% of the record (1981-2013). Mainly North American and European sites fulfill this criterion, so it is not a true global record. Cloudiness is also provided from the ERA-Interim reanalysis.

Historically, 2013 was the sixth least cloudy year, $1.1 \%$ less cloudy than the mean for the 33-year PATMOS-x record, the primary data set used here. There is general agreement among the satellite records, although this deteriorates away from the common reference period of 2000-09, especially for CLARA-A1. However, there is comparative interannual stability in mean global cloudiness since 2000. Variability in the early part of the CLARA-A1 record may in part be attributed to the combined effect of imperfect diurnal sampling and satellite drift. Cloud detection 
over semi-arid areas during daytime also contributes and is more pronounced during the 1980s when no morning satellites were used. In the case of PATMOS$\mathrm{x}$, which like CLARA-A1 is derived from the AVHRR (Advanced Very High Resolution Radiometer) sensor, a diurnal correction has been applied to account for this issue (Foster and Heidinger 2013). There is no consensus in any long-term trends among the records.

Global cloudiness in 2013 was characterized by a lack of any strong ENSO signal and an almost complete lack of statistically significant positive anomaly regions (Plate 2.1d; Online Fig. S2.13). Accordingly, there were few maritime cloudiness anomalies over the tropical and subtropical Pacific, as seen in Plate $2.1 \mathrm{~d}$ where the cloudiness anomaly is defined as the 2013 cloudiness minus the climatological mean cloudiness (1981-2010, using PATMOS-x). Negative anomalies occurred off the northern coasts of Alaska and Scandinavia, consistent with the negative phase of the Arctic Oscillation present early in the year (section 2e1). But, although the negative annual anomalies are significant at the 5\% level, the Arctic Oscillation shifted to a positive phase in the middle of the year, contributing to some of the wettest months on record for Alaska and Norway.

Several significant (at the 5\% level) negative continental anomalies correspond to severe drought (compare Plate $2.1 \mathrm{~h}$ ) or heat extremes. In the western United States and southern Africa (including Madagascar) these anomalies corresponded with severe drought conditions. In southern China, South Korea, and Japan the reduced cloudiness corresponded with heat extremes in the summer months, while in Russia warm extremes were observed in the winter months (see Online Fig. S2.13; sections 7b, d, g).

ENSO affects the global distribution of cloudiness through enhancement/suppression of large-scale convection in the western Pacific and corresponding suppression/enhancement of convection in the central Pacific driven by SST and low-level wind gradients between the central equatorial Pacific and Indonesia. While the historical ENSO signal can be seen in the Hövmoller for 1981-2013 in Online Fig. 2.14 , it is not clear how consistently the geographic distribution of mean annual cloudiness relates to the strength of ENSO alone. To this end, the annual mean total cloudiness anomalies for each year in the PATMOS-x record have been calculated here. The geographic region between $70^{\circ} \mathrm{N}$ and $70^{\circ} \mathrm{S}$ is considered, as the lack of radiometric contrast between clouds and the surface in polar regions introduces significant uncertainty into the detection process.

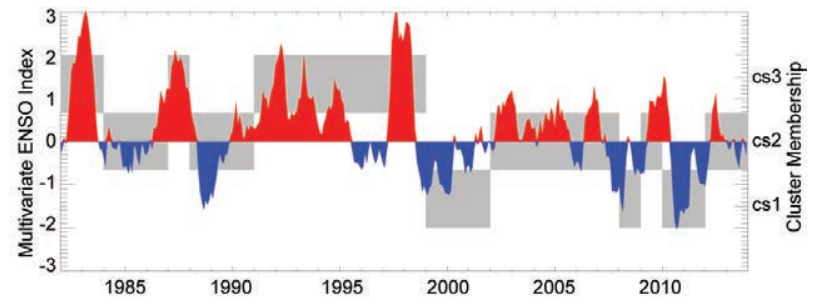

FIG. 2.17. Multivariate ENSO index for 1982-2013 plotted over the associated cluster (cs) membership for each year during that period. Shaded grey boxes represent membership in one of the three clusters: csl, cs2, or cs3 (right axis). (Source: http://www.esrl.noaa.gov/psd/enso/mei/table.html.)

A clustering algorithm is applied (Anderberg 1973), which sorts those years with similar spatial patterns of cloudiness into distinct groups or 'clusters'. Three clusters were created and when plotted annually along with a multivariate ENSO index (Wolter and Timlin 1998; Fig. 2.17) it is clear that ENSO is a primary driver of cloudiness, as cluster membership corresponds closely with index value. Each cluster can be thought of as a "climate state" (CS). In this context, CS1 represents La Niña conditions and corresponds to negative cloudiness anomalies over the central equatorial and southeastern Pacific, CS2 represents ENSO-neutral conditions with neutral cloudiness, and CS3 represents El Niño conditions with positive cloudiness anomalies over the central equatorial and southeastern Pacific. The year 2013 was determined to fit into CS2, with relatively average cloudiness conditions. The last time a year was classified as CS3 was 1998, before the start of MODIS and MISR record, though it should be noted that increasing the number of clusters allows for more refined ENSO states. For example when five clusters are created one represents weak El Niño conditions with positive cloudiness anomalies concentrated in the central Pacific, to which 2002 would belong.

\section{5) River Discharge-H. Kim and T. Oki}

As an integral connection between overland precipitation and freshwater supply to oceans, river discharge is an essential component in the global water cycle. Its availability has affected civilizations considerably through cultural and economic impacts over time. However, due to the absence of direct observations at the global scale and the decreasing number of gauge stations (Fekete et al. 2012), off-line hydrologic modeling is still required to estimate river discharge at long-term global scales. Global discharge excluding Greenland and Antarctica is estimated as a subset of the Ensemble Land Surface Estimator (ELSE; Kim et 
al. 2009). The Japanese 25-year Reanalysis (JRA-25; Onogi et al. 2007) provides surface meteorological variables from 1979 through 2013 to force the land surface model Minimal Advanced Treatments of Surface Interaction and RunOff (MATSIRO; Takata et al. 2003). Realistic month-to-month variability is introduced using the Global Precipitation Climatology Project Version 2.2 (GPCP; Huffman et al. 2012) and Global Precipitation Climatology Centre (GPCC; Rudolf and Rubel 2005) monthly observational precipitation products. Due to the lagged update frequency of the GPCC Full Data Reanalysis Version 6 , the Monitoring product Version 4 is used for the period of 2011-13. In order to reconcile the time series of these two separated periods, a trend-preserving statistical bias correction (Watanabe et al. 2012) is applied. In addition, a wind-induced under-catch correction (Legates and Willmott 1990) is applied to GPCC precipitation estimates. Simulated runoff is routed through a global river transfer model, Total Runoff Integrated Pathway (TRIP; Oki and Sud 1998). Simulations are validated over 29 global river basins which encompass approximately 25\% (32 358232 $\left.\mathrm{km}^{2}\right)$ of the global terrestrial area $\left(130764683 \mathrm{~km}^{2}\right)$. Both flux (discharge) and storage (terrestrial water storage) terms are compared against Global Runoff Data Center in-situ observations and the Gravity Recovery And Climate Experiment (GRACE; Tapley et al. 2004) satellite remote sensing data, respectively (http://hydro.iis.u-tokyo.ac.jp/ hjkim/tws@2009GRL/).

Plates $2.1 \mathrm{i}$ and $2.1 \mathrm{j}$ show spatial variability of the global river discharge and runoff anomaly in 2013, and Fig. 2.18 shows continent-wise runoff anomaly estimations during the recent four years. Strong spatial variability is apparent during 2013. Within South America, the northwestern part of the continent and most of the Amazon basin show wetter conditions
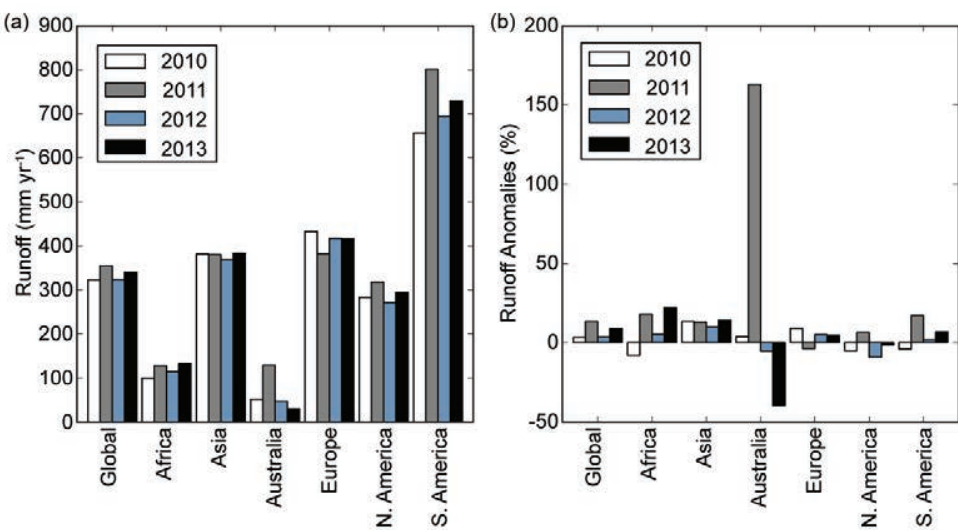

FIG. 2.I8. Global and continental estimations for runoff (a) absolute values ( $\left.\mathrm{mm} \mathrm{yr}^{-1}\right)$ and (b) anomalies relative to the 1979-2013 base period (\%) during 2010-13 from the ELSE system. than the climatological mean (1979-2013) in contrast to the drier conditions of the southeastern parts such as Rio de la Plata and Tocantins. In the annual analysis, most of North America suffers from drier conditions than normal, except in the southeastern part of the United States. During the last four years runoff from North America tends to be below the long-term mean, and 2013 is the second driest year following 2012. While the Nile River has more freshwater discharge, the other major river basins on the African continent (e.g., Congo, Niger, Zambezi, and Orange) show less discharge in 2013. The annual discharge from this continent is consistently below the average for the last few years. Relatively weak interannual variability is found in the recent annual estimates of discharge from the European continent. Mediterranean countries are wetter on average while northern European countries are drier leading to a neutral continental balance. The high latitudes of the Eurasia continent and East Asia show negative anomalies particularly for the Yenisei River and its vicinity and rivers in China. The Ob, Amur, and Brahmaputra Rivers transport more water than average. Australia shows extremely large interannual variability. The discharge in 2013 shows a significant negative relative anomaly in contrast to the extreme positive anomaly in 2011.

6) Groundwater and terRestrial WAter StORAGEM. Rodell, D. P. Chambers, and J. S. Famiglietti

Terrestrial water storage (TWS) comprises groundwater, soil moisture, surface water, snow, and ice. Groundwater typically varies more slowly than the other TWS components because it is not in direct contact with the atmosphere; however, it often has a larger range of variability on multiannual timescales (Rodell and Famiglietti 2001; Alley et al. 2002). In situ groundwater data are only archived and made available by a few countries. However, monthly TWS variations observed by the Gravity Recovery and Climate Experiment (GRACE; Tapley et al. 2004) satellite mission, which launched in 2002, are a reasonable proxy for unconfined groundwater at climatic scales.

Changes in mean annual TWS from 2012 to 2013 are plotted in Plate $2.1 \mathrm{k}$ as equivalent depths of water in $\mathrm{cm}$. TWS can be thought of as an integrator of other hydroclimatic variables (see Plates 2.1d-2.11). Many parts of the Northern Hemisphere saw a recovery in 2013 from 
the dry conditions of 2012, while drought continued in other areas. The massive drought that covered most of North America in 2012 abated in much of the eastern and central United States and Canada, but worsened to near-record levels in the southwestern United States. Europe and Russia also recovered from a dry 2012. The year was mixed in southern Asia, with drought afflicting Bangladesh and eastern and southern India. Depletion of aquifers by pumping for irrigation continued in northern India (Rodell et al. 2009; Tiwari et al. 2009) and the North China Plain (Feng et al. 2013), while heavy rains in parts of Turkey and the Middle East helped raise otherwise depressed water levels (Voss et al. 2013). Parts of southern Africa, including Angola and Namibia, went from moderately dry in 2012 to severe drought in 2013. In South America, the central Amazon became extremely wet, while parts of coastal Brazil and Venezuela were dry for most of the year. Australia as a whole lost a large amount of TWS in 2013. Significant reductions in TWS in Greenland, Antarctica, and southern coastal Alaska represent ongoing ice sheet and glacier ablation, not groundwater depletion.

Figures 2.19 and 2.20 show time series of zonal mean and global, deseasonalized monthly TWS anomalies from GRACE, excluding Greenland and Antarctica. Data gaps occur when the satellites were powered down to conserve battery life. Recovery from the unusually dry conditions of 2012 can be seen, particularly in the northern midlatitudes (Fig. 2.19), and also in the global land (Fig. 2.20). The global TWS anomaly ended 2012 at $-15 \mathrm{~cm}$, reached an 11-year minimum of $-18 \mathrm{~cm}$ in February 2013, and recovered to $-2 \mathrm{~cm}$ by December 2013.

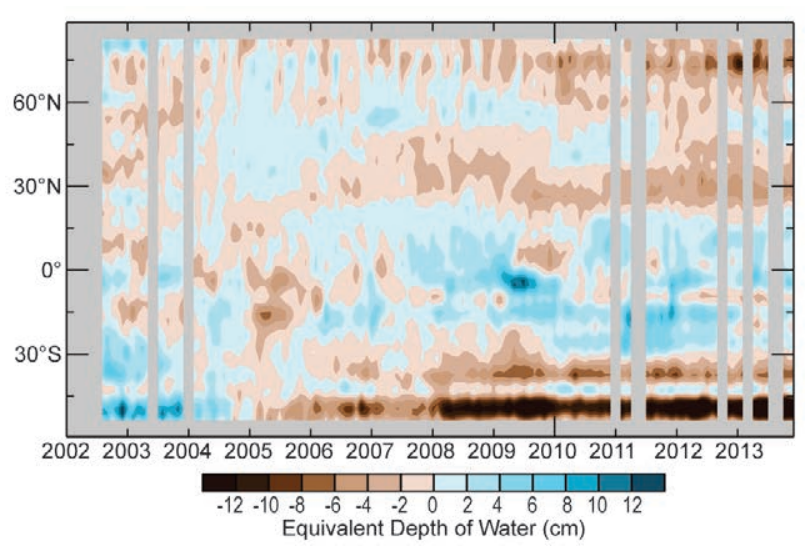

FIG. 2.19. Zonal mean terrestrial water storage anomalies (2003-07 base period) in cm equivalent depth of water, from GRACE. Gray areas indicate months when data were unavailable.

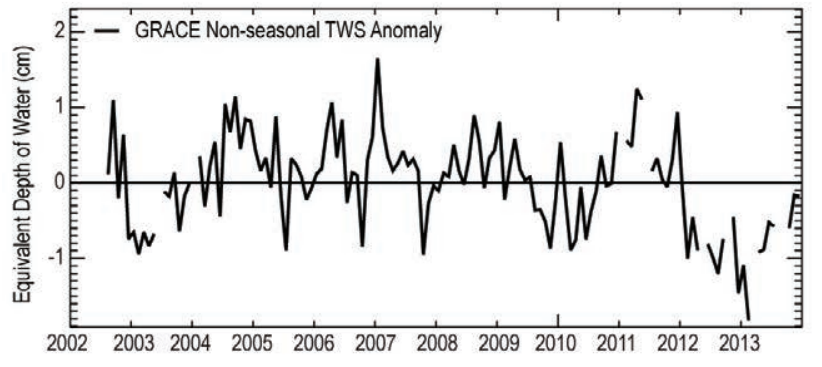

FIG. 2.20. Global average terrestrial water storage anomalies, in cm equivalent depth of water, calculated using a 2003-07 base period. Data gaps occur when the satellites were powered down to conserve battery life.

7) SOIL MOISTURE-W. A. Dorigo, D. Chung, R. M. Parinussa, C. Reimer, S. Hahn, Y. Y. Liu, W. Wagner, R. A. M. de Jeu, C. Paulik, and G. Wang

Soil moisture is both a manifestation and a driver of the complex interactions between the water, energy, and biogeochemical cycles at the Earth's surface (e.g., Taylor et al. 2012). Monitoring long-term changes in its mean values and variability is thus pivotal for understanding the effects of climate change (Seneviratne et al. 2010). In 2012 the Climate Change Initiative (CCI) of the European Space Agency released a soil moisture dataset (ECV soil moisture) that amalgamates global observations from various space-borne radiometers and scatterometers (De Jeu et al. 2012a; Liu et al. 2012). Recently, the ECV soil moisture product has undergone several algorithmic improvements and has been complemented with observations from the Coriolis Windsat and GCOM-W AMSR2 sensors to continue the legacy of C-band observations in the passive microwave domain. The observation record now spans a 35-year period (late 1978-present). Anomalies are based on a 1991-2012 climatology. The first 13 years contain different dataset characteristics and so are not included in the climatology.

Plate 2.11 shows where in 2013 either dry (brown) or wet (blue) anomalous conditions prevailed. Anomalous dry conditions were observed in particular in the Southern Hemisphere, e.g., in Argentina, northeastern Brazil, southern Africa, and Australia. These areas are particularly sensitive to drought during the El Niño phase of ENSO (Bauer-Marschallinger et al. 2013; Miralles et al. 2014). However, ENSO conditions were neutral throughout 2013 (see section 2e1). For some of the drought-affected regions (e.g., northeastern Brazil and southern Africa) strong anomalous negative soil moisture conditions were present in 2012 (Parinussa et al. 2013) and continued in 2013. The monthly anomaly maps (Online Fig. S2.15) show that negative anomalies were particularly evident during the first half of 2013, but gradually decreased towards 
the end of the year, except for Australia where heat records throughout the year led to an annual high temperature record (BoM 2014; also see Sidebar 7.5). Dry conditions were also observed in southeastern Europe in summer, caused by a lack of precipitation and high temperatures (see section 7f). After several extremely dry summers in a row (De Jeu et al. 2011, 2012b; Parinussa et al. 2013), central Eurasia experienced neutral conditions in 2013 (Online Fig. S2.15). Similarly, in the southeast and central parts of the United States, after several very dry years, drought conditions recovered towards the end of summer; however, conditions deteriorated in the far west in the course of 2013, with record to near-record dryness (see section 7b2). This evolution is visible in the monthly maps (Online Fig. S2.15).

Extremely wet conditions during boreal summer likely prompted several major flood events such as those that occurred in the eastern parts of Russia and northeast China in August 2013. Anomalously wet conditions were also observed in March in Spain, which received more than triple its average precipitation for this month. Extremely wet conditions in South Asia (June, July, and October) and Brazil (December) contributed to floods and landslides.

On a global scale, 2013 soil moisture did not strongly deviate from the last few years (Fig. 2.21). This is mainly attributed to the absence of a strong ENSO anomaly which drives the major year-to-year variability in average terrestrial wetness conditions. ENSO-driven global variations are particularly visible during the El Niño of 1997-98 and the La Niña of 2010-11, and closely correspond to the dynamics observed in terrestrial water storage from GRACE (Boening et al. 2012). When looking at the entire time series, average soil moisture conditions over 2013 seem to confirm the slight general drying trend as

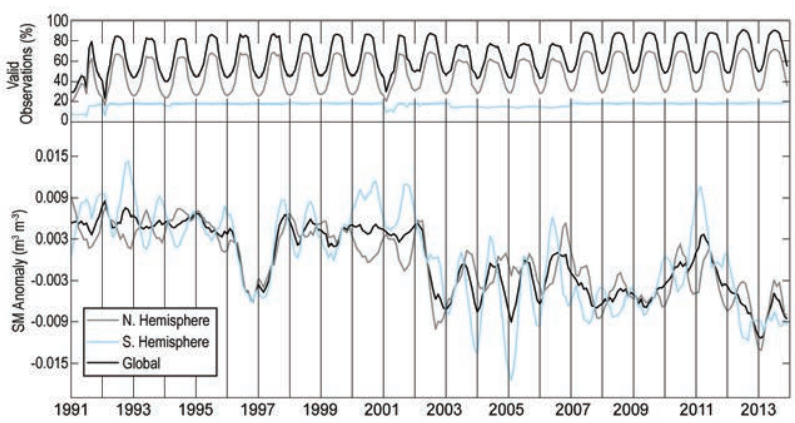

FIG. 2.2I. ESA's CCI ECV SM time series of average global soil moisture anomalies $\left(\mathrm{m}^{3} \mathrm{~m}^{-3}\right)$ for the period 199I-2013 (relative to the 199I-2012 base period). The top plot shows the percentage of land pixels with valid observations.

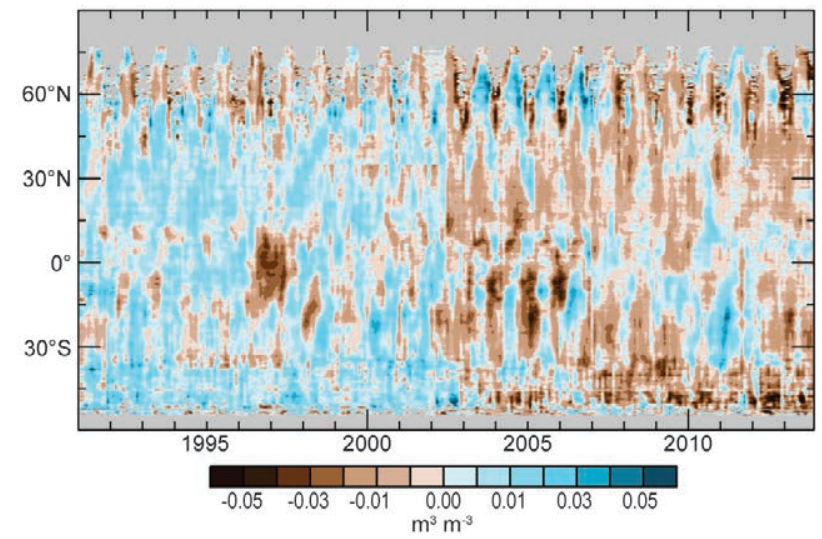

FIG. 2.22. Time-latitude diagram of ECV soil moisture anomalies $\left(\mathrm{m}^{3} \mathrm{~m}^{-3}\right)$ with respect to baseline period 1991-2012.

observed by Dorigo et al. (2012), but are not in line with recent trends in global evaporation (Miralles et al. 2014) or drought severity (van der Schrier et al. 2013). These differences between products are due to various factors, including the physical mechanisms and forcing of the latter two products and the incomplete global coverage of the ECV soil moisture product, which is masked for dense vegetation and frozen soil conditions (see also Fig. 2.21).

The year-to-year and seasonal variability is even more apparent at regional scales (Fig. 2.22). For example, for the southern midlatitudes, an alternation of dry and wet periods can be observed, including the 2001-09 Australian Millennium Drought (van Dijk et al. 2013), followed by extremely wet conditions in 2010-11, and turning back to drought conditions again during the last two years. The figure also illustrates that the general drying trend observed for the Northern Hemisphere over the last decade is observed across the entire midlatitudes, including the southern United States and the Mediterranean.

\section{e. Atmospheric circulation}

I) Mean sea level pressure-R. Allan and C. K. Folland

El Niño and La Niña can be measured by the Southern Oscillation index (SOI), the normalized MSLP difference between Tahiti and Darwin (Allan et al. 1996). It can also be measured using sea surface temperatures (SSTs; e.g., see Fig. 4.1). El Niños (negative SOI) and La Niñas (positive SOI) vary in magnitude, duration, and evolution, with no two events exactly the same. Major El Niño and La Niña events can be near-global in their influence on world weather patterns, owing to ocean-atmosphere interactions across the Indo-Pacific region with teleconnections to higher latitudes in both hemispheres. 


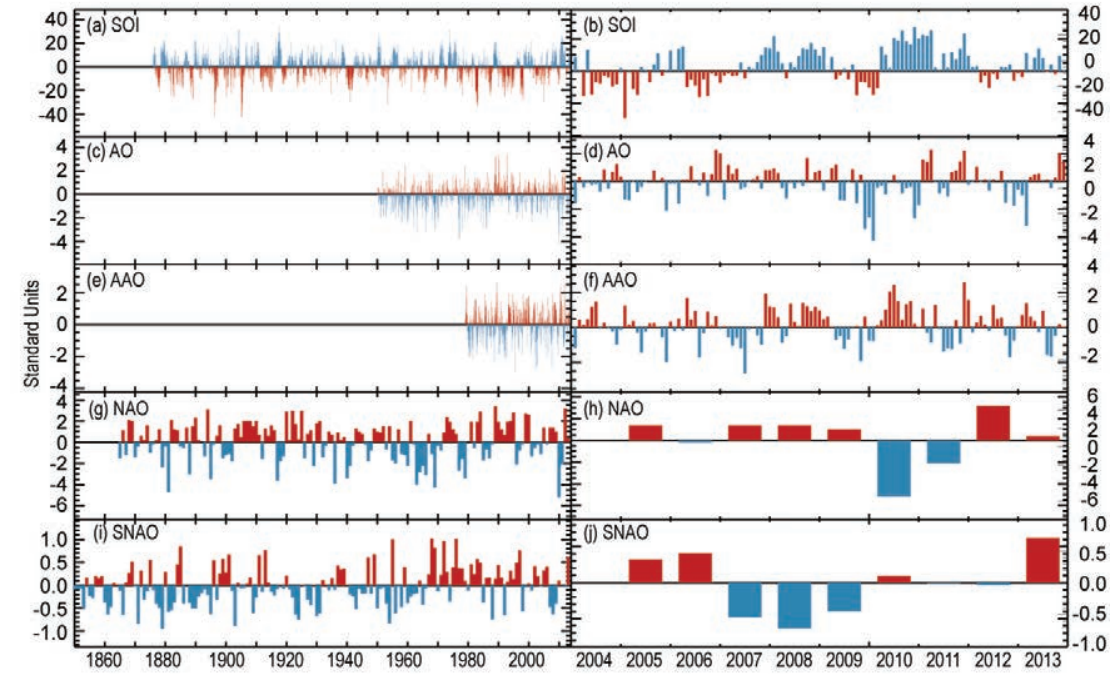

FIG. 2.23. Time series for modes of variability described using sea level pressure for the complete period of record $(a, c, e, g, i)$ and last ten years $(b, d, f, h, j) .(a),(b$,$) Southern Oscillation index (SOl) provided by the Aus-$ tralian Bureau of Meteorology (ftp://ftp.bom.gov.au/anon/home/ncc/www Isco/soi/soiplaintext.html). (c),(d,) Arctic Oscillation (AO) provided by NCEP Climate Prediction Center (http://www.cpc.ncep.noaa.gov /products/precip/CWlink/daily_ao_index/ao.shtml). (e),(f) Antarctic Oscillation (AA) provided by NOAA Earth System Research Laboratory (http://www.esrl.noaa.gov/psd/data/correlation/aao.data). (g),(h,) Winter (Dec-Feb) North Atlantic Oscillation (NAO) average provided by the NCAR (https://climatedataguide.ucar.edu/climate-data /hurrell-north-atlantic-oscillation-nao-index-station-based). (i),(j), Summer (Jul-Aug) North Atlantic Oscillation (SNAO) average.

Since the termination of the protracted La Niña episode in early 2012, near-normal SOI values persisted until early 2013 , after which values were mainly positive for the rest of the year (Fig. 2.23a,b). However, these values did not reach the threshold for an official La Niña event, and overall 2013 was ENSO-neutral.

The SOI is arguably the most global mode of sea level pressure variability. Other regionally notable modes are shown in Fig. 2.23. In late 2012, positive North Atlantic Oscillation (NAO; see Fig. 2.24a,c)/
Arctic Oscillation (AO) conditions favored a westerly regime and wet weather over Europe, with major flooding episodes in the United Kingdom. But in early 2013 this westerly circulation pattern was replaced by more easterly winds over western Europe and the United Kingdom, leading to colder, snowy weather (see section $7 \mathrm{f}$ for more details).

In contrast, the Northern Hemisphere winter of 2013/14 experienced a different mix of conditions. Since December 2012, the North Pacific anticyclone has been anomalously strong and persistent, leading to prolonged drought in California (Plates $2.1 \mathrm{~d}-2.1 \mathrm{~m})$. This strong anticyclone (Fig. 2.24a,b) was accompanied in the Northern Hemisphere early winter of 2013/14 by a positive $\mathrm{AO}$, a deep trough over Canada and the United States, and a southerly displaced and enhanced subtropical jet-stream extending across the Atlantic to the United Kingdom and Europe under strong positive NAO conditions (Fig. 2.24d). This led to severe cold winter conditions in much of the United States and a succession of major midlatitude storms being steered across the Atlantic to Ireland and the United Kingdom.

In the Southern Hemisphere, the Antarctic Oscillation (AAO) did not exhibit strong features during the austral summers of 2012/13 or early 2013/14 (Fig. $2.23 \mathrm{e}, \mathrm{f})$. (a)

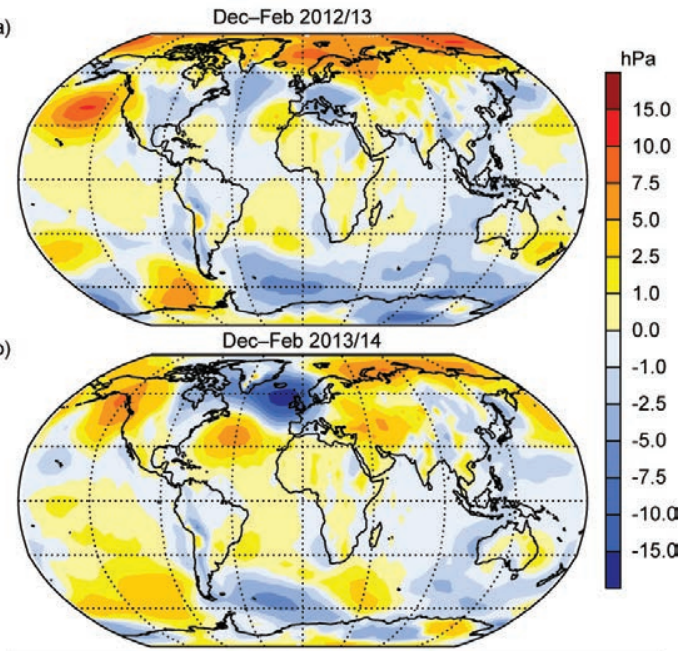

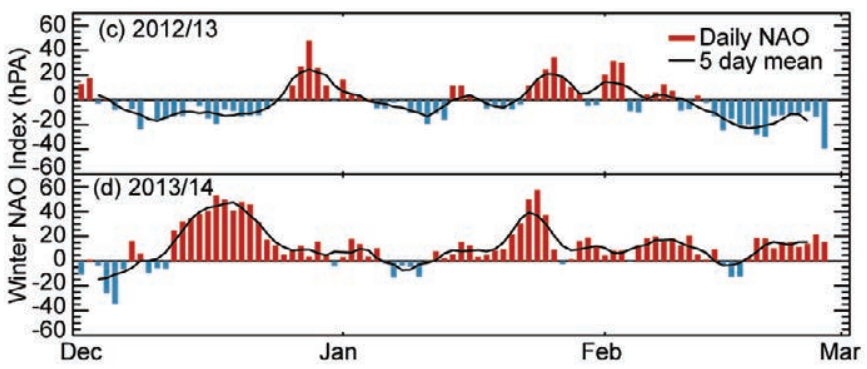

Fig. 2.24. Boreal winter sea level pressure anomalies (hPa, 1981-2010 base period) averaged over Dec-Feb for (a) $2012 / 13$ and (b) $2013 / 14$. NAO daily time series $(\mathrm{hPa})$ for the winter of (c) 20I2/13 and (d) 20/3/14. The data shown are from HadSLP2r (Allan and Ansell 2006). 

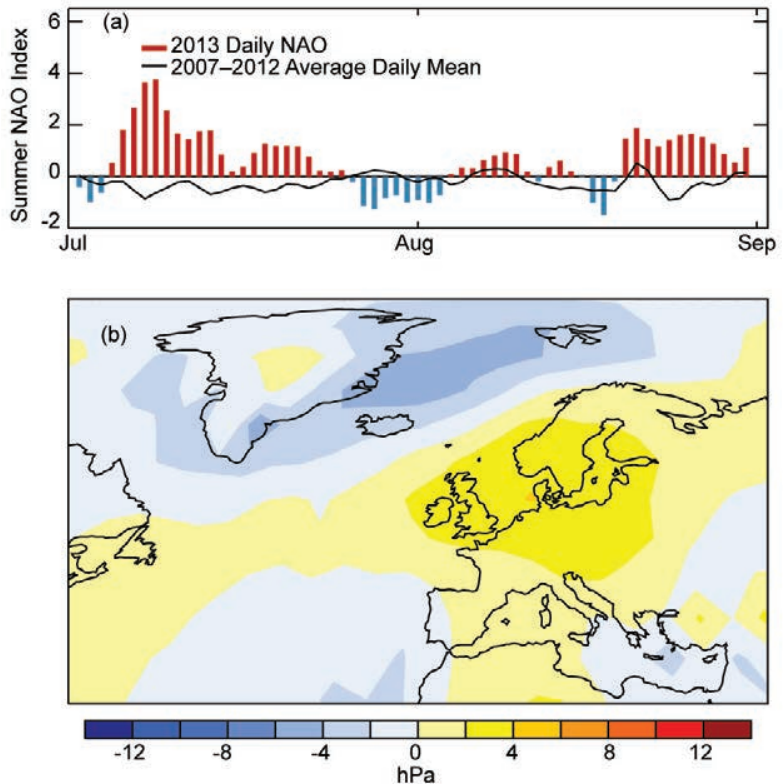

Fig. 2.25. Boreal summer (Jul-Aug) NAO patterns for 2013. (a) Daily SNAO index anomalies from I98I-2010 for summer 2013 against the 2007-12 average using NCEP reanalysis MSLP data. (b) Pattern of summer 2013 MSLP anomalies (hPa) from 198I-2010 over Europe using HadSLP2r (Allan and Ansell 2006).

In the main boreal summer months of July and August, the summer NAO (SNAO), which has a northward displaced pattern compared to the winter NAO (Folland et al. 2009), behaved differently from the generally negative phase observed during the high summers of 2007-12. Figure 2.25a shows daily SNAO values expressed as anomalies from 1981-2010 for July and August 2013 compared to the daily average for 2007-12. The strongly positive phase in 2013 was the first since 2006, except for a marginally above-zero value in 2010, reflected in the pattern of North Atlantic and Europe MSLP anomalies for high summer 2013 (Fig. 2.25b). The pattern is much like that of the positive phase the SNAO in Folland et al. (2009). The strong anticyclonic anomaly over northwest Europe was associated with generally warm and dry conditions (Online Figs. S2.16, S2.17) so that 2013 was the 14th warmest high summer in the central England temperature record back to 1659. England and Wales rainfall was correspondingly dry at $84 \%$ of average, the first dry July and August since 2006 (see section $7 \mathrm{f}$ for more details).

2) SURFACE WINDS

(i) Land surface wind speed-I. Tobin, P. Berrisford, R. J. H. Dunn, R. Vautard, and T. R. McVicar

Surface wind over land is observed at weather stations using anemometers a few meters above the (a)

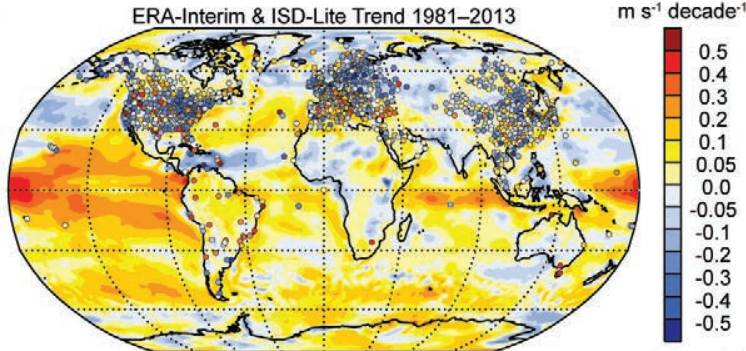

(b)

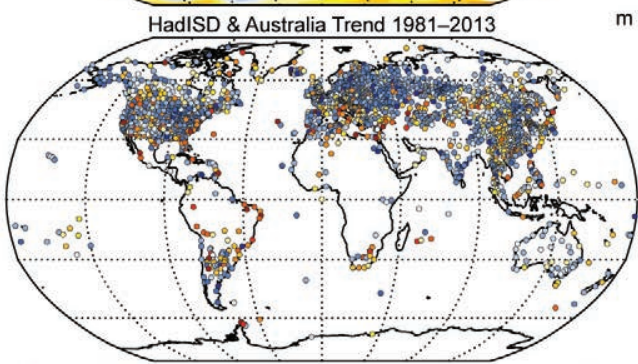

(c)

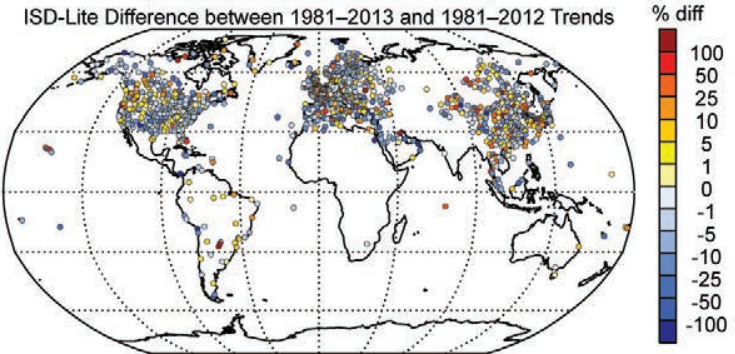

FIG. 2.26. Trends in land surface wind speed. (a) ISDLIte (points) and ERA-Interim (grids) decadal trends over the 198I-2013 period. (b) HadISD and Australian stations (McVicar et al. 2008) decadal trends over the $198 \mathrm{I}-2013$ period. (c) ISD-Lite trend differences (in \% of $\mathrm{m} \mathrm{s}^{-1}$ decade $^{-1}$ ) for 198I-2013 compared to 198I-20I2.

ground. Surface wind speed can vary rapidly over time and space, and station networks are irregularly distributed and sparse, especially in the Southern Hemisphere (see station positions in Plate 2.1n; Fig. 2.26), leading to concerns about representativeness. Following McVicar et al. (2013), three strictly quality controlled datasets are used here: reduced ISD-Lite (Vautard et al. 2010), HadISD (Dunn et al. 2012), mainly over the Northern Hemisphere, and an Australian database (McVicar et al. 2008) made up of about 1350, 2500, and 40 stations, respectively. Reanalysis products provide contiguous global information (ERA-Interim is used here, Dee et al. 2011; Online Fig. S2.18) but exhibit shortcomings in capturing surface winds, as many surface-layer processes controlling wind are not adequately represented (McVicar et al. 2008; Pryor et al. 2009; Vautard et al. 2010). Years prior to 1981 suffer from a significant lack of records in the ISD-Lite database and are thus not considered. 
While still below the long-term climatology, 2013 overall winds recorded at stations represent a small increase $\left(\sim 0.05 \mathrm{~m} \mathrm{~s}^{-1}\right)$ compared to the preceding three years (Fig. 2.27a). The exception is North America where 2013 wind speed was the fourth lowest on record since 1981. Over Europe 2013 was the 10 th (12th) lowest year according to Table 2.5. Regional average climatology and trends for land surface winds 198I-20I3 using ISD-Lite with HadISD in parentheses, and McVicar et al. (2008) for Australia.

\begin{tabular}{|c|c|c|c|}
\hline Region & $\begin{array}{c}\text { Climatological Mean } \\
\text { I98I-2010 }\left(\mathrm{m} \mathrm{s}^{-1}\right)\end{array}$ & $\begin{array}{c}\text { Decadal Linear } \\
\text { Trend I98I-20I3 } \\
\left(\mathrm{m} \mathrm{s}^{-1} \text { decade-1) }\right.\end{array}$ & $\begin{array}{c}\text { Total Number } \\
\text { of Stations }\end{array}$ \\
\hline Globe & $3.5(3.3)$ & $-0.077(-0.088)$ & I379 (2538) \\
\hline North America & $3.8(3.7)$ & $-0.122(-0.117)$ & $364(608)$ \\
\hline Europe & $3.8(3.7)$ & $-0.072(-0.100)$ & $488(661)$ \\
\hline Central Asia & $2.4(2.8)$ & $-0.067(-0.153)$ & $53(319)$ \\
\hline East Asia & $2.8(2.6)$ & $-0.065(-0.069)$ & $247(399)$ \\
\hline Australia & 2.1 & -0.069 & $4 I$ \\
\hline
\end{tabular}

ISD-Lite (HadISD), and it was also the 10th lowest year over Australia. The year 2013 was an average year over central and eastern Asia, which exhibit slightly negative anomalies in ISD-Lite and small positive anomalies in HadISD. Figures 2.27b and $\mathrm{c}$ show that this short-term strengthening of mean wind speed relative to previous years was made up of an increase in frequency of low and moderate winds $\left(>3 \mathrm{~m} \mathrm{~s}^{-1}\right)$, especially over Asia. However, it was not accompanied by an increase in strong wind $(>10 \mathrm{~m}$ $\left.\mathrm{s}^{-1}\right)$ frequency which is similar to previous years over all the regions. Both categories remain below the 1981-2010 climatological average, by $2 \%$ and $0.02 \%$, respectively, according to ISD-Lite.

Spatial patterns of anomalies are shown in Plate 2.1n and Online Fig. S2.18. The magnitude of anomalies does not exceed $0.5-1 \mathrm{~m} \mathrm{~s}^{-1}$ for most stations. North America is dominated by negative anomalies while other regions are characterized by both negative and positive anomalies. The large-scale anomaly

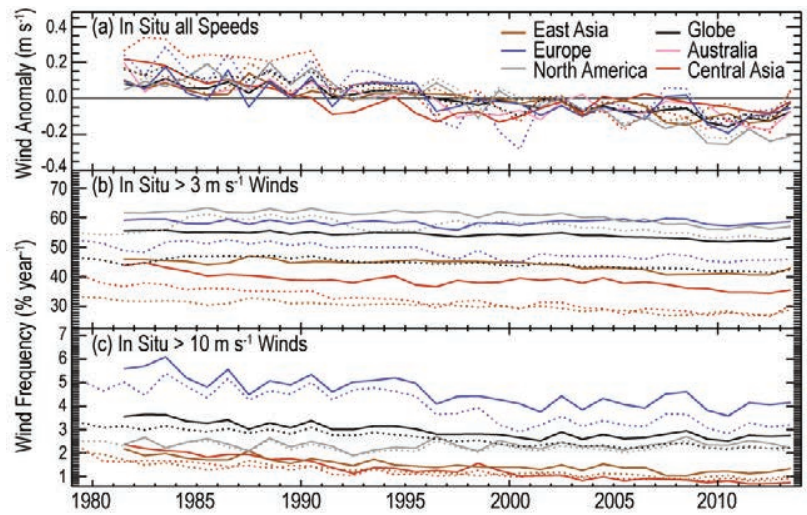

Fig. 2.27. Time series in land surface wind speeds and strength frequency for the globe and various regions using ISD-Lite and HadISD. (a) Area-average annual anomalies relative to the $198 \mathrm{I}-2010$ base period. (b) Area-averaged annual frequencies of wind speeds $>3$ $\mathrm{m} \mathrm{s}^{-1}$. (c) Area-average annual frequencies of wind speeds $>10 \mathrm{~m} \mathrm{~s}^{-1}$. patterns shown by ERA-Interim are consistent with station data and the anomaly magnitude is overall reasonably reproduced despite the substantial spatial resolution difference between datasets (point vs $\sim 0.7^{\circ}$ $\times 0.7^{\circ}$ grid). Over northern and southern Africa and Saudi Arabia ERA-Interim shows extended positive anomalies; however, there are no stations located in these regions from ISD-Lite or HadISD with which to compare. Likewise, South America is characterized by positive anomalies in ERA-Interim, similar to the previous three years (Peterson et al. 2011; Vautard et al. 2012; McVicar et al. 2013).

With regard to the northern midlatitudes and Australia, 2013 is embedded in a 33-year stilling trend, ranging on average from about 0.07 to $0.1 \mathrm{~m}$ $\mathrm{s}^{-1}$ decade $^{-1}$ (Table 2.5; Fig. 2.26a,b). The slowdown of land surface winds has already been reported over many regions (see McVicar et al. 2012 for a review; Dadaser-Celikand and Cengiz 2013; C. Lin et al. 2013; Azorin-Molina et al. 2014). In 2013 this tendency continued over North America. The shortterm strengthening of winds observed over other regions only slightly affects the trend assessment $(75 \%$ of ISD-Lite stations considered here exhibit trend assessment changes of less than 15\% compared with 2012; Fig. 2.26). Although the ERA-Interim pattern of trends is consistent with station data, the magnitude is significantly underestimated as previously noted with other reanalysis products (McVicar et al. 2008; Pryor et al. 2009; Vautard et al. 2010).

This stilling is not fully understood and does not necessarily reflect wind tendency at higher levels (Vautard et al. 2010; Troccoli et al. 2012). Vegetation cover increase, air pollution, thermal and pressure gradient decrease, and urbanization are among the identified causes, which differ among regions (Dadaser-Celik and Cengiz 2013; C. Lin et al. 2013; Azorin-Molina et al. 2014; McVicar et al. 2013). 
(ii) Ocean surface wind speed-C. Mears

Estimates of globally-averaged wind over the oceans obtained from satellite-borne microwave radiometers were slightly lower than average for 2013 (Wentz 1997; Wentz et al. 2007; Fig. 2.28; Online Fig. S2.19). Estimates from reanalysis products differ with JRA-55 and ERA-Interim showing that 2013 was windier than normal, and MERRA showing the opposite. Reanalysis winds, which are in relatively good agreement with both the satellite data and each other from 1990-2009, diverge after 2010. The in situ data show larger trends than the satellite datasets. When comparing global means between in situ datasets and satellite datasets, it is important to note that the area coverage of the in situ datasets is less, with areas of missing or poorly sampled data in the tropical Pacific and the Southern Ocean. The newer JRA-55 product is in better agreement with the satellite measurements than the previous JRA- 25 product, which showed a larger increasing trend during the satellite period than JRA-55. All products show an increasing trend from 1990 to 2007, followed by a drop-off in 2008-09, and a recovery in 2010. Since then the winds have slackened.

During 2013, winds showed positive anomalies in the central tropical Pacific (Plate 2.1n). These anomalies were present and much larger during the 2010-12 period. Other regions with positive anomalies include

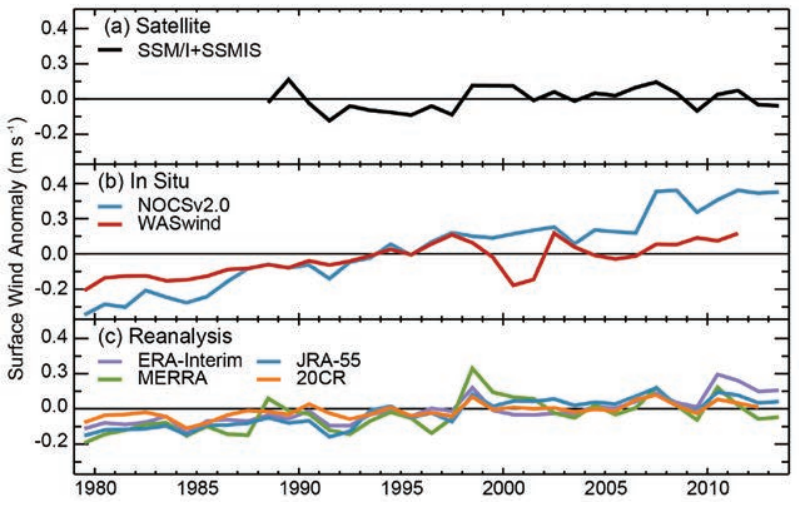

FIG. 2.28. Globally-averaged oceanic wind speeds from (a) satellites, (b) in situ measurements, and (c) reanalysis output. Satellite estimates were produced by Remote Sensing Systems by combining intercalibrated data from 10 satellite-borne microwave radiometers (SSM/I, AMSR-E, SSMIS, and WindSat) WASwind is made from an adjusted version of the ICOADS dataset, which consists of measurements from ships and moored buoys (Tokinaga and Xie 20II). The NOCSv2.0 dataset is also made using the ICOADS data, but is constructed using a different procedure (Berry and Kent 2009, 20II). Reanalysis output is described in Fig. 2.I. The reference period for the combined measurements is $1988-2010$.

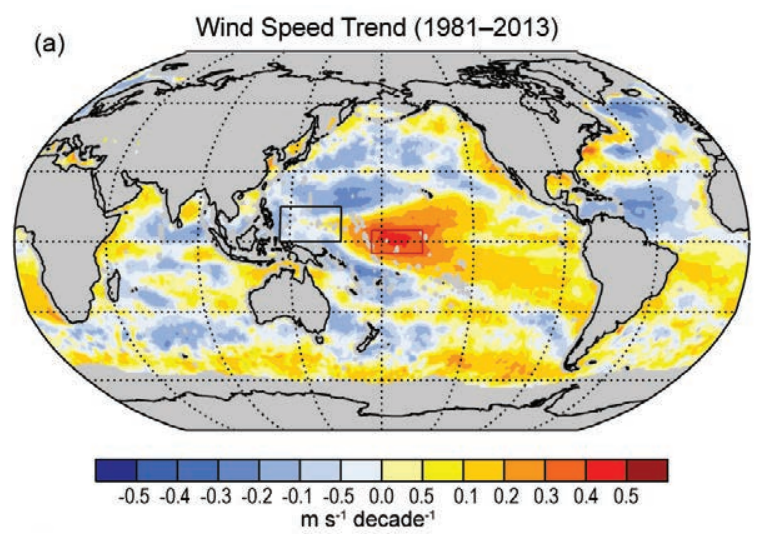

(b)

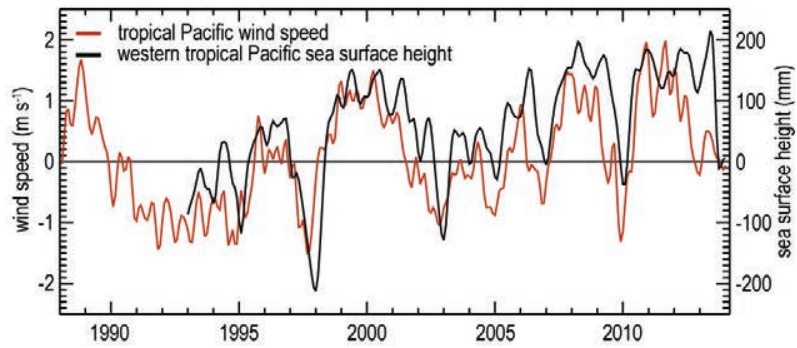

FIG. 2.29. (top) Linear trends in wind speed ( $\left.\mathrm{m} \mathrm{s}^{-1}\right)$ for 1988-2013 from the satellite data. (bottom) Wind speed anomalies ( $\left.\mathrm{m} \mathrm{s}^{-1}\right)$ from the red box in the central tropical Pacific and sea surface height anomalies $(\mathrm{mm})$ from the black box in the western tropical. Positive wind anomalies lead to a piling up of water at the western edge of the basin.

off the eastern coast of North America, west of Spain, the Mediterranean Sea, the northern Indian Ocean, and the Pacific Ocean south of about $50^{\circ} \mathrm{S}$. The Gulf of Alaska showed a large negative anomaly in association with persistent high pressure (Plate $2.1 \mathrm{~m}$ and section 2e1).

A trend map of wind speed over the satellite era (1988-2013; Fig. 2.29a) shows a region of increasing windiness in the central tropical Pacific. These winds typically blow toward the west, leading to increases sea surface height in the western Pacific that are strongly correlated with the wind anomalies (Fig. 2.29b).

\section{f. Earth radiation budget}

I) EARTH RADIATION BUDGET AT TOP-OF-ATMOSPHERED. P. Kratz, P. W. Stackhouse, Jr., T. Wong, P. Sawaengphokhai, A. C. Wilber, S. K. Gupta, and N. G. Loeb

The Earth's radiation budget (ERB) at the topof-atmosphere (TOA) is defined as the sum of the incoming total solar irradiance (TSI), the reflected shortwave radiation (RSW), and the outgoing longwave radiation (OLR). Since the relationship between the incoming and outgoing energies defines 
Table 2.6. Global-annual mean TOA radiative flux changes between 2012 and 2013 , the 2013 global annual mean radiative flux anomalies relative to their corresponding 200I-12 mean climatological values, and the 2-sigma interannual variabilities of the 200I-12 global-annual mean fluxes (all units in $\mathrm{W} \mathrm{m}^{-2}$ ) for the outgoing longwave radiation (OLR), total solar irradiance (TSI), reflected shortwave (RSW) and total net fluxes. All flux values have been rounded to the nearest $0.05 \mathrm{~W} \mathrm{~m}-2$.

\begin{tabular}{|c|c|c|c|}
\hline & $\begin{array}{c}\text { One Year Change } \\
(2013 \text { minus 20I2) } \\
(\mathrm{W} \mathrm{m-2})\end{array}$ & $\begin{array}{c}\text { 20I3 Anomaly } \\
(\text { Relative to 200I-12) } \\
\left(\mathrm{W} \mathrm{m}^{-2}\right)\end{array}$ & $\begin{array}{c}\text { Interannual Variability } \\
(200 \mathrm{I}-12) \\
\left.(\mathrm{W} \mathrm{m})^{-2}\right)\end{array}$ \\
\hline OLR & +0.25 & -0.05 & \pm 0.50 \\
\hline TSI & +0.00 & +0.05 & \pm 0.20 \\
\hline RSW & +0.45 & +0.20 & \pm 0.40 \\
\hline Net & -0.70 & -0.10 & \pm 0.70 \\
\hline
\end{tabular}

Aqua spacecraft since March 2000 and July 2002, respectively. This report focuses on the most recent measurements relative to the longterm CERES dataset.

The monthly mean anomaly time series for the TOA flux components covering March 2000-December 2013 are presented in Fig. 2.30. The OLR oscillated between $\pm 0.60 \mathrm{~W} \mathrm{~m}^{-2}$ throughout 2013 before reaching a neutral value of $-0.04 \mathrm{~W} \mathrm{~m}^{-2}$ in December 2013. The observed OLR variability is generally consistent with the Atmospheric Infrared Sounder (AIRS) the climate state of the Earth-atmosphere system, quantifying these values is of utmost importance in understanding the energy budget that drives weather processes, climate forcing, and climate feedbacks.

An analysis of all measurements from 2012-13 (Table 2.6) shows that the global annual mean OLR increased by $\sim 0.25 \mathrm{~W} \mathrm{~m}^{-2}$ and the RSW increased by $\sim 0.45 \mathrm{~W} \mathrm{~m}^{-2}$. Over the same timeframe, the TSI remained essentially constant. The sum of these components amounts to a reduction of $\sim 0.70 \mathrm{~W} \mathrm{~m}^{-2}$ in the total net radiation into the Earth climate system for 2013 compared with 2012. Relative to the multiyear data average (2001-12), the 2013 global-annual mean flux anomalies (Table 2.6) are $-0.05,+0.05,+0.20$, and $-0.10 \mathrm{~W} \mathrm{~m}^{-2}$ for OLR, TSI, RSW, and total net flux, respectively. These changes are within the corresponding 2-sigma interannual variability for this period.

Prior to August 2013, the TSI data were obtained from either the Total Irradiance Monitor (TIM) instrument aboard the SOlar Radiation and Climate Experiment (SORCE) spacecraft or other satellite data renormalized to SORCE (Kopp and Lean 2011). After the SORCE spacecraft's battery failure in July 2013, the TSI data were obtained from the Royal Meteorological Institute of Belgium (RMIB) composite dataset (Dewitte et al. 2004). To merge the SORCE and RMIB datasets, a time-dependent scaling factor was used to calibrate the differences between the two datasets from March 2003 through June 2013. The RMIB data was then used to simulate SORCE TSI values for July-December 2013. The RSW and OLR data were obtained from the Clouds and the Earth's Radiant Energy System (CERES) mission (Wielicki et al. 1998), which has been deriving flux data from the CERES measurements taken aboard the Terra and
OLR data (monthly AIRX3STM.006 product; not shown). A comparison of the OLR to the multivariate ENSO index (not shown) revealed no trend in the OLR, consistent with the relatively neutral ENSO condition persisting throughout 2013. The absorbed shortwave (TSI - RSW) fluctuated between -0.81 and $+0.97 \mathrm{~W} \mathrm{~m}^{-2}$ during 2013, ending the year at the maximum. The total net anomaly, which contains the combined OLR and absorbed shortwave anomalies,

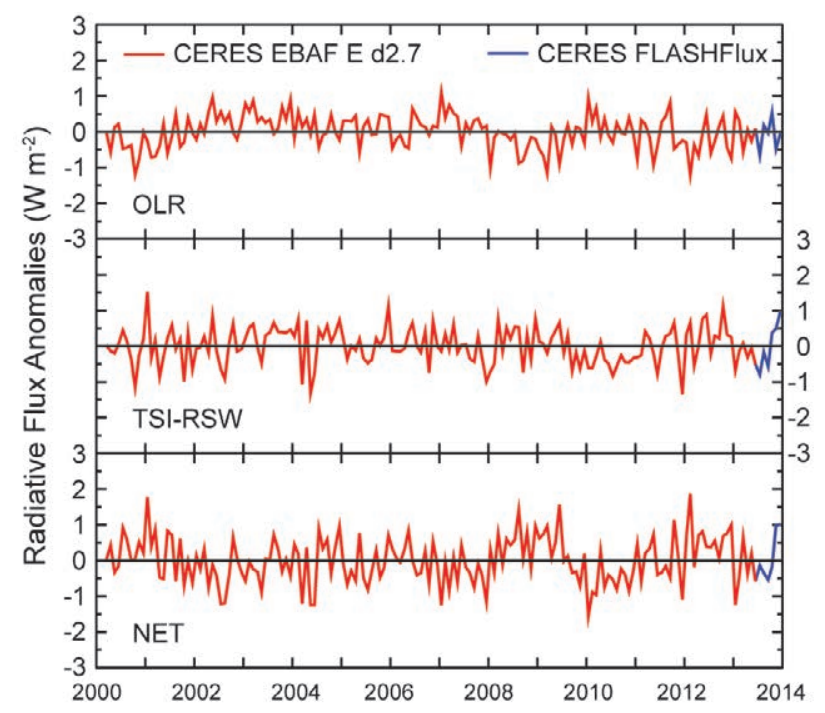

Fig. 2.30. Time series of global-monthly mean deseasonalized anomalies ( $\left.\mathrm{W} \mathrm{m}^{-2}\right)$ of TOA earth radiation budget for OLR (upper panel), absorbed shortwave (TSI - RSW; middle panel), and total net (TSI - RSW OLR; lower panel) from Mar 2000 to Dec 2013. Anomalies are relative to the calendar month climatology derived for the $200 \mathrm{I}-12$ period. The time series shows the CERES EBAF Ed2.7 IDeg data (3/2000 to 6/2013) in red and the CERES FLASHFlux data (7/2013 to $12 / 2013)$ in blue; see text for merging procedure (Source: https://eosweb.larc.nasa.gov/project/ceres/ceres_table.) 
began 2013 with a pronounced minimum of $-1.24 \mathrm{~W}$ $\mathrm{m}^{-2}$, then oscillated between $\pm 0.60 \mathrm{~W} \mathrm{~m}^{-2}$ for most of the year before rising to a maximum of $+1.02 \mathrm{~W} \mathrm{~m}^{-2}$ at the end of 2013.

Temporal analysis from March 2000 to December 2013 was achieved through the merger of two ERB datasets: (1) the CERES EBAF (Energy Balanced And Filled) Ed2.7 product (Loeb et al. 2009, 2012), March 2000-June 2013, and (2) the CERES FLASHFlux (Fast Longwave and Shortwave Radiative Fluxes) 3A product (Kratz et al. 2014; Stackhouse et al. 2006), July-December 2013. The FLASHFlux components are normalized to the EBAF Ed2.7 data using TOA fluxes from both datasets for the 1-year overlap period from July 2012-June 2013. The EBAF data products use TSI from the SORCE mission while the FLASHFlux data products assume a constant TSI, modified only for earth-sun distance. The FLASHFlux TSI data were then adjusted to the combined SORCE and renormalized RMIB data and the RSW was scaled accordingly. The resulting 2-sigma monthly uncertainty of the normalization procedure for the 1-year overlap period was $\pm 0.34, \pm 0.05, \pm 0.84$, and $\pm 0.93 \mathrm{~W} \mathrm{~m}^{-2}$ for the OLR, TSI, RSW, and NET radiation, respectively. The normalization coefficients were then applied to the FLASHFlux data to obtain an EBAF-compatible TOA radiative flux time series through the end of 2013. Owing to the observed variability in the six months extending beyond the EBAF data, long-term trend analyses with the merged data set are discouraged due to the natural fluctuation in ERB components, the uncertainty from the data merging process, and potential for drift in the FLASHFlux product.

2) Mauna Loa Clear-sky atmospheric solar transMISSION-K. Lantz

Atmospheric solar transmission has been measured for five and a half decades by the Global Monitoring Division (GMD) of the National Atmospheric and Oceanic Administration (NOAA) at the Mauna Loa Observatory (MLO). Mauna Loa Observatory is at $3400 \mathrm{~m}$ elevation on the northern slope of the Mauna Loa volcano on the Big Island of Hawaii. The remote location and high altitude make it wellsuited for studying changes in the free troposphere with limited local influences. A clear-sky "apparent" solar transmission (AT) is calculated using the ratio of direct-beam broadband pyrheliometer measurements at fixed atmospheric paths (air mass; Ellis and Pueschel 1971). The AT is advantageous because it is independent of the radiometer calibration and the extraterrestrial irradiance. The MLO AT is particu- larly sensitive to changes in background stratospheric aerosols and the influence of volcanic eruptions. Studies have examined the variability in the MLO AT due to water vapor, ozone, volcanic aerosol, aerosol transport from Asia, and atmospheric circulation changes associated with the quasi-biennial oscillation (QBO; Bodhaine et al. 1981; Dutton et al. 1985, Dutton 1992; Dutton and Bodhaine, 2001).

The updated clear-sky AT from the 1958-2013 monthly record is computed from daily early morning values to remove boundary layer influences due to upslope winds (Fig. 2.31a). The aerosol signal from the eruptions of Agung, El Chichón, and Mount Pinatubo in 1964, 1982, and 1991, respectively, are clearly visible in the record. The 6-month running smoothed fit to the monthly values highlights the seasonal trends in the data that have been attributed primarily to Asian aerosol transport in the spring (Bodhaine et al. 1981). This seasonal variability of the clear-sky AT has an amplitude of 0.007. A 24-month running smoothed fit highlights the longer-term changes. The gray dashed line reflects the cleanest background observed from 1958 to 1962 in the record, except for a brief period in 1978. The average clear-sky AT in 2013 has increased with respect to 2012 but is still not as clean as the cleanest background observed between 1958 and 1962.

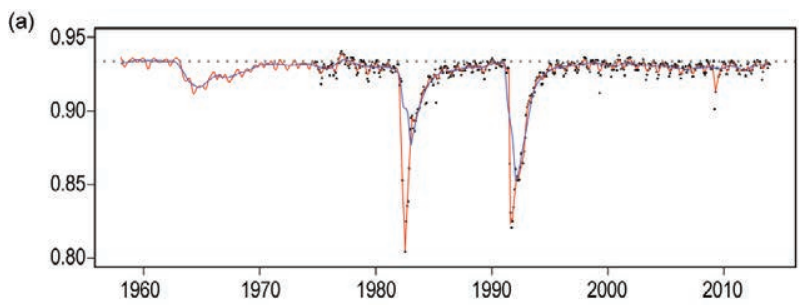

(b)

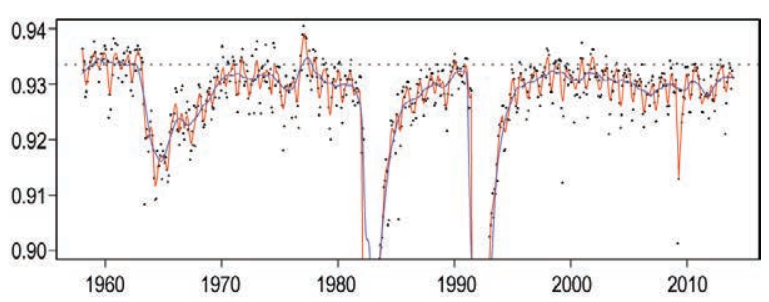

Fig. 2.3I. (a) Monthly mean of the clear-sky apparent transmission at MLO. Means are determined from the early morning values. The green line is the 6-month running smoothed fit, and the blue line is the 24month smoothed fit using only monthly means that include at least 10 days. The dashed line is the background level from 1958-72. (b) Yearly averages of the 10 cleanest days of the year for the clear-sky apparent transmission (black squares) and the aerosol optical depth from a collocated PFR (red dots). 
Annual clear-sky AT averages of the 10 cleanest days are useful for viewing stratospheric background air while limiting the influence of local air pollution events or contamination by cirrus clouds. Previous studies showed that the annual clear-sky AT returned to near-background conditions after the eruption of Mount Pinatubo with a subsequent slow decrease in the clear-sky AT that was in concert with a slow increase in the background annual average MLO AOD (PFR) both based on the 10 cleanest days in the year from the years 2000 to 2010 (Solomon et al. 2011). This decrease in AT from 2000-10 is also clearly evident in the 24-month running smoothed fit in Fig. 2.31b. Solomon et al. (2011) showed that four independent data-sets confirmed an increasing background stratospheric aerosol from 2000-10 (i.e., clear-sky AT at MLO, PFR AOD at MLO, stratospheric AOD from lidar at MLO, and AOD from tropical satellite measurements above $15 \mathrm{~km}$ ). This was attributed to possible smaller volcanic eruptions since 2000 (Vernier et al. 2011). This changing background stratospheric aerosol was shown to have implications for climate change and changes in surface temperature (Solomon et al. 2011). Earlier work suggested a possible leveling of this decreasing AT after 2010 (Dutton 2012). The additional years in the MLO AT record continue to show a "persistently variable background" AT but it is no longer decreasing and shows leveling in the last few years (Fig. 2.31b).

\section{g. Atmospheric composition}

I) LONG-LIVED GREENHOUSE GASES-E. J. Dlugokencky,

B. D. Hall, S. A. Montzka, G. Dutton, J. Mühle, and J. W. Elkins

Carbon dioxide $\left(\mathrm{CO}_{2}\right)$ is the dominant longlived greenhouse gas (LLGHG) contributing to climate forcing; since 1750 its radiative forcing has increased by $1.88 \mathrm{~W} \mathrm{~m}^{-2}$ or $\sim 65 \%$ of the increased forcing by all LLGHGs (see http://www.esrl.noaa.gov/gmd/aggi/aggi.html). When systematic $\mathrm{CO}_{2}$ measurements began at Mauna Loa, Hawaii, (MLO) in 1958, the annual mean mole fraction was $\sim 315$ parts per million (ppm). In May 2013 daily-averaged $\mathrm{CO}_{2}$ at MLO exceeded $400 \mathrm{ppm}$ for the first time (see http://www.esrl.noaa.gov/gmd/ccgg/trends/index.html). This $27 \%$ increase is mainly due to a fourfold rise in anthropogenic $\mathrm{CO}_{2}$ emissions from fossil fuel combustion and cement production. The $\mathrm{CO}_{2}$ growth rate has correspondingly increased from $0.7 \mathrm{ppm}$ $\mathrm{yr}^{-1}$ in the early 1960 s to $2.1 \mathrm{ppm} \mathrm{yr}^{-1}$ during the last decade. About half of the $\mathrm{CO}_{2}$ emitted remains in the atmosphere; the rest is taken up by the oceans and terrestrial biosphere. The annual atmospheric increase varies considerably from year to year, ranging from $0.7 \pm 0.1$ to $2.8 \pm 0.1 \mathrm{ppm} \mathrm{yr}^{-1}$ since 1990 . This is explained largely by variations in natural fluxes influenced by the phase of ENSO (Bastos et al. 2013). In 2013 the globally averaged $\mathrm{CO}_{2}$ mole fraction at Earth's surface was $395.3 \pm 0.1 \mathrm{ppm}$ (Fig. 2.32a), an increase of $2.8 \pm 0.1 \mathrm{ppm}$ over the 2012 mean.

Atmospheric methane $\left(\mathrm{CH}_{4}\right)$ has contributed $\sim 0.5$ $\mathrm{W} \mathrm{m} \mathrm{m}^{-2}$ direct radiative forcing since 1750 . Indirect effects from the production of tropospheric ozone $\left(\mathrm{O}_{3}\right)$ and stratospheric water $\left(\mathrm{H}_{2} \mathrm{O}\right)$ added another $\sim 0.2 \mathrm{~W} \mathrm{~m}^{-2}$. Atmospheric methane is produced by natural ( 40\%) and anthropogenic ( 60\%) sources. Natural sources include wetlands, geological sources, oceans, and termites (Dlugokencky et al. 2011). Anthropogenic sources include agriculture (ruminants, rice), fossil fuel extraction and use, biomass burning, landfills, and waste. Fossil fuel exploitation (coal, oil, and natural gas) contributes $\sim 20 \%$ of total global $\mathrm{CH}_{4}$ emissions (Kirschke et al. 2013). New methods of oil and gas extraction may emit large amounts of $\mathrm{CH}_{4}$ locally (e.g., Karion et al. 2013), but these emissions
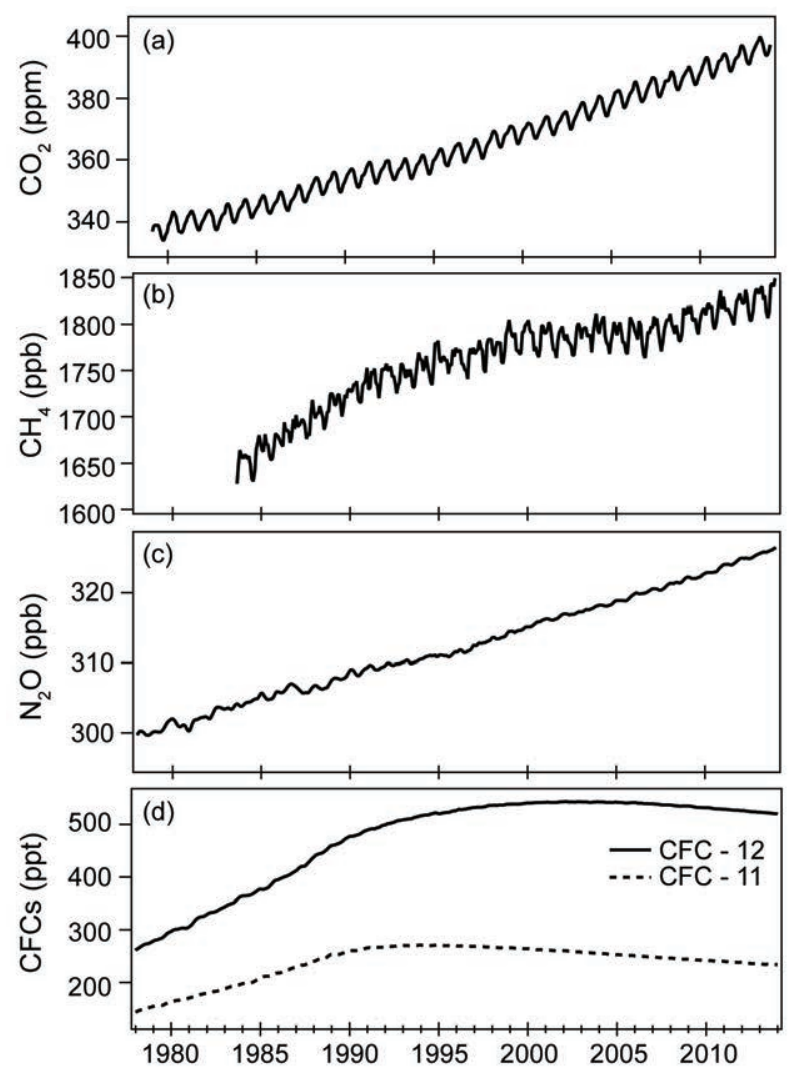

FIG. 2.32. Mole fractions (dry air) of (a) $\mathrm{CO}_{2}$ (ppm), (b) $\mathrm{CH}_{4}$ (ppb), (c) $\mathrm{N}_{2} \mathrm{O}$ (ppb), and (d) CFC-I2, and CFC-II (ppt) from air samples collected at the NOAA Mauna Loa Observatory, Mauna Loa, Hawaii. 
are currently small relative to the anthropogenic total. Atmospheric $\mathrm{CH}_{4}$ has increased by about a factor of 2.5 since the pre-industrial era (1750). The annual rate of increase of $>10$ parts per billion (ppb) $\mathrm{yr}^{-1}$ in the 1980s slowed dramatically to near zero in the early 2000s, then in 2007 jumped to $\sim 6 \mathrm{ppb} \mathrm{yr}^{-1}$ and has remained fairly steady since (Fig. 2.32b). Global emissions are estimated to be $\sim 540 \mathrm{Tg} \mathrm{CH}_{4} \mathrm{yr}^{-1}( \pm 10 \%)$ based on observations of the global $\mathrm{CH}_{4}$ burden and an estimate of its atmospheric lifetime ( 9.1 yr). This top-down emission estimate provides an important constraint on bottom-up inventories of $\mathrm{CH}_{4}$ emissions that tend to overestimate the global total (Kirschke et al. 2013). The same observation-based mass-balance estimation of global emissions can also be applied to most other LLGHGs. Based on NOAA background air sampling sites, the globally averaged $\mathrm{CH}_{4}$ mole fraction at Earth's surface in 2013 was $1814.1 \pm 0.8$ ppb, a $5.7 \pm 0.9 \mathrm{ppb}$ increase from 2012 that conforms to the average growth rate since 2007 .

Nitrous oxide $\left(\mathrm{N}_{2} \mathrm{O}\right)$ currently exerts the third strongest climate forcing of the LLGHGs after $\mathrm{CO}_{2}$ and $\mathrm{CH}_{4}$. Nitrous oxide is produced in soils by both the oxidation of ammonium and the denitrification of nitrate. About one-third of $\mathrm{N}_{2} \mathrm{O}$ emissions are related to human activities, and about two-thirds of these are related to the agricultural application of nitrogencontaining fertilizers, including manure (UNEP 2013; Davidson 2009; Reay et al. 2012). The mean global atmospheric $\mathrm{N}_{2} \mathrm{O}$ mole fraction in 2013 was 325.9 ppb, an increase of 0.9 ppb from 2012 (Fig. 2.32c). This growth rate exceeds the 2000-13 average of 0.78 $\pm 0.01 \mathrm{ppb} \mathrm{yr}^{-1}$ and is consistent with the more recent 2010-13 mean growth rate of $0.92 \pm 0.02 \mathrm{ppb} \mathrm{yr}^{-1}$.

Halogenated gases, such as chlorofluorocarbons (CFCs), hydrochlorofluorocarbons (HCFCs), and hydrofluorocarbons (HFCs), also contribute to radiative forcing. While the atmospheric mole fractions of some CFCs, such as CFC-12 and CFC-11 are decreasing (Fig. 2.32d), the atmospheric burdens of their industrial replacements HCFC-22 and HFC134a are increasing (Fig. 2.33). After a period of enhanced growth in HCFC-22 that began around 2005 (Montzka et al. 2009) the growth rate of HCFC-22 in the atmosphere slowed slightly in recent years. The abundance of sulfur hexafluoride $\left(\mathrm{SF}_{6}\right)$, used in high-voltage electrical transmission equipment, also continues to increase. The mean global $\mathrm{SF}_{6}$ mole fraction in 2013 was 7.91 parts per trillion (ppt), 0.32 ppt higher than in 2012. Global annual mean mole fractions of a number of trace gases, along with their 2012 to 2013 changes are listed in Table 2.7.

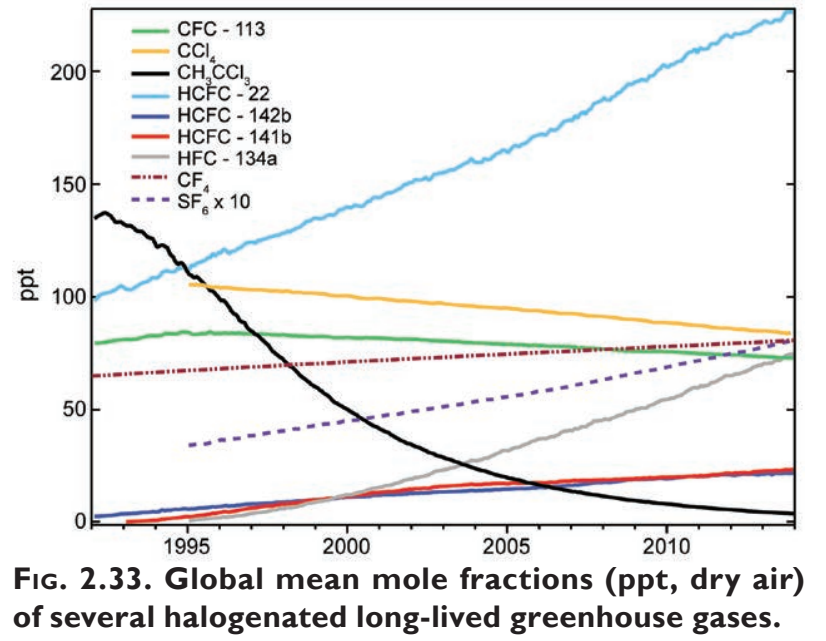

Recent trends in the combined radiative forcing by five major LLGHGs $\left(\mathrm{CO}_{2}, \mathrm{CH}_{4}\right.$, $\mathrm{N}_{2} \mathrm{O}, \mathrm{CFC}-11$, and CFC-12) and 15 minor gases are illustrated by the NOAA Annual Greenhouse Gas Index (AGGI; Hofmann et al. 2006; http://www.esrl.noaa.gov/gmd/aggi/). This index represents the annual composite radiative forcing by these gases relative to 1990, the Kyoto Protocol baseline year. The AGGI does not include indirect radiative effects (e.g., influences on ozone and water vapor). Based on the 2013 global mole fractions of LLGHGs and 15 minor gases there has been an additional $2.92 \mathrm{~W} \mathrm{~m}^{-2}$ of direct radiative forcing since the pre-industrial era. The 2013 AGGI (Fig. 2.34) of $1.34\left(2.92 \mathrm{~W} \mathrm{~m}^{-2} / 2.18 \mathrm{~W} \mathrm{~m}^{-2}\right)$ depicts a $34 \%$ increase since 1990 in the radiative forcing by the gases included in the AGGI.

2) Ozone-depleting gases-B. Hall, S. A. Montzka, G. Dutton, and J. W. Elkins

In addition to direct radiative forcing, long-lived gases containing chlorine and bromine also influence radiative forcing indirectly through destruction of stratospheric ozone. The atmospheric burdens of many of the most potent ozone-depleting gases have been declining in response to production and consumption restrictions imposed by the Montreal Protocol on Substances that Deplete the Ozone Layer and its Amendments (Figs. 2.32d, 2.33). Surface mole fractions of methyl chloroform $\left(\mathrm{CH}_{3} \mathrm{CCl}_{3}\right)$, which has a relatively short lifetime of five years, have declined $95 \%$ from peak values in the early 1990s (Fig. 2.33). Gases with longer lifetimes (Table 2.7) are declining more slowly.

Equivalent effective stratospheric chlorine (EESC) provides an estimate of the loading of ozone-reactive halogen in the stratosphere (and, therefore, the poten- 
Table 2.7. Mole fractions, radiative efficiencies and lifetimes of chemicals considered in the AGGI $\left(\mathrm{CO}_{2}\right.$ in ppm, $\mathrm{N}_{2} \mathrm{O}$ and $\mathrm{CH}_{4}$ in ppb, and all others in ppt).

\begin{tabular}{|c|c|c|c|c|c|c|}
\hline $\begin{array}{l}\text { Industrial Designation } \\
\text { or Common Name }\end{array}$ & $\begin{array}{l}\text { Chemical } \\
\text { Formula }\end{array}$ & AGGI & ODGI & $\begin{array}{c}\text { Radiative } \\
\text { Efficiency } \\
\left(\mathrm{W} \mathbf{m}^{-2} \mathrm{ppb}^{-1}\right)^{\mathrm{a}}\end{array}$ & $\begin{array}{c}\text { Mean Surface } \\
\text { Mole Fraction, } \\
2013 \text { [change } \\
\text { from prior } \\
\text { year]b }\end{array}$ & $\begin{array}{c}\text { Lifetime } \\
\text { (years) }\end{array}$ \\
\hline Carbon Dioxide & $\mathrm{CO}_{2}$ & $Y$ & $\mathrm{~N}$ & $1.37 \times 10^{-5}$ & $395.3[2.8]^{c}$ & \\
\hline Methane & $\mathrm{CH}_{4}$ & $\mathrm{Y}$ & $\mathrm{N}$ & $3.63 \times 10^{-4}$ & $|8| 4 . \mid[5.7]^{c}$ & 9.1 \\
\hline Nitrous oxide & $\mathrm{N}_{2} \mathrm{O}$ & $\mathrm{Y}$ & $\mathrm{N}$ & $3.00 \times 10^{-3}$ & $325.9[0.9]^{c}$ & 123 \\
\hline \multicolumn{7}{|c|}{ Chlorofluorocarbons } \\
\hline CFC-II & $\mathrm{CCl}_{3} \mathrm{~F}$ & $Y$ & $Y$ & 0.26 & $234.5[-1.9]^{c}$ & 52 \\
\hline CFC-I2 & $\mathrm{CCl}_{2} \mathrm{~F}_{2}$ & $\mathrm{Y}$ & $\mathrm{Y}$ & 0.32 & $521.8[-2.9]^{\mathrm{c}}$ & 102 \\
\hline CFC-113 & $\mathrm{CCl}_{2} \mathrm{FCClF}_{2}$ & $\mathrm{Y}$ & $\bar{Y}$ & 0.30 & $73.1[-0.7]^{c}$ & 93 \\
\hline \multicolumn{7}{|c|}{ Hydrochlorofluorocarbons } \\
\hline HCFC-22 & $\mathrm{CHCIF}_{2}$ & $Y$ & Y & 0.21 & $223.6[5.6]^{c}$ & 12 \\
\hline HCFC-I4Ib & $\mathrm{CH}_{3} \mathrm{CCl}_{2} \mathrm{~F}$ & Y & Y & 0.16 & $23.2[0.9]^{c}$ & 9.4 \\
\hline HCFC-142b & $\mathrm{CH}_{3} \mathrm{CCIF}_{2}$ & Y & Y & 0.19 & $21.8[0.4]^{c}$ & 18 \\
\hline \multicolumn{7}{|c|}{ Hydrofluorocarbons } \\
\hline HFC-134a & $\mathrm{CH}_{2} \mathrm{FCF}_{3}$ & $Y$ & $\mathrm{~N}$ & 0.16 & $72.4[4.9]^{\mathrm{c}}$ & 14 \\
\hline HFC-I52a & $\mathrm{CH}_{3} \mathrm{CHF}_{2}$ & $Y$ & $\mathrm{~N}$ & 0.10 & $6.7[0] \mathrm{c}$ & 1.6 \\
\hline HFC-I43a & $\mathrm{CH}_{3} \mathrm{CF}_{3}$ & $\mathrm{Y}$ & $\mathrm{N}$ & 0.16 & $13.4[1.1] \mathrm{c}$ & 51 \\
\hline HFC-I25 & $\mathrm{CHF}_{2} \mathrm{CF}_{3}$ & Y & $\mathrm{N}$ & 0.23 & $13.0[1.6] \mathrm{c}$ & 31 \\
\hline HFC-23 & $\mathrm{CHF}_{3}$ & $Y$ & $\mathrm{~N}$ & 0.18 & $25.9[0.9] \mathrm{c}$ & 228 \\
\hline \multicolumn{7}{|c|}{ Chlorocarbons } \\
\hline Methyl Chloroform & $\mathrm{CH}_{3} \mathrm{CCl}_{3}$ & $Y$ & $Y$ & 0.07 & $6.3[-1.3]^{c}$ & 5.0 \\
\hline Carbon Tetrachloride & $\mathrm{CCl}_{4}$ & $Y$ & $\bar{Y}$ & 0.17 & $84.4[-1.0]^{c}$ & 25 \\
\hline Methyl Chloride & $\mathrm{CH}_{3} \mathrm{Cl}$ & $\mathrm{N}$ & $\mathrm{Y}$ & 0.01 & $544[3]^{c}$ & 1.0 \\
\hline \multicolumn{7}{|c|}{ Bromocarbons } \\
\hline Methyl Bromide & $\mathrm{CH}_{3} \mathrm{Br}$ & $\mathrm{N}$ & $\bar{Y}$ & 0.004 & $6.9[-0.01] c$ & 0.8 \\
\hline Halon I2II & $\mathrm{CBrClF}_{2}$ & $\mathrm{Y}$ & $\mathrm{Y}$ & 0.29 & $3.81[-0.11] \mathrm{c}$ & 16 \\
\hline Halon I30I & $\mathrm{CBrF}_{3}$ & Y & Y & 0.30 & $3.22[0.02]^{c}$ & 72 \\
\hline Halon 2402 & $\mathrm{CBrF}_{2} \mathrm{CBrF}_{2}$ & Y & Y & 0.31 & $0.44[-0.01]^{c}$ & 28 \\
\hline \multicolumn{7}{|c|}{ Fully fluorinated species } \\
\hline Sulfur Hexafluoride & $\mathrm{SF}_{6}$ & $\bar{Y}$ & $\mathrm{~N}$ & 0.57 & $7.91[0.32]^{c}$ & 3,200 \\
\hline PFC-14 & $\mathrm{CF}_{4}$ & $\mathrm{~N}$ & $\mathrm{~N}$ & 0.09 & $80.5[0.7]^{c}$ & $\sim 50,000$ \\
\hline PFC-116 & $\mathrm{C}_{2} \mathrm{~F}_{6}$ & $\mathrm{~N}$ & $\mathrm{~N}$ & 0.25 & $4.33[0.08] \mathrm{c}$ & $\sim 10,000$ \\
\hline
\end{tabular}

a Radiative efficiencies were taken from IPCC AR5 (Myhre et al. 2013). Steady-state lifetimes for $\mathrm{CH}_{4}$ were taken from Myhre et al. (2013), from $\left(\mathrm{CH}_{3} \mathrm{Br}\right.$ and $\left.\mathrm{CH}_{3} \mathrm{Cl}\right)$ Montzka et al. (2011), all others from Ko et al. (2013). Note that Ko et al. (2013) recommends a longer lifetime for CFC-11: 52 yr compared to 45 yr in Montzka et al. (2011).

b Mole fractions are global surface means determined from the NOAA global cooperative air sampling network (Hofmann et al. 2006), except for PFC-14, PFC-116, and HFC-23, which are measured by AGAGE (Mühle et al. 2010; Miller et al. 2010). Changes indicated in brackets are the differences between the 2013 and 2012 global mean mole fractions.

c Preliminary estimate for 2013. 


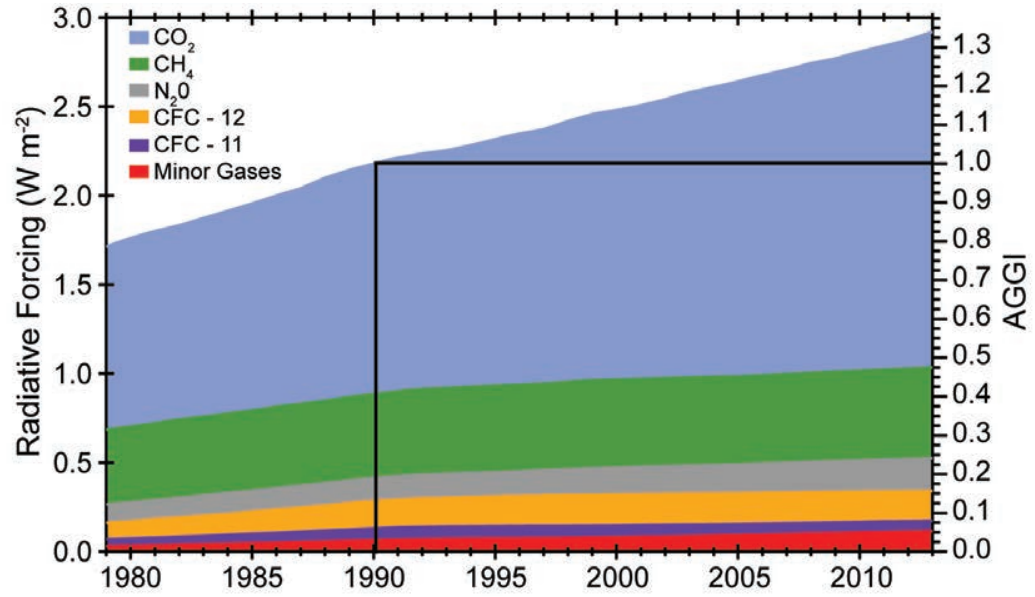

FIG. 2.34. Direct radiative forcing ( $\mathrm{W} \mathrm{m}^{-2}$ ) due to LLGHG (left axis) and the Annual Greenhouse Gas Index (right axis). The 2013 AGGI value is 1.34 , indicating that direct radiative forcing due to LLGHG has increased $34 \%$ since 1990.

tial to deplete stratospheric ozone). EESC is derived from surface measurements of ozone-depleting gases and weighting factors that include surface to stratosphere transport times, mixing during transit, photolytic reactivity, and bromine's enhanced efficiency in destroying ozone relative to chlorine (Fig. 2.35a; Schauffler et al. 2003; Newman et al. 2007; Montzka et al. 2011). Progress towards decreasing the stratospheric halogen load back to its 1980 level, a benchmark often used to assess ozone layer recovery, is evaluated by the NOAA Ozone-Depleting Gas Index (ODGI; Hofmann and Montzka 2009). The ODGI relates EESC in a given year to the peak and 1980 EESC values (Fig. 2.35b).

The EESC is calculated for two representative stratospheric regions (polar and middle latitudes) that differ in transit times and reactive halogen liberation. On average, it takes an air parcel about 3 and 5.5 years from its time of stratospheric entry (mainly in the tropics) to reach the ozone layer above the midlatitudes and poles, respectively. EESC values over the poles are significantly greater than over the midlatitudes because more halogen is liberated in transit to the polar region. At the beginning of 2013, EESC (ODGI) values were $\sim 3880$ ppt (84) and $\sim 1650$ ppt (62) over Antarctica and the midlatitudes of both hemispheres, respectively (Fig. 2.35a). The ODGI for Antarctica depicts a $16 \%$ decline in EESC towards the 1980 benchmark from its peak in 2001-02 through the beginning of 2013 (Fig. 2.35b). There was a 38\% decline in ODGI over the midlatitudes from 1997 to the beginning of 2013. Both regions show similar decreases in EESC from peak values, but the relative ODGI scale indicates greater progress towards the
1980 benchmark for the midlatitude stratosphere because of the smaller difference between its peak and 1980 EESC values.

3) Aerosols-A. Benedetti, L. T. Jones, J. W. Kaiser, J.-J. Morcrette, and S. Rémy

Atmospheric aerosols were prominently discussed in the recent Fifth Assessment Report (AR5) of the Intergovernmental Panel on Climate Change (Boucher et al. 2013). While there is general agreement between the various estimates of the net impact of aerosols on the reduction of solar radiation due to reflection, there are still large uncertainties in the role of absorbing aerosols such as black carbon that have a net warming impact at the surface. It is noteworthy that atmospheric composition reanalyses are now appearing side-by-side with the pure modeling approach; these are often based on an ensemble of models (e.g., AEROCOM, http://aerocom.met.no). For example in AR5, one of

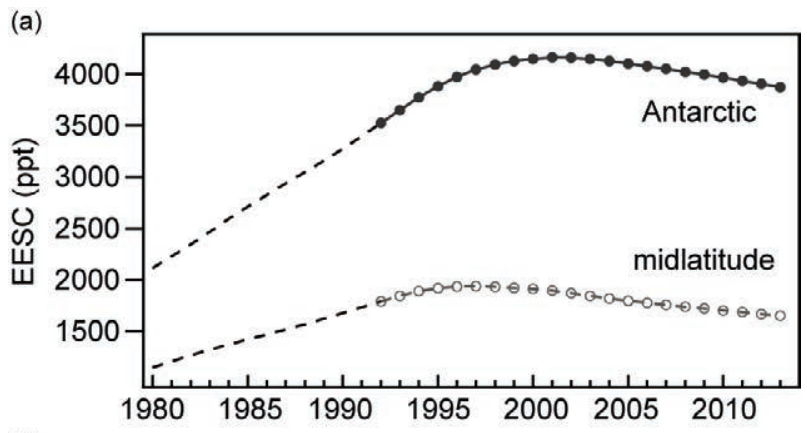

(b)

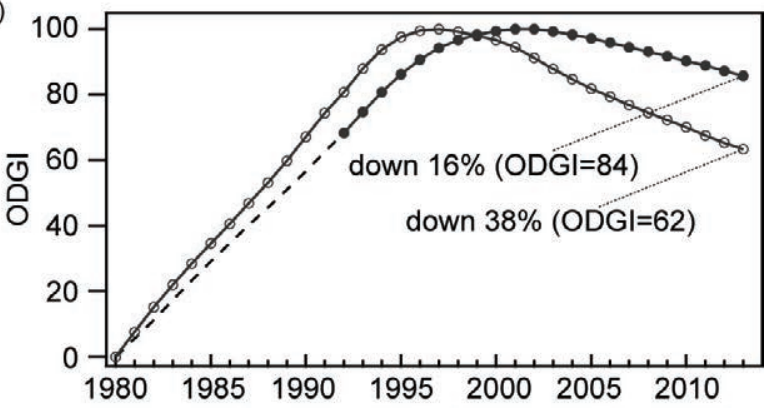

FIG. 2.35. (a) Equivalent effective stratospheric chlorine (EESC, ppt), and (b) the NOAA Ozone-Depleting Gas Index (ODGI). The ODGI represents the relative mole fractions of reactive halogen in the midlatitude and Antarctic stratosphere scaled such that ODGI $=100$ at maximum EESC, and zero in 1980. Both EESC and ODGI are derived from NOAA surface measurements of ozone-depleting substances (symbols) or WMO scenarios (Daniel et al. 20II; dashed lines). 
the aerosol forcing estimates is based on the Monitoring Atmospheric Composition and Climate (MACC) reanalysis of satellite observations (Bellouin et al. 2013).

State-of-the-art aerosol reanalyses optimally incorporate satellite observations into atmospheric models that couple aerosol processes with the meteorology. Estimates of total aerosol optical depth (AOD) are well constrained by the satellite observations, while the speciated aerosol information is derived from the model. Limitations of current aerosol reanalyses include short time series, unknown biases in emission and removal processes, uncertainties in the optical properties of aerosols, and a limited availability of constraining satellite observations. However, such reanalyses represent a useful tool for assessing the current state of these important atmospheric constituents.

The MACC/MACC-II data assimilation system was used to produce a reanalysis of atmospheric composition, including aerosols, for the years 2003-12 (Morcrette et al. 2011; Inness et al. 2013). The aerosol model provides concentrations and optical depths for five species: desert dust, sea salt, organic matter, black carbon, and sulfate. All relevant physical processes such as emissions, wet/dry deposition, and sedimentation are included. The spatial resolution of this dataset is $\sim 80 \mathrm{~km}$.

The aerosol model underwent further development after the completion of this 10 -year reanalysis with the aim of increasing its forecasting skill. Modifications to the dust parameterization in the new model version lead to larger amounts of mineral dust while changes in the meteorological model produce weaker surface winds over the remote oceans and a decrease in sea-salt aerosols. The modified model was used to produce an analysis for 2013 at a resolution of $\sim 40 \mathrm{~km}$ that, like the 10 -year reanalysis, used 4DVAR assimilation of AOD observations at $550 \mathrm{~nm}$ from the MODIS sensors, including a global adaptive bias correction. Biomass burning emissions for 2013 were provided by the Global Fire Assimilation System (GFAS) inventory (Kaiser et al. 2012) that estimates emissions from MODIS observations of fire radiative power. The 10-year reanalysis employs GFAS-based fire emissions for 2009-12 and the GFED3 inventory for 2003-08 (van der Werf et al. 2010).

Aerosol anomalies are determined by subtracting the multiyear average from the annual mean for a given year; however, due to the large changes in desert dust and sea salt in the recent model version, only the anomalies for carbonaceous aerosols
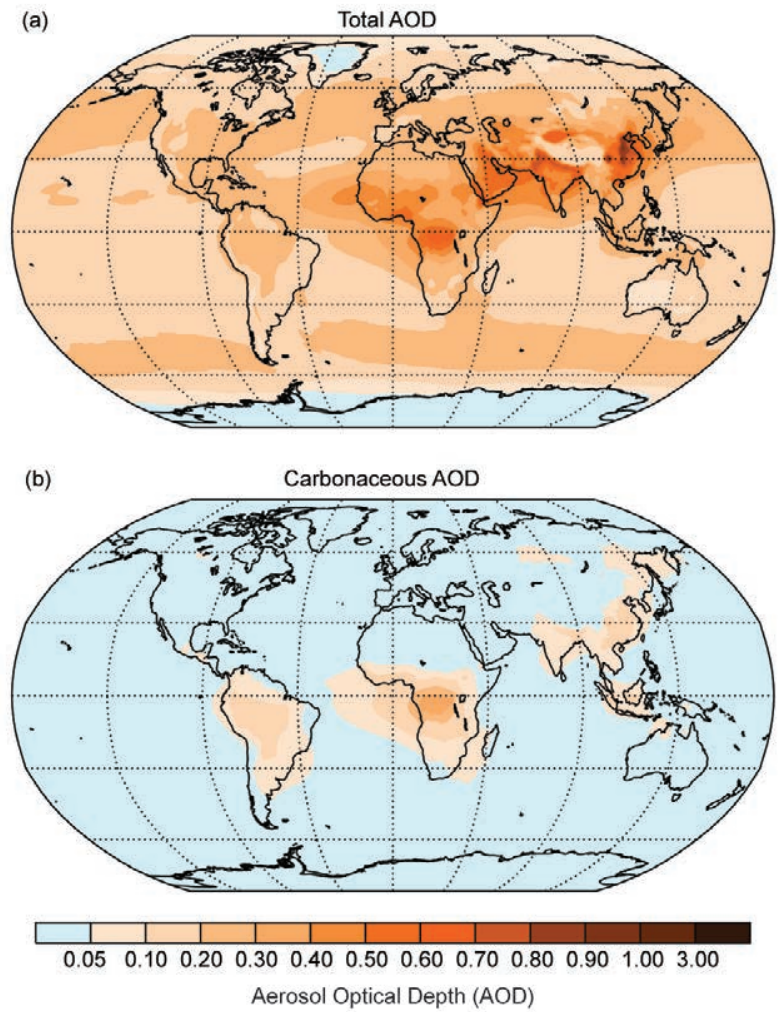

FIG. 2.36. (a) Total AOD and (b) carbonaceous AOD from the MACC reanalysis averaged over the period 2003-12.

are presented here. These are defined as the sum of anthropogenic organic matter, black carbon, and biomass burning emissions. Results are presented with a focus on the strongest seasonal anomalies in Northern Hemisphere summer (June-August, JJA) and fall (September-November, SON) 2013.

Global maps of the time-averaged total AOD and carbonaceous AOD from the MACC-II reanalysis are shown in Fig. 2.36 for the period 2003-12. Note the widespread pollution over most of Asia, particularly China and India, the large values over the Arabian Peninsula where the effects of dust and anthropogenic aerosols are compounded, the large biomass burning region in Central Africa, and the seasonal biomass burning signal in South America. The anomaly map for carbonaceous AOD for JJA 2013 is displayed in Fig. 2.37a. A striking feature of the boreal summer 2013 is smoke from the extensive burning in Canada being carried into the Atlantic Ocean towards Europe by a strong jet stream. At the same time more localized but intense fires were burning in Colorado. Figure 2.37a also shows the active burning season in Siberia and Central Africa. Figure 2.37b presents a similar plot for SON 2013. Noteworthy features include the persistent positive anomaly over Africa and the negative anomaly in biomass burning over 

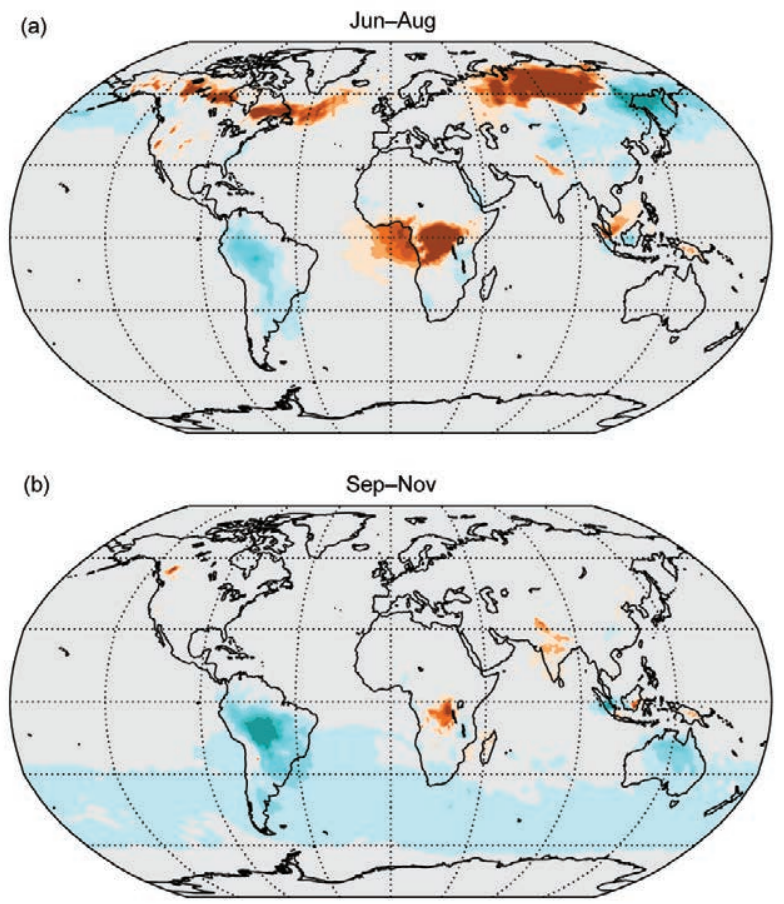

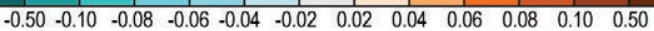
Aerosol Optical Depth (AOD)

Fig. 2.37. AOD anomaly in carbonaceous aerosols for (a) Jun-Aug 2013 and (b) Sep-Nov 2013.

South America, possibly connected to the decreasing trend in deforestation. The anomalies identified in the biomass-burning aerosol fields are consistent with the 2013 carbon monoxide and fire anomalies reported in sections $2 \mathrm{~g} 7$ and $2 \mathrm{~h} 4$ respectively.

4) Stratospheric ozone-M. Weber, W. Steinbrecht, R. van $\operatorname{der}$ A, M. Coldewey-Egbers, V. E. Fioletov, S. M. Frith, C. S. Long, D. Loyola, and J. D. Wild

Annual mean total ozone values for 2013 were similar to the 1998-2008 decadal average in the midlatitudes and were above average in the tropics and high latitudes of both hemispheres (Plate 2.1p). The positive 2013 anomalies for both polar regions were greater than 25 Dobson Units (DU). Significant negative anomalies (below $-10 \mathrm{DU}$ ) observed in the North Pacific near the Aleutian Islands are attributed to warmth associated with persistent ridging in the lower stratosphere over this region. The band of positive ozone anomalies surrounding the equator is a typical dynamical pattern caused by the westerly phase of the quasi-biennial oscillation (QBO).

The annual mean anomalies at middle to polar latitudes are largely determined by the ozone amounts during the winter and spring seasons. These depend on stratospheric meteorological conditions that ex- hibit strong interannual variability (Steinbrecht et al. 2011; Weber et al. 2011). Positive anomalies in the Southern Hemisphere polar region (see Plate 2.1p) are related to the rather weak and small ozone hole in winter/spring 2013 (see section 6g). Spring total ozone values for 2013 in the Arctic (March) and Antarctic (October) were close to and greater than their decadal averages, respectively (Fig. 2.38).

In Fig. 2.39, time series of total ozone since 1970 from different data sources are shown for several zonal bands: global $\left(60^{\circ} \mathrm{S}-60^{\circ} \mathrm{N}\right)$, midlatitudes $\left(35^{\circ}-60^{\circ}\right)$ in both hemispheres, and the tropics $\left(20^{\circ} \mathrm{S}-20^{\circ} \mathrm{N}\right)$. The global average for 2013 is at the high end of the range of values observed since 2000 , as might be expected from the 2013 maximum in solar cycle 24 . As in the tropics, a quasi-biennial variation is also evident in the extratropics.

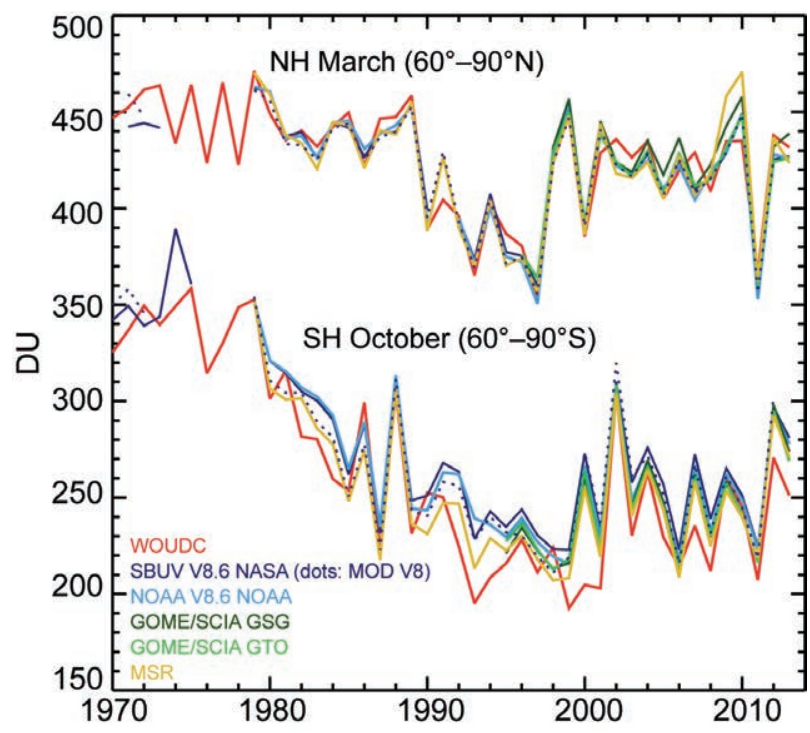

Fig. 2.38. Total polar ozone (DU) over the NH (Mar) and $\mathrm{SH}(\mathrm{Oct})$ polar regions. WOUDC ground-based data combining Brewer, Dobson, SAOZ, and filter spectrometer measurements (red: Fioletov et al. 2002, 2008); the merged BUVISBUV satellite data from NASA (MOD V8.6, dark blue: McPeters et al. 2013; Chiou et al. 2013) and NOAA (light blue: Wild et al. 20I2), the SBUV/TOMS/OMI merged data (MOD V8, dark blue dotted, Stolarski and Frith 2006), two merged time series using GOME/SCIAMACHYI GOME-2 satellite data: GSG from University of Bremen (dark green: Kiesewetter et al. 2010; Weber et al. 20II) and GTO from ESA/DLR (light green: Loyola et al. 2009; Chiou et al. 2013). The MSR (multisensor reanalysis) assimilates various satellite data and algorithm versions after correction with respect to collocated WOUDC ground-based measurements (yellow: van der $A$ et al. 2010). Ground-based data from 2013 are preliminary as some have not yet been submitted to the WOUDC database. 


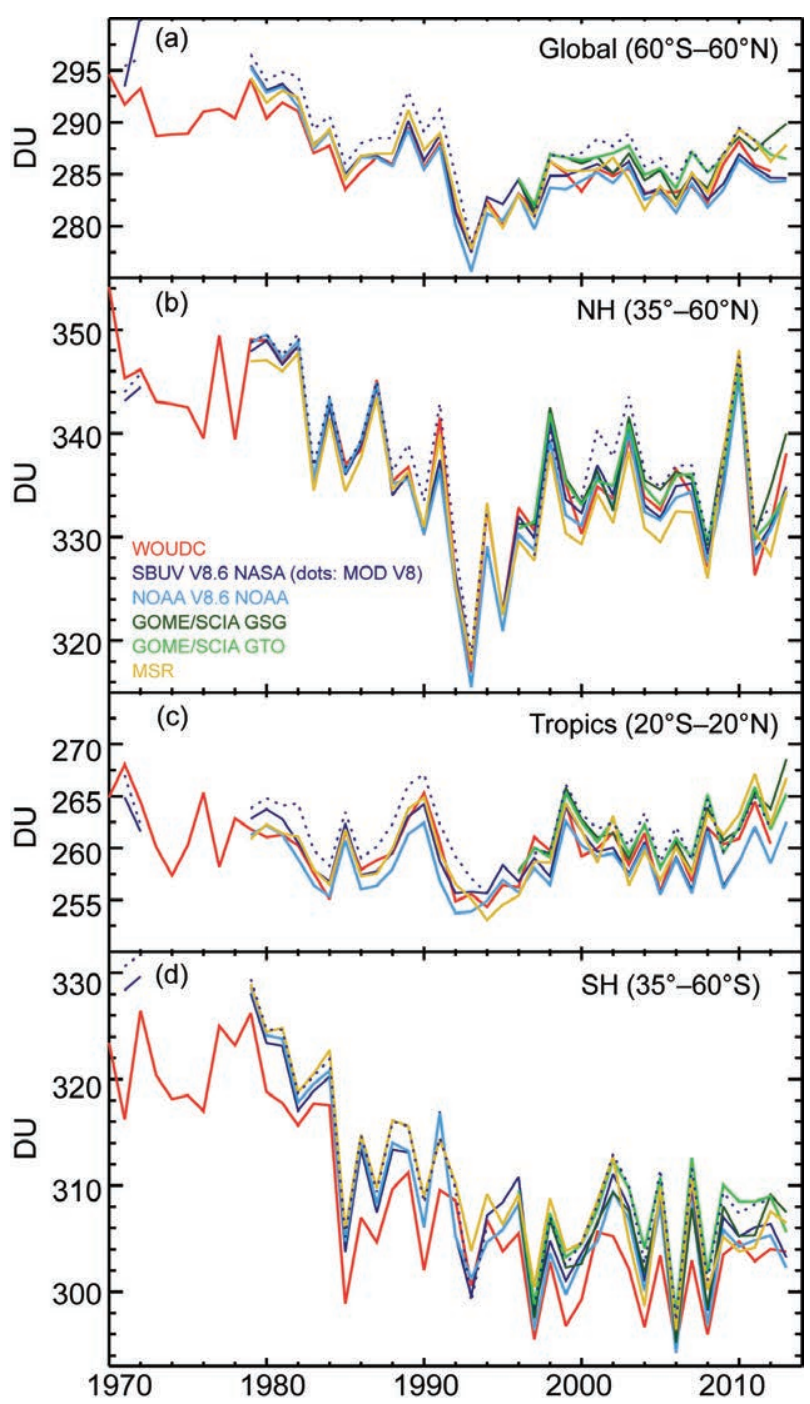

FIg. 2.39. Total ozone annual zonal means (DU) $1970-2013$ for (a) $60^{\circ} \mathrm{S}-60^{\circ} \mathrm{N}$ (global), (b) $35^{\circ}-60^{\circ} \mathrm{N}$ (NH), (c) $20^{\circ} \mathrm{S}-20^{\circ} \mathrm{N}$ (tropics), and (d) $35^{\circ}-60^{\circ} \mathrm{S}$ (SH). Same data sources as described in Fig. 2.38. For some stations the ground-based WOUDC data for 2013 are not yet available so the annual mean values are only presented for the middle latitudes.

The large decline in global ozone between 1980 and the early 1990s was followed by a rapid increase and subsequent leveling off of Northern Hemisphere ozone values. In the Southern Hemisphere, total ozone shows no significant change since the early 1990s except for interannual variability. The substantial minima in Northern Hemisphere and global ozone in the early 1990s (Fig. 2.39) are related to enhanced levels of volcanic aerosols from Mount Pinatubo. The major eruption in 1991 provided additional surfaces for heterogeneous chemical reactions that remove ozone (WMO 1999). Total ozone values in the Southern Hemisphere did not show a similar minimum following Pinatubo because of additional long-wave radiative heating by aerosols, enhanced planetary wave activity (strengthening the Brewer Dobson circulation), and stronger QBOinduced downwelling in the Southern Hemisphere extratropics. These ozone-enriching mechanisms effectively compensated for the post-Pinatubo aerosolrelated ozone depletion in the Southern Hemisphere (Schnadt Poberaj et al. 2011; Aquila et al. 2013).

Despite the considerable year-to-year variability, the leveling off of total ozone values since the mid1990s attests to the success of the Montreal Protocol and its Amendments in phasing out ozone-depleting substances (see section 2g2; e.g., Kiesewetter et al. 2010; Mäder et al. 2010; Steinbrecht et al. 2011; Chehade et al. 2013; Frossard et al. 2013; Kuttipurath et al. 2013; Nair et al. 2013). Apart from variability in tropical ozone related to the 11-year solar cycle, QBO, and ENSO, there has been no statistically significant change in the tropics since the early 1990s (Chehade et al. 2013).

Upper stratospheric ozone has the largest sensitivity to changes in the stratospheric halogen loading due to the smaller influence of dynamical factors in that region. It is therefore easier to detect evidence of anthropogenic ozone recovery in the upper stratosphere (Newchurch et al. 2003) than in the lower stratosphere where most of the total ozone column resides. Ozone in the upper stratosphere $(35-45 \mathrm{~km})$ measured by ground-based and satellite instruments is shown in Fig. 2.40. Ozone decreased substantially by $10 \%-15 \%$ from the early 1980 s until the mid-1990s (Steinbrecht et al. 2009; Jones et al. 2009). Since 2000, the various upper stratospheric records show signs of an increase of up to 5\% through 2013 at most stations except Mauna Loa, Hawaii, where ozone has remained more or less constant since the mid-1990s (Fig. 2.40). Upper stratospheric ozone is influenced by changes in the atmospheric burdens of ODS and greenhouse gases (Fleming et al. 2011; Gillett et al. 2011). The observed long-term behavior of ozone in the upper stratosphere is consistent with the earlier increase and subsequent slow decline of the stratospheric halogen loading (Fig. 2.35). 


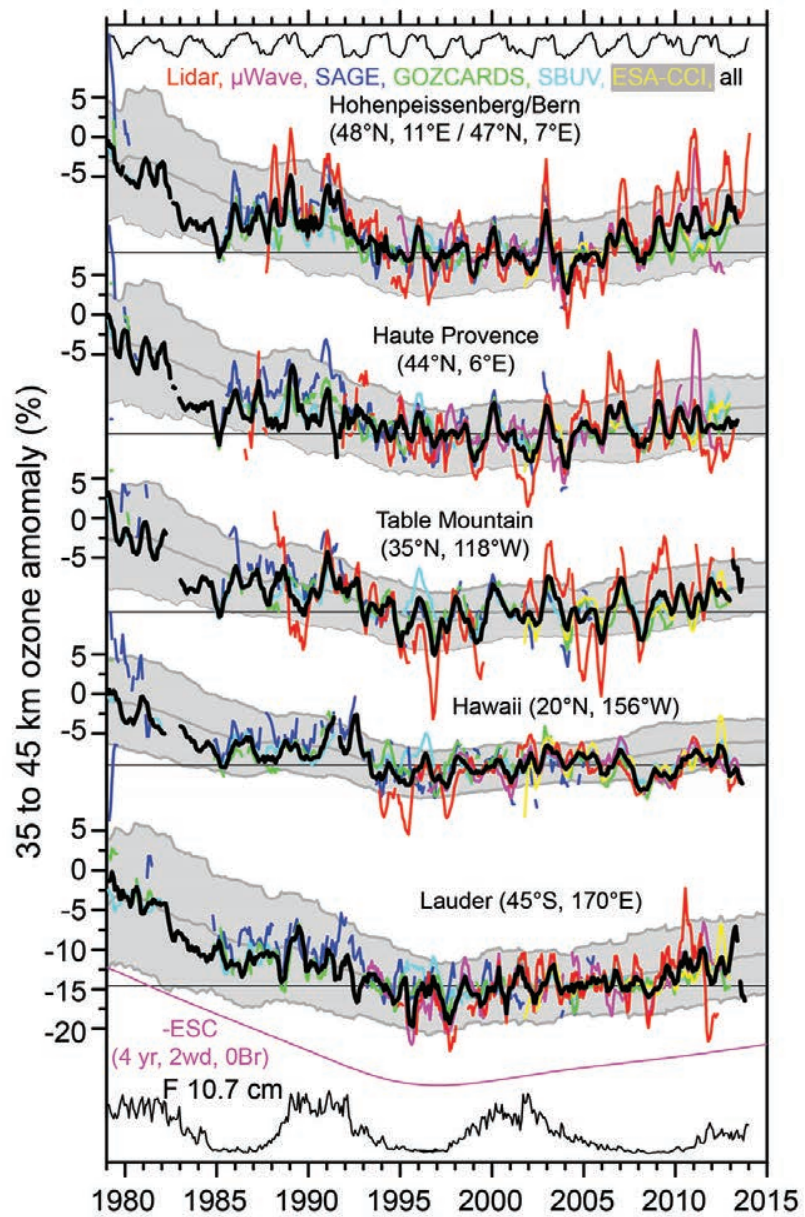

FIG. 2.40. Time series of ozone anomalies (\%) in the upper stratosphere as observed by ground-based lidars and microwave radiometers at five stations of the Network for the Detection of Atmospheric Composition Change and by satellite instruments. Anomalies are derived by subtracting the average annual cycle of each data record between 1998 and 2008 , but the percent scale is set to zero at the beginning of data in 1979. Satellite data are $10^{\circ}$ zonal means centered at the station latitudes. The GOZCARDS data record merges SAGE and HALOE data (up to 2005) with AURA-MLS data (since 2004; Froidevaux et al. 2014, manuscript submitted to J. Geophys. Res.). SBUV is the SBUV V8.6 merged dataset provided by NASA (McPeters et al. 20I3). ESA$C C I$ is the average anomaly from the OSIRIS, SMR, GOMOS, MIPAS, and SCIAMACHY satellite datasets since 2000 (Sofieva et al. 20I3). The thick black line is the average anomaly from all data sets. For clarity, data are smoothed by a 5-month running mean. The grey shading, obtained from CCMVal-I model simulations, shows the running 24-month multimodel mean \pm 2 std. dev. of individual model monthly means. The black lines at the top and bottom are proxies for QBO and solar flux, respectively. The pink line at the bottom is an inverted proxy for stratospheric chlorine loading. Updated from Steinbrecht et al. 2009.
5) Stratospheric water vapor-D. F. Hurst, S. M. Davis, and K. H. Rosenlof

Anomalies in tropical lower stratospheric water vapor were strongly negative (dry) at the start of 2013. Observations by the Aura Microwave Limb Sounder (MLS) during January 2013 depict tropical anomalies as large as $-1.0 \mathrm{ppmv}(-30 \%)$ at $82 \mathrm{hPa}$ (Fig. 2.41a). By July, the dry tropical anomalies had weakened but had also spread out globally in the lower stratosphere (Fig. 2.41b). In general, the dry anomalies in July 2013 were stronger and more globally pervasive than in July 2012 (see figure 2.37 in Hurst and Rosenlof 2013). However, in January 2013 there were contrasting positive (wet) anomalies over the high latitudes of each hemisphere. The Arctic anomalies may be related to the strong sudden stratospheric warming event in January 2013 (see section 2b3) accompanied by enhanced downwelling of older, wetter air into the lower stratosphere. Wet anomalies over the high southern latitudes are attributed to relatively weak dehydration within the smaller and warmer Antarctic vortex in 2012 that had split into two parts by early November (Long and Christy 2013; Newman et al. 2013).

The seasonal variability of water vapor abundance in the lower tropical stratosphere is predominantly
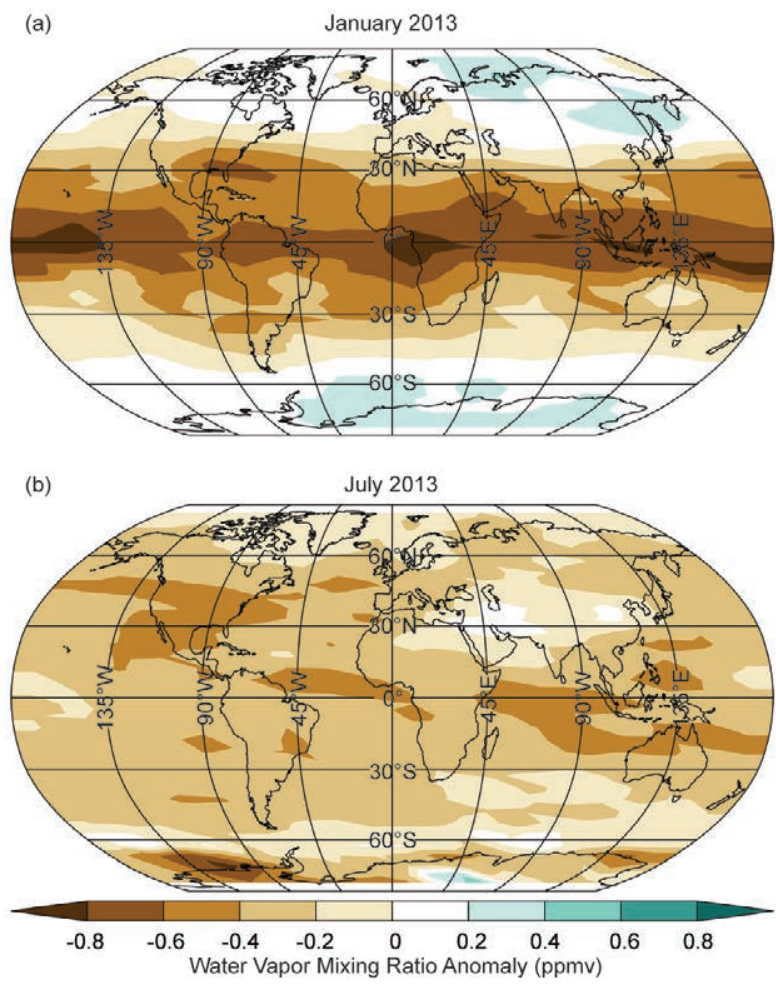

FIG. 2.4I. Global stratospheric water vapor anomalies (ppmv) centered at $82 \mathrm{hPa}$ in Jan (a) and Jul (b) 2013 from the Aura Microwave Limb Sounder. Anomalies are differences from monthly mean water vapor mixing ratios for 2004-13. 
controlled by the annual cycle of cold-point tropopause temperatures in the tropical tropopause layer (TTL). The resulting cycle in water vapor is visible in the tropical MLS data at $100 \mathrm{hPa}$ (Fig. 2.42a). The erosion of this annual cycle in water vapor is evident as the Brewer-Dobson circulation carries tropical air masses upwards. Interannual variations in tropical lower stratospheric water vapor are more overt when viewed as anomalies. In October 2012 the weak dry anomaly at $100 \mathrm{hPa}$ intensified, remained strong until early 2013, then weakened (Fig. 2.42b). This behavior is consistent with cold-point tropopause temperatures (Fig. 2.43c, blue curve) reaching a six-year minimum in late 2012 due to the downward propagation of an easterly (cold) QBO phase into the TTL and then increasing throughout 2013 as the QBO phase became westerly.

The Aura MLS has now amassed near-global stratospheric water vapor measurements since August 2004. These data can be combined with measurement records from balloon-borne frost point hygrometers to evaluate trends. Figure 2.43 presents time series of zonally- and monthly-averaged MLS retrievals and data from quasi-monthly soundings of NOAA frost point hygrometers (FPH) at Boulder, Colorado; Hilo, Hawaii; and Lauder, New Zealand, and of cryogenic frost point hygrometers (CFH) at San Jose, Costa Rica. Agreement between the FPH and MLS at $82 \mathrm{hPa}$ ranges from $\pm 0.3 \%$ at Lauder to $\pm 6 \%$ at Hilo. Deeper

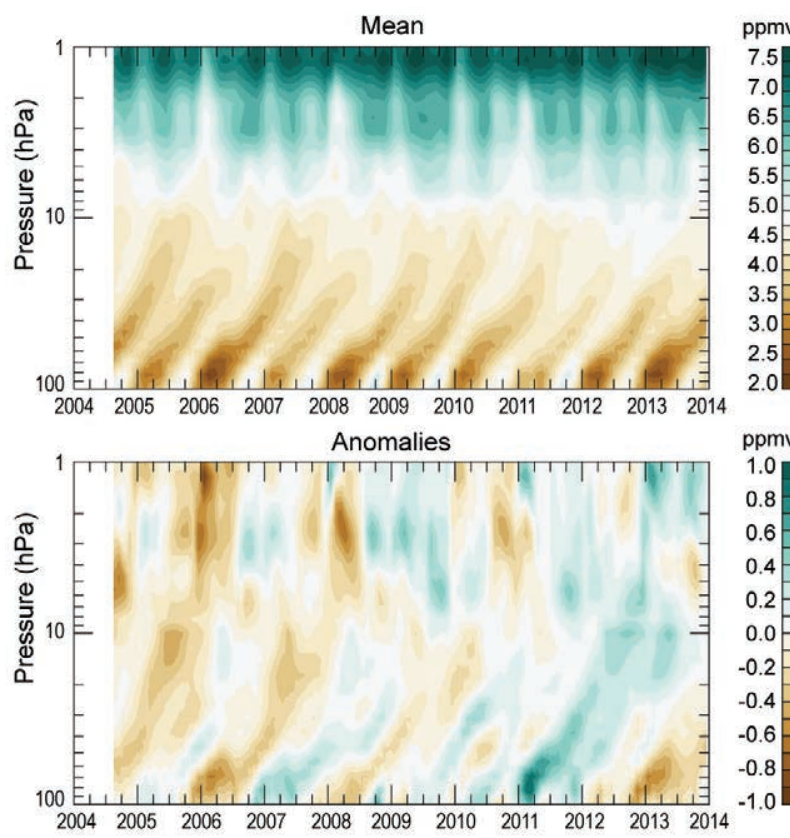

FIG. 2.42. Time series of MLS vertical profiles (hPa) of monthly zonal mean mixing ratios (ppmv, top) and anomalies (ppmv, bottom) in the tropical band $15^{\circ} \mathrm{N}-15^{\circ} \mathrm{S}$. in the stratosphere $(68-26 \mathrm{hPa})$ the long-term $\mathrm{FPH}$ MLS agreement is better than 1\% (Hurst et al. 2014).

The 2013 anomalies at $82 \mathrm{hPa}$ over the Hilo and San Jose tropical sites (Figs. 2.43b,c) depict increases of 0.4-0.8 ppmv (15\%-25\%) after two-year decreases of 1.2-1.4 ppmv (40\%-45\%). The expectation that the tropical increase would propagate to the middle latitudes within several months was not entirely met (Fig. 2.43); the 2013 data instead show only a weak increase of $0.2 \mathrm{ppmv}$ at Boulder and a decrease of 0.3 ppmv at Lauder (Figs. 2.43a,d). Lower stratospheric water vapor over these two sites was evidently influenced by more than just transport from the tropics. The timing of the 2013 increase at Boulder implicates a tropical source but the substantially weakened tropical signal suggests other influences. For Lauder at 82 $\mathrm{hPa}$, dry remnants of the 2013 Antarctic vortex may have reduced water vapor mixing ratios more than they were enhanced by the tropical increase.
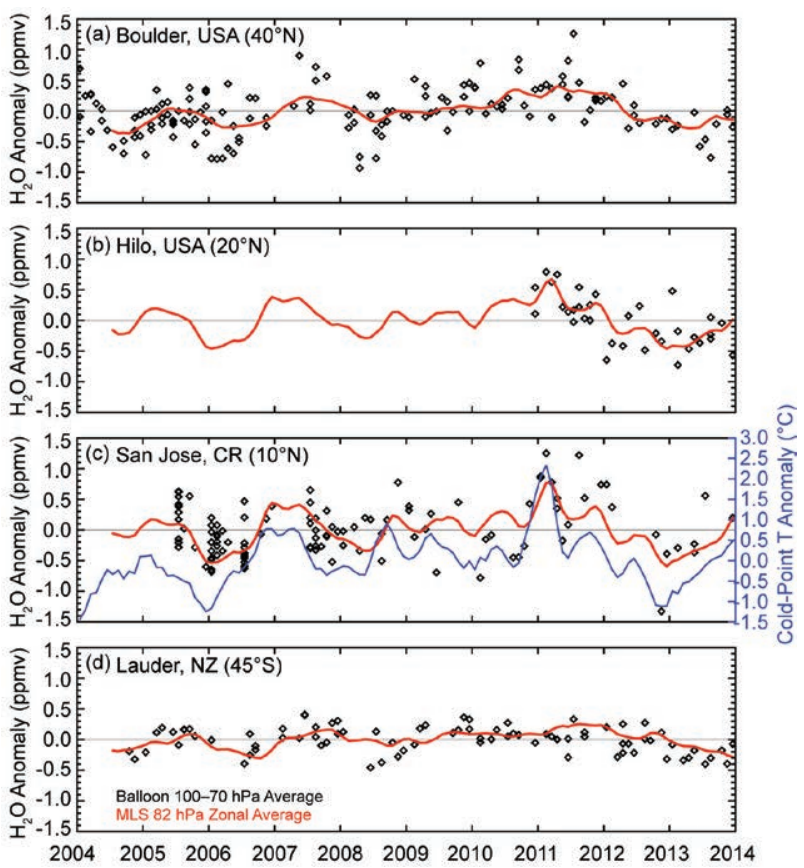

FIG. 2.43. Lower stratospheric water vapor anomalies (ppmv) at $82 \mathrm{hPa}$ over four frost point (FP) hygrometer sounding stations. Anomalies of individual FP soundings (black) and of monthly zonal averages of MLS retrievals in the $5^{\circ}$ latitude band containing each FP station (red) are shown. High-resolution FP vertical profile data were averaged between 70 and $100 \mathrm{hPa}$ to emulate the averaging kernel used for MLS retrievals at $82 \mathrm{hPa}$. Each monthly zonal mean value for MLS is distilled from 2000-3000 profiles. Tropical cold-point temperature anomalies $\left({ }^{\circ} \mathrm{C}\right.$ ) based on the MERRA reanalysis (c, blue curve) illustrate good correspondence with water vapor anomalies in the tropical lower stratosphere. 
6) Tropospheric ozone-0. R. Cooper and J. Ziemke

The State of the Climate in 2012 report marked the first appearance of tropospheric ozone in this annually recurring series (Cooper and Ziemke 2013), with a summary of 1990-2010 surface and free-tropospheric ozone trends around the globe based on in situ observations reported in the peerreviewed literature. A similar summary for 2013 is not possible due to the absence of any systematic procedure for routinely updating ozone trends based on in situ observations at the surface and in the free troposphere. However, procedures are in place for timely updates to tropospheric column ozone (TCO) derived from the Ozone Monitoring Instrument (OMI) and Microwave Limb Sounder (MLS) remote sensing instruments onboard NASA's polar orbiting Aura satellite (Ziemke et al. 2006, 2011). Therefore, this assessment of tropospheric ozone in 2013 relies on the OMI/MLS TCO product, spanning 2005-13 (Figs. 2.44, 2.45).

The average 2013 tropospheric ozone burden $\left(60^{\circ} \mathrm{S}-60^{\circ} \mathrm{N}\right)$ from OMI/MLS was $275 \mathrm{Tg}, 2.5 \%$ above the 2005-12 mean of $268 \mathrm{Tg}$ (Fig. 2.45; Plate 2.10). Relative enhancements during 2013 in the Northern Hemisphere $(\mathrm{NH})$ and Southern Hemisphere (SH) were similar at $2.8 \%$ and $2.2 \%$, respectively, but the seasons and latitudes at which the enhancements occurred differ hemispherically (Fig. 2.45). The strongest positive anomalies of $6.6 \%, 5.0 \%$, and $5.1 \%$ in the $\mathrm{NH}$ were in the tropical latitudes during winter (DJF), spring (MAM), and summer (JJA), respectively. In the $\mathrm{SH}$, the strongest enhancements occurred in the extratropics with anomalies of 5.8\%, $4.0 \%$, and $4.1 \%$ in summer (DJF), fall (MAM), and winter (JJA), respectively. There was a negative anomaly of $-4.1 \%$ in the $\mathrm{SH}$ tropics during spring (SON). Simulations of tropospheric ozone by chemical transport models indicate that the burden fluctuates interannually

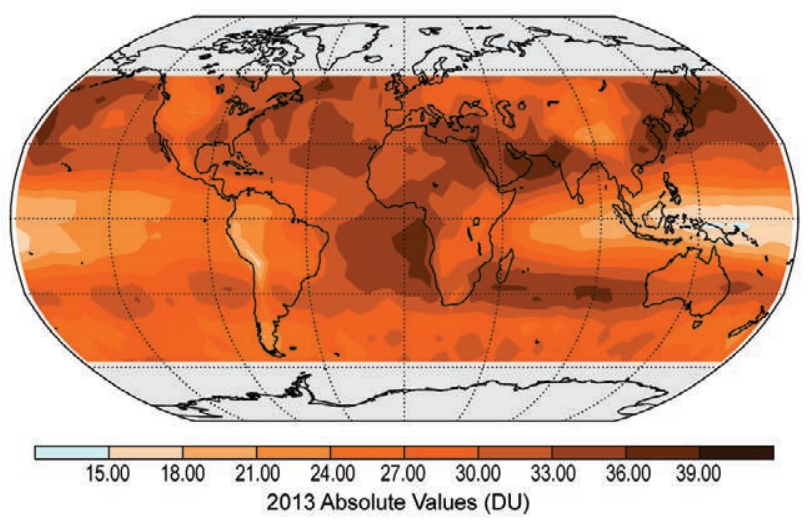

FIG. 2.44. Average OMI/MLS tropospheric column ozone (DU) for 2013.

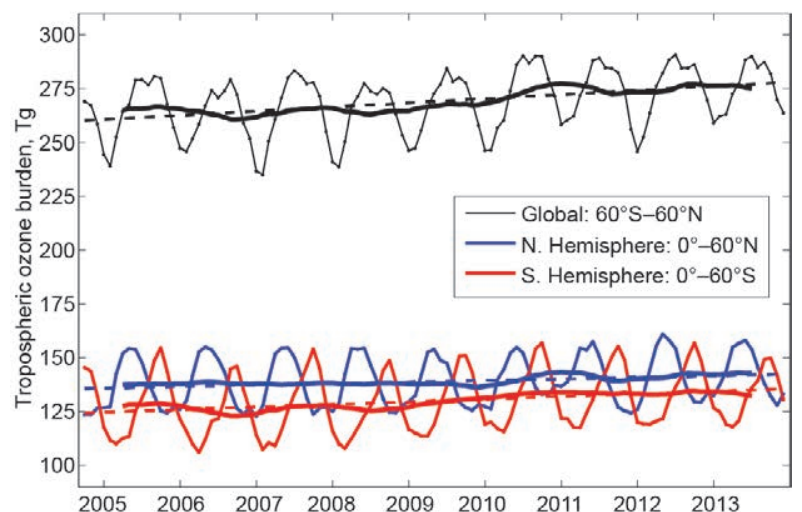

FIG. 2.45. Monthly (Oct 2004-Dec 20I3) OMI/MLS detected tropospheric ozone burden $(\mathrm{Tg})$ from $60^{\circ} \mathrm{S}$ to $60^{\circ} \mathrm{N}$ (thin black line), with 12 -month running mean (thick black line) and least-squares linear regression line (black dashed line). Similarly, results are shown for the Northern Hemisphere (blue) and Southern Hemisphere (red).

and seasonally due to variability in: (1) ozone transport from the stratosphere (Ordóñez et al. 2007; Voulgarakis et al. 2011; Hess and Zbinden 2013); (2) photochemical processes modulated by large-scale meteorology driven by ENSO (Doherty et al. 2006; Koumoutsaris et al. 2008; Voulgarakis et al. 2010); and (3) variability in biomass burning emissions (Leung et al. 2007; Sauvage et al. 2007). Modelling studies have not yet been conducted to determine the causes of the 2013 ozone anomalies.

From October 2004 through December 2013, the global tropospheric ozone burden increased significantly at a linear rate of $1.9 \pm 0.9 \mathrm{Tg} \mathrm{yr}^{-1}(\mathrm{p}<0.01)$, with growth rates of $0.7 \pm 0.8 \mathrm{Tg} \mathrm{yr}^{-1}(\mathrm{p}=0.08)$ and $1.2 \pm$ $1.0 \mathrm{Tg} \mathrm{yr}^{-1}(\mathrm{p}=0.01)$ in the $\mathrm{NH}$ and $\mathrm{SH}$, respectively (Fig. 2.45). Since tropospheric ozone abundance is influenced by the ENSO cycle, the relatively short OMI/MLS time series precludes the conclusion that the linear increase in the tropospheric ozone burden is part of a long-term trend. Several more years of data are required to confidently detect a trend beyond the noise associated with meteorological cycles. Chemistry-climate models would then be required to attribute any observed trends to changes in emissions (anthropogenic or natural; Young et al. 2013; Parrish et al. 2014; Cooper et al. 2014, manuscript submitted to Elementa), transport patterns (Lin et al. 2014), meteorology (Voulgarakis et al. 2010), or influence from the stratosphere (Hess and Zbinden 2013). 
7) Carbon monoxide-J. Flemming and A. Inness

Though carbon monoxide (CO) is not a direct climate forcing agent it influences the abundance of greenhouse gases like methane $\left(\mathrm{CH}_{4}\right)$ through hydroxyl radical $(\mathrm{OH})$ chemistry and plays an important role in the production of tropospheric ozone (Hartmann et al. 2013). CO is emitted to the atmosphere during incomplete combustion of fossil fuels and biomass and is produced in situ by the oxidation of $\mathrm{CH}_{4}$ and other organic trace gases. Combustion and in situ sources typically produce similar amounts of $\mathrm{CO}$ each year. $\mathrm{CO}$ has a lifetime of $1-2$ months and is therefore a good indicator of the long-range transport of pollutants.

The Monitoring of Atmospheric Composition and Climate (MACC) data assimilation system provides analyses and forecasts of atmospheric composition (Inness et al. 2013). A reanalysis of atmospheric composition for 2003-12 and a near-real time analysis for 2013 assimilated total column CO retrievals between $65^{\circ} \mathrm{N}$ and $65^{\circ} \mathrm{S}$ from MOPITT (Deeter et al. 2010; Deeter 2011) from 2003 onwards (Version 4 during 2003-12, Version 5 in 2013), and between $70^{\circ} \mathrm{N}$ and $70^{\circ} \mathrm{S}$ from IASI (George et al. 2009; Clerbaux et al. 2009) since April 2008. The satellite observations were assimilated in the ECMWF's Integrated Forecasting System, which was coupled to the chemical transport model MOZART-3 (Kinnison et al. 2007) as described in Flemming et al. (2009). The anthropogenic emissions of the assimilating model were taken from the MACCity inventory (Granier et al. 2011) that accounts for projected trends in the emissions. Biomass burning emissions from the GFED (v3.0) inventory (van der Werf et al. 2010) were used for the years 2003-08. Since 2009 daily biomass burning emissions from MACC's GFAS, Version 1.0 (Kaiser et al. 2012) have been employed. The MACC CO dataset provides the global three-dimensional distribution of $\mathrm{CO}$ and is used here to assess CO total column anomalies for 2013.

The climatological distribution of total column CO for 2003-13 is presented as the medians of monthly averages during this period (Fig. 2.46). In general there is a hemispheric gradient in total column values, with $2 \times 10^{18}$ molecules $\mathrm{cm}^{-2}$ in the Northern Hemisphere and $1 \times 10^{18}$ molecules $\mathrm{cm}^{-2}$ in the Southern Hemisphere. Regional maxima are located over central Africa due to intensive biomass burning and over Southeast Asia and southern Asia because of strong anthropogenic emissions. Outflow from these regions increases $\mathrm{CO}$ column values over adjacent regions in the eastern Atlantic and the west-

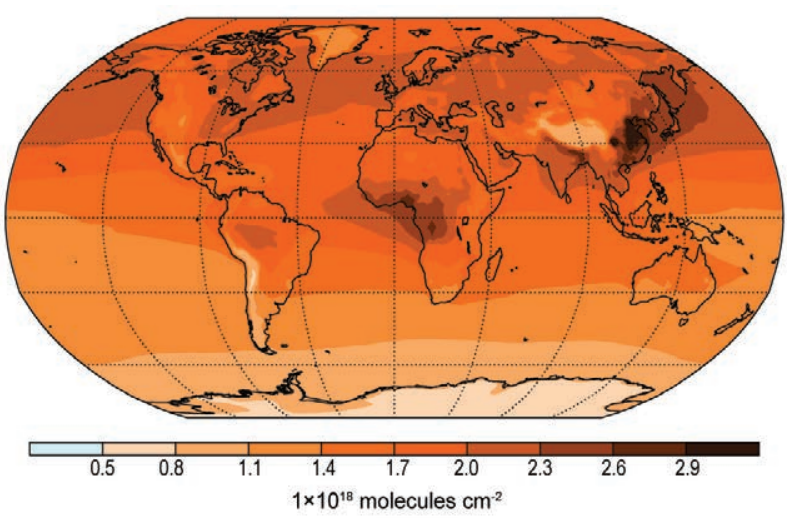

FIG. 2.46. MACC average total column carbon monoxide (CO) for the period 2003-13 (in units of $1 \times 10^{18}$ molecules $\mathrm{cm}^{-2}$ ).

ern Pacific. In the Southern Hemisphere, away from the main emissions sources, the typical background CO mixing ratios of 40-60 ppb vary little with height in the troposphere. In the Northern Hemisphere and the biomass burning regions of the tropics, typical mixing ratios range from $\sim 60 \mathrm{ppb}$ in the upper troposphere to about $150 \mathrm{ppb}$ near the surface. In regions of high emissions the $\mathrm{CO}$ mixing ratios can be more than 10 times these typical values.

Without further calibration, changes to the assimilated satellite retrievals and the relatively short period covered by the MACC CO reanalysis make it insufficiently consistent for the investigation of longterm trends. During 2003-13, the MACC reanalysis shows CO trends of $-0.7 \%$ and $-0.9 \% \mathrm{yr}^{-1}$ for the globe and Northern Hemisphere, respectively, if estimated by linear fits. Trends of $-1 \% \mathrm{yr}^{-1}$ were also found for the globe and Northern Hemisphere in a study of CO measurements by different satellite-based instruments during the last decade (Worden et al. 2013).

To investigate the spatial distribution of the anomalies in 2013, a latitude-dependent bias correction was applied to the climatological distribution to remove long-term trends. No regional absolute anomalies $>10 \%$ were found for the 2013 average CO columns. On seasonal time scales, a positive $\mathrm{CO}$ anomaly $>0.3$ $\times 10^{18}$ molecules $\mathrm{cm}^{-2}(>20 \%)$ occurred over Northern Siberia in June-August (JJA) due to large fires in July (Fig. 2.47a). During this period, there was also a positive anomaly over tropical Africa due to seasonal biomass burning (see section 2h4). In 2013, the fire season in tropical South America was less intense than the decadal average, leading to negative anomalies of more than $-0.2 \times 10^{18}$ molecules $\mathrm{cm}^{-2}(-10 \%)$ in both JJA (Fig. 2.47a) and September-November (SON) as well as less CO outflow over the Southern Atlantic Ocean in SON (Fig. 2.47b). 

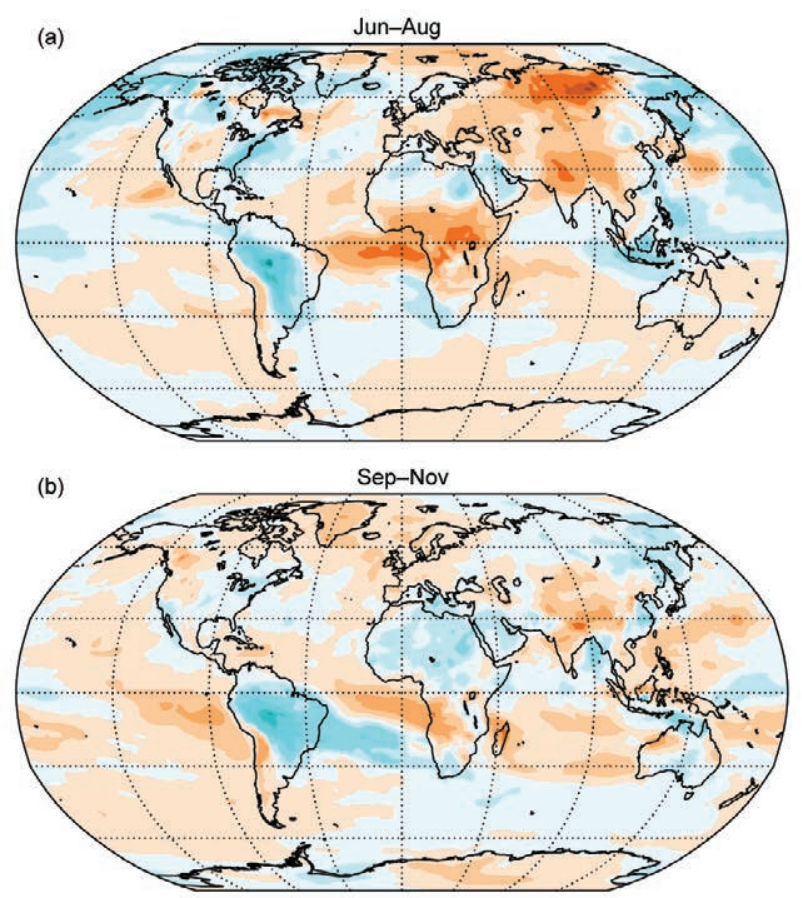

$\begin{array}{lllllllllllll}0.80 & -0.60 & -0.40 & -0.20 & -0.10 & -0.05 & 0.00 & 0.05 & 0.10 & 0.20 & 0.40 & 0.60 & 0.80\end{array}$ $1 \times 10^{18}$ molecules $\mathrm{cm}^{-2}$

FIG. 2.47. MACC anomalies of the total column $\mathrm{CO}$ for (a) Jun-Aug and (b) Sep-Nov in 2013 with respect to the period 2003-13 (in units of $\mathrm{I} \times 1018$ molecules $\mathrm{cm}^{-2}$ ).

\section{h. Land surface properties}

I) FOREST BIOMASS - S. Quegan, P. Ciais, and M. Santoro

While inventories and in situ measurements form the basis of much of our knowledge about the worldwide values and distribution of biomass, there are enormous data gaps, especially in the tropical belt, and also regarding the current status of the vast Eurasian forests. Although mechanisms such as the UNFCCC Reducing Emissions from Deforestation and Forest Degradation initiative (REDD+) have spurred efforts to establish national forest inventory systems in several tropical countries, the recent production of regional to continental scale biomass datasets has relied on satellite data analysis and coordination of in situ measurements. There has also been considerable effort devoted to testing satellite-derived pan-tropical biomass maps using both airborne lidar and in situ data.

Methods to derive biomass in boreal and temperate forests from long time series of C-band Envisat satellite radar data (Santoro et al. 2011) have been applied to estimate the carbon stock of Northern Hemisphere forests north of $30^{\circ} \mathrm{N}$ as of 2010 (Thurner et al. 2014; Fig. 2.48). Although available at $0.01^{\circ}$ resolution (http://www.biomasar.org), Santoro et al. (2013) demonstrate that accuracy at this scale is comparatively poor, and spatial averaging provides more reliable results: at $0.5^{\circ}$ spacing, estimated growing stock volume has a relative accuracy of $20 \%-30 \%$ when tested against inventory data. The associated global estimates of carbon stored in boreal, temperate mixed and broadleaf, and temperate coniferous forests are 40.7, 24.5, and 14.5 Pg C respectively, with estimated accuracies of around 33\%-40\% (Thurner et al. 2014).

Continued assessment of the pan-tropical biomass maps of Saatchi et al. (2011) and Baccini et al. (2012) has revealed significant regional differences between them, although when aggregated to country or biome scale these disagreements tend to decrease (Mitchard et al. 2013). Of current concern is the lack of satellites in orbit capable of providing information on forest biomass. The biomass maps produced by Santoro et al. (2013) and Thurner et al. (2014) are derived from a long time series of C-band radar data produced by the Envisat ASAR instrument, which failed in April 2012. Estimates of the biomass in lower biomass tropical woodlands (e.g., Mitchard et al. 2009) relied on the Japanese Space Agency (JAXA) ALOS-PALSAR L-band radar, which failed in May 2011. Both the Baccini et al. (2012) and Saatchi et al. (2011) tropical biomass maps are based on height measurements from Icesat, which failed in 2009. The situation should ease with the launch of the European Sentinel-1A and 1B C-band satellites in spring 2014 and 2015, respectively, and the JAXA ALOS-2 L-band radar in spring 2014. An important development was the selection by the European Space Agency in May 2013
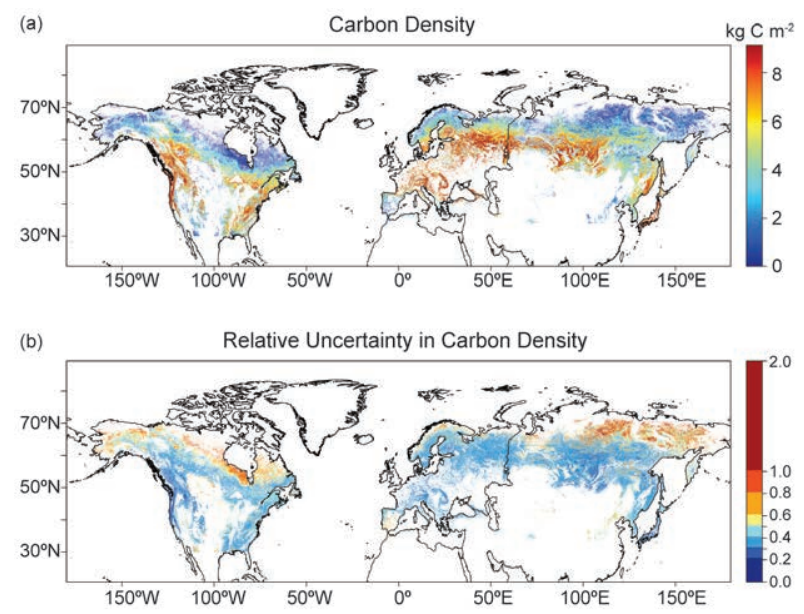

FIG. 2.48. (a) Spatial distribution of total forest carbon density (tree stems + branches + roots + foliage, $\mathrm{kg} \mathrm{C}$ $\mathrm{m}^{-2}$ ) in NH boreal and temperate forests. (b) Corresponding relative uncertainty (a value of I means $100 \%$ uncertainty). (Source: Thurner et al. 2014.) 
of the BIOMASS mission, a P-band radar dedicated to global forest biomass measurements (European Space Agency 2012), but this will not launch before 2020 .

Local studies in the boreal zone have used allometric relations between biomass and forest height measured by the TanDEM-X satellite to derive biomass with root mean square accuracy between $16 \%$ and $20 \%$ at stand level (Askne et al. 2013; Solberg et al. 2013). This technique requires an accurate digital elevation model, which is not available at global scale, in particular for dense tropical forests; hence, it may not be possible to infer biomass worldwide from the 90-m global dataset expected to be soon available from TanDEM-X.

Collation of above-ground biomass data from 260 sample plots across 12 countries in intact closed canopy tropical forests in west, central, and east Africa sampled between 1978 and 2012 (Lewis et al. 2013) closes a major gap in current knowledge, and reveals that these forests are characterized by high biomass values (mean value $396 \mathrm{Mg} \mathrm{ha}^{-1}$ ) concentrated in fewer trees per unit area compared to either Amazonia or Borneo. Regression indicates that both climate and soil properties affect the biomass of the region; in particular, high temperatures and high rainfall in the wettest months are both associated with lower biomass.

\section{2) Land surface Albedo dynamics-B. Pinty}

The land surface albedo represents the fraction of solar radiation scattered backward by land surfaces. In the presence of vegetation, surface albedo results from complex nonlinear radiation transfer processes. These determine the amount of radiation that is scattered by the vegetation and its background, transmitted through the vegetation layer, or absorbed by the vegetation layer and its background (Pinty et al. 2011a,b; Pinty 2012).

The geographical distribution of normalized anomalies in visible (Fig. 2.49a) and near-infrared (Fig. 2.49b) surface albedo for 2013, calculated with respect to the 2003-13 base period [for which two MODIS sensors are available; Schaaf et al. (2002) report the original development], are shown in Plates 2.1q,r. Mid- and high latitude regions of the Northern Hemisphere are characterized by both positive and negative anomalies mainly as a consequence of interannual variations in snow cover, amount, and duration in winter and spring seasons. The large negative anomalies over southeastern Europe, Ukraine, Turkey, and regions of the Balkans and Caucasus are probably associated with a below-average snow cover. In contrast, the spring season snowfall and snowpack over northern and parts of central United States, Canada, and northeastern China correspond to well-identified positive anomalies (section 2c2; http://snowcover.org). The amplitude of these changes can reach $\pm 30 \%$ in relative units, and are larger in the visible than in the near-infrared domain although with the same sign.

Snow-free regions experienced dramatic variations with noticeable negative anomalies in both spectral domains in Australia, Namibia, central India, the Indus valley, southeastern United States, and the Amazon basin. Northeast Brazil, central regions of Argentina and South Africa, western Russia and central Siberia, and to a lesser extent, eastern regions of Central America and Mexico had positive anomalies, in particular in the visible domain. These are generally associated with less-favorable-than-normal vegetation growing conditions (see section $2 \mathrm{~h} 3$ ) although contamination of the albedo retrievals by subpixel clouds and heavy aerosol load (especially in intertropical regions) may induce some artifacts and
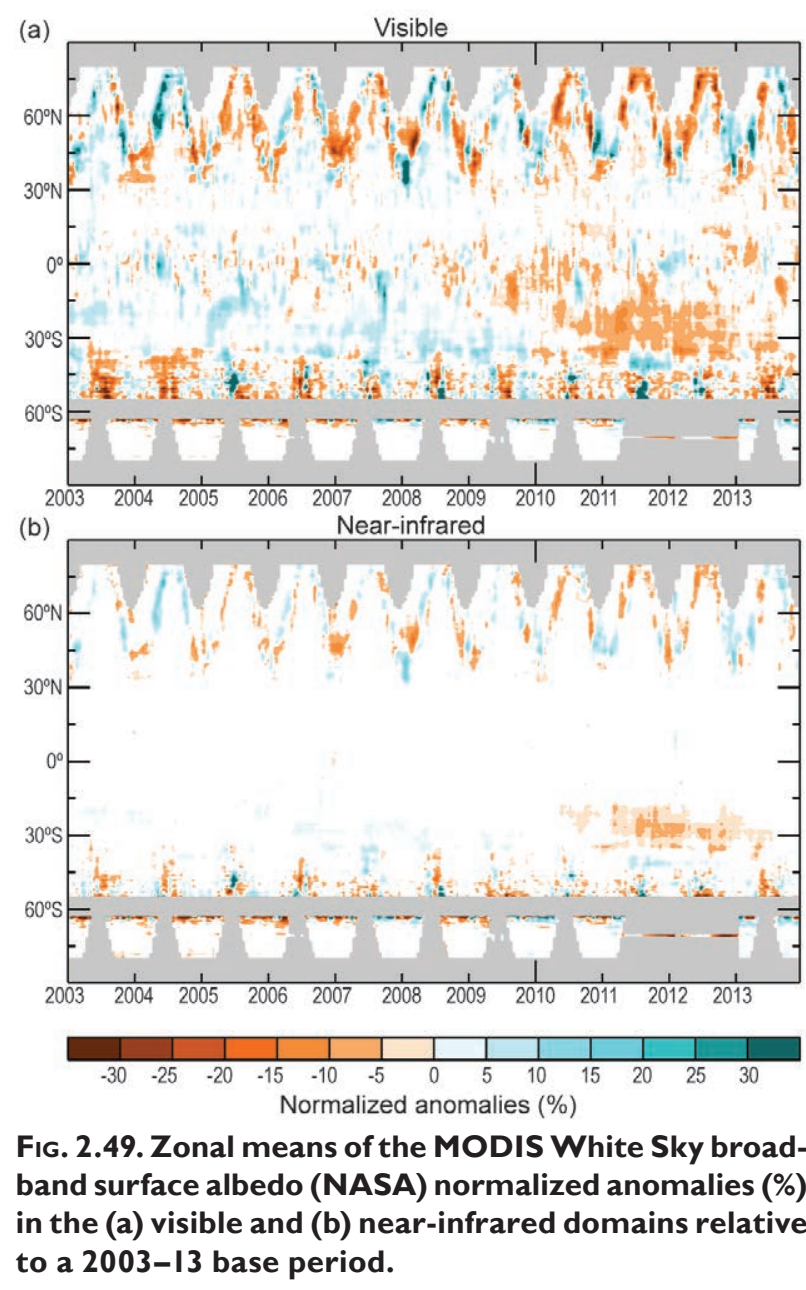


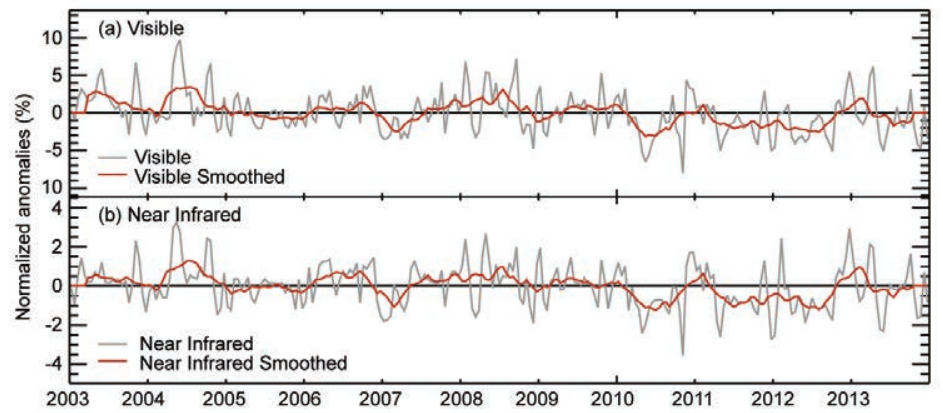

FIG. 2.50. Globally-averaged MODIS White Sky broadband surface albedo (NASA) normalized anomalies (\%) in the (a) visible and (b) near-infrared domains relative to a 2003-13 base period.

limit the observation sampling required for reliable estimates of surface albedo quantities. Spain, China, and southern India had well-identified negative anomalies notably in the visible domain. Many of these variations are attributable to vegetation dynamics over these regions sensitive to stress from ambient conditions and, in particular, water availability.

Analysis of the zonally-averaged albedo anomalies in the visible (Fig. 2.49a) and near-infrared (Fig. 2.49b) spectral domain indicates considerable interannual variations related to snow events in winter and spring at mid- and high latitudes but also in vegetation conditions in spring and summer. The persistent negative anomalies from 2010 between $20^{\circ}$ and $40^{\circ} \mathrm{S}$ are no longer detectable from mid-2013, featuring a return to average conditions.

The fluctuations of the globally-averaged normalized anomalies (Fig. 2.50$)$ are within $\pm 7 \%( \pm 2 \%)$ in the visible (near-infrared) domain. The anomalies are not estimated over Antarctica due to missing products. In contrast to preceding years dominated by negative anomalies mainly from 2010, 2013 does not exhibit a significant departure from the multiyear average conditions. There are slightly positive (negative) anomalies in boreal winter (summer). Figure 2.50 also indicates the presence of spectrally correlated multiannual variations during 2003-13 with positively biased values at the beginning of this period but with an apparent return to average conditions in 2013.

\section{3) Terrestrial Vegetation dynamics-N. Gobron}

Analysis of a 16-year record shows that significant spatio-temporal variations in vegetation dynamics occurred on regional and continental scales during 2013 (see Plate 2.1s). The state of vegetation is examined by merging estimates of the Fraction of Absorbed Photosynthetically Active Radiation (FAPAR) from 1998 to 2013 from three different sen- sors (Gobron et. al. 2010; Pinty et al. 2011b; Gobron and Robustelli 2013).

The largest negative anomalies (unfavorable for vegetation) occurred over northeastern Brazil, central Argentina, and the Volga region and Siberia in Russia. Various regions in Australia and Africa (Chad and Botswana) as well as the southeastern United States were affected as well but to a lesser extent. The largest positive annual anomalies appear over eastern China, southeastern regions of Russia, Indonesia, and Canada. Limited positive anomalies occurred over central and north India as well as central Europe, the African equatorial belt, and central South America.

Northeastern Brazil suffered from significant drought in early 2013 that strongly limited vegetation activity during the year. Central Argentina suffered from a drought and a heat wave, which reduced both cropland and grassland photosynthetic activities. A large fraction of Russia, exhibiting a negative anomaly, experienced both extreme temperatures and drought events during summer 2013 which yielded a strong decrease in vegetation activities. Vegetation was also stressed over United Kingdom by the cold spring which slowed the growth of croplands and grasslands. Following the slow recovery of vegetation in Australia in 2010-11, several regions, including western Queensland and New South Wales, observed new seasonal records of high temperatures (see Sidebar 2.1) and low precipitation.

Eastern China was again marked by strong positive anomalies correlated with high precipitation rates compared to previous years. High rainfall over Indonesia yielded strong positive anomalies. Canada had a favorable year for crops. Vegetation health over

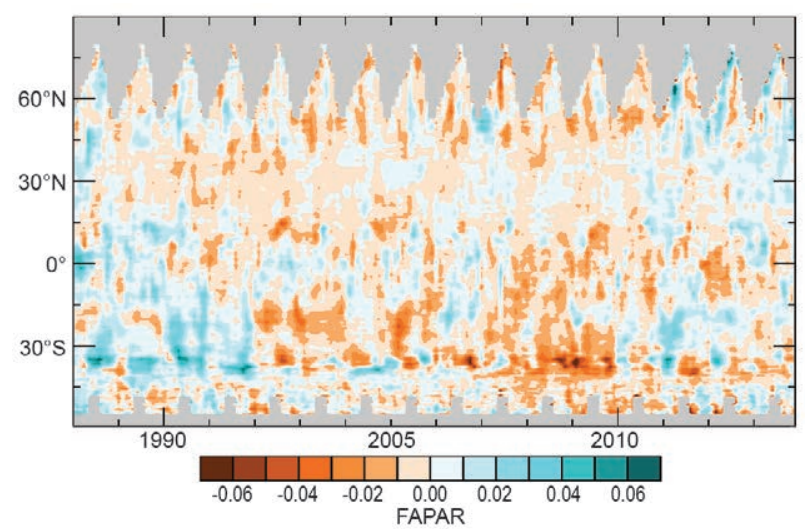

FIG. 2.5I. SeaWiFS/MERIS/MODIS TIP monthly average anomaly (relative to a 1998-2013 base period) time series of latitudinally averaged Fraction of Absorbed Photosynthetically Active Radiation (FAPAR). 


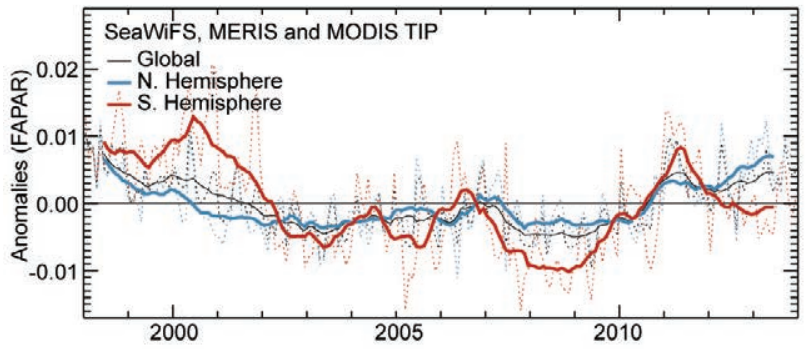

FIG. 2.52. SeaWiFS/MERIS/MODIS TIP Global average monthly FAPAR anomalies with a 6-month running mean (1998-2013 base period) at global scale (black), and over the SH (red) and NH (blue).

a large part of central Europe was better by comparison with past years.

Zonally-averaged monthly mean anomalies (Fig. 2.51) illustrate differences between the two hemispheres, with persistent negative anomalies occurring over the Southern Hemisphere during all seasons from approximately 2002 to 2009. In contrast, since 2010 , modest positive anomalies were observed over regions located between $20^{\circ}$ and $45^{\circ} \mathrm{S}$ but the tendency appeared to decrease in 2013. Figure 2.51 illustrates stronger negative anomalies over regions south of $20^{\circ} \mathrm{S}$ for the first half of 2013 and a larger area with positive anomalies in the Northern Hemisphere since mid-2012.

The mean globally-averaged anomalies (Fig. 2.52), smoothed using a six-month running average, indicate that 2013 corresponds to a relatively healthy state of vegetation at global scale and over the Northern Hemisphere. Relatively large fluctuations are discernible over the Southern Hemisphere with a limited negative anomaly in 2013.

4) BIOMASS BURNING-J. W. Kaiser and G. R. van der Werf The burning of vegetation impacts several radiative forcing agents including the concentration of the greenhouse gases $\mathrm{CO}_{2}, \mathrm{CH}_{4}$, and $\mathrm{N}_{2} \mathrm{O}$, and aerosols. In addition, fires can change land surface characteristics such as biomass, albedo, and roughness, for example when forest is replaced by agriculture. Fires occur in most biomes, and due to spatial and temporal heterogeneity, most information on large-scale fire activity is derived from satellites. Fires are started by lightning or by humans, the latter being most important in the tropics where fire is often used to manage the land. Interannual variability in climatic conditions can influence the occurrence of fires in the tropics through changes to vegetation mass and desiccation. Fires occur less frequently in temperate and boreal regions. In general, these fires burn more often and consume larger areas when climate is favorable.

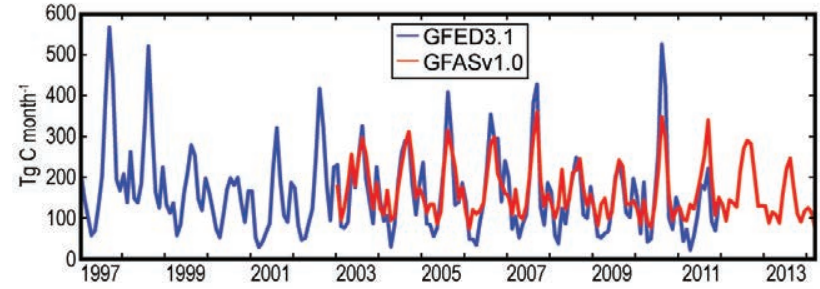

Fig. 2.53. Monthly global fire activity in terms of carbon

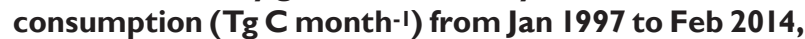
from GFED3.I and GFASvI.0 inventories.

The Global Fire Emissions Database version 3 (GFED3; Giglio et al. 2010; van der Werf et al. 2010) utilizes satellite-derived burned area as an input dataset for a biogeochemical model that computes biomass and the fraction of biomass that is burned, the parameters needed to estimate fire carbon emissions. These GFED estimates have been used to calibrate the Global Fire Assimilation System (GFASv1.0; Kaiser et al. 2012) which uses satellite observations from fires that burn during the satellite overpass instead of burned area. Fire emissions estimates from GFAS are available in near real time (http://atmosphere.copernicus.eu/fire).

Fires consumed on average about $2 \mathrm{Pg}$ of carbon (C) $\mathrm{yr}^{-1}$ over the GFAS era covering 2003-12. Highest emissions (2.3 $\mathrm{Pg} \mathrm{C} \mathrm{yr}^{-1}$ ) occurred in 2003, while 2009 had the least emissions during that period (Table 2.8; Fig. 2.53). The highest fire years in the GFED3 record were 1997 (2.7 $\left.\mathrm{Pg} \mathrm{C} \mathrm{yr}^{-1}\right)$ when peat fires raged over Indonesia and 1998 (2.8 $\left.\mathrm{Pg} \mathrm{C} \mathrm{yr}^{-1}\right)$ when several regions experienced particularly strong fire seasons.

In most years, almost $85 \%$ of total emissions originate in the tropics and subtropics. The boreal regions of Asia and America contribute most of the remainder (Fig. 2.54). During 2013, negative anomalies in the key biomass burning regions in South America,

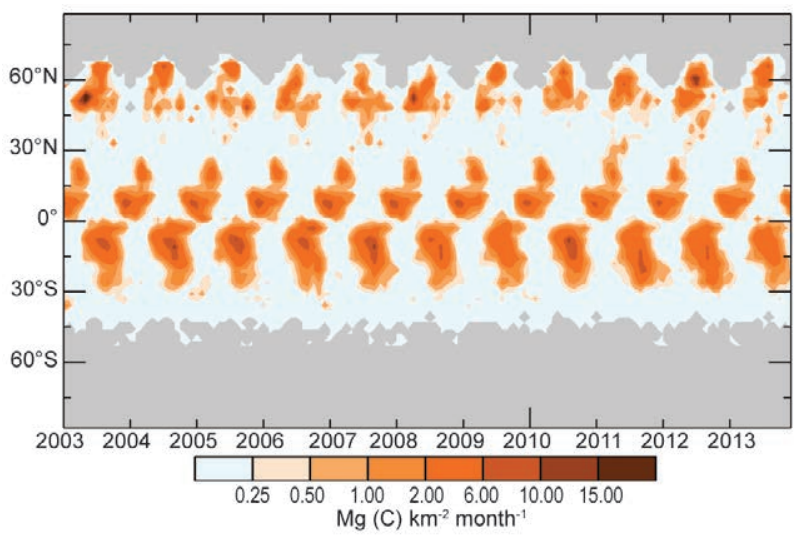

FIG. 2.54. Monthly fire activity in terms of carbon consumption ( $\mathrm{Mg} \mathrm{C} \mathrm{m}^{-2} \mathrm{yr}^{-1}$ ) represented as Hovmüller plot for 2003-13, from GFASvI.0 inventory. (The linear y-axis accentuates high latitudes.) 


\begin{tabular}{|c|c|c|c|c|c|c|}
\hline \multirow{2}{*}{$\begin{array}{c}\text { Time Period } \\
\text { Quantity } \\
\text { Tg C yr-1 }\end{array}$} & & \multicolumn{2}{|c|}{$2003-12$} & \multirow{2}{*}{$\frac{2013}{\text { Value }}$} & \multicolumn{2}{|c|}{2013 w.r.t. $2003-12$} \\
\hline & & Mean & Range & & $\begin{array}{l}\text { Absolute } \\
\text { Anomaly }\end{array}$ & $\begin{array}{l}\text { Relative } \\
\text { Anomaly }\end{array}$ \\
\hline Global & & 2050 & $\mid 774-2312$ & 1652 & -398 & $-19 \%$ \\
\hline $\mathrm{N}$ America & $\begin{array}{c}30^{\circ}-57^{\circ} \mathrm{N} \\
30^{\circ}-170^{\circ} \mathrm{W}\end{array}$ & 101 & $71-138$ & 138 & +37 & $+37 \%$ \\
\hline C America & $\begin{array}{c}0^{\circ}-30^{\circ} \mathrm{N} \\
30^{\circ}-170^{\circ} \mathrm{W}\end{array}$ & 64 & 49-91 & 71 & +7 & $+11 \%$ \\
\hline SH America & $\begin{array}{c}0^{\circ}-60^{\circ} \mathrm{S} \\
30^{\circ}-170^{\circ} \mathrm{W}\end{array}$ & 331 & $177-458$ & 153 & -178 & $-54 \%$ \\
\hline Europe and Mediterranean & $\begin{array}{c}30^{\circ}-75^{\circ} \mathrm{N} \\
60^{\circ} \mathrm{E}-30^{\circ} \mathrm{W}\end{array}$ & 35 & $26-62$ & 19 & -16 & $-47 \%$ \\
\hline NH Africa & $\begin{array}{c}0^{\circ}-30^{\circ} \mathrm{N} \\
60^{\circ} \mathrm{E}-30^{\circ} \mathrm{W}\end{array}$ & 408 & $331-458$ & 348 & -60 & $-15 \%$ \\
\hline SH Africa & $\begin{array}{c}0^{\circ}-35^{\circ} \mathrm{S} \\
60^{\circ} \mathrm{E}-30^{\circ} \mathrm{W}\end{array}$ & 524 & $488-591$ & 529 & +5 & $+1 \%$ \\
\hline N Asia & $\begin{array}{c}30^{\circ}-75^{\circ} \mathrm{N} \\
60^{\circ} \mathrm{E}-170^{\circ} \mathrm{W}\end{array}$ & 213 & $105-470$ & $|3|$ & -82 & $-39 \%$ \\
\hline SE Asia & $\begin{array}{c}10^{\circ}-30^{\circ} \mathrm{N} \\
60^{\circ} \mathrm{E}-170^{\circ} \mathrm{W}\end{array}$ & 130 & $95-162$ & 116 & -14 & $-11 \%$ \\
\hline Tropical Asia & $\begin{array}{c}10^{\circ} \mathrm{N}-10^{\circ} \mathrm{S} \\
60^{\circ} \mathrm{E}-170^{\circ} \mathrm{W}\end{array}$ & 91 & $22-218$ & 49 & -41 & $-46 \%$ \\
\hline Australia & $\begin{array}{c}10^{\circ}-50^{\circ} \mathrm{S} \\
60^{\circ} \mathrm{E}-170^{\circ} \mathrm{W}\end{array}$ & 152 & $52-288$ & 97 & -55 & $-36 \%$ \\
\hline Western US & $\begin{array}{c}30^{\circ}-49^{\circ} \mathrm{N} \\
100^{\circ}-130^{\circ} \mathrm{W} \\
\end{array}$ & 23 & $8-42$ & 24 & +1 & $+5 \%$ \\
\hline Siberia & $\begin{array}{c}50^{\circ}-75^{\circ} \mathrm{N} \\
60^{\circ}-170^{\circ} \mathrm{W}\end{array}$ & 161 & $6 I-4 \mid 4$ & 108 & -53 & $-33 \%$ \\
\hline
\end{tabular}

Africa, Australia, and northern Asia reduced the global biomass burning budget by $19 \%$ to $1.6 \mathrm{Pg} \mathrm{C}$ $\mathrm{yr}^{-1}$ (Table 2.8; Plate 2.1t). The seasonal time series of fire emissions in Online Fig. S2.20 confirm that the low anomaly of the global fire activity occurred at the same time as the low anomaly of South American fire activity. Only North America experienced a significant increase in fire activity with a budget of $136 \mathrm{Tg}$ $\mathrm{C} \mathrm{yr}^{-1}$, which is $37 \%$ above average.

The global average fire activity was lower during 2013 than during the preceding 10 years covered by GFAS. According to the longer GFED3 record, several regions with a negative anomaly in 2013 have experienced even lower fire seasons further in the past. But these were usually compensated for by positive emissions anomalies, something that did not happen in 2013.

South America, Europe, and the Mediterranean also experienced their lowest fire activities since 2003. The record negative anomaly of South America cannot be entirely explained by reduced deforesta- tion activity because the PRODES project reports an increase in deforestation during 2013 as compared to 2012 (INPE 2014). However, the link between annual deforestation and fire rates is not always straightforward and lags between deforestation and fire can occur.

Several large fire events were noticeable during 2013 (Plate 2.1t; Online Fig. S2.21). Emissions from agricultural fires used for land clearing in Sumatra led to extreme air pollution in Singapore (ECMWF 2013). However, these fires were relatively local and appear to be largely compensated by otherwise reduced fire activity in the region; also, the smoke was blown directly from Sumatra to Singapore in this case. Around the beginning and end of July large fires burned in Quebec and Siberia, respectively. The Quebec fires extended the region of large boreal fires in North America eastward. The main Siberian fire activity was shifted northward compared to the preceding decade. The time series in Online Fig. S2.20 shows that fire activity was mostly concentrated in two 
periods; one at the beginning of the main fire season, around $1 \mathrm{May}$, and the other at its end, around $1 \mathrm{Au}-$ gust. The signature of several large fire events in the western United States is also discernible even though their emissions are hardly relevant on a global scale.

The carbon monoxide and carbonaceous aerosol anomalies reported in sections $2 \mathrm{~g} 3$ and $2 \mathrm{~g} 7$ are largely consistent with the observed fire anomalies. These are generally negative in South America and Australia and positive in North America, in particular from
Quebec with the main wind direction into the North Atlantic. The meridional dipole in the Siberian fire anomaly is reflected in a zonal dipole in the aerosol anomaly. For Sumatra, both anomalies show a mixed signal. However, the positive aerosol anomaly in South America is much more pronounced than the only slightly positive fire anomaly, pointing to a potential underestimation of the fire activity in this region. 
S50 | BAMF JULY 2014 
3. GLOBAL OCEANS - M. L. Newlin and M. C. Gregg, Eds.

a. Overview-M. C. Gregg and M. L. Newlin

In 2013 the global oceans were characterized by a persistent pattern wherein saltier (higher evaporation) regions of the ocean surface continued to be anomalously salty and fresher (higher precipitation) regions continued to be anomalously fresh. The salt content in near-surface low latitude waters increased while intermediate waters formed at higher latitudes had decreased salt content. Notably, the South Pacific was fresher in 2013 compared to the long-term mean.

Global mean sea level (GMSL) continued to rise during 2013, on pace with a 20-year linear trend of $3.2 \mathrm{~mm} \mathrm{yr}^{-1}$. A portion of this trend $\left(0.5 \mathrm{~mm} \mathrm{yr}^{-1}\right)$ has been attributed to natural variability associated with the Pacific decadal oscillation (PDO; Hamlington et al. 2013), as well as ongoing contributions from the melting of glaciers and ice sheets and ocean warming (Rhein et al. 2013). Warming of the upper $(0-700 \mathrm{~m})$ oceans accounts for about $63 \%$ of the total increase in energy storage in the climate system from 1971 to 2010 (Rhein et al. 2013), and warming from $700 \mathrm{~m}$ depth to the ocean floor adds about another $30 \%$. Melting ice and warming land account for about 3\% each, and the warming atmosphere accounts for about $1 \%$ over those four decades.

The sea surface temperature anomaly (SSTA) was dominated by a negative PDO pattern in the North Pacific and by ENSO neutral conditions. The global ocean mean SSTA warmed by about $0.04^{\circ} \mathrm{C}$ compared with 2012, with the most warming in the North Pacific, which reached a historic high in 2013.

The substantial warming south of Bering Strait, Gulf of Alaska, and northeast Pacific (compared to 2012) appeared to be largely forced by atmospheric fluxes associated with a strong anomalous anticyclonic circulation near the Gulf of Alaska and a westerly surface wind anomaly in the northeast Pacific. This persistent high-pressure system promoted large-scale atmospheric subsidence farther to the south and altered the atmospheric flow pattern. As a result, the westerly winds in the North Pacific weakened significantly. The weakened winds reduced the rate of evaporation, leading to less latent heat loss from the ocean, which, in turn, caused the ocean warming. Ocean heat content also showed a warming trend in the western tropical Pacific and cooling trend in the eastern tropical Pacific from 1993 to 2013, consistent with overall trade-wind intensification during that time period. No large-scale equatorial surface current anomalies persisted for more than a month in the tropical Pacific basin compared to 2012. The annual average zonal current anomalies reveal a continuing northward shift of the Kuroshio Extension with a narrower and stronger annual signature.

Most of the subpolar North Atlantic warmed from 2012 to 2013 with the exception of parts of the Nordic Seas, which cooled. The observed meridional heat transport decrease in the full 8.5-year time series is likely due to interannual and decadal variability and the Gulf Stream shift southward back to its climatological position. Salinity increased in the upper 100 $m$ of the North Atlantic with substantial freshening around $100-500-\mathrm{m}$ depth (primarily north of $30^{\circ} \mathrm{N}$ ). The Indian Ocean exhibited a widespread and significant warming trend in many regions; almost no regions had a statistically significant cooling trend.

Observations based on carbon system and $\mathrm{pH}$ measurements at ocean time-series stations in the North Atlantic and North Pacific indicate decreasing $\mathrm{pH}$ with rates ranging between $-0.0014 \mathrm{yr}^{-1}$ and $-0.0024 \mathrm{yr}^{-1}$. Unlike previous years, the global phytoplankton distributions revealed that the relationship of decreasing Chla with increasing SST was not equally prominent. In particular, regions of strong warming across the Pacific were often dominated by increases in Chla though there is uncertainty in the current satellite record.

\section{b. Sea surface temperatures-Y. Xue, Z. Hu, A. Kumar, V. Banzon, T. M. Smith, and N. A. Rayner}

Sea surface temperatures (SST) play a key role in regulating climate and its variability by modulating air-sea fluxes and tropical precipitation anomalies. In particular, slow variations in SST such as those associated with the El Niño-Southern Oscillation (ENSO), Atlantic multidecadal oscillation (AMO), Pacific decadal oscillation (PDO), Indian Ocean dipole (IOD), and Atlantic Niño, are potential sources of predictability for climate fluctuations on timescales of a season and longer (Deser et al. 2010). A summary of global SST variations in 2013 is presented, with emphasis on the recent evolutions of ENSO and PDO, and also discussed with respect to the historical record since 1950 .

To quantify uncertainties in SST variations, three SST datasets were used for this analysis: (1) the weekly Optimal Interpolation SST version 2 (OISST; Reynolds et al. 2002); (2) the Extended Reconstructed SST version 3b (ERSST; Smith et al. 2008); and (3) the (UK) Met Office Hadley Centre's sea ice and SST dataset (HadISST1; Rayner et al. 2003). The weekly OISST is a satellite-based analysis that uses in situ data for bias 

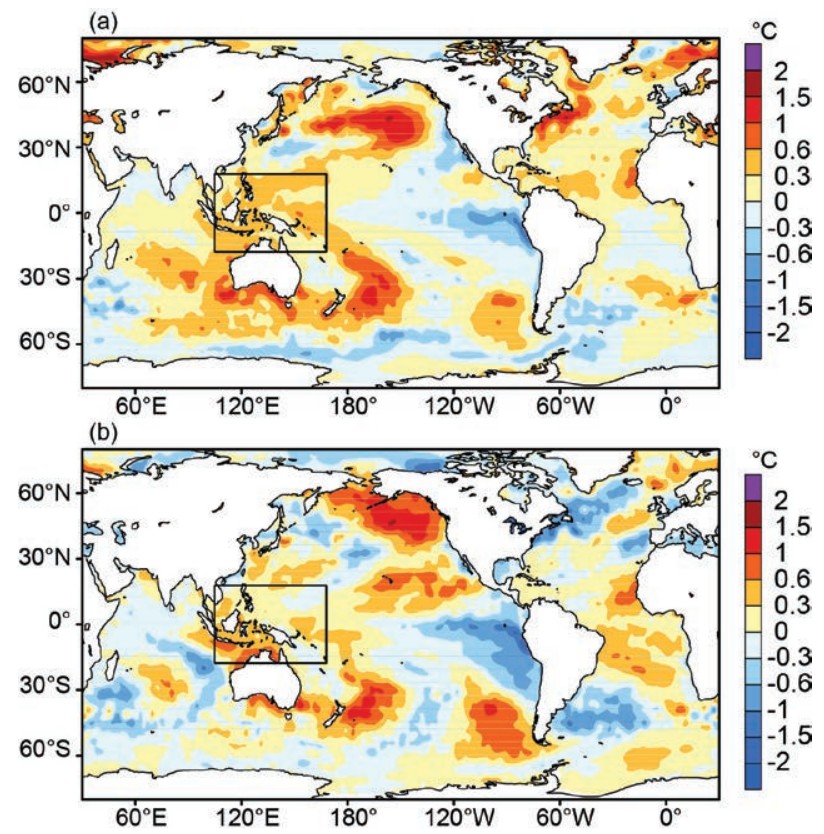

Fig. 3.I. (a) Yearly average OISST anomaly $\left({ }^{\circ} \mathrm{C}\right.$, relative to $1981-2010$ average) in 2013, (b) 2013 minus 2012 OISST anomaly. The box shows the area in which the normalized average SSTA is shown in Fig. 3.3a,b.

adjustments of the Advanced Very High Resolution Radiometer (AVHRR) data, and has been available since November 1981. The ERSST and HadISST1 are historical analyses beginning in the 19th century, and both use statistical procedures developed over the recent period $90^{\circ} \mathrm{N}$ (a) to extend the SST analysis back in time when in situ observations were sparse. ERSST includes in situ data only, while HadISST1 includes both in situ measurements and AVHRR retrievals from 1982 onwards. Although ERSST and HadISST1 are among the best historical datasets, both involve bias corrections, tuning, and interpolations, which cause uncertainties, especially back to early periods of observations. The focus here is on intercomparison of the basin scale means among the three products, leaving regional differences among SST products to specific research publications. In this section, SST variations are quantified as SST anomalies (SSTAs) defined as departures from the 1981-2010 average (http://www .cpc.ncep.noaa.gov/products/people /yxue/sstclim).
The yearly mean SSTA in 2013 (Fig. 3.1a) was characterized by positive SSTA in the central North Pacific, Indo-Pacific warm pool (IPWP), and the North Atlantic and negative SSTA in the eastern equatorial Pacific (EPAC). The SSTA in the North Pacific resembled the negative phase of the PDO pattern (Mantua et al. 1997) and the normalized monthly PDO index averaged to be -1.2 in 2013. The SSTA in the Indo-Pacific was characterized by a dipole pattern with a positive center over IPWP and a negative center in EPAC. The average SSTA over IPWP, labeled as the box in Fig. 3.1, was more than +1 standard deviation (STD), while the SSTA average in EPAC was less than -0.5 STD.

The 2013 minus 2012 SSTA differences (Fig. 3.1b) show that there was a substantial warming south of Bering Strait, Gulf of Alaska, and northeast Pacific. The warming appeared to be largely forced by atmospheric fluxes associated with a strong anomalous anticyclonic circulation near the Gulf of Alaska and westerly surface wind anomaly in the northeast Pacific (see Fig. 3.9). There was a cooling in the southeast Pacific, along the east coast of North America, and subpolar North Atlantic. The tropical Atlantic was warmer in 2013 than in 2012.

The temporal evolution of seasonal mean SSTA in 2013 is shown in Fig. 3.2. The boreal winter
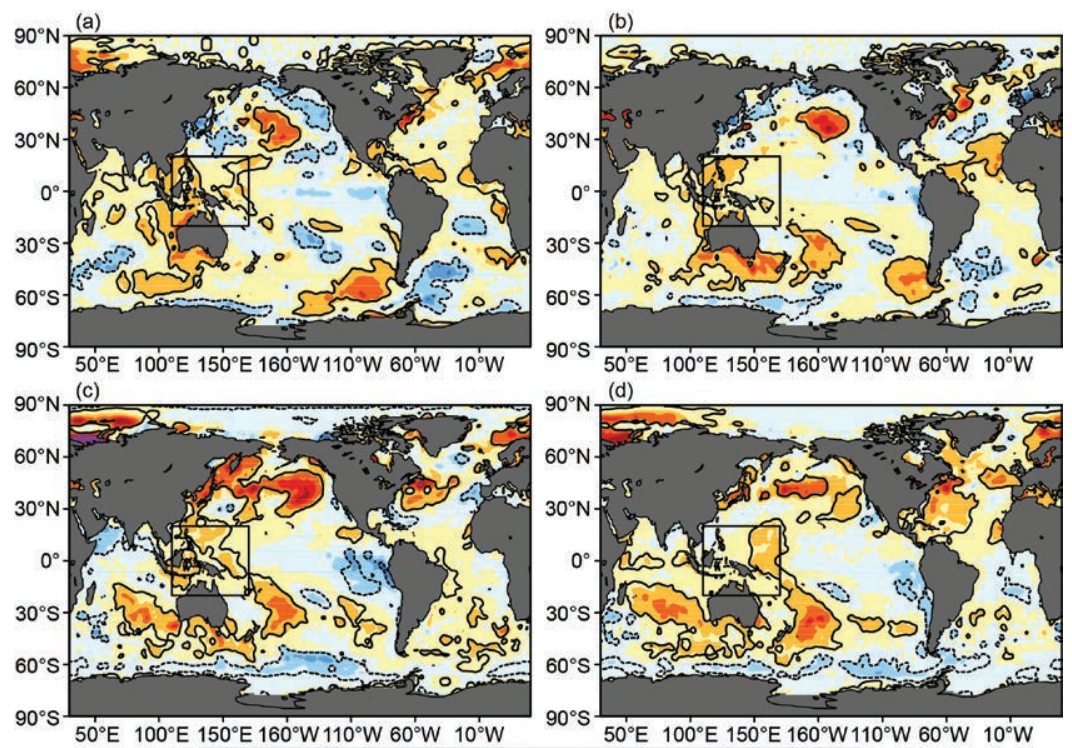

$$
\begin{array}{lllllllllll}
-2.5 & -2 & -1.5 & -1 & -0.5 & 0 & 0.5 & 1 & 1.5 & 2 & 2.5
\end{array}
$$

FIG. 3.2. Seasonal average SSTA from OISST (shading, ${ }^{\circ} \mathrm{C}$, relative to 198I-2010 average) for (a) Dec 20I2-Feb 20I3, (b) Mar-May 2013, (c) Jun-Aug 2013, and (d) Sep-Nov 2013. The contours are $+I$ and $-I$ normalized seasonal average SSTA based on seasonally-averaged standard deviation over 1981-2010. The box shows the area in which the normalized average SSTA is shown in Fig. 3.3a,b. 
2012/13 (December-February) was characterized by a negative PDO pattern in the North Pacific and ENSO-neutral conditions in the tropical Pacific [with definition of ENSO based on three-month running average of the NINO3.4 index with a threshold of $+0.5^{\circ} \mathrm{C}\left(-0.5^{\circ} \mathrm{C}\right)$ for El Niño (La Niña); see section $4 \mathrm{~b}$ for details]. Both ENSO-neutral and negative PDO conditions persisted throughout 2013 (see NINO3.4 and PDO indices in Fig. 3.3a,c). The positive SSTA over IPWP exceeding +1 STD persisted throughout 2013. Negative SSTA of more than -1 STD emerged in the eastern Pacific during summer and persisted into fall 2013. The SSTA in the North Atlantic was mostly positive during 2013.

To further understand the persistent positive SSTA over IPWP, the normalized monthly SSTA average was calculated in the box labeled in Fig. 3.1, referred to as Indo-Pacific warm pool SSTA (WSSTA). Figure 3.3a shows that WSSTA exceeded +1 STD during
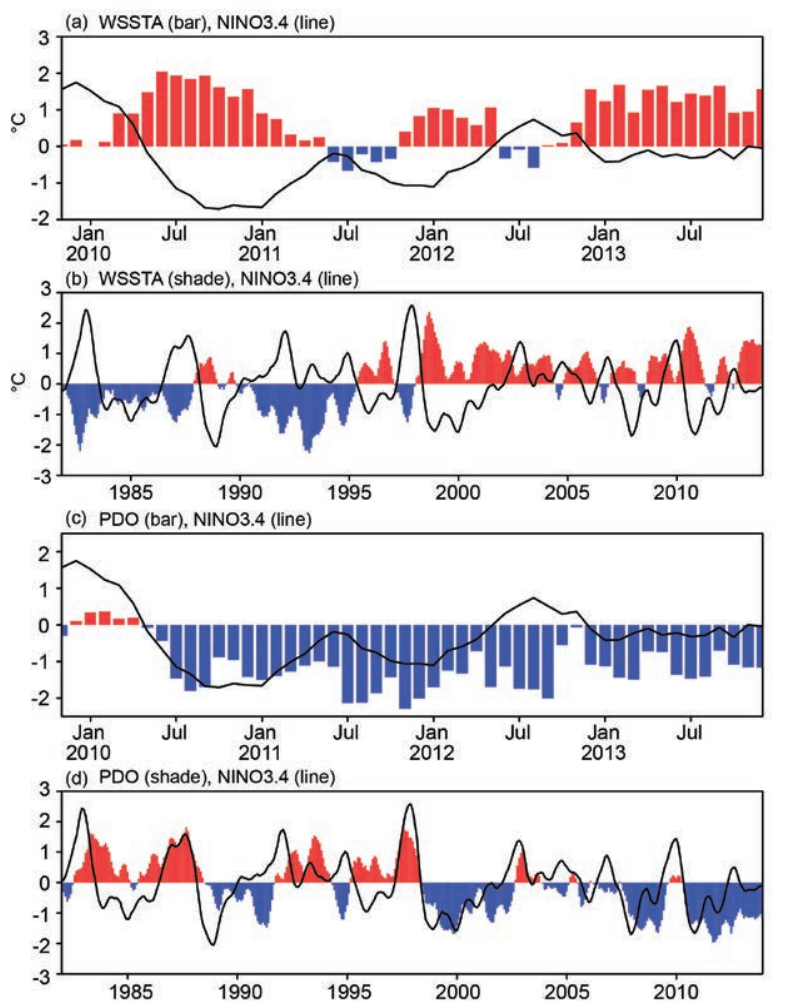

FIG. 3.3. (a) Monthly normalized average SSTA $\left({ }^{\circ} \mathrm{C}\right)$ over Indo-Pacific warm pool in the box shown in Fig. 3.2, labeled as WSSTA (bar) and monthly normalized NINO3.4 index (average SSTA in $170^{\circ}-120^{\circ} \mathrm{W}, 5^{\circ} \mathrm{S}-$ $5^{\circ} \mathrm{N}$; line) for $2010-13$ and (b) 5 -month running mean of SSTA indices $\left({ }^{\circ} \mathrm{C}\right)$ for $1982-2013$; SSTA is relative to 198I-2010 average. (c) Monthly normalized PDO index (bar) and NINO3.4 index (line) for 2010-13 and (d) 5-month running mean of PDO and NINO3.4 index for 1982-2013. most of 2013 and 2010, in contrast to 2011 and 2012 when WSSTA was less than 0.5 STD. The time series since 1982 (Fig. 3.3b) shows that WSSTA (shading) was mostly negative before 1999 and positive after 1999. The sudden warming over IPWP is related to a multidecadal shift that happened around 1999 (Lyon et al. 2013). WSSTA is generally out-of-phase with NINO3.4 with a correlation -0.45 for the period 1982-2013. However, the correlation between WSSTA and NINO3.4 was -0.53 before 1999 and -0.31 after 1999. The weakened out-of-phase relationship between WSSTA and NINO3.4 after 1999 is probably related to the weakened ENSO variability after 1999 (Hu et al. 2013). In addition, the multidecadal shift around 1999 also contributes to the weakened relationship. The persistent positive WSSTA after 1999 likely forces persistent La Niña-like atmospheric circulations with enhanced convections over Indonesia and suppressed convections near the dateline. This was the case in 2013 (see http://www.cpc.ncep.noaa.gov /products/GODAS).

The connection between the ENSO cycle and PDO is further explored. The PDO index is defined as the standardized time series of the projection onto the 1st empirical orthogonal function (EOF) of monthly ERSST in the North Pacific north of $20^{\circ} \mathrm{N}$ during the period 1900-93 following the approach of Mantua et al. (1997). There was a switch from positive to negative PDO around June 2010 which coincided with the onset of the 2010/11 La Niña (Fig. 3.3c). This negative PDO phase has persisted since that time. The time series for 1982-2013 (Fig. 3.3d) shows that negative PDO tends to be in phase with, but lasts longer than, La Niña. In addition, there was a regime shift of PDO around 1999. After 1999 negative PDO was more frequent than the positive PDO, while before 1999 positive $\mathrm{PDO}$ was more frequent. The correlation between monthly PDO and NINO3.4 at zero lag is 0.42 in 1982-2013, while it is 0.38 in $1982-98$ and 0.51 in 1999-2013. The higher correlation since 1999 is partly attributed to the fact that both the PDO and NINO3.4 were in prevalent negative phases since 1999.

The historical perspective of the yearly mean SSTA in 2013 was next investigated. Figure 3.4 shows the average SSTAs in the (a) tropical Pacific, (b) tropical Indian Ocean, (c) tropical Atlantic, (d) North Pacific, (e) North Atlantic, and (f) global ocean. The SSTA time series of OISST are largely consistent with ERSST in the common period 1982-2013. HadISST also agrees well with OISST and ERSST except it is generally cooler in the tropical Indian Ocean, where the differences reach up to $0.2^{\circ} \mathrm{C}$. 

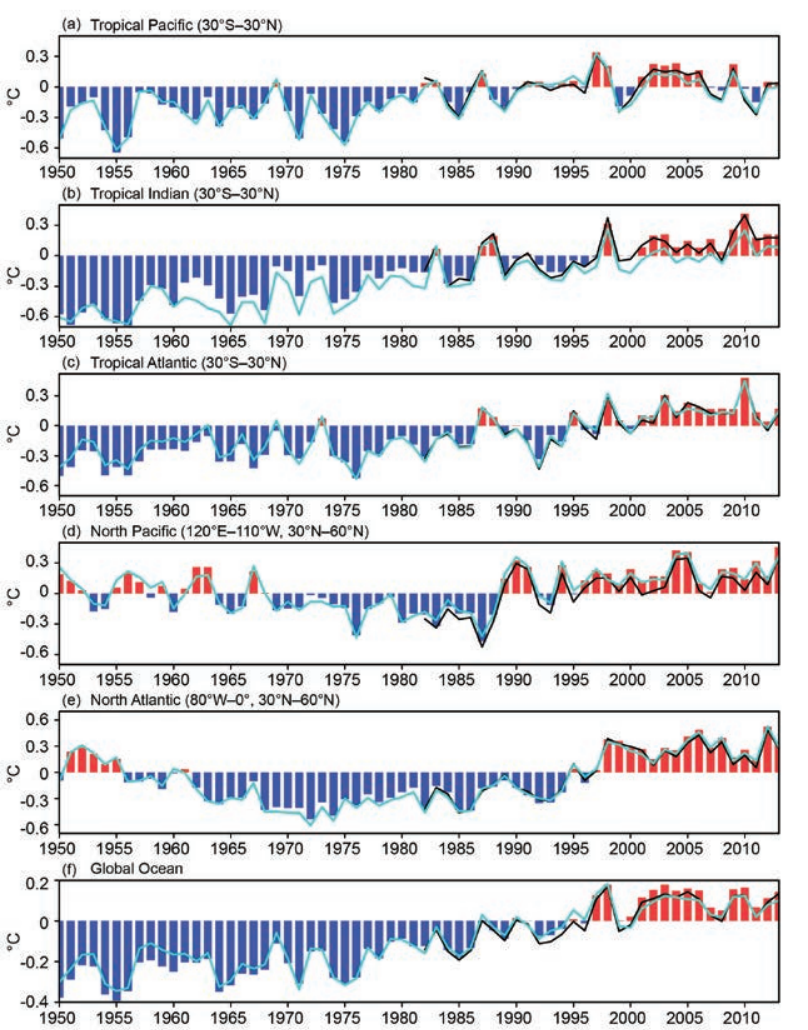

FIG. 3.4. Yearly mean SSTA $\left({ }^{\circ} \mathrm{C}\right.$, relative to $198 \mathrm{I}-2010$ average) from ERSST, and HadISST (blue line) for 1950-20I3 (bar) and OISST for 1982-20 I3 (black line) averaged over the (a) tropical Pacific, (b) tropical Indian Ocean, (c) tropical Atlantic, (d) North Pacific, (e) North Atlantic, and (f) global ocean.

The mean SSTA in the global ocean was dominated by a warming trend superimposed with interannual variations largely associated with El Niño and La Niña events (Fig. 3.4f). For example, the peaks and valleys in the global ocean SSTA often correspond with those in the tropical Pacific SSTA (Fig. 3.4a). The global ocean SSTA warmed by about $0.04^{\circ} \mathrm{C}$ (Fig. 3.4f). After a 30-year period (1970-99) of a warming trend in the global ocean SST $\left(+0.11^{\circ} \mathrm{C}\right.$ decade ${ }^{-1}$ in ERSST and $+0.06^{\circ} \mathrm{C}_{\text {decade }}{ }^{-1}$ in HadISST), the past decade in 2000-13 had little further trend $\left(+0.007^{\circ} \mathrm{C}\right.$ decade $^{-1}$ in ERSST and $+0.02^{\circ} \mathrm{C}$ decade ${ }^{-1}$ in HadISST) .

The tropical Indian Ocean SSTA is dominated by an upward trend with an increase of $0.9^{\circ} \mathrm{C}$ from 1950 to 2010 when the historical high value was reached (Fig. 3.4b). The interannual variations in the tropical Indian Ocean SSTA correspond well with those in the tropical Pacific SSTA due to the remote influences of ENSO. In the tropical Atlantic, SSTA was mostly negative before 1995, and warmed significantly from $-0.43^{\circ} \mathrm{C}$ in 1992 to $+0.31^{\circ} \mathrm{C}$ in 2003 . The positive
SSTA largely persisted from 2003 to 2009 , then suddenly increased to the historical high value $+0.46^{\circ} \mathrm{C}$ in 2010 (Fig. 3.4c), due to the combined influences of $\mathrm{El}$ Niño, long-persistent negative phase of NAO, as well as the long-term trend (Hu et al. 2011). Since 2010, the tropical Atlantic SST has cooled down substantially. The North Pacific SSTA trended downward from 1950 to 1987 , but rebounded from $-0.5^{\circ} \mathrm{C}$ in 1987 to $0.31^{\circ} \mathrm{C}$ in 1990 , and has been persistently positive since then (Fig. 3.4d). The North Pacific SSTA increased $0.27^{\circ} \mathrm{C}$ from 2012 to 2013 , and reached a historical high in 2013. The North Atlantic SSTA trended downward from 1951 to early 1970s, and then trended upward, reaching a peak value in 2006. From 2006 to 2010, the SSTA had a downward trend, but rebounded and reached a historical high in 2012 (Fig. 3.4e). There was a cooling of $-0.21^{\circ} \mathrm{C}$ from 2012 to 2013.

C. Ocean heat content-G. C. Johnson, J. M. Lyman, J. K. Willis, T. Boyer, J. Antonov, S. A. Good, C. M. Domingues, and N. Bindoff Storage and transport of heat in the ocean are central to aspects of climate such as ENSO (Roemmich and Gilson 2011), tropical cyclones (Goni et al. 2009), sea level rise and the global energy budget (Church et al. 2011), constraining global warming scenarios (Otto et al. 2013), and melting of ice sheet outlet glaciers around Greenland (Straneo and Heimbach 2013) and the Antarctic (Rignot et al. 2013).

An estimate of upper $(0-700 \mathrm{~m})$ ocean heat content anomaly (OHCA) for 2013 (Fig. 3.5a) is computed from a combination of in situ ocean temperature data and satellite altimetry data (hereafter referred to as the combined estimate). In situ data are from (UK) Met Office Hadley Center EN3 V2a (Ingleby and Huddleston 2007), derived mostly from the World Ocean Database (Boyer et al. 2009), but with a January 2014 download of Argo (Roemmich et al. 2009) data. Updated mechanical and expendable bathythermograph (MBT and XBT) bias corrections from Ishii and Kimoto (2009) are applied, along with a statistical quality control (Lyman and Johnson 2014). Since OHCA changes are related to depth-integrated ocean temperature changes, increases in OHCA are sometimes referred to here as warming and OHCA decreases as cooling. Some of the data used in this analysis are preliminary, pending delayed-mode scientific quality control; however, strong regional signals are unlikely to change upon data finalization.

Upper OHCA in 2013 (Fig. 3.5a) shows typical eddy and meander signatures (Johnson et al. 2012a). Similarly, differences of upper OHCA between 2013 

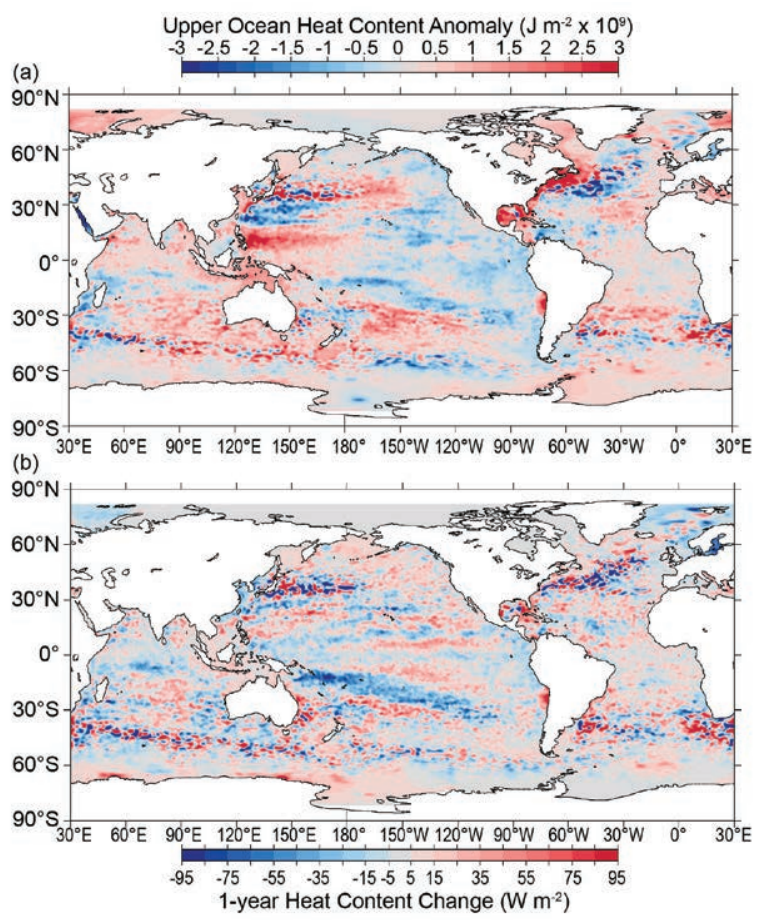

FIG. 3.5. (a) Combined satellite altimeter and in situ ocean temperature data estimate of upper $(0-700 \mathrm{~m})$ ocean heat content anomaly (OHCA; $\times 109 \mathrm{~J} \mathrm{~m}^{-2}$ ) for 2013 analyzed following Willis et al. (2004), but using an Argo monthly climatology and displayed relative to a 1993-2013 average. (b) The difference of 2013 and 2012 combined estimates of OHCA expressed as a local surface heat flux equivalent ( $\mathrm{W} \mathrm{m-2}$ ). For panel comparisons, note that $95 \mathrm{~W} \mathrm{~m}^{-2}$ applied over one year results in a $3 \times 10^{9} \mathrm{~J} \mathrm{~m}^{-2}$ change of OHCA.

and 2012 (Fig. 3.5b) exhibit typical interannual variability. OHCA variability (and net increases) are also found from 700 to $2000 \mathrm{~m}$ in depth (Levitus et al. 2012) and even in the abyssal ocean below (Purkey and Johnson 2013). These variations, as well as salinity and mass signals, all contribute to local sea level anomalies (Leuliette and Willis 2011). Despite these additional factors, there are many large-scale visual similarities between the combined estimate of upper OHCA (Fig. 3.5a) and sea level (see Fig. 3.28a) fields in 2013. This similarity reflects mostly the large contribution of upper OHCA variations to sea level variations (Church et al. 2010), but also to a lesser extent the influence of the altimeter data in the combined estimate (Willis et al. 2004).

Large-scale patterns are evident in the combined estimate of upper OHCA for 2013 (Fig. 3.5a) and its difference from 2012 (Fig. 3.5b). The pattern of annual mean OHCA (Fig. 3.5a) on the equator in the Pacific exhibits slightly cool values in the east and slightly warm values in the west. This relatively neutral pat- tern is consistent with the persistence of near-neutral conditions for ENSO in the Pacific from 2012 through 2013 (section 4b).

In 2013, the North Pacific (Fig. 3.5a) showed a pattern of anomalous warmth in the central Pacific and cold in the eastern Pacific that is typical of the negative phase of the Pacific decadal oscillation (PDO; Mantua et al. 1997), although this pattern was weaker in 2013 than in 2012. Extratropical SST anomalies in 2013 exhibited a similar pattern (see Fig. 3.1). South of the Kuroshio Extension in the western Pacific there was a cool patch between $20^{\circ}$ and $30^{\circ} \mathrm{N}$ that contrasts with the anomalously warm patch to the south that extended well east of the Philippines. There were strong zonal surface current anomalies co-located with these two features (see Fig. 3.17a).

In the South Pacific, the strong band of cooling from 2012 to 2013 (Fig. 3.5b) that extended from east of the Solomon Islands to about $30^{\circ} \mathrm{S}, 100^{\circ} \mathrm{W}$ is associated with an increase in eastward tendency of surface velocity (see Fig. 3.17b) and an increase in Ekman suction (anomalous upwelling) owing to changes in the winds (see Fig. 3.9b). This cooling broke up a band of anomalously warm upper OHCA in the South Pacific extending from the Solomon Islands in the west to about $30^{\circ} \mathrm{S}, 100^{\circ} \mathrm{W}$ (Fig. 3.5a) that had been present at various latitudes since 2006 (Johnson et al. 2013a; previous State of the Climate reports). However, much of the South Pacific south of the Tropic of Capricorn $\left(\sim 23^{\circ} \mathrm{S}\right)$ remained anomalously warm in 2013.

Upper OHCA in the Indian Ocean remained mostly warm in 2013 (Fig. 3.5a) compared to the 1993-2013 average, with a prominent cool patch in the southern half of the Mozambique Channel, where strong cooling occurred between 2012 and 2013 (Fig. 3.5b). Cooling from 2012 to 2013 in a band around $8^{\circ} \mathrm{S}$ is associated with an increase in eastward flow to the north and westward flow to the south (see Fig. 3.17b), consistent with an increase in the strength of the thermocline ridge at that latitude and an increase in Ekman suction just south of the equator extending westward from Indonesia (see Fig. 3.9b).

Much of the subpolar North Atlantic warmed from 2012 to 2013 (Fig. 3.5b), although some of the Nordic Seas cooled. With these changes, in this region a small portion of the Irminger Sea and some patches west of Norway remained colder than average in 2013 (Fig. 3.5a). In 2013, as in 2012 (Johnson et al. 2013a), there was a meridional dipole of OHCA along the Gulf Stream extension, warm to the northwest and cool to the southeast. The tropical Atlantic mostly warmed from 2012 to 2013 (Fig. 3.5b); hence it remained 
warmer than the 1993-2013 average, with some cool patches along the tropical cyclone path from Africa to the Antilles (Fig. 3.5a).

A few distinct (Fig. 3.6a) and statistically significant (Fig. 3.6b) regional patterns stand out in the 1993-2013 local linear trends of upper OHCA. In the Indian Ocean, the warming trend is widespread and statistically significant in many locations, with almost no regions of statistically significant cooling trends in that ocean.

In the Atlantic Ocean, the Labrador, western Irminger, and Nordic Seas have all trended warmer over 1993-2013 (Fig. 3.6a), reflecting a robust regional warming trend over the interval (Fig. 3.6b). These changes may result from changes in the wind stress curl linked to changes in Atlantic multidecadal variability (AMV) since 1993 (Häkkinen et al. 2013). Eastern portions of the subtropical Atlantic and most of the tropics also trend warmer across both hemispheres. Statistically significant cooling trends in the Atlantic are limited to the Gulf Stream extension,
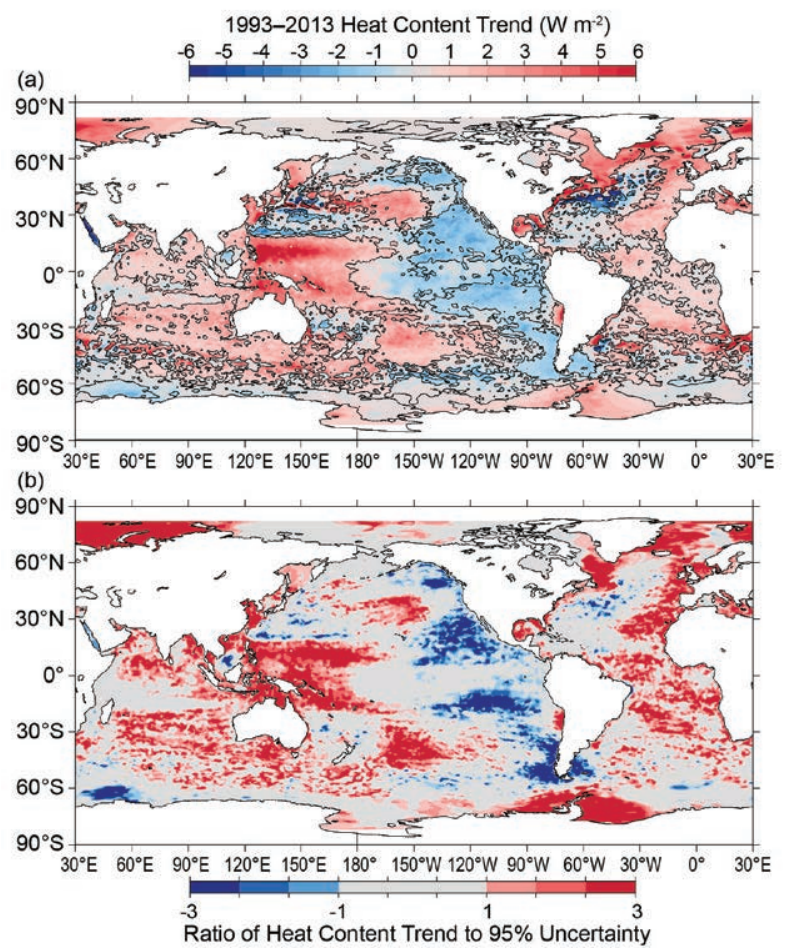

FIG. 3.6. (a) Linear trend from 1993-2013 of the combined satellite altimeter and in situ ocean temperature data estimate of upper (0-700 m) ocean heat content anomaly OHCA (W $\left.\mathrm{m}^{-2}\right)$ analyzed following Willis et al. (2004) but relative to a monthly Argo climatology. Areas with statistically significant trends are outlined in black. (b) Signed ratio of the linear trend to its $95 \%$ uncertainty estimate, with increasing color intensity showing regions with increasingly statistically significant trends. probably related to a southward shift in that current over the past few years. This shift is expected with an overall declining NAO index (Pérez-Hernández and Joyce 2014), but recent subtropical cooling has also been linked to a reduction in the Atlantic meridional overturning circulation (Cunningham et al. 2013).

Statistically significant (Fig. 3.6b) 1993-2013 regional trends in the Pacific Ocean (Fig. 3.6a) include warming in the western tropical Pacific and extraequatorial cooling in the east, consistent (via the geostrophic relation) with general strengthening of the interior subtropical-tropical circulation attributed to trade wind intensification (Merrifield et al. 2012). The statistically significant warming in the central North Pacific and cooling south of Alaska and off the west coast of North America are also consistent with an overall downward trend in the PDO index since 1993. There is a similar trend pattern in the South Pacific.

The overall 1993-2013 trends in Southern Ocean upper OHCA are towards warming, consistent with previous analyses (Böning et al. 2008), but with some cooling trends in localized regions, most notably around South America (Fig. 3.6a). The apparent trends adjacent to Antarctica are located in both in situ and altimeter data-sparse regions and may not be as robust as suggested by the statistics (Fig. 3.6b).

Warming of the upper (0-700 $\mathrm{m}$ ) oceans accounts for about $63 \%$ of the total increase in energy storage in the climate system from 1971 to 2010 (Rhein et al. 2013), and warming from $700 \mathrm{~m}$ depth to the ocean floor adds about another $30 \%$. Melting ice and warming land account for about $3 \%$ each, and the warming atmosphere accounts for about $1 \%$ over those four decades.

Four different upper ocean estimates of globallyintegrated in situ OHCA (Fig. 3.7) reveal a large increase in global integrals of that quantity since 1993. While each of the curves appears to show interannual to decadal variability in upper ocean heat content, they do not always agree in the details (Abraham et al. 2013; Church et al. 2013). These details differ for a variety of reasons including differences in climatology and base period, treatment of the seasonal cycle, mapping methods, instrument bias corrections, quality control, and other factors (Lyman et al. 2010). Some of these factors are not taken into account in some of the displayed uncertainties, and the offsets applied to the curves for display are arbitrary. Uncertainties in annual estimates of global upper OHCA only permit statistically significant trends to be estimated over about 10 years or longer (Lyman 2012). 


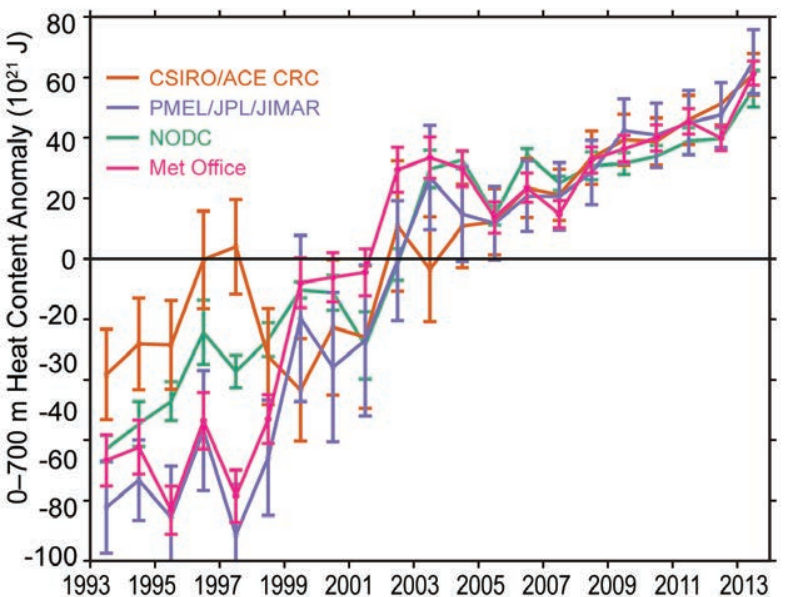

Fig. 3.7. Time series of annual average global integrals of in situ estimates of upper $(0-700 \mathrm{~m})$ OHCA $\left(\times 10^{21} \mathrm{~J}\right.$, or ZJ) for 1993-2013 with standard errors of the mean. The CSIRO/ACE CRC estimate (http://www.cmar.csiro.au Isealevel/thermal_expansion_ocean_heat_timeseries .html) and its uncertainties are updated following Domingues et al. (2008), except without a 3-year running filter applied. The PMEL/JPL/JIMAR estimate assumes a representative average (Lyman and Johnson 2014) using data and instrument bias corrections described in the text with uncertainty estimate methodology following Lyman et al. (2010). The NODC estimate (http://www.nodc.noaa.gov/OC5/indprod .html) follows Levitus et al. (20l2). Uncertainties are estimated solely from the variance of quarterly estimates of OHCA. The (UK) Met Office estimate is computed from gridded monthly temperature anomalies (relative to 1950-2013) calculated from EN4.0.2 (Good et al. 2013) data following Palmer et al. (2007). An updated version of the instrument bias corrections of Gouretski and Reseghetti (2010) was applied. Uncertainty estimates follow Palmer and Brohan (20II). For comparison, all estimates have been individually offset (vertically on the plot), first to their individual 2004-13 averages (the best sampled time period), and then to their collective 1993-2013 average (the record length).

The rate of heat gain from linear trends fit to each of the global integral estimates from 1993 through 2013 (Fig. 3.7) are $0.29( \pm 0.12), 0.48( \pm 0.13), 0.34$ $( \pm 0.09)$, and $0.42( \pm 0.25) \mathrm{W} \mathrm{m}^{-2}$ applied over Earth's surface area $\left(5.1 \times 10^{14} \mathrm{~m}^{2}\right)$ for the CSIRO/ACE CRC, PMEL/JPL/JIMAR, NODC, and (UK) Met Office estimates, respectively. These trends are all statistically different from zero and agree within their quoted $5 \%$ to $95 \%$ range of uncertainty. The uncertainty estimates for the trends are based on the residuals, taking their temporal correlation into account when estimating of the degrees of freedom (Von Storch and Zwiers 1999). d. Ocean surface heat and momentum fluxes-L. Yu, X. Jin, P. W. Stackhouse Jr., Y. Xue, and A. Kumar

The net heat flux $\left(\mathrm{Q}_{\text {net }}\right)$ at the ocean surface is the sum of solar radiation (SW), longwave radiation (LW), turbulent latent heat ( $\mathrm{LH})$, and sensible heat (SH) fluxes. The balance of these heat exchange processes is fundamental to the understanding of the role of the ocean in mitigating radiative perturbations and modulating the global climate. Global maps of surface heat fluxes and winds are now being produced from satellite observations and by incorporating outputs of numerical weather prediction models as supplemental datasets. The net heat flux presented here is a combination of surface fluxes produced by two flux projects. One is the Objectively Analyzed air-sea Fluxes (OAFlux) project(http://oaflux.whoi.edu) at the Woods Hole Oceanographic Institution (Yu and Weller 2007; Yu et al. 2008) that provides turbulent $\mathrm{LH}$ and $\mathrm{SH}$ estimates from using an optimal blending of flux-related variables from satellite retrievals and atmospheric reanalyses. The other project is the CERES (Clouds and Earth's Radiant Energy Systems) Fast Longwave And Shortwave Radiative Fluxes (FLASHFlux) project (http://flashflux.larc.nasa.gov) at the NASA Langley Research Center (Stackhouse et al. 2006; Kratz et al. 2014) that delivers global daily surface SW and LW flux products in near real-time (within 1 week). The OAFlux project has recently expanded to the global analysis of daily 10 -m vector wind fields through synthesizing satellite radiometers and scatterometers (Yu and Jin 2012, 2014, manuscript submitted to J. Geophys. Res.). The wind-driven ocean circulation is a major mechanism for redistributing solar heating over the global oceans and contributes to much of the change observed in heat content (see Fig. 3.5), ocean salinity (see Fig. 3.11), sea level (see Fig. 3.28), and ocean surface currents (see Fig. 3.17).

The annually-averaged $\mathrm{Q}_{\text {net }}$ in 2013 is displayed in Fig. 3.8a, showing that the maximum ocean heat gain $\left(>120 \mathrm{~W} \mathrm{~m}^{-2}\right)$ is associated with the equatorial cold tongues, and the maximum ocean heat loss $\left(<140 \mathrm{~W} \mathrm{~m}^{-2}\right)$ with the western boundary currents (WBCs) regimes. Compared to 2012 (Fig. 3.8b), $\mathrm{Q}_{\text {net }}$ in 2013 had an enhanced net heat loss (negative difference anomalies) over the Atlantic basin and an enhanced net heat gain (positive difference anomalies) over the Pacific basin and the subtropical south Indian Ocean. In the North Atlantic Ocean, the net heat loss anomalies exceeded $20 \mathrm{~W} \mathrm{~m}^{-2}$ both north of $30^{\circ} \mathrm{N}$ and in the tropical latitudes. Sandwiched between the two regions of heat loss (negative) anomalies is a narrow latitudinal band of weak positive difference anomalies, forming a tripole pattern 
(a) Qnet $(\mathrm{SW}+\mathrm{LW}+\mathrm{LH}+\mathrm{SH}) \quad$ Mean 2013
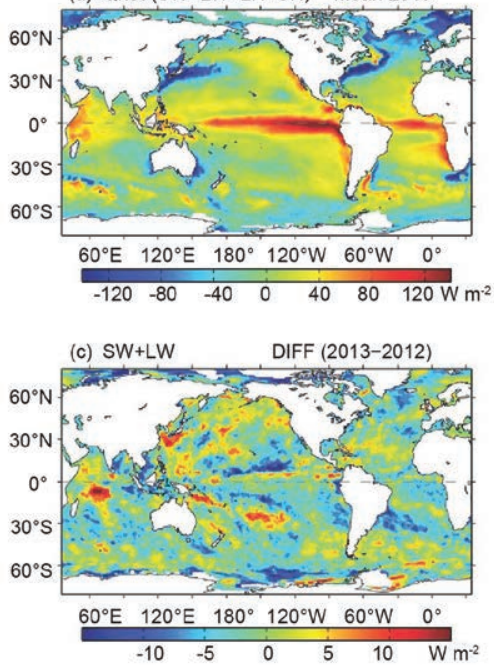
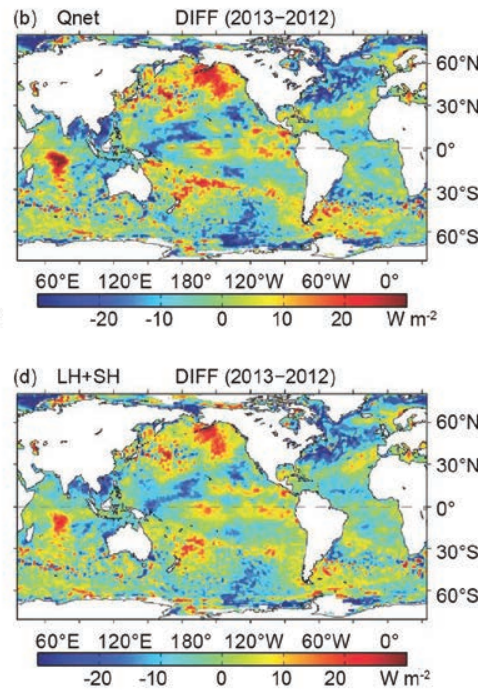

which began in May 2010, continued to be negative in 2013 (see Fig. 3.2). The relationship between the PDO phase and the persistent high-pressure system over the Gulf of Alaska is not currently known.

The net heat flux appears to have also contributed to the change in SST anomalies in the tropical Indian Ocean. Enhanced net heating was observed in the south central Indian Ocean due to both increased downward radiation and decreased latent and sensible heat fluxes in response to the weakened wind speed (Fig. 3.9a). Correspondingly, SST in the area increased by more than $1^{\circ} \mathrm{C}$ in 2013 (see Fig. 3.1). Yet, not all SST anomalies FIG. 3.8. (a) Annual average net heat flux into the ocean $\left(\mathbf{Q}_{\text {net }}\right)$ in were induced by $Q_{\text {net }}$. For instance, the
2013. Positive (negative) values denote ocean heat gain (loss). (b) SST in the eastern tropical Pacific deAnnual average difference in $\mathbf{Q}_{\text {net }}$ between 2013 and 20I2. (c) and (d) creased by more than $1^{\circ} \mathrm{C}$ in 2013 , but the are the 2013-2012 difference anomalies in surface radiation (SW + LW) and turbulent heat fluxes (LH + SH), respectively. In (b)-(d), positive (negative) anomalies denote ocean gains (losses) of heat by more than $20 \mathrm{~W} \mathrm{~m}^{-2}$ in the same pein 2013 compared to 2012. (Source: SW/LW produced by FLASHFlux and LH/SH by OAFlux.)

of $\mathrm{Q}_{\text {net }}$ difference anomalies. The pattern is shown in both surface net radiation SW + LW (Fig. 3.8c) and turbulent $\mathrm{LH}+\mathrm{SH}$ (Fig. 3.8d) difference anomalies, with the magnitude of the latter being about five times larger than that of the former. The occurrence of the difference pattern was in close association with the atmospheric conditions of a predominantly positive NAO phase in 2013 (see Fig. 3.4).

In sharp contrast to the North Atlantic, much of the North Pacific Ocean in 2013 experienced an enhanced oceanic heat gain (positive anomalies), with the central basin and the Gulf of Alaska the center of intensive heating $\left(>20 \mathrm{~W} \mathrm{~m}^{-2}\right)$. SSTs in these two areas increased by more than $1^{\circ} \mathrm{C}$ (see Fig. 3.1). The close association of the surface warming with the abnormally high net heat input is a clear indication that the extra heating received at the ocean surface contributed to the increase of local SST. In 2013, nearsurface atmospheric circulation in the North Pacific was dictated by a persistent high-pressure system centered over the Gulf of Alaska, which promoted large-scale atmospheric subsidence farther to the south and altered the atmospheric flow pattern. As a result, the westerly winds in the North Pacific weakened significantly (Fig. 3.9a). The weakened winds reduced the rate of evaporation, leading to less latent heat loss from the ocean (Fig. 3.8d), which, in turn, caused the ocean warming. The negative PDO phase,
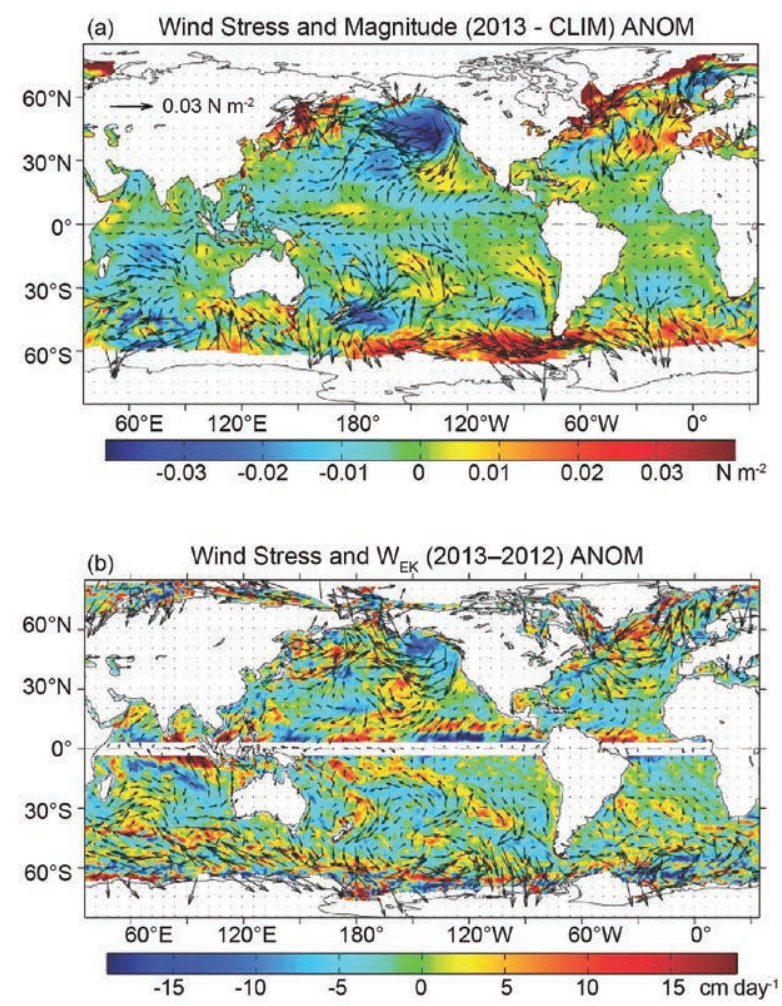

FIG. 3.9. (a) The 2013 wind stress magnitude anomalies (colored background) superimposed with vector anomalies from OAFlux. The 25-year (1988-20I2) average was used to compute the anomalies. (b) The 2013 - 2012 difference anomalies in Ekman vertical velocity ( $w_{E K}$, unit: $\mathbf{c m}$ day-1$^{-1}$; colored background) and wind stress (vectors). Positive (negative) values denote upwelling (downwelling) anomalies. 
riod. In fact, the increase of $\mathrm{Q}_{\text {net }}$ was a response to the cooler SST, as the latter led to less latent heat loss from the ocean (Fig. 3.8d) and hence, more net downward heat flux. In the tropics, it is known that ENSO SSTs are governed more by ocean dynamics through winddriven upwelling of cold water from the thermocline (Wyrtki 1981). This SST-LH-Q ${ }_{\text {net }}$ relationship, which was apparently at work in 2013, implies that Qnet has acted as a damping mechanism to the existing SST anomalies, suppressing the growth of ENSO SSTs. The changing relationships between $\mathrm{Q}_{\text {net }}$ and SST from one basin to another demonstrate that the global climate system is influenced by intricate feedbacks between the ocean and the atmosphere.

The changes of the 2013 wind stress relative to the 1988-2012 average and the 2012 condition are shown in Fig. 3.9a,b, respectively. The anomaly pattern associated with the persistent high-pressure system over the Gulf of Alaska was the most noted pattern in 2013. The near-surface atmospheric circulation was altered, which weakened the westerly winds over the North Pacific significantly. Aside from the North Pacific, weakened winds were observed in the southeast trades over the south Indian Ocean and also on the northern edge of Southern Hemisphere (SH) westerlies over the $30^{\circ}-50^{\circ} \mathrm{S}$ latitudinal band. By contrast, the southern edge of $\mathrm{SH}$ westerlies, strengthened considerably in the Pacific and Atlantic sectors.

The spatial variations of wind stress cause divergences and convergences of the Ekman transport, leading to a vertical velocity, denoted Ekman pumping velocity $w_{E K}$, at the base of the Ekman layer. The convergent flow drives downwelling and the divergent flow drives upwelling from beneath. This pattern of vertical motion brings the interior of the ocean into motion and sets the wind-driven gyre circulation. Computation of $w_{E K}$ follows the equation: $w_{E K}=1 / \rho \Delta \times(\tau / f)$, where $\rho$ is the density and $f$ the Coriolis force. Figure 3.9b shows the $2013-2012$ $w_{E K}$ difference anomalies with superimposition of the difference anomalies of surface wind stress vectors. It is evident that the Ekman pumping in the central North Pacific and the Gulf of Alaska enhanced significantly (negative anomalies) in 2013, in relation to the weakening of the westerly winds associated with the high-pressure system stationed in the region. The changes of $w_{E K}$ in the near-equatorial downwelling regions are also noted, with downwelling enhanced in the eastern Pacific sector (negative anomalies) but weakened in the central equatorial Pacific and Atlantic (positive anomalies). Changes at latitudes poleward of $60^{\circ} \mathrm{S}$ are also noticeable; the predominant negative difference anomalies suggest a weakening of the upwelling in the region.

Yearly variability of $Q_{\text {net }}$ over the global oceans is dominated by $\mathrm{LH}+\mathrm{SH}$. The long-term perspective of the change in the $2013 \mathrm{LH}+\mathrm{SH}$ can be seen from the 1958-2013 annual time series of the globallyaveraged LH + SH (Fig. 3.10a). The 2013 average value was slightly lower compared to 2012, continuing the downward trend that started around 2000. The tendency toward reversing the upward trend that dictated the decades of 1980 s and 1990s holds strong. Since 1958, LH + SH showed a minimum at $99 \mathrm{~W}$ $\mathrm{m}^{-2}$ in 1977 and a maximum at $109 \mathrm{~W} \mathrm{~m}^{-2}$ in 1999, with LH being the major contributor. Yearly variability of the near-surface wind derived from satellite observations since 1988 is displayed in Fig. 3.10b, showing that the upward trend in the 1990s has leveled off since 1999 and the long-term tendency of the globally-averaged winds in the recent decade has remained steady.

The OAFlux winds have an averaged root-meansquare (rms) difference of $0.71 \mathrm{~m} \mathrm{~s}^{-1}$ in wind speed (9\%) and $17^{\circ}$ in wind direction when compared to more than 120 buoys (Yu and Jin 2012). The OAFlux heat flux analysis has an rms difference of $9.6 \mathrm{~W} \mathrm{~m}^{-2}$ (8\%) for $\mathrm{LH}$ and $2.6 \mathrm{~W} \mathrm{~m}^{-2}$ (15\%) for SH (Yu et al. 2008). The FLASHFlux has an rms error of $29.3 \mathrm{~W}$

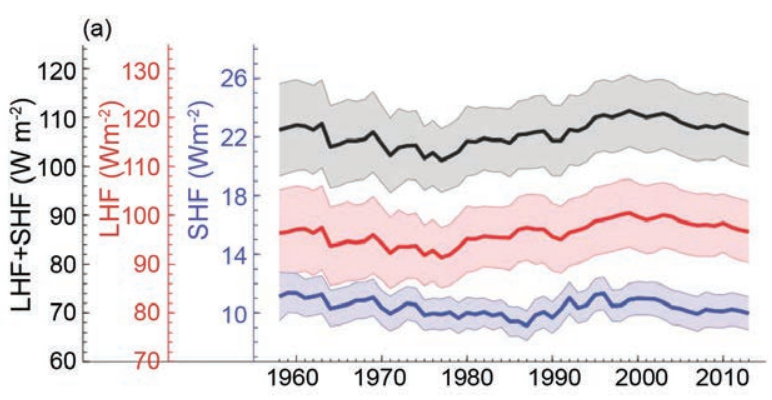

(b)

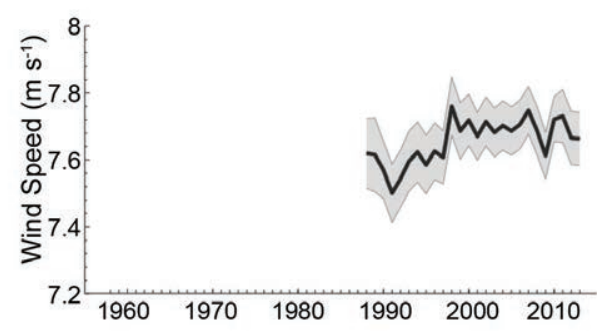

FIG. 3.I0. (a) Year-to-year variations of global-averaged annual mean latent plus sensible heat flux (LHF + SHF; W m-2, black curve), latent heat flux (LHF; W m-2, red curve), and sensible heat flux (SHF; $\mathrm{W} \mathrm{m}^{-2}$, blue curve) from OAFlux. (b) Year-to-year variations of globalaveraged annual mean wind speed $\left(\mathrm{m} \mathrm{s}^{-1}\right)$ from OAFlux. The shaded areas indicate the error bars of the fluxes and wind speed estimates at the $95 \%$ confidence level. 
$\mathrm{m}^{-2}$ (15.7\%) for downward SW and $18.6 \mathrm{~W} \mathrm{~m}^{-2}(6.0 \%)$ for downward LW (Kratz et al. 2010). The FLASHFlux algorithm has been upgraded to version 3a from 2012 onward, with improvements most evident in the SW component. The fidelity of the OAFlux and FLASHFlux in 2013 was analyzed using the surface fluxes from the NCEP/Climate Forecast System Reanalysis (CFSR; Saha et al. 2010). There was an overall good agreement in $\mathrm{LH}$ and $\mathrm{SH}$ anomaly pattern, and also in $\mathrm{Q}_{\text {net }}$ because of the dominance of $\mathrm{LH}+\mathrm{SH}$ over $\mathrm{SW}+\mathrm{LW}$ in the $\mathrm{Q}_{\text {net }}$ anomalies. There were differences in the SW + LW anomalies between satellite and model products, albeit the broad-scale patterns were similar.

e. Sea surface salinity-G. C. Johnson, J. M. Lyman, G. S. E. Lagerloef, and H.Y. Kao

Ocean storage and transport of freshwater are intrinsic to aspects of global climate, including the water cycle (e.g., Schanze et al. 2010), El Niño (e.g., Roemmich and Gilson 2011), and anthropogenic climate change (e.g., Held and Soden 2006). Since 2004, the achievement of near-global coverage by Argo (Roemmich et al. 2009) has allowed an annual assessment of upper ocean salinity and its complement, freshwater, usually measured within a few meters of the ocean surface. Although somewhat less accurate, the Aquarius satellite (http://aquarius.nasa.gov/index.html) has measured sea surface salinity (SSS) for the top $\mathrm{cm}$ of the global ocean with greater temporal and spatial resolution since August 2011. These two complementary data sources are used to examine annual and seasonal SSS variability, respectively.

The in situ data, downloaded from an Argo Global Data Assembly Center in January 2014, are a mix of real-time (preliminary) and delayed-mode (scientific quality-controlled). The estimates presented here could change after all data have been subjected to careful scientific quality control. Analysis procedures for Argo follow Johnson and Lyman (2012). For Aquarius, SSS release V2.8.1 swath data interpolated to $1^{\circ} \times 1^{\circ}$ monthly maps with a bilinear fit and $150-\mathrm{km}$ radius are used.

Climatological SSS patterns are correlated with surface freshwater flux-the sum of evaporation, precipitation, and river runoff (e.g., Schanze et al. 2010) - but advection and mixing are also important in many locations on seasonal (Yu 2011) and longer (Lagerloef et al. 2010) time scales. In each ocean basin, subtropical salinity maxima centered between roughly $20^{\circ}$ and $25^{\circ}$ in latitude (Fig. 3.11, gray contours) are signatures of the predominance of evaporation over precipitation. Conversely, in most regions where climatological surface salinities are relatively fresh, such as the high latitudes and the intertropical convergence zones (ITCZs), precipitation generally dominates over evaporation.

The 2013 SSS anomalies (Fig. 3.11a, colors) reveal some large-scale patterns that also hold from 2004 to 2013. The regions around the subtropical salinity maxima are generally salty with respect to World Ocean Atlas (WOA) 2009 (Antonovetal. 2010), except in the center of the South Pacific and in the eastern south Indian Ocean, where strong interannual variations, discussed below, disrupt that pattern. Most of the high-latitude climatologically fresh regions appear fresher overall than WOA 2009, including in the vicinity of much of the Antarctic Circumpolar Current near $50^{\circ} \mathrm{S}$ and in portions of the subpolar gyres of the North Pacific and Atlantic. These multiyear patterns are consistent with an increase in the hydrological cycle over the
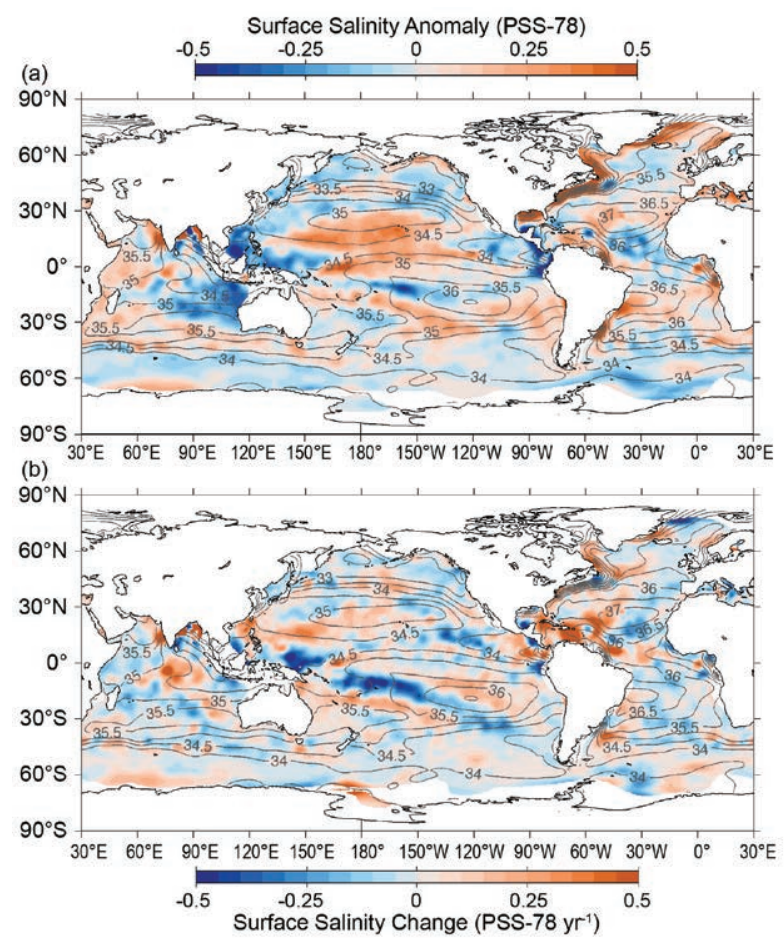

Fig. 3.II. (a) Map of the 2013 annual surface salinity anomaly estimated from Argo data (colors in PSS-78) with respect to monthly climatological salinity fields from WOA 2009 yearly average (gray contours at 0.5 PSS-78 intervals). (b) The difference of 2013 and 2012 surface salinity maps estimated from Argo data [colors in PSS-78 $\mathrm{yr}^{-1}$ to allow direct comparison with (a)]. White ocean areas are too data-poor to map. While salinity is often reported in practical salinity units, or PSU, it is actually a dimensionless quantity reported on the 1978 Practical Salinity Scale (PSS-78; Fofonoff and Lewis 1979). 
oceans (more evaporation in drier locations and more precipitation in rainy areas) as seen in simulations of global warming, which suggest this signal might be discernible since the 1980s (Held and Soden 2006). While anomalous ocean advection could influence the SSS pattern over decadal time scales, changes observed at the local extrema are presumably relatively insensitive to such effects. This SSS anomaly pattern and its interpretation are consistent with other analyses (Boyer et al. 2005; Hosoda et al. 2009; Durack and Wijffels 2010). Changes in ocean interior salinity values also appear consistent with an increase in the hydrological cycle (Helm et al. 2010).

The large relatively fresh patch in 2013 west of Australia and the Indonesian Throughflow (Fig. 3.11a, colors) was also more prominent in 2012 (Johnson et al. 2013b). The strong 2010-12 La Niña, coupled with a negative Indian Ocean dipole and a strong positive southern annular mode, deposited a huge amount of rain on and around Australia in 2010 and 2011 (Fassulo et al. 2013), likely freshening surface waters. La Niña is also associated with an anomalously strong Indonesian Throughflow (England and Huang 2005), which transports relatively fresh waters westward into the Indian Ocean. Most of the rest of the Indian Ocean was saltier than the climatology in 2013.

Sea surface salinity changes from 2012 to 2013 (Fig. 3.11b, colors) strongly reflect 2013 anomalies in precipitation (see Plate. 2.1h) and to a lesser extent year-to-year changes in evaporation, with the latter being closely related to latent plus sensible heat flux changes (see Fig. 3.8d). Advection by anomalous ocean currents (see Fig. 3.17) also plays a role in sea surface salinity changes.

The most prominent large-scale freshening patterns from 2012 to 2013 were in the western tropical Pacific warm pool and along a band in the South Pacific-strongest east of the Solomon Islands, but extending, albeit weakly, to just west of the southern end of South America (Fig. 3.11b, colors). These features are associated with anomalously strong precipitation in 2013 (see Plate 2.1h). The South Pacific feature is also associated with upper ocean cooling (see Fig. $3.5 b$ ), and more eastward surface velocity (see Fig. 3.17b) from 2012 to 2013, suggesting influence of a slow down or southward shift of the South Equatorial Current. There was also some freshening under the ITCZ in the eastern tropical North Pacific that is associated with anomalously strong precipitation in 2013 (see Plate 2.1h). In the Indian Ocean, surface salinity increased from 2012 to 2013 in the central equatorial Indian Ocean, possibly owing at least in part to advection by more eastward surface currents (see Fig. 3.17b) and in the Northern Bay of Bengal and Arabian Seas, largely decreasing elsewhere. In addition, while the western Atlantic generally got saltier from 2012 to 2013, the eastern Atlantic generally freshened.

Trends for 2004-13 are estimated by local linear fits to annual average SSS maps (Fig. 3.12a), and are discussed with the ratio of these trends to their 95\% significance (Fig. 3.12b). The starting year is 2004 because that is when Argo coverage became near global. Striking trend patterns are found in all three oceans. Saltier surface values in the western and central tropical Pacific extend into the eastern Pacific subtropics in both hemispheres. Large-scale freshening is evident in the eastern tropical South Pacific. Some freshening also occurs in the western subtropics of each hemisphere in the Pacific, west of the Philippine Islands, and in the Indian Ocean northwest of Australia (the latter again perhaps owing to the influence of La Niña over the past few years). The western south Indian Ocean exhibits a trend towards saltier surface salinity values. Much of the Atlantic north of $30^{\circ} \mathrm{N}$ is

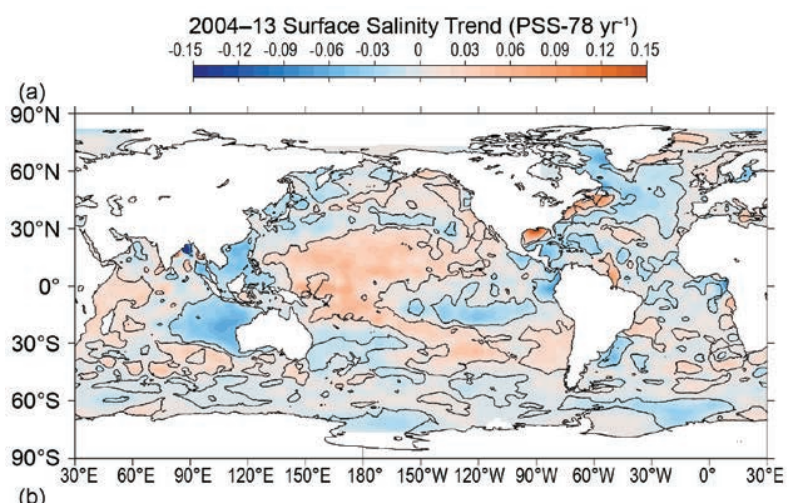
(b)

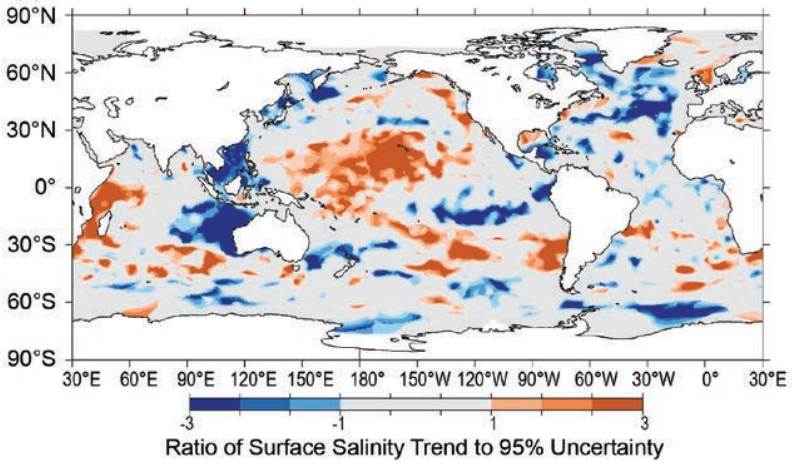

FIG. 3.I2. (a) Map of local linear trends estimated from annual surface salinity anomalies for 2004-13 from Argo data (colors in PSS-78 $\mathrm{yr}^{-1}$ ). (b) Signed ratio of the linear trend to its $95 \%$ uncertainty estimate, with increasing color intensity showing regions with increasingly statistically significant trends. White ocean areas are too data-poor to map. 
freshening. These trends over the past decade differ somewhat from previously reported multidecadal trends (Boyer et al. 2005; Hosoda et al. 2009; Durack and Wijffels 2010). These differences are not surprising given the different time periods over which the trends are computed.

The patterns of SSS differences of 2013 from 2012 derived from Aquarius data (Fig. 3.13b, colors) are reassuringly similar to those made from the Argo maps (Fig 3.11b, colors); however, in some locations the changes are visibly different in amplitude. The Argo differences also tend to have a bit more variance (on the scale of the Argo mapping and sampling scales) than do the Aquarius differences.

Maps from Aquarius data can be useful for examining the SSS seasonal cycle in detail (Fig. 3.13a); their agreement with Argo climatologies (e.g., Schmidtko et al. 2013) has improved between version 2.0 (e.g., Johnson et al. 2013b) and version 2.8.1 (Fig. 3.13a). Notably, version 2.8.1 exhibits high-latitude freshening from spring to fall that was not evident in version 2.0 , and is now in better agreement with the sea-

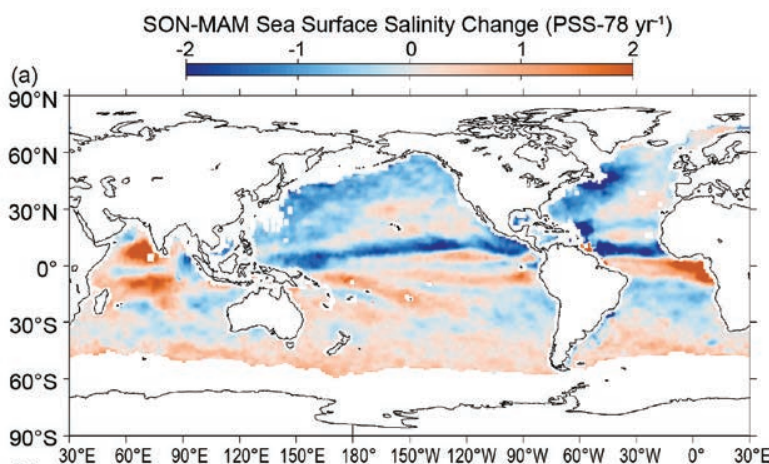

(b)

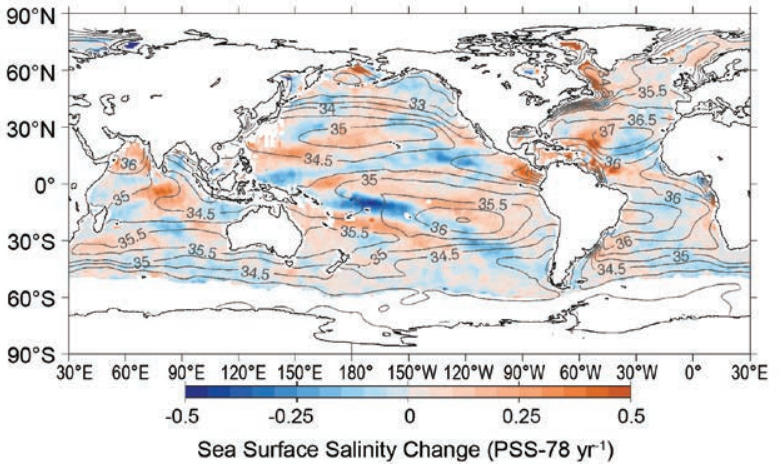

FIG. 3.13. Aquarius V2.8.I SSS differences between (a) Sep-Nov and Mar-May 2013 monthly maps (colors in PSS-78), and (b) SSS differences of 2013 and 2012 from the means of differences of monthly maps (colors in PSS-78) with WOA 2009 values (yearly average of monthly maps, gray contours at 0.5 PSS-78 intervals) overlaid. White ocean areas have excessive land or ice contamination in the Aquarius field of view. sonal cycle from Argo. Substantial freshening from March-May (MAM) to September-November (SON) is clear in the western Pacific fresh pool and under the ITCZ across the Pacific and Atlantic as tropical precipitation maxima shift with the seasons. Seasonal salinification just south of the equator in the Pacific is likely owing to mean Ekman advection acting on a seasonally varying salinity gradient (Yu 2011). There is strong salinification in the central tropical Indian Ocean between MAM and SON. Broadscale patterns of salinification between winter and summer in the eastern subtropics (Fig. 3.13a) in both hemispheres are typical of the seasonal cycle and most likely owing to entrainment of fresher water from below in the winter (Johnson et al. 2012b).

\section{f. Subsurface salinity-T. Boyer, J. Antonov, J. Reagan, C. Schmid, and R. Locarnini}

Evaporation minus precipitation $(E-P)$ is well correlated with mixed layer salinity over much of the world's ocean (Yu 2011). It is difficult to accurately measure evaporation and precipitation over the ocean, so near-surface salinity can be used to constrain E-P estimates (Schmitt 2008; Yu 2011). $E-P$ surface forcing has led to an intensification of the global hydrological cycle over the last 50 years, increasing salinity at the sea surface in areas dominated by evaporation and decreasing salinity in areas dominated by precipitation (Durack and Wijffels 2010; Durack et al. 2012). These surface changes are entrained into the subsurface ocean. Globally, nearsurface salt content has increased in recent times compared to long-term averages, while intermediate waters have decreased in salinity (Roemmich and Gilson 2009; Helm et al. 2010). These changes are reflected in changes to ocean water mass composition and circulation patterns. Subsurface salinity changes, along with sea surface salinity (SSS) changes and ocean surface fluxes are important for understanding changes to the ocean and in the atmosphere, both of which affect the global climate system.

To investigate changes to subsurface salinity, all available subsurface salinity profile data for 2013 were used to derive $1^{\circ}$ average gridded salinity anomalies at standard depths from the surface to $2000 \mathrm{~m}$. The anomalies were calculated as differences from the 1955-2006 average (Antonov et al. 2010). Differences from recalculated salinity anomaly fields for 2012 are also used to investigate year-to-year variations in salinity. A full description of the method can be found in Boyer et al. (2012). 
At present, the single largest source of salinity profiles for the world's ocean is the Argo program with its fleet of profiling floats (Roemmich et al. 2009). From this program, 144463 salinity profiles were used in the process of calculating subsurface salinity anomalies for 2013. About two-thirds of all float profiles reach 2000 decibars. Because it takes a minimum of six months of data to calculate a final adjustment for salinity drift, less than $10 \%$ of the profiles are of the higher level quality-controlled delayed-mode data. For this reason, real-time salinity data with basic quality control were also utilized in this study. Of these, 80952 profiles include salinity drift adjustments calculated for earlier cycles in a floats lifetime.

In addition to the Argo data, another major source of salinity data is 27743 daily average profiles from tropical moored buoys (http://www.pmel.noaa.gov /tao/). Included are data from the TAO/TRITON array in the Pacific, PIRATA in the Atlantic, and RAMA in the Indian Ocean, where the deepest measurement was usually at 500-m depth. Almost all buoys are located within $10^{\circ}$ latitude of the equator. There also were 14143 CTD casts largely concentrated in the northwest Pacific and northwest Atlantic and 20320 profiles from gliders (localized mostly in the Gulf of Mexico, far western Pacific, and northeast Atlantic), most of which were made available through the Global Temperature and Salinity Profile Project (GTSPP). In order to examine the year-to-year change in salinity, anomaly fields for 2012 were recalculated based on updated quality control provided by Argo. A total of 48558 of the 133518 Argo salinity profiles recorded in 2012 that were used in this study have now been delayed-mode quality controlled. All salinity and salinity anomaly data were examined using quality control procedures outlined in Boyer et al. (2013a) and are available through the World Ocean Database (Boyer et al. 2013a). All derived fields can be found at http://www.nodc.noaa.gov/OC5/3M HEAT_CONTENT/. Average salinity anomalies for the upper $100 \mathrm{~m}$ at each $1^{\circ}$ grid were also computed. The geographic distribution of these fields is similar to SSS fields as presented in section 3e.

The zonally-averaged difference between salinities in the Pacific Ocean in 2013 and the long-term average are shown in Fig. 3.14a. The zonally averaged differences $> \pm 0.1$ (blue and red shaded areas) in Fig. $3.14 \mathrm{a}$, and subsequent figures, are significant at the $5 \%$ confidence level based on Student T tests. Much of the South Pacific was fresher than average in 2013, with the exception of the upper $250 \mathrm{~m}$ in the subtrop-

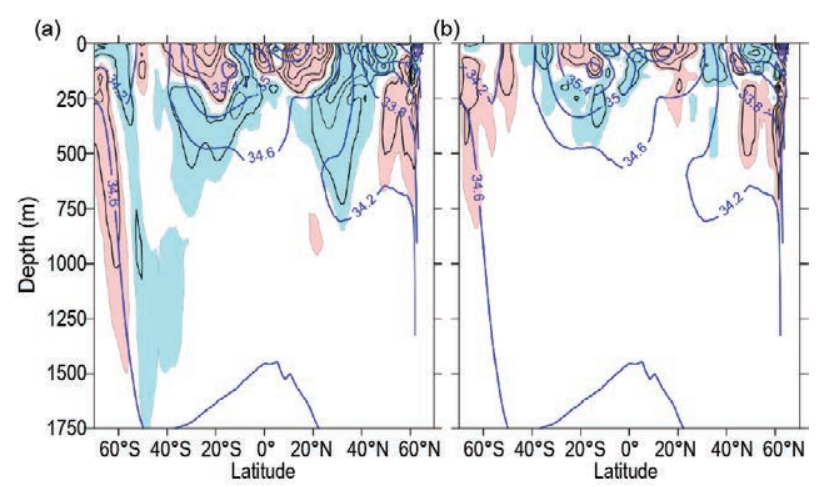

FIG. 3.14. Zonally-averaged (a) 2013 salinity anomaly and (b) 2013 minus 2012 salinity field for the Pacific Ocean. For both figures, blue shading represents negative (fresh) anomalies <-0.0I, red shading represents positive (salty) anomalies $>0.01$. The contour interval for the anomalies is $\mathbf{0 . 0 2}$. In the background of each figure (thick blue contours) is the zonally averaged climatological mean salinity (WOA09). Contour intervals for the background are 0.4. All values are PSS-78 .

ics and along the equator. Below the higher salinity area in the subtropics, freshening was stronger in 2013 than in 2012 . Between $50^{\circ} \mathrm{S}$ and $40^{\circ} \mathrm{S}$ a freshening relative to average was observed even at depths exceeding $1500 \mathrm{~m}$. Meijers et al. (2011) attribute the freshening in this region to southward movement of the Antarctic Circumpolar Current and water mass changes possibly due to increased precipitation and ice melt. Farther south along the 34.6 isohaline, higher salinity relative to the long-term mean was found. The 2013 salinity anomalies in the South Pacific are comparable to the 2012 salinity anomalies (Boyer et al. 2013b), but with increased salinities reaching deeper in many areas. For example, the area of high salinity south of $50^{\circ} \mathrm{S}$ in 2013 (Fig. 3.14b) extends to depths greater than $750 \mathrm{~m}$ along the 34.6 isohaline near $60^{\circ} \mathrm{S}$. Salinity in the upper $100 \mathrm{~m}$ (see Fig. 3.11a) shows a large positive salinity anomaly relative to the average under the South Pacific convergence zone (SPCZ), sloping from near the equator in the far western Pacific to around $30^{\circ} \mathrm{S}$ in the eastern Pacific, similar to 2011 (Johnson et al. 2013b), whereas this feature was weaker in 2012 (see Fig. 3.11b). In the North Pacific, as for 2012, 2013 differed from average with saltier conditions in the upper $250 \mathrm{~m}$ near the equator. Freshening at midlatitudes down to $750-\mathrm{m}$ depth, is consistent with the thermocline freshening described by Ren and Riser (2010). Salinity increase exceeding 0.02 occurred in 2013 relative to 2012 below $250 \mathrm{~m}$ north of $40^{\circ} \mathrm{N}$ in the Pacific, including the Bering Sea area. In fact, 2013 salinity in the Bering Sea was similar to 2011 with higher salinity relative 
to the long-term trend, while a freshening was seen in this area in 2012.

Between the mid-1950s and the mid-1990s an increase in salinity in the subtropical and tropical North Atlantic was coupled with a decrease in salinity in the subpolar North Atlantic (Curry et al. 2003; Boyer et al. 2007; Wang et al. 2010). Since the mid-1990s, both the subtropical and subpolar North Atlantic exhibit increased salinity (Boyer et al. 2007; Wang et al. 2010). This pattern persisted into 2013 (Fig. 3.15a), with the exception of a freshening around $50^{\circ} \mathrm{N}$. Most of the North Atlantic increased in salinity in 2013 compared to 2012 in the upper 100 $\mathrm{m}$, with substantial freshening $(>0.02)$ in $100-500-\mathrm{m}$ depth primarily north of about $30^{\circ} \mathrm{N}$, in contrast to 2012 where there was freshening over 2011 from the surface to $750-\mathrm{m}$ depth (Fig. 3.15b). Freshening $>0.02$ extends deeper than $500-\mathrm{m}$ depth around $30^{\circ} \mathrm{N}$. This area of freshening expands at shallower depths, with its maximum extent at 150-m depth between $15^{\circ}$ and $40^{\circ} \mathrm{N}$. At shallower depths, the tropical and subtropical regions of the North Atlantic experienced a large increase in salinity $(>0.06)$. It may be that the freshening signal in the North Atlantic in 2012 was a short-lived anomaly in the decadal signal of increased salinity in the subpolar and subtropical North Atlantic. In contrast to the North Atlantic, the South Atlantic salinity signal in 2013 indicates that the long-term trend was strengthened when compared with the anomalies for 2012. Positive salinity anomalies exceeding 0.06 were found for 2013 down to $250-\mathrm{m}$ depth from $5^{\circ}-25^{\circ} \mathrm{S}$, with anomalies exceeding 0.02 below $500 \mathrm{~m}$ south of $20^{\circ} \mathrm{S}$. South of $40^{\circ} \mathrm{S}$ in the Atlantic Ocean, a deep freshening is observed, to depths below $750 \mathrm{~m}$, shoaling to the south, where the freshening is limited to the upper $100-\mathrm{m}$ depth. Between 2012 and 2013, the positive salinity anomalies weakened in the upper $150 \mathrm{~m}$ between the

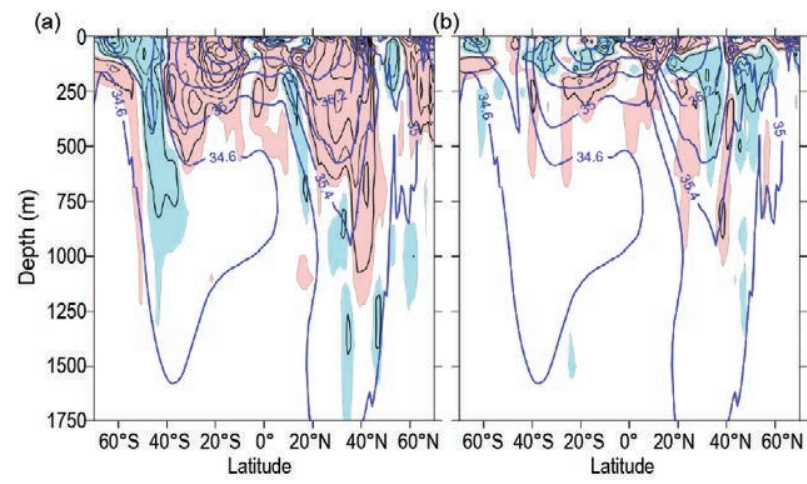

FIG. 3.15. Zonally-averaged (a) 2013 salinity anomaly and (b) 2013 minus 2012 salinity field for the Atlantic Ocean. equator and $40^{\circ} \mathrm{S}$, whereas they strengthened below $150-\mathrm{m}$ depth (Fig. 3.15b). South of $40^{\circ} \mathrm{S}$, the trends between 2012 and 2013 were strengthened.

In the Indian Ocean, the differences between 2013 salinity zonal means and the long-term average (Fig. 3.16a) include deep (>1000-m depth) freshening south of the equator, interrupted by increased salinity in the midlatitude south Indian Ocean from the surface narrowing to a maximum depth of $800 \mathrm{~m}$ at $40^{\circ} \mathrm{S}$. In the upper $100 \mathrm{~m}$ (see Fig. 3.11a), the salty anomaly at latitudes north of $30^{\circ} \mathrm{S}$ is confined to the western half of the Indian Ocean, with freshening in the eastern Indian Ocean. South of $30^{\circ} \mathrm{S}$, the positive anomaly extends across the entire basin in a narrow band north of $50^{\circ} \mathrm{S}$. The salinity change from 2012 to 2013 in the south Indian Ocean was small $(<0.02$; Fig. 3.16b), except south of $60^{\circ} \mathrm{S}$, where there were limited observations, and just south of the equator in the upper $100 \mathrm{~m}$. Most of the North Indian Ocean zonally-averaged anomalies for 2013 continue to be salty down to depths exceeding $700 \mathrm{~m}$. From 2012 to 2013, changes in the north Indian Ocean larger than 0.02 were mainly confined to the upper 150 -m depth and are of the opposite sign when compared with the changes from 2011 to 2012. The fresh anomaly in the upper 100-m depth (see Fig. 3.11b) is less than 0.02 in the central equatorial Indian Ocean, which is smaller than the salty anomaly in the western equatorial Indian. This is the opposite pattern as found between 2011 and 2012. There was a positive Indian Ocean dipole (IOD, east-west temperature gradient $>0.5^{\circ} \mathrm{C}$ ) in both 2011 and 2012, but a negative IOD in 2013 . It is unclear if there is any relation between the IOD and the upper $100-\mathrm{m}$ average salinity anomaly. In the northern reaches of the Indian Ocean, following the same pattern seen between 2011 and 2012, the eastern Arabian Sea was saltier in 2013 than 2012, while the western Arabian Sea was fresher. Opposite to the

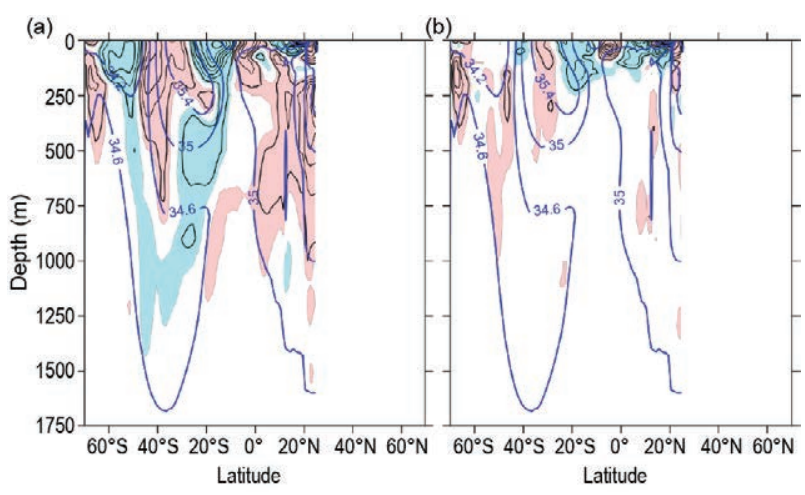

FIG. 3.16. Zonally-averaged (a) 2013 salinity anomaly and (b) 2013 minus 2012 salinity field for the Indian Ocean. 
pattern between 2011 and 2012, the northeast Bay of Bengal was saltier in 2013 than 2012, while the rest of the Bay of Bengal was fresher in 2013 than in 2012.

\section{g. Surface currents-R. Lumpkin, G. Goni, and K. Dohan}

This section describes ocean surface current changes, transports derived from ocean surface currents, and features such as rings inferred from surface currents. Surface currents are obtained from in situ (global array of drogued drifters and moorings) and satellite (altimetry, wind stress, and SST) observations. Transports are derived from a combination of sea height anomaly (from altimetry) and climatological hydrography. See previous State of the Climate reports, from 2011 and before, for details of these calculations. Anomalies are calculated with respect to the time period 1992-2007. Global zonal current anomalies and changes in anomalies from 2012 are shown in Fig. 3.17 and discussed below for individual ocean basins.

\section{I) Pacific Ocean}

Compared to the dramatic changes in 2012, 2013 was a relatively quiescent year in the tropical Pacific basin. It began with average January westward surface current anomalies of -25 to $-30 \mathrm{~cm} \mathrm{~s}^{-1}$ (negative $=$ westward) across the equatorial Pacific in the band $170^{\circ} \mathrm{E}-90^{\circ} \mathrm{W}$, where the climatological westward speed is $\sim 65 \mathrm{~cm} \mathrm{~s}^{-1}$. By February, these equatorial anomalies had diminished dramatically and were present only in the longitude band $90^{\circ}-150^{\circ} \mathrm{W}$. Throughout the remainder of 2013 , no large-scale equatorial anomalies persisted for more than a month.

The eastward North Equatorial Countercurrent (NECC) at $5^{\circ}-8^{\circ} \mathrm{N}$ was $\sim 10-20 \mathrm{~cm} \mathrm{~s}^{-1}$ faster than its climatological average from January until August. The longitude of anomalously fast NECC currents shifted westward through these months, located at $90^{\circ}-140^{\circ} \mathrm{W}$ in January, $130^{\circ}-160^{\circ} \mathrm{W}$ in June, and $130^{\circ} \mathrm{W}-180^{\circ}$ in August. These anomalies weakened in September-October, and in November the NECC was close to its climatological strength across the basin.

In March, strong eastward anomalies of 20$30 \mathrm{~cm} \mathrm{~s}^{-1}$ developed at $2^{\circ} \mathrm{S}$ along $100^{\circ}-150^{\circ} \mathrm{W}$, where the climatological currents are near zero. The location of the anomalies propagated westward and diminished in magnitude through May, located at $150^{\circ} \mathrm{W}-180^{\circ}$ in May when they were last seen.

The annual-average zonal current anomaly for 2013 in the Pacific (Fig. 3.17a) highlights the NECC anomalies at $5^{\circ}-8^{\circ} \mathrm{N}$ that persisted through most of the year west of the dateline (see above). In the band $145^{\circ}-170^{\circ} \mathrm{E}$, anomalies of $15 \mathrm{~cm} \mathrm{~s}^{-1}$ at $20^{\circ} \mathrm{N}$ indicated a strengthening of the eastward Subtropical Countercurrent, while anomalies of $-15 \mathrm{~cm} \mathrm{~s}^{-1}$ at $22^{\circ} \mathrm{N}$ corresponded to a strengthening of the westward flow located at this latitude. Alternating zonal bands of $\sim 20 \mathrm{~cm} \mathrm{~s}^{-1}$ anomalies at $33^{\circ}-36^{\circ} \mathrm{N}, 140^{\circ}-160^{\circ} \mathrm{E}$ were consistent with a northward shift of the Kuroshio Extension from its annual climatological position, a shift seen since 2010. For the period 2010-13, the Kuroshio has exhibited a narrower and stronger annual mean signature, shifted approximately $1^{\circ}$ in latitude to the north compared to 2006-09. While the climatological latitude of the Kuroshio core at $150^{\circ} \mathrm{E}$ is $\sim 34.3^{\circ} \mathrm{N}$, the core of the current in 2013 was at $\sim 36.0^{\circ} \mathrm{N}$, slightly south of the mean position during $2012\left(36.7^{\circ} \mathrm{N}\right)$. The 2013 minus 2012 map (Fig. 3.17b) is dominated by the strong eastward anomalies that were present in February-August 2012 (Lumpkin et al. 2013).

Surface current anomalies in the equatorial $\mathrm{Pa}-$ cific typically lead SST anomalies by several months, with a magnitude that scales with the SST anomaly magnitude. Recovery to normal current conditions is also typically seen before SST returns to normal. Thus, current anomalies in this region are a valuable predictor of the evolution of SST anomalies and their related climate impacts. This leading nature can

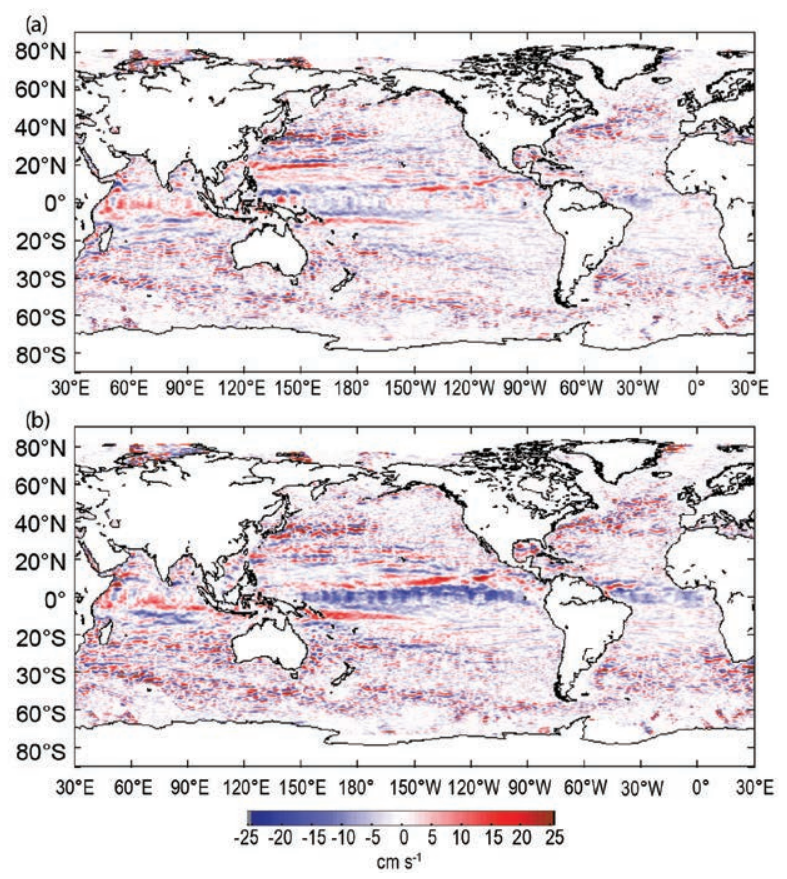

FIG. 3.17. Global zonal geostrophic anomalies for (a) 2013 and (b) 2013 minus 2012, in $\mathrm{cm} \mathrm{s}^{-1}$, derived from a synthesis of drifters, altimetry, and winds. 
(a)

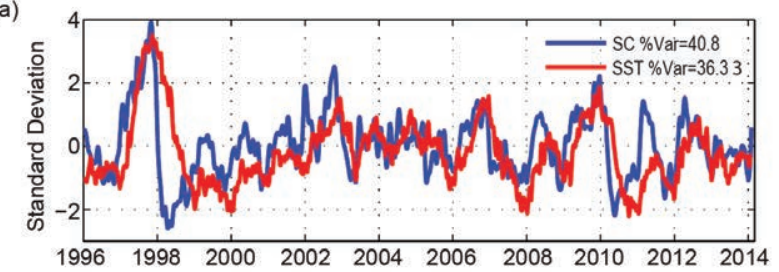

(b)

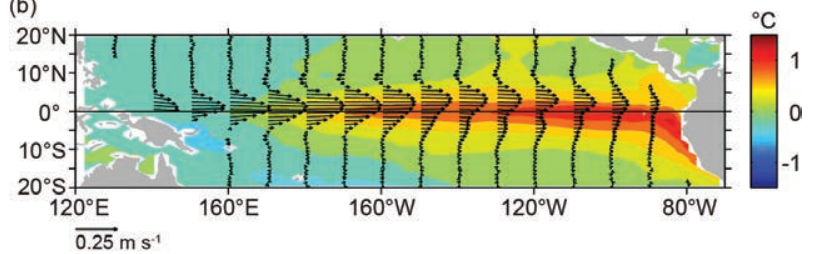

FIG. 3.18. Principal EOF of surface current (SC) and of SST anomaly variations in the tropical Pacific from the OSCAR model (Bonjean and Lagerloef 2002). (a) Amplitude time series of the EOFs normalized by their respective standard deviations for 1996 through 31 Jan 20I4. (b) Spatial structures of the SC (vectors, $\mathrm{m} \mathrm{s}^{-1}$ ) and SST (color, ${ }^{\circ} \mathrm{C}$ ) EOFs.

be seen in the first principal empirical orthogonal function (EOF) of surface current (SC) anomaly and separately of SST anomaly in the tropical Pacific basin (Fig. 3.18). In the period 1993-2013, the maximum correlation between SC and SST is $R=0.70$ with SC leading SST by 76 days. Throughout 2013, this mode exhibited weak fluctuations around a slightly negative value for both SC and SST.

\section{2) INDIAN OCEAN}

In the western equatorial Indian Ocean, the year began with $\sim 20 \mathrm{~cm} \mathrm{~s}^{-1}$ eastward anomalies over the region $2^{\circ} \mathrm{S}-2^{\circ} \mathrm{N}, 40^{\circ}-70^{\circ} \mathrm{E}$. These anomalies were erased in February-March by the westward equatorial currents that develop during the northeast monsoon season (c.f., Beal et al. 2013). Eastward anomalies were also present in this region in August-November, although they were weaker and not as spatially coherent as in January. Outside this region, at scales larger than mesoscale, surface currents in the Indian Ocean were close to their climatological monthly values until May (i.e., after the northeast monsoon) when eastward anomalies of $15-30 \mathrm{~cm} \mathrm{~s}^{-1}$ developed at $60^{\circ}-90^{\circ} \mathrm{E}, 2^{\circ} \mathrm{S}-$ $1^{\circ} \mathrm{N}$. The climatological May current in this band is $60 \mathrm{~cm} \mathrm{~s}^{-1}$ at $1^{\circ} \mathrm{S}$. These anomalies weakened through June-July but remained present, and reintensified in August to $15-20 \mathrm{~cm} \mathrm{~s}^{-1}$, extending as far south as $8^{\circ} \mathrm{S}$ in the same longitude band. In October, strong $\left(-20\right.$ to $\left.-30 \mathrm{~cm} \mathrm{~s}^{-1}\right)$ westward anomalies appeared at $0^{\circ}-3^{\circ} \mathrm{N}, 60^{\circ}-90^{\circ} \mathrm{E}$, erasing the pattern of eastward anomalies north of $\sim 4^{\circ} \mathrm{S}$ (although eastward anomalies persisted at $4^{\circ}-6^{\circ} \mathrm{S}$ ). These westward anomalies persisted through November. By December, currents

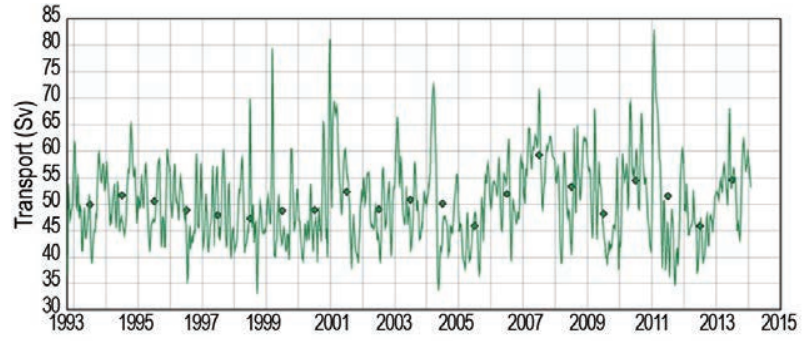

FIG. 3.19. Altimetry-derived transport of the Agulhas Current (Sv) from a combination of sea height anomaly and climatological hydrography. (Source: http://www.aoml.noaa.gov/phod/altimetry /cvar/agu/index.php.)

in the central Indian Ocean basin had returned to their climatological strengths.

The Agulhas Current transport is a key indicator of Indian-Atlantic ocean interbasin water exchanges (Goni et al. 1997). As noted in last year's report, the altimetry-derived annual mean transport of the Agulhas Current (Fig. 3.19) decreased abruptly in mid-2011 compared to its long-term (1993-2013) mean; this reduced transport persisted through 2012 but increased above the long-term average in 2013. In 2012, the annual mean Agulhas transport was $~ 46$ Sv, which (along with 2005) was the lowest annual mean observed since the beginning of the altimetric record in 1993. This increased to an annual average of $54 \mathrm{~Sv}$ in 2013, a maximum surpassed only by one year (2007) in the record. Preliminary results indicate that five rings were shed during 2013, which is the average annual value.

\section{3) AtLantic Ocean}

In January 2013, currents in the central equatorial Atlantic $\left(6^{\circ} \mathrm{S}-4^{\circ} \mathrm{N}, 5^{\circ}-30^{\circ} \mathrm{W}\right)$ exhibited $10-20 \mathrm{~cm} \mathrm{~s}^{-1}$ eastward anomalies, reversing their direction from the climatological westward flow at $\sim 5 \mathrm{~cm} \mathrm{~s}^{-1}$. By February these anomalies were present in strength only at the latitude of the NECC, $5^{\circ}-6^{\circ} \mathrm{N}$, while they reduced to $<10 \mathrm{~cm} \mathrm{~s}^{-1}$ elsewhere. Eastward anomalies persisted in the NECC until May. In August, westward equatorial anomalies developed across the basin, reaching $-20 \mathrm{~cm} \mathrm{~s}^{-1}$ at $2^{\circ} \mathrm{S}$ in the longitude band $5^{\circ}-35^{\circ} \mathrm{W}$. These anomalies persisted in strength through September and weakened in October-November to $\sim 10$ $\mathrm{cm} \mathrm{s}^{-1}$, disappearing entirely by December.

During 2013, the velocity fields suggest that the annually-averaged Gulf Stream remained close to its climatological position. This is in contrast to 2012, when large-scale surface current anomalies indicated a northward shift of the Gulf Stream of $1^{\circ}-1.5^{\circ}$ latitude. The North Brazil Current (NBC), which sheds 


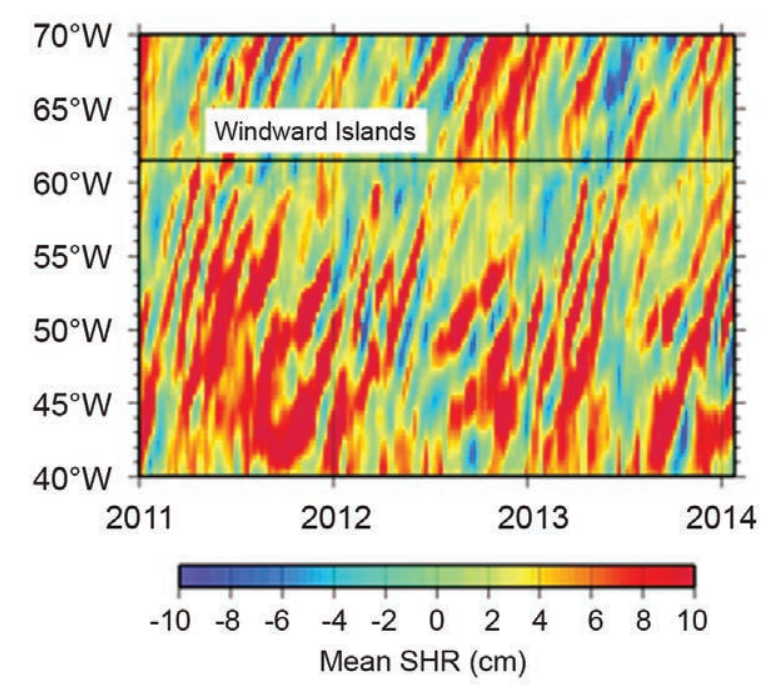

FIG. 3.20. Space-time diagram of de-seasoned sea height residual values $(\mathrm{cm})$ along the NBC ring corridor during 20II-I4. (Source: http://www.aoml.noaa.gov /phod/altimetry/cvar/nbc.)

rings that carry waters from the Southern Hemisphere into the North Atlantic basin, exhibited an annual transport close to climatology and shed eight rings, a larger-than-average value (Goni and Johns 2003). Sea height anomalies in the region, which have generally increased since 2001 (apart from the anomalous low years of 2003 and 2008), continued to exhibit higher-than-average values in 2013 (Fig. 3.20).

In the southwest Atlantic Ocean, the Brazil Current carries waters from subtropical to subpolar regions. The separation of the Brazil Current front from the continental shelf break continued to exhibit annual periodicity driven by wind stress curl variations (c.f., Goni and Wainer 2001). However, the annual mean separation of the front was at its average (1993-present) latitude after having exhibited extreme southward anomalies of up to $2^{\circ}$ latitude during 2002-11 (http://www.aoml.noaa.gov/phod /altimetry/cvar/mal/BM_anm.php). That southward shift was related to a multidecadal oscillation or was in response to a secular trend in South Atlantic temperatures (c.f., Lumpkin and Garzoli 2010; Goni et al. 2011).

\section{h. Meridional overturning circulation observations in the} North Atlantic Ocean-M. 0. Baringer, G. McCarthy, J. Willis, M. Lankhorst, D. A. Smeed, U. Send, D. Rayner, W. E. Johns, C. S. Meinen, S. A. Cunningham, T. 0. Kanzow, E. Frajka-Williams, and J. Marotzke

The ocean's meridional overturning circulation (MOC) is the large-scale "conveyor belt" that redistributes heat, fresh water, carbon, and nutrients around the globe. Variability in the MOC domi- nates the variability of transported properties (not variability in the properties themselves), and so the discussion here is focused on the mean and variability of the MOC. For discussion of the importance of the $\mathrm{MOC}$ and the state of understanding of this the reader is referred to previous State of the Climate reports (e.g., Baringer et al. 2013) and recent reviews such as Macdonald and Baringer (2013), Lozier (2012), and Srokosz et al. (2012). This section reports the results provided by three MOC observing systems in the North Atlantic at $16^{\circ} \mathrm{N}, 26^{\circ} \mathrm{N}$, and $41^{\circ} \mathrm{N}$.

As part of the $26^{\circ} \mathrm{N}$ system, the Florida Current (FC, as the Gulf Stream is called at this latitude) has been measured since 1982. Measurements continued through 2013; however, the computer recording system failed twice, leading to two brief gaps in the time series during 28 October-4 November 2013 and during 15 December 2013-3 January 2014. The median transport (from 1982 to 2013) of the Florida Current is $32.0 \pm 0.26 \mathrm{~Sv}$ (standard error of the mean based on an integral time scale of about 20 days) with an insignificant downward trend of $-0.25 \pm 0.28$ Sv decade ${ }^{-1}$ (errors using 95\% significance with a decorrelation time scale of about 20 days). In 2013 the annual median was $31.7 \pm 1.7 \mathrm{~Sv}$ with the annually-averaged transport essentially equivalent to the long-term average; the 2013 median is within the middle 50\% of all annual averages. The daily FC transport values as compared to all previous years (Fig. 3.21a) indicate that 2013 was unusual in that there were several low transport values (extremes defined as outside the 95\% confidence limits) during 8-14 March, 10-17 October, and early December. The lowest transport observed (19.7 Sv) occurred on 11 March. This low value was the ninth lowest transport recorded since 1982. During 2013 there was only one high transport event that exceeded the $95 \%$ confidence limits: during 10-12 June the transport reached $40.2 \mathrm{~Sv}$.

The RAPID-MOC/MOCHA/WBTS $26^{\circ} \mathrm{N}$ mooring array continues to provide a twice-daily estimate of basin-wide MOC strength (Fig. 3.22) and is the most complete MOC existing observing system, measuring the full water column across the full basin and absolute transports in boundary currents (see Rayner et al. 2010 for details). McCarthy et al. (2012) noted statistically significant low MOC transport in the winter of 2009/10, showing that the low transport was predominantly caused by both a decrease in the northward Ekman transport and particularly by an increase in the southward interior transport: the overturning weakened as the gyre strengthened. Downturns in the overturning circulation such as 

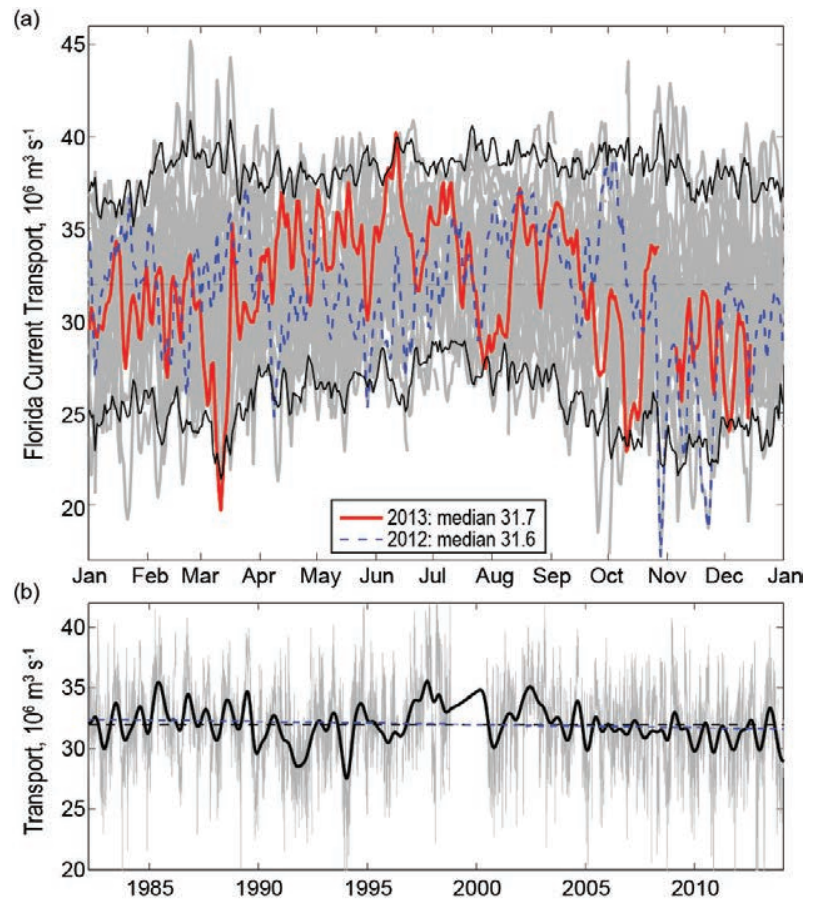

FIG. 3.2I. (a) Daily estimates of the transport $\left(\times 10^{6} \mathrm{~m}^{3}\right.$ $\mathrm{s}^{-1}$ ) of the Florida Current during 2013 (red solid line) compared to 2012 (dashed blue line). Daily values for years since 1982 are shown in light gray and the $\mathbf{9 5 \%}$ confidence interval of daily transport values computed from all years is shown in solid black line; the long-term annual mean is dashed black. (b) Daily estimates of the Florida Current transport $\left(\times 10^{6} \mathrm{~m}^{3} \mathrm{~s}^{-1}\right)$ for the full time series record (light gray), a smoothed version of transport (heavy black line; using a I2-month secondorder butterworth filter), the mean transport for the full record (dashed black) and the linear trend from 1982 to present (dashed blue).

this have been shown to cool the subtropical North Atlantic (Cunningham et al. 2013). The MOC and interior transports data (INT) presented in Fig. 3.22 extend the record reported last year from April 2011 through October 2012, while FC and Ekman transport data are available through 2013; MOC estimates based on mooring data require substantially more lead time because a ship is typically required to go to the site to retrieve the data. During this period there was significantly low MOC transport from 4 May to 20 June 2012 (average MOC of $10.8 \mathrm{~Sv}$ vs. the long-term mean of $17.3 \mathrm{~Sv}$ ). The FC contributes about the same reduction during this period as the Ekman transport (about $-1.5 \mathrm{~Sv}$ ), which is half the size of the interior transport contribution (about $-3.2 \mathrm{~Sv}$ ). It is the sum of the Ekman, Florida Current, and interior components that makes up the MOC at this latitude and the 2012 low transport shows a clear dominance of the interior transport changes driving low MOC values. The long-term trend of the MOC is $-5.4 \pm 4.5$ Sv decade-1 (using 95\% confidence assuming a 45-day decorrelation scale); this means there is $95 \%$ confidence the decrease in the MOC is greater than $0.8 \mathrm{~Sv}$ decade-1. Smeed et al. (2014) examine in detail this downward trend in the MOC and note that the largest changes have occurred since 2008 (as can be readily seen from the annual averages noted on Fig. 3.22).

The $26^{\circ} \mathrm{N}$ array is not the only array estimating the strength of the MOC in the North Atlantic. At $41^{\circ} \mathrm{N}$ the MOC in the North Atlantic is being estimated using a combination of profiling Argo floats (that measure the ocean temperature and salinity in the upper $2000 \mathrm{~m}$ on broad spatial scales) and altimetry derived surface velocity (see Willis and Fu 2008 for complete details). The data sources for this MOC
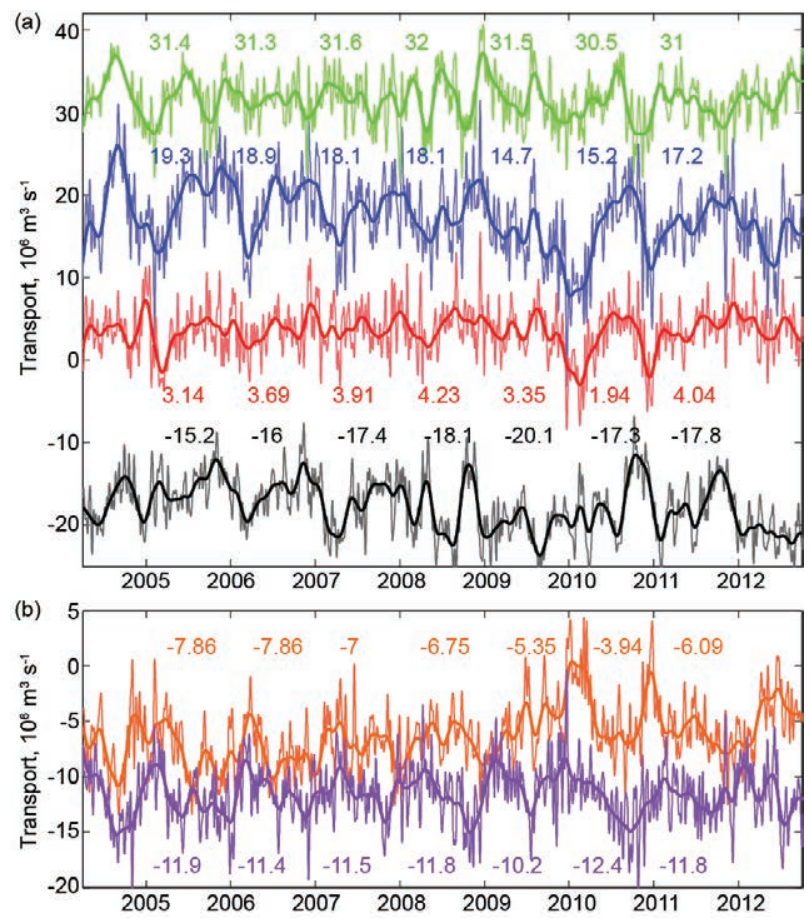

Fig. 3.22. Daily estimates of the (a) strength $\left(\times 10^{6} \mathrm{~m}^{3}\right.$ $\mathrm{s}^{-1}$ ) of the meridional overturning circulation (blue line) and its components, the Florida Current (green), winddriven Ekman transport (red), and the geostrophic interior (black), as measured by the UK National Environmental Research Council (NERC) Rapid Climate Change Program (RAPID-WATCH), the NSF's Meridional Overturning and Heat transport Array proposal, and the NOAA Western Boundary Time Series project (WBTS), and (b) Lower North Atlantic Deep Water (3000-5000-m depth; orange line) and Upper North Atlantic Deep Water (II00-3000-m depth; purple line). The volume transports have a 10 -day low pass filter applied to the daily values (Rayner et al. 2010) and the annual averages of the transports for each year are shown in the associated color text (in Sv). 
estimate are available in near real-time and hence the time series has been extended from May 2012 (reported last year) to October 2013 (Fig. 3.23). Furthermore, near $16^{\circ} \mathrm{N}$, the MOC is being estimated by a mooring array of inverted echo sounders, current meters, and dynamic height moorings that measure the deep circulation that is the southward flowing part of the MOC conveyor belt that sends North Atlantic Deep Water towards the equator (see Send et al. 2011 for further details). For this report, the $16^{\circ} \mathrm{N}$ data has been updated from June 2011 to October 2013, the date of the last cruise. The updated data from all three latitudes were 90-day low-pass filtered and plotted in Fig. 3.23. The mean MOC based on these estimates decreases to the north $(22.8 \mathrm{~Sv}$ at $16^{\circ} \mathrm{N} ; 17.3 \mathrm{~Sv}$ at $26^{\circ} \mathrm{N} ; 13.8 \mathrm{~Sv}$ at $\left.41^{\circ} \mathrm{N}\right)$. Similarly, the variability decreases to the north (as described by the standard deviation: $4.2 \mathrm{~Sv}$ at $16^{\circ} \mathrm{N} ; 3.4 \mathrm{~Sv}$ at $26^{\circ} \mathrm{N} ; 2.9$ $\mathrm{Sv}$ at $\left.41^{\circ} \mathrm{N}\right)$. All three time series have a seasonal cycle, which is most prominent at $26^{\circ} \mathrm{N}$ and $41^{\circ} \mathrm{N}$ (Fig. 3.23). There are different phases for each, with $41^{\circ} \mathrm{N}$ having a maximum MOC in May-July, $26^{\circ} \mathrm{N}$ having a broad maximum in July-November (Kanzow et al. 2010), and $16^{\circ} \mathrm{N}$ having a maximum southward flow (and hence stronger MOC) in November-January. Of note

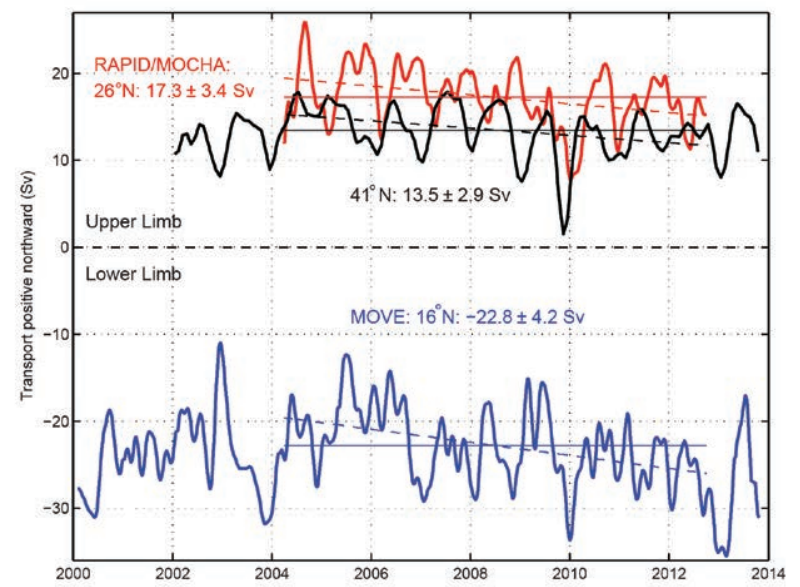

FIG. 3.23. Estimates of the MOC (Sv) in the Atlantic Ocean from the Argo/Altimetry estimate at $41^{\circ} \mathrm{N}$ (black; Willis 2010), the RAPID-WATCH/MOCHA/ WBTS $26^{\circ} \mathrm{N}$ array (red; Rayner et al. 2010), and the German/NOAA MOVE array at $16^{\circ} \mathrm{N}$ (blue; Send et al. 20II). All time series have a three-month second-order butterworth low pass filter applied. Horizontal lines are the mean transport during similar time periods as listed in the corresponding text. Dashed lines are the trends for each series over the same time period. For the MOVE data the net zonal and vertical integral of the deep circulation represents the lower limb of the MOC (with a negative sign for the southward flow) and hence a stronger negative southward flow represents an increase in the MOC. with the most recent data, the $16^{\circ} \mathrm{N}$ data has stronger southward flow, reaching filtered values above -34 $\mathrm{Sv}$; the new $26^{\circ} \mathrm{N}$ data is slightly lower than the longterm average and the newest $41^{\circ} \mathrm{N}$ data is similar to the long-term average. Various authors have reported longer-term MOC trends ranging from zero (Willis 2010 using the first seven years of data from $41^{\circ} \mathrm{N}$ ) to a -3 Sv decade-1 decrease (Send et al. 2011 using the first 9.5 years of data from $16^{\circ} \mathrm{N}$ ), to the largest decrease of $-5.4 \mathrm{~Sv}$ decade $^{-1}$ (Smeed et al. 2014 using the first 8.5 years of data from $26^{\circ} \mathrm{N}$ ). Using the overlapping time period of these observations (2 April 2004 to 2 October 2012) which includes more recent data than reported by Willis (2010) and Send et al. (2011), there is an insignificant trend in the MOC of $-3.3 \pm 6.5$ Sv decade -1 at $41^{\circ} \mathrm{N}$, while at $26^{\circ} \mathrm{N}$ there is a strong decrease in the MOC of $-5.1 \pm 4.1$ Sv decade ${ }^{-1}$ (using $95 \%$ confidence limits; Fig. 3.23). However, at $16^{\circ} \mathrm{N}$ the deep southward flow has recently been increasing, suggesting a possible increase of the MOC at 8.4 $\pm 5.6 \mathrm{~Sv}$ decade ${ }^{-1}$. At $26^{\circ} \mathrm{N}$ where both the upper and deep southward flows are measured, the decreasing MOC is seen to be compensated by a reduction in the southward export of lower North Atlantic Deep Water (LNADW) in the depth range of 3-5 $\mathrm{km}$ (perhaps surprisingly there is no trend in export of upper North Atlantic Deep Water in the depth range 1.1-3 km). The decrease in export of LNADW is $4.6 \pm 3.9 \mathrm{~Sv}$ decade $^{-1}$ (Fig. 3.22b; Smeed et al. 2014). From the full time series from $41^{\circ} \mathrm{N}$ and $16^{\circ} \mathrm{N}$, the MOC trends decrease, becoming insignificant $(-0.9$ $\pm 4.6 \mathrm{~Sv}$ decade ${ }^{-1}$ at $41^{\circ} \mathrm{N}$ and $-2.3 \pm 2.9 \mathrm{~Sv}^{\circ}$ decade $^{-1}$ at $\left.16^{\circ} \mathrm{N}\right)$. At these time scales, there appears to be no consistent trend in the MOC at these latitudes. Note that statistically significant changes can be found using various subsets of these time series; however, the interpretation of any trend should consider regional, interannual, and decadal variability that may not be linked to longer-term trends.

i. Meridional oceanic heat transport in the Atlantic Ocean-M. 0. Baringer, W. E. Johns, S. Garzoli, S. Dong, D. Volkov, and W. R. Hobbs

The meridional overturning circulation is related to the meridional heat transport (MHT) in the oceans, and the variability of MHT can impact heat storage, sea-level rise, and air-sea fluxes, and hence influence local climate on land. Time series of the oceanic heat transport are more rare than time series of the meridional overturning circulation because they involve the product of temperature and velocity to be resolved across a trans-basin section where 
total mass transport can be accounted for. This report includes MHT time series data from $26^{\circ} \mathrm{N}, 41^{\circ} \mathrm{N}$, and $35^{\circ} \mathrm{S}$ in the Atlantic Ocean.

The MHT at $26^{\circ} \mathrm{N}$ is based on the MOC array of moorings, cabled observations, and Argo profiling float data described in Johns et al. (2011); like the meridional overturning circulation estimates from this array (section 5h), the MHT reported this year has been updated to include new estimates from April 2011 through October 2012 . At $26^{\circ} \mathrm{N}$ the median MHT from April 2004 to October 2012 was 1.25 $\pm 0.36 \mathrm{PW}$ ( $1 \mathrm{PW}=1015 \mathrm{~W}$; Fig. 3.24). The MHT time series follows the general variability of the MOC time series at this latitude. The total MHT is composed of the sum of temperature transports from the Florida Current (median $2.52 \pm 0.25 \mathrm{PW}$ standard deviation), Ekman temperature transport $(0.35 \pm 0.29 \mathrm{PW})$, and interior ocean temperature transport $(-1.60 \pm 0.30$ PW). The annual median MHT shows a decrease in the MHT in 2009 and 2010 (including negative values in December 2010 for the 10-day low pass filtered data), which then returned to average values in 2011, reported for the first time in this report (Fig. 3.24). The MHT was fairly unremarkable in 2011 and 2012 (Fig 3.24b), except in May and June 2012 when the transport was low for that time of year. For the full time series, the Ekman transport accounts for about $60 \%$ of the variance of the MHT (0.77 correlation), while the Florida Current accounts for about $30 \%$ of the variance ( 0.55 correlation). Unlike the MOC, the interior circulation appears to play a lesser role in the variability overall; however, it can be a dominant factor during certain time periods (e.g., McCarthy et al. 2012). The MHT shows a statistically significant decrease of $-0.3 \pm 0.25 \mathrm{PW}$ decade ${ }^{-1}$ (95\% confidence limits) from April 2004 to October 2012 (using the full 8.5-year time series); however, this decrease is largely due to the lows in 2009 and 2010 and is likely a signal of interannual and decadal variability rather than a longer-term secular change.

At $35^{\circ} \mathrm{S}$ in the South Atlantic, MHT has been estimated using a combination of expendable bathythermograph (XBT) data and Argo profiling floats (Garzoli et al. 2012; Dong et al. 2009). From July 2002 to January 2014 the median of the MHT near $35^{\circ} \mathrm{S}$ is $0.55 \pm 0.16 \mathrm{PW}( \pm 1$ standard deviation; Fig. 3.25). At $41^{\circ} \mathrm{N}$ the MHT was estimated by Hobbs and Willis (2012) using altimetry and Argo profiling float data. The median MHT near $41^{\circ} \mathrm{N}$ has not been updated since Baringer et al. (2013), and from January 2002 to September 2010 is $0.50 \pm 0.10 \mathrm{PW}$. There is no significant trend at $41^{\circ} \mathrm{N}$ or $35^{\circ} \mathrm{S},-0.04 \pm 0.23$
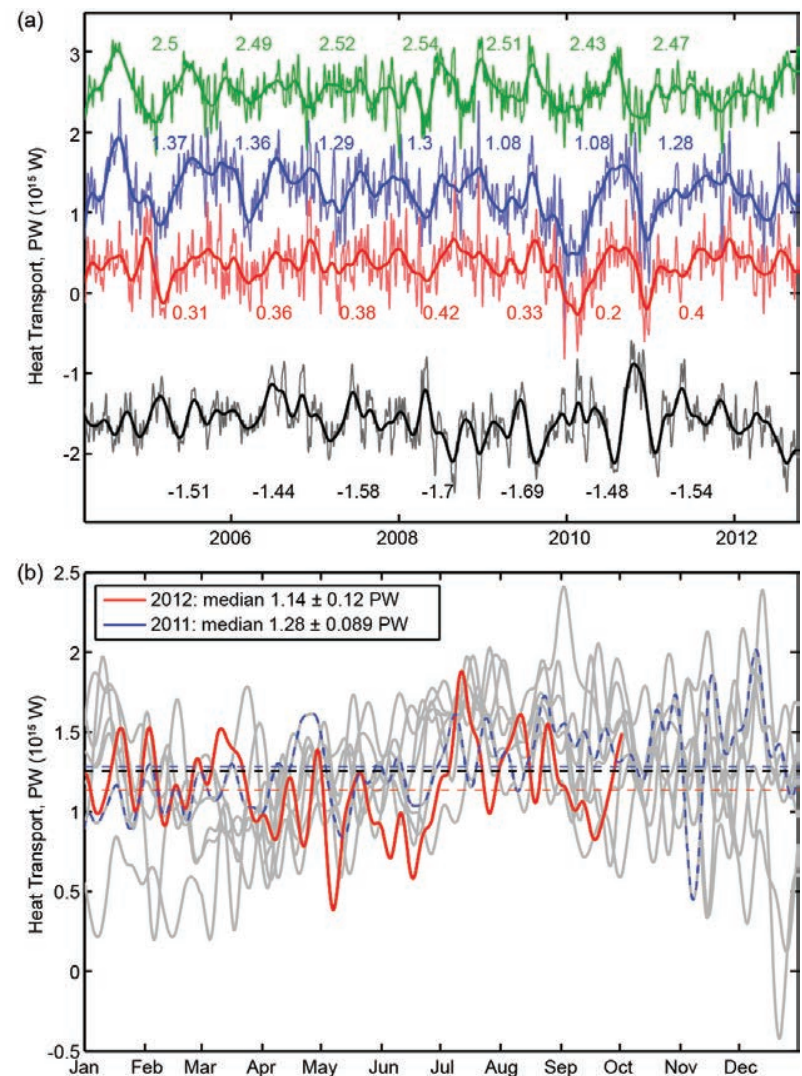

Fig. 3.24. (a) Daily estimates at $26.5^{\circ} \mathrm{N}$ of the strength $(\times 1015 \mathrm{~W})$ of the meridional heat transport (blue line) and its associated temperature transport components, the Florida Current (green), wind-driven Ekman transport (red), and the geostrophic interior (black), as measured by the UK National Environmental Research Council (NERC) Rapid Climate Change Program (RAPID-WATCH), the National Science Foundation's Meridional Overturning and Heat transport Array proposal, and the NOAA Western Boundary Time Series project (WBTS). The high frequency heat transports have a I0-day low pass filter applied to the daily values (Rayner et al. 2010), the smooth curve (heavy lines) represent $\mathbf{9 0}$-day low pass filtered data. The annual averages of the transports for each year are shown in the associated color text. (b) MHT ( $\times 1015 \mathrm{~W}$ ) from 2012 (red), $201 \mathrm{l}$ (dashed blue), and all other years (gray) plotted as a function of month. Thin horizontal dashed lines are annual mean values for 2012 (red), 201 I (blue), and all years (black).

PW and $+0.12 \pm 0.12$ PW, respectively (Fig. 3.25). The eddy-permitting global ECCO2 data synthesis (Menemenlis et al. 2005) follows nearly exactly the MHT at $41^{\circ} \mathrm{N}$, while its average is too low at $26^{\circ} \mathrm{N}$ and $35^{\circ} \mathrm{S}$; however, the correlation is actually highest at $26^{\circ} \mathrm{N}$ (correlation $=0.8$ ). The state estimation is least correlated with observations at $35^{\circ} \mathrm{S}$ and has much larger variance in general. Overall, the heat trans- 

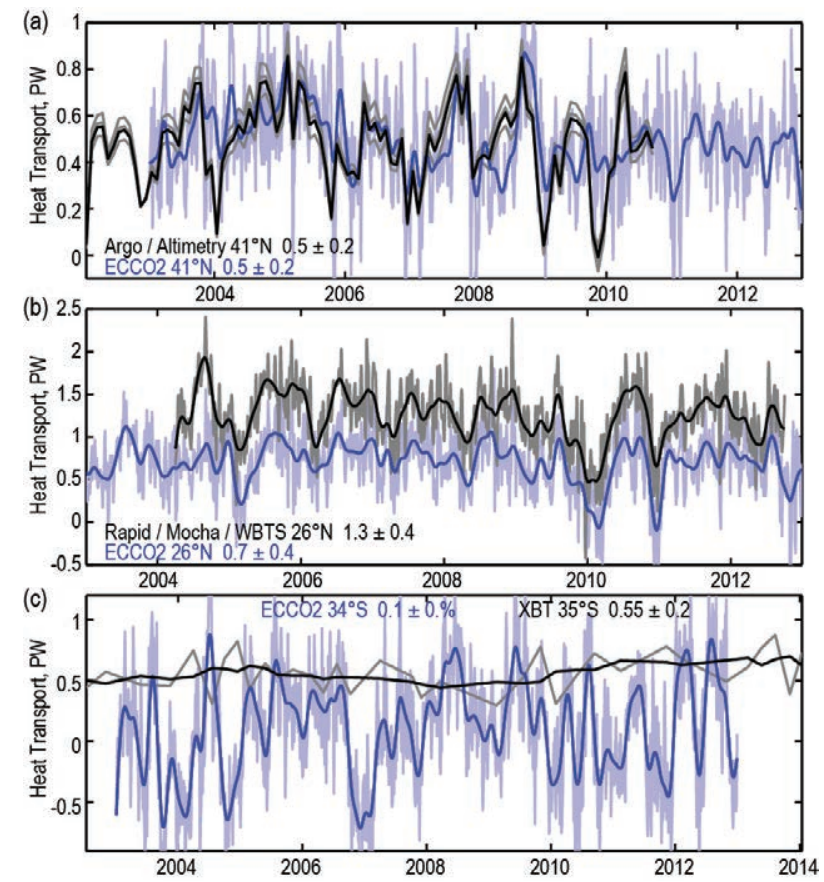

FIG. 3.25. Observed time series of meridional heat transport (PW) at (a) $41^{\circ} \mathrm{N}$ (profiling floats), (b) $26^{\circ} \mathrm{N}$ (mooring/hydrography) and (c) $30^{\circ}-35^{\circ} \mathrm{S}$ (XBTs) in the Atlantic compared to the monthly estimates from the ECCO2 state estimation (light blue line) and a 3-month low pass of ECCO2 data (blue line). In (a) the black line is the estimate MHT and the gray lines represents the error in the estimate (Hobbs and Willis 20I2). In (b) the black line is the observed data filtered with a 3-month low pass filter and the gray lines are the underlying I2-hourly data. In (c) the gray line is the quarterly estimated MHT from XBTs and the black line is a yearly boxcar filter to those quarterly estimates.

port was fairly average in 2012 . In 2013 , near $35^{\circ} \mathrm{S}$ the MHT was larger than usual (with August 2013 data falling higher than $97.5 \%$ of the other estimates at this latitude).

j. Sea level variability and change-M. A. Merrifield, P. Thompson, E. Leuliette, R. S. Nerem, B. Hamlington, D. P. Chambers, G. T. Mitchum, K. Mclnnes, J. J. Marra, M. Menéndez, and W. Sweet Global mean sea level (GMSL) continued to rise during 2013, on pace with a 20-year linear trend of $3.2 \mathrm{~mm} \mathrm{yr}^{-1}$ (Fig. 3.26a). A portion of this trend $(0.5$

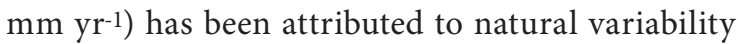
associated with the Pacific decadal oscillation (PDO; Hamlington et al. 2013) as well as to ongoing contributions from the melting of glaciers and ice sheets and ocean warming (Rhein et al. 2013). While interannual variations in GMSL occur regularly, there is no evidence of a hiatus in sea-level rise as has been observed in the surface temperature record over the last decade (Trenberth and Fasullo 2013).
Interannual fluctuations in GMSL about the trend are largely linked to exchanges of water with the continents due to changes in precipitation patterns, including the pronounced minima of 2010-11 and maxima of 2012-13 (Boening et al. 2012; Fasullo et al. 2013). Over 2011-12, global mean sea level rose at $\sim 10 \mathrm{~mm} \mathrm{yr}^{-1}$ as it recovered from the 2010-11 minima. This is also reflected in the changes in global mean ocean mass measured by satellite gravimetry (Fig. 3.26a) and in global mean continental water storage (see section 2d6). The highest regional sea surface height (SSH) trends occur in the western equatorial Pacific with strong positive trends extending across northern Australia (White et al. 2014, manuscript submitted to Earth-Sci. Rev.) and associated weak to negative trends along the eastern boundary of the $\mathrm{Pa}$ cific (Fig. 3.26b). The regional sea level trend pattern is reflected in the Southern Oscillation and Pacific decadal oscillation indices in the Pacific (Merrifield et al. 2012; Zhang and Church 2012) and northern Australia (White et al. 2014, manuscript submitted to Earth-Sci. Rev.) and is a result of multidecadal
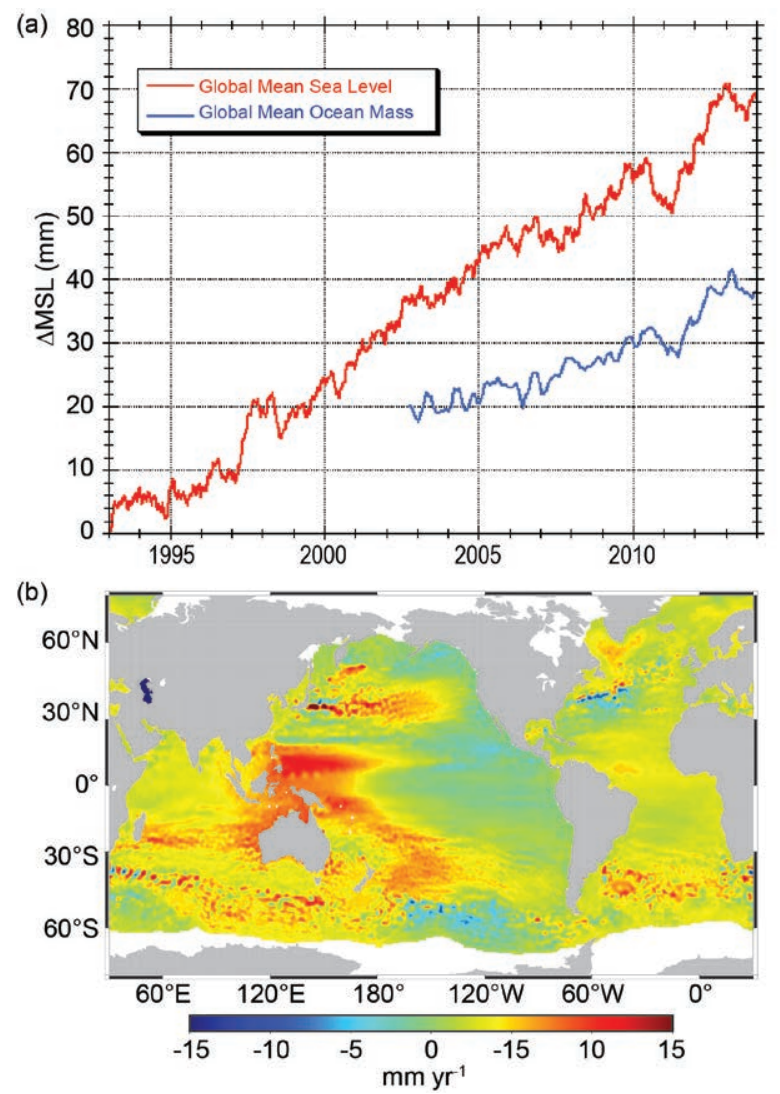

FIG. 3.26. (a) Global mean sea level $\left(\mathrm{mm} \mathrm{yr}^{-1}\right)$ and global mean ocean mass (ppm; seasonal variations removed, 60-day smoothing applied). (b) Regional SSH trends $\left(\mathrm{mm} \mathrm{yr}^{-1}\right)$ 1993-2013. 
fluctuations in equatorial and midlatitude winds (Merrifield et al. 2012; Moon et al. 2013).

Maps of SSH averaged over three-month intervals show the anomalous seasonal evolution of regional change during 2013. The positive SSH anomalies around Australia and Southeast Asia during the first half of the year (Fig. 3.27a,b) reflect a moderate La Niña state that relaxed toward an ENSO-neutral state during the second half of 2013 (Fig. 3.27c,d). Positive anomalies in the southeast Indian Ocean persisted throughout the year as anomalies associated with the early-year La Niña conditions propagated westward away from the Australian coast as Rossby waves (Fig. 3.27a-d).

Substantial negative anomalies in the Baltic Sea during the first quarter (Fig. 3.27a) increased steadily to positive values by the end of the year (Fig. 3.27d). This change is linked to a transition from negative to positive phase in both the Arctic and North Atlantic Oscillations. The phase change in these modes also resulted in a moderate decrease of SSH in the Mediterranean Sea (Fig. 3.27a-d). And SSH decreased during 2013 over most of the Southern Ocean (Fig. 3.27a-d). This is most apparent in the South Pacific, where the decreased gradient across the Antarctic Circumpolar Current may reflect the transition from positive to negative values of the southern annular mode.

Annually-averaged sea level during 2013 (Fig. 3.28a) reflects the La Niña-like conditions in the throughout the year. The PDO index was consistently tropical Pacific and Indian Oceans that persisted

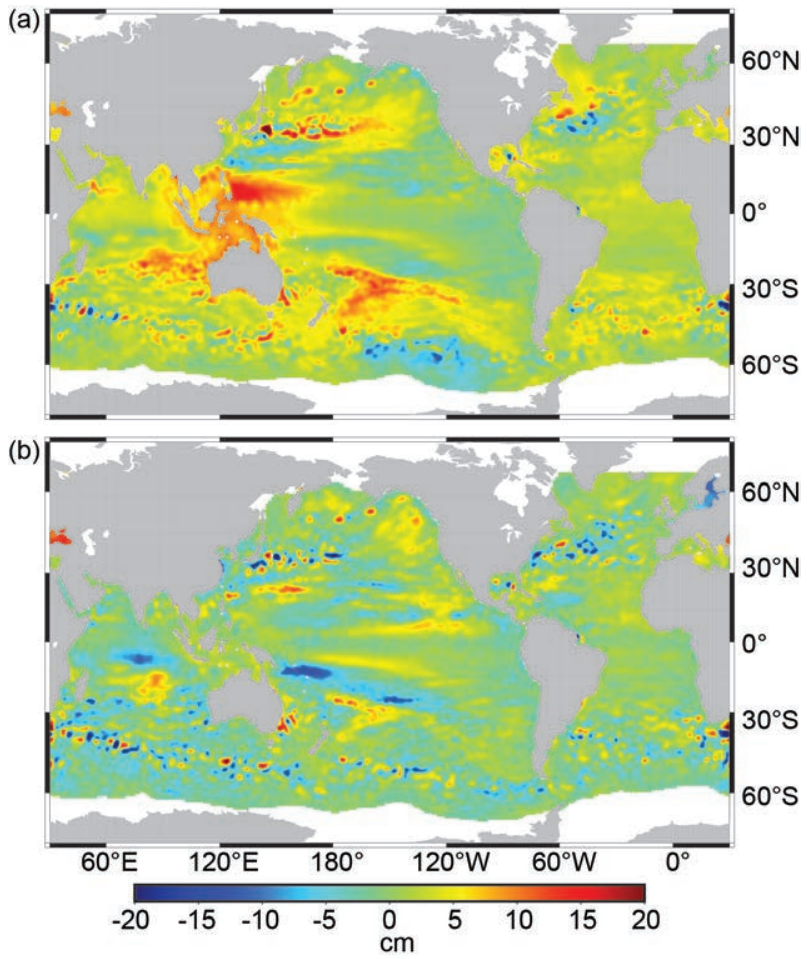

FIG. 3.28. (a) $2013 \mathrm{SSH}$ annual mean anomaly (cm) from the 1993-2012 average. (b) The difference between 2013 and 2012 annual means $(\mathrm{cm})$.

negative throughout most of 2013, as it has been since mid-2010. The 2013 sea level field is characteristic of a negative PDO phase with low sea level anomalies along the eastern boundary of the Pacific that extend westward across the basin at low latitudes (Merrifield et al. 2012; Zhang and Church 2012). Higher-than-average sea levels at midlatitudes in the northeast Pacific correspond to negative wind stress curl anomalies in the Aleutian Low region (see Fig. 3.9). In the Southern Ocean, the broad region of lower-than-average sea levels west of the southern tip of South America remained essentially unchanged from 2012. Anomalies were positive north of the Gulf Stream and Kuroshio extensions and negative south of these regions, which suggests intensified western boundary currents during 2013. The difference between annual mean SSH maps from 2013 and 2012 shows little change in the large-scale regional features of the $\mathrm{SSH}$ field (Fig. $3.28 b$ )

Extreme coastal sea levels are ex-

FIG. 3.27. SSH seasonal anomalies $(\mathrm{cm})$ for 2013 relative to the 1993 2012 average, obtained using the multimission gridded sea surface height altimeter product produced by Ssalto/Duacs and distributed by AVISO, with support from CNES (http://www.aviso.oceanobs.com).
Extreme coastal sea levels are examined using daily averages obtained from a global network of tide gauges 

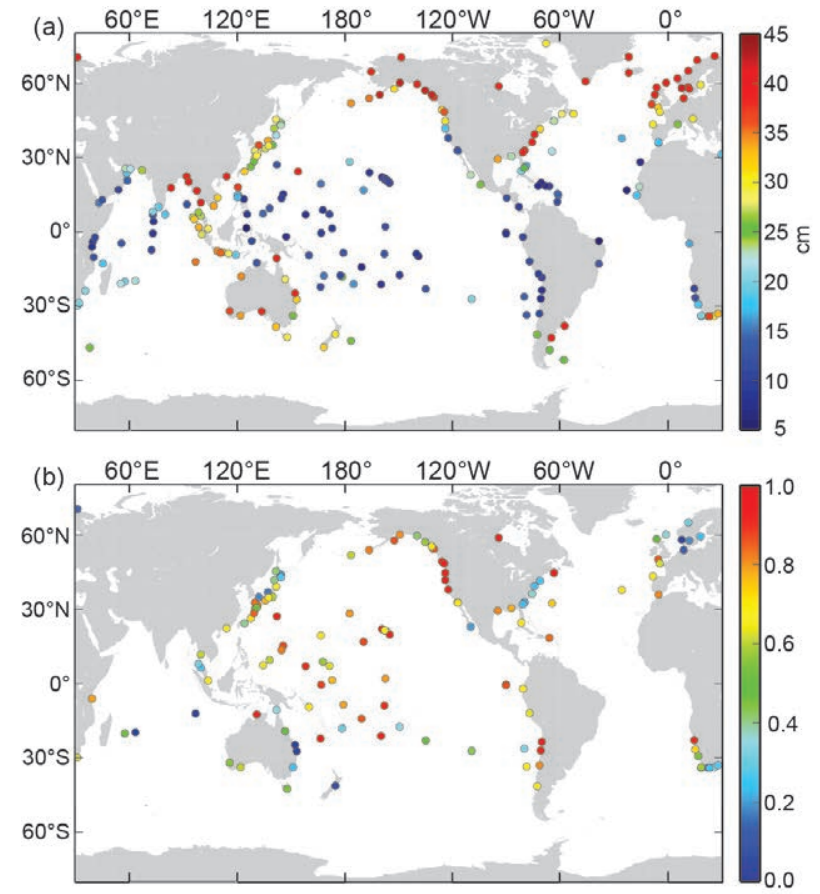

FIG. 3.29. (a) Average of the $2 \%$ highest daily-averaged sea level values $(\mathrm{mm})$ from tide gauges. (b) Probability of exceeding the values in panel (a) based on a GEV fit to stations with at least 25 years of data.

(Fig. 3.29a). The average of the upper 2\% highest daily values exhibits a characteristic meridional structure that reflects higher storminess at mid- and high latitudes compared to the tropics. The probability of 2013 sea level extremes is estimated by performing a generalized extreme value fit to records with at least 25 years of data. The probability of exceeding the 2013 values (Fig. 3.29b) shows that relatively unusual activity occurred around Scandinavia, parts of Australia and New Zealand, and at scattered island stations in the Indian Ocean. Extremes during 2013 were relatively modest along the western coast of North America and at the majority of tropical Pacific island sites. However, it should be noted that extreme sea levels caused by severe storms such as those associated with Typhoon Haiyan were not well captured by the available tide gauge stations in the Philippines. The issue of the localized nature of extreme sea levels caused by severe storms, such as tropical cyclones, has also been noted for other tropical locations (e.g., Hoeke et al. 2013; McInnes et al. 2014).

k. Global ocean carbon cycle-R. A. Feely, R. Wanninkhof, C. L. Sabine, J. T. Mathis, T. Takahashi, and S. Khatiwala

I) Sea-Air Carbon dioxide fluXes

The ocean plays an important role in the climate system as a large sink for anthropogenic carbon di- oxide $\left(\mathrm{CO}_{2}\right)$ and thereby partially mitigates the largescale effects of human-induced $\mathrm{CO}_{2}$ emissions into the atmosphere. The air-sea flux of $\mathrm{CO}_{2}$ is computed from the observed difference in the partial pressure of $\mathrm{CO}_{2}$ across the air-water interface $\left(\triangle \mathrm{pCO}_{2}=\mathrm{pCO}_{2 \text { sw }}\right.$ $\mathrm{pCO}_{2 \text { air }}$ ), the solubility of $\mathrm{CO}_{2}$ in seawater, and the gas transfer velocity (Wanninkhof et al. 2009). Estimates of the net air-sea $\mathrm{CO}_{2}$ flux based on measurements of partial pressure of $\mathrm{CO}_{2}$ in near-surface seawater $\left(\mathrm{pCO}_{2 \mathrm{sw}}\right)$ and in the marine boundary air show that the extratropics are major oceanic sinks of atmospheric $\mathrm{CO}_{2}$ and the tropics are major sources (Fig. 3.30). The development of the surface ocean $\mathrm{CO}_{2}$ maps involves continued processing of the ocean carbon datasets generated from volunteer observing ships and moorings and working with Lamont-Doherty Earth Observatory (LDEO) to update sea-air $\mathrm{CO}_{2}$ flux climatology (Takahashi et al. 2009, 2013). The process then uses these data along with satellite-based sea-surface temperature and global multiplatform wind products to develop algorithms to make global seasonal $\mathrm{CO}_{2}$ flux maps.

The $\mathrm{LDEO} \mathrm{pCO}_{2}$ database was used to generate an updated sea-air $\mathrm{CO}_{2}$ flux climatology in the Regional Carbon Cycle Analysis Project (RECCAP) as reported in Wanninkhof et al. (2013). The gridded $\mathrm{pCO}_{2}$ dataset was used along with a consistent global wind speed product, the cross-calibrated multiplatform (CCMP) winds (Atlas et al. 2011). Other adjustments to the estimate of Takahashi et al. (2009) include incorporating the impact of El Niño on global sea-air fluxes, a new assessment of sea-ice coverage, and extrapolation of data to the coastline. The updated net sea-air

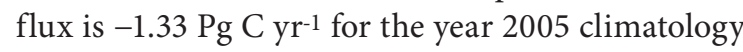

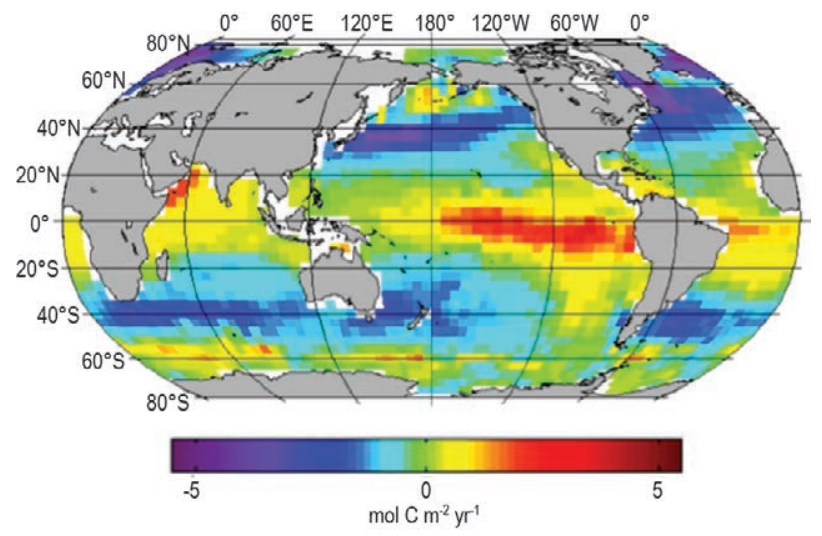

FIG. 3.30. Updated sea-air $\mathrm{CO}_{2}$ flux (mol C m-2 $\left.\mathrm{yr}^{-1}\right)$ climatology yielding a net global sea-air flux of $-1.33 \mathrm{Pg} \mathrm{C} \mathrm{yr}^{-1}$. The most recent release of the climatological $\mathrm{pCO}_{2}$ maps centered on the year 2005 can be obtained at http://www.ldeo.columbia.edu/res/pi /CO2/carbondioxide/global_ph_maps/pco2_maps.html. 
(Fig. 3.30) compared to the value of $-1.22 \mathrm{Pg} \mathrm{C} \mathrm{yr}^{-1}$ for the 2000 climatology (Takahashi et al. 2009) using the same consistent treatment of $\triangle \mathrm{pCO}_{2}$ fields, gas transfer, and wind speeds. The $\Delta \mathrm{pCO}_{2}$ fields of Takahashi et al. $(2009,2013)$ with the new wind fields and new gas exchange algorithms are used such that consistent regional and global flux estimates are made over 19 years using the approach of Park et al. (2006, 2010a,b) and Park and Wanninkhof (2012).

Monthly estimates of sea-air $\mathrm{CO}_{2}$ fluxes and related fields based on the empirical approach of Park et al. $(2010 \mathrm{a}, \mathrm{b})$ are provided as a user-friendly graphical interface at http://cwcgom.aoml.noaa.gov/erddap/griddap/aomlcarbonfluxes.graph. As an example, boreal summer 2013 (Fig. 3.31) shows a decreased uptake during June 2013 equivalent to $0.4 \mathrm{Pg} \mathrm{C} \mathrm{yr}^{-1}$ compared to the 30 -year average. This anomaly is caused by a combination of larger equatorial outgassing due to enhanced upwelling and decreased uptake in the subpolar gyres as determined from the flux anomaly option of the interface (not shown).

Wanninkhof et al. (2013) recently completed a synthesis of global sea-air $\mathrm{CO}_{2}$ fluxes and temporal trends from 1990-2009 (Figs. 3.32 and 3.33; Table 3.1). The estimates were based on analyses of ocean inverse models (OIM), atmospheric inverse models (AIM), ocean general circulation models with biogeochemistry (OBGCM), and empirical estimates based on surface water $\mathrm{CO}_{2}$ observations. The major conclusion is that global ocean $\mathrm{CO}_{2}$ inventory changes over the last two decades, based on different observational and modeling approaches, show good agreement with an average ocean anthropogenic $\mathrm{CO}_{2}$ uptake estimate of $-2.2 \pm 0.4 \mathrm{Pg} \mathrm{C}$. The values based on sea-air $\mathrm{CO}_{2}$ fluxes are on the lower side of the estimates from models and interior estimates. While the magnitude appears well constrained, the interannual variability

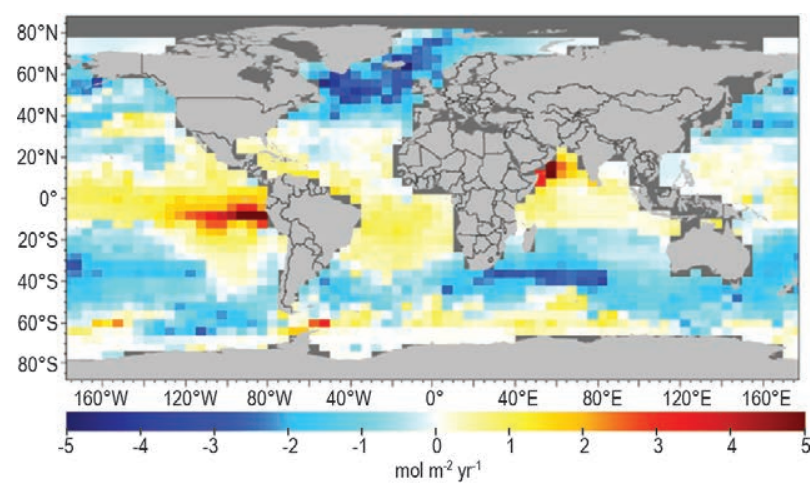

FIG. 3.3I. Global sea-air $\mathrm{CO}_{2}$ fluxes for Jun 2013 using the empirical approach of Park et al. (20/0b) and remotely sensed wind and SST data from NOAA Coastwatch.

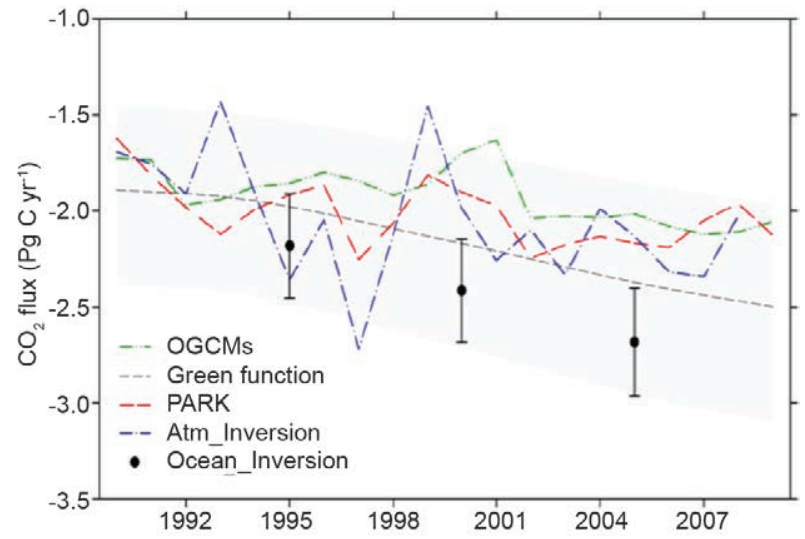

Fig. 3.32. Anthropogenic sea-air $\mathrm{CO}_{2}$ fluxes based on the empirical approach of Park et al. (2010a) and different modeling approaches from Wanninkhof et al. (20I3). The anthropogenic $\mathrm{CO}_{2}$ flux is the contemporary flux minus the riverine carbon input $(\approx 0.45 \mathrm{Pg} \mathrm{C}$ $\left.y^{-1}\right)$ where fluxes into the ocean are negative.

and trends between different approaches are quite different, indicating the need for continued work on observational time series.

The interannual variability over the two decades for the OIM and OBGCMs and empirical approaches

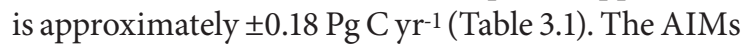
showed twice as large interannual variability as the other approaches $\left(\approx 0.4 \mathrm{Pg} \mathrm{C} \mathrm{yr}^{-1}\right)$, which is attributed to incomplete separation of terrestrial and oceanic $\mathrm{CO}_{2}$ sources and sinks in the AIMs. Consistent differences in the 20-year trend of sea-air $\mathrm{CO}_{2}$ were observed between methods. Those relying on ocean interior carbon and tracer measurements yielded a

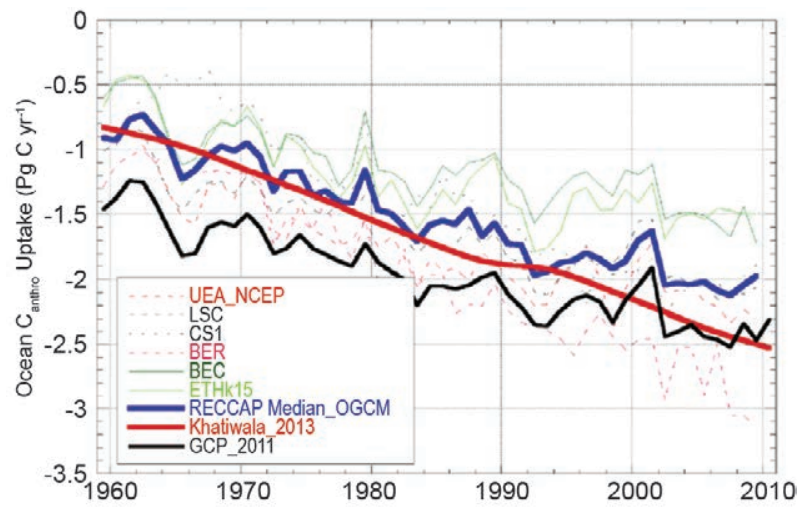

Fig. 3.33. The 50-year globally-integrated ocean anthropogenic $\mathrm{CO}_{2}$ uptake from coupled ocean biogeochemistry general circulation models (OBGCMs) used in RECCAP. The thin solid and dashed lines show the increasing annual uptake of the different models and their interannual variability. The thick solid blue line is the median of the OBGCMs; the thick solid red line is the output of the Green function method (Khatiwala et al. 20I3) and the thick black line is the result from the Global Carbon Project (GCP) ocean model ensemble. 


\begin{tabular}{|c|c|c|c|c|c|}
\hline Approach & $\begin{array}{c}\text { Anthropogenic } \\
\mathrm{CO}_{2} \text { Flux } \\
\mathrm{PgC} \mathrm{yr}^{-1}\end{array}$ & $\begin{array}{l}\text { Uncertainty } \\
\text { Pg C yr-1 }\end{array}$ & $\begin{array}{c}I A V e \\
\operatorname{Pg} \subset \text { yr-1 }^{-1}\end{array}$ & $\begin{array}{c}\text { SAVf } \\
\mathrm{Pg} C \mathrm{yr}^{-1}\end{array}$ & $\begin{array}{c}\text { Trend } \\
(\text { Pg } C ~ y r-1) \text { decade-I }\end{array}$ \\
\hline Empirical & -2 & $\pm 0.6^{\mathrm{a}}$ & 0.2 & \pm 0.61 & -0.15 \\
\hline OBGCM & -1.9 & $\pm 0.3 \mathrm{~b}$ & 0.16 & \pm 0.38 & -0.14 \\
\hline Atm. Inversion & -2.1 & $\pm 0.3 \mathrm{c}$ & 0.4 & \pm 0.41 & -0.13 \\
\hline Ocean Inversion & -2.4 & $\pm 0.3^{d}$ & & & $-0.5 i$ \\
\hline $\begin{array}{l}\text { Interior (Green } \\
\text { function)g }\end{array}$ & -2.2 & \pm 0.5 & & & -0.35 \\
\hline $\mathrm{O}_{2} / \mathrm{N}_{2}{ }^{\mathrm{h}}$ & -2.2 & \pm 0.6 & & & \\
\hline $\mathrm{O}_{2} / \mathrm{N}_{2}{ }^{\mathrm{i}}$ & -2.5 & \pm 0.7 & & & \\
\hline
\end{tabular}

a Root mean square of uncertainty in different components of the flux.

b Median absolute deviation of the six model outputs used to determine the median (for six model outputs: LSC, $\mathrm{UEA}_{\mathrm{NCEP}}$, CSI, BER, BEC, $\mathrm{ETH}_{\mathrm{k} 15}$ ).

c Median absolute deviation of the 11 model outputs used to determine the median.

d Median absolute deviation of the 10 model outputs used to determine the median.

e Interannual variability (IAV) for the median values of the six models list in b.

f Subannual variability (SAV) for the median values (for five model outputs: LSC, UEA ${ }_{\text {NCEP }}$ CSI, BEC, ETH k15 $_{\text {). }}$. $\mathrm{g}$ Based on interior ocean changes using transient tracers and a Green function (Khatiwala et al. 2009, 2013).

h For 1993-2003 (Manning and Keeling 2006).

i For 2000-10 (Ishidoya et al. 2012).

j Calculated using steady ocean circulation and $\mathrm{CO}_{2}$ uptake proportional to atmospheric $\mathrm{CO}_{2}$ increases.

global trend of increasing carbon uptake ranging from 0.35 to 0.5 ( $\left.\mathrm{Pg} \mathrm{C} \mathrm{yr}^{-1}\right)$ decade $^{-1}$ while those relying on surface water $\mathrm{CO}_{2}$ values such as OBGCMs and empirical estimates gave values of $\sim 0.15$ (Pg C $\left.\mathrm{yr}^{-1}\right)$ decade $^{-1}$. The differences are attributed to the insensitivity of interior measurements to changes in surface biogeochemistry resulting from climate reorganizations and global change. The relatively short time record (two decades) of consistent measurements and model input parameters precludes a definitive attribution of the differences in trends between the different methods.

\section{2) Ocean carbon InVEntory}

The global ocean is continuing to take up a substantial fraction of the anthropogenic $\mathrm{CO}_{2}\left(\mathrm{C}_{\text {ant }}\right)$ emissions from the atmosphere and, as a consequence, is a significant mediator of global climate change. Estimates based on data-constrained models indicate that the anthropogenic carbon inventory has increased from about $118 \pm 20 \mathrm{Pg} \mathrm{C}$ in 1994 to about $155 \pm 26$ $\mathrm{Pg} \mathrm{C}$ in 2010 (about $28 \%$ of the total anthropogenic $\mathrm{CO}_{2}$ emissions over that time period; Khatiwala et al. 2013; Fig. 3.34).

The U.S. CLIVAR/ $\mathrm{CO}_{2}$ Repeat Hydrography Program is providing new information about the

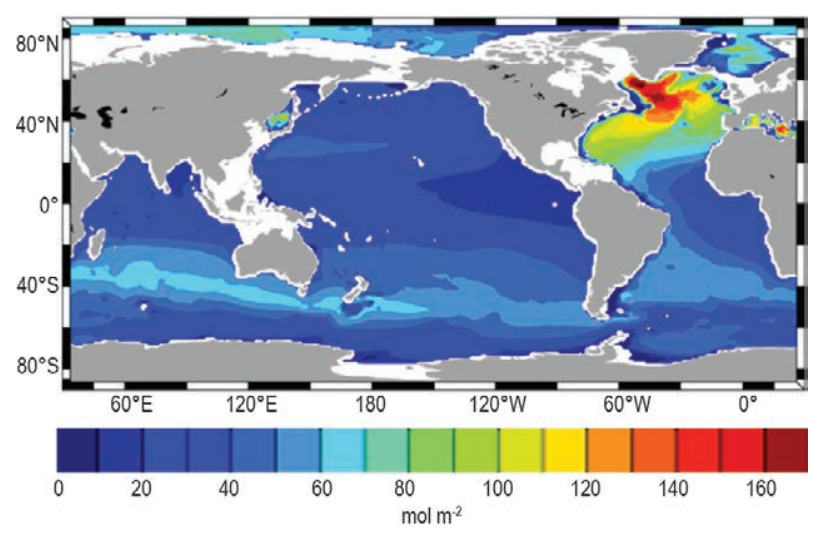

FIG. 3.34. Column inventories for $C_{\text {ant }}\left(\mathrm{mol} \mathrm{m}^{-2}\right)$ in 2010. (Source: Khatiwala et al. 2013.)

uptake and storage of carbon within the ocean interior by determining the change in $\mathrm{C}_{\mathrm{ant}}$ concentration between cruise occupations. Over the last decade, several approaches have been developed to make these determinations using a multiple linear regression method (Friis et al. 2005; Sabine and Tanhua 2010; Clement and Gruber 2014). The effort has continued its basin-wide approach with a focus on the Pacific with a data synthesis project called PACIFICA (see http:// cdiac.ornl.gov/oceans/PACIFICA). These data are now being included in the more extensive 2nd Global Ocean 
Data Analysis Project (GLODAP-2; Key et al. 2004). In 2013, data from three occupations of the Repeat Hydrography P2 Line in the South Pacific were used to examine changes in dissolved inorganic carbon (DIC) inventories (Fig. 3.35). The changes in DIC are being driven by air-sea exchange at the surface, but also by ventilation processes in the subsurface waters. The high DIC values shown in Fig. 3.35b,d,f between 500 and $1000 \mathrm{~m}$, particularly in the western Pacific, are a result of deep ventilation in these areas. The accumulation of DIC in surface waters is much more pronounced between the 2004 and 2013 occupations due to increasing levels of $\mathrm{CO}_{2}$ in the atmosphere during that decade. Over the 20-year span of data observations, DIC accumulation in the upper $500 \mathrm{~m}$ ranged from $<10 \mu$ moles $\mathrm{kg}^{-1}$ in the central Pacific to $>35 \mu$ moles kg-1 in the eastern and western edges of the basin.

The role of the Southern Ocean (SO) continues to be an important factor in understanding the ocean carbon cycle and for predicting future changes in the ocean. A number of recent studies suggest that as much as $40 \%$ of ocean uptake of $\mathrm{C}_{\text {ant }}$ occurs in this region (see Sabine and Feely 2007). However, the amount of $\mathrm{C}_{\text {ant }}$ that is stored in deep and bottom layers is still uncertain. Significant differences can be found between indirect measurement-based approaches and ocean models (Fig. 3.35). Data from the GLODAP (Global Ocean Data Analysis Project) and CARINA (CARbon dioxide IN the Atlantic Ocean) databases were used to develop a $\mathrm{CO}_{2}$-data-
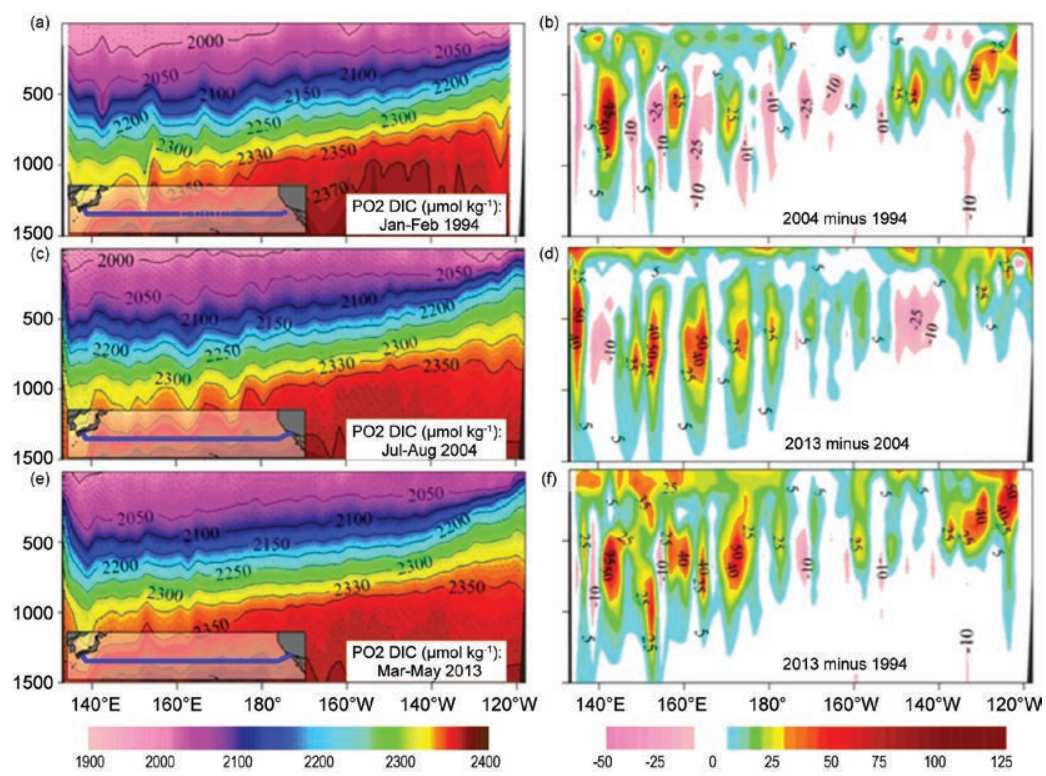

FIG. 3.35. Cross-section of discrete DIC data ( $\mu$ moles $\left.\mathbf{~ k g}^{-1}\right)$ from the PO2 line taken in (a) 1994, (c) 2004, and (e) 2013. (b), (d), and (f) show the differences in DIC concentrations between the occupations. based "back-calculation" method that provides $\mathrm{C}_{\text {ant }}$ concentration and inventory estimates in the $\mathrm{SO}$ region $\left(>45^{\circ} \mathrm{S}\right)$. The method addresses both water mass mixing and the non-steady state nature of the air-sea $\mathrm{CO}_{2}$ disequilibrium $\left(\Delta \mathrm{C}_{\mathrm{dis}}\right)$ term. Water mass mixing was computed using the extended optimum multiparametric (eOMP) analysis. In addition, published parameterizations were used to obtain more reliable values of $\Delta \mathrm{C}_{\mathrm{dis}}$. Results from the new approach were compared with those from the $\Delta \mathrm{C}^{*}$ method, the TrOCA method, and two different tracer-based approaches: the transit-time distribution (TTD) and Green function (GF) methods (Pardo et al. 2014). The TTD, GF, and the new back-calculation methods give similar estimates for the $\mathrm{SO}$ inventory (with reference to the year 1994) of $30 \pm 2,22 \pm 2$, and $29 \pm 3 \mathrm{Pg} \mathrm{C}$, respectively (Fig. 3.36). Antarctic Bottom Water shows $\mathrm{C}_{\text {ant }}$ concentrations of $9 \pm 1,3 \pm 0.3,6 \pm 1 \mu \mathrm{mol} \mathrm{kg}{ }^{-1}$, contributing $6 \%-12 \%$ of the SO inventory. The $\Delta \mathrm{C}^{*}$ and TrOCA methods seem to yield lower and higher values, respectively, for both the total $\mathrm{C}_{\mathrm{ant}}$ inventory and $\mathrm{C}_{\text {ant }}$ concentrations in deep water layers. Results from the new approach suggest that deep and bottom layers of the water column in the SO contain, in general, low concentrations of $\mathrm{C}_{\text {ant }}$ compared with subsurface and intermediate layers but higher than those recorded in the global databases. It is important to note that, as deep and bottom layers in the SO fill two of the most voluminous water masses of the global ocean, even these relatively low values of $\mathrm{C}_{\mathrm{ant}}$ can be of considerable importance when computing the inventories in the water column, mostly in the SO but also in the ocean interior where, over time, bottom waters are moving.

The storage rate of anthropogenic carbon dioxide can also be assessed by determining the change in $\mathrm{C}_{\mathrm{ant}}$ concentration. Large-scale observations of the storage rate are in general agreement with that expected from the increase in atmospheric $\mathrm{CO}_{2}$ concentrations and with the tracer-based estimates. However, there are significant spatial and temporal differences in the degree to which the inventory of $\mathrm{C}_{\text {ant }}$ tracks changes in the atmosphere. For example, the subpolar North Atlantic is an area with high variability in circulation and deep water formation, influencing the $\mathrm{C}_{\text {ant }}$ inventory. 

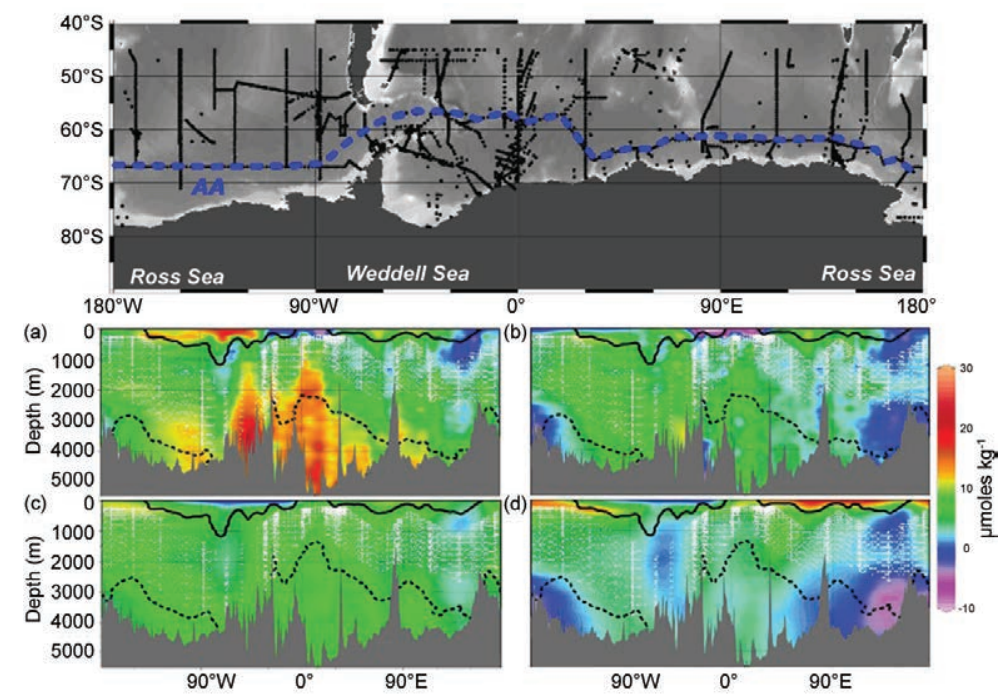

Fig. 3.36. Method dependent estimates of $\mathbf{C}_{\text {ant }}$ ( $\left.\boldsymbol{\mu m o l e s} \mathbf{~ k g}^{-1}\right)$ in the $\mathrm{yr}^{-1}$ (Bates 2007; Santana-Casiano et al. Antarctic Circumpolar Current: (a) TrOCA $-\Delta \mathbf{C}^{*}$; (b) $\mathbf{C}_{\mathbf{T}}{ }^{\circ}-\Delta \mathbf{C}^{*}$; 2007; Dore et al. 2009; Olafsson et al. (c) TTD $-\Delta$ C*; $^{*}$ and (d) GF $-\Delta C^{*}$. (Source: Pardo et al. 20I4.)

Large differences in storage rates have been observed on decadal and subdecadal time scales (Wanninkhof et al. 2010; Khatiwala et al. 2013).

\section{3) ANTHROpogenic ocean ACIDIFICATION}

Since the beginning of the Industrial Revolution the release of carbon dioxide $\left(\mathrm{CO}_{2}\right)$ from human industrial and agricultural activities has resulted in the release of approximately $555 \mathrm{Pg} \mathrm{C}$ into the atmosphere (Rhein et al. 2013; Fig. 3.37). During this period, the ocean has absorbed about $155 \mathrm{Pg} \mathrm{C}$ from the atmosphere, or a little more than a quarter of the total carbon emissions.

The uptake of excess $\mathrm{CO}_{2}$ from anthropogenic sources by the ocean lowers the $\mathrm{pH}$ and changes the chemical composition of seawater through the thermodynamic equilibrium of $\mathrm{CO}_{2}$ with seawater. When the excess $\mathrm{CO}_{2}$ is absorbed by seawater the dissolved $\mathrm{CO}_{2}$ forms a weak acid $\left(\mathrm{H}_{2} \mathrm{CO}_{3}\right)$, which dissociates in seawater such that the $\mathrm{pH}$, carbonate ion $\left(\mathrm{CO}_{3}{ }^{2-}\right)$, and calcium carbonate $\left(\mathrm{CaCO}_{3}\right)$ mineral saturation state $\left(\Omega=\left[\mathrm{Ca}^{2+}\right]\left[\mathrm{CO}_{3}{ }^{2-}\right] / \mathrm{Ksp}^{*}\right)$ of seawater decrease while bicarbonate ion $\left(\mathrm{HCO}_{3}{ }^{-}\right)$increases (Fig. 3.38). The uptake of $\mathrm{CO}_{2}$ in the surface ocean results in gradual decrease in the $\mathrm{pH}$ of seawater, a process commonly referred to as ocean acidification (Broecker and Clark 2001; Caldeira and Wickett 2003; Feely et al. 2009). Since the beginning of the industrial era there has been a decrease in surface open-ocean $\mathrm{pH}$ of 0.1 , corresponding to a $26 \%$ increase in the hydrogen ion concentration $\left[\mathrm{H}^{+}\right]$concentration of seawater (Orr et al. 2005; Doney et al. 2009; Feely et al. 2009).
The biological consequences of decreases in $\mathrm{pH}$ and $\mathrm{CO}_{3}{ }^{2-}$ on marine organisms and ecosystems are only recently being studied in detail (e.g., Orr et al. 2005; Orr 2011; Fabry et al. 2008; Doney et al. 2009; Gattuso and Hansson 2011).

Monthly observations at time series sites reflect changes in both the natural carbon cycle and the uptake of anthropogenic $\mathrm{CO}_{2}$ from the atmosphere. The observations are based on carbon system and $\mathrm{pH}$ measurements at ocean timeseries stations in the North Atlantic and North Pacific (Rhein et al. 2013). The results indicate decreasing $\mathrm{pH}$ with rates ranging between $-0.0014 \mathrm{yr}^{-1}$ and -0.0024 2009; González-Dávila et al. 2010; Bates 2012). There was good agreement between the long-term $\mathrm{pH}$ decreases in the Bermuda Atlantic Time Series (BATS; $-0.0019 \pm 0.0001$ ), European Station for Time Series in the Ocean (ESTOC; -0.0017 \pm 0.0001 ), and Hawaii Ocean time series (HOT) at station ALOHA $(-0.0018 \pm 0.0001)$. Data from the northernmost station off Iceland showed the largest $\mathrm{pH}$ decrease $(-0.0024 \pm 0.0002)$. Directly measured $\mathrm{pH}$ differences in the surface mixed layer from a CLIVAR/ $\mathrm{CO}_{2}$ Repeat Hydrography cruise section in the central North Pacific Ocean between Hawaii and

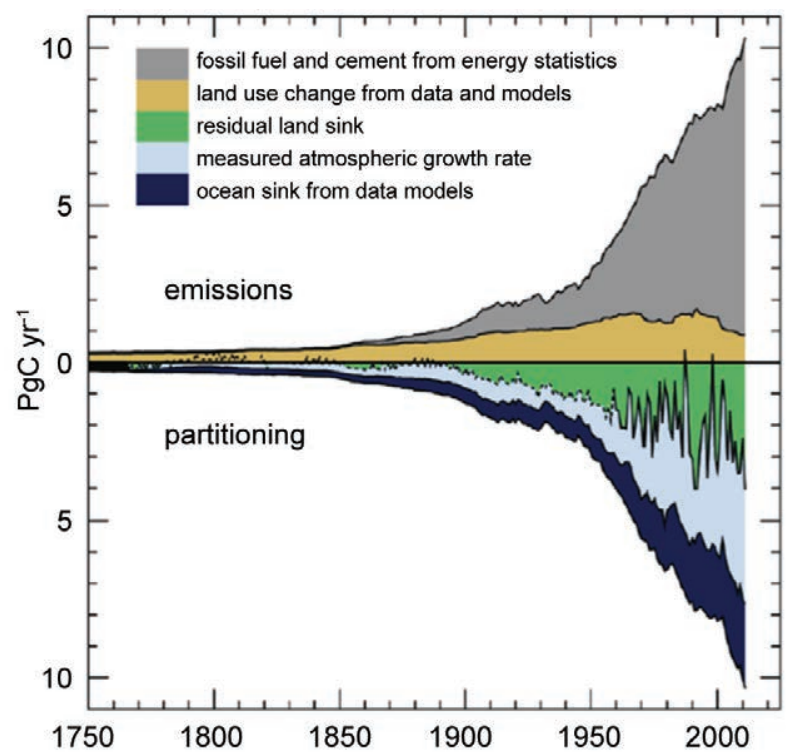

FIG. 3.37. Temporal changes in the partitioning of anthropogenic $\mathrm{CO}_{2}$ emissions between the atmosphere, oceans, and terrestrial biosphere. (Source: Ciais et al. 2013.) 

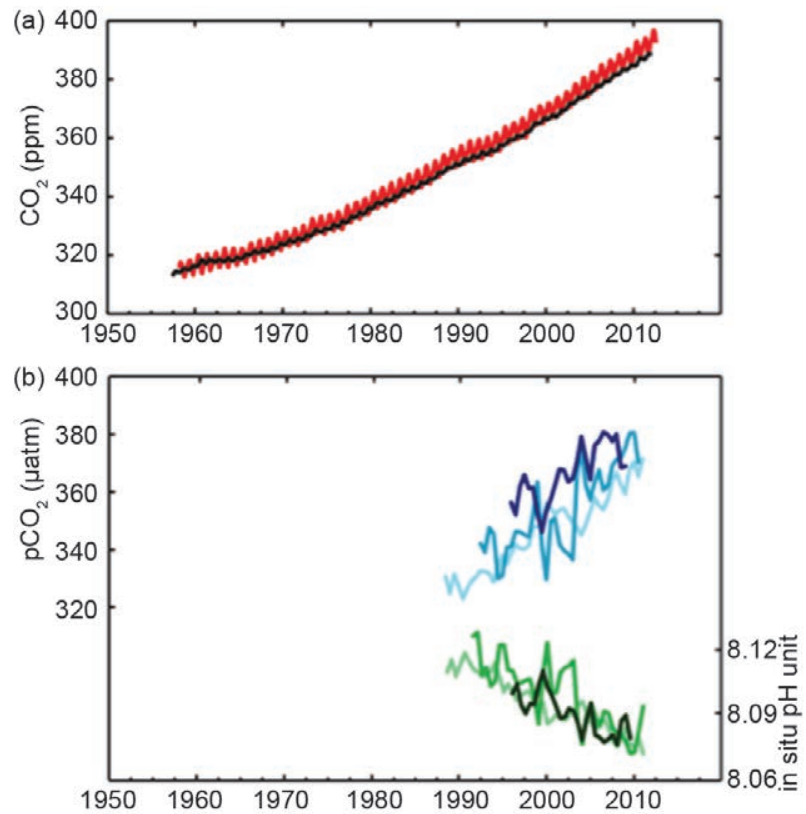

FIG. 3.38. Multiple observed indicators of a changing global carbon cycle: (a) atmospheric concentrations of carbon dioxide $\left(\mathrm{CO}_{2}\right)$ from Mauna Loa $\left(19^{\circ} 32^{\prime} \mathrm{N}\right.$,

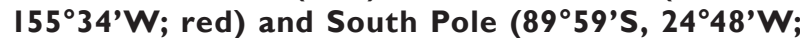
black) since 1958. (b) Partial pressure of dissolved $\mathrm{CO}_{2_{2}}$ at the ocean surface (blue curves) and in situ pH (green curves), a measure of the acidity of ocean water. Measurements are from three stations from the Atlantic ( $29^{\circ} 10^{\prime} \mathrm{N}, 15^{\circ} 30^{\prime} \mathrm{W}$, dark blue/dark green; $31^{\circ} 40^{\prime} \mathrm{N}$, $64^{\circ} 10^{\prime} \mathrm{W}$, light blue/light green) and the Pacific Oceans $\left(22^{\circ} 45^{\prime} \mathrm{N}, 158^{\circ} 00^{\prime} \mathrm{W}\right.$, blue/green) (Source: Alexander et al. 2013.)

Alaska showed a $\mathrm{pH}$ decline of $-0.0017 \mathrm{yr}^{-1}$ between 1991 and 2006, in agreement with observations at the HOT site (Byrne et al. 2010). This rate of $\mathrm{pH}$ change is also consistent with repeat transects of $\mathrm{CO}_{2}$ and $\mathrm{pH}$ measurements in the western North Pacific (winter: $-0.0018 \pm 0.0002 \mathrm{yr}^{-1}$; summer: $-0.0013 \pm 0.0005 \mathrm{yr}^{-1}$; Midorikawa et al. 2010). The $\mathrm{pH}$ changes in Southern Ocean surface waters are less certain because of the paucity of long-term observations there, but $\mathrm{pCO}_{2}$ measurements collected by ships-of-opportunity indicate similar rates of $\mathrm{pH}$ decrease there (Takahashi et al. 2009).

4) Global ocean phytoplankton-B. A. Franz, M. J. Behrenfeld, D. A. Siegel, and P. J. Werdell

Marine phytoplankton are responsible for roughly half the net primary production (NPP) on Earth, fixing atmospheric $\mathrm{CO}_{2}$ into food that fuels global ocean ecosystems and drives the ocean's biogeochemical cycles. Phytoplankton growth is highly sensitive to variations in ocean physical properties, such as upper ocean stratification and light availability within this mixed layer. Satellite ocean color sensors, such as the Sea-viewing Wide Field-of-view Sensor (SeaWiFS; McClain 2009) and Moderate Resolution Imaging Spectroradiometer (MODIS; Esaias 1998), provide observations of sufficient frequency and geographic coverage to globally monitor physically-driven changes in phytoplankton distributions. In practice, ocean color sensors retrieve the spectral distribution of visible solar radiation reflected upward from beneath the ocean surface, which can then be related to changes in the photosynthetic phytoplankton pigment, chlorophyll- $a$ (Chl $a$; measured in $\mathrm{mg} \mathrm{m}^{-3}$ ). Here, global Chla data for 2013 are evaluated within the context of the 16-year continuous record provided through the combined observations of SeaWiFS (1997-2010) and MODIS on Aqua (MODISA; 2002-present). Ocean color measurements from the recently launched Visible and Infrared Imaging Radiometer Suite (VIIRS; 2011-present) are also considered, but results suggest that the temporal calibration of the VIIRS sensor is not yet sufficiently stable for quantitative global change studies. All MODISA (version 2013.1), SeaWiFS (version 2010.0), and VIIRS (version 2013.1) data presented here were produced by NASA using consistent Chla algorithms.

Annual mean Chla concentrations from MODISA were computed in $4.6 \times 4.6 \mathrm{~km}^{2}$ equal area bins (Campbell et al. 1995) and mapped to an equirectangular projection. The resultant average Chla distribution for 2013 (Fig. 3.39) is consistent with the well-established, physically-driven distribution of

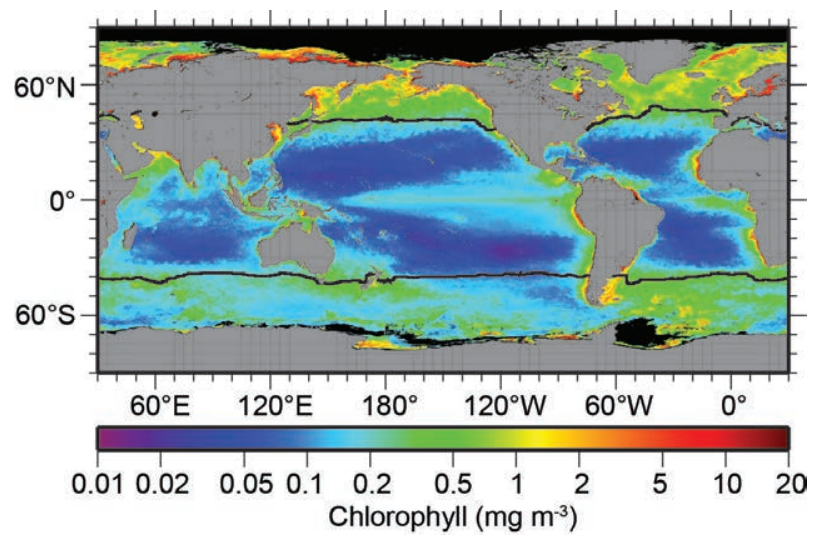

FIG. 3.39. Annual mean Chla distribution ( $\left.\mathrm{mg} \mathrm{m}^{-3}\right)$ derived from MODISA for 2013. Also shown is the location of the mean $15^{\circ} \mathrm{C} \mathrm{SST}$ isotherm (black lines) delineating the boundary of the permanently stratified ocean (PSO). Chla data are from the NASA Reprocessing of MODISA, version 2013.I. Data are averaged into geo-referenced equal area bins of approximately $4.6 \times$ $4.6 \mathrm{~km}^{2}$ (Campbell et al. 1995) and mapped to an equirectangular projection centered at $150^{\circ} \mathrm{W}$. 
nutrients (e.g., Siegel et al. 2013). Chla values during 2013 ranged over three orders of magnitude, from $<0.05 \mathrm{mg} \mathrm{m}^{-3}$ in the central ocean gyres to $>50 \mathrm{mg} \mathrm{m}^{-3}$ in nutrient-rich coastal and subpolar waters. Global changes in Chla during this past year were calculated for each geographic bin by subtracting monthly average values for 2013 from values during 2012, and then averaging the monthly anomaly fields to produce an annually-averaged distribution (Fig. 3.40a). Identical calculations were performed on MODISA SST $\left({ }^{\circ} \mathrm{C}\right)$ data to produce an equivalent 2013 SST anomaly (Fig. 3.40b). Positive correlations and inverse correlations between these Chla and SST anomalies are shown in Fig. 3.40c, following the graphical approach of O’Malley et al. (2010). Chlorophyll concentrations during 2013 were also compared to values for the full MODISA mission lifespan (Fig. 3.41). For this analysis, monthly climatological average Chl $a$ values (2002-13) were subtracted from monthly values for each year to produce an anomaly time series.

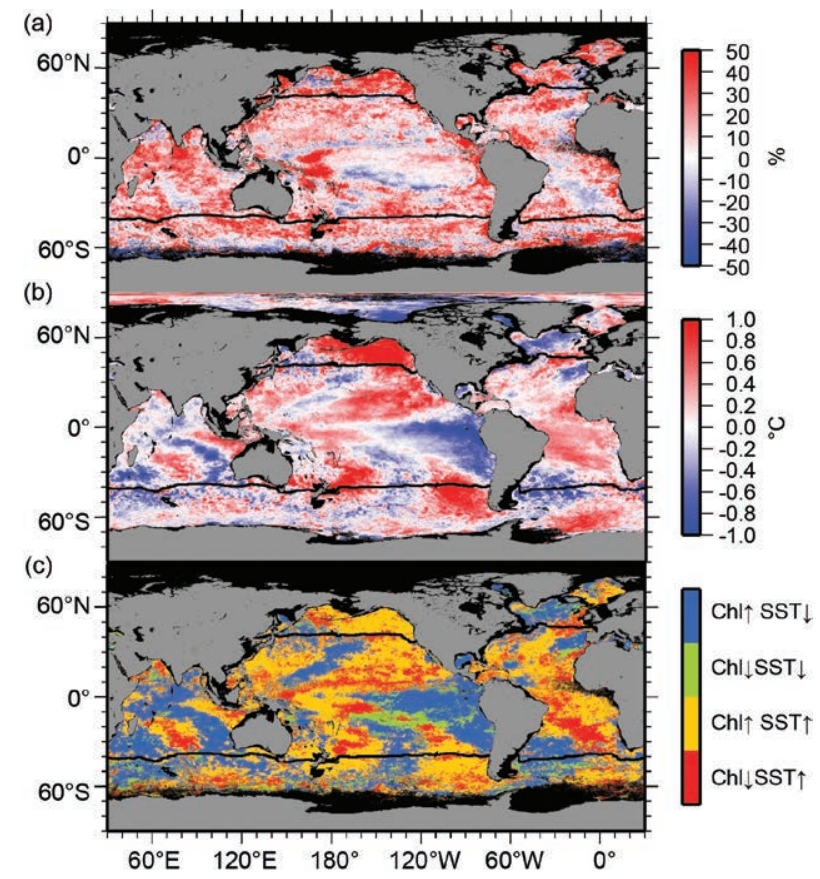

FIG. 3.40. Spatial distribution of summed monthly (a) Chla anomalies (\%) and (b) SST anomalies $\left({ }^{\circ} \mathrm{C}\right.$ ) for MODISA, where monthly differences were derived relative 2012 data. Chla is expressed as \% difference from 20I2, while SST is shown as an absolute difference. Panel (c) identifies relationships between the sign of SST and Chla anomalies from panels (a) and (b), with colors differentiating sign pairs. Also shown in each panel is the location of the mean $15^{\circ} \mathrm{C} \mathrm{SST}$ isotherm (black lines) delineating the permanently stratified ocean.
In Figs. 3.39 and 3.40, black lines at approximately $40^{\circ} \mathrm{N}$ and $40^{\circ} \mathrm{S}$ delineate the relatively stable, permanently-stratified ocean (PSO) from higherlatitude systems, where strong seasonality in surface mixing, temperature, and sunlight drive strong annual plankton cycles. The PSO occupies $\sim 74 \%$ of the global ocean surface area, maintains annual-average surface temperatures $>15^{\circ} \mathrm{C}$, and remains perpetually depleted in surface nutrients (Behrenfeld et al. 2006). Previous studies and annual State of the Climate assessments (e.g., Behrenfeld et al. 2006; O’Malley et al. 2010; Siegel et al. 2012) have demonstrated significant inverse correlations between chlorophyll and SST anomalies for the PSO. The expectation for these stratified waters is that a warming sea surface layer is associated with shallower mixing depths, reduced vertical nutrient transport, and higher average mixed layer light levels that together drive decreases in phytoplankton chlorophyll (Behrenfeld et al. 2006). Consistent with these earlier studies, the 2013 versus 2012 anomalies show that regions of decreasing SST (a proxy for stratification) (Fig. 3.40b) were associated with increasing Chla (Fig. 3.40a). The predominance of this relationship is illustrated in Fig. 3.40c by the abundance of blue pixels relative to green. However, the surprising finding for 2013 was that the opposite relationship of decreasing Chla with increasing SST was not equally prominent (i.e., red pixels do not clearly outnumber yellow pixels in Fig. 3.40c). In particular, regions of strong warming across the $\mathrm{Pa}$ cific were often dominated by increases in Chla (Fig. 3.40c). The reason for this discrepancy from previous years is not clear, but an issue with MODISA Chla retrievals during the past two years cannot yet be ruled out. Regarding this latter possibility, it is noted that: (1) monthly average Chla values during 2012 were at times lower than during the extreme 1998 El Niño year (Fig. 3.41a), yet surface ocean physical properties were not so anomalous during 2012 as in 1998, and (2) the rise in Chla during 2013 (Fig. 3.41a) was expressed throughout almost the entirety of the global ocean (i.e., Fig. 3.40a is predominantly red), which is inconsistent with previous years, including the extreme 1998 event (Behrenfeld et al. 2001).

The multimission record of monthly mean Chla for the PSO, starting with the SeaWiFS mission and extending into the MODISA and VIIRS eras (OBPG 2013), exhibits three primary features shown in Fig. 3.41a: (1) annual maxima in Chla associated with Northern Hemisphere spring-summer phytoplankton blooms; (2) a general offset between MODISA and SeaWiFS data during their 2002 to 2010 overlap 

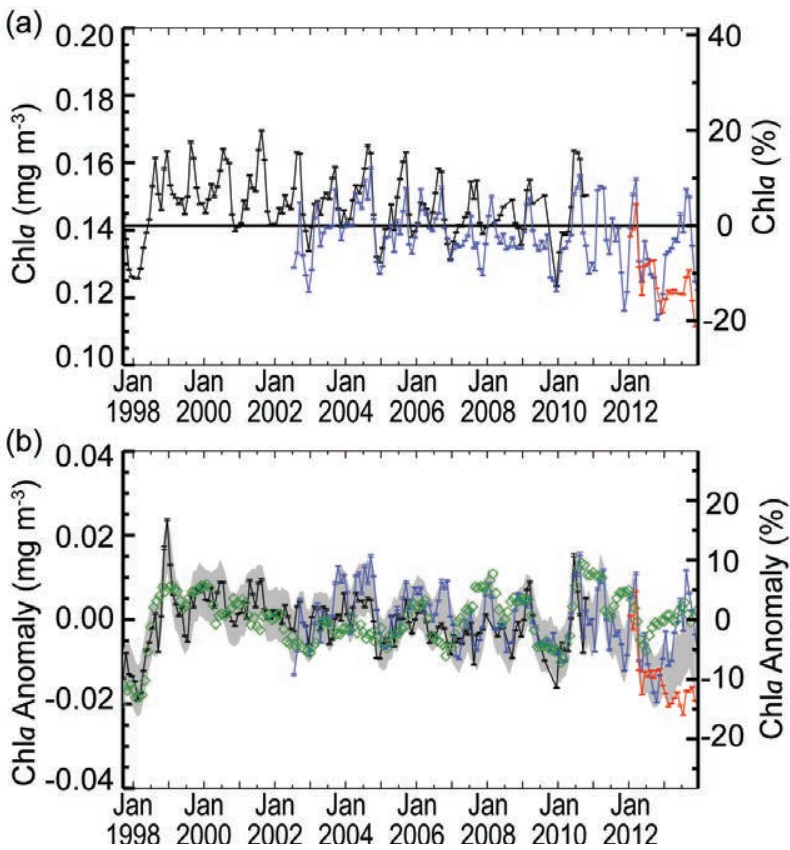

FIG. 3.4I. Sixteen-year, multimission record of Chla [mg m-3 (left) and \% (right)] averaged over the PSO for SeaWiFS (black), MODISA (blue), and VIIRS (red): (a) Independent record from each mission, with horizontal black line indicating the multi-mission mean Chla concentration for the region, and (b) monthly anomaly after subtraction of the monthly climatological mean (SeaWiFS relative to SeaWiFS climatology, MODISA and VIIRS relative to MODISA climatology). The gray region in (b) shows the averaged difference between SeaWiFS and MODISA over the common mission lifetime. Green diamonds show the multivariate ENSO index, inverted and scaled to match the range of the Chla anomalies.

period; and (3) a strong divergence between MODISA and VIIRS Chla for 2013. Regarding the latter feature, the trend in the VIIRS record through 2013 is flat or declining and remains near a historic low. This inconsistent behavior is believed to be due to temporal changes in radiometric performance of the VIIRS instrument that are currently being assessed.

With respect to SeaWiFS and MODISA data, the offset between sensors is essentially eliminated in the time series of Chla monthly anomalies (Fig. 3.41b). Also shown in Fig. 3.41b is the multivariate ENSO index (MEI; Wolter and Timlin 1998), which generally tracks large-scale temporal variability in the monthly mean PSO Chla record (Behrenfeld et al. 2006; Franz et al. 2013). Over the 16-year time series, Chla concentrations in the PSO have varied by $\pm 15 \%$ around a long-term mean of approximately $0.14 \mathrm{mg} \mathrm{m}^{-3}$, with largest variations generally associated with El Niño to La Niña climatic events. Mean
Chla concentrations in the PSO trended upward from late 2012 to October 2013, for a total increase of approximately $10 \%$, and then declined during the last few months of 2013. This range of variability in MODISA Chla is within the envelope of the long-term record, and the directional character of the trends is consistent with expectations based on the change in MEI, but as previously discussed the magnitude of the change between 2012 and 2013 may not be accurately quantified in the current satellite record. The trend in VIIRS data for 2013, on the other hand, is entirely inconsistent with MEI changes thus adding support for the conclusion that VIIRS trends in 2013 are dominated by instrumental error (Fig. 3.41b). These errors and uncertainties in the 2012 and 2013 ocean color records from MODISA and VIIRS can potentially be reduced as more calibration data are collected and instrument radiometric degradation models are improved, but the results illustrate the caution that must be taken when interpreting ocean color measurements that are so highly sensitive to instrument calibration and characterization accuracy (Siegel and Franz 2010).

Caution is also warranted in the interpretation of satellite-observed temporal trends in Chla concentration as indicators of climate-driven changes in phytoplankton net primary production (Behrenfeld et al. 2008; Siegel et al. 2013). Phytoplankton adjust their cellular chlorophyll content in response to environmental changes in light and nutrient availability, and this physiological response can contribute an order of magnitude variability in Chla that can dominate monthly to interannual variations in PSO anomalies. As such, changes in the satellite time series can either reflect physiological variability or changes in abundance, with these two sources of variability having strongly divergent implications on NPP. Interpretation of the Chla record is also complicated by limitations in the ability to separate optical signals of phytoplankton abundance from colored dissolved organic matter, which is simply assumed to co-vary in the traditional band-ratio algorithms employed here (e.g., Siegel et al. 2013). 
4. THE TROPICS - H. J. Diamond, Ed.

a. Overview-H. J. Diamond

From the standpoint of the El Niño-Southern Oscillation (ENSO), indications are that ENSO-neutral conditions prevailed throughout the year, though mostly on the cool side of neutral.

Overall, global tropical cyclone (TC) frequency during 2013 was slightly above average with a total of 94 storms (the 1981-2010 global average is 89), and was higher than in the previous three seasons, including 2010, which featured the lowest numbers of global TCs since the start of the satellite era (generally considered to have begun after 1970). Only the Western North Pacific Basin experienced abovenormal activity in 2013; all other basins were either at or below normal levels. Globally, only four TCs reached the Saffir-Simpson hurricane wind scale Category 5 intensity level-three in the Western North Pacific Basin and one in the North Indian Ocean. This number of TCs (four) was just one more than the all-time lowest global number of Category 5 storms (recorded in both 2011 and 2012) since the Dvorak intensity estimation method was introduced in the 1980s (Diamond 2012).

This chapter consists of eight sections: (1) ENSO and the tropical Pacific; (2) tropical intraseasonal activity; (3) seasonal TC activity in the seven TC basins: the North Atlantic, Eastern North Pacific, Western North Pacific, North Indian and South Indian Oceans, Southwest Pacific, and Australia; (4) TC heat potential, which aids in summarizing the section for TCs from an ocean heat perspective; (5) global monsoon summary; (6) intertropical convergence zone behavior in the Pacific and Atlantic basins; (7) the Atlantic warm pool (AWP); and (8) the Indian Ocean dipole. The global monsoon summary section is new in response to feedback received for the inclusion of such a global summary. It is not intended to replace the more detailed monsoon descriptions included in the Regional Climates chapter. Finally, two sidebar articles detailing the unusually quiet North Atlantic hurricane season and the unique and destructive nature of the Western North Pacific Basin's Typhoon Haiyan are also included. b. ENSO and the Tropical Pacific-G. D. Bell, M. L'Heureux, and M. Halpert

I) OCEANIC CONDITIONS

ENSO is a coupled ocean-atmosphere phenomenon over the tropical Pacific Ocean. Opposite phases of ENSO, El Niño and La Niña, are classified by NOAA's Climate Prediction Center (CPC) using the Niño-3.4 index, which is based on the area-averaged sea surface temperature (SST) anomalies in the eastcentral equatorial Pacific $\left(5^{\circ} \mathrm{N}-5^{\circ} \mathrm{S}, 170^{\circ}-120^{\circ} \mathrm{W}\right)$.

A time series of the weekly Niño-3.4 index for 2013 shows slightly cooler-than-average SSTs throughout the year, with departures generally in the range of $-0.2^{\circ}$ to $-0.4^{\circ} \mathrm{C}$ (Fig. $4.1 \mathrm{a}$ ). There were only three short periods in which the index became positive (early April, early September, and late November). The latter two periods were associated with the downwelling phases of equatorial oceanic Kelvin waves (see Fig. 4.7).

The Oceanic Niño index (ONI) is a three-month running average of the Niño-3.4 index, and is used by NOAA to monitor and predict ENSO and also to
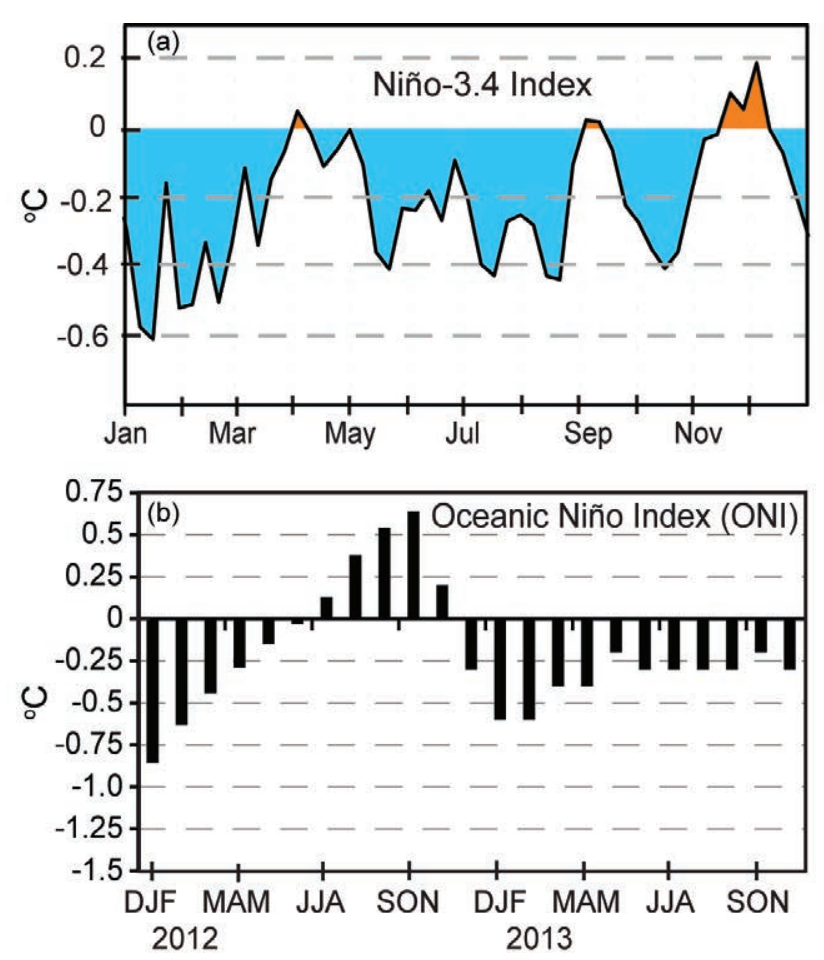

FIG. 4.I. Time series of (a) weekly SST anomalies $\left({ }^{\circ} \mathrm{C}\right)$ in the Niño-3.4 region $\left(5^{\circ} \mathrm{N}-5^{\circ} \mathrm{S}, 170^{\circ}-120^{\circ} \mathrm{W}\right)$ and $(\mathrm{b})$ the Oceanic Niño Index (ONI, ${ }^{\circ} \mathrm{C}$ ) from DJF 2012/13 through OND 2013. Values in (a) are departures from the 198I-2010 weekly adjusted OI climatology (Smith and Reynolds 1998). Values in (b) are derived from the ERSST-v3b dataset (Smith et al. 2008). 

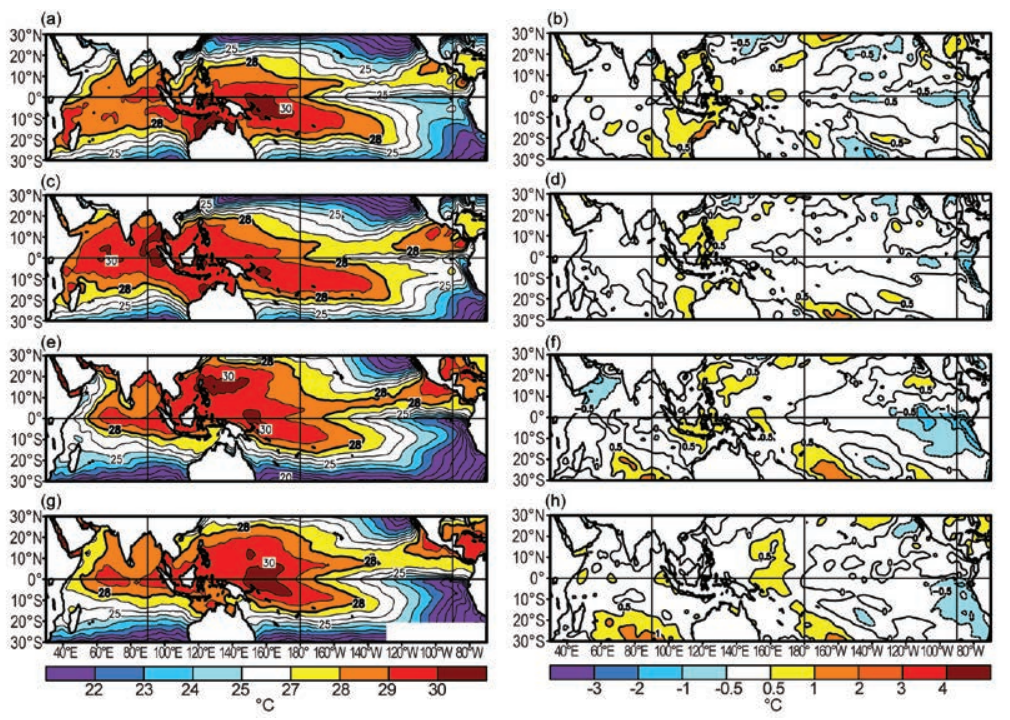

FIG. 4.2. Seasonal SST (left) and anomaly (right) for (a, b) DJF 20I2/13, (c, d) MAM 2013, (e, f) JJA 2013 and (g, h) SON 2013. Contour interval for total (anomalous) $\mathrm{SST}$ is $1^{\circ} \mathrm{C}\left(0.5^{\circ} \mathrm{C}\right)$. Anomalies are departures from the 198I-20I0 seasonal adjusted OI SST climatology (Smith and Reynolds 1998).

classify ENSO events historically1. A time series of the ONI shows values slightly cooler than $-0.5^{\circ} \mathrm{C}$ early in the year, followed by values near $-0.3^{\circ} \mathrm{C}$ for April-June (AMJ) though the end of the year (Fig. 4.1b). These values indicate ENSO-neutral conditions throughout the year, though mostly on the cool side of neutral.

The spatial structure and seasonal evolution of the tropical Pacific SSTs and anomalies during 2013 are shown in Fig. 4.2. Equatorial SSTs were slightly below average in the far eastern Pacific throughout the year, and above average in the far western Pacific especially during the latter part of the year (Fig. 4.2h). Consistent with these conditions, subsurface temperatures in the vicinity of the oceanic thermocline were above average west of the dateline throughout the year (Fig. 4.3), and below average in the eastern Pacific during DecemberFebruary (DJF) 2012/13 through June-August (JJA) 2013 (Figs. 4.3b-d). Temperatures along the thermocline were also above average over the central equatorial Pacific during JJA and September-November (SON), reflecting a gradual build-up of oceanic heat content over the course of the year (Figs. $4.3 \mathrm{c}, \mathrm{d}$ ).

\footnotetext{
${ }^{1}$ For historical purposes, the CPC classifies an El Niño (La Niña) episode when the Oceanic Niño index (ONI) is greater (less) than or equal to $+0.5^{\circ} \mathrm{C}\left(-0.5^{\circ} \mathrm{C}\right)$ for five consecutive overlapping seasons (as measured by the ERSST-v3b dataset, Smith et al. 2008); see http:// www.cpc.ncep.noaa.gov/products/analysis_monitoring/ensostuff /ensoyears.shtml.
}

\section{2) AtMospheric circulation}

On the whole, near-average atmospheric wind and convection patterns reflected ENSO-neutral throughout the year (Figs. 4.4, 4.5). The main wind anomalies were found over the western equatorial Pacific during DJF through JJA, in association with anomalous low-level easterly winds (Fig. $4.4 \mathrm{a}-\mathrm{c}$ ) and anomalous upper-level southwesterly winds (Fig. 4.5a-c). This wind pattern was associated with enhanced convection over the Maritime Continent and far western equatorial Pacific, and with above-average SSTs in the western Pacific. In contrast, convection was slightly suppressed near the dateline during much of the year.

During JJA, the low-level circulation also featured anomalous westerly winds extending from the eastern sub-

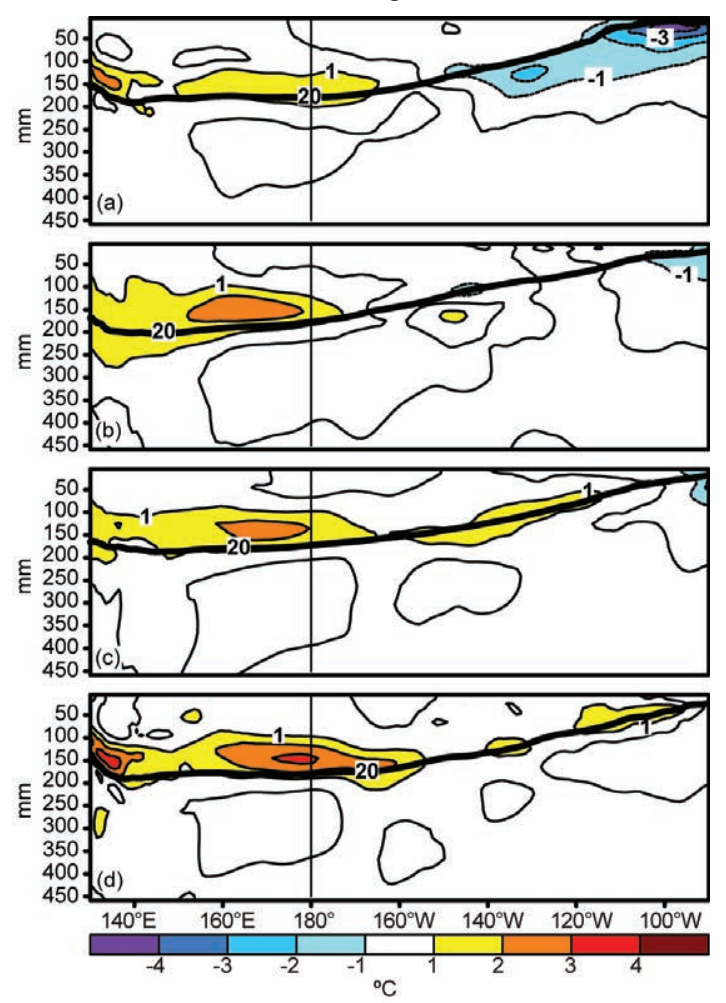

FIG. 4.3. Equatorial depth-Iongitude section of ocean temperature anomalies $\left({ }^{\circ} \mathrm{C}\right.$ ) averaged between $5^{\circ} \mathrm{N}$ and $5^{\circ} \mathrm{S}$ during (a) DJF 20I2/I3, (b) MAM 20I3, (c) JJA 2013 , and (d) SON 20I3. The $20^{\circ} \mathrm{C}$ isotherm (thick solid line) approximates the center of the oceanic thermocline. The data are derived from an analysis system that assimilates oceanic observations into an oceanic GCM (Behringer et al. 1998). Anomalies are departures from the $1981-2010$ period monthly means. 
(a)
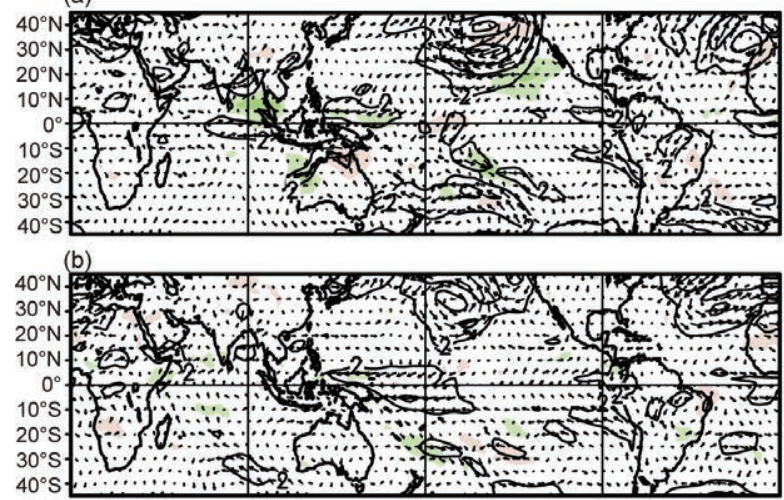

(c)
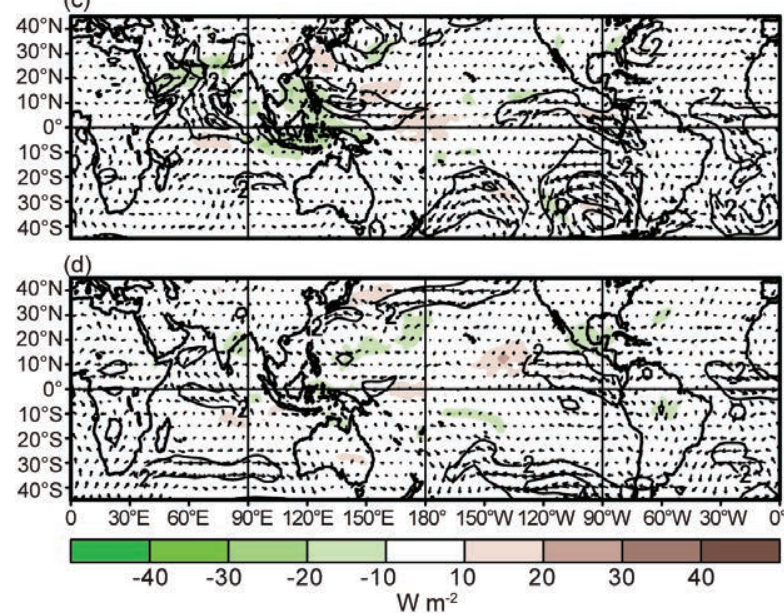

Fig. 4.4. Anomalous $850-\mathrm{hPa}$ wind vectors and speed (contours, $\mathrm{m} \mathrm{s}^{-1}$ ), and anomalous OLR (shaded, $\mathrm{W} \mathrm{m}^{-2}$ ), during (a) DJF 20I2/I3, (b) MAM 20I3, (c) JJA 20I3, and (d) SON 2013. Anomalies are departures from the I98I-20I0 period monthly means.

tropical North Pacific to equatorial western Africa (Fig. 4.4c). This pattern has been present since 1995 and is partly associated with the warm phase of the Atlantic multidecadal oscillation and concurrent enhancement of the west African monsoon system (G. D. Bell et al. 2011, 2013).

c. Tropical intraseasonal activity-S. Baxter, J. Gottschalck, and G. D. Bell

Tropical intraseasonal variability was prominent during 2013 in both the atmosphere and ocean. Three aspects of this variability included the Madden-Julian oscillation (MJO; Fig. 4.6; Madden and Julian 1971, 1972, 1994; Zhang 2005), atmospheric Kelvin and equatorial Rossby waves (Wheeler and Kiladis 1999; Wheeler and Weickmann 2001), and equatorial oceanic Kelvin wave activity (Fig. 4.7). There were three distinct periods of MJO activity, spanning a total of eight months. There were two distinct periods of nearly two months each (Fig. 4.6, blue boxes), dur- (a)

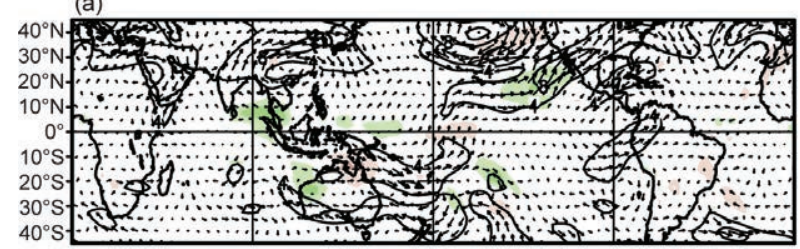

(b)

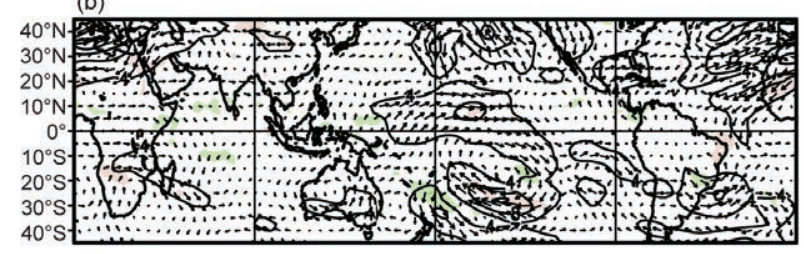

(c)

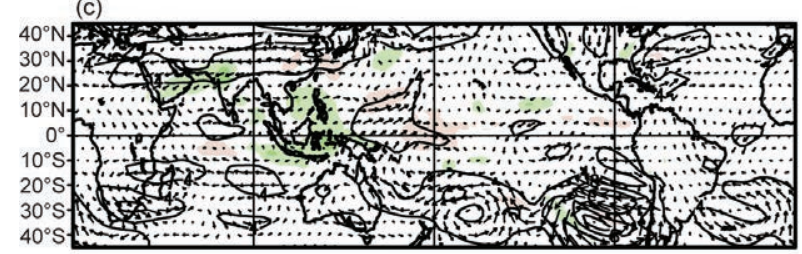

(d)

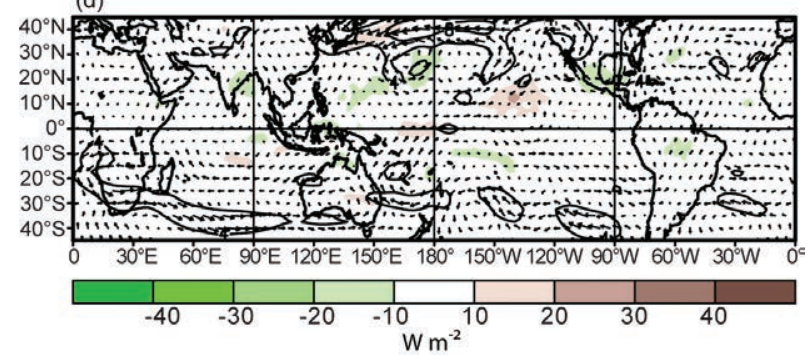

FIG. 4.5. Anomalous 200-hPa wind vectors and speed (contours, $\mathrm{m} \mathrm{s}^{-1}$ ), and anomalous OLR (shaded, $\mathbf{W} \mathrm{m}^{-2}$ ), during (a) DJF 20I2/I3, (b) MAM 20I3, (c) JJA 20I3, and (d) SON 2013. Anomalies are departures from the I98I-20I0 period monthly means.

ing which rapidly propagating atmospheric Kelvin waves dominated the pattern of tropical convective variability. There were also three occurrences each of downwelling and upwelling oceanic Kelvin waves, collectively spanning nearly eight months.

The MJO is a leading climate mode of tropical convective variability that occurs on intraseasonal timescales. The convective anomalies associated with the MJO often have the same spatial scale as ENSO, but differ in that they exhibit a distinct eastward propagation and generally traverse the globe in 30-60 days. The MJO can strongly affect the tropical and extratropical atmospheric circulation patterns, and may produce ENSO-like anomalies on subseasonal timescales (Knutson and Weickmann 1987; Kiladis and Weickmann 1992; Mo and Kousky 1993; Kousky and Kayano 1994; Kayano and Kousky 1999; Riddle et al. 2012). The MJO is often quite variable in a given year, with periods of moderate-to-strong activity sometimes followed by little or no activity. Overall, 


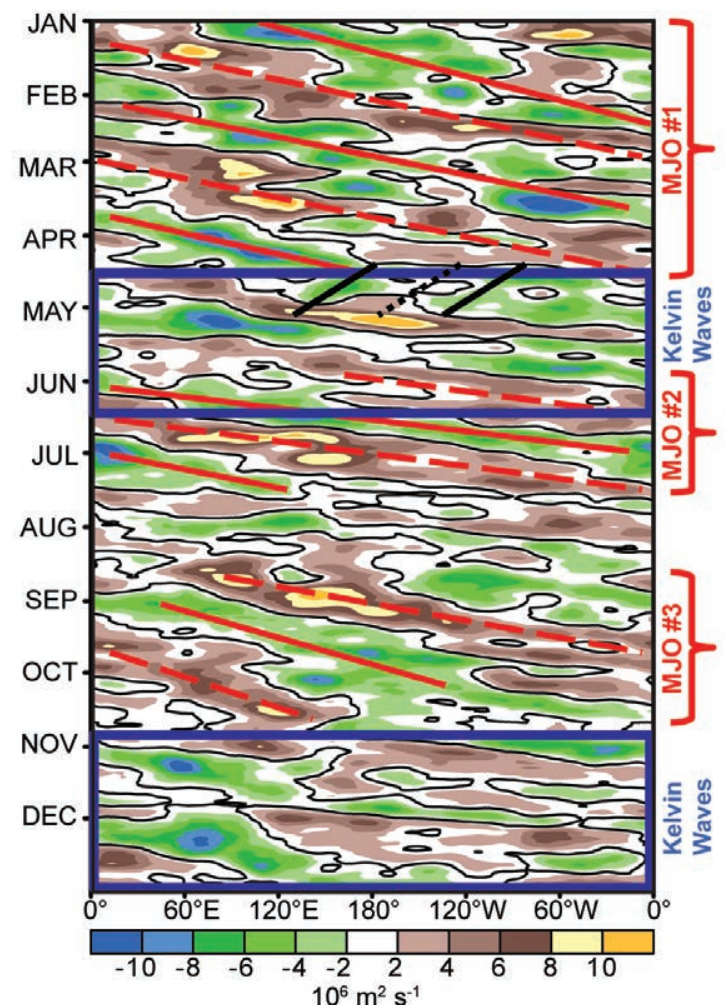

Fig. 4.6. Time-longitude section for 2013 of anomalous $200-\mathrm{hPa}$ velocity potential $\left(\times 10^{6} \mathrm{~m}^{2} \mathrm{~s}^{-1}\right)$ averaged between $5^{\circ} \mathrm{N}$ and $5^{\circ} \mathrm{S}$. For each day, the period mean is removed prior to plotting. Green (brown) shading highlights likely areas of anomalous divergence and rising motion (convergence and sinking motion). Red lines and labels highlight the main MJO episodes. Blue boxes denote periods of atmospheric Kelvin wave activity discussed in text, and solid (dotted) black lines denote enhanced (suppressed) convective phases of an important equatorial atmospheric Rossby wave. Anomalies are departures from the 1981-2010 base period daily means.

the MJO tends to be most active during neutral and weak ENSO periods, and is often absent during strong El Niño events (Hendon et al. 1999; Zhang and Gottschalck 2002; Zhang 2005).

The MJO may be diagnosed as continuous eastward propagation of $200-\mathrm{hPa}$ velocity potential anomalies around the globe. A time-longitude section of this parameter shows the three main MJO episodes during 2013 (Fig. 4.6), which included (1) a strong and long-lived episode from January to early April (MJO \#1); (2) a strong, short-lived, and rapidly propagating episode from June to early July (MJO \#2); and (3) a long-lived episode during much of September and October (MJO \#3).

The first MJO episode (MJO \#1) featured a zonal wave-1 pattern of strong convective anomalies and had a periodicity of approximately 45 days. Both the enhanced convective phase (negative anomalies) and suppressed convective phase (positive anomalies) of this MJO propagated around the globe nearly three times. The event ended during April when westwardpropagating atmospheric equatorial Rossby waves became the dominant feature (Fig. 4.6, black lines).

Some of the largest impacts from this prolonged MJO episode include the triggering of a downwelling oceanic Kelvin wave and interaction with the extratropics. The Kelvin wave was triggered during early February by a relaxation of the trade winds as enhanced convection propagated eastward across the Maritime Continent. This wave reached the eastern Pacific in March and resulted in a vastly decreased magnitude of negative upper-ocean heat content anomalies (Fig. 4.7).

The extratropical impacts from MJO \#1 were most prominent in March and were associated with a combination of suppressed convection and anomalous upper-level convergence over the eastern Indian Ocean and anomalous upper-level divergence over the eastern Pacific Ocean. These conditions likely contributed to an eastward extension of the East Asian jet stream and to an intensifying negative phase of the Arctic Oscillation during March (see Fig. A1.4; H.

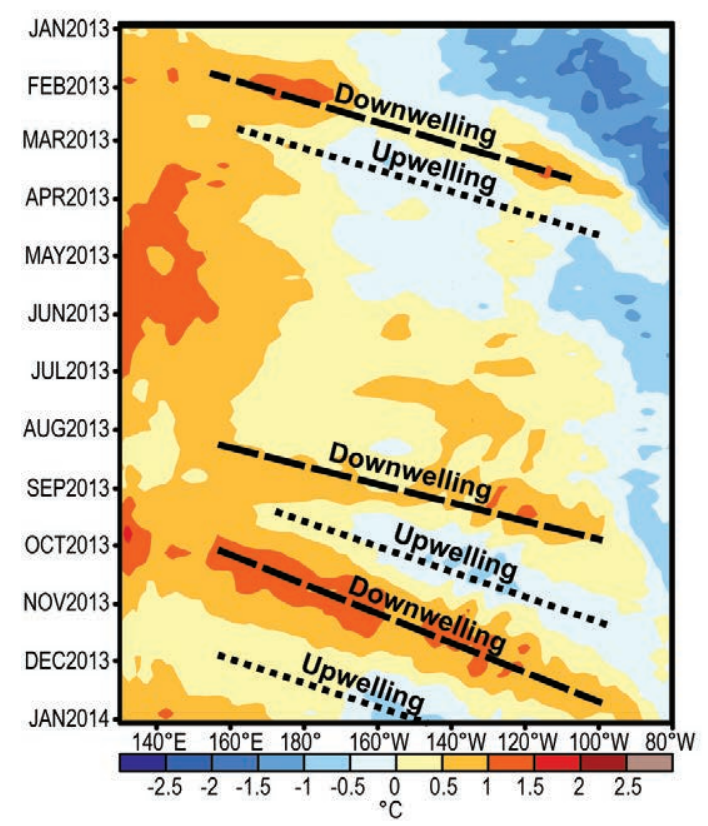

FIG. 4.7. Time-longitude section for 2013 of the anomalous upper Pacific Ocean (0-300 m) heat content averaged between $5^{\circ} \mathrm{N}$ and $5^{\circ} \mathrm{S}$. Blue (yellow/red) shading indicates below (above) average heat content. The downwelling (dashed lines) and upwelling (dotted lines) phases of equatorial oceanic Kelvin waves are indicated. Anomalies are departures from the 198I-2010 base period pentad means. 
Lin et al. 2009; Cassou 2008), which had substantial extratropical impacts that included anomalously cold surface air temperatures during March across central Canada, the east-central United States, much of Europe, north west Russia, and parts of Japan (see Fig. A1.3).

This MJO was followed by a two-month period in which atmospheric Kelvin waves, indicated by a faster propagation of the velocity potential anomalies, were the prominent intraseasonal features in the tropical atmosphere (Fig. 4.6, blue boxes). The second MJO episode of 2013 (MJO \#2, Fig. 4.6) began in June and ended in early July. As is common with many MJO episodes, its convective signal was partially masked by the atmospheric Kelvin wave activity, which resulted in a faster eastward propagation of the velocity potential anomalies (Roundy 2012; Sobel and Kim 2012). This MJO event exhibited phase speed on the high end of the MJO envelope, with a period of roughly 30 days.

The third MJO episode (MJO \#3) of 2013 lasted from early September through late October, with a periodicity of approximately 50 days. In early and mid-September, the enhanced phase of this MJO propagated eastward across the western and central Pacific and the suppressed phase propagated across the Western Hemisphere. This configuration likely contributed to an uptick in tropical cyclone activity across the Western North Pacific Basin, while helping to suppress activity across the Eastern North Pacific and Atlantic Basins (Mo 2000; Klotzbach 2010). By mid-October the enhanced phase of this MJO had propagated across the tropical Atlantic Ocean but did little to enhance Atlantic TC activity. Other than June, this was the only instance during 2013 in which the MJO was conducive to Atlantic TC activity.

Also associated with $\mathrm{MJO}$ \#3, enhanced convection over the western equatorial Pacific during October helped to weaken the trade winds and initiate a downwelling equatorial oceanic Kelvin wave similar to that associated with MJO \#1. This wave was the strongest of the year and eventually reached the South American coast in late December (Fig. 4.7). During November and December, the tropical intraseasonal variability again featured a series of atmospheric Kelvin waves. Additionally during early November and again in early December, there were impressive bursts of convective activity over the Indian Ocean, which may have been triggered by the atmospheric Kelvin waves but subsequently exhibited little eastward propagation.

\section{d. Tropical Cyclones}

I) OVERVIEW-H. J. Diamond

The International Best Track Archive for Climate Stewardship (IBTrACS) comprises historical tropical cyclone (TC) best-track data from numerous sources around the globe, including all of the WMO Regional Specialized Meteorological Centers (RSMC; Knapp et al. 2010). To date, IBTrACS represents the most complete compilation of TC data and offers a unique opportunity to revisit the global climatology of TCs. Using IBTrACS data (Schreck et al. 2014, manuscript submitted to Mon. Wea. Rev.), a 30-year average value for storms (from WMO-based RSMC numbers) is noted for each basin.

The global tallying of total TC numbers is challenging and involves more than simply adding up basin totals because some storms cross basin boundaries, some basins overlap, and multiple agencies are involved in tracking and forecasting TCs. Compiling the activity (using WMO information) over all eight TC basins, the 2013 season (2012/13 in the Southern Hemisphere) had 94 named storms (wind speeds $\geq 34$ kts or $18 \mathrm{~m} \mathrm{~s}^{-1}$ ), which is slightly above the 1981-2010 average of 89 , and the 2013 total was higher than the previous three seasons, with 2010 having the lowest number of global named storms since the start of the satellite era. The 2013 season also featured 50 hurricanes/typhoons/cyclones (HTC; wind speeds $\geq 64$ kts or $33 \mathrm{~m} \mathrm{~s}^{-1}$ ), which is also above the 1981-2010 average of 44 HTCs (Knapp et al. 2010). Of these, 14 (below the global average of 19) reached major HTC status (wind speeds $\geq 96 \mathrm{kts}$ or $49 \mathrm{~m} \mathrm{~s}^{-1}$; WMO 2014).

There were four Category 5 systems during the year: Francisco, Lekima, and Haiyan (named Yolanda in the Philippines region) in the western North Pacific; and Phailin in the North Indian Ocean. This is one more Category 5 storm than during the previous two seasons in 2011 and 2012, which saw the lowest global number of Category 5 storms during the satellite era. However, there were several Category 3 and 4 intensity-level systems that had major impacts in 2013: (1) Evan, Freda, and Sandra in the southwest Pacific; (2) Lehar and Madi in the North Indian Ocean; (3) Danas, Utor, and Wipha in the western North Pacific; (4) Felleng in the South Indian Ocean; and (5) Rusty and Narelle in the Australian region.

The North Atlantic Basin season was unusually quiet despite the absence of El Niño conditions (see Sidebar 4.1 for more detailed information). The only basin with above-normal activity in 2013 was the Western North Pacific, which featured the most wellpublicized and destructive storm of the year: Super 
Typhoon Haiyan. The nature and climatology of Haiyan was unique and Sidebar 4.2 is included to better document this event.

2) Atlantic Basin-G. D. Bell, C. W. Landsea, S. B. Goldenberg, R. J. Pasch, E. S. Blake, J. Schemm, and T. B. Kimberlain

(i) 2013 Seasonal activity

The 2013 Atlantic hurricane season produced 13 named storms, of which only 2 became hurricanes, and none became major hurricanes. The HURDAT2 1981-2010 seasonal averages are 11.8 tropical storms, 6.4 hurricanes, and 2.7 major hurricanes (Landsea and Franklin 2013). The 2013 season ties 1982 for the

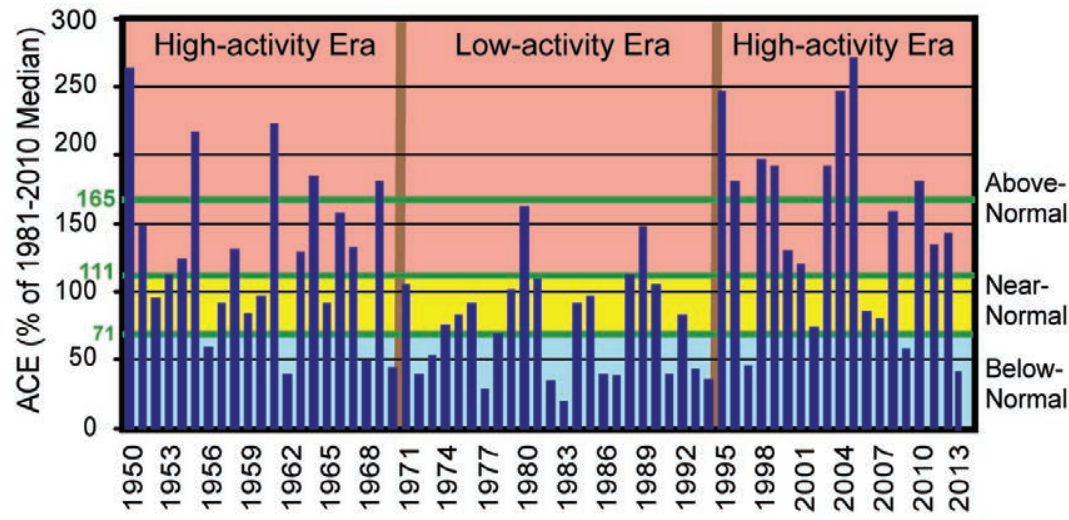

FIG. 4.8. NOAA's Accumulated Cyclone Energy (ACE) index expressed as percent of the $198 \mathrm{I}-2010$ median value. ACE is calculated by summing the squares of the 6-hourly maximum sustained wind speed (kt) for all periods while the storm is at least tropical storm strength. Pink, yellow, and blue shadings correspond to NOAA's classifications for above-, near-, and below-normal seasons, respectively. The $165 \%$ threshold for a hyperactive season is indicated. Vertical brown lines separate high- and low-activity eras. fewest hurricanes in the recent historical record from 1950 to present, and is the first season since 1994 with no major hurricanes. The entire life cycle of both hurricanes occurred within the period of 9-16 September.

The seasonal accumulated cyclone energy (ACE) value (Bell et al. 2000) was only $39 \%$ of the $1981-2010$ median (Fig. 4.8) ${ }^{2}$. This is the 10th lowest value since records began in 1950 and satisfies NOAA's criteria for a below-normal season (see http://www.cpc.ncep .noaa.gov/products/outlooks/background_information .shtml).

The 2013 ACE value, as well as the numbers of hurricanes and major hurricanes, are the lowest of the current high-activity era for Atlantic hurricanes that began in 1995 (Landsea et al. 1998; Goldenberg et al. 2001; Bell and Chelliah 2006; Bell et al. 2013). Thirteen seasons since 1995 (68\%) have been above normal and only three (16\%) have been below normal. Only one of these below-normal seasons (2013) occurred in the absence of El Niño, which is an indicator of how unusual the 2013 season was. In fact, the 2013 values for every parameter (except number of named storms) were below 1997, a year with one of the strongest El Niños in over 50 years. More details on the unusually quiet 2013 season can be found in Sidebar 4.1.

2 ACE is calculated by summing the squares of the six-hourly maximum sustained wind speed (knots) for all periods while the storm is at least tropical storm strength.

A main delineator between above- and belownormal seasons (Fig. 4.9) is the frequency of hurricanes and major hurricanes that originate as named storms within the main development region [MDR; green boxed region in Fig. 4.10a, which encompasses the tropical Atlantic Ocean and Caribbean Sea between $9.5^{\circ}$ and $21.5^{\circ} \mathrm{N}$ (Goldenberg et al. 2001; Bell and Chelliah 2006)]. Only six named storms formed in the MDR during 2013, producing one hurricane (Humberto) and having a total ACE value that was $18 \%$ of the median. These numbers are comparable to the average MDR activity of a below-normal season,

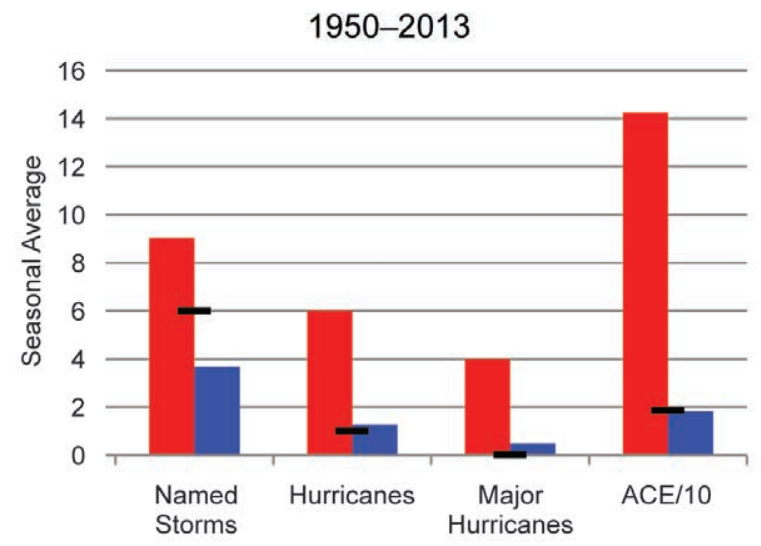

FIG. 4.9. Seasonal activity associated with storms first named in the Atlantic MDR. Red bars show the averages for above-normal seasons, blue bars show the averages for below-normal seasons, and black lines show the 2013 MDR activity. Season classifications are based on NOAA's criteria (see http://www.cpc.ncep .noaa.gov/products/outlooks/background_information .shtml). 
(a)
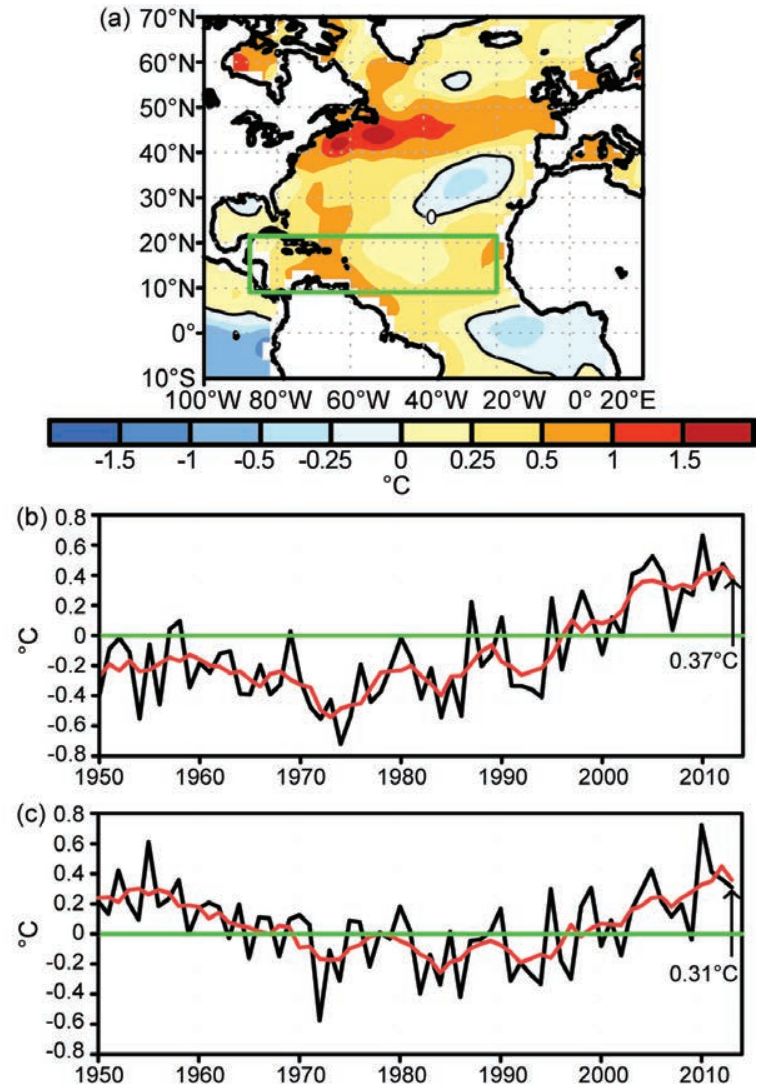

Fig. 4.10. (a) ASO $2013 \mathrm{SST}$ anomalies $\left({ }^{\circ} \mathrm{C}\right)$. (b) Time series during 1950-2013 of ASO area-averaged SST anomalies in the MDR [green box in (a)]. (c) Time series showing the difference between ASO areaaveraged SST anomalies in the MDR and those for the entire global tropics $\left(20^{\circ} \mathrm{N}-20^{\circ} \mathrm{S}\right)$. Red lines show a 5-pt. running mean of each time series. Anomalies are departures from the ERSST-v3b (Smith et al. 2008) 1981-2010 period monthly means.

and are at least six times lower than the above-normal season averages (six hurricanes and an ACE value of $142 \%$ of the median).

\section{(ii) Storm tracks}

The 2013 Atlantic hurricane season featured three distinct sets of storm tracks. The first was related to five named storms that formed over the central and eastern tropical and subtropical Atlantic. Only one of these storms made landfall-Tropical Storm Chantal in the Caribbean islands. The second set of tracks reflected three named storms that formed in the Bay of Campeche and made landfall in eastern Mexico. Of these storms, Ingrid was the only hurricane of the season to make landfall. The third set of tracks reflected two tropical storms that moved across the central Gulf of Mexico. One of these systems, Tropical Storm Andrea, was the first named storm of the season and the only U.S. landfalling storm, striking northwestern Florida before moving across southeastern Georgia and South Carolina and becoming extratropical in North Carolina.

\section{(iii) Atlantic sea surface temperatures}

SSTs in the MDR were above average during the peak months (August-October, ASO) of the season, with the largest departures (between $+0.5^{\circ}$ and $+1.0^{\circ} \mathrm{C}$ ) observed across the eastern half of the Caribbean Sea (Fig. 4.10a). The mean SST departure within the MDR was $+0.37^{\circ} \mathrm{C}$. This value is the seventh highest in the $1950-2013$ record (Fig. $4.10 \mathrm{~b}$ ) and is $0.3^{\circ} \mathrm{C}$ warmer than the average departure for the entire global tropics (Fig. 4.10c). This relative warmth within the MDR has been present since 1995 and is a feature of the warm phase of the Atlantic multidecadal oscillation (AMO; Enfield and Mestas-Nuñez 1999; Goldenberg et al. 2001; G. D. Bell et al. 2011, 2013), and this makes the relative inactivity for the season all the more unusual.

\section{(iv) Atmospheric circulation}

The below-normal Atlantic hurricane season was largely the result of a set of exceptionally nonconducive atmospheric conditions within the MDR. One suppressing factor was the presence of strong ( $\geq 8$ $\mathrm{m} \mathrm{s}^{-1}$ ) 200-850 $\mathrm{hPa}$ vertical wind shear across most of the tropical Atlantic Ocean, Caribbean Sea, and Gulf of Mexico (Fig. 4.11), with above-average shear observed across the Caribbean Sea and Gulf of Mexico (not shown). Areas of weaker shear were confined to the southeastern MDR and Bay of Campeche. This signal is in stark contrast to a typical above-normal season, which features weak shear across large portions of the MDR.

Also during ASO 2013, large areas within the MDR experienced anomalous upper-level conver-

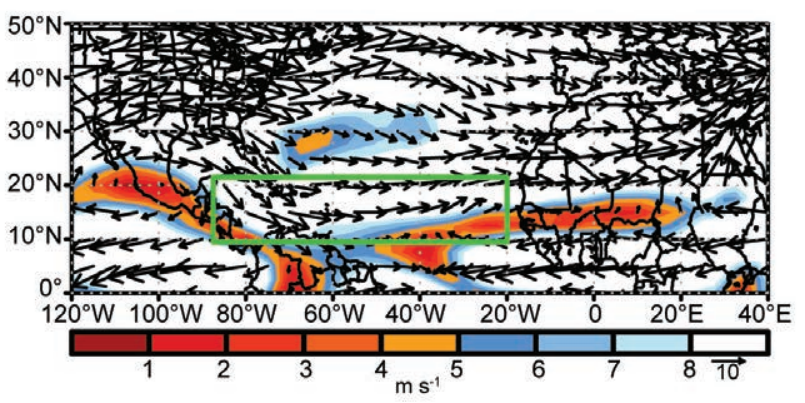

FIG. 4.II. ASO 2013 vertical wind shear magnitude and vectors $\left(\mathrm{m} \mathrm{s}^{-1}\right)$. Shading indicates areas where the vertical wind shear magnitude is $\leq 8 \mathrm{~m} \mathrm{~s}^{-1}$. Green box denotes the MDR. Vector scale is below right of color bar. 
gence and lower-level divergence (Fig. 4.12a), along with anomalous mid- and low-level sinking motion (Fig. 4.12b) and drier air (Fig. 4.12c). None of these conditions are conducive to TC formation. Furthermore, the conducive phase of the MJO (Mo 2000) did not substantially offset these non-conducive conditions since it was present for only a brief period in early September and mid-October (see Fig. 4.6).

Climate factors such as El Niño and the cold phase of the AMO can produce non-conducive conditions within the MDR, but neither of these factors were present during ASO 2013. Instead, the observed conditions were related to a strong and persistent anomalous 200-hPa wave pattern that extended from North America to the eastern North Atlantic (Fig. 4.13a). This wave pattern had no apparent large-scale climate links. Key features of this pattern (ridge and trough axes shown by thick black lines in Fig. 4.13c) include: (1) an amplified ridge extending northward from Mexico; (2) a downstream amplified trough over the western subtropical North Atlantic and Caribbean Sea (called the tropical upper-tropospheric trough, TUTT); and (3) an amplified ridge over the central and eastern subtropical North Atlantic.

This wave pattern contributed to the non-conducive conditions within the MDR in two primary ways. First, its associated northwesterly flow from the Great Lakes to the southern Caribbean Sea (Fig. 4.13a) produced anomalous northerly and northwesterly vertical wind shear across the entire Caribbean Sea, resulting in the anomalously strong shear observed across the western half of the MDR (Fig. 4.13b).

Second, the strong curvature of the wave pattern was likely the primary contributor to the anomalous upper-level convergence and sinking motion across

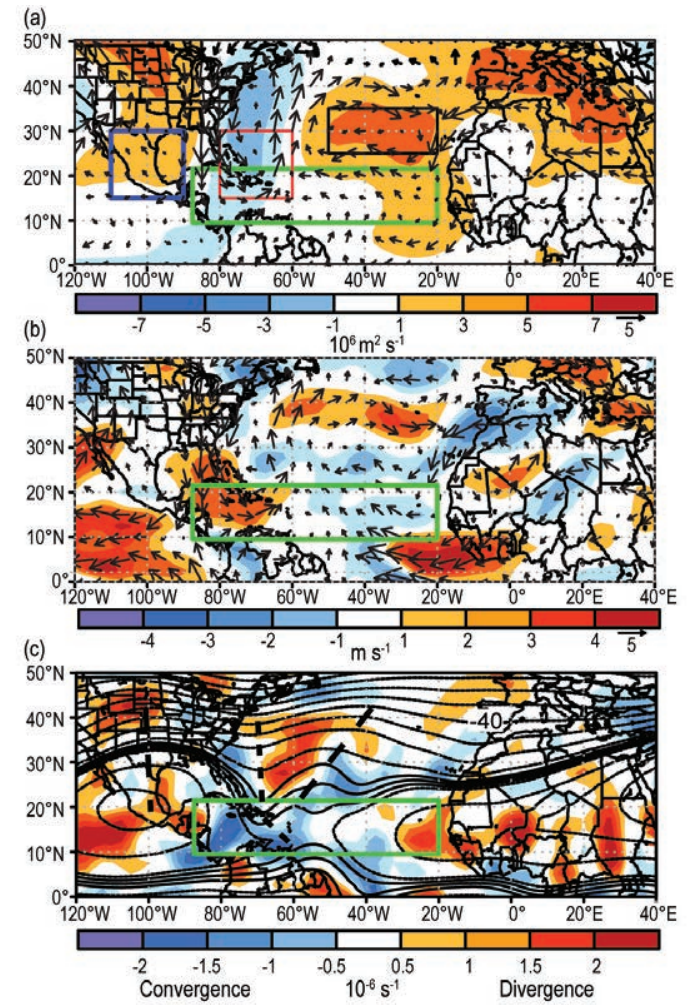

FIG. 4.13. ASO 2013 circulation and anomalies: (a) 200 $\mathrm{hPa}$ anomalous streamfunction (shaded, $\times 10^{-6} \mathrm{~m}^{2} \mathrm{~s}^{-1}$ ) and wind vector $\left(\mathrm{m} \mathrm{s}^{-1}\right),(\mathrm{b})$ 200-850 $\mathrm{hPa}$ anomalous magnitude of vertical wind shear and anomalous shear vector $\left(\mathrm{m} \mathrm{s}^{-1}\right)$, and (c) total $200-\mathrm{hPa}$ streamfunction (contours, interval is $5 \times 10^{6} \mathrm{~m}^{2} \mathrm{~s}^{-1}$, with additional solid contours at an interval of $\left.\mathrm{I} \times 10^{6} \mathrm{~m}^{2} \mathrm{~s}^{-1}\right)$ and anomalous divergence (shaded, $\times 10^{-6} \mathrm{~s}^{-1}$ ). Boxes in (a) show index regions for Figs. 4.14 and 4.15. Vector scales for $(a, b)$ are shown below right of color bar. Thick dashed lines in (c) identify ridge and trough axes of persistent wave pattern discussed in text. Green boxes in all panels indicate the MDR. Anomalies are based on the 198I-2010 climatology.
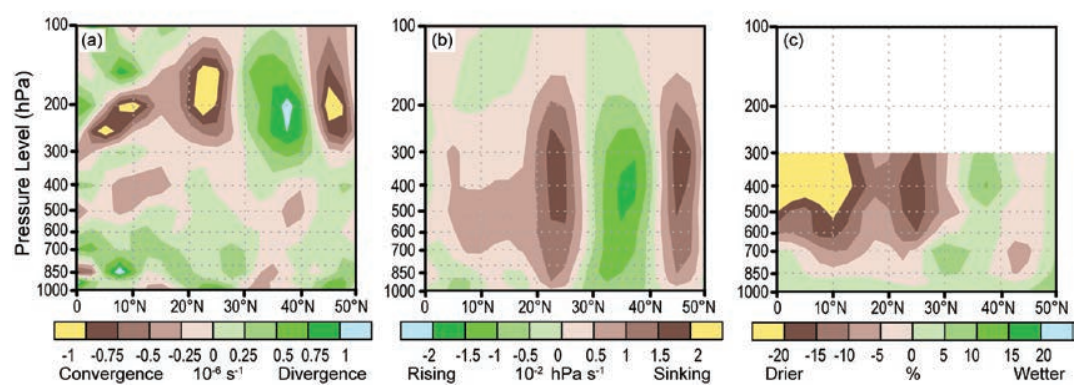

FIG. 4.I2. Aug-Oct 2013 height-latitude sections averaged between $40^{\circ}-60^{\circ} \mathrm{W}$ of (a) anomalous divergence $\left(\times 10^{-6} \mathrm{~s}^{-1}\right)$, (b) anomalous vertical velocity ( $\left.\times 10^{-2} \mathrm{hPa} \mathrm{s}^{-1}\right)$, and (c) percent of normal specific humidity. Green shading indicates anomalous divergence, anomalous rising motion, and increased moisture, respectively. Brown shading indicates anomalous convergence, anomalous sinking motion, and decreased moisture. Climatology and anomalies are with respect to the $1981-2010$ period monthly means. the western and central MDR. This area was part of a much larger region of upper-level convergence located between the amplified ridge (over Mexico) and the downstream TUTT axis, which is an area within midlatitude wave patterns known for upper-level convergence and descending motion. Similarly, a strong ridge within the eastern portion of the wave pattern contributed to the anomalous upper-level convergence and sinking motion over the central MDR, and also over the central subtropical North Atlantic north of the MDR. 
Given these relationships, it is of interest to quantify the relative strength of the 200-hPa wave pattern during ASO 2013, along with its historical frequency of occurrence. The analysis is based upon ASO standardized streamfunction indices for the three regions shown in Fig. 4.13a [Mexico (blue box), the Caribbean Sea and western subtropical North Atlantic (orange box), and the eastern North Atlantic (black box)].

The index time series (dating back to 1970) shows that streamfunction anomalies within the Caribbean Sea region (Fig. 4.14, orange bars) typically have the same sign as those in both the Mexico (Fig. 4.14a, blue bars) and east Atlantic (Fig. 4.14b, black bar) regions. These relationships are reflected in their strong index correlations ( 0.86 and 0.73 , respectively). In contrast, the ASO 2013 anomalies in the Caribbean Sea region had an opposite sign of the other two regions. There is only one other instance in the record (the belownormal 1994 season which featured three hurricanes, no major hurricanes, and an ACE of 35\% of the me-
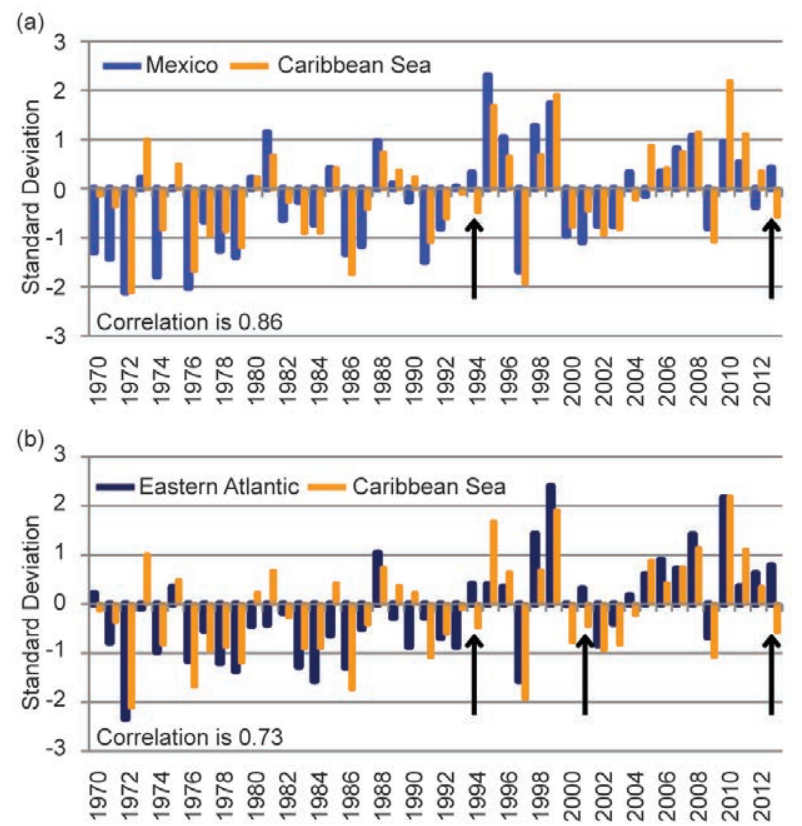

FIG. 4.I4. ASO standardized streamfunction indices for the period 1970-2013 averaged over the boxed regions shown in Fig. 4.13a. Panel (a) shows indices for the Mexico (blue) and Caribbean Sea (orange) regions and panel (b) shows indices for the eastern Atlantic (black) and Caribbean Sea (orange) regions. The indices are calculated by first standardizing the ASO streamfunction anomalies at each grid point, and then standardizing the area-averaged value of the standardized grid-point anomalies. The correlations between the Mexico and Caribbean Sea indices and between the Eastern Atlantic and Caribbean Sea indices are given in panels (a) and (b), respectively. All standardizations are based on the 1981-2010 climatology. dian) in which a similar wave pattern existed with the amplitudes of all three indices exceeding 0.25 standard deviations.

An examination of the differences in index amplitudes between the three regions shows that the ASO 2013 wave pattern was of record strength (Figs. $4.15 \mathrm{a}, \mathrm{b})$. Similarly, the standardized index that is the sum of the anomaly differences from Figs. $4.15 \mathrm{a}$ and b (Fig. 4.15c) was also of record strength (+3 standard deviations), exceeding the next largest value (+2 standard deviations during ASO 1994) by a full standard deviation.

The analysis shows that the exceptionally nonconducive conditions within the MDR during ASO 2013 were linked to a rare (only twice since 1970) upper-level wave pattern of record strength that extended from Mexico to the eastern North Atlantic. It is of note that El Niño was present when this pattern last occurred in ASO 1994, but this was not the case during 2013.

This wave pattern does not have a known relationship to other climate factors and it therefore has a low probability of prediction on seasonal time scales.

$$
\text { (a) }
$$
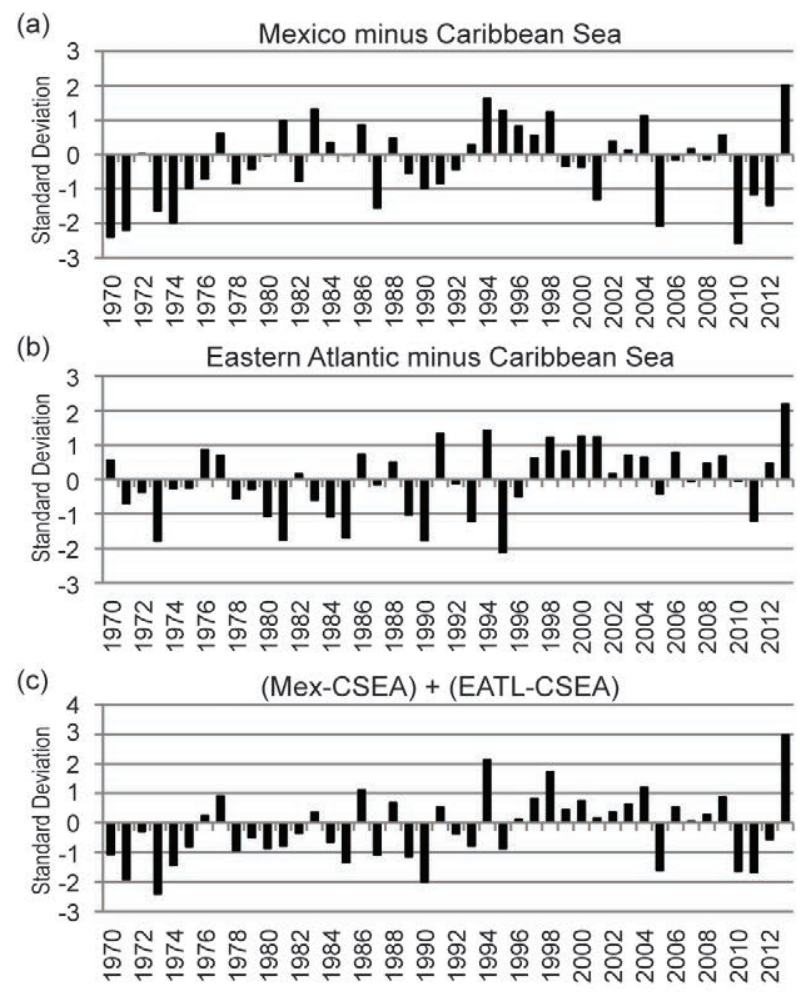

FIG. 4.I5. ASO standardized indices for the period 1970-2013 based on (a) the Mexico minus Caribbean Sea indices from Fig. 4.14a, panel (b) the east Atlantic minus the Caribbean Sea indices from Fig. 4.14b, and (c) the indices in panel (a) minus those in (b). All standardizations are based on the 198I-2010 climatology. 
Based on this analysis and on the ongoing warm phase of the AMO, the suppressed 2013 Atlantic hurricane season provides no indication that the current high-activity era for Atlantic hurricanes has ended.

3) Eastern North Pacific and Central North PACIFIC BASINS-M. C. Kruk, C. J. Schreck, and T. Evans

\section{(i) Seasonal activity}

The Eastern North Pacific (ENP) Basin is officially split into two separate regions for the issuance of warnings and advisories by NOAA's National Weather Service. NOAA's National Hurricane Center is responsible for issuing warnings in the eastern part of the basin that extends from the Pacific Coast of North America to $140^{\circ} \mathrm{W}$, while NOAA's Central Pacific Hurricane Center in Honolulu, Hawaii, is responsible for issuing warnings in the central North Pacific (CNP) region between $140^{\circ} \mathrm{W}$ and the dateline. This section summarizes the TC activity in both warning areas using combined statistics, along with information specifically addressing the observed activity and impacts in the CNP region.

The ENP/CNP hurricane season officially spans from 15 May to 30 November. Hurricane and tropical storm activity in the eastern area of the basin typically peaks in September, while in the central Pacific TC activity normally reaches its seasonal peak in August (Blake et al. 2009). During the 2013 season, a total of 20 named storms formed in the combined ENP/CNP Basin, with only 2 of these forming in the CNP (very close to the dateline). This total included nine hurricanes and one major hurricane. The 1981-2010 IBTrACS seasonal averages for the basin are 16.5 named storms, 8.5 hurricanes, and 4.0 major hurricanes.

An above-normal number of five named storms developed or entered into the CNP during 2013 (Fig. 4.16). Although half the TCs that formed in 2013 reached hurricane intensity, the ACE index for 2013 indicates many of the storms were weak and shortlived, with a seasonal value of only $70.1 \times 10^{4} \mathrm{kt}^{2}$ (Fig. 4.16), which is well below the 1981-2010 mean of 137.0 $\times 10^{4} \mathrm{kt}^{2}$ (Bell et al. 2000; Bell and Chelliah 2006).

\section{(ii) Environmental influences on the 2013 season}

Figure 4.17 illustrates the background conditions for TC activity in the ENP and CNP during 2013. Consistent with the marginal La Niña conditions, weak cool SST anomalies were observed near the equator and along the Central American coast (Fig. 4.17a). Most of the TCs formed over an area of warm SST anomalies to the north off the Mexican coast. This also coincided with a broad region of enhanced
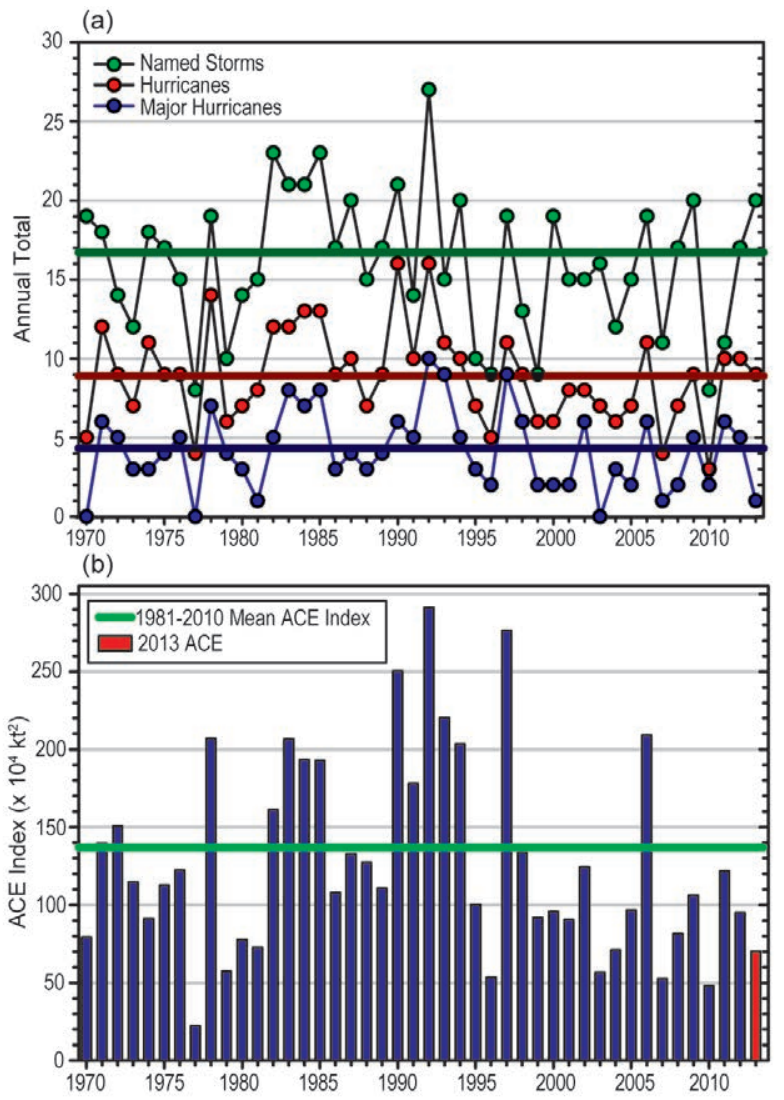

FIG. 4.16. Seasonal TC statistics for the ENP basin over the period 1970-2013: (top) number of named storms, hurricanes, and major hurricanes, and (bottom) the ACE Index $\left(\times 10^{4} \mathrm{kt}^{2}\right)$ with the seasonal total of 2013 highlighted in red. The time series shown includes the corresponding 198I-2010 base period means for each parameter.

convection that extended from $140^{\circ} \mathrm{W}$ eastward to the Gulf of Mexico (Fig. 4.17b). Meanwhile, the ITCZ was generally suppressed and shifted northward, as indicated by the positive outgoing longwave radiation (OLR) anomalies along $5^{\circ} \mathrm{N}$ and negative anomalies near $12^{\circ} \mathrm{N}$. Vertical wind shear magnitudes were generally close to their climatological values (Fig. $4.17 \mathrm{c})$; however, the vertical wind shear anomalies were generally easterly in the ENP, which might have also favored cyclogenesis.

Figure $4.17 \mathrm{~d}$ shows a broad area of $850-\mathrm{hPa}$ westerly anomalies near the equator, with easterly anomalies to the north, similar to what occurred in 2012 (Diamond 2013). This combination produced the region of enhanced cyclonic vorticity within which most of the ENP storms developed. Many of these storms developed where the enhanced vorticity intersected the westerly anomalies. The westerlies could have strengthened easterly wave activity in this region through barotropic energy conversion 

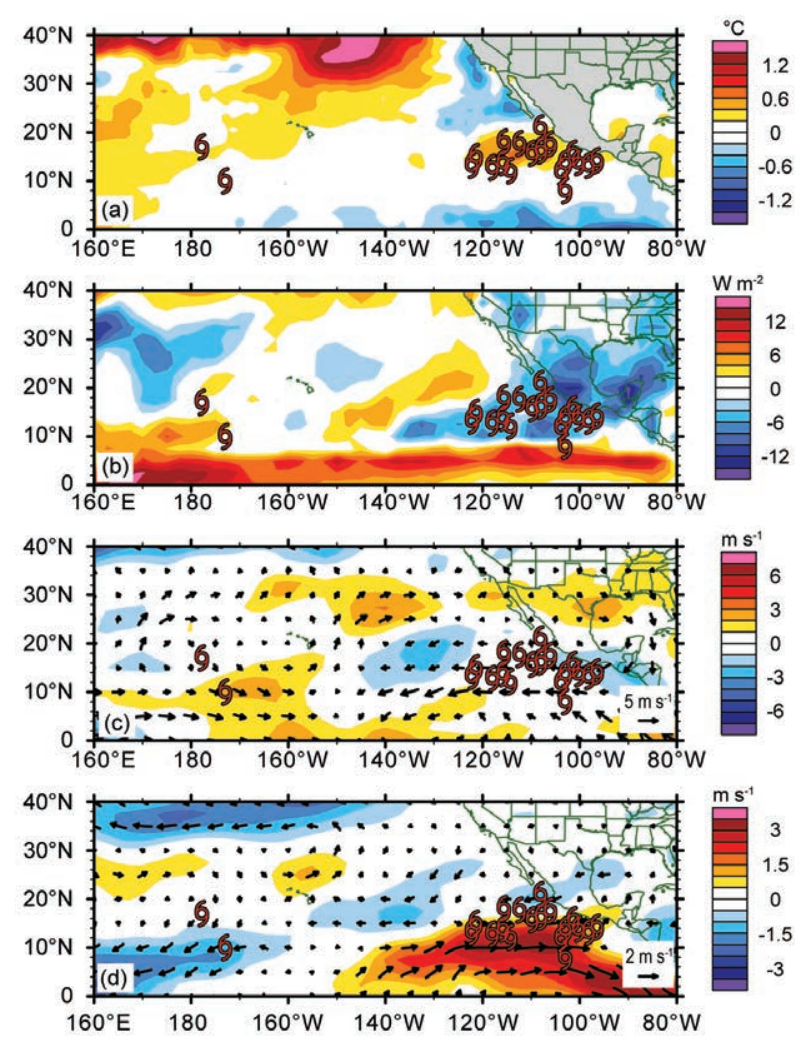

Fig. 4.I7. Maps of May-Nov 2013 anomalies of (a) SST, (b) OLR, (c) 850-200-hPa vertical wind shear vector (arrows) and scalar (shading) anomalies, and (d) 850-hPa winds (arrows) and zonal wind (shading) anomalies. Anomalies are relative to the annual cycle from 198I-2010, except for SST which is relative to 1982-20 10 due to data availability. Hurricane symbols denote where each ENP TC attained tropical storm intensity. Wind data are obtained from the NCEP-DOE Reanalysis 2 (Kanamitsu et al. 2002).

and wave accumulation (Maloney and Hartmann 2001; Aiyyer and Molinari 2008). During 2013, these westerlies were also associated with a persistent upper level trough off the coast of Baja California that helped steer many of the TCs to make landfall in that region (Farfán et al. 2012).

ENP TC activity is strongly influenced by the MJO (Maloney and Hartmann 2001; Aiyyer and Molinari 2008; Slade and Maloney 2013) and recent studies have found a greater role for convectively coupled Kelvin waves in modulating tropical cyclogenesis (Schreck and Molinari 2011; Ventrice et al. 2012a,b). Figure 4.18 uses OLR to examine the evolution of convection during the 2013 ENP hurricane season. Following Kiladis et al. (2005, 2009), the black contours identify the MJO-filtered anomalies and the green contours are filtered for Kelvin waves. Easterly waves are also apparent in the unfiltered anomalies (shading) as westward moving features, such as the

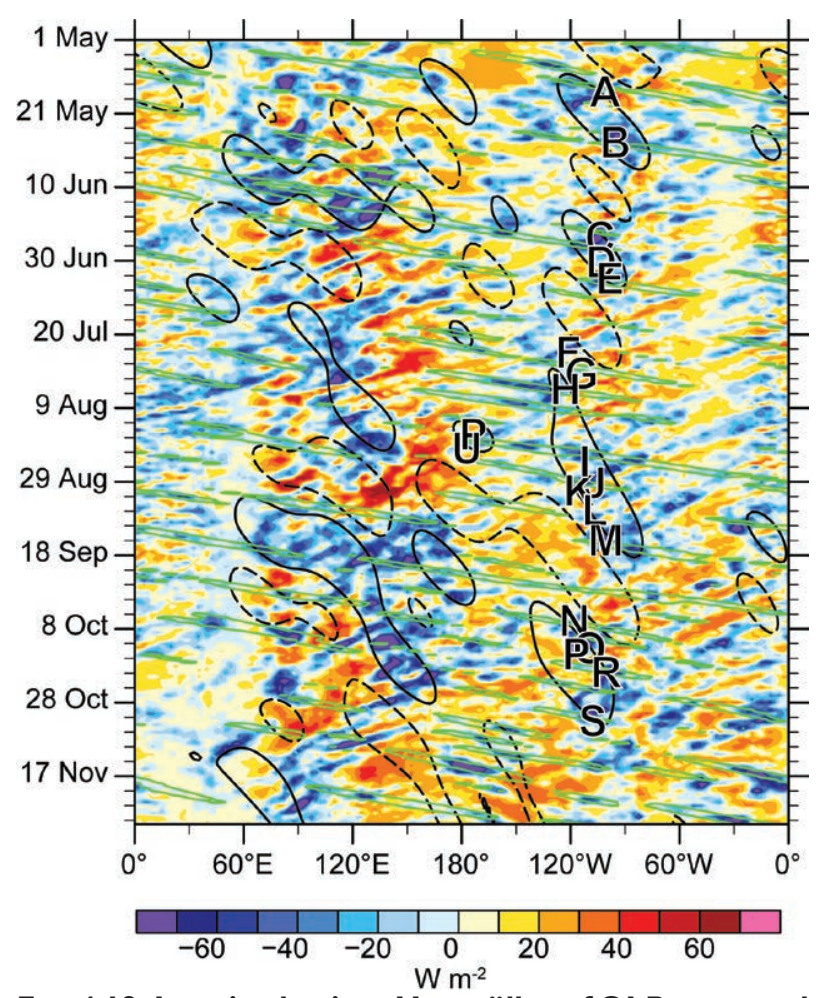

FIG. 4.I8. Longitude-time Hovmöller of OLR averaged $10^{\circ}-20^{\circ} \mathrm{N}$. Unfiltered anomalies from a daily climatology are shaded. Black contours denote MJO-filtered anomalies at $+10 \mathrm{~W} \mathrm{~m}^{-2}$ (dashed) and - $10 \mathrm{~W} \mathrm{~m}^{-2}$ (solid). Kelvin-filtered anomalies are contoured in green at $-10 \mathrm{~W} \mathrm{~m}$.2 Letters indicate the genesis of ENP TCs.

ones leading up to Tropical Storm Juliette and Hurricane Manuel.

The MJO played a dominant role in modulating ENP TC activity during 2013. Nearly every ENP TC developed within periods of active MJO convection over the ENP associated with an MJO (black solid contours) that could be traced back to signals in the western North Pacific (WNP). The suppressed phases of the MJO (black dashed contours) are also consistent with the quiet periods in early June, early July, and late September. The only storms that were not clearly associated with the MJO were Tropical Storm Flossie and Hurricanes Gil and Henriette, which were the only three storms of the season to traverse from the ENP to the CNP.

Tropical Storms Pewa and Unala in the CNP are of particular interest as both storms appear to have developed in association with a Kelvin wave (green contours) that connected the dissipating MJO in the WNP with the intensifying convection in the ENP. Such a connection is consistent with recent studies that have found that the MJO often transitions to a Kelvin-like structure in the Western Hemisphere (Straub et al. 2006; Sobel and Kim 2012). 


\section{(iii) TC impacts}

During the 2013 season, 9 of the season's 20 combined ENP/CNP tropical storms affected the western coast of Mexico and Baja California. The long-term annual average number of landfalling storms onto the western coast of Mexico is 1.8 (Raga et al. 2013). The first was Hurricane Barbara (28-30 May), which had maximum sustained winds of $65 \mathrm{kt}\left(33 \mathrm{~m} \mathrm{~s}^{-1}\right)$ and a minimum central pressure of $983 \mathrm{hPa}$. Barbara made landfall in Chiapas, Mexico, on 29 May and became the easternmost storm in the historical record to make landfall in the basin. Ahead of the storm, moderate rains fell in El Salvador, resulting in flooded roads and some damaged homes. In Mexico, Barbara brought torrential rains in a 24-hour period, severely impacting small fishing villages and flooding roads leading to many resorts in Acapulco, Mexico.

Hurricane Erick had maximum sustained winds of $70 \mathrm{kt}\left(36 \mathrm{~m} \mathrm{~s}^{-1}\right)$ and moved northwest and parallel to the coasts of Mexico and Baja California. Although the storm remained offshore throughout its lifecycle, extensive flooding was reported in Nayarit, Mexico, with rivers overflowing their banks and hundreds of people being rescued from the floodwaters.

Tropical Storm Ivo impacted Mexico in late August. Similar to Erick, Ivo moved northwest roughly parallel to the Mexican coastline. Maximum sustained winds for Ivo reached $40 \mathrm{kt}\left(21 \mathrm{~m} \mathrm{~s}^{-1}\right)$ and the storm forced the closure of seven ports in Baja California. Rains from Ivo damaged highways and water supply lines to the city of Loreto were destroyed. While the storm quickly dissipated before making landfall, residual moisture was channeled northward into the southwestern United States, causing heavy flooding rains from San Bernardino County to Needles, California, and eventually Las Vegas, Nevada.

The strongest storm of the season was Major Hurricane Raymond, which developed on 20 October south of Acapulco, Mexico. Within 24 hours of initial development, Raymond achieved hurricane status and further strengthened until reaching peak intensity with maximum sustained winds of $140 \mathrm{kt}$ $\left(72 \mathrm{~m} \mathrm{~s}^{-1}\right)$. Though Raymond never made landfall, its close proximity to the Mexican coast led to periods of heavy rainfall near Acapulco over a 48-hour period. The flooding rains left nearly 600 residents homeless in the Mexican state of Guerrero.

\section{4) Western North Pacific Basin—S. J. Camargo}

The TC season in the Western North Pacific (WNP) Basin for 2013 was above normal, and this takes into account most measures of TC activity.
According to the Joint Typhoon Warning Center (JTWC), there were a total of 35 TCs that were active in the basin, which is equal to the top 25th percentile of the climatological distribution. Twenty-nine became named tropical storms (the climatological median is 26 , the 75 th percentile is 29.5 ), sixteen of which became typhoons, and five evolved into super typhoons, as noted in Fig. 4.19a. The Regional Specialized Meteorological Center (RSMC), Tokyo, operated by the Japan Meteorological Agency (JMA), compiled tracks for a total of 31 TCs (in the top quartile of the JMA climatological distribution of 27), with 10 tropical storms, 8 severe tropical storms, and 13 typhoons. The climatological average numbers of TCs (1951-76) or tropical storms, super tropical storms, and typhoons (1977-2013) according to JMA are depicted in Fig. 4.19b. The 1981-2010 median IBTrACS seasonal averages for the basin are 25 tropical storms, 16.5 typhoons, and 7.5 major typhoons.

The first storm of 2013 was Tropical Storm Sonamu, which formed in January, followed by Tropical Depression 02W in February. There were no storms during March, April, or May. This lull was followed by the active month of June, when four TCs formed: Tropical Storms Yagi, Leepi, and Bebinca, and Typhoon Rumbia. In contrast, July was a quiet month, with only two storms : Tropical Storm Cimaron and Typhoon Soulik. Eight storms were active in the WNP in August: Tropical Depression 13W; Tropical Storms Jebi, Mangkhut, Unala, and KongRey; Typhoons Trami and Pewa; and Super Typhoon Utor; while Tropical Storm Unala and Severe Tropical Storm Pewa both formed in the Central North Pacific basin and moved into the Western North Pacific.

In September, six storms formed: Tropical Depression 18W, Tropical Storms Toraji and Man-Yi, Typhoons Pabuk and Wutip, and Super Typhoon Usagi. October had nine TCs active in the basin, matching the previous historical record: Tropical Depression 27W; Tropical Storm Sepat; Typhoons Fitow, Nari, Wipha, and Krosa; and Super Typhoons Danas, Francisco, and Lekima. November had three storms: Tropical Depression Podul, Tropical Storm $30 \mathrm{~W}$, and the very powerful Super Typhoon Haiyan (see Sidebar 4.2 for more details). Climatologically, $64 \%$ of tropical storms reach typhoon intensity; in 2013 only 55\% percent reached this threshold. In contrast, climatologically $23 \%$ of typhoons attain super typhoon intensity; in 2013 the percentage was higher at $31 \%$.

The cumulative number of named storms (Fig. $4.19 \mathrm{c})$ and super typhoons were above normal, and 

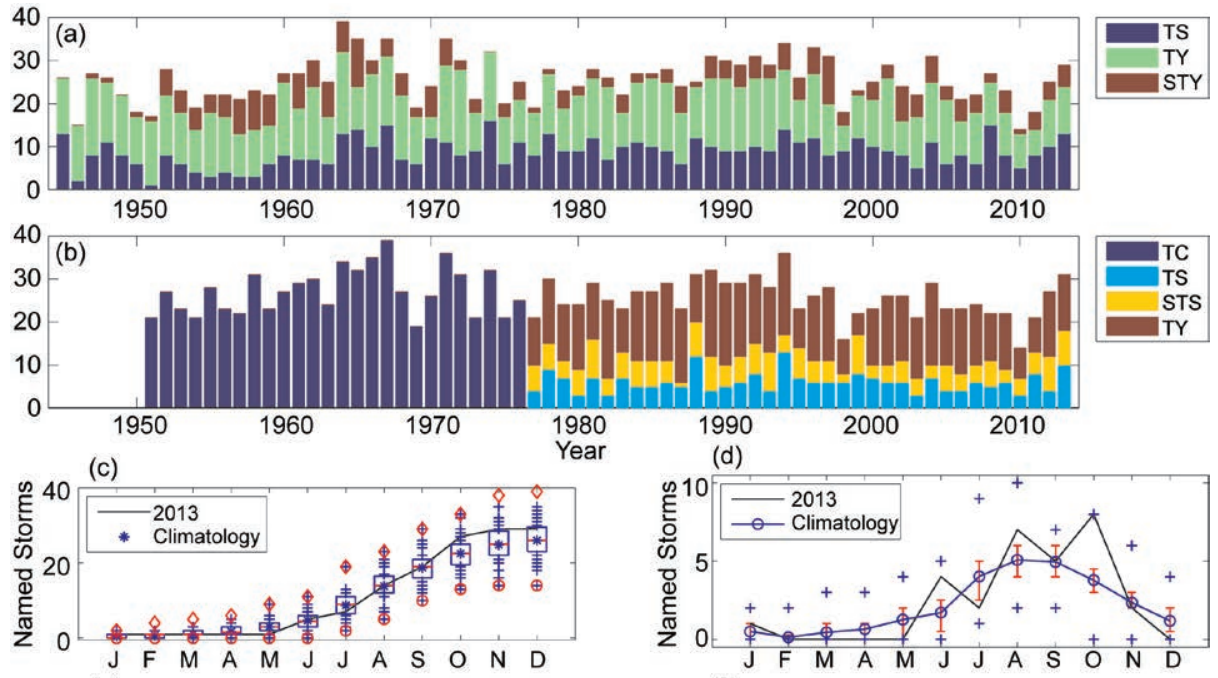

(e)
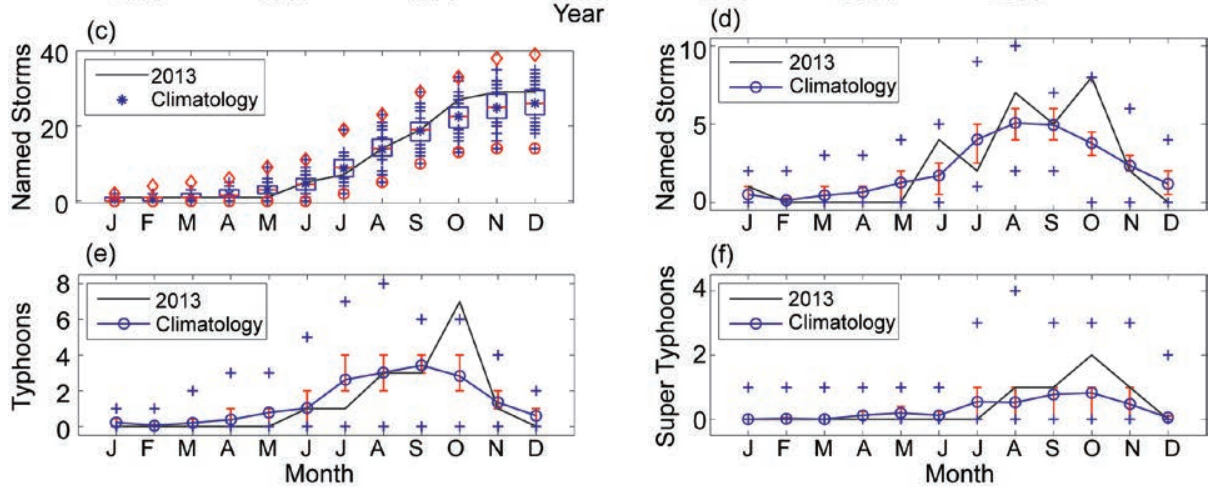

Fig. 4.19. (a) Number of tropical storms (TSs), typhoons (TYs) and super typhoons (STYs) per year in the western North Pacific (WNP) for the period 1945-2013 based on the JWTC best-track dataset. (b) Number of tropical cyclones (TCs, TS intensity or higher) from 195I to 1976; number of TSs, severe tropical storms (STSs) and TYs from 1977 to 2013 based on the JMA best-track dataset. (c) Cumulative number of tropical cyclones with TS intensity or higher (named storms), per month in the WNP: 2013 (black line), and climatology (1971-2010) as box plots [interquartile range: box, median: red line, mean: blue asterisk, values in the top or bottom quartile: blue crosses, high (low) records in the 1945-20I2 period: red diamonds (circles)]. Panels (d), (e), and (f) show the number of NSs, TYs and STYs, respectively, per month in 2013 (black line) and the climatological mean (blue line), the blue plus signs denote the maximum and minimum monthly historical records and the red error bars show the climatological interquartile range for each month (in the case of no error bars, the upper and/or lower percentiles coincide with the median). [Sources: 1945-20I2 JTWC best-track dataset, 2013 JTWC preliminary operational track data for panels (a), (c), (d), (e), and (f). 195 I-20I3 RSMC-Tokyo, JMA best-track dataset for panel (b).]

close to the 75th percentile range of the climatological averages (29.5 tropical storms and 5 super typhoons). In contrast, the cumulative number of typhoons was equal to the mean climatological value of 16 . Climatologically, June was a very active month with four TCs; the maximum number of TCs in June in the historical record was five (in 2004; see Fig. 4.19d).

The total ACE was close to the climatological median (Fig. 4.20a). The bulk of the seasonal ACE occurred in October, when four typhoons and three super typhoons were active in the basin and was the second highest in the historical record for that month, behind 1992. The only other month with an abovenormal ACE value was November, largely attributed to Super Typhoon Haiyan; total ACE was in the top quartile of the climatological distribution for that month. Individually, Super Typhoon Haiyan (3-11 November) and Super Typhoon Francisco (16-25 October) each had ACE values in the top decile per storm climatologically and contributed $13.3 \%$ and $12.6 \%$, respectively, to the total basin ACE in 2013. Other TCs in the top quartile of the climatological and historical distributions of ACE per storm were Super Typhoons Lekima, Usagi, Soulik, and Utor, contributing a combined $57.3 \%$ of the total ACE for the season.

There were 136.5 days with TCs in 2013, below the climatological median of 157.25 There were 97.75 days with storms that reached tropical storm intensity or higher, also below the climatological median of 111.75. From those active days, 50.75 had typhoons, below the climatological median of 55.6 days. There were 21 days with major typhoons (Categories 3-5), slightly above the climatological median of 20 days. In 2013, the percentage of days with typhoons and super typhoons were $37 \%$ and $15 \%$, near the climatological median (38\%) and the 75th percentile (16\%) of their climatological distributions, respectively. The median lifetime of named storms in 2013 was 6 days, below the climatological median of 8 days and close to the climatological bottom quartile (5.75 days). From the 29 TCs, 11 had a lifetime in the bottom quartile of the climatology, and only 1 in the top quartile (weak Tropical Storm 30W), which lasted 19.5 days, but reached tropical storm intensity for just a short time (and the reason it was not named). Super Typhoon 

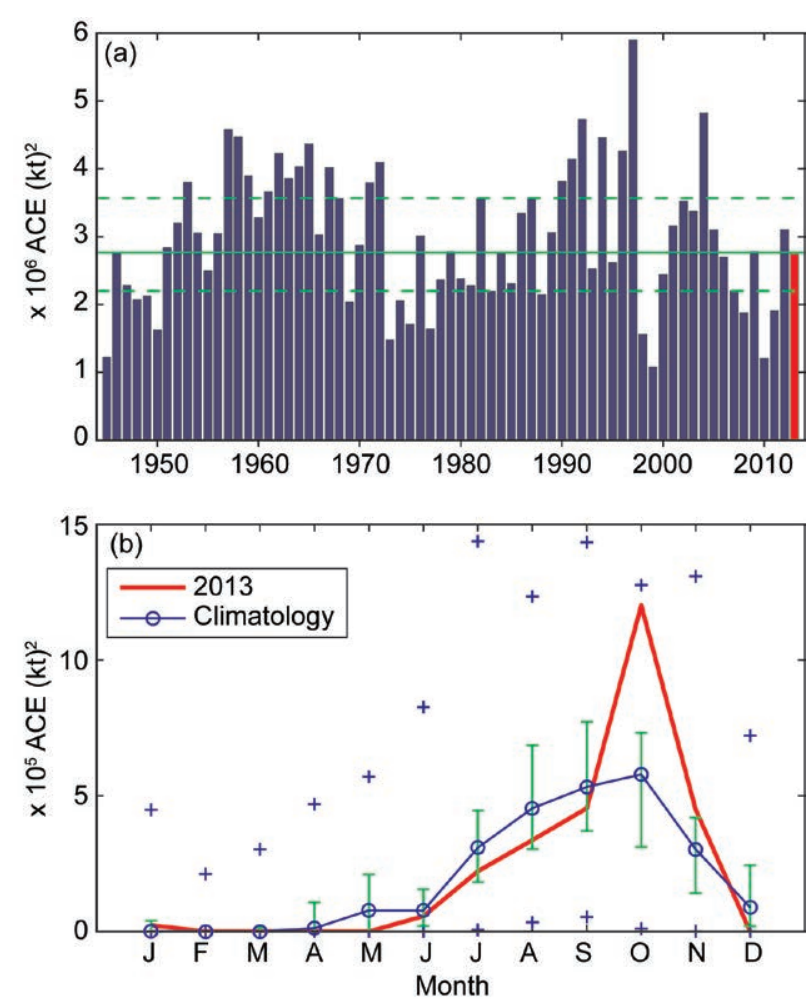

FIg. 4.20. (a) Accumulated Cyclone Energy (ACE) index per year in the WNP for 1945-2013. The solid green line indicates the median for the climatology years 197|-2010, and the dashed lines show the climatological 25th and 75th percentiles. (b) ACE index per month in 2013 (red line) and the median during 197I-2010 (blue line), where the green error bars indicate the 25th and 75th percentiles. In case of no error bars, the upper and/or lower percentiles coincide with the median. The blue "+" signs denote the maximum and minimum values during the period 1945-2012. (Source: 1945-20I2 JTWC best-track dataset, 2013 JTWC preliminary operational track data.)

Francisco and Typhoon Pewa were the second most long-lived storms of the season, each lasting 10 days.

The mean genesis location in 2013 was $15.2^{\circ} \mathrm{N}$, $137.1^{\circ} \mathrm{E}$, which was shifted northwestward of the climatological mean genesis position $\left(13.1^{\circ} \mathrm{N}, 142.8^{\circ} \mathrm{E}\right)$. The mean track position $\left(20.5^{\circ} \mathrm{N}, 128.6^{\circ} \mathrm{E}\right)$ was also shifted northwestward of the mean climatological track position $\left(19.1^{\circ} \mathrm{N}, 133.7^{\circ} \mathrm{E}\right)$. This northwestward shift is typical of La Niña years; however, in 2013 ENSO-neutral conditions were present throughout the year. Nineteen TCs made landfall in 2013, above the 1951-2010 climatological 75th percentile of 18 (median is 15). Eight systems made landfall as a tropical depression (median is three); five storms made landfall as a tropical storm (median is six); five made landfall as a typhoon with Category 1-2 (median is four); and one, Super Typhoon Haiyan, as an intense major TC (mean ${ }^{3}$ is 0.7$)$.

Figure 4.21 shows environmental conditions associated with the TC activity in 2013. The SST anomalies in the July-October period (Fig. 4.21a) were small in the basin, with exception of a positive anomaly near Japan. The monsoon trough zonal winds (Fig. 4.21b) maximum extension was just east of the Philippines and, together with the $600-\mathrm{hPa}$ relative humidity positive anomalies in the western part of the basin (Fig. 4.21c), can explain the westward shift in the genesis location in the basin. Not surprisingly, the genesis potential index (GPI; Emanuel and Nolan 2004; Camargo et al. 2007) also had positive anomalies in the western part of the basin, especially near the Philippines and the South China Sea. With respect to Super Typhoon Haiyan, more details are presented in Sidebar 4.2.

5) North Indian Ocean-M. C. Kruk and K. L. Gleason The North Indian Ocean (NIO) TC season typically extends from April to December, with two peaks in activity, during May-June and again in November when the monsoon trough is positioned over tropical waters in the basin. TCs in the NIO basin normally develop over the Arabian Sea and Bay of Bengal between $8^{\circ}$ and $15^{\circ} \mathrm{N}$. These systems are usually shortlived and relatively weak, and often quickly move into the Indian subcontinent.

According to the JTWC, the 2013 TC season produced six tropical storms, three cyclones, and one major cyclone (Fig. 4.22a). The 1981-2010 IBTrACS seasonal averages for the basin are 3.9 tropical storms, 1.4 cyclones, and 0.6 major cyclones. The season produced its highest ACE index since 1972 with a value of $48.9 \times 10^{4} \mathrm{kt}^{2}$, which is almost four times higher than the 1981-2010 mean of $12.5 \times 10^{4} \mathrm{kt}^{2}$ (Fig. 4.22b). Typically, there is enhanced TC activity, especially in the Bay of Bengal, during the cool phase of ENSO (Singh et al. 2000); however, most of this season was characterized by near-neutral ENSO conditions.

The NIO season started much earlier when compared to the 2012 season (Diamond 2013), with the first storm occurring 10-16 May. Cyclone Mahasen developed in the central Bay of Bengal and began a slow westward and then northward track towards Bangladesh. The storm made landfall on 16 May near the Patuakhali district of Bangladesh, with maximum sustained winds of $50 \mathrm{kt}\left(26 \mathrm{~m} \mathrm{~s}^{-1}\right)$ and

3 The mean is used for this category as the median is 0 . 

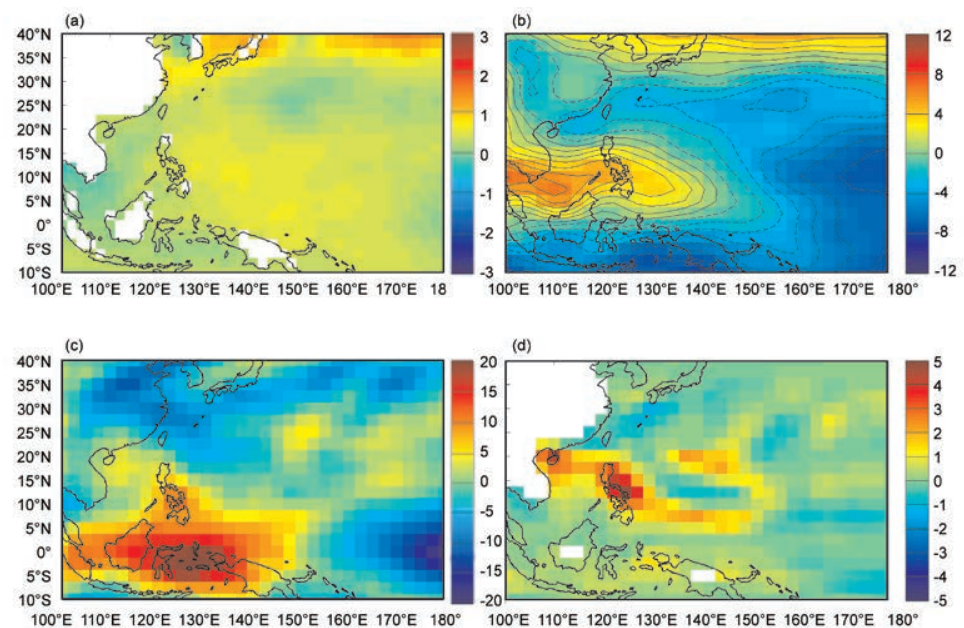

FIG. 4.2I. (a) SST anomalies for Jul-Oct (JASO) 20I3. (b) Zonal winds in JASO 2013 (positive contours are shown in solid lines, negative contours in dash dotted lines, and the zero contour in a dotted line). (c) Relative humidity $600-\mathrm{hPa}$ anomalies in JASO 2013. (d) Genesis potential index anomalies in JASO 2013. [Source: atmospheric variables: NCEP/NCAR reanalysis data (Kalnay et al. 1996); SST (Smith and Reynolds 2005).]
Cyclones Helen (19-23 November) and Lehar (19-28 November) both impacted southern India. Helen formed in the Bay of Bengal near the Andaman Islands on 17 November and slowly gathered strength before reaching TC status on the 19th. The storm had maximum sustained winds of $60 \mathrm{kt}\left(31 \mathrm{~m} \mathrm{~s}^{-1}\right)$ before interacting with the Indian subcontinent and weakening, making landfall just south of Machilipatnam, Andhra Pradesh.

Cyclone Lehar was the second most intense storm of the 2013 NIO season, with peak maximum sustained winds of $75 \mathrm{kt}$ $\left(39 \mathrm{~m} \mathrm{~s}^{-1}\right)$. Lehar developed over the Malay Peninsula and intensified as it moved into the warmer waters of the Andaman Sea and eventually the Bay of Bengal. It continued on a slow west-northwest track until landfall in Andhra Pradesh and Odisha on 28 November. produced widespread destruction to coastal areas. More than 60 deaths were reported in Bangladesh and neighboring Myanmar.

The most noteworthy storm of the season was Phailin, which became a very severe cyclonic storm during 9-12 October with peak winds of $140 \mathrm{kt}$ $\left(72 \mathrm{~m} \mathrm{~s}^{-1}\right)$ and an estimated minimum central pressure of $910 \mathrm{hPa}$. Phailin made landfall with $100 \mathrm{kt}$ $\left(52 \mathrm{~m} \mathrm{~s}^{-1}\right)$ winds near Gopalpur along the Odisha coast on 12 October and became the second strongest storm ever to make landfall in India, following that of Cyclone 05B (the Odisha super cyclone) in 1999. Phailin is noted for its rapid intensification over the Bay of Bengal, increasing from $65 \mathrm{kt}\left(33 \mathrm{~m} \mathrm{~s}^{-1}\right)$ sustained winds to over $125 \mathrm{kt}\left(64 \mathrm{~m} \mathrm{~s}^{-1}\right)$ in just a 12hour period. The cyclone maintained at least $100 \mathrm{kt}$ $\left(52 \mathrm{~m} \mathrm{~s}^{-1}\right)$ winds for 63 consecutive hours, helping propel the storm's ACE value to $17.5125 \times 10^{4} \mathrm{kt}^{2}$, or about $35 \%$ of the entire season's ACE total.

Heavy rainfall, averaging $250-350 \mathrm{~mm}$, led to flooding and landslides in the interior areas of Odisha and Andhra Pradesh, while storm surge flooding was prevalent along the Odisha coastline. It was also estimated that over 250000 homes were partially or fully destroyed and more than 600000 hectares of agriculture were lost. Due to vastly improved early warning systems and preparedness, the death toll from Phailin was estimated to be 39 . This contrasts with the nearly 10000 people who were killed during the 1999 Odisha super cyclone.
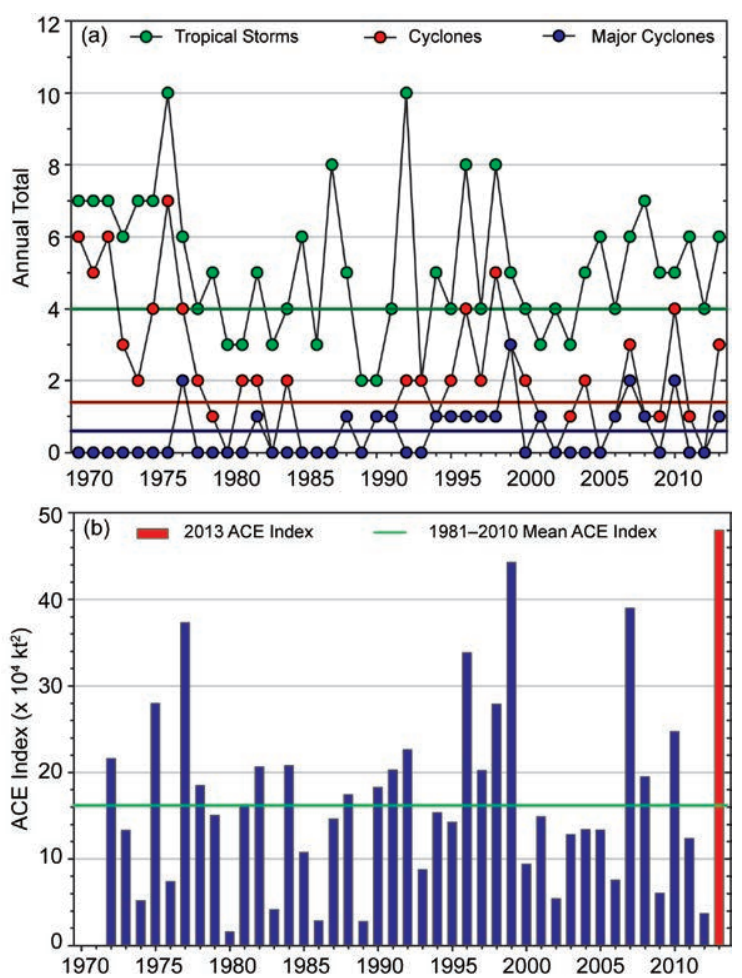

FIG. 4.22. Annual TC statistics for the NIO for 19702013: (a) number of named storms, cyclones, and major cyclones and (b) the estimated annual ACE Index (in $\left.\mathbf{k t}^{2} \times \mathrm{10}^{4}\right)$ for all TCs during which they were at least tropical storm strength or greater intensity (Bell et al. 2000). The 198I-2010 base period means are included in both (a) and (b). 
6) South Indian OCEAN-K. L. Gleason and M. C. Kruk

The South Indian Ocean (SIO) Basin extends south of the equator from the African coastline to $105^{\circ} \mathrm{E}^{4}$, with most cyclones developing south of $10^{\circ} \mathrm{S}$. The SIO TC season extends from July to June encompassing equal portions of two calendar years (the 2013 season is comprised of storms from July to December 2012 and from January to June 2013). The peak activity typically occurs during December-April when the ITCZ is located in the Southern Hemisphere and migrating toward the equator. Historically, the vast majority of landfalling cyclones in the SIO impact Madagascar, Mozambique, and the Mascarene Islands, including Mauritius and La Réunion.

The historical SIO TC data is probably the least reliable of all the TC basins (Atkinson 1971), primarily due to a lack of historical record keeping by individual countries and no consistent, centralized monitoring agency; however, the historical dataset for the region has been updated (Knapp et al. 2010). The historical data are noticeably deficient before reliable satellite data were operationally implemented in the region beginning about 1983. The RSMC on La Réunion now serves as the official monitoring agency for TC activity within the basin (WMO 2012).

The 2012/13 SIO storm season was near average with ten tropical storms, seven cyclones, and one major cyclone (Fig. 4.23a). The 1981-2010 IBTrACS seasonal median averages are eight tropical storms, four cyclones, and one major cyclone. The season is also reflected in the 2012/13 ACE index of $89.9 \times 10^{4}$ $\mathrm{kt}^{2}$, which was near the 1981-2010 average of $91.5 \times$ $10^{4} \mathrm{kt}^{2}$ (Fig. 4.23b). This is the first year since 2008 with a near-average ACE value for the SIO; as noted in Fig 4.23b, the ACE values have been below to well below normal for that past few years.

Of note, Cyclone Anais developed in mid-October 2012 near the Chagos Islands and strengthened into a Category 3 storm, the strongest storm on record so early in the season (equivalent to a major hurricane in the Atlantic during April) 5 . The most intense storm of the season, Cyclone Felleng, attained Category 4 strength with maximum sustained winds of $89 \mathrm{kt}$ (46 $\mathrm{m} \mathrm{s}^{-1}$ ) in late January 2013. Although it never made

\footnotetext{
${ }^{4}$ In order to generate consistent basin statistics, the SIO basin boundary overlaps with the Australian Bureau of Meteorology's operational warning area from $90^{\circ}$ to $105^{\circ} \mathrm{E}$.

5 The Saffir-Simpson scale is used as the standard in this report for identifying the intensity of TCs in the South Indian Ocean Basin.
}
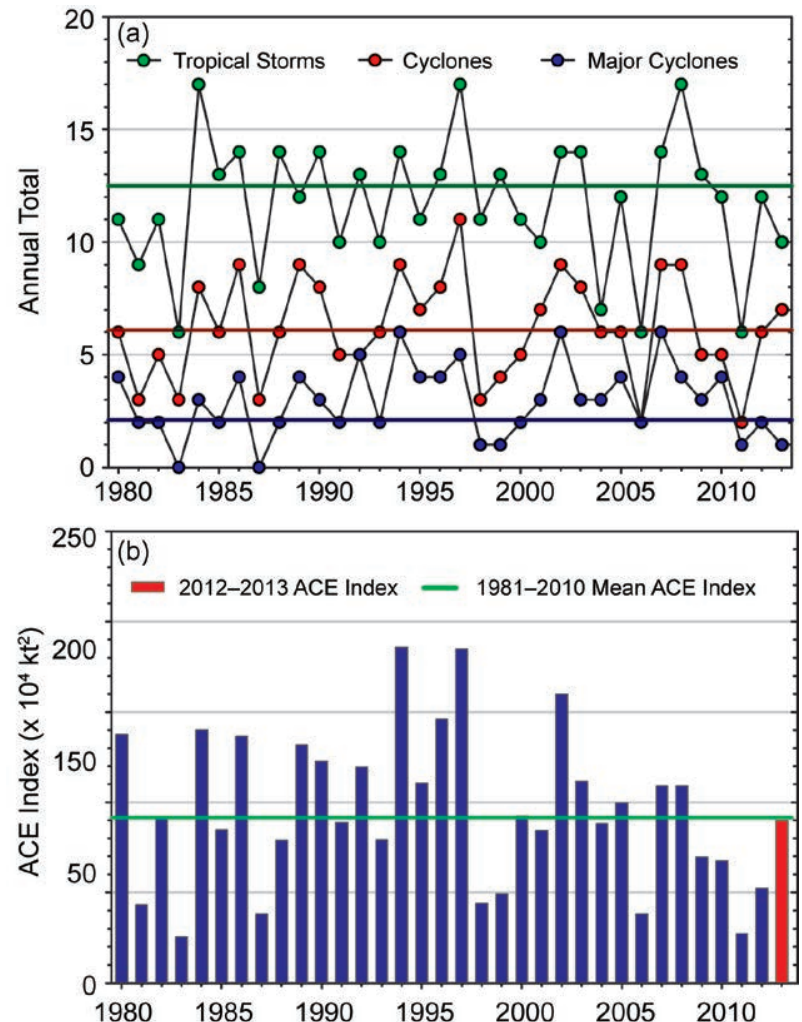

FIG. 4.23. Annual TC statistics for the SIO for I9802013: (a) number of tropical storms, cyclones, and major cyclones and (b) the estimated annual ACE Index (in $\mathrm{kt}^{2} \times \mathrm{I04}^{4}$ ) for all TCs during which they were at least tropical storm or greater intensities (Bell et al. 2000). The 1981-2010 base period means are included in both (a) and (b). Note that the ACE Index is estimated due to a lack of consistent 6-h-sustained winds for each storm.

landfall, Felleng impacted both Réunion and Madagascar with heavy winds and rainfall. In La Plaine des Cafres, Réunion, $512 \mathrm{~mm}$ of rain fell during a 24-hour period.

Cyclone Haruna was the only TC to make landfall during the season. Resulting from a break in the subtropical ridge, Haruna vacillated over the Mozambique Channel for a week, bringing copious rainfall to the western coast of Madagascar. Peak sustained

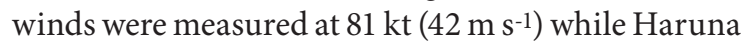
remained over the Mozambique Channel. Haruna made landfall in southwestern Madagascar near Manombo as a Category 2 cyclone on 22 February with wind gusts of up to $91 \mathrm{kt}\left(47 \mathrm{~m} \mathrm{~s}^{-1}\right)$. Landfalling tropical cyclones in this region of Madagascar are unusual. Twenty-six fatalities were reported and thousands were left homeless. 


\section{7) Australian Region Basin-B. C. Trewin}

\section{(i) Seasonal activity}

The 2012/13 TC season was near normal in the broader Australian basin (areas south of the equator and between $90^{\circ}$ and $160^{\circ} \mathrm{E}$, which includes Australian, Papua New Guinea, and Indonesian areas of responsibility). The season produced 9 named storms, near the 1983/84-2010/11 average (coincident with comprehensive satellite coverage of the region) of 10.8, and consistent with ENSO-neutral conditions. The 1981-2010 IBTrACS seasonal averages for the basin are 9.9 named storms, 7.5 TCs, and 4.0 major TCs, which compares with the 2012/13 counts of 9,5 , and 2 , respectively. TC categories in this basin are based on the Australian TC intensity scale (http://www .bom.gov.au/cyclone/about/intensity.shtml).

There were five named storms in the eastern sector of the Australian region during 2012/13 (two of which reached their peak intensity after moving into the southwest Pacific region), four in the northern sector, and five in the western sector. Two systems made landfall in Australia as TCs: one in Western Australia and one in Queensland.

\section{(ii) Landfalling and other significant TCs}

The most significant storm of the season in the Australian region was Tropical Cyclone Rusty. Rusty reached TC intensity on 24 February near $17^{\circ} \mathrm{S}, 118^{\circ} \mathrm{E}$, and then tracked generally southwards towards the Pilbara coast of Western Australia. It reached Category 4 intensity early on 27 February, with maximum sustained winds of $90 \mathrm{kt}\left(46 \mathrm{~m} \mathrm{~s}^{-1}\right)$, and weakened slightly before making landfall as a Category 3 system later that day near Pardoo Station, about $150 \mathrm{~km}$ east of Port Hedland. The slow movement of the cyclone resulted in an extended period of high winds and heavy rain, with gale-force winds continuing at Port Hedland for 39 consecutive hours, an unprecedented event. Rain from the remnant system extended south to Kalgoorlie and beyond; at Pardoo, $520 \mathrm{~mm}$ was recorded over 26-28 February. Only minor wind damage was reported from Rusty but flooding was widespread, and there was considerable disruption to the resources industry, with the port at Port Hedland closed for 86 hours.

Narelle was slightly more intense than Rusty [Category 4, maximum sustained winds $100 \mathrm{kt}\left(54 \mathrm{~m} \mathrm{~s}^{-1}\right)$ ]. It reached TC intensity on 8 January, well off the western Australian coast, and moved southwest roughly parallel with the coast, reaching its peak intensity on 11 January. The following day Narelle made its closest approach to the coast, passing approximately $330 \mathrm{~km}$ northwest of Exmouth, before weakening steadily and falling below cyclone intensity on 15 January west of Geraldton. While Narelle did not make landfall, it disrupted shipping and offshore oil and gas operations, and its precursor low caused damaging floods in parts of Indonesia.

TC Oswald formed from a low that had been meandering in the Gulf of Carpentaria from 17 January. It reached minimal Category 1 intensity (35 kt or $18 \mathrm{~m} \mathrm{~s}^{-1}$ ) and was named as it moved towards the east coast of the Gulf on 21 January, making landfall north of Kowanyama. The remnant tropical low remained intact and tracked southeast through inland eastern Australia, generally on a track parallel with and about $100-200 \mathrm{~km}$ inland from the coast, eventually emerging over water south of Sydney on 30 January. Oswald was responsible for substantial flooding over many coastal regions of Queensland and New South Wales. Among the most significantly affected regions was the Burnett River catchment in Queensland; the 1-day catchment average rainfall for 27 January of $206.8 \mathrm{~mm}$ exceeded the previous record by nearly $70 \%$. The river reached a record height at Bundaberg, where extensive flooding occurred. Record flood heights also occurred on the Clarence River at Grafton, in northern New South Wales, but levees limited damage there. The Brisbane River catchment, which received similar rainfalls to those experienced in the 2011 floods, was spared similarly severe flooding because of dry antecedent conditions, although there was destructive flooding in some southern parts of the catchment, where the 24-hour rainfall total reached $744 \mathrm{~mm}$ at Upper Springbrook in the Gold Coast hinterland, and $709 \mathrm{~mm}$ at Mount Castle on the escarpment northeast of Warwick. A number of tornadoes were also reported during the event. Six deaths were attributed to Oswald and its remnant low, and reported damage was in excess of $\$ 2$ billion US dollars.

A system that was operationally named Peta, but was downgraded to a tropical depression on postanalysis, formed off the coast between Broome and Port Hedland, and moved south to make landfall on 23 January at Point Sansom, near Karratha. Shipping was disrupted and there was widespread flooding. Hooley and Wittenoom, in the inland Pilbara, recorded 377 and $350 \mathrm{~mm}$ of rain, respectively, during 24-25 January.

TCs Sandra and Freda were two eastern region cyclones which both peaked as Category 4 systems outside the Australian region and are described in more detail in section $4 \mathrm{~d} 8$. 
8) Southwest Pacific Basin-A. M. Lorrey, N. C. Fauchereau, P. R. Chappell, S. Ready, and H. J. Diamond

(i) Seasonal activity

Tropical cyclone activity began in December 2012 and extended until the end of April, with Queensland, Australia, and Samoa experiencing significant impacts and loss of life during the course of the season. Storm track data for November 2012-April 2013 period was gathered from the Fiji Meteorological Service, Australian Bureau of Meteorology, and New Zealand MetService. Following the climatological definition put forward by Diamond et al. (2012), the Southwest Pacific Basin $\left(135^{\circ} \mathrm{E}-120^{\circ} \mathrm{W}\right)$ had eight tropical cyclones (Fig. 4.24), including four severe tropical cyclones ${ }^{6}$.

The 1981-2010 South Pacific Enhanced Archive of Tropical Cyclones (SPEArTC) seasonal averages indicates 10.4 tropical cyclones and 4.3 major tropical cyclones usually occur in the basin each year. The ratio of severe TCs relative to the total number of named TCs was 50\%, and significant impacts to infrastructure and loss of human life occurred in the Cook Islands even as a result of a lower-order tropical storm. Six deaths and $>\$ 2.5$ billion US dollars in damage was caused by Category 1 Tropical Cyclone

${ }^{6}$ This basin also utilizes the Australian TC intensity scale.

Oswald in northeast Australia, making it the most damaging storm to hit Queensland since 1999. Severe Tropical Cyclone Evan caused four deaths (with another ten missing and presumed dead) and damage in excess of $\$ 160$ million US dollars in Samoa, and there were two fatalities in New Caledonia associated with Severe Tropical Cyclone Freda.

\section{(ii) Landfalling and other significant TCs}

The first TC of the season, Evan, developed as a tropical depression within the South Pacific convergence zone (SPCZ) northeast of Fiji on 9 December. TC Evan strengthened to Category 2 status and made landfall in Samoa with maximum sustained winds in excess of $59 \mathrm{kt}\left(30 \mathrm{~m} \mathrm{~s}^{-1}\right)$ and gusts up to $94 \mathrm{kt}(48$ $\mathrm{m} \mathrm{s}^{-1}$. The storm then reversed course, making a northwest loop around Samoa before turning southwest and accelerating toward Fiji. On 17 December, Evan reached Fiji as a Category 4 storm (mean central pressure of $943 \mathrm{hPa}$ ) and affected those islands with maximum sustained winds of up to $124 \mathrm{kt}(64 \mathrm{~m}$ $\left.\mathrm{s}^{-1}\right)$. The system turned south and began to weaken on 19 December, with the post-tropical remnants of the storm bringing heavy rain and strong winds to northern New Zealand during 21-22 December.

TC Freda spawned north of Efate, Vanuatu, and began moving westward while intensifying and becoming a Category 1 storm on 28 December as

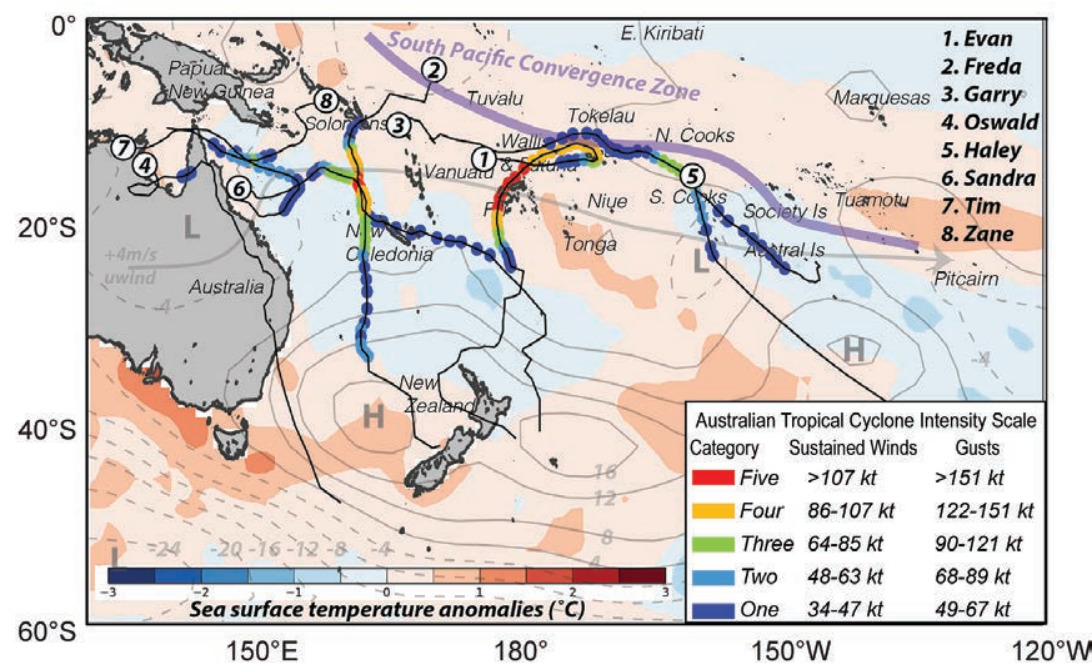

FIG. 4.24. TCs in the Southwest Pacific Basin. Solid black lines indicate each storm track, while the number for each storm (noted in chronologic sequence of occurrence in the upper right corner) indicates TC genesis location. SST anomalies $\left({ }^{\circ} \mathrm{C}\right), 4 \mathrm{~m} \mathrm{~s}^{-1}$ steering wind, surface pressure anomalies (geopotential at $1000-\mathrm{hPa}$ ), and the location of the SPCZ (purple line) are shown for reference. Omega (used to define the core location of the SPCZ) and the steering wind information are shown for the $500-\mathrm{hPa}$ geopotential height. SST anomalies are plotted relative to the austral warm season (Nov-Apr) 198I-2010 climatology. Geopotential height contours are in meters. it passed south of the Solomon Islands, impacting Makira, Rennell, and Bellona Islands with strong winds, rainfall, and storm wave action. Freda turned south and peaked at Category 4 status on 30 December, with maximum sustained winds of $100 \mathrm{kt}(51 \mathrm{~m}$ $\left.\mathrm{s}^{-1}\right)$, as reported by RSMC Nadi (in Fiji). The storm weakened to a Category 1 storm before recurving southeast and clipping the northern tip of New Caledonia's Grande Terre Island followed by the Loyalty Islands on 2 January. Two people drowned in New Caledonia and more than 3000 lost power. The system dissipated on 4 January south of Fiji.

On 14 January, a tropical disturbance developed to the southeast of Guadalcanal, intensified into TC Garry while north of Wallis and Futuna, and rapidly 
traveled east towards the waters north of Samoa. TC Garry increased to a Category 2 strength system on 22 January with a minimum central pressure of 984 $\mathrm{hPa}$ and tropical storm force winds extending 50 nautical miles from the storm eye and sustained at $45 \mathrm{kt}\left(23 \mathrm{~m} \mathrm{~s}^{-1}\right)$ with wind gusts of up to $50 \mathrm{kt}(26 \mathrm{~m}$ $\left.\mathrm{s}^{-1}\right)$. Garry peaked as a Severe Category 3 storm north of Suwarrow and Palmerston Island in the Northern Cook Islands, with average wind speeds estimated at $80 \mathrm{kt}\left(41 \mathrm{~m} \mathrm{~s}^{-1}\right)$ and gusts up to $110 \mathrm{kt}\left(57 \mathrm{~m} \mathrm{~s}^{-1}\right)$.

In January, a Category 1 TC, Oswald, made landfall on the Cape York Peninsula on 21 January with winds of $35 \mathrm{kt}\left(18 \mathrm{~m} \mathrm{~s}^{-1}\right)$. The storm traversed the peninsula and turned due south, traveling almost the entire length of Queensland over land as a deteriorating system. Significant impacts from waves and winds in Cairns included downed power lines and damage to coastal communities, with many extreme rainfall records broken that led to flooding and road closures. Total damages exceeded $\$ 2.5$ billion US dollars and six people died.

The final severe TC during the season formed on 7 March in the Queensland region and was named Sandra the next day as it rapidly intensified in the Coral Sea from a Category 1 to Category 2 tropical cyclone. Convection strengthened over TC Sandra's center as it was located northwest of Noumea, New Caledonia, while it moved eastward into RSMC Nadi's area of responsibility and further intensified into a Severe Category 3 system (minimum central pressure estimated at $968 \mathrm{hPa}$ ). Upon reaching Category 4 status on 9 March over the eastern Coral Sea, wave action and maximum sustained winds of 76 $\mathrm{kt}\left(39 \mathrm{~m} \mathrm{~s}^{-1}\right)$ with gusts in excess of $108 \mathrm{kt}\left(56 \mathrm{~m} \mathrm{~s}^{-1}\right)$ impacted the Solomon Islands. Vanuatu received in excess of $380 \mathrm{~mm}$ of rainfall at some locations. The storm turned southeast, then due south, tracking along a trajectory to the west of New Caledonia when it peaked on 11 March with maximum sustained wind

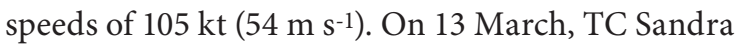
then passed within $220 \mathrm{~km}$ of Lord Howe Island in the North Tasman Sea as a Category 1 storm on 14 March, bringing destructive wind gusts of $81 \mathrm{kt}(42 \mathrm{~m}$ $\mathrm{s}^{-1}$ ) that downed trees and littered roads with debris along with heavy ocean swells that brought rough surf and rip currents to Australia's east coast. Remnants of the storm brought severe thunderstorms, tornadoes, and heavy rainfall to the Taranaki region of New Zealand's North Island. e. Tropical cyclone heat potential—G. J. Goni, J. A. Knaff, and $\mathrm{I}-\mathrm{I}$ Lin

This section summarizes the previously described TC basins from the standpoint of tropical cyclone heat potential (TCHP), by focusing on upper ocean temperature conditions during the season with respect to average values. The TCHP (Goni and Trinanes 2003), defined as the excess heat content above $26^{\circ} \mathrm{C}$ in the water column contained between the sea surface and the depth of the $26^{\circ} \mathrm{C}$ isotherm, has been linked to TC intensity changes (Shay et al. 2000; Goni and Trinanes 2003; and I-I Lin et al. 2008, 2009). In addition, the magnitude of the in situ TCHP has also been identified as impacting maximum potential intensity (MPI) through modulating the during-TC air-sea coupling flux supply (Mainelli et al. 2008; I-I Lin et al. 2013). In general, fields of TCHP show high spatial and temporal variability associated with oceanic mesoscale features, interannual variability, or long-term decadal variability that can be detected with satellite altimetry (Goni et al. 1996; I-I Lin et al. 2008; Goni et al. 2009; Pun et al. 2014).

To examine the TCHP interannual variability, anomalies (departures from the 1993-2012 mean values) are computed during the months of TC activity in each hemisphere: June-November in the Northern Hemisphere and November-April in the Southern Hemisphere. In general, these anomalies show large variability within and among the TC basins.

In most of the ocean basins, the number of tropical cyclones remained similar to last year, except for the tropical Atlantic. Most of the basins continue to exhibit positive TCHP anomalies, except for the Arabian Sea and large areas of the South Pacific Basin (Fig. 4.25). The North Atlantic Basin continued exhibiting positive anomaly values of TCHP as previous years. However, there was only one hurricane in the Gulf of Mexico and one in the tropical North Atlantic, compared with 12 hurricanes in this region during the 2012 season. The Gulf of Mexico (part of the North Atlantic Basin) continued exhibiting positive anomalies except for a region susceptible to the spatial variability of the Loop Current, which had negative anomalies. The WNP Basin usually exhibits anomalies related to ENSO variability, and has been undergoing a long-term decadal subsurface warming associated with the La Niña-like conditions over the last decade (Kosaka and Xie 2013; England et al. 2014). The TCHP over the west Pacific MDR $\left(4^{\circ}-19^{\circ} \mathrm{N}\right.$, $\left.122^{\circ} \mathrm{E}-180^{\circ}\right)$ has been observed to increase considerably as well (Pun et al. 2013; Goni et al. 2013). During 2013, this warming continued in the western North 


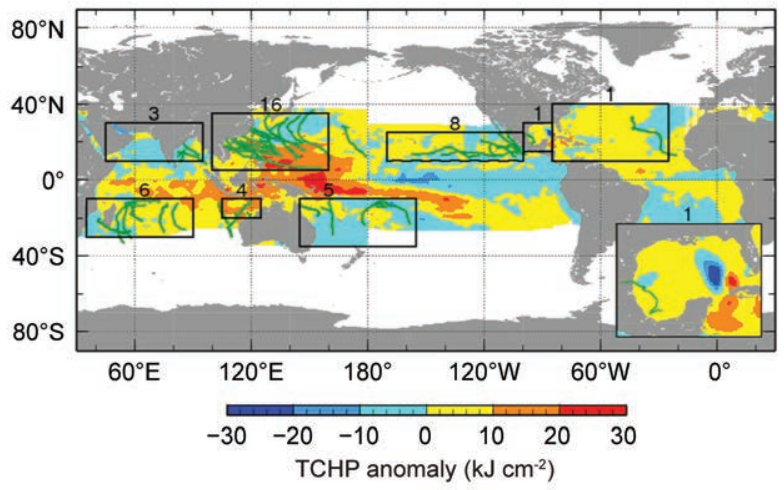

FIG. 4.25. Global anomalies of TCHP corresponding to 2013 computed as described in the text. The boxes indicate the seven regions where TCs occur: from left to right, SIO, NIO, NWP, Southeast Indian, Southwest Pacific, ENP, and North Atlantic (shown as Gulf of Mexico and tropical Atlantic separately). The green lines indicate the trajectories of all tropical cyclones reaching at least Category I (I-minute average wind $\geq 64$ kts) and above during Nov 2012-Apr 2013 in the Southern Hemisphere and Jun-Nov 2013 in the Northern Hemisphere. The numbers above each box correspond to the number of Category I and above cyclones that travel within each box. The Gulf of Mexico conditions during Jun-Nov 2013 are shown in the insert in the lower right corner.

Pacific and TCHP is currently at the highest level in 20 years. The TCHP fields in the west Pacific MDR since 1993, when altimetry became available, have increased by an average of $15 \%$.

For each basin, the differences in the TCHP values between the most recent cyclone season and the previous season (Fig. 4.26) follow the same overall pattern as the differences between the 2012 and 2011 seasons (Goni et al. 2013). Some notable differences occurred in the NWP; west of Madagascar in the SIO; the NIO in the Bay of Bengal; and the northern tropical and subtropical areas of the North Atlantic, where TCHP values increased with respect to the previous season. The largest changes were in the South Pacific where warm anomalies are depicted in a large region toward the central equatorial Pacific while negative anomalies developed in the subtropics off the eastern coast of Australia.

During the 2013 season, the basins exhibited the following TCHP anomalies:

- As described in section $4 \mathrm{~d} 4$, four TCs attained Category 5 super typhoon intensity. The most notable was Haiyan, which intensified over the WNP region from a Category 1 to a Category 5 storm associated with significant subsurface warming over a region of high TCHP values that ranged from $100-125 \mathrm{~kJ} \mathrm{~cm}^{-2}$ (Fig. 4.27b).

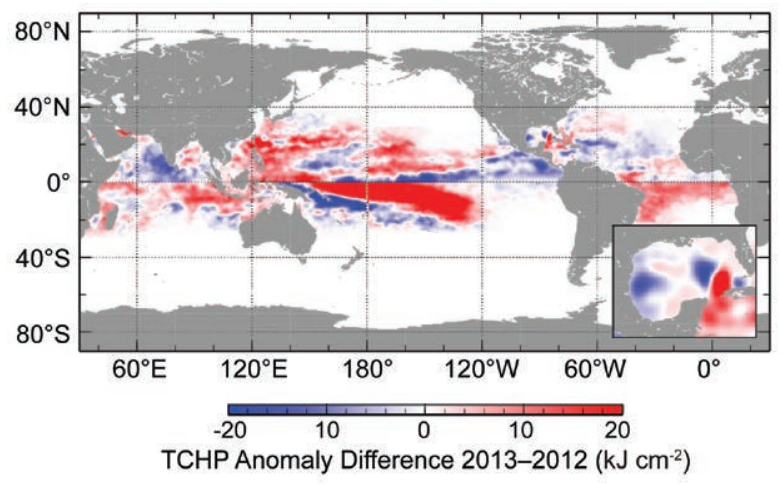

Fig. 4.26. Differences between the TCHP fields in 2013 and 2012.

In the WNP, as confirmed by two decades of the $\mathrm{TAO} /$ Triton mooring and satellite observations, the TCHP increased by about $10 \%$, as compared to the early 90s (Pun et al. 2013). Haiyan's fast translation speed $\left(7-11 \mathrm{~m} \mathrm{~s}^{-1}\right)$ during intensification minimized the cooling effect. As Haiyan continued traveling over this favorable TCHP region with subsurface warmth for another 36 hours, its sustained winds reached the highest wind speed ever assigned to a TC by the JTWC with a value of $170 \mathrm{kt}\left(85 \mathrm{~m} \mathrm{~s}^{-1}\right)$. Typhoon Usagi intensified over the same region, and within 24 hours, it also rapidly intensified into a Category 5 system. The pre-typhoon TCHP values ranged from $110-125 \mathrm{~kJ} \mathrm{~cm}^{-2}$, comparable to Haiyan (Fig. 4.27a).

- In the NIO Basin, TC Phailin (Fig. 4.27c) was the second strongest TC to make landfall in India on record. On 10 October, Phailin became a Category 1 tropical cyclone in the Bay of Bengal and one day later rapidly intensified to a Category 5 TC, with maximum sustained winds of $160 \mathrm{kt}$ $\left(82 \mathrm{~m} \mathrm{~s}^{-1}\right)$. This intensification coincided with its path traveling over warm waters with TCHP values slightly above $50 \mathrm{~kJ} \mathrm{~cm}^{-2}$. The intensification of this cyclone produced a cooling of the surface waters of approximately $3^{\circ} \mathrm{C}$.

- In the SIO Basin, TC Felleng formed in January 2013, reaching maximum intensity of 115 kt $\left(59 \mathrm{~m} \mathrm{~s}^{-1}\right)$ at approximately $16.2^{\circ} \mathrm{S}$ on 30 January at 1200 UTC. The TCHP under this TC track only reached $50 \mathrm{~kJ} \mathrm{~cm}^{-2}$ at the time of its maximum intensity (Fig. 4.27d); however, the storm developed a well-defined eye, with a deep, intense ring of convection forming in the eyewall (http://weather.noaa.gov/pub/data/raw/wt /wtio30.fmee.txt). The associated cooling of $3^{\circ} \mathrm{C}$ and $25 \mathrm{~kJ} \mathrm{~cm}^{-2}$ in SST and TCHP, respectively, are typical values for intense TCs. 

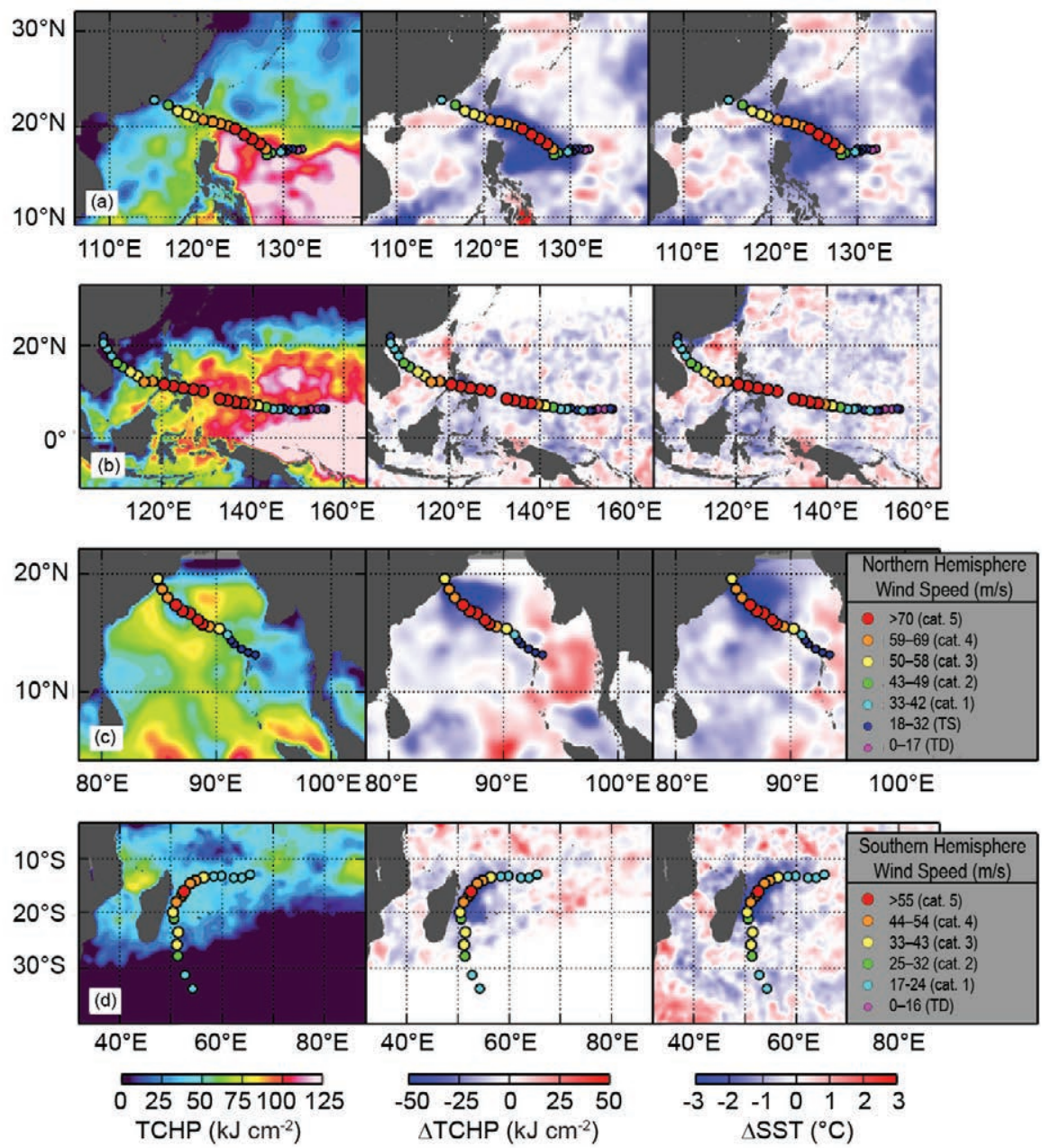

Fig. 4.27. (Left) TCHP and surface cooling given by the difference between postand pre-storm values of (center) tropical cyclone heat potential and (right) sea surface temperature for tropical cyclones (a) Usagi, (b) Haiyan, (c) Phailin, and (d) Felleng. The TCHP values correspond to two days before each cyclone reaches its maximum intensity value.

\section{f. Global monsoon summary-B. Wang}

Global monsoon (GM) is the dominant mode of annual variation of the tropical-subtropical precipitation and circulation (Wang and Ding 2008), and thus a defining feature of seasonality and a major mode of variability of the Earth's climate system. Figure 4.28 summarizes the monsoon rainfall anomalies for the period November 2012-October 2013, which is a global monsoon year that includes both the $\mathrm{SH}$ summer monsoon (SHSM) from November 2012 to April 2013 and the NH summer monsoon (NHSM) from May to October 2013.

The global land monsoon precipitation is strongly influenced by the status of ENSO, especially the land areas of Asia, Australia, northern Africa, and Central America (Wang et al. 2012). From November 2012 to October 2013, the equatorial Pacific SSTs were near normal except for a moderate cooling in the far eastern Pacific. Given the ENSO-neutral status, no coordinated monsoon rainfall anomalies were expected on a global scale, and as such the global monsoon anomalies would be expected to be near average overall. This was indeed the case for 2013, as shown in Fig. 4.28. Significant monsoon rainfall anomalies, however, did occur on local and regional scales. The SHSM rainfall over land areas tended to be moderately below normal with deficient rainfall over northeast Australia and Madagascar. The NHSM rainfall over land shows a mixed pattern of regional anomalies: above-normal rainfall occurred over northern India and southwest Mexico while deficient rainfall occurred in the East Asian subtropics and Nigeria-Cameroon.

Figure 4.29 shows the time series of the monsoon precipitation and low-level circulation indices. Note that the precipitation indices represent the total amount of precipitation over both land and ocean. The definitions of circulation indices for each monsoon region are shown in Table 4.1 (Yim et al. 2013). In 2013, the majority of summer monsoon systems, including western North Pacific (WNP), North American (NA), northern African (NAF), southern African (SAF), and Australian (AUS), had normal seasonal mean strength with an average precipitation and circulation index value $<0.5$ standard deviation. The precipitation and circulation indices together represent the strength of each regional monsoon system. The Indian (I) summer monsoon in 2013 was strong (the precipitation index was +0.8 standard deviation and the circulation index was +2.5 standard deviation). On the other hand, the East Asian (EA) summer monsoon and South American (SA) summer 
(a) Nov 2012-Apr 2013

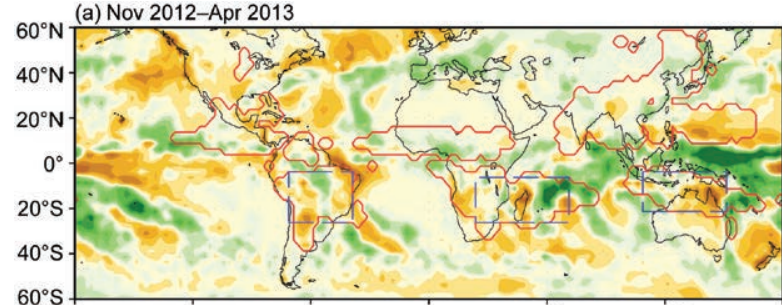

(b) May-Oct 2013

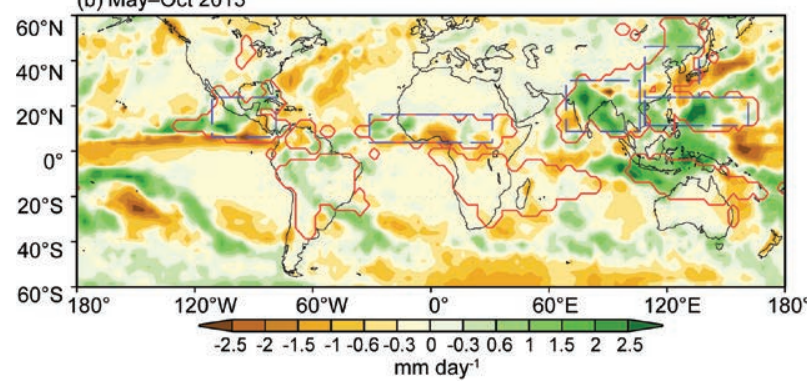

FIG. 4.28. Precipitation anomalies $\left(\mathrm{mm} \mathrm{day}^{-1}\right)$ averaged for (a) Nov 2012-Apr 2013 and (b) May-Oct 2013. The red lines outline the global monsoon precipitation domain that is defined by (a) the annual range (local summer minus winter) precipitation exceeding $300 \mathrm{~mm}$ and (b) the summer mean precipitation exceeding $55 \%$ of the total annual precipitation amount (Wang and Ding 2008). Here the local summer denotes May-Sep for the NH and Nov-Mar for the SH. The precipitation indices for each regional monsoon are defined by the areal mean precipitation in the corresponding rectangular regions (dashed blue), which are highly correlated with the precipitation averaged over the corresponding real regional monsoon domains. The rainfall data are from the Global Precipitation Climatology Project analysis (Huffman et al. 2009).
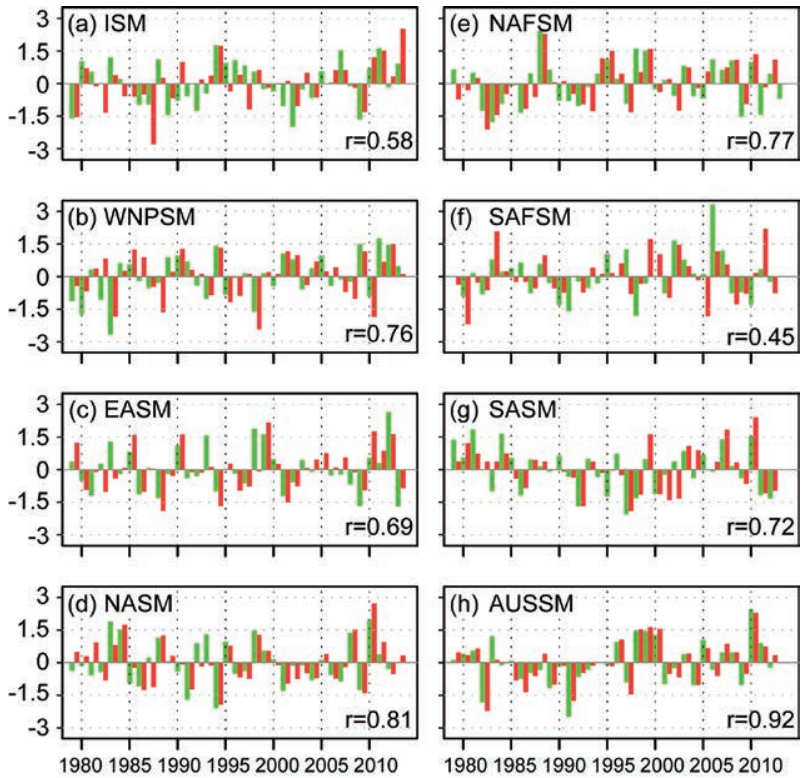

FIG. 4.29. Normalized summer mean precipitation (green) and circulation (red) indices in each of eight regional monsoons. The indices are normalized by their corresponding standard deviation. The numbers shown in the corner of each panel denote the correlation coefficient between seasonal mean precipitation and circulation indices.

monsoon systems were below normal by about one standard deviation. The compensation between the Indian and East Asian summer monsoon made the total NHSM near normal. The total strength of the SHSM was also slightly negative but remained in the

Table 4.I. Definition of regional summer monsoon circulation indices and their correlation coefficients (CCs) with the corresponding regional summer monsoon precipitation indices for the period 1979-2013. All circulation indices are 850 -hPa vorticity indices except northern African (NAF) and East Asian (EA). The correlation coefficients were computed using monthly time series (Jun-Sep in NH and Dec-Mar in SH). The bolded numbers represent significance at $99 \%$ confidence level.

\begin{tabular}{|c|c|c|}
\hline Region & Definition of Vorticity Circulation Index & CC \\
\hline I & $\begin{array}{l}\text { U850 }\left(5^{\circ}-15^{\circ} \mathrm{N}, 40^{\circ}-80^{\circ} \mathrm{E}\right) \text { minus } \\
\text { U850 }\left(25^{\circ}-35^{\circ} \mathrm{N}, 70^{\circ}-90^{\circ} \mathrm{E}\right)\end{array}$ & 0.76 \\
\hline WNP & $\begin{array}{l}\text { U850 }\left(5^{\circ}-15^{\circ} \mathrm{N}, 100^{\circ}-130^{\circ} \mathrm{E}\right) \text { minus } \\
\text { U850 }\left(20^{\circ}-35^{\circ} \mathrm{N}, 110^{\circ}-140^{\circ} \mathrm{E}\right)\end{array}$ & 0.82 \\
\hline EA & V850 $\left(20^{\circ}-40^{\circ} \mathrm{N}, 120^{\circ}-140^{\circ} \mathrm{E}\right)$ & 0.70 \\
\hline NA & $\begin{array}{l}\text { U850 }\left(5^{\circ}-15^{\circ} \mathrm{N}, 130^{\circ}-100^{\circ} \mathrm{W}\right) \text { minus } \\
\text { U850 }\left(20^{\circ}-30^{\circ} \mathrm{N}, 110^{\circ}-80^{\circ} \mathrm{W}\right)\end{array}$ & 0.82 \\
\hline NAF & $\mathrm{U} 850\left(0^{\circ}-15^{\circ} \mathrm{N}, 60^{\circ}-10^{\circ} \mathrm{W}\right)$ & 0.74 \\
\hline SA & $\begin{array}{l}\text { U850 }\left(5^{\circ}-20^{\circ} \mathrm{S}, 70^{\circ}-40^{\circ} \mathrm{W}\right) \text { minus } \\
\text { U850 }\left(20^{\circ}-35^{\circ} \mathrm{S}, 70^{\circ}-40^{\circ} \mathrm{W}\right)\end{array}$ & 0.81 \\
\hline SAF & $\begin{array}{l}\text { U850 }\left(5^{\circ}-15^{\circ} \mathrm{S}, 20^{\circ}-50^{\circ} \mathrm{E}\right) \text { minus } \\
\text { U850 }\left(20^{\circ}-30^{\circ} \mathrm{S}, 30^{\circ}-55^{\circ} \mathrm{E}\right)\end{array}$ & 0.70 \\
\hline AUS & $\begin{array}{l}\text { U850 }\left(0^{\circ}-15^{\circ} \mathrm{S}, 90^{\circ}-130^{\circ} \mathrm{E}\right) \text { minus } \\
\text { U850 }\left(20^{\circ}-30^{\circ} \mathrm{S}, 100^{\circ}-140^{\circ} \mathrm{E}\right)\end{array}$ & 0.90 \\
\hline
\end{tabular}


near-normal range. Note that these results are for the summer mean monsoon strength. Over the Indian and WNP summer monsoon regions, there were large month-to-month fluctuations due to intraseasonal oscillation. The Indian monsoon was strong in June and July, but became weak in August. The WNP monsoon became extremely strong in September (not shown), and remained that way through early November. The other regions had moderate monthto-month variation.

\section{g. Intertropical convergence zones}

\section{I) PACIFIC-A. B. Mullan}

The Pacific intertropical convergence zone (ITCZ) lies approximately parallel to the equator with a slight northeasterly tilt, and varies in position from around $5^{\circ}-7^{\circ} \mathrm{N}$ during February-May to $7^{\circ}-10^{\circ} \mathrm{N}$ in August-November. The South Pacific convergence zone (SPCZ) extends diagonally from around Solomon Islands $\left(10^{\circ} \mathrm{S}, 160^{\circ} \mathrm{E}\right)$ to near $30^{\circ} \mathrm{S}, 140^{\circ} \mathrm{W}$, and is most active during November-April. In the far western Pacific, these two convergence bands merge into the Australian and East Asian monsoon troughs, which are most active in the summer seasons of their respective hemispheres: December-March in the South Pacific (northern Australia) and June-September in the western North Pacific (Federated States of Micronesia, Republic of Marshall Islands, and other US-affiliated Pacific islands).

The positions of the Pacific convergence zones are strongly influenced by the status of ENSO, and because of the strong meridional rainfall gradients in the convergence zones, so is rainfall on many Pacific islands. In general, both the ITCZ and SPCZ are closer to the equator in El Niño seasons. During 2013, ENSOneutral conditions generally prevailed; however, some La Niña characteristics were present during the year, with below-average sea surface temperatures in the eastern equatorial Pacific for January-August, and slightly enhanced low-level easterly trade winds in the western half of the Pacific basin for much of the first half of 2013.
NASA's ENSO Precipitation Index (Curtis and Adler 2000; http://trmm.gsfc.nasa.gov/trmm_rain/Events /thirty_day.html), which quantifies the rainfall changes in the Indonesian and central Pacific regions from the TRMM rainfall imagery, was below -1.0 (La Niña-like rainfall pattern) for most of the April-August period.

Figure 4.30 summarizes the convergence zone behavior for 2013 and allows comparison of the 2013 seasonal variation against the 1998-2012 climatology. Rainfall transects over $20^{\circ} \mathrm{N}$ to $30^{\circ} \mathrm{S}$ are presented for each quarter of the year, averaged across successive $30^{\circ}$ longitude bands, starting in the western Pacific at $120^{\circ}-150^{\circ} \mathrm{E}$.

For January-September 2013 (Fig. 4.30a-c), the ITCZ exhibited a more skewed orientation than usual, being slightly closer to the equator west of the dateline, but farther north in the $150^{\circ}-120^{\circ} \mathrm{W}$ sector. West of the dateline $\left(150^{\circ} \mathrm{E}-180^{\circ}\right.$ sector $)$, the equatorward displacement of the ITCZ produced significant drought conditions in many western Pacific U.S. islands (http://www.prh.noaa.gov/peac/), including Yap $\left(8^{\circ} \mathrm{N}\right)$, Guam $\left(13.5^{\circ} \mathrm{N}\right)$, and Kwajalein $\left(9^{\circ} \mathrm{N}\right)$. The large anomalously dry region in the western Pacific around $10^{\circ} \mathrm{N}$ and corresponding wetter conditions at similar latitudes east of $150^{\circ} \mathrm{W}$ are evident in the 2013 annual-average anomaly rainfall field (Fig. 4.31). The enhanced dryness along the equator near the dateline, a feature often occurring in La Niña years, is also evident in Figs. 4.30 and 4.31.
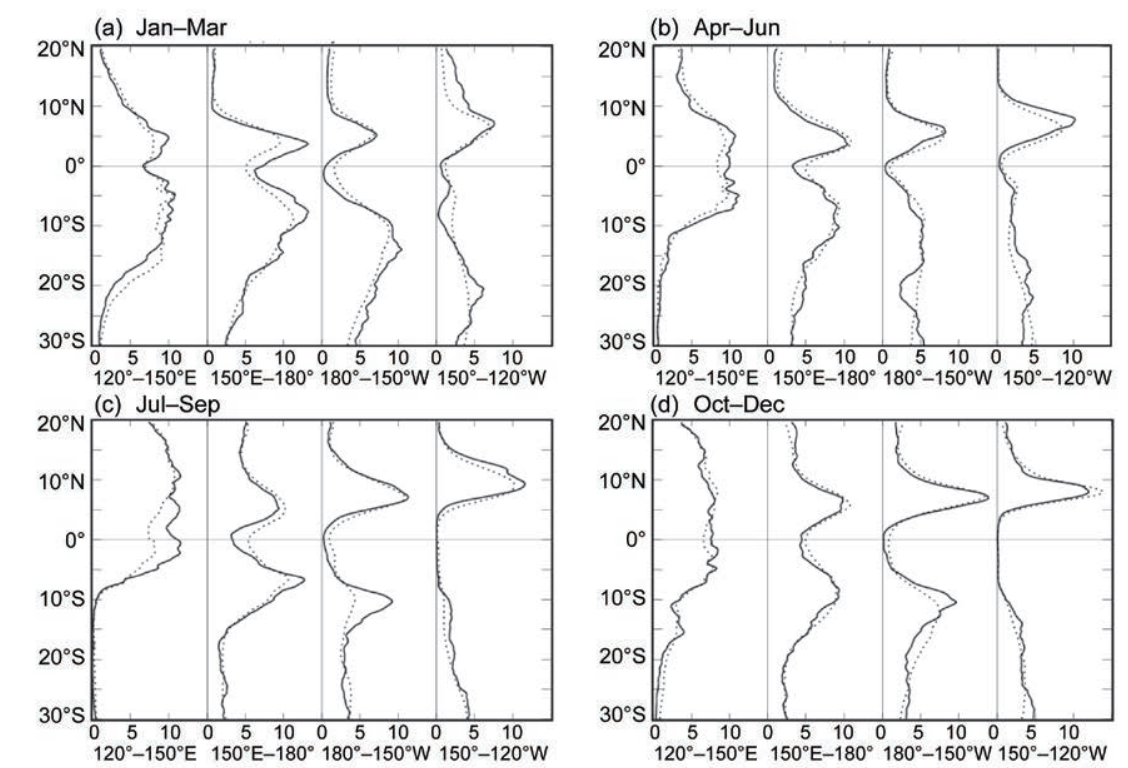

FIG. 4.30. Rainfall rate ( $\left.\mathrm{mm} \mathrm{day}^{-1}\right)$ from TRMM analysis (3B43 version 7 ) for the four quarters of $2013(\mathrm{a}-\mathrm{d})$. The separate panels within each quarter show the 2013 rainfall cross-section between $20^{\circ} \mathrm{N}$ and $30^{\circ} \mathrm{S}$ (solid line) and the 1998-2012 climatology (dotted line) for four $30^{\circ}$ sectors from $120^{\circ}-150^{\circ} \mathrm{E}$ to $150^{\circ}-120^{\circ} \mathrm{W}$. 


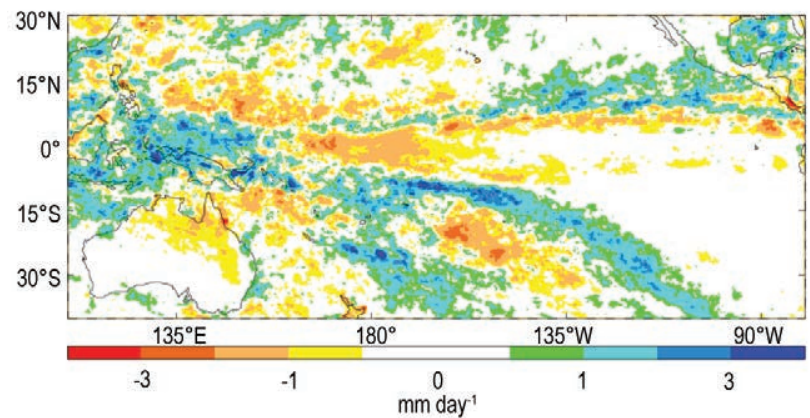

FIG. 4.3I. TRMM-3B43 annual average precipitation anomaly $\left(\mathrm{mm} \mathrm{day}^{-1}\right)$ for 2013 with respect to the 1998-20I2 average.

In the westernmost monsoon-dominated sector of Fig. $4.30\left(120^{\circ}-150^{\circ} \mathrm{E}\right)$, some pronounced seasonal rainfall anomalies occur. In the southern monsoon period of January-March 2013 (Fig. 4.30a), rainfall did not penetrate as far south as usual, producing substantial dry conditions south of about $13^{\circ} \mathrm{S}$ (northeastern Australia). During July-September (Fig. 4.30c), rainfall over the Maritime Continent region was enhanced by about $30 \%$ over its climatological value between about $5^{\circ} \mathrm{N}$ and $5^{\circ} \mathrm{S}$. The wetter conditions coincided with higher-than-usual SSTs around Indonesia and the Philippines. In September, an active period of TC formation began, culminating in Super Typhoon Haiyan in November.

The SPCZ exhibited generally higher rainfall intensities than normal, especially in the second half of $2013\left(180^{\circ}-150^{\circ} \mathrm{W}\right.$ sector in Figs. $4.30 \mathrm{c}, \mathrm{d}$, and Fig. 4.31). Figure 4.31 also shows that SPCZ convection was particularly vigorous along $10^{\circ} \mathrm{S}$ east of the dateline. However, the convective activity seemed to split into two parts to the east of Fiji. Rainfall was above normal for the year over and south-southeast of Fiji $\left(18^{\circ} \mathrm{S}, 175^{\circ} \mathrm{E}\right)$, but south of $15^{\circ} \mathrm{S}$ and east of about $160^{\circ} \mathrm{W}$ there was an extensive drier-thannormal region. This set-up caused strong contrasts in rainfall across the South Pacific Islands. Thus, Tonga ( $10^{\circ}$ east of Fiji) and the Marquesas Islands in the northern part of French Polynesia were generally wetter than normal through much of 2013, whereas many dry months were experienced in central and southern French Polynesia (http://www.niwa.co.nz /climate/icu).

Figure $4.30 \mathrm{~d}$ for the $180^{\circ}-150^{\circ} \mathrm{W}$ sector also suggests that the SPCZ during October-December was equatorward of its normal position, which seems surprising for an ENSO-neutral season. Figure 4.32, which shows south-north rainfall transects for each of the 16 years available from TRMM archive, clarifies the interpretation. In this season, the latitude of

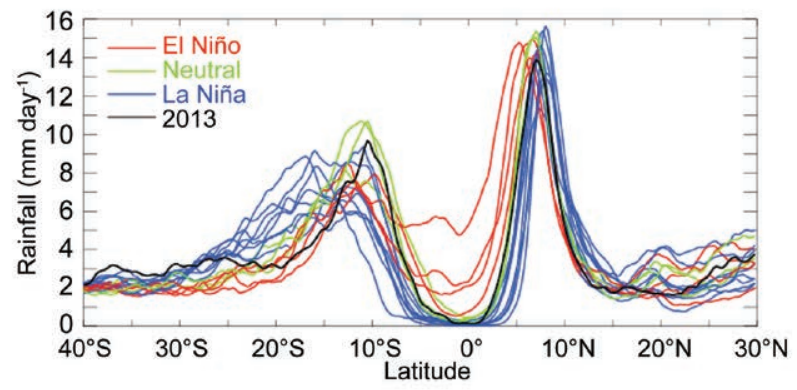

FIG. 4.32. TRMM-3B43 rainfall rate $\left(\mathrm{mm}^{\text {day-1}}{ }^{-1}\right)$ for OctDec period for each year 1998 to 2013 , averaged over the longitude sector $180^{\circ}-150^{\circ} \mathrm{W}$. The cross-sections are color coded by ENSO phase according to NOAA's ONI, except for 2013 (ENSO-neutral) shown in black.

the SPCZ rainfall peak tends to be similar in both ENSO-neutral and El Niño years, although rainfall decreases more sharply poleward of this maximum during El Niño years; however, La Niña years have the peak rainfall displaced significantly poleward, and so drag the climatological peak southwards as well. Thus, Fig. 4.32 shows both ITCZ and SPCZ peak rainfalls align well with the observed locations of other ENSO-neutral years.

\section{2) Atlantic-A. B. Pezza and C. A. S. Coelho}

The Atlantic ITCZ is a well-organized convective band that oscillates approximately between $5^{\circ}-12^{\circ} \mathrm{N}$ during July-November and $5^{\circ} \mathrm{N}-5^{\circ} \mathrm{S}$ during JanuaryMay (Waliser and Gautier 1993; Nobre and Shukla 1996). Equatorial Kelvin waves can modulate the ITCZ interannual variability and ENSO is also known to influence it on the seasonal time scale (Münnich and Neelin 2005). In 2013, the prevailing scenario was that of weak negative sea surface temperature anomalies in the equatorial Pacific near the South American coast associated with neutral ENSO conditions, with no clear teleconnective forcing driving the behavior of the Atlantic ITCZ (Fig. 4.33). However, the intraseasonal activity within the Atlantic sector responded to the typical "seesaw" mechanism between the hemispheres in terms of water temperature and anomalous horizontal divergence, as exemplified in March by an ITCZ well to the north of its climatological position (following the warm water in the North Atlantic) and corresponding suppressed convection on the eastern Amazon and northeastern Brazil (Figs. 4.34, 4.35).

Based on the local influences outlined above, the year could be divided into January-May as a predominantly dry period in the eastern Amazon and northeastern Brazil, and into June-December as a moderately wet period (Fig. 4.34a,b). In June/July, the positive anomalies to the north of the equator 


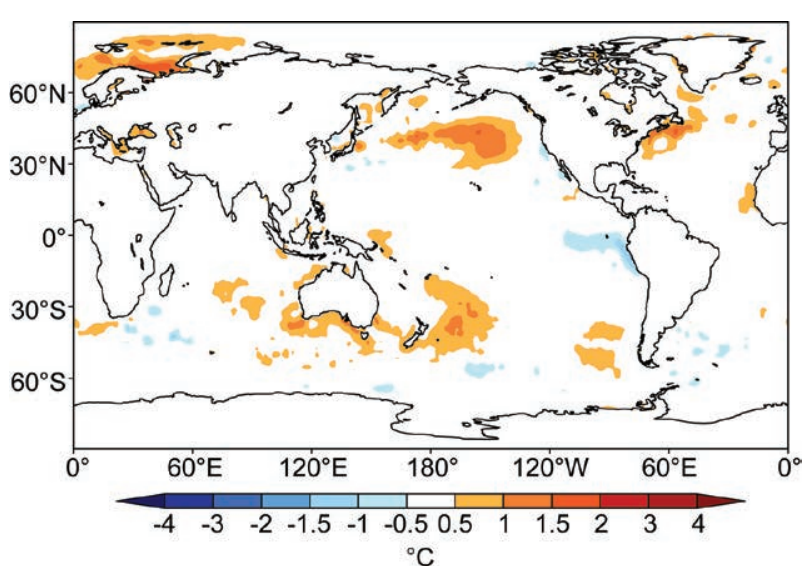

FIG. 4.33. Spatial distribution of average global sea surface temperature anomalies $\left({ }^{\circ} \mathrm{C}\right.$, Reynolds et al. 2002) during 2013.

somewhat dissipated (see the partial reversal of the Atlantic Index, Fig. 4.35b), reducing the subsidence forcing on the Brazilian coast and hence helping explain the more favorable rainfall pattern in the second half of the year. The historical interplay of the SST gradient between the South and the North Atlantic is well depicted by the aforementioned Atlantic Index (Fig. 4.35b), which shows a predominance of negative conditions (unfavorable for convection within the South Atlantic ITCZ) over the last few years.

\section{h. Atlantic warm pool-C. Wang}

The Atlantic warm pool (AWP) is a large body of warm water in the lower latitudes of the North Atlantic Ocean, comprising the Gulf of Mexico, the Caribbean Sea, and the western tropical North Atlantic (Wang and Enfield 2001, 2003). Previous studies have shown that the AWP plays an important role in Atlantic TC activity, and provides a moisture source for North America, and thus affects rainfall

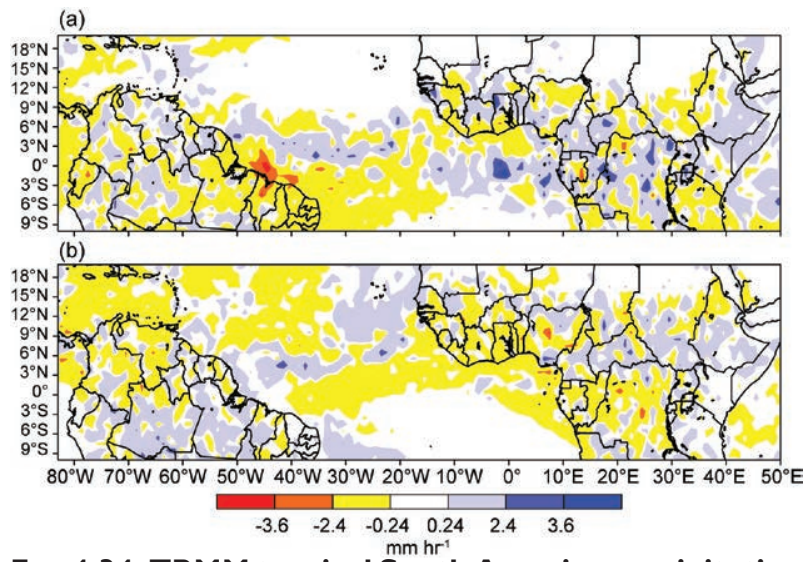

FIG. 4.34. TRMM tropical South America precipitation anomalies ( $\left.\mathrm{mm} \mathrm{hr}^{-1}\right)$ with respect to 1998-20I2 for (a) Jan-May 2013 and (b) Jun-Dec 2013.
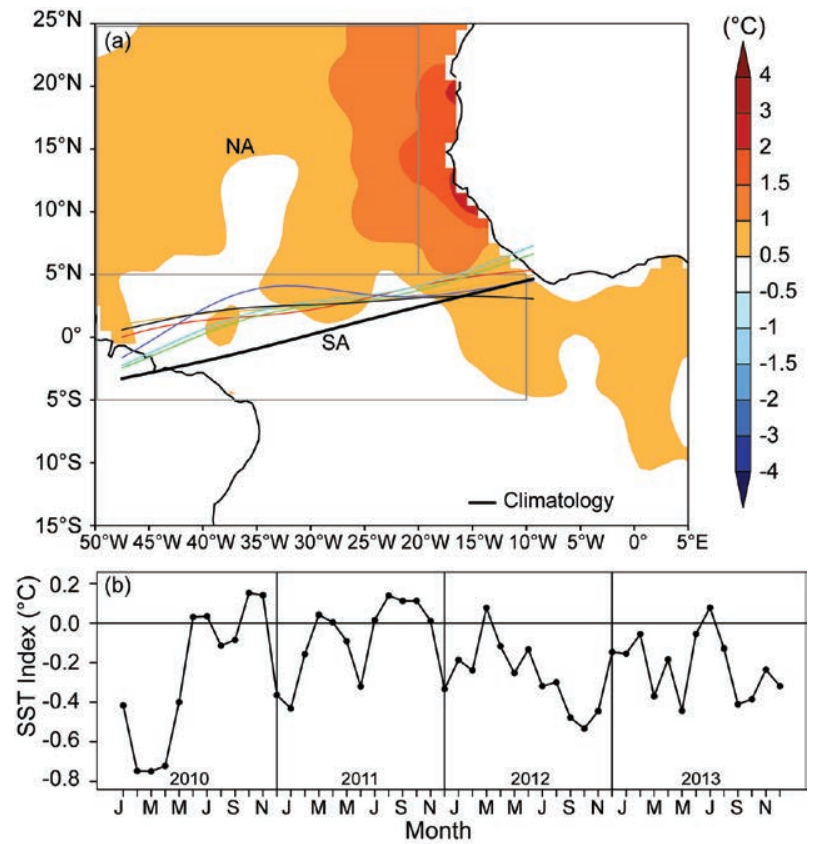

FIG. 4.35. (a) Atlantic ITCZ position inferred from outgoing longwave radiation during Mar 2013. The colored thin lines indicate the approximate position for the six pentads of Mar 20I3. The black thick line indicates the Atlantic ITCZ climatological position. The SST anomalies (Reynolds et al. 2002) for Mar 2013 based on the 1982-20I2 climatology are shaded. The two boxes indicate the areas used for the calculation of the Atlantic Index in 4.35b; (b) Monthly SST anomaly time series averaged over the South American sector (SA region, $5^{\circ} \mathrm{S}-5^{\circ} \mathrm{N}, 10^{\circ}-50^{\circ} \mathrm{W}$ ) minus the SST anomaly time series averaged over the North Atlantic sector (NA region, $5^{\circ}-25^{\circ} \mathrm{N}, 20^{\circ}-50^{\circ} \mathrm{W}$ ) for the period $2010-$ 13 forming the Atlantic Index. The positive phase of the index indicates favorable conditions for enhanced Atlantic ITCZ activity.

in the central United States (Wang et al. 2006, 2008a, 2011; Drumond et al. 2011). Unlike the Indo-Pacific warm pool, which straddles the equator, the AWP is normally north of the equator. Another unique feature of the AWP is that it does not exist in the boreal winter if the AWP is defined by SSTs warmer than $28.5^{\circ} \mathrm{C}$ (Wang and Enfield 2001). In addition to the large seasonal cycle, AWP variability occurs on both interannual and multidecadal timescales and has exhibited a long-term warming trend (Wang et al. 2006, $2008 \mathrm{~b}$ ). Figures $4.36 \mathrm{a}, \mathrm{b}$ depict the long-term total and detrended June-November (JJASON) AWP area indices. The multidecadal and interannual variations of the AWP are displayed in Figs. 4.36c,d respectively.

The multidecadal variability (Fig. $4.36 \mathrm{c}$ ) shows that the AWPs were larger during the period 1930-60, as well as after the late 1990s; and smaller during 1905-25 and 1965-95. The periods for large and small 
The 2013 Atlantic hurricane season threw a few "curve balls" for forecasters and was the "wild pitch" that triggered lengthy discussions among weather and climate scientists. What was predicted to be a very active season with at least seven hurricanes (about one-third of those projected to be major hurricanes) turned out to produce only two Category I hurricanes and just $20 \%$ of the predicted ACE. It was the quietest Atlantic hurricane season since 1994 in terms of major hurricanes (none), since 1983 in terms of ACE, and since 1968 for lowest peak intensity of the season's strongest storm.

Signals that convinced long-range forecasters to anticipate a very active season included anomalously-warm SSTs in the MDR, the absence of El Niño conditions, below-normal sea level pressures in the tropical Atlantic, and persistence of the positive phase of the AMO (Schlesinger and Ramankutty 1994) early in 2013, among other predictors. During neutral or negative phases of ENSO, upper-level wind shear in the tropical Atlantic is generally relatively weak. Neutral ENSO conditions were correctly predicted to be present by most forecast models during the 2013 hurricane season. The expectation that neutral ENSO conditions and a positive phase of the AMO would continue was key to the prediction of at least three major hurricanes - a relationship described by Klotzbach and Gray (2008).

The big question coming out of the season was "why so little activity when most standard pre-season predictors indicated favorable storm formation conditions?" The primary clue was found over the eastern tropical Atlantic and within the MDR where the peak of the season was characterized by enhanced subsidence. Additionally, SSTs evolved in an unusual manner with little warming in the MDR during the spring and first half of summer when surface water should be warming. While tropical Atlantic SSTs were warmer than normal, cool anomalies were evident in the subtropical eastern Atlantic during the early part of the hurricane season (Fig. SB4.Ib). This area has been shown in several studies including Klotzbach (20II), to be a critical area for Atlantic hurricane activity. Cold anomalies in this region tend to generate strongerthan-normal baroclinicity, thereby contributing to cold upper-level lows, which enhance African easterly wave recurvature in the eastern part of the basin.

A similar pattern evolved in the higher latitudes of the North Atlantic. This evolution signalled what would be a short-term reversal of the longer-term positive phase of the AMO since the mid-1990s. These observations,
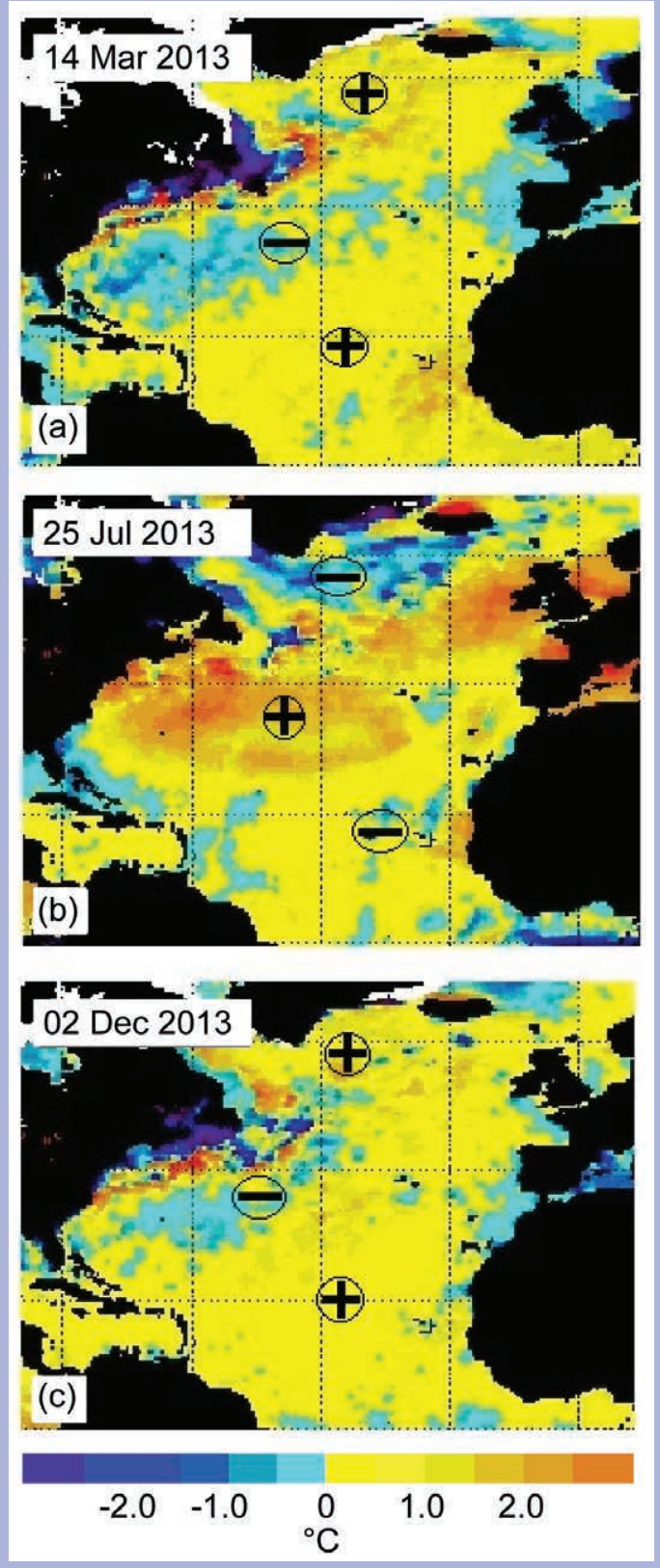

FIG. SB4.I. NOAA/NESDIS $50-\mathrm{km}$ mean weekly SST anomaly $\left({ }^{\circ} \mathrm{C}\right.$ ) for (a) $14 \mathrm{Mar}$, (b) $25 \mathrm{Jul}$, and (c) $02 \mathrm{Dec}$ 2013.

however, raise more questions. Were the enhanced subsidence in the MDR and the "flat-lined" SST (see Fig. SB4.2) related? It certainly appears that way, given that the trade winds strengthened during that period which in turn arrested the usual warming of surface waters necessary to promote convective cloud formation. Dry air from the Saharan region was also advected into the MDR 


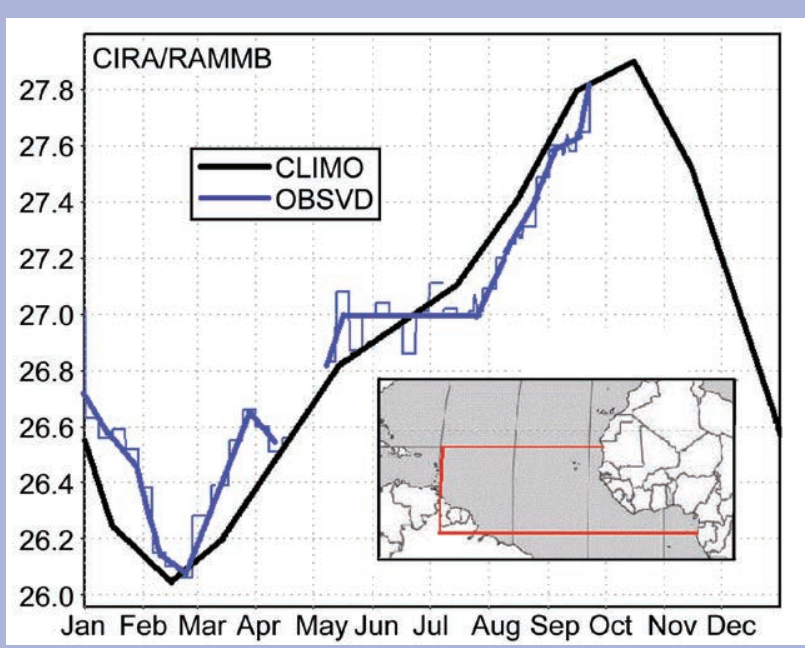

FIG. SB4.2. CIRA/RAMMB area-averaged SST throughout the MDR during 2013. Climatological values shown in black and observed shown in blue. Note the anomaly reversal from May to Jul.

by the enhanced trade winds. Another source of dry air (and wind shear) appeared to be from numerous cyclonic eddies diving southward during a commensurate reversal of the North Atlantic Oscillation (NAO) from negative to positive. Enhanced subsidence implies weaker easterly waves in the eastern Atlantic and a reduced likelihood of TC formation. Although convection was plentiful over the western part of the basin, above-normal vertical wind shear squelched the development of many storms that attempted to form there. Mid-tropospheric subsidence was also detected over the MDR (see http://typhoon.atmos .colostate.edu/).

From August to October the SST anomaly and AMO states returned to their early spring pattern almost as quickly as they deviated early in the year (the similarity between SST anomaly structures in Fig. SB4.la and c is quite remarkable); however, it appears there was a lagged storm-suppressing impact that affected the MDR during the midst of the season. This intraseasonal change is a reminder that sometimes predictability may be limited to a shorter timeframe, and in the future sudden changes to the AMO cycle (or perhaps even the NAO) may serve as a shorter-term predictor within the season.

Two important questions remain: (I) Does potential exist to anticipate these sudden changes in the AMO? (2) Could the behavior in 2013 simply be a harbinger of a "flip" in the phase of the AMO from the current positive state to a negative one? The last time such a quiet season occurred was in 1994, at the end of the previous long-term negative phase of the AMO. There can be occasional "blips" in the phase or magnitude of the oscillation as seen in Fig. SB4.3. In 1968 there was a sharp drop in storm activity corresponding to a "dip" in the AMO index during that generally active era; however, the following year was extremely active. Data covering the past $\sim 150$ years of hurricane activity in the North Atlantic indicate that a period of $\sim 60$ years can be expected between peaks of hurricane activity, so the current active phase is more likely than not to persist for at least a few more years.

In summary, while many of the large-scale conditions typically associated with active TC seasons in the Atlantic were present (e.g., anomalously warm tropical Atlantic, absence of El Niño conditions, anomalously low tropical Atlantic sea level pressures), very dry midlevel air combined with midlevel subsidence and stable lapse rates to significantly suppress the 2013 Atlantic hurricane season. These unfavorable conditions were likely generated by a significant weakening of the strength of the AMO/ Atlantic thermohaline circulation during the late spring and into the early summer. This very dry midlevel air is well-illustrated in figure 27 from last year's TC forecast verification report that shows the relative humidity anomalies at $600 \mathrm{hPa}$; that report is available at http:// hurricane.atmos.colostate.edu/Forecasts/2013/nov2013 /nov2013.pdf.

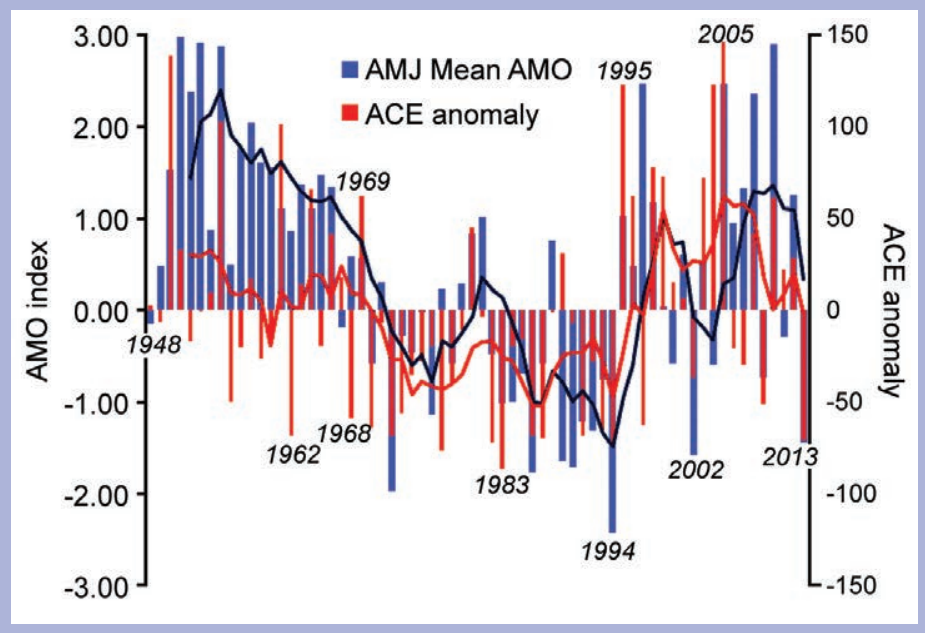

FIG. SB4.3. Apr-Jun (AMJ) mean of the AMO and season-total ACE anomaly from 1948 to 2013 . Five-year running mean indicated with bold lines. 
(a) Total

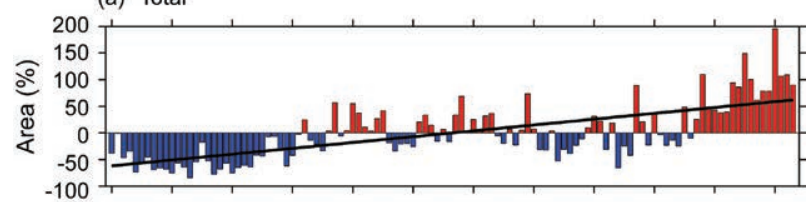

(b) Detrended

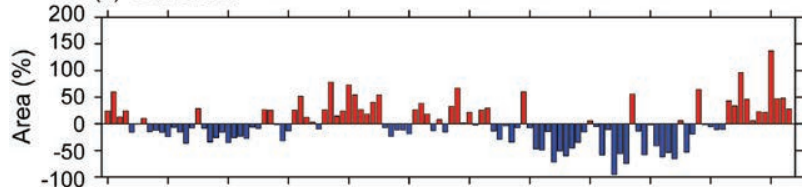

(c) Multidecadal

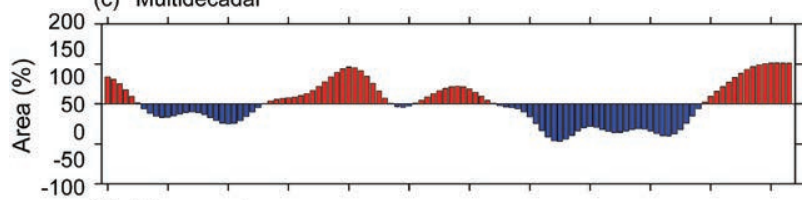

(d) Interannual

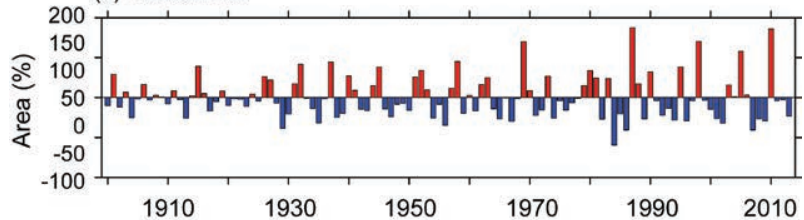

FIG. 4.36. The AWP index from 1900-2013. The AWP area index (\%) is calculated as the anomalies of the area of SST warmer than $28.5^{\circ} \mathrm{C}$ divided by the climatological Jun-Nov AWP area. Shown are the (a) total, (b) detrended (removing the linear trend), (c) multidecadal, and (d) interannual area anomalies. The multidecadal variability is obtained by performing a seven-year running mean to the detrended AWP index. The interannual variability is calculated by subtracting the multidecadal variability from the detrended AWP index. The black straight line in (a) is the linear trend that is fitted to the total area anomaly. The extended reconstructed SST data set is used.

AWPs coincide with the warm and cool phases of the Atlantic multidecadal oscillation (AMO; Delworth and Mann 2000; Enfield et al. 2001). That is, AWP variability is tied to simultaneous alterations of SST in the high latitudes of the North Atlantic in a mode that operates primarily on a multidecadal timescale. Wang et al. (2008b) showed that the influences of the AMO on TC activity and climate might operate through the atmospheric changes induced by the AWP. The interannual AWP variability reflects both the local oceanic/atmospheric processes and the remote delayed influence of Pacific ENSO. The JJASON AWP interannual index of Fig. 4.36d is significantly correlated with the prior December-February (DJF) Niño3 region of SST anomalies, indicating a delayed ENSO effect on the AWP (Wang et al. 2008b). A recent study showed that the equatorial Amazon rainfall during the austral summer is negatively related to the following boreal summer's AWP SST, manifesting the remote ENSO impact on the AWP SST through its modulation of the Amazon rainfall (Misra and DiNapoli 2013). However, the contemporaneous correlation of the JJASON Niño3 SST anomalies and JJASON AWP index is not statistically significant. This reflects the facts that (1) large/small AWPs in the summer and fall have no clear relation to contemporaneous El Niño/La Niña development, and (2) by the summer and fall of the following year the Pacific El Niño/La Niña anomaly has almost always disappeared.

The AWP was larger than its climatological mean each month in 2013, with the largest AWP occurring in September (Fig. 4.37a). The AWP usually appears in May and peaks in September; however, the 2013 AWP variation was unique as it appeared early in March with a second peak in April. A new study demonstrates that the onset date of the AWP during 1979-2012 ranged from late April to early August (Misra et al. 2014). This indicated that the early onset of the 2013 AWP in March was the earliest onset during the recent decades. Because SSTs were warmer than $28.5^{\circ} \mathrm{C}$ in the equatorial western Atlantic from March 2013 (Fig. 4.37c), the AWP started to appear in March. In April, the warmer water in the equatorial western Atlantic further developed and merged with the warmer water in the equatorial eastern Atlantic (Fig. 4.37d). By May, the warmer water decayed in the equatorial western Atlantic (Fig. 4.37e). As in previous years, the AWP started to develop in June between the Gulf of Mexico and Caribbean Sea with the $28.5^{\circ} \mathrm{C}$ SST almost overlapped with the climatological AWP (Fig. 4.37f). By July and August, the AWP was well developed in the Gulf of Mexico and Caribbean Sea and reached eastward to the western tropical North Atlantic (Fig. 4.37g,h). By September, the AWP had further expanded southeastward and the isotherm of $28.5^{\circ} \mathrm{C}$ covered almost the entire tropical North Atlantic (Fig. 4.37i). The AWP started to decay after October when the waters in the Gulf of Mexico began cooling (Fig. 4.37j,k).

Previous studies have shown that AWP variability affects the Atlantic hurricane tracks (Wang et al. 2011). An eastward expansion of the AWP tends to shift the focus of cyclogenesis eastward, therefore decreasing the probability for hurricane landfall in the southeastern United States. A large AWP also weakens the North Atlantic subtropical high and produces the eastward TC steering flow anomalies along the eastern seaboard of the United States. Due to these two mechanisms, hurricanes are generally steered toward the north and northeast during a large AWP year. The TC steering flow anomalies in 2013 
(a) AWP Area

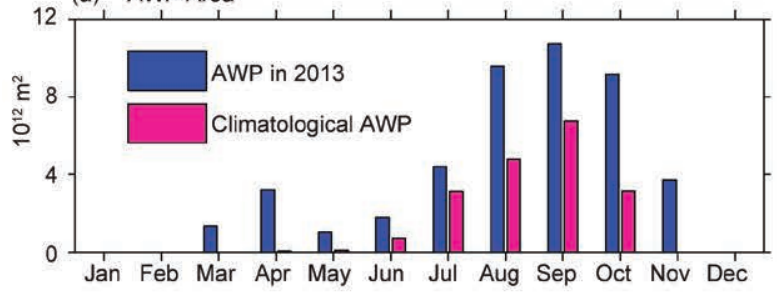

(b) Feb

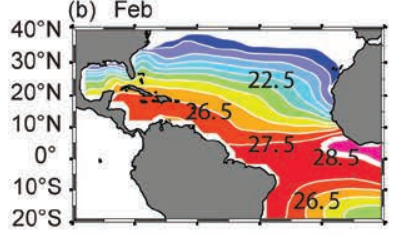

(d) Apr
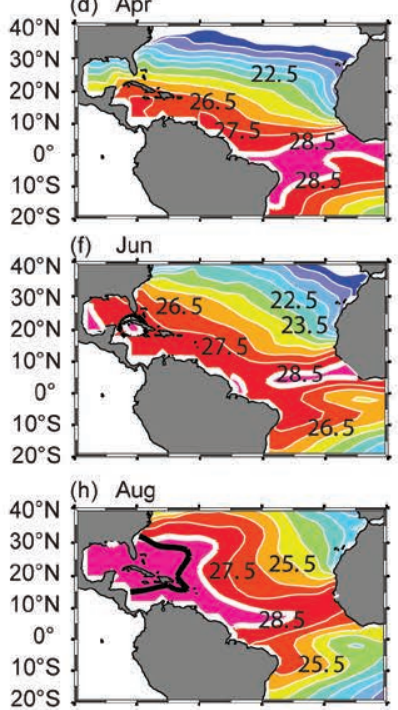

$20^{\circ} \mathrm{S}$

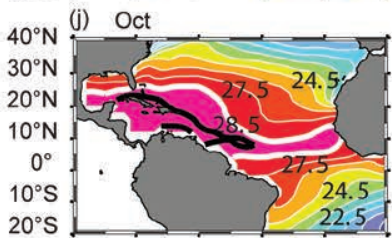

$100^{\circ} \mathrm{W} 80^{\circ} \mathrm{W} 60^{\circ} \mathrm{W} 40^{\circ} \mathrm{W} 20^{\circ} \mathrm{W} 0^{\circ} 100^{\circ} \mathrm{W} 80^{\circ} \mathrm{W} 60^{\circ} \mathrm{W} 40^{\circ} \mathrm{W} 20^{\circ} \mathrm{W} 0^{\circ}$

$\begin{array}{lllllllllll}18.5 & 19.5 & 20.5 & 21.5 & 22.5 & 23.5 & 24.5 & 25.5 & 26.5 & 27.5 & 28.5\end{array}$

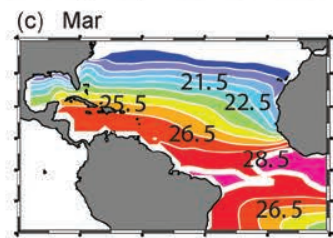

(e) May

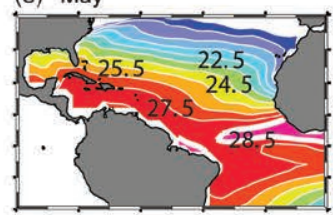

(g) Jul
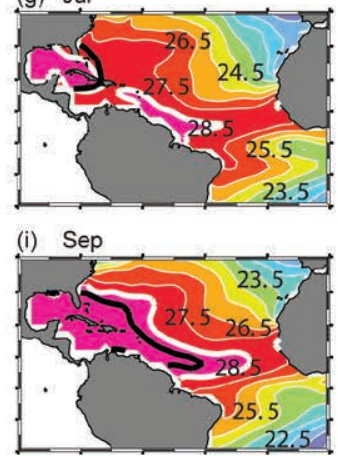

(k) Nov

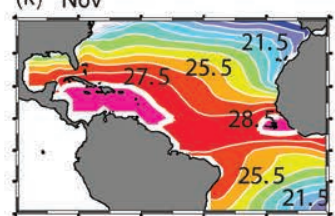

(Fig. 4.38). Associated with these patterns were mostly the eastward and southeastward flow anomalies in the western tropical North Atlantic, and the northward and northeastward flow anomalies in the open ocean of the North Atlantic. An exception was in November during which the TC steering flow anomalies were westward in the hurricane MDR (Fig. 4.38f), but only one storm, Melissa, formed southeast of Bermuda during that month. The distribution of the 2013 TC steering flow was unfavorable for TCs to make landfall in the southeastern United States. While a large AWP is consistent with the fact that no storms made landfall in the southeastern United Stated in 2013 (either by decaying or moving northward or northeastward), the AWP had no apparent enhancing effect on the number of TCs for the North Atlantic TC season (section $4 \mathrm{~d} 2$ ) as a large AWP typically results in more TCs (Wang et al. 2006).

\section{i. Indian Ocean dipole-J.-J. Luo}

Interannual climate variability in the tropical Indian Ocean (IO) is driven either by local oceanatmosphere interactions or by the Pacific ENSO in the presence of interbasin interactions (e.g., Luo et al. 2010). The Indian Ocean dipole (IOD) is one major internal climate mode in the IO that may induce considerable climate anomalies in many countries surrounding the IO. The IOD normally starts in boreal summer, peaks in Northern Hemisphere fall, and declines rapidly in early boreal winter. During May-September 2013, a negative IOD (nIOD) event occurred, characterized by anomalous SST warming in the tropical eastern IO and cooling in the west. Compared to previous events in 1990, 1992, 1996, 1998, 2001, 2005, and 2010 (Luo 2011), the 2013 nIOD was short-lived and weak with warming anomalies in the eastern IO of $<0.5^{\circ} \mathrm{C}$ and a maximum cooling anomaly in the west of about $-0.4^{\circ} \mathrm{C}$ in July (Fig. 4.39). The east warming/west cooling SST dipole structure is linked with stronger-than-normal surface westerlies in the central equatorial IO (Ucio) as noted in Fig. $4.39 \mathrm{~b}$; and this is reminiscent of the canonical air-sea coupled feature of nIOD. Note that this nIOD signal occurred along with a weak cooling condition in the Pacific. Such co-occurrence of IOD and ENSO has been found often in the historical records.

SSTs in major parts of the tropical IO during 2013 were warmer than normal except the western IO during June-August (Fig. 4.40). This may be partly due to the rapid rise of the IO SST over past decades in response to increasing greenhouse gas emissions (Hoerling et al. 2004). The fast surface warming in 

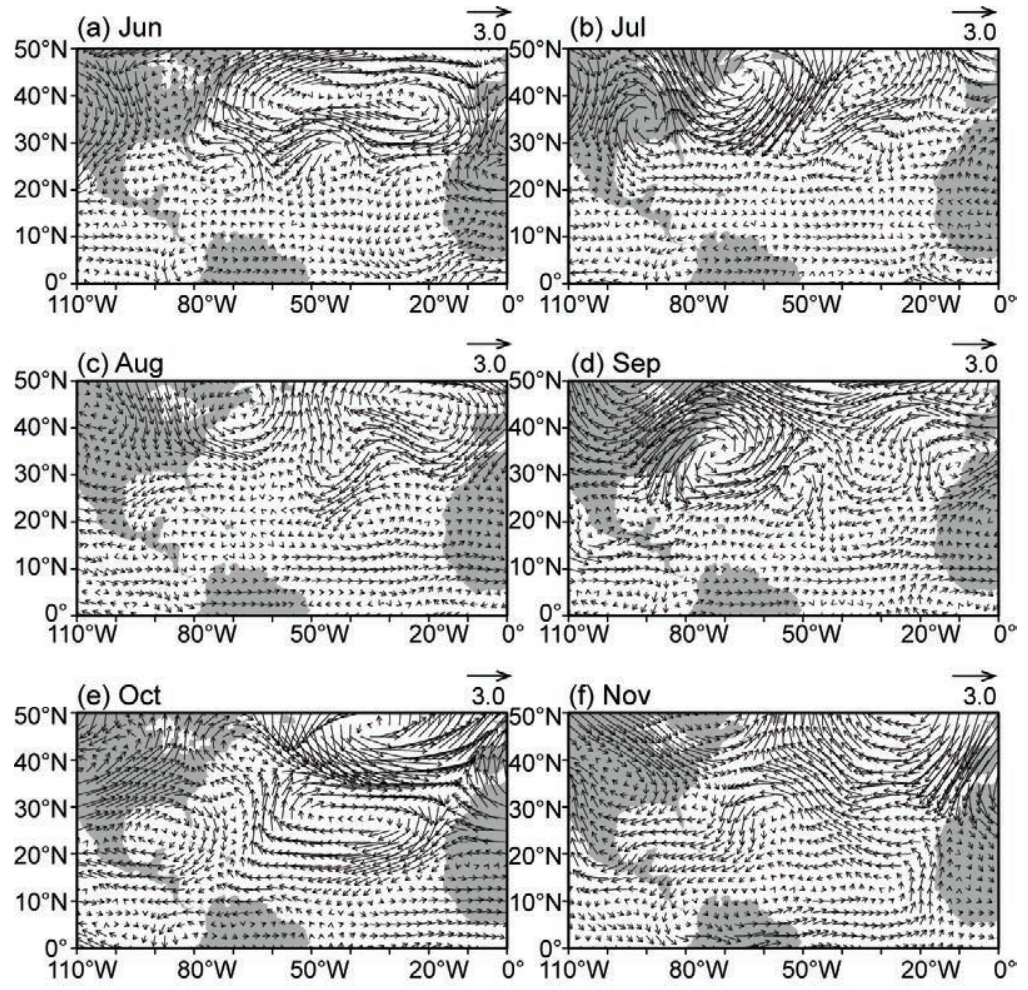

FIG. 4.38. The TC steering flow anomalies in the 2013 Atlantic hurricane season of (a) Jun, (b) Jul, (c) Aug, (d) Sep, (e) Oct, and (f) Nov. The TC steering flow anomalies are calculated by the vertically-averaged wind anomalies from $850-200 \mathrm{hPa}$ relative to the climatology of 197I-2000. The NCEP-NCAR reanalysis field is used.

the IO was found to play a key role in generating a La Niña-like climate regime shift in the Pacific by inducing excessive easterlies in the western-central Pacific via modifying the Walker Cell (Luo et al. 2012), and hence may have contributed to the weak cooling condition and stronger-than-normal easterly trade winds in the Pacific throughout 2013. Anomalous easterlies in the western central Pacific and westerlies in the IO converged in the Indonesia area, in association with the persistent surface

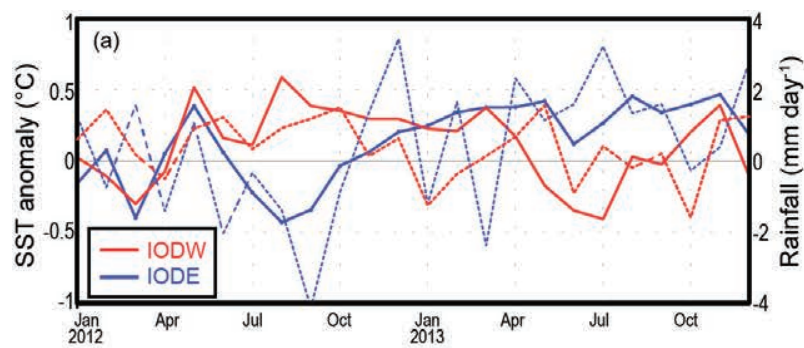

warming in the eastern IO and La Niñalike cooling in the Pacific. This induced stronger-than-normal rainfall in the eastern IO-western Pacific during 2013, which is superimposed with active intraseasonal oscillations (Fig. 4.40). Strong westerly bursts occurred in the Ucio during January, May, August, and December in association with the occurrence of eastward-propagating intraseasonal oscillations (Fig. 4.39b). These intraseasonal westerly winds forced noticeable oceanic downwelling Kelvin waves and generated subsurface warming in the eastern equatorial IO (Fig. 4.41a). Note that despite the stronger-than-normal westerlies during late 2012 to early 2013, SSTs in both the eastern and western IO were above normal; this is likely due to dry conditions and hence more solar radiation heating (Fig. 4.39). The Pacific weak warming condition in late 2012 might also contribute to the tropical IO warming during late 2012 to early 2013.

During March-May 2013, the IO basinwide SST warming persisted despite the prevailing westerly anomalies (Fig. 4.40b). The basin-wide anomalous westerlies might be ascribed to the persistent upper ocean warming in the east (and along the west coast of Sumatra) and excessive rainfall over the Maritime Continent, partly in association with the Pacific weak cooling condition. While the westerlies tend to maintain the warming in the east by deepening the ocean thermocline there, the abovenormal westerlies in the western IO acted to cool SSTs by enhancing surface evaporation and latent heat loss. This contributed to cold SST anomalies in the west during May-August. As a result, a negative dipole structure

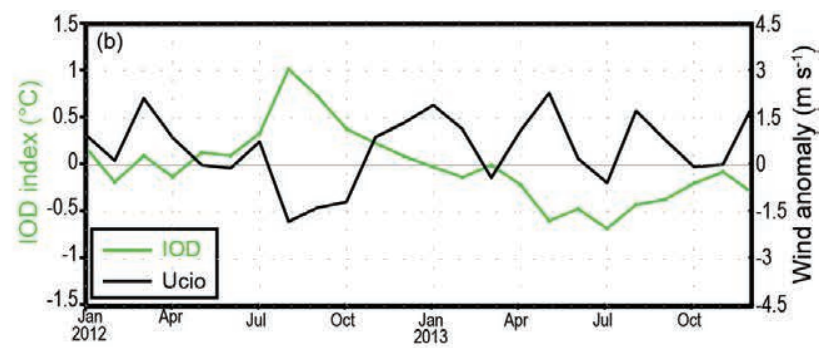

FIG. 4.39. (a) Monthly anomalies of SST ( ${ }^{\circ} \mathrm{C}$, solid lines) and precipitation ( $\mathrm{mm}$ day-1, dashed lines) in the eastern (IODE, $10^{\circ} \mathrm{S}-0^{\circ}, 90^{\circ}-110^{\circ} \mathrm{E}$ blue lines) and western pole (IODW, $10^{\circ} \mathrm{S}-10^{\circ} \mathrm{N} 50^{\circ}-70^{\circ} \mathrm{E}$, red lines) of IOD. (b) As in (a), but for the IOD index (measured by the SST difference between IODW and IODE, green line) and surface zonal wind anomaly $\left(\mathrm{m} \mathrm{s}^{-1}\right)$ in the central equatorial 10 (Ucio; $5^{\circ} \mathrm{S}-5^{\circ} \mathrm{N}, 70^{\circ}-90^{\circ} \mathrm{E}$, black line). The anomalies were calculated relative to the 1982-2012 climatology. These are based on the NCEP optimum interpolation SST (Reynolds and Chelton 2010), monthly GPCP analysis (available at http://precip.gsfc.nasa.gov/), and JRA-25 atmospheric reanalysis (Onogi et al. 2007). 

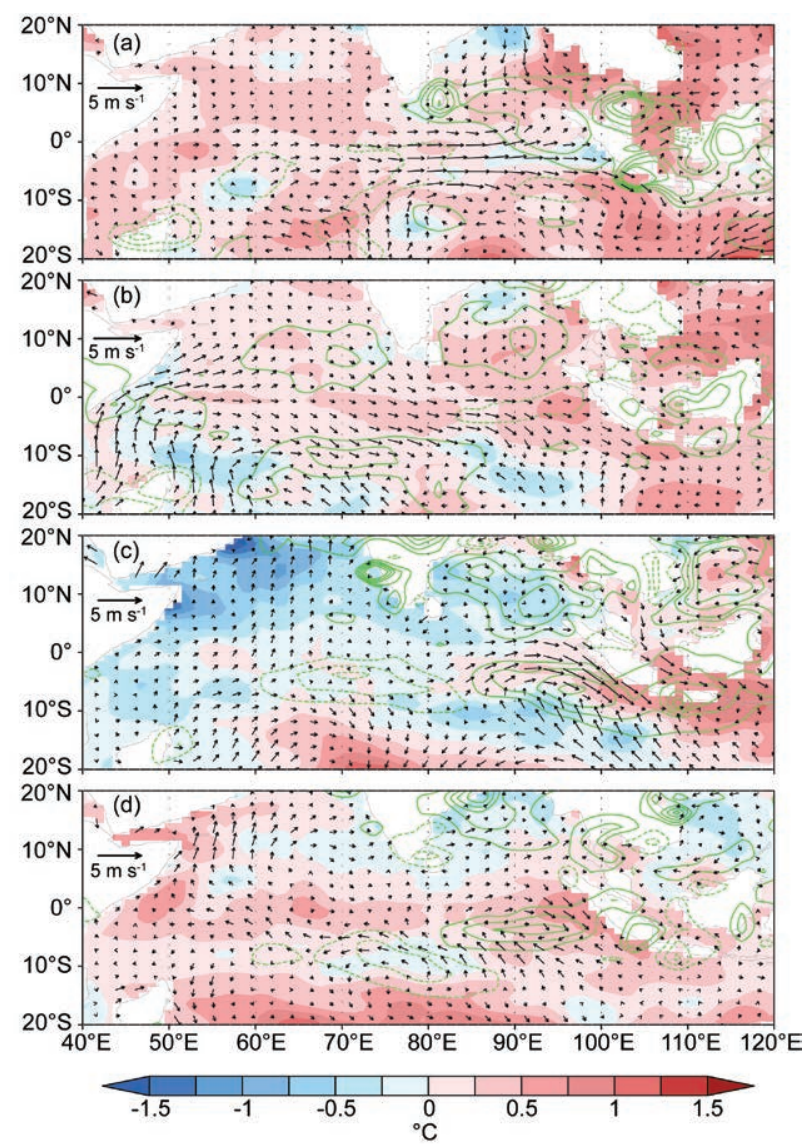

FIG. 4.40. SST $\left({ }^{\circ} \mathrm{C}\right.$, colored scale), precipitation (green contour: $\pm 1, \pm 2, \ldots, \pm 5 \mathrm{~mm}$ day $^{-1}$. Solid/dashed lines denote positive/negative values), and surface wind anomalies during (a) Dec-Feb 20I2/13, (b) Mar-May 2013, (c) Jun-Aug 2013, and (d) Sep-Nov 2013.
The weak 2013 nIOD appeared to be caused by several factors, including the multidecadal basin-wide warming trend in response to increasing greenhouse gas forcing, active westerly wind bursts related to intraseasonal oscillations, and weak La Niña-like conditions in the Pacific. Additionally, a downwelling Rossby wave in the south IO, primarily driven by anticyclonic wind forcing associated with the positive IOD in late 2012 , continuously propagated westward at $12^{\circ}-8^{\circ} \mathrm{S}$ (Fig. 4.41) and may have also contributed to the nIOD in late 2013. developed during June-August, with dry conditions in the west and excessive rainfalls in the eastern IO (Fig. 4.40). The equatorial westerly anomalies in this season, however, were confined east of $80^{\circ} \mathrm{E}$ with near-normal winds in the central region, probably owing to intraseasonal disturbances (Figs. 4.39, 4.40). This suggests that the local air-sea coupling was not strong enough to maintain/ enhance the nIOD development. During September-November, the SST warming in western IO rebounded quickly due to reduced cloudiness in that region. Consequently, the negative SST dipole collapsed and basin-wide warming appeared (Fig. 4.40d). (a) D20 anomaly $\left(2^{\circ} \mathrm{S}-2^{\circ} \mathrm{N}\right)$

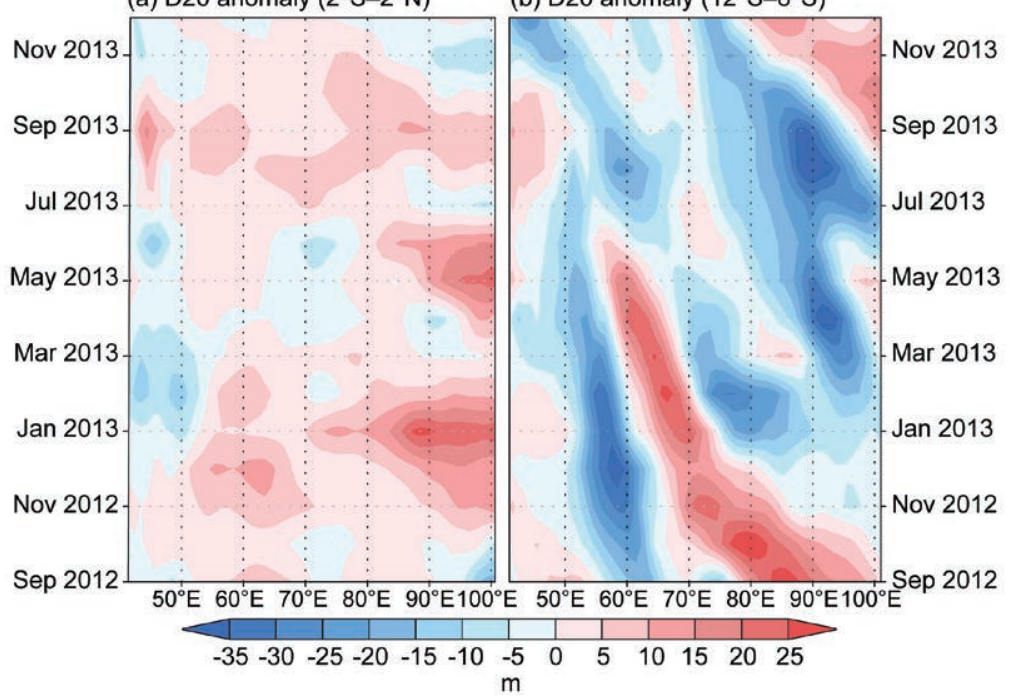

FIG. 4.41. $20^{\circ} \mathrm{C}$ isotherm depth (D20, $\mathrm{m}$ ) anomalies in (a) the equatorial Indian Ocean $\left(2^{\circ} \mathrm{S}-2^{\circ} \mathrm{N}\right)$ and (b) off-equatorial south Indian Ocean $\left(12^{\circ}-8^{\circ} \mathrm{S}\right)$ in 2013 . The data are derived from the NCEP ocean reanalysis available at http://www.cpc.ncep.noaa.gov/products/GODAS/. 
On the morning of 8 November, Super Typhoon Haiyan (christened "Yolanda" by Philippine authorities; Fig. SB4.4) roared ashore in the Visayas region of the Philippines. This cyclone caused catastrophic destruction and thousands of casualties, particularly within Samar and Leyte Provinces. The city of Tacloban suffered heavy damage from powerful winds and enormous storm surge. The plight of this city became the focus of world media attention and subsequent international relief efforts. The Joint Typhoon Warning Center (JTWC) estimated Haiyan's one-minute sustained winds at $170 \mathrm{kt}(87.5 \mathrm{~m}$ $\left.\mathrm{s}^{-1}\right)$ when the storm first touched land in Guiuan in eastern Samar. This preliminary wind speed estimate, which must still be officially validated, would make Haiyan the strongest tropical cyclone at landfall, surpassing the old record of $165 \mathrm{kt}\left(84.9 \mathrm{~m} \mathrm{~s}^{-1}\right)$ set by Hurricanes Camille (1969) and Allen (1980) in the North Atlantic Basin, and Super Typhoon Tip (1979) in the Western North Pacific. Prior to landfall, the eye of Super Typhoon Haiyan passed directly over Kayangel Atoll, the northernmost island in the Republic of Palau.

Haiyan was the final typhoon of 2013 in the Western North Pacific Basin, forming at a very low latitude south of Pohnpei Island and then proceeding quickly westward in Micronesia. This cyclone became a super typhoon (maximum sustained one-minute winds of $130 \mathrm{kt}$ or 66.9 $\mathrm{m} \mathrm{s}^{-1}$ ) to the east of Palau, just before it tracked directly over Kayangel, causing much destruction but no loss of life. Continuing on a west-northwestward track it made landfall close to the city of Tacloban in Leyte province of the central Philippines. Haiyan was the second super typhoon in less than a year to directly affect the Republic of Palau and islands in the southern provinces of the Philippines; Super Typhoon Bopha impacted these regions in early December 2012 as noted in Diamond (2013) and Fig. SB4.5.

On 7 November, the JTWC estimated the intensity of Haiyan to be $170 \mathrm{kt}\left(87.5 \mathrm{~m} \mathrm{~s}^{-1}\right)$, which was the highest wind speed ever assigned to a TC by the JTWC and surpassed the previous record wind speed of $165 \mathrm{kt}$ (84.9 $\mathrm{m} \mathrm{s}^{-1}$ ) assigned to Super Typhoon Tip during October 1979 by $5 \mathrm{kt}\left(2.6 \mathrm{~m} \mathrm{~s}^{-1}\right)$. The word "assigned" is appropriate because Tip's $165 \mathrm{kt}\left(84.9 \mathrm{~m} \mathrm{~s}^{-1}\right)$ peak wind was not actually measured, but was based on a wind-pressure relationship. Haiyan's $170 \mathrm{kt}\left(87.5 \mathrm{~m} \mathrm{~s}^{-1}\right)$ peak wind was based on the wind speed equivalent for a Dvorak satellite signature of T8.0 (the highest on the Dvorak scale; Fig. SB4.5). It reached this speed with an impressive and extremely cold cirrus cloud canopy in Fig. SB4.6 (note the extremely cold dark gray shading of the eye wall cloud tops) that was much colder than the Atlantic conditions used to develop the original Dvorak scale (Dvorak 1984). Currently, however, there is no consensus on how to handle the much colder western Pacific tropopause in Dvorak classifications.

While there has not been any storm in recent history as severe as Haiyan to impact Tacloban, there are two documented historical occurrences over 100 years ago of typhoons with similar impact. An intense typhoon in late October 1897 (http://www.rappler.com/move-ph/issues /disasters/typhoon-yolanda/44062-leyte-1897-typhoon) was similar to Haiyan in terms of its path, destructive capacity, and very high storm surge. The communities and churches of Samar and Leyte, including Guiuan, Tacloban,

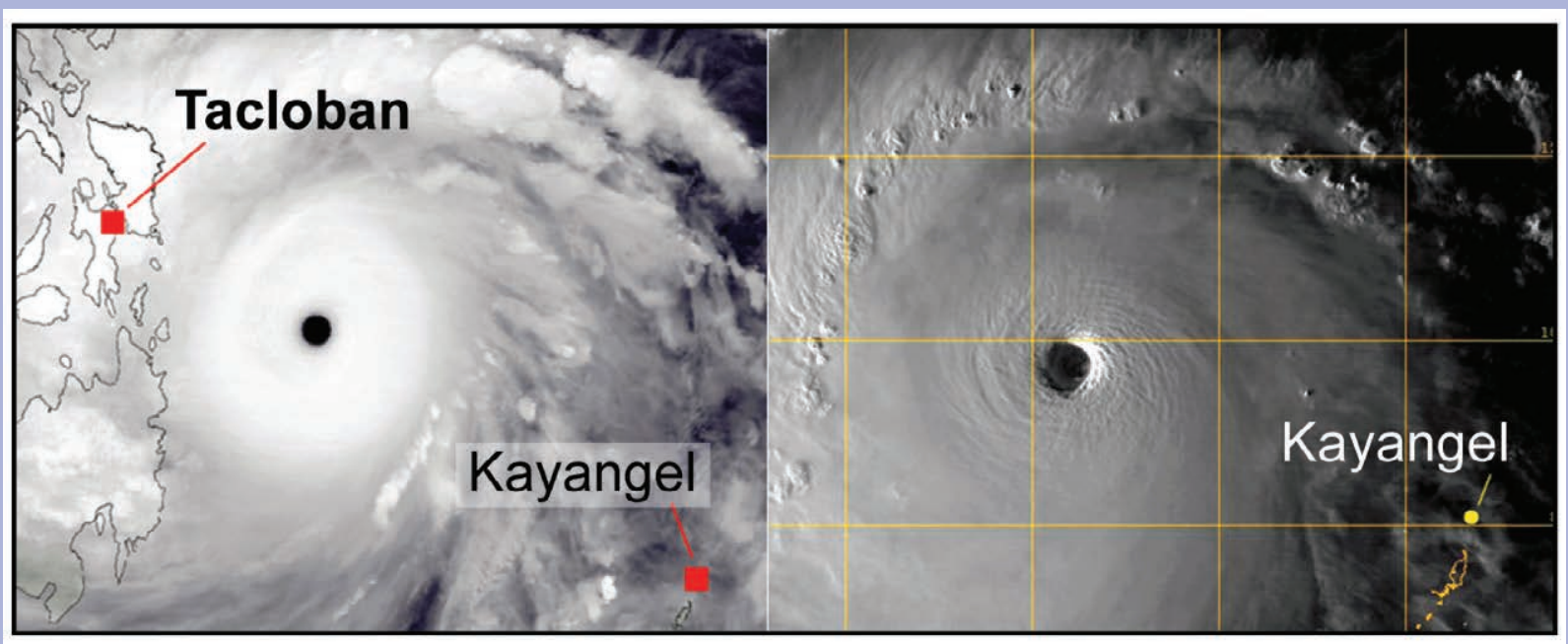

FIG. SB4.4. Super Typhoon Haiyan. Infrared image (left) and visible image (right). 


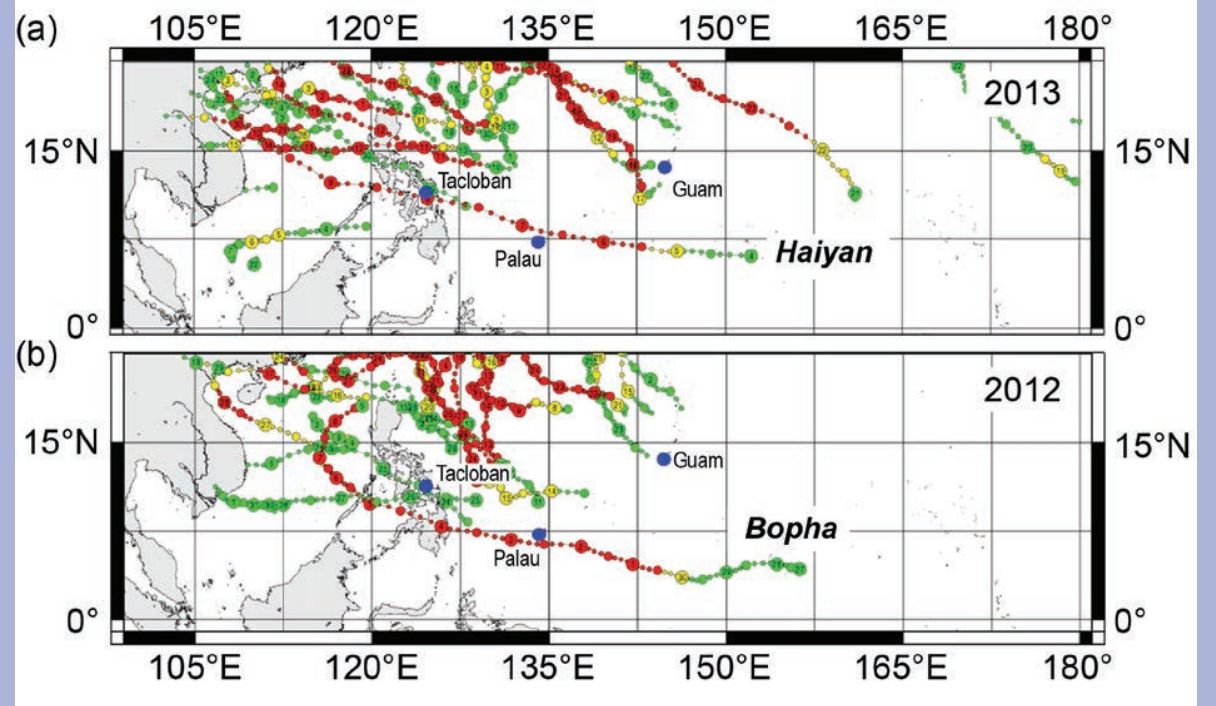

FIG. SB4.5. Tracks of (a) 2013 and (b) 2012 typhoons in the WNP. -tacloban-storm-killing - I5000-resurface) ran a story headlined, " 15,000 die in Philippine storm”. It reads, in part: "The typhoon swept the Visayas and is said to have practically destroyed Tacloban, the capital city of Leyte, and to have wrought enormous damage and loss of life at Capiz, ......15,000 persons were probably killed and wounded in a typhoon ... probably half the population of the two cities had been lost."

The major cause of damage and loss of life during and Palo were destroyed and hundreds of residents were killed. Similar to Haiyan, the 1897 typhoon first made landfall near Guiuan in Samar Province, then proceeded to Tacloban. Hernani on the eastern Samar coast experienced a storm surge of $7.3 \mathrm{~m}$, while the storm surge reached $4-5 m$ in the vicinity of Tacloban.

Another extremely powerful typhoon swept along a path similar to Haiyan in November 1912. The Washington Herald issue of 20 November 1912 (http://www.philstar. com/headlines/2013/11/19/1258482/19/2-reports
Haiyan's passage through the Philippine archipelago appears to have been from the accompanying storm surge. A major focus of devastation was on the east coast of Samar and Leyte, with a particular focus on Tacloban. The tremendous storm surge may have been high as 7.5 $\mathrm{m}$, which would make it a candidate for the highest storm surge ever observed in the Philippines and all of East Asia, surpassing the confirmed surge of $7.3 \mathrm{~m}$ that struck the Philippines in 1897 (Arafiles and Alcances 1978). Much of the city of Tacloban sits less than $5 \mathrm{~m}$ above sea level.

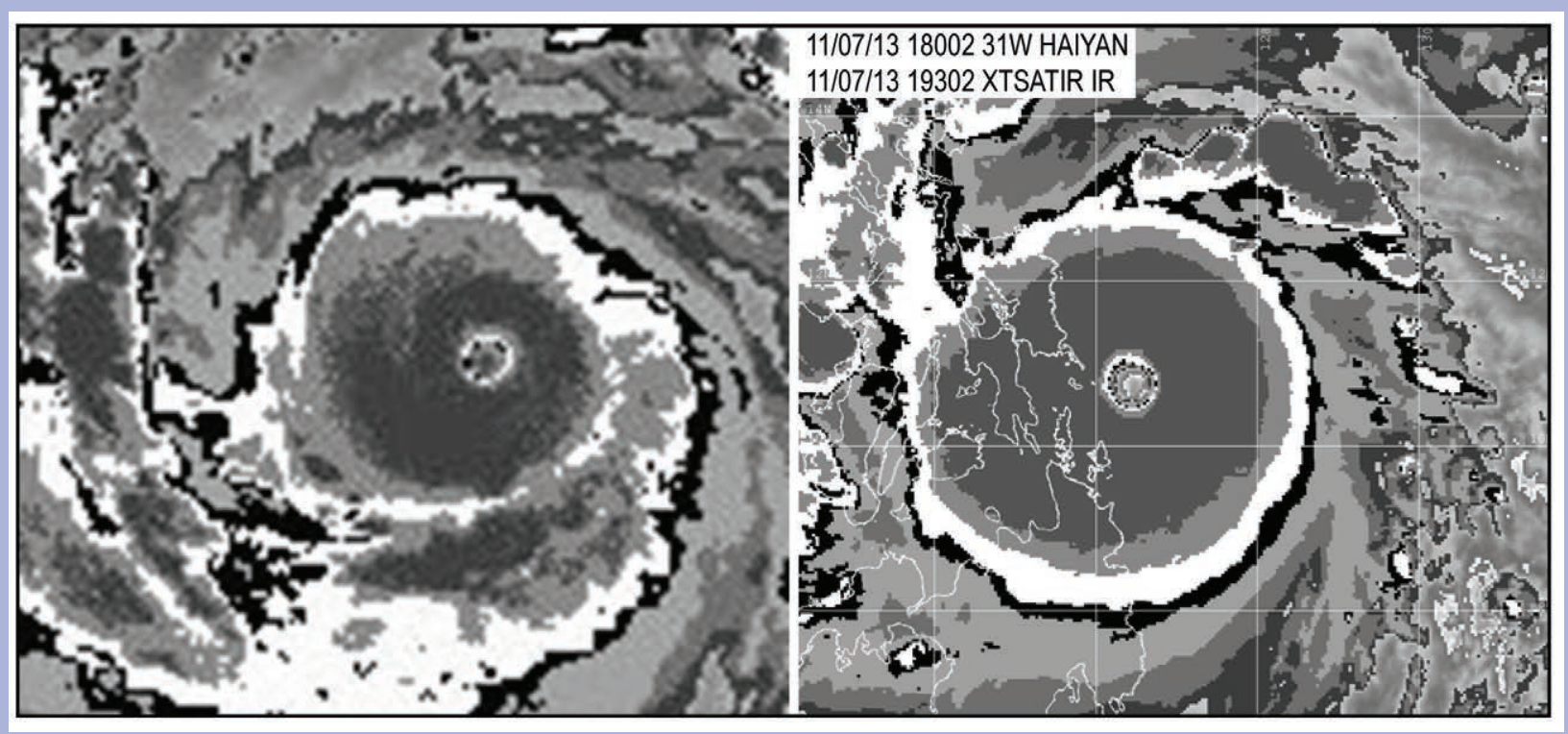

FIG. SB4.6. Enhanced infrared images of Typhoons Tip (left) and Haiyan (right) at peak intensities of $165 \mathrm{kt}$ (85 $\left.\mathrm{m} \mathrm{s}^{-1}\right)$ and $170 \mathrm{kt},\left(87 \mathrm{~m} \mathrm{~s}^{-1}\right)$ respectively. Note the extremely cold dark gray shading of the eye wall cloud tops. 
Early surge estimates at Tacloban are 6.5 $\mathrm{m}$ at the airport and possibly 8.5-9.1 $\mathrm{m}$ in downtown Tacloban. The downtown surge height estimates are based on eyewitness accounts from the iCyclone chase team (http://www.icyclone.com).

The surge came rapidly in some locations with nearly the same force and rapidity of a destructive tsunami (e.g., http://www.youtube.com / watch?v=rS0gv4Xbw7w). The configuration of the coastline, and its location at the head of San Pedro Bay on the northwest reaches of Leyte Gulf, make Tacloban particularly vulnerable to storm surge. Early modeling results from the Deltares Engineering Group in the Netherlands (e.g., Fig. SB4.7), indicate a surge height of at least $5 \mathrm{~m}$ at Tacloban.

The sea level in the region of the central Philippines (and eastward into Micronesia) is currently at historical highs. Since 1970, the mean sea level at Legaspi in the Visayan Island group of the central Philippines has risen by $200 \mathrm{~mm}$. Regardless of the cause, the $200 \mathrm{~mm}$ rise of mean sea level is roughly $20 \%$ of the magnitude of the range of the astronomical tide at

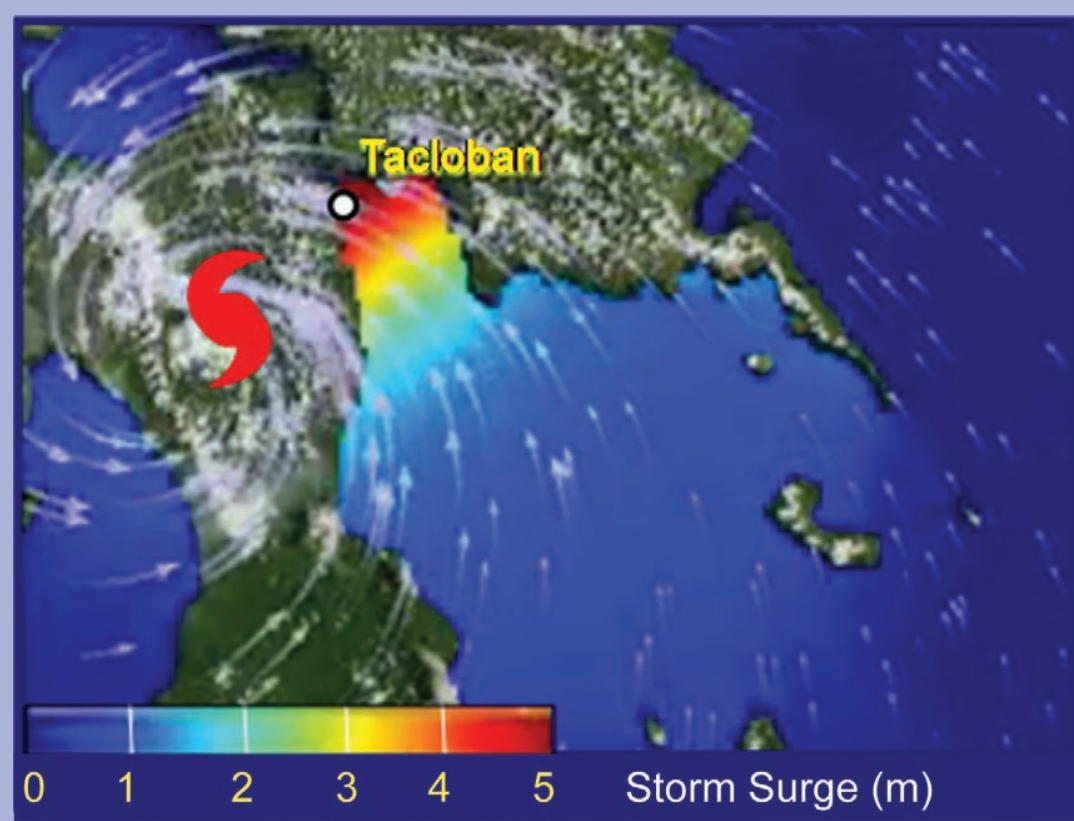

FIG. SB4.7. Model simulation of Haiyan's storm surge shows how Haiyan's winds generated a surge that targeted Tacloban, with water levels exceeding $5 \mathrm{~m}$, not including any effect from the tide or wave heights. (Source: Deltares Engineering Group.)

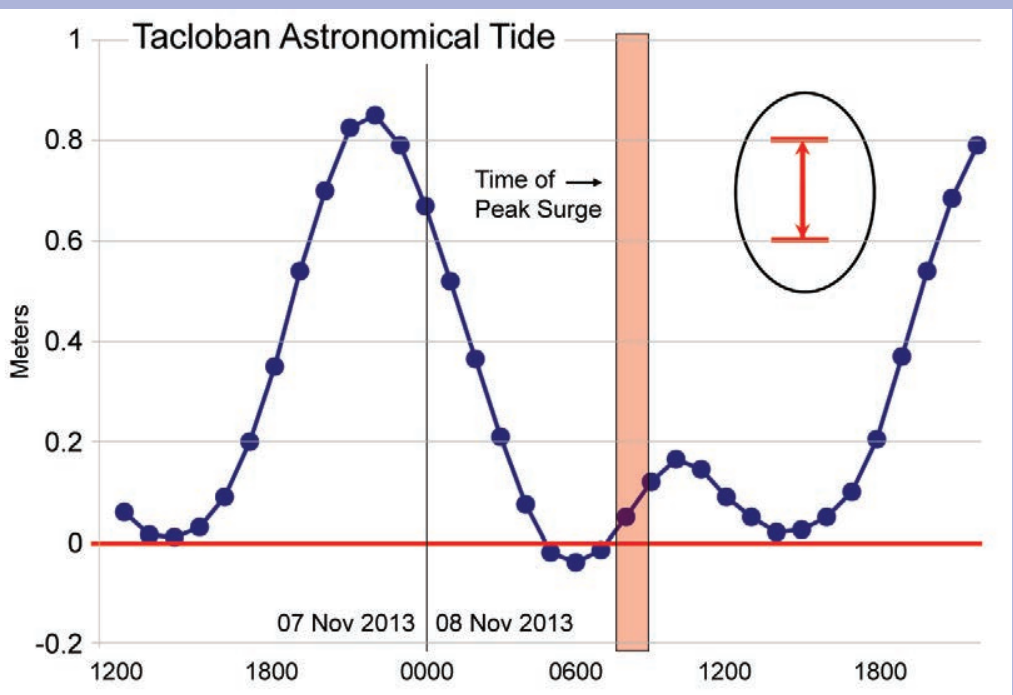

FIG. SB4.8. Astronomical tide at Tacloban at 1200 local time on 7 Nov to 2200 local time on 8 Nov. The shaded region depicts the timing of the peak storm surge. The inset in the black oval illustrates the comparative magnitude of the $200-\mathrm{mm}$ rise of mean sea level in the region from 1970 to present.

Tacloban (Fig. SB4.8). However, the peak surge at Tacloban during Haiyan occurred at a time of relatively low water level. The addition of $200 \mathrm{~mm}$ to the low astronomical water level at the time would still have left the water level $0.5 \mathrm{~m}$ below the expected high tide for that day.

In summary, Haiyan's extreme intensity and deadly power immediately fueled speculation on the role of climate change in its occurrence and behavior. Haiyan's behavior was unusual on several counts: (I) high intensity at such a low latitude (i.e., $\sim 5^{\circ} \mathrm{N}$ ); (2) extreme intensity for the overall basin; (3) record-setting landfall intensity; (4) destructive and deadly power in the Philippines; and, (5) its one-year follow-on to a similar unusual low-latitude intense Typhoon Bopha in 2012. With Haiyan potentially achieving record global typhoon wind intensity, it is likely that a special team will have to be assembled to investigate the legitimacy of this new record and to place Haiyan in its proper ranking among the pantheon of the world's most powerful tropical cyclones. 
5. THE ARCTIC -M. 0. Jeffries and J. Richter-Menge, Eds. a. Overview-M. 0. Jeffries and J. Richter-Menge

The Arctic chapter describes observations of a variety of physical variables that encompass the atmosphere, ocean, and land. There were strong spatial and temporal contrasts in a number of variables during 2013. Illustrating the influence of significant interannual variability, some variables were similar to what was observed in 2012, while others were very different.

The mean annual air temperature in 2013 over the Arctic land area was similar to that of 2012, and it was the seventh warmest year observed in the Arctic since records began in the early 20 th century. Negative (cold) winter air temperature anomalies across Eurasia were followed by positive (warm) spring air temperature anomalies, which were linked to a new record low Eurasian snow cover extent in May and early (3-4 weeks) lake ice break-up. Across the Arctic Ocean, low spring air temperatures extended from Iceland through Greenland and northern Canada to Alaska, which experienced its coldest April since 1924. Despite the relatively cool North American spring, snow cover extent in June was well below average.

The rate of snow cover loss over Northern Hemisphere land areas in June between 1979 and 2013 was $-19.9 \%$ decade $^{-1}$ (relative to the 1981-2010 average). This exceeds the rate of September sea ice loss over the same time period $\left(-13.7 \%\right.$ decade $\left.^{-1}\right)$, adding further compelling evidence of the observed rapid response of both the terrestrial and marine cryosphere to Arctic amplification in surface temperature trends.

Minimum sea ice extent in September was 1.69 million $\mathrm{km}^{2}$ higher than the record minimum of 2012, yet it was still 1.12 million $\mathrm{km}^{2}(18 \%)$ below the 1981-2010 average and the sixth lowest minimum extent since satellite observations began in 1979. A similar contrast between 2013 and 2012 conditions occurred on the Greenland ice sheet, where melting in 2013 was detected over $44 \%$ of the surface; a much lower value than the record $97 \%$ melt extent of 2012. The ice-sheet-wide albedo in 2013 was the highest since 2008, and the surface mass balance along the K-transect in west Greenland was much closer to the 1990-2010 average than it was in 2012.

Summer 2013 was characterized by a positive North Atlantic Oscillation, which gave rise to persistent low pressure over Greenland and adjacent regions, positive air temperature anomalies in western Eurasia, and a large area of anomalously low air temperatures stretching from Greenland through the high Canadian Arctic and across the Arctic Ocean to eastern Eurasia. As well as influencing sea ice extent and Greenland ice sheet melting, these conditions likely contributed to stronger cyclonic forcing over the Canada Basin, where the freshwater content of the upper ocean decreased by $7 \%$ and very little multiyear ice drifted into the Beaufort Sea north of Alaska and beyond into the East Siberian Sea.

Adjacent to the Beaufort Sea, new record high temperatures at 20-m depth were measured at some permafrost observatories on the North Slope of Alaska and in the Brooks Range. Permafrost temperatures also continued to rise elsewhere in the Arctic, including Canada, Russia, and the Nordic region. Atmospheric $\mathrm{CO}_{2}$ and $\mathrm{CH}_{4}$ concentrations increased by $3.2 \mathrm{ppm}$ and $5.0 \mathrm{ppb}$, respectively, between 2012 and 2013. Each value is the same as the global increase during the same period, consistent with Arctic atmospheric $\mathrm{CO}_{2}$ and $\mathrm{CH}_{4}$ increases being due to export from lower latitudes rather than a consequence of increases in Arctic sources, e.g., thawing permafrost.

An unusually early stratospheric sudden warming event in January 2013 halted chemical destruction of ozone in the atmosphere. Consequently, the minimum total ozone column in March (414 Dobson Units) was $35 \%$ higher than the record minimum of 2011 and $13 \%$ higher than the $2000-10$ average. Because of the above-average ozone levels in spring 2013, UV levels measured in the high Arctic were below the climatological mean for prolonged periods at several measurement sites.

b. The lower atmosphere: air temperature, clouds and surface radiation-J. Overland, J. Key, E. Hanna, I. HanssenBauer, B.-M. Kim, S.-J. Kim, J. Walsh, M. Wang, U. Bhatt, Y. Liu, R. Stone, C. Cox, and V. Walden

I) Mean annual surface air temperature

The mean annual air temperature in 2013 was similar to 2012 and the seventh warmest year observed in the Arctic since records began in the early 20th century (Fig. 5.1). The first 13 years of the 21st century (2001-13) were about $1.0^{\circ} \mathrm{C}$ warmer than the last 20 years of the 20th century (1981-2000). Decadal-long, positive (warm) anomalies occurred in all parts of the Arctic, an indication that the early 21st century temperature increase is due to global warming rather than natural regional variability (Overland 2009). The temperature increase in the Arctic-more than double that observed at lower latitudes-is a manifestation of "Arctic Amplification" (Overland et al. 2011; Stroeve et al. 2012). 


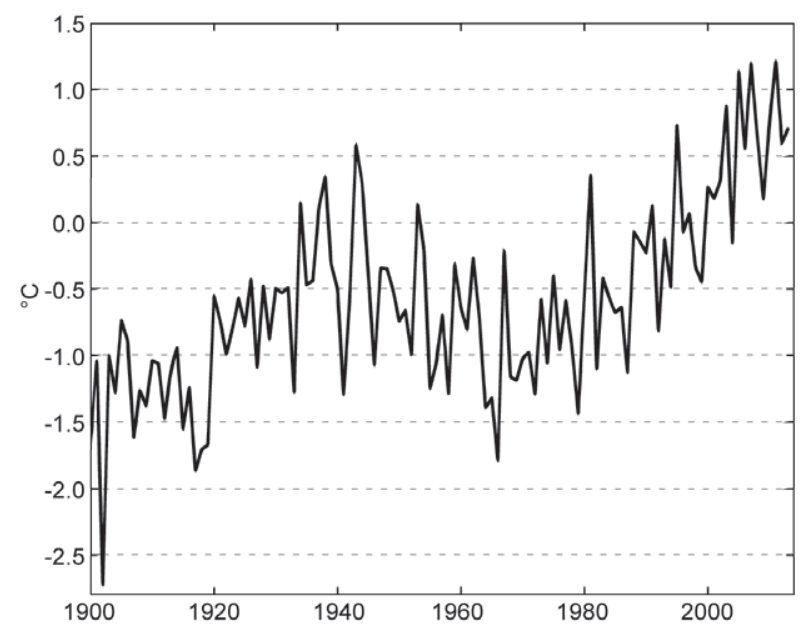

FIG. 5.I. Arctic-wide annual mean surface air temperature anomalies $\left({ }^{\circ} \mathrm{C}\right)$ for land stations north of $60^{\circ} \mathrm{N}$ for the period 1900-2013 relative to 198I-2010 base period. (Source: CRUTEM4 dataset, http://www.cru .uea.ac.uk/cru/data/temperature/.)

2) Seasonal and regional surface air temperature VARIABILITY

The annual mean air temperature in 2013 (Fig. 5.1) was influenced by positive and negative variability in seasonal and regional anomalies. (Fig. 5.2).
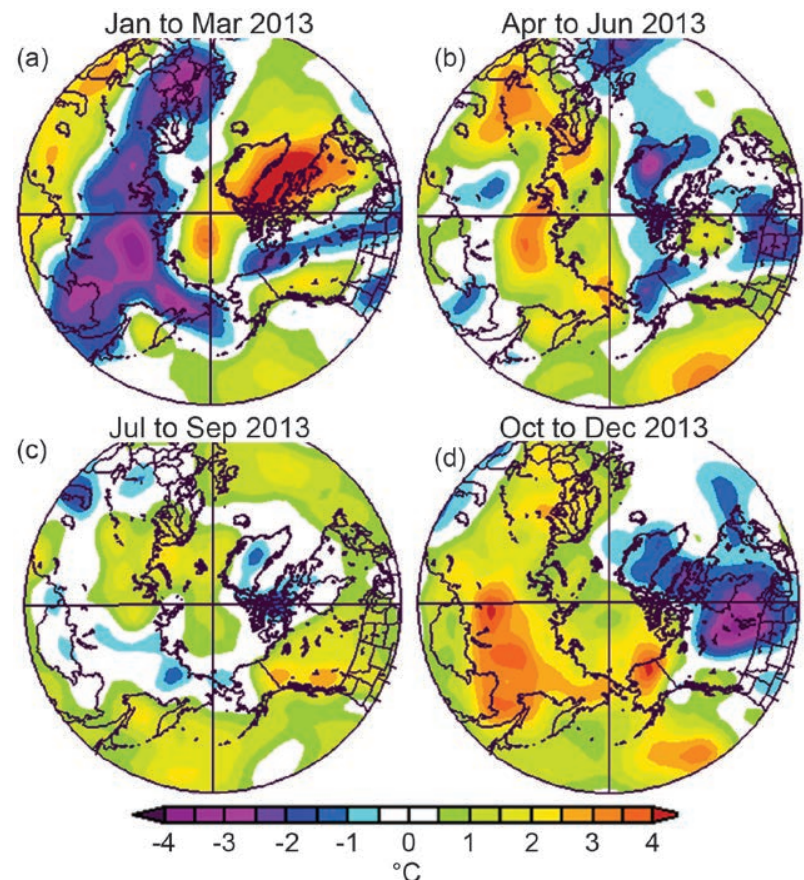

FIG. 5.2. Seasonal near-surface air temperature anomalies $\left({ }^{\circ} \mathrm{C}\right)$ in 2013 relative to the $1981-2010$ base period in (a) winter (Jan-Mar), (b) spring (Apr-Jun), (c) summer (Jul-Sep), and (d) fall (Oct-Dec). Temperature analyses are from slightly above the surface layer (at 925-hPa level), which emphasizes large spatial patterns rather than local features. (Source: NOAA/ ESRL, http://www.esrl.noaa.gov/psd/.)
In winter 2013, Alaska enjoyed above-normal temperatures (Fig. 5.2a). The Arctic Basin also remained anomalously warm. A strong winter high temperature anomaly developed over the Baffin Bay region, with record high temperatures in March along the coast of west Greenland (see section 5j). In contrast, winter was particularly cold in Eurasia, from Scandinavia across the continent to easternmost Siberia (Fig. 5.2a).

In spring, the temperature anomaly pattern (Fig. 5.2b) was almost the opposite of the winter pattern. An area of anomalously low temperatures stretched from Iceland through Greenland and northern Canada to Alaska. Interior Alaska experienced its coldest April since 1924 and budburst/green-up of birch and aspen was the latest (26 May) since observations began in 1972 (Alaska Climate Research Center 2013). In contrast, anomalously high temperatures occurred over much of the Arctic Basin and Eurasia (Fig. 5.2b). The temperature anomalies observed in winter and spring 2013 were consistent with largescale pressure and atmospheric circulation patterns, where positive 850-hPa geopotential height anomalies occurred in winter (Fig. 5.3a) and negative anomalies occurred in the spring (Fig. 5.3b). The 850 -mb level winds give the large-scale circulation pattern that controls most of the lower level temperature field. Clockwise (anticyclonic) atmospheric circulation in winter (Fig. 5.3a) in the Atlantic Arctic advected colder air into Asia and warmer Atlantic air into northeastern North America. In spring (Fig. 5.3b), the atmospheric circulation reversed, with warmer air in particular being advected into Eurasia, where record low snow cover extent occurred in May (see section $5 \mathrm{~h}$ ). The change in atmospheric circulation between winter and spring (Fig. 5.3a,b) corresponded

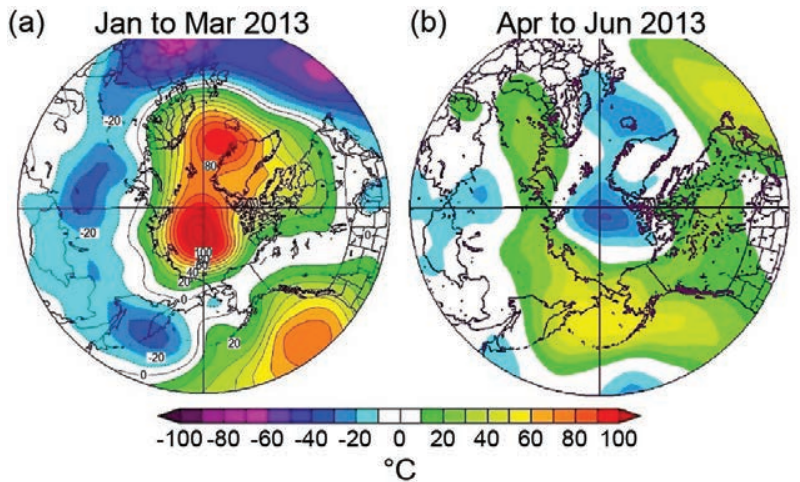

FIG. 5.3. The $850-\mathrm{mb}$ geopotential height anomalies for (a) Jan-Mar and (b) Apr-Jun. The anomalies are calculated relative to the 198I-2010 average for each period. (Source: National Centers for Environmental Prediction.) 
to a shift in the Arctic Oscillation, from negative in winter, especially in March, to positive in the spring.

Summer 2013 remained anomalously warm in Eurasia (Fig. 5.2c) and in Alaska, where an abrupt transition in late May to much-above normal temperatures heralded one of the hottest summers on record. For example, Fairbanks, in the Interior, experienced a record 36 days with maximum temperatures of $27^{\circ} \mathrm{C}$ or higher. In contrast to Eurasia and Alaska, anomalously low temperatures occurred over northernmost Canada and Greenland (Fig. 5.2c).

The relative coolness of Greenland, northernmost Canada, and the adjacent high Arctic Ocean in summer 2013 (Fig. 5.2c) is particularly evident when air temperature is compared to that of the period 2007-12 (Fig. 5.4a), when the six lowest minimum sea ice extents in the satellite record occurred (see section 5f; Perovich et al. 2013). Air temperatures across a broad swath of the Arctic Ocean in 2013 were $1^{\circ}-3^{\circ} \mathrm{C}$ lower than during 2007-2012 and associated with a geographically extensive, but weak low pressure field (Fig. 5.4b). The relatively low temperatures are consistent with the increase in the minimum extent of the 2013 summer sea ice cover, relative to the record low in 2012 (see section 5f). Similarly, $1^{\circ}-2^{\circ} \mathrm{C}$ lower temperatures over Greenland in summer 2013 (Fig. 5.4a) contributed to lower surface melt extent and duration, surface mass balance, and river discharge than recent years (see section $5 \mathrm{j}$ ).

Fall temperatures (Fig. 5.2d), with positive temperature anomalies over the central Arctic, show typical conditions of the last decade related to reduced sea ice cover. This is the Warm Arctic-Cold Continent
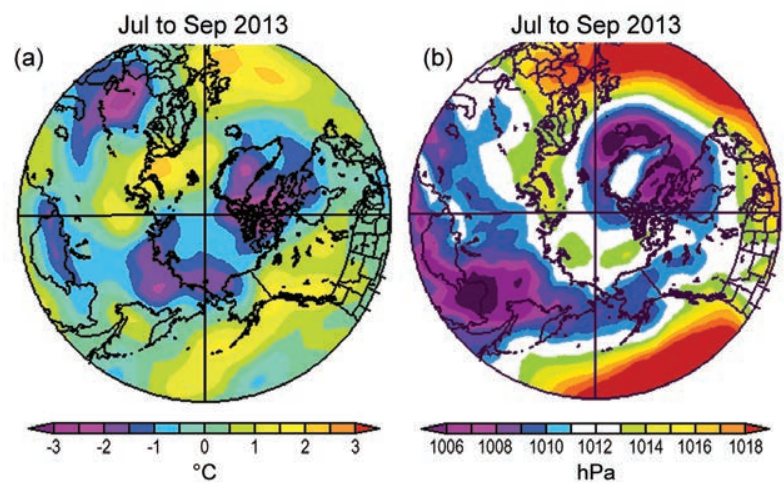

Fig. 5.4. (a) Near-surface air temperature $\left({ }^{\circ} \mathrm{C}\right)$ anomalies for summer (Jul-Sep) 2013 relative to the 2007-12 average. (b) Mean sea level pressure ( $\mathrm{hPa}$ ) field for summer (Jul-Sep) 2013. Temperature analyses are from slightly above the surface layer (at 925-hPa level) which emphasizes large spatial patterns rather than local features. (Source: NOAA/ESRL, http://www.esrl .noaa.gov/psd/.) pattern of cold continental temperatures over northeastern North America associated with warm central Arctic temperatures, similar to 2009, 2010, and 2012 (Overland et al. 2011).

\section{3) Cloud cover and surface Radiation budget}

Winter 2012/13 was characterized by belowaverage cloud cover over the western Arctic Ocean, particularly in January (Fig. 5.5a) and February, when cloud cover was $20 \%$ below the 2002-11 average. In contrast, early summer cloud cover in the same region was 15\%-20\% above average (Fig. 5.5b). As with the surface temperature anomalies, the cloud cover anomalies were consistent with large-scale pressure and atmospheric circulation patterns (see Fig. 5.3). Positive wintertime geopotential height anomalies and anticyclonic (high pressure) circulation, as was the case from January through March over the western Arctic Ocean, generally result in less cloud cover, while negative anomalies are associated with increased cyclonic activity and greater cloud cover (Liu et al. 2007). Over the Arctic Ocean, clouds radiatively warm the surface during winter and cool the surface in mid-summer. This relationship has been observed with surface measurements during the SHEBA experiment (Intrieri et al. 2002) and at Barrow, Alaska (Stone 1997), and with satellite data on a broader scale (Wang and Key 2005). The effect of the observed 2013 cloud cover anomalies on the surface radiation budget is one of decreased net longwave radiation during mid-winter, which results in radiative cooling at the surface, and decreased solar insolation during early summer, which also results

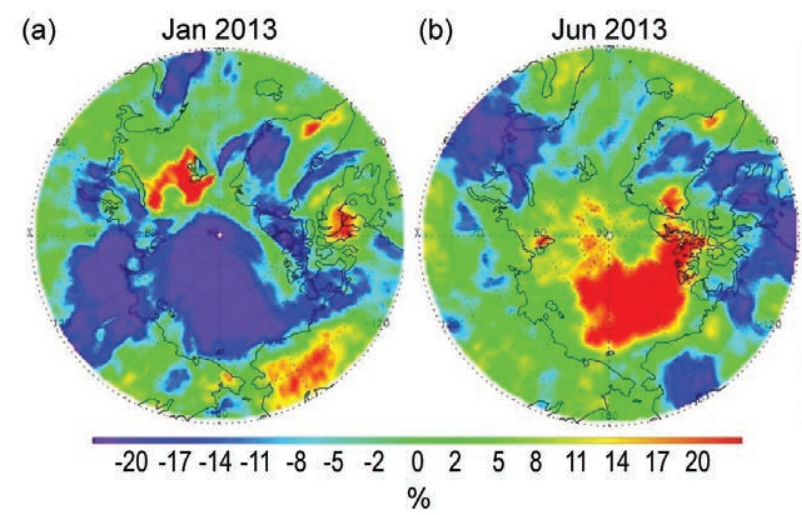

FIG. 5.5. Cloud cover anomalies (\%) in (a) Jan and (b) Jun 2013. The anomalies are calculated relative to the 2002-II average for each month from observations by the Moderate Resolution Imaging Spectroradiometer (MODIS) on the Aqua satellite. [Source: MODIS LI and Atmosphere Archive and Distribution System (LAADS).] 


\section{SIDEBAR 5.I: RAPID ARCTIC WARMING AND MIDLATITUDE WEATHER PATTERNS: ARE THEY CONNECTED?-J. FRANCIS, S. VAVRUS,}

AND Q. TANG

The sea ice cover on the Arctic Ocean is dwindling, particularly in summer, spring snow on Arctic land areas is disappearing earlier, the Greenland ice sheet is losing mass, and other signs of a dramatically warming Arctic are emerging. Loss of ice and snow, among other factors, amplifies global temperature changes through numerous positive feedbacks that make the Arctic more sensitive to change than any other region on Earth. In recent decades the Arctic has warmed at least twice as fast as the rest of the Northern Hemisphere. Recent studies suggest that the rapidly warming Arctic may be linked to observed extreme weather events, such as cold spells (Tang et al. 20I3a; Cohen et al. 20I3) and heat waves (Tang et al 2013b) in Northern Hemisphere continents, as well as wet summers in western Europe (Screen 2013). However, the mechanisms that connect Arctic warming to extreme weather at lower latitudes remain elusive.

The disproportionate high-latitude warming, known as Arctic amplification, may have significant impacts on the large-scale atmospheric circulation of the Northern Hemisphere because the difference in temperature between the Arctic and midlatitudes is a fundamental driver of the polar jet stream. When the temperature difference is large, the westerly winds of the jet stream tend to be strong and its path is relatively straight around the hemisphere. When the difference is smaller, the upper-level zonal flow weakens and tends to meander more with larger north-south excursions (Thompson and Wallace 2001; Palmén and Newton 1969). Arctic amplification causes the thickness of atmospheric layers to increase more in the north, leading Francis and Vavrus (2012) to hypothesize that the peaks of ridges should elongate northward and thus further increase the north-south amplitude of the flow's waviness. Weaker zonal winds owing to the reduced poleward temperature difference cause waves to travel eastward more slowly; thus, Arctic amplification should retard the progression of largescale atmospheric waves, leading to more persistent weather patterns.
Some links in this hypothesized chain of events are clearly observed in the real world and in model simulations, but the emergence only recently of Arctic amplification amid the noise of natural variability (Fig. SB5.I) limits detection of its effects on the midlatitude circulation, contributing to the lack of statistically significant circulation changes (Screen and Simmonds 2013). Arctic amplification is largest in fall and winter, owing primarily to feedbacks involving sea-ice loss and increased atmospheric water vapor (Screen and Simmonds 2010); thus, the atmospheric response should become evident first and be largest in cold seasons. Indeed, a significant decrease in zonalmean wind at $500 \mathrm{hPa}$ during fall (October-December) is apparent (Fig. SB5.2; see also figure 4a in Barnes 2013). In other seasons, when Arctic amplification is weaker (spring and summer) and/or less concentric around the pole (winter), the areas of weaker zonal winds coincide with regions where the poleward temperature gradient has declined. Anomalies in the $1000-500 \mathrm{hPa}$ thickness in and zonal winds for winter (January-March) shown in Fig. SB5.3 illustrate this behavior. This suggests that as Arctic amplification strengthens in all seasons, the zonal wind reduction and its effects on weather patterns will become more pronounced.

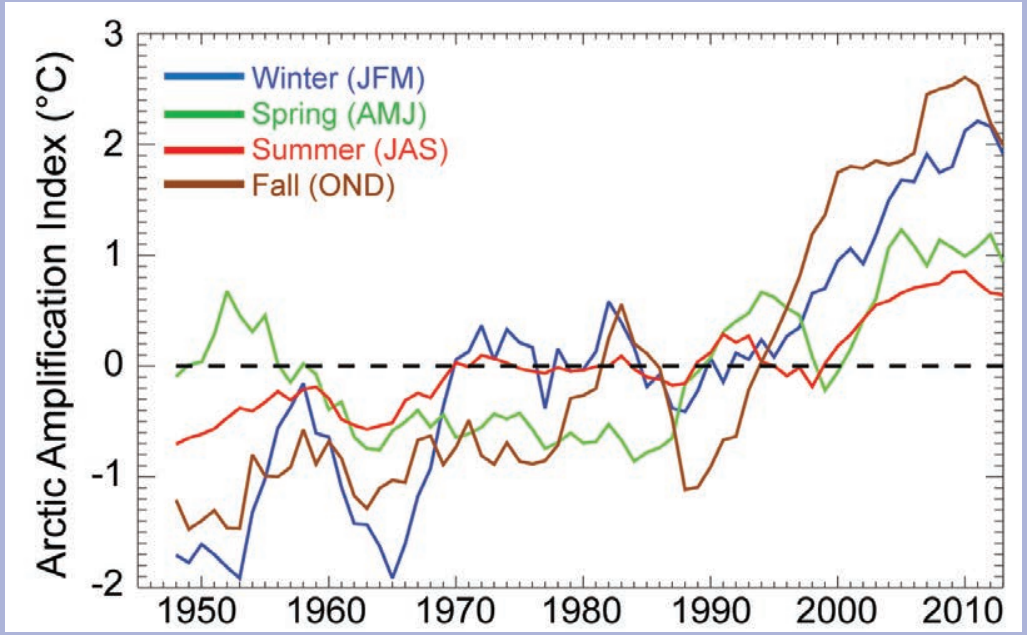

FIG. SB5.I. Five-year running mean time series of seasonal-mean Arctic amplification, calculated as the difference in air temperature anomalies $\left({ }^{\circ} \mathrm{C}\right.$, relative to $1948-2013$ average) at $1000 \mathrm{hPa}$ between the Arctic $\left(70^{\circ}-90^{\circ} \mathrm{N}\right)$ and midlatitudes $\left(30^{\circ}-70^{\circ} \mathrm{N}\right)$. (Source: NOAA/ ESRL, http://www.esrl.noaa.gov/psd/.) 


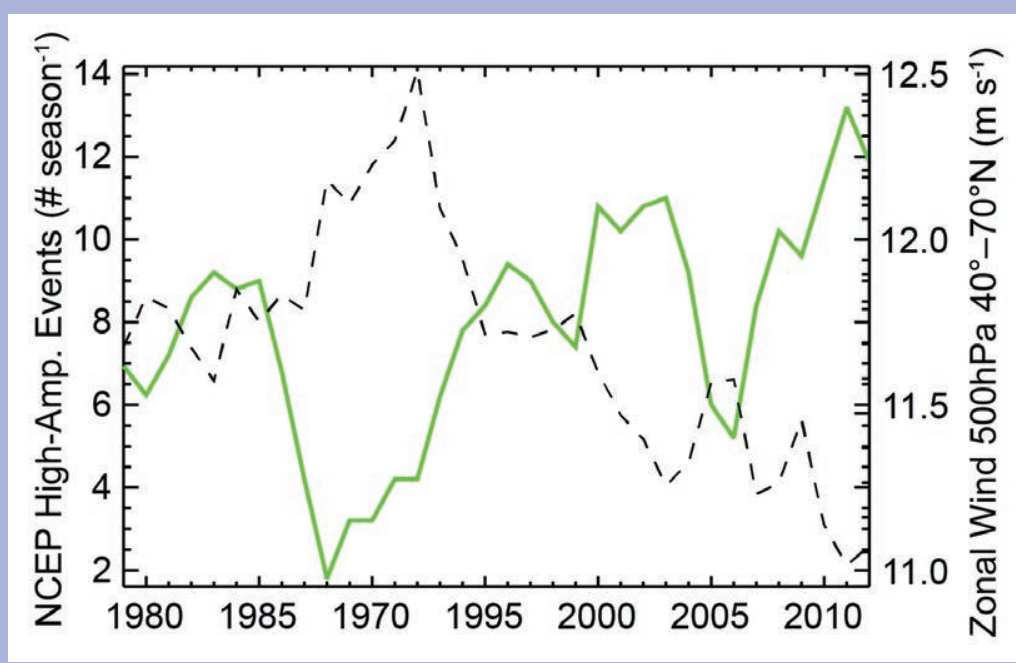

FIG. SB5.2. Five-year running mean of high-amplitude ( $>35^{\circ} \mathrm{N}$ latitude) wave events (days season-1) during fall in the NH (green line) based on the daily maximum/minimum latitude difference of the $5600-\mathrm{m}$ height contour of the $500-\mathrm{hPa}$ pressure level. The black dashed line is the corresponding zonal-mean zonal wind speed $\left(\mathrm{m} \mathrm{s}^{-1}\right)$ at $500 \mathrm{hPa}$ between $40^{\circ}-70^{\circ} \mathrm{N}$. Note the general anti-correlation between the two data sets $(r=\mathbf{- 0 . 6 8})$. (Source: NCEP/NCAR reanalysis, http:// www.esrl.noaa.gov/psd/.)

Support for the rest of the Francis and Vavrus (2012) hypothesis is less solid-namely, whether a weaker zonal flow leads to larger amplitude waves, slower wave propagation speeds, and more persistent weather patterns. Statistically robust evidence of increasing north-south wave amplitude and slower propagation speed has not been established, which is not surprising given the emergence only recently of Arctic amplification and the large natural variability of the atmosphere. However recent studies provide some supporting evidence of these responses during fall and summer (e.g., Screen and Simmonds 2013; Francis and Vavrus 2012). A significant reduction in $500-\mathrm{hPa}$ wave speeds during fall was reported by Barnes (2013), but the response was not apparent in higher-level winds. Although the frequency of blocking-high patterns has not been increasing consistently since 1979 across all seasons, regions, and different measurement techniques (Barnes et al. 20I4), high-amplitude upper-level patterns (not necessarily blocking highs) do appear to be increasing in the Northern Hemisphere during fall (Fig. SB5.2), particularly during the past two decades, when Arctic amplification has become more pronounced, and $500-\mathrm{hPa}$ zonal winds have decreased by approximately $10 \%$.

Much research is still needed to understand better the mechanisms by which midlatitude weather patterns will respond to the changing climate system, and particularly if and how they may be affected by Arctic amplification. There is also much to learn about the interplay among Arctic amplification and modes of natural variability (such as ENSO, the PDO, and $A M O$ ), as well as the behavior and trends in weather patterns by region and season as the Earth and the Arctic experience unabated warming.
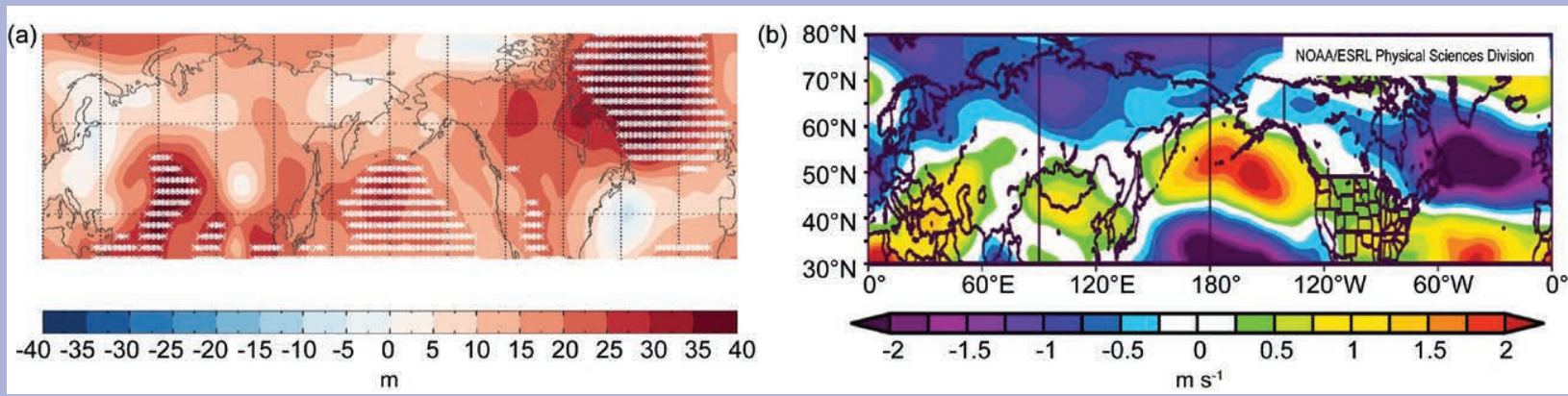

FIG. SB5.3. Anomalies (relative to $1981-2010$ average) in (a) $1000-500-h P a$ thickness (m) and in (b) 500-hPa zonal winds $\left(\mathrm{m} \mathrm{s}^{-1}\right)$ for winter during $2000-12$. White asterisks in (a) indicate $>95 \%$ confidence in difference from the mean. (Source: NCEP/NCAR reanalysis, http://www.esrl.noaa.gov/psd/.) 
in surface cooling. This can be seen in the field of January net radiation at the surface (Fig. 5.6a). Aboveaverage surface radiation loss prevailed over most of the Arctic Basin during the month, centered in the region of the Laptev, East Siberian, and Chukchi Seas, where the negative cloud anomaly was also centered. There is also empirical evidence of a decrease in net radiation in response to reduced cloud cover (Fig. 5.5a) at the NOAA Baseline Observatory in Barrow, Alaska. During January 2013, there was a reduction in net surface radiation of approximately $12 \mathrm{~W} \mathrm{~m}^{-2}$ (Key et al. 2013) in response to a $-18 \%$ sky cover anomaly relative to the 2002-11 average. The January net radiation anomalies are consistent with the cloud cover anomalies throughout most of the Arctic such that decreased cloud amounts resulted in decreased (more negative) net radiation from radiative cooling. In June, below-average net surface radiation corresponds to above-average cloud cover over and northwestward of the Canadian Arctic Archipelago (Figs. 5.5b, 5.6b), where downwelling solar radiation is reduced by cloud cover. Over the central Arctic Ocean, the surface temperature anomaly in June was near zero or slightly positive, as was the surface net radiation anomaly. In much of this area the cloud cover was up to $20 \%$ above average, implying a neutral cloud forcing, with shortwave and longwave cloud effects similar in magnitude but opposite in sign, offsetting one another. Overall, the cloud radiative effect on the surface energy budget was larger in January than in June. The influence of the January-February cloud anomaly on the September 2013 ice extent is discussed in Liu and Key (2014).

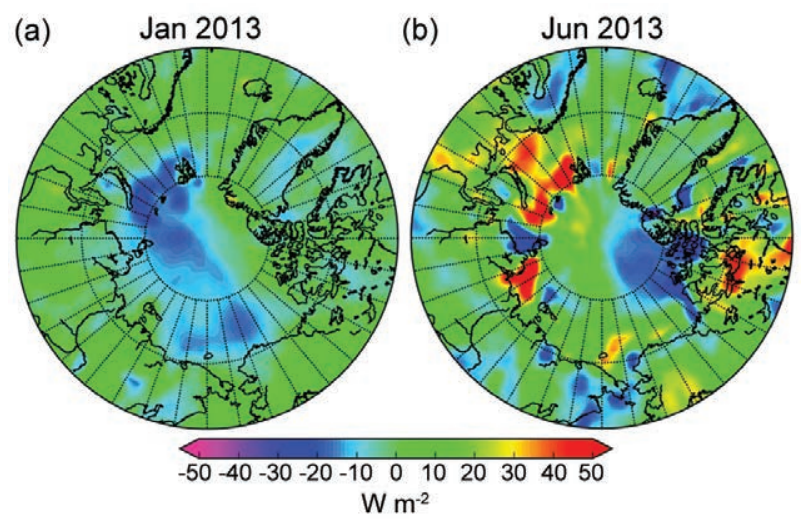

FIG. 5.6. (a) Jan and (b) Jun 2013 net radiation ( $\left.W \mathrm{~m}^{-2}\right)$ anomalies at the surface (net longwave plus net shortwave) derived from ERA-Interim (Dee et al. 20II). A positive anomaly indicates that the surface is gaining energy, and vice-versa. The anomalies are calculated relative to the 2002-II average for each month, consistent with the cloud anomalies in Fig. 5.5.
C. Arctic ozone-G. Bernhard, G. Manney, V. Fioletov, J.-U. Grooß, and R. Müller

The total ozone column in the Arctic measured by satellites and ground-based instruments during spring 2013 exceeded the average of the last decade. The minimum total ozone column for March, averaged over the "equivalent latitude" (Butchart and Remsberg 1986) band $63^{\circ}-90^{\circ} \mathrm{N}$, was 414 Dobson Units (DU). This value is $47 \mathrm{DU}$ above the most recent decadal average (2000-10) of 367 DU, 17 DU above the earlier historical period (1979-88) of 397 DU and comparable to observations in previous warm winters that did not have significant ozone depletion (e.g., 1999, 2001, and 2006; Fig. 5.7). The record minimum of the satellite era was 308 DU, set in 2011.

With few exceptions, in 2013 there were no extended areas with large $(>10 \%)$ deviations of the monthly mean total ozone column from the historical (1979-1988) mean (Bernhard et al. 2013a, figure 11). Exceptions include a region with elevated ( 10\%) total ozone over northern Scandinavia in February. In March, areas with total ozone more than $10 \%$ below average were observed over northern Canada and the North Pole, while positive anomalies of similar magnitude were centered over the Kola Peninsula, Russia, and northern Scandinavia. Monthly anomalies for April remained within $\pm 10 \%$ of average throughout the Arctic. Average total ozone for May over Iceland was elevated by about $15 \%$.

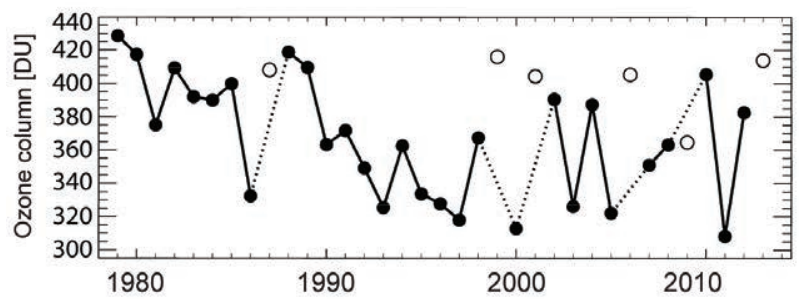

FIG. 5.7. Time series of area-averaged minimum total ozone for Mar in the Arctic, calculated as the minimum of daily average column ozone poleward of $63^{\circ} \mathrm{N}$ equivalent latitude. Open circles are also for Mar, but represent years in which the polar vortex broke up before Mar. Ozone in those years was relatively high because of mixing with air from lower latitudes and higher altitudes, and the lack of significant chemical ozone depletion. [Source: adapted from Müller et al. (2008), updated using ERA-Interim reanalysis data (Dee et al. 20II). Ozone data from 1979-20I2 are based on the combined total column ozone database produced by Bodeker Scientific (http://www.bodekerscientific.com/data/total-column-ozone); 2013 data are from the Ozone Monitoring Instrument aboard the NASA Aura satellite.] 
The relatively high ozone concentrations in 2013 compared to those observed during the last decade resulted from a large increase in stratospheric temperatures during the first half of January 2013 (Fig. 5.8a). Similar "stratospheric sudden warming" (SSW) has occurred in late winter and early spring in many years of the last two decades, but is less common for early January. The early winter timing of the SSW in January 2013 halted the chemical destruction of ozone in the stratosphere. The contrast between the meteorological conditions in 2012/13 with those in 2010/11, when a persistently cold stratosphere and prolonged high chlorine activation caused severe ozone destruction, highlights the large range of interannual variability in Arctic winter conditions, and hence in Arctic ozone (Fig. 5.7).

The temporal evolution of several variables that were crucial for the rate and extent of stratospheric ozone loss during the winter/spring of 2012/13 is il-
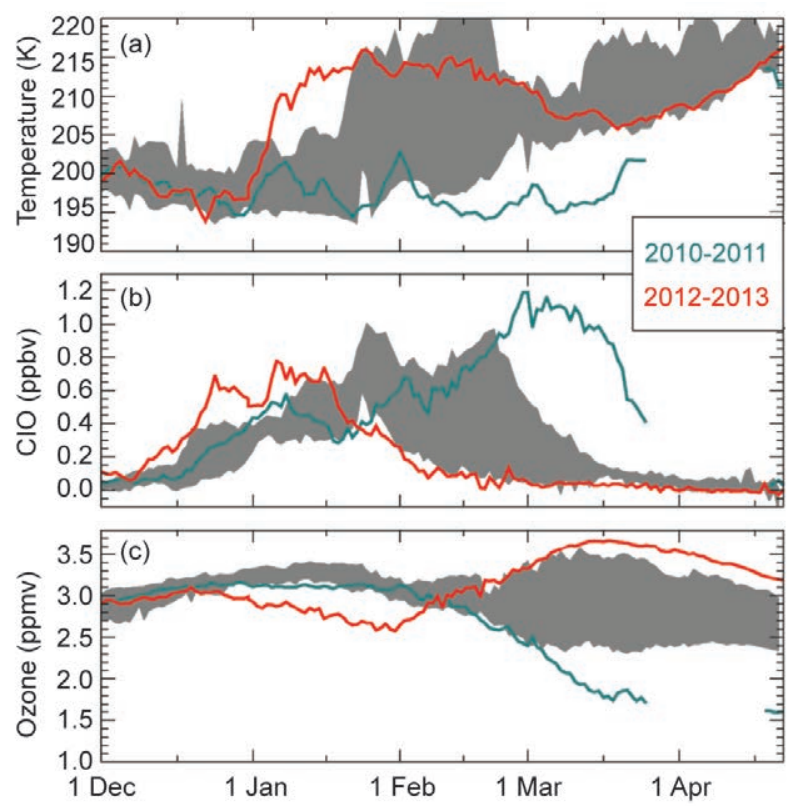

FIG. 5.8. Averages of (a) high-latitude stratospheric temperatures (K), (b) chlorine monoxide (ppbv), and (c) ozone (ppmv) from NASA Aura Microwave Limb Sounder measurements. Observations during the 2012/13 Arctic winter (red lines) are compared with similar data from the 2010/II Arctic winter (bluegreen lines), when unprecedented chemical ozone loss occurred. Gray shading indicates the range of values observed between winter 2004/05 and winter $2011 / 12$ (excluding the extreme minimum of 2010/1I when the first ever Arctic ozone hole was observed). Temperature and mixing ratios refer to the $485 \mathrm{~K}$ potential temperature surface (altitude of $\sim 18 \mathrm{~km}$ ) and were averaged over the area of the stratospheric polar vortex. lustrated in Fig. 5.8. Stratospheric temperatures in December 2012 were among the lowest on record (Fig. 5.8a). Low temperatures, below about $195 \mathrm{~K}\left(-78^{\circ} \mathrm{C}\right)$, facilitated the formation of polar stratospheric clouds (PSC), which occur at altitudes between about 15 and $25 \mathrm{~km}$. Chemical reactions on PSC cloud particles transform inactive forms of chlorine, such as chlorine nitrate $\left(\mathrm{ClONO}_{2}\right)$ and hydrogen chloride $(\mathrm{HCl})$, to active, ozone-destroying forms of chlorine such as chlorine monoxide (ClO). The conversion of inactive to active forms is indicated by the increase in $\mathrm{ClO}$ (Fig. 5.8b) following the start of PSC occurrence. $\mathrm{ClO}$ concentrations remained elevated for about one month after the start of the SSW event.

Ozone destruction occurs as long as chlorine is activated in regions that experience sunlight. Even with chlorine activated, ozone destruction is typically small in December and January when the polar regions are in darkness. Owing to the large SSW event, the polar vortex in late 2012 and early 2013 was shifted away from the North Pole and was exposed to more sunlight than usual. The steady decrease in ozone between late December and late January (Fig. $5.8 c$ ) indicates that significant chemical ozone loss occurred.

Chlorine was finally deactivated in early February (Fig. 5.8b) and ozone increased, primarily because of an influx of ozone from higher altitudes. After mid-February, ozone concentrations in the Arctic stratosphere were the highest since 2005 (Fig. 5.8c). Thus, the SSW in January and the associated rise in stratospheric temperatures prevented extensive ozone losses in 2013, in stark contrast to the situation in 2011, when low temperatures persisted into spring, resulting in unprecedented ozone destruction during that year (Manney et al. 2011).

\section{d. UV radiation-G. Bernhard, V. Fioletov, A. Heikkilä, B. Johnsen,}

\section{T. Koskela, K. Lakkala, T. Svendby, and A. Dahlback}

Ultraviolet radiation, expressed here as the UV Index (UVI), is a measure of the ability of UV radiation to cause erythema (sunburn) in human skin (WHO 2002; McKinlay and Diffey 1987). In addition to the total ozone column (see section 5c), the UVI depends greatly on the sun angle and cloud cover, as well as other factors (Weatherhead et al. 2005) such as aerosols (liquid and solid particles suspended in air) and surface conditions (e.g., snow and ice cover). In the Arctic, the UVI scale ranges from 0 to about 7 , with sites closest to the North Pole having the smallest peak radiation and UVI values $<4$ all year. UVI 
values $<5$ indicate low to moderate risk of erythema (WHO 2002).

At high latitudes, satellite-based estimates of the surface UVI are subject to large uncertainties because it is difficult to distinguish snow and ice reflectivity (which increases the UVI) from cloud reflectivity (which decreases the UVI) with current space-borne sensors (Tanskanen et al. 2007; Ialongo et al. 2011; Herman et al. 2013). UV radiation is, therefore, assessed with ground-based instruments that are deployed at latitudes between $60^{\circ}$ and $83^{\circ} \mathrm{N}$ in Canada, Alaska, the center of the Greenland ice sheet, Svalbard, Norway, and Finland. Because of the above-average ozone amounts observed in spring 2013 (see section 5c) UV levels measured in the high Arctic were below the climatological mean for prolonged periods at several stations. However, the timing of these low-UV episodes was not uniform across the Arctic. For example at Alert, at $83^{\circ} \mathrm{N}$ in the Canadian high Arctic and approximately $700 \mathrm{~km}$ from the North Pole, the UVI remained continuously below the climatological mean between 28 April and 27 May 2013 (Fig. 5.9a). In contrast, UVI measurements at Ny-Ålesund, in the Svalbard archipelago north of Scandinavia and approximately $1000 \mathrm{~km}$ from the North Pole, were below the climatological mean during February and March 2013 when absolute UVI values were below 1 (Fig. 5.9b).

UV intensities in southern Scandinavia were mostly controlled by cloud variability and UV levels in 2013 remained within the range of historical (1995-2012) measurements. Enhanced UV levels were observed in northern Scandinavia during May and early June. For instance, UV levels at Sodankylä, at $67^{\circ} \mathrm{N}$ in northern Finland, were close to historical maxima between 16 May and 7 June 2013 (Fig. 5.9c), and, on average, the UVI was elevated by $38 \%$ compared to the climatological mean. The enhancement was mostly caused by low cloudiness, but satellite observations provided by the Tropospheric Emission Monitoring Internet Service (TEMIS, http://www .temis.nl/) indicate that advection of low-ozone air from lower latitudes was also a contributing factor.

Clouds lead to a large variability in UV levels on time scales of minutes to days, but the effect is largely reduced when the ground is covered by fresh snow (Bernhard et al. 2008). Measurements at Alert (Fig. 5.9a), and to a lesser extent at Ny-Ålesund (Fig. $5.9 \mathrm{~b}$ ), show a large asymmetry between spring (low variability) and fall (high variability) because the

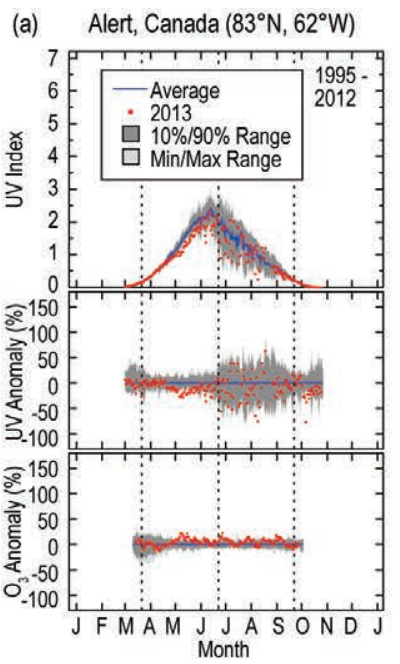

(b) Ny-Alesund, Svalbard $\left(79^{\circ} \mathrm{N}, 12^{\circ} \mathrm{E}\right)$

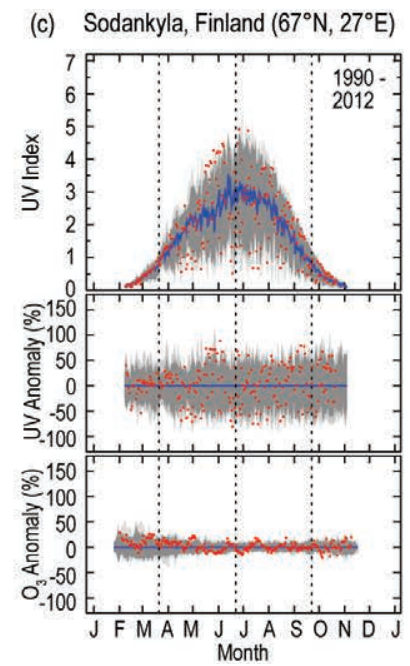

(d) Summit, Greenland $\left(73^{\circ} \mathrm{N}, 38^{\circ} \mathrm{W}\right)$
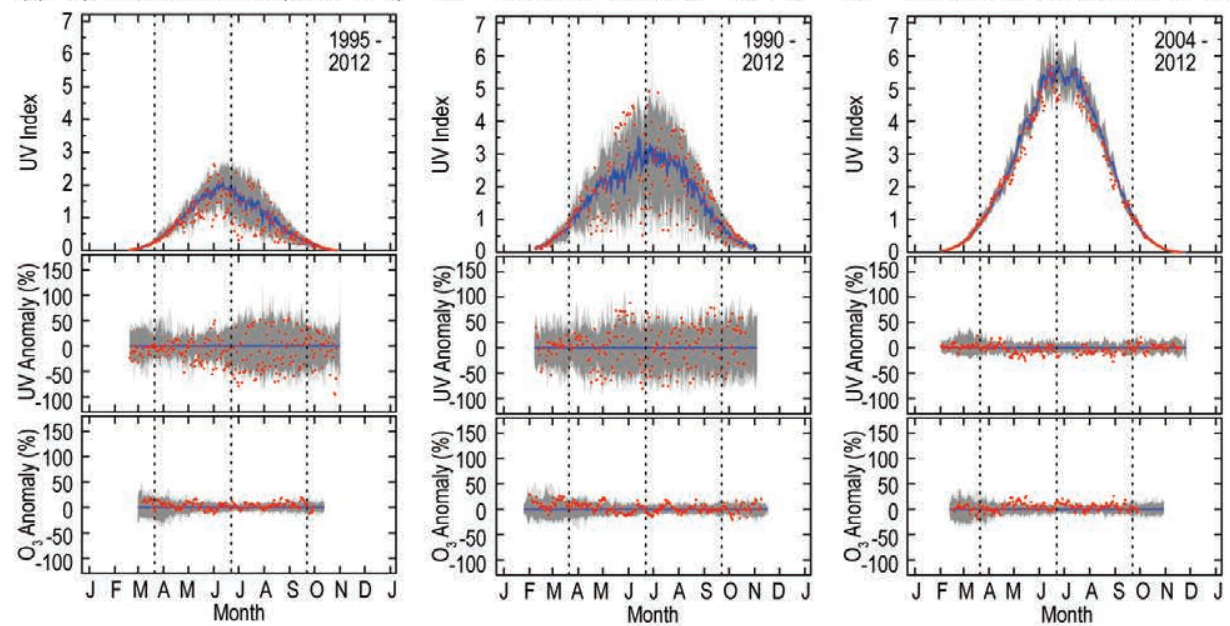

FIG. 5.9. Seasonal variation of the UV index (UVI) measured by ground-based radiometers at (a) Alert, Canada, (b) Ny Allesund, Svalbard, Norway, (c) Sodankylä, Finland, and (d) Summit, Greenland. Data are based on the UVI averaged over a 2 -hr period centered at solar noon. The top panel for each site compares UVI in 2013 (red dots) with the average noontime UVI (blue line), the range between the 10 th and 90 th percentile (dark shading), and the range of historical minima and maxima (light shading). Average (climatological mean) and ranges were calculated from measurements of the years indicated in the top-right corner of each UVI panel. The center horizontal panel shows the relative UVI anomaly calculated as the percentage departure from the climatological mean. The bottom panel shows a similar anomaly analysis for total ozone derived from measurements of the following satellites: TOMS/Nimbus7 (199I-92), TOMS/Meteor3 (1993-94), TOMS/EarthProbe (1996-2004), and OMI (2005-13). The shaded ranges for the ozone data set are based on data for I99I-20I2. Ozone data are available at http://avdc.gsfc.nasa.gov/index.php?site=|593048672\&id=28 and http://ozoneaq.gsfc.nasa.gov. Vertical broken lines indicate the vernal equinox, summer solstice, and autumnal equinox. Additional geographical and meteorological information for the four locations is provided by Bernhard et al. (20l3b). 
surface at these sites is covered by snow until about June and free of snow thereafter until the beginning of the following winter. In addition, the sky at Alert is mostly clear in the spring while clouds are prevalent in the summer. The location of Summit Station (Fig. 5.9d), close to the center of the Greenland ice sheet, is snow-covered year-round and the variability introduced by clouds is thus small. The well-known anti-correlation between total ozone and the UVI (Weatherhead et al. 2005) is therefore not masked by cloud variability at this site. For example, the UVI at Summit Station remained continuously below the mean between 26 April and 19 May 2013-with UVI measurements dropping below historical (2004-12) minima on several days-when the ozone column was elevated (Fig. 5.9d).

e. Carbon dioxide and methane-L. Bruhwiler, E. J. Dlugokencky, T. Laurila, and D. Worthy

Atmospheric carbon dioxide $\left(\mathrm{CO}_{2}\right)$ and methane $\left(\mathrm{CH}_{4}\right)$ are responsible for $\sim 82 \%$ of increased direct radiative forcing by long-lived greenhouse gases since 1750 ; in 2012 this amounted to 2.35 out of $2.87 \mathrm{~W} \mathrm{~m}^{-2}$ (see http://www.esrl.noaa.gov/gmd/aggi/, an update of Hofmann et al. 2006). Natural emissions of these gases are of particular interest in the Arctic where there are large vulnerable reservoirs of carbon in soil and clathrates that may eventually be released to the atmosphere by thawing and decomposition. Since the mobilization of Arctic soil carbon is expected to increase with rising air temperatures, it might act as a positive feedback on global climate. Detection of trends in greenhouse gas emissions from Arctic sources is difficult, however, because the changes are expected to be small in comparison to the much larger midlatitude and tropical emissions that are transported to the Arctic atmosphere.

Current understanding of $\mathrm{CO}_{2}$ and $\mathrm{CH}_{4}$ in the Arctic atmosphere is based on in situ measurements by national monitoring programs. Currently, $\mathrm{CO}_{2}$ and $\mathrm{CH}_{4}$ data are available for 16 Arctic sites (Fig. 5.10; Table 5.1) maintained by NOAA, Environment Canada, the Finnish Meteorological Institute, and collaborators in Norway and Iceland. The longest time

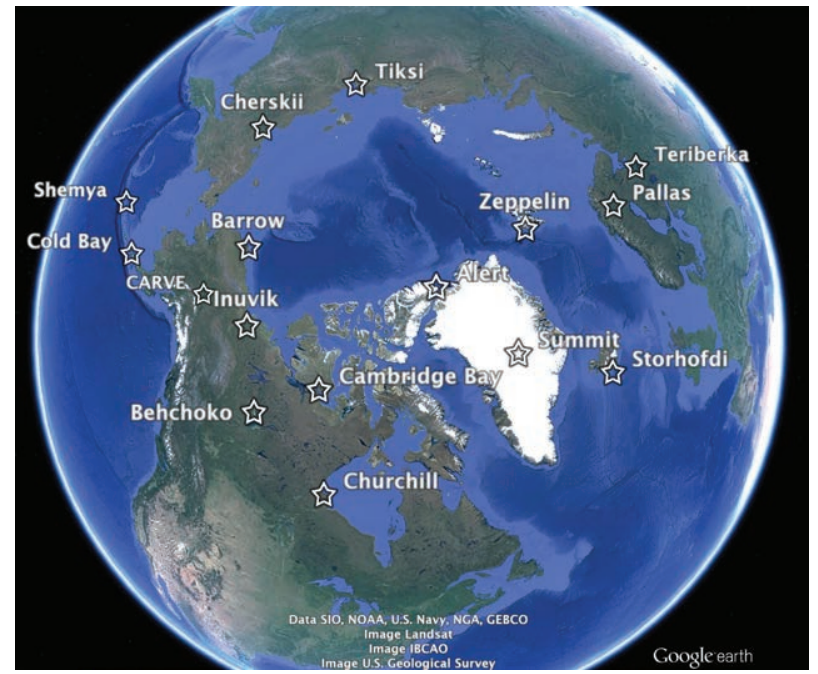

FIG. 5.I0. Locations of high northern latitude sites where atmospheric $\mathrm{CO}_{2}$ and $\mathrm{CH}_{4}$ are monitored.

series are from Barrow, Alaska, US (1983-present) and Alert, Nunavut, Canada (1985-present). In recent years, more sites have been added, including Pallas, Finland (2002-present) and several new sites in the Canadian Arctic. Maintaining long observational records is critical to timely detection of Arctic-wide trends in greenhouse gas emissions.

$\mathrm{CO}_{2}$ and $\mathrm{CH}_{4}$ measurements are generally made in one of two ways. Continuous, high-frequency measurements collected near local sources using in situ analyzers can improve understanding of regional processes that are responsible for surface-atmospheric exchange of $\mathrm{CO}_{2}$ and $\mathrm{CH}_{4}$. Discrete whole-air samples collected about weekly, then shipped to a central analysis laboratory, are useful for capturing Arctic-scale features in greenhouse gas concentration.

\begin{tabular}{|c|c|c|c|c|}
\hline Measurement Site & Lat. & Lon. & $\mathrm{CO}_{2}$ & $\mathrm{CH}_{4}$ \\
\hline Alert, Nunavut, Canada & $82^{\circ} \mathrm{N}$ & $62^{\circ} \mathrm{W}$ & 1985 & 1985 \\
\hline Barrow, Alaska, US & $71^{\circ} \mathrm{N}$ & $156^{\circ} \mathrm{W}$ & 1971 & 1983 \\
\hline Behchoko, Northwest Territories, Canada & $62^{\circ} \mathrm{N}$ & $116^{\circ} \mathrm{W}$ & 2010 & 2010 \\
\hline Cambridge Bay, Nunavut, Canada & $69^{\circ} \mathrm{N}$ & $105^{\circ} \mathrm{W}$ & 2010 & 2010 \\
\hline CARVE Tower, Alaska, US & $65^{\circ} \mathrm{N}$ & $147^{\circ} \mathrm{W}$ & 2012 & 2012 \\
\hline Cherskii, Russia & $68^{\circ} \mathrm{N}$ & $161^{\circ} \mathrm{E}$ & & 2008 \\
\hline Churchill, Manitoba, Canada & $58^{\circ} \mathrm{N}$ & $94^{\circ} \mathrm{W}$ & 2007 & 2007 \\
\hline Cold Bay, Alaska, US & $55^{\circ} \mathrm{N}$ & $162^{\circ} \mathrm{W}$ & 1978 & 1983 \\
\hline Inuvik, Northwest Territories, Canada & $68^{\circ} \mathrm{N}$ & $133^{\circ} \mathrm{W}$ & 2012 & 2012 \\
\hline Pallas-Sammaltunturi, Finland & $68^{\circ} \mathrm{N}$ & $24^{\circ} \mathrm{E}$ & 2001 & 2001 \\
\hline Shemya Island, Alaska, US & $52^{\circ} \mathrm{N}$ & $174^{\circ} \mathrm{W}$ & 1985 & 1985 \\
\hline Storhofdi, Vestmannaeyjar, Iceland & $63^{\circ} \mathrm{N}$ & $20^{\circ} \mathrm{W}$ & 1992 & 1992 \\
\hline Summit, Greenland & $72^{\circ} \mathrm{N}$ & $38^{\circ} \mathrm{W}$ & 1997 & 1997 \\
\hline Teriberka, Russia & $62^{\circ} \mathrm{N}$ & $35^{\circ} \mathrm{E}$ & 1998 & 1999 \\
\hline Tiksi, Russia & $71^{\circ} \mathrm{N}$ & $128^{\circ} \mathrm{E}$ & 2010 & 2010 \\
\hline Zeppelin, Ny-Alesund, Svalbard, Norway & $78^{\circ} \mathrm{N}$ & $12^{\circ} \mathrm{E}$ & 1994 & 1994 \\
\hline
\end{tabular}




\section{SIDEBAR 5.2: RADIATIVE FORCING BY BLACK CARBON IN THE ARCTIC—P. K. QUINN, A. STOHL, A. BAKLANOV, M. G. FLANNER, A. HERBER, K. KUPIAINEN, K. S. LAW, J. SCHMALE, S. SHARMA, V. VESTRENG, AND K. VON SALZEN}

Black carbon (BC) is the most efficient atmospheric particulate species at absorbing visible light. Consequently, it exerts a warming effect that contrasts with the cooling effect of purely scattering aerosol components such as sulfate. However, pure BC particles rarely occur in the atmosphere. Soon after emission, BC becomes mixed with other components such as sulfate and organics. BC-containing particles can have either a warming or a cooling effect on climate depending on their altitude and the albedo of the underlying surface relative to the albedo of the $B C$ haze itself. The albedo of the haze depends on the relative amounts of all of the chemical components present, their mixing state, and whether they primarily scatter or absorb light. BC-containing aerosols, unlike greenhouse gases, are short-lived, with a lifetime in the atmosphere on the order of days to weeks. While recognizing that reductions in $\mathrm{CO}_{2}$ emissions are required for long-term mitigation of Arctic warming, it has been suggested that reducing emissions of $B C$ could reduce projected global mean warming and slow the rate of warming in the short term in the Arctic (Shindell et al. 2012; Bowerman et al. 2013).

Atmospheric BC concentrations in the Arctic have declined since the 1990s (Sharma et al. 2013), and the $\mathrm{BC}$ content of Arctic snow is now no higher than it was thirty years ago (Clarke and Noone 1985; Doherty et al. 20I0), but BC-containing aerosols will likely continue to influence Arctic climate through several different forcing mechanisms. Atmospheric BC can directly warm the Arctic atmosphere by absorbing solar radiation that would otherwise have been reflected back to space or absorbed by the surface (far right panel in Fig. SB5.4). The added atmospheric heating subsequently increases the downward longwave radiation to the surface and decreases the temperature difference between the surface and the atmosphere, thereby warming the surface. With the highly reflective snow and ice surfaces typical of the Arctic, even a moderately absorbing aerosol can lead to a heating of the surface-atmosphere column. The average daily radiative efficiency of atmospheric BC (units of $W$ $\mathrm{g}^{-1}$ ) in the Arctic summer is greater than in most other environments because of the long sunlight exposure and presence of highly reflective clouds, snow, and sea ice (e.g., Cess 1983). As summer progresses and open water appears within the sea ice cover, and melt ponds form on the ice surface, the direct forcing efficiency by atmospheric $B C$ decreases because the surface becomes less reflective. Similarly, it is reasonable to expect that forcing by atmospheric BC will become weaker as snow, sea ice, and glacier extent and surface albedo decrease under a warming climate (Flanner et al. 2009).

BC deposited to snow and ice surfaces enhances the absorption of solar radiation at the surface and warms the lower atmosphere, which can initiate snow and ice melt earlier in the season (left center panel in Fig. SB5.4). Even very low $B C$ concentrations ( $P p b$ ) of deposited $B C$ have an impact because the absorptivity of $B C$ is about five orders of magnitude greater than ice at visible wavelengths. In addition, multiple scattering in surface snow greatly increases the path-length of photons and the probability that they will encounter non-ice particles (Warren and Wiscombe 1980). Snow darkening drives an equilibrium temperature response, per unit of radiative forcing, several times that of $\mathrm{CO}_{2}$ (Koch et al. 2009). This large impact occurs because all of the energy associated with the forcing is deposited directly into the snow and ice covers, components of the Earth system responsible for powerful positive feedback (e.g, Robock 1983; Hansen and Nazarenko 2004).

Radiative forcing by $B C$ can also result from the impact of aerosols on cloud distributions, lifetime, and microphysical properties. By increasing the number of cloud droplets and decreasing cloud droplet size, aerosols can lead to an increase in reflectivity and cloud optical thickness (first indirect effect) and to an increase in cloud lifetime and a decrease in precipitation (second indirect effect; e.g., Twomey 1977). Both of these changes result in greater reflection of solar shortwave radiation back to space and a cooling at the surface (right center panel in Fig. SB5.4). In contrast, when the cloud droplet number concentration of thin Arctic liquid-phase clouds is increased through interaction with anthropogenic aerosols, the clouds become more efficient at trapping and re-emitting longwave radiation, which results in a warming at the surface (Garrett and Zhao 2006; far left column in Fig. SB5.4). BC can also impact clouds through semi-direct effects associated with atmospheric heating. Depending on circumstances, $\mathrm{BC}$-induced heating can either stabilize the atmosphere and increase low-level cloud formation (Hansen et al. 2005), inhibit cloud formation, or increase 


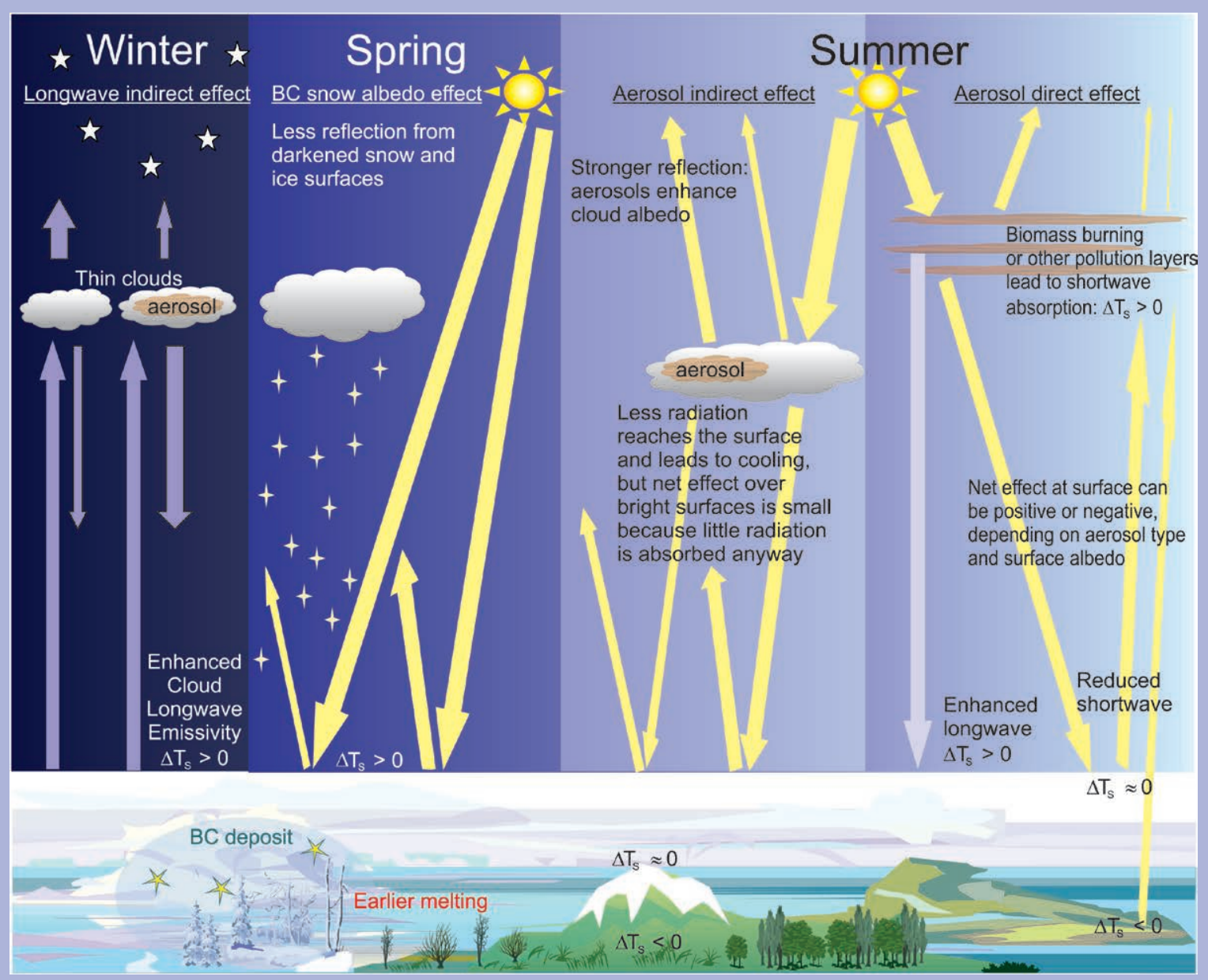

FIG. SB5.4. Forcing mechanisms in the Arctic due to black carbon. $\Delta \mathbf{T}_{s}$ indicates the surface temperature response.

the evaporation rate of clouds (e.g., Ackerman et al. 2000; Jacobson 2010). Simulating these indirect and semi-direct effects remains a challenge for global-scale models, especially in the Arctic. Both the sign and magnitude of the net forcing due to nonlinear interactions between $\mathrm{BC}$ and clouds in the Arctic are uncertain.

Further complicating the impact of BC on Arctic climate is that forcing exerted by $B C$ outside of the Arctic can result in changes in energy transport through the atmosphere and oceans to the Arctic (Shindell and Faluvegi 2009). For example, BC-heated air masses can travel from midlatitudes to the Arctic.

In the past few years there has been a concerted effort by the scientific community to quantitatively estimate the climate impacts of BC, both globally and within the Arctic (e.g., Bond et al. 2013; Quinn et al. 2008). Currently, there is no single appropriate environmental indicator to assess the Arctic climate response to changes in emissions of $\mathrm{BC}$ and co-emitted species including organic carbon and sulfate. Hence, only an integrated evaluation will reduce the large uncertainties and improve estimates of BC's climate impacts. Such an evaluation requires accurate emission inventories of local and remote sources, longterm monitoring and process-oriented measurements, and global models capable of realistic transport of BC to the Arctic and depositional losses en route and within the Arctic. In addition, models must accurately capture feedbacks induced by BC, including those associated with snow, glacier, and sea-ice loss, cloud changes, and dynamical changes. 
Measurements made by both approaches are typically calibrated with standards based on WMO mole fraction scales maintained at NOAA ESRL. Uncertainties estimated using a Monte Carlo method for the NOAA zonal means in Figs. 5.11a and 5.11b are 0.3-0.6 ppm for $\mathrm{CO}_{2}$ and 2-4 ppb for $\mathrm{CH}_{4}$ weekly averages.

Observations of atmospheric $\mathrm{CO}_{2}$ (Fig. 5.11a) averaged for the Arctic observation sites show that $\mathrm{CO}_{2}$ continued to increase in 2013 (3.2 ppm higher than in 2012, the same as the global increase). At present, trends in Arctic atmospheric $\mathrm{CO}_{2}$ due to changes in Arctic productivity or respiration are difficult to distinguish from midlatitude anthropogenic emissions;
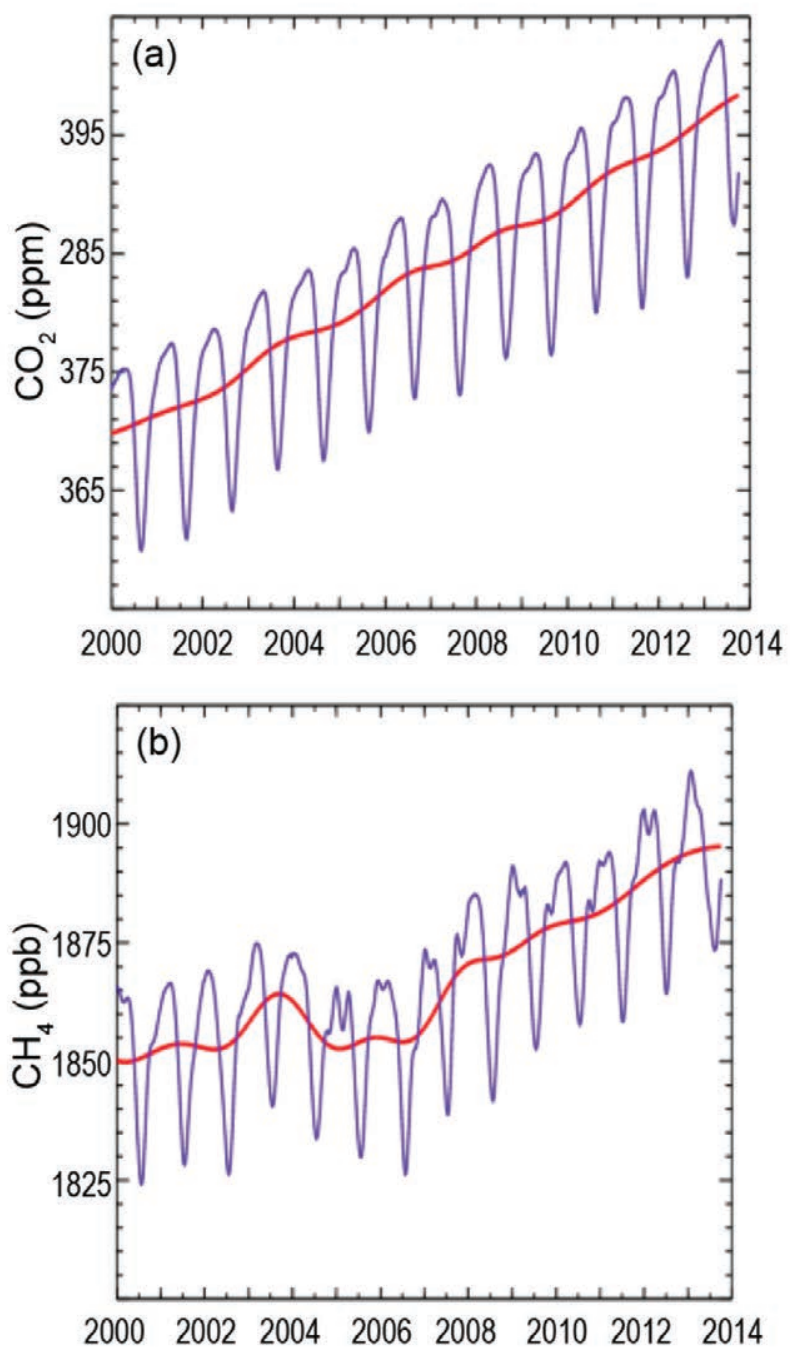

Fig. 5.I I. Weekly averages of (a) $\mathrm{CO}_{2}(\mathrm{ppm})$ and (b) $\mathrm{CH}_{4}$ (ppb) for 16 high northern latitude sites (blue curves) with deseasonalized trends (red curves). The seasonal $\mathrm{CO}_{2}$ cycle reflects uptake by the terrestrial biosphere during the NH growing season and respiration during the winter months. The minimum in the $\mathrm{CH}_{4}$ seasonal cycle occurs during the $\mathrm{NH}$ summer due to solar radiation-dependent photochemical destruction. most of the increase in atmospheric $\mathrm{CO}_{2}$ in the Arctic is from combustion of fossil fuels at midlatitudes.

After a period of stability from 1999 to 2006 (the reasons for this are not fully understood and it is a topic of continuing research), $\mathrm{CH}_{4}$ in the Arctic atmosphere began increasing in 2007 (Fig. 5.11b). In 2013, $\mathrm{CH}_{4}$ was $5.0 \mathrm{ppb}$ (preliminary estimate) higher than in 2012, equal to the increase in global $\mathrm{CH}_{4}$. The increase in global $\mathrm{CH}_{4}$ is attributed to a combination of increased tropical natural emissions and emissions from fossil fuel production, agriculture, and waste (Bruhwiler et al. 2014; Bergamaschi et al. 2013). Although interannual variability in Arctic emissions is captured in the Arctic observations, large sustained increases in $\mathrm{CH}_{4}$ emissions from Arctic sources have not been observed.

f. Sea ice cover-D. Perovich, S. Gerland, S. Hendricks, W. Meier, M. Nicolaus, J. Richter-Menge, and M. Tschudi

I) Sea ICE EXTent

Sea ice extent is a fundamental descriptor of the state of the Arctic sea ice cover. Satellite-based passive microwave instruments have been used to determine sea ice extent since 1979. There are two months each year that are of particular interest: September, at the end of summer, when the sea ice reaches its annual minimum extent, and March, at the end of winter, when the ice reaches its annual maximum extent. The sea ice extent in March 2013 and September 2013 are presented in Fig. 5.12.

Based on estimates produced by the National Snow and Ice Data Center (NSIDC), the sea ice cover reached a minimum annual extent of 5.10 million
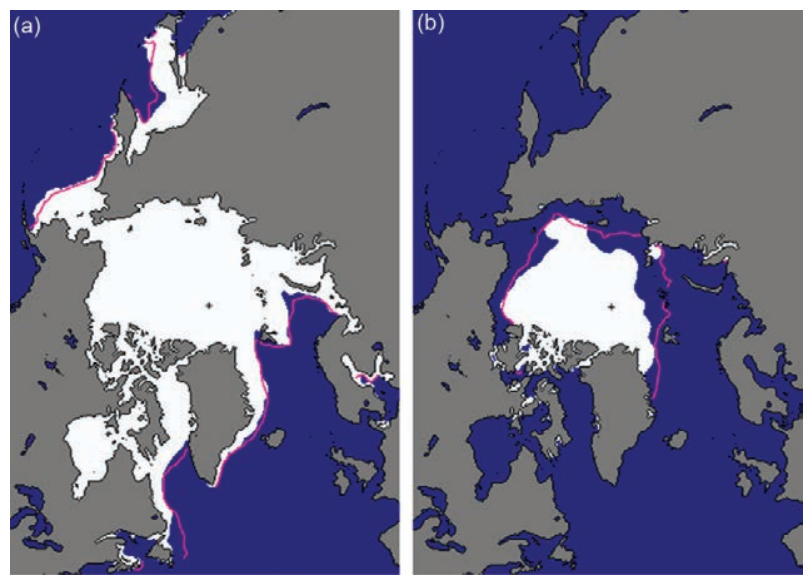

FIG. 5.12. Sea ice extent in (a) Mar and (b) Sep 2013, illustrating the respective monthly averages during the winter maximum and summer minimum extents. The magenta lines indicate the median ice extents during the period 198I-2010. (Source: NSIDC, http://nsidc .org/data/seaice_index.) 
$\mathrm{km}^{2}$ on 13 September 2013. This was 1.69 million $\mathrm{km}^{2}$ higher than the record minimum of 3.41 million $\mathrm{km}^{2}$ set in 2012 and the largest September minimum ice extent since 2006 (Fig. 5.13). However, the 2013 summer minimum extent was still 1.12 million $\mathrm{km}^{2}$ (18\%) below the 1981-2010 average minimum ice extent. The March 2013 ice extent reached a maximum value of 15.04 million $\mathrm{km}^{2}$ (Fig. 5.13), 3\% below the 1981-2010 average. This was slightly less than the March 2012 value, but typical of the past decade.

The September monthly average trend is $-13.7 \%$ decade $^{-1}$ relative to the 1981-2010 average (Fig. 5.13). Trends are smaller during March $\left(-2.4 \%\right.$ decade $\left.^{-1}\right)$ but are still decreasing and statistically significant. There was a loss of 9.69 million $\mathrm{km}^{2}$ of sea ice between the March and September extents. This is the smallest seasonal decline since 2006.

\section{2) Age of the ICE}

Key ice physical properties, such as surface roughness, melt pond coverage, and thickness, vary according to the age of the ice. The age of the ice can be determined using satellite observations and drifting buoy records to track ice parcels over several years (Tschudi et al. 2010). This method has been used to provide a record of ice age since 1984. The distribution of ice of different ages (Fig. 5.14) illustrates the extensive loss in recent years of the older ice types (Maslanik et al. 2011).

Although the minimum sea ice extent increased somewhat in 2013 compared to recent years, the distribution of ice age continued to favor first-year ice (ice that has not survived a melt season), which

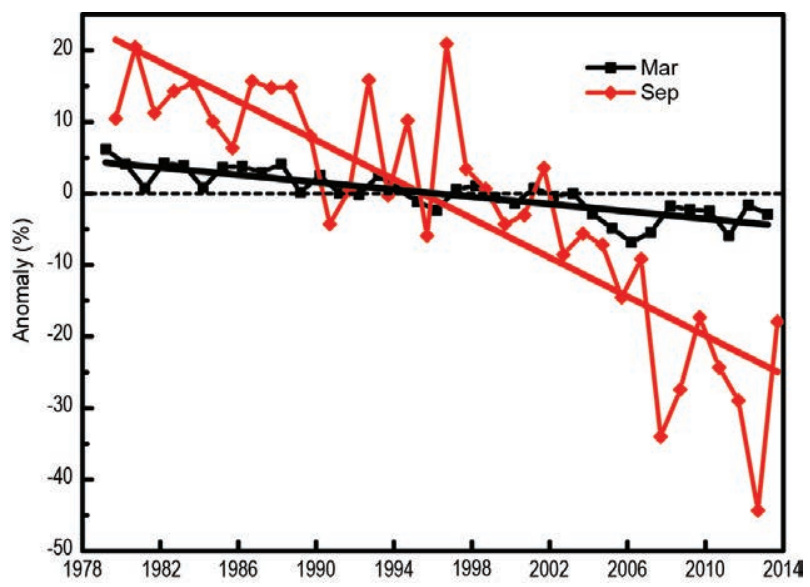

FIG. 5.13. Time series of ice extent anomalies measured in Mar (maximum ice extent) and Sep (minimum ice extent). The anomaly value for each year is the difference (in \%) in ice extent relative to the average values for the period 198I-2010. The black and red lines are least squares linear regression lines.

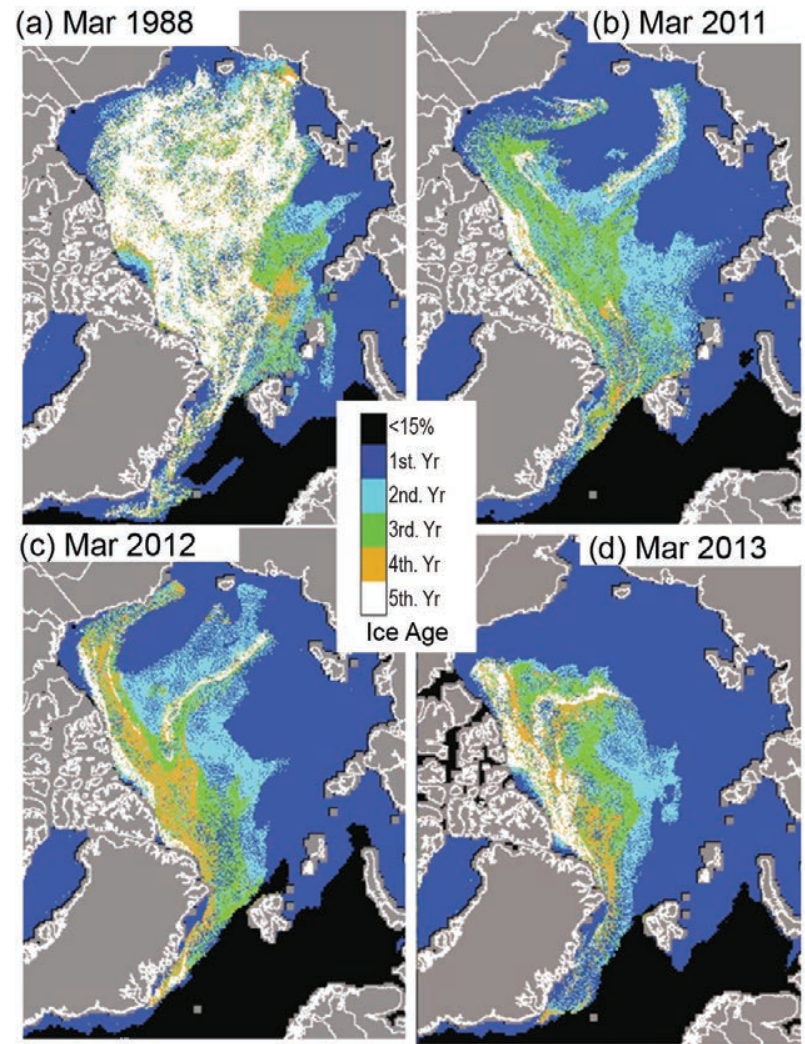

FIG. 5.I4. Sea ice age in Mar (a) 1988, (b) 20II, (c) 20I2, and (d) 2013, determined using satellite observations and drifting buoy records to track the movement of ice floes.

is the thinnest ice type (e.g., Maslanik et al. 2007). In March 1988, 58\% of the ice pack was composed of first-year ice, an amount that increased to $78 \%$ in March 2013. Meanwhile, the trends continue for the recent loss of the oldest and thicker ice types, which accelerated starting in 2005 (Maslanik et al. 2011). For the month of March, the oldest ice (four years and older) decreased from $26 \%$ of the ice cover in 1988 to $19 \%$ in 2005 and to $7 \%$ in 2013.

At the end of winter 2012/13, little multiyear ice was detected in much of the Beaufort Sea (Fig. 5.14d; Richter-Menge and Farrell 2013). There is no precedent in the satellite-derived record of ice age for the near-absence of old ice in this region. This condition appears to have been due to a combination of the previous year's record sea ice retreat and a lack of subsequent transport of multiyear ice into the Beaufort Sea during winter 2012/13. Negligible multiyear ice transport into the Beaufort Sea continued during summer 2013, consistent with stronger cyclonic (counterclockwise) wind forcing during this period (see section 5g). Multiyear ice did not drift into Siberian Arctic waters either, which is also rare. Instead, 
multiyear ice remained confined to the region north of Greenland and northernmost Canada during 2013.

\section{3) ICE THICKNESS}

Another key state variable for the Arctic sea ice cover is ice thickness. In recent years, ice thickness has been estimated over limited regions by aircraft, e.g., the NASA Operation IceBridge (Richter-Menge and Farrell 2013), and over large regions by satellite. The CryoSat- 2 satellite, operated since 2011 by the European Space Agency, measures ice freeboard, the height of ice floes above the water line. Preliminary analysis indicates that the CryoSat- 2 freeboard estimates are comparable to in situ field measurements, with a level of uncertainty that is comparable to other airborne and satellite-based observations (Ricker et al. 2014). Calculation of the actual sea-ice thickness from freeboard requires knowledge of snow depth, but in general higher freeboard indicates thicker sea ice. Therefore, freeboard maps in spring for the period 2011-13 are a proxy for sea ice thickness at the time of maximum ice extent. During the three years of CryoSat-2 observations, the average freeboard within the Arctic Basin decreased by $0.04 \mathrm{~m}$, from $0.23 \mathrm{~m}$ in 2011 to $0.19 \mathrm{~m}$ in 2013 (Laxon et al. 2013). Assuming there were no significant changes in snow depth, the decline in freeboard amounts to an average sea ice thinning of $0.32 \mathrm{~m}$, from $2.26 \mathrm{~m}$ in 2011 to $1.94 \mathrm{~m}$ in 2013. As with the ice age maps (Fig. 5.14), CryoSat-2 freeboard maps (Perovich et al. 2013, figure 22) indicate that most of the thickest and oldest ice occurs to the north of Greenland and northernmost Canada, and is a small proportion of the total sea ice cover at the end of winter.

g. Ocean temperature and salinity-M.-L. Timmermans, I. Ashik, I. Frolov, H. K. Ha, R. Ingvaldsen, T. Kikuchi, T. W. Kim, R. Krishfield, H. Loeng, S. Nishino, R. Pickart, I. Polyakov, B. Rabe, U. Schauer, P. Schlosser, W. M. Smethie, V. Sokolov, M. Steele, J. Toole, W. Williams, R. Woodgate, and S. Zimmerman

I) Summer sea surface temperature

Recent summers with reduced sea-ice cover (see section 5f) have seen increased solar absorption into the surface Arctic Ocean, with the distribution of sea surface temperatures (SST) reflecting sea ice retreat patterns. Arctic Ocean average SSTs in August 2013 ranged between $\sim 0^{\circ}$ and $4^{\circ} \mathrm{C}$, with even higher SSTs in some marginal seas (Fig. 5.15). While most Arctic boundary regions displayed anomalously warm SSTs in August 2013, relative to the 1982-2006 August average (Fig. 5.15), cold anomalies were evident in the Chukchi and East Siberian Seas. The cooler SSTs
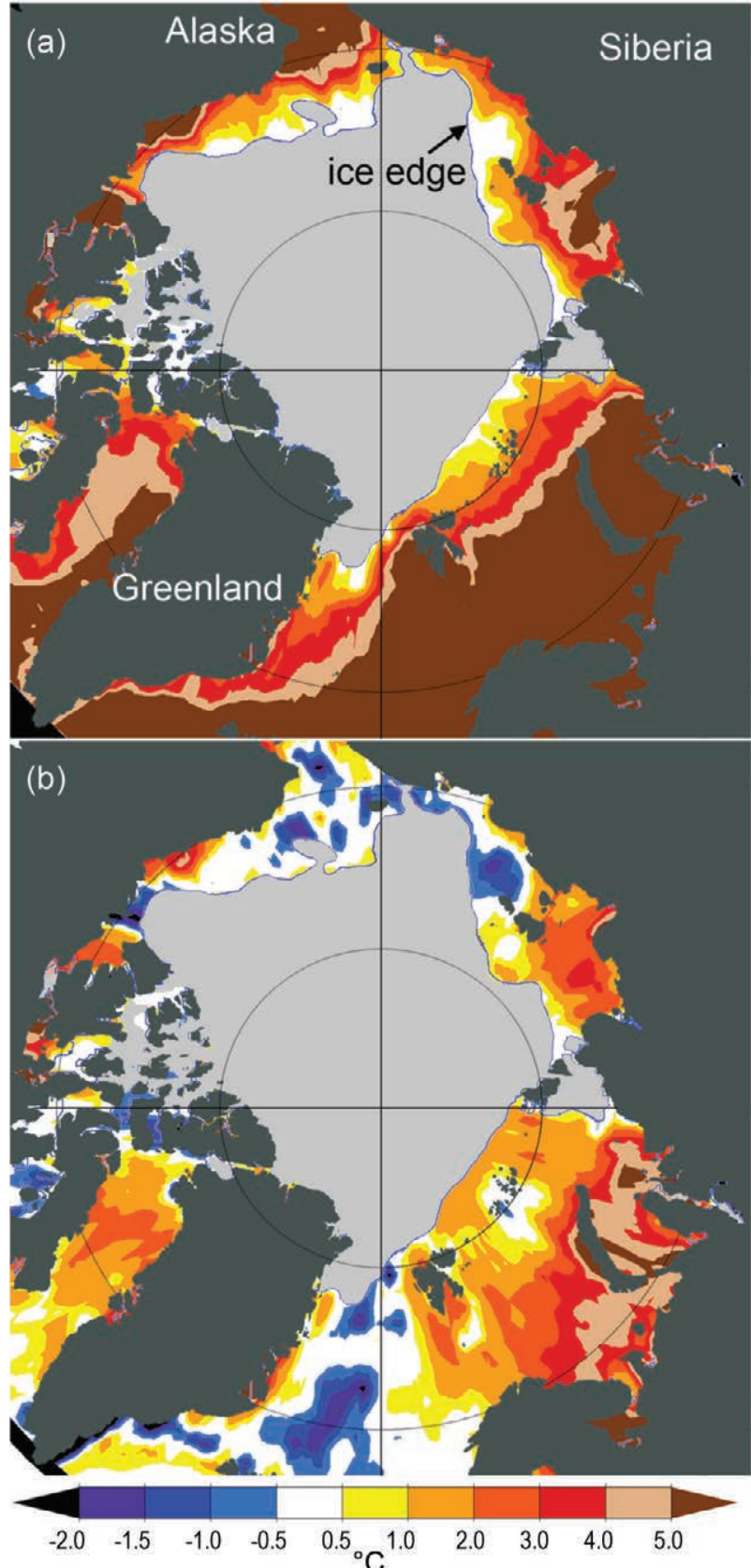

Fig. 5.15. (a) Average Aug 2013 SST $\left({ }^{\circ} \mathrm{C}\right.$ ) and (b) Aug 2013 SST anomalies $\left({ }^{\circ} \mathrm{C}\right)$ relative to the Aug 1982-2006 average. Anomalies are derived from satellite data according to Reynolds et al. (2007). The gray area shows the average Aug 2013 sea-ice extent according to the National Snow and Ice Data Center.

in these regions are linked to later and less extensive sea-ice retreat; anomalously cold August SSTs related to unusual sea-ice extent patterns were also observed in this region in 2012 (Timmermans et al. 2013b). Anomalously warm August SSTs in the Barents and Kara Seas are related to earlier ice retreat in these regions and possibly also to the advection of anomalously warm water from the North Atlantic. 
Hydrographic data show surface waters in the vicinity of the Barents Sea Opening in September 2013 were about $3^{\circ} \mathrm{C}$ warmer than in September 2012. SSTs in the southern Barents Sea in September 2013 were as high as $11^{\circ} \mathrm{C}$ and up to $5^{\circ} \mathrm{C}$ above the $1977-2006$ average (Trofimov and Ingvaldsen 2014).

\section{2) UPPER OCEAN SALINITY}

Salinity in the upper several hundred meters of the Arctic Ocean is set by sea ice melt/growth cycles, influxes from the Pacific and Atlantic oceans, river input, net precipitation, and redistribution by wind forcing and mixing. The central Canada Basin is the freshest region of the Arctic Ocean, and the saltiest upper ocean is observed at the boundaries of the Eurasian Basin and the Barents Sea (Fig. 5.16, which illustrates salinity at a depth of $20 \mathrm{~m}$, within the wellmixed surface layer for most of the year). Relative to the 1970s, the major upper-ocean salinity differences in 2013 (similar to 2012; see Timmermans et al. 2013a, figure 24) were saltier waters in the central Eurasian Basin and fresher waters in the Beaufort Gyre region of the Canada Basin. The main differences in upperocean salinity in 2013 relative to 2012 included saltier surface waters in the region north of Greenland and Ellesmere Island, Canada, and in the northern part of the East Siberian Sea/western Canada Basin.

\section{3) FreshWATER CONTENT}

Freshwater content in the Arctic Ocean has an important relationship to sea ice and climate; increased freshwater, for example, strengthens ocean stratification, impeding vertical heat transport from deeper waters. Liquid freshwater content in the upper Arctic Ocean basins showed an increasing trend from 1992 to 2012 of about $600 \pm 300 \mathrm{~km}^{3} \mathrm{yr}^{-1}$, based on observed salinity profiles (Rabe et al. 2014). The maximum liquid freshwater content anomaly is centered in the Beaufort Gyre (Fig. 5.17). In total, during 2003-13 the Beaufort Gyre accumulated more than $5000 \mathrm{~km}^{3}$ of freshwater (measured relative to a salinity of 34.8 ), a gain of approximately $25 \%$ (update to Proshutinsky et al. 2009) compared to the 1970s (see figure 5.24b in Timmermans et al. 2013b). Most of this increase occurred between 2004 and 2008.

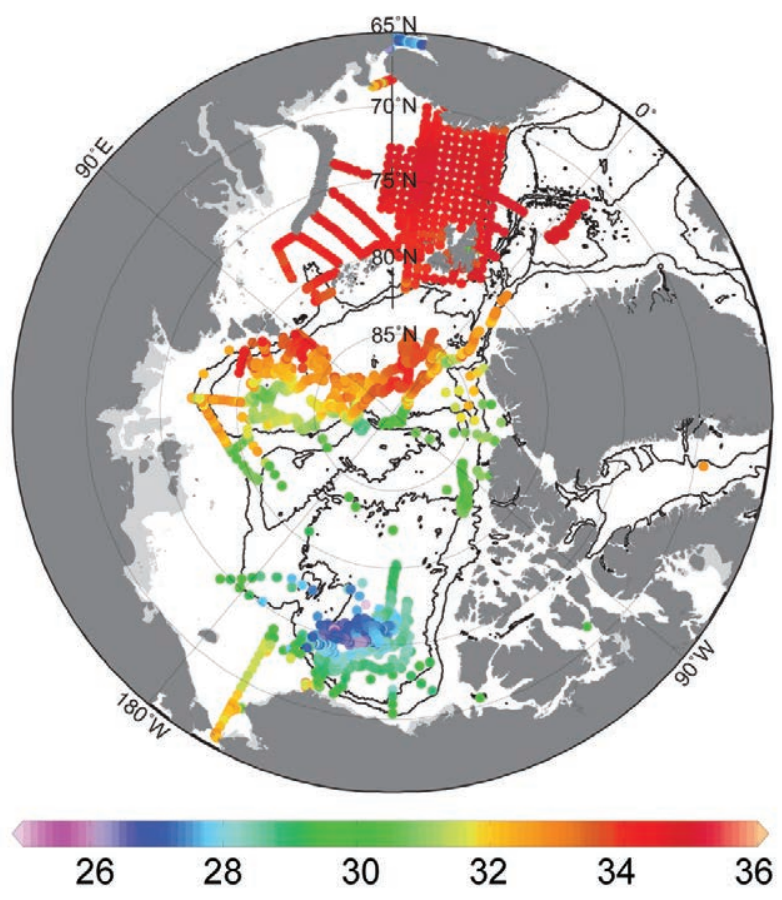

FIG. 5.16. Average salinity at 20-m depth in 2013 . Contour lines show the $500-\mathrm{m}$ and $2500-\mathrm{m}$ isobaths. Salinities are reported using the Practical Salinity Scale (unitless). Data are from multiple sources, including various hydrographic expeditions by different countries and institutions, and ice-tethered profilers (http://www.whoi.edu/itp).

In 2013, a reduction in freshwater content by about $7 \%$ was observed relative to 2012 (cf. Timmermans et al. 2013b, figure 5.24c). This reduction may be attributed in part to stronger cyclonic (counterclockwise) wind forcing in summer 2013 (compared to previous years) that drove divergence of surface waters in the region. It is of note that trends in Beaufort Gyre heat

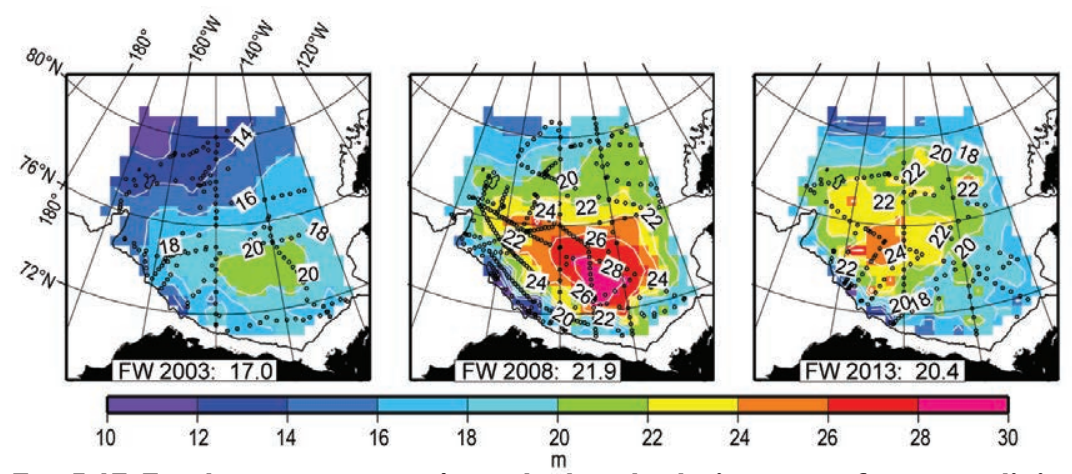

FIG. 5.I7. Freshwater content ( $\mathrm{m}$, calculated relative to a reference salinity of 34.8) in the Beaufort Gyre of the Canada Basin based on hydrographic surveys in 2003, 2008, and 2013. Inset numbers at the bottom of each panel give total freshwater volume $\left(\times 1000 \mathrm{~km}^{3}\right)$ in the region. Black dots depict hydrographic station locations. Data are from the Beaufort Gyre Observing System (BGOS)/Joint Ocean Ice Studies (JOIS) project (http:/l www.whoi.edu/beaufortgyre) and other Canada Basin expeditions. 


\section{SIDEBAR 5.3: OCEAN ACIDIFICATION IN THE ARCTIC-J. T. MATHIS, J. N. CROSS, W. EVANS, L. ANDERSON, AND M. YAMAMOTO-KAWAI}

In recent years, ocean acidification has emerged as one of the dominant issues in marine science, particularly in highlatitude regions, where its progression has been greater than many other ocean basins (e.g., Fabry et al. 2009; Steinacher et. al. 2009; Mathis et al. 20II; Yamamoto-Kawai et al. 20I3). It has been widely shown that the uptake of anthropogenic $\mathrm{CO}_{2}$ from the atmosphere fundamentally alters the chemistry of seawater by lowering its $\mathrm{pH}$ (reducing the alkalinity) and decreasing the saturation states $(\Omega)$ of calcium carbonate $\left(\mathrm{CaCO}_{2}\right)$ minerals that are critical for the formation and maintenance of biogenic shells and tests (e.g., Feely et al. 2009; Cooley and Doney 2009; Kroeker et al. 2010).

Ocean acidification studies began in earnest in the Arctic Ocean during the early 1990s (Jutterström and Anderson 2005) and progressed slowly until a few large-scale studies of the Chukchi and Beaufort Seas (Fig. SB5.5), and the Nordic Seas were conducted in the 2000s. While these early studies were designed to broadly examine the carbon cycle, they provided the first evidence that aragonite became undersaturated in the bottom waters of the shallow shelf seas, particularly in summer and fall months (e.g., Bates et al. 2009), and that the halocline of the Canada Basin (Fig. SB5.5) was undersaturated in the carbonate mineral aragonite throughout the year (Jutterström and Anderson 2005). Since 2008, dozens of comprehensive ocean acidification projects have been conducted in the Arctic by a number of nations, including the United States, Canada, Sweden, Japan, South Korea, China, and Germany, with a commensurate increase in understanding of the controls on ocean acidification. New insights from surveys throughout the Arctic Ocean basin have clearly shown that the intrusion of anthropogenic $\mathrm{CO}_{2}$ is not the only driver of reductions in $\mathrm{pH}$ and $\Omega$ in the region. Several other processes, such as melting sea ice, terrestrial and marine organic matter respiration, and upwelling are exacerbating the effects of ocean acidification, leading to rapid changes in the marine environment. Furthermore, the role that the differing shelf environments (inflow, interior, and outflow) have in conditioning the water column (Carmack and Wassmann 2006) throughout the year can be critical in determining the intensity of carbonate mineral undersaturation events on seasonal timescales. In a seminal paper on the changing carbonate chemistry of the Arctic Ocean, YamamotoKawai et al. (2009) showed that increasing sea ice melt water in the Canada Basin is causing a sharp reduction in $\Omega$ in the surface waters due to the dilution effect on calcium carbonate ions. These results showed that, in summer, aragonite $\Omega$ had decreased from $\sim 1.5$ in 1997 to $\sim 1.0$ in 2008 and that the areas most affected were located in the eastern Canada Basin. If the

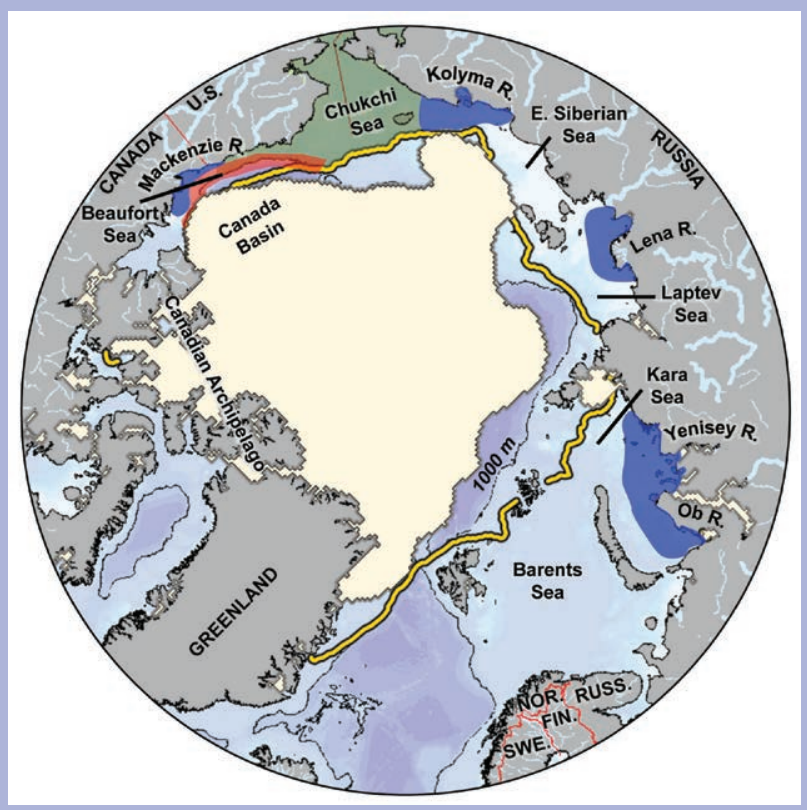

FIG. SB5.5. Polar view of the Arctic Ocean, highlighting the various regional drivers of ocean acidification: respiration-dominated shelves (green); plumes from the Ob, Yenisey, Lena, Kolyma, and Mackenzie Rivers (the major arctic rivers, blue); upwelling regions (red). Sep 2013 ice extent is light yellow and the mean Sep ice extent for 1976-present is the bold dark yellow line. Shelf types are: inflow shelves (Chukchi and Barents Seas), interior shelves (Kara, Laptev, East Siberian, and Beaufort Seas), outflow shelves (Canadian Arctic Archipelago). The shelf break is indicated by the $1000-\mathrm{m}$ isobath (thin black line). Water with a depth $>1000-\mathrm{m}$ is purple.

current trajectory of sea ice loss continues (see section $5 f$ ), it is likely that larger areas of the Canada Basin will be inundated with waters that are undersaturated in aragonite, making them potentially corrosive to shell building organisms like pteropods (Bednaršek et al. 2012).

One of the most dominant drivers of carbonate mineral undersaturations over the Arctic continental shelves is the respiration of organic matter (Bates and Mathis 2009; Anderson et al. 2010) that is either produced during seasonally intense phytoplankton blooms or delivered by rivers and coastal erosion (Fig. SB5.5). In the Chukchi Sea (Fig. SB5.5), seasonally high rates of primary production are largely uncoupled from grazing and this leads to large quantities of organic matter to be exported to the bottom waters. As the organic matter is respired and converted back into $\mathrm{CO}_{2}$, the $\mathrm{pH}$ and $\Omega$ of the bottom waters are reduced and aragonite as well as calcite can 
become undersaturated for a few months each year (Mathis and Questel 2013). A portion of this water then ventilates the halocline of the Canada Basin (Mathis et al. 2007) and causes this subsurface layer at 75-150 m depth to be undersaturated in aragonite. The Chukchi Sea, like the Barents Sea (Fig. SB5.5), is an inflow shelf and receives a consistent supply of nutrients from the North Pacific Ocean via the Bering Strait (see section $5 g$ ) that sustain a productive growing season. However, the greater depth of the Barents Sea shelf, together with higher grazing rates, limit the degree of focused deposition of organic matter and the occurrence and severity of undersaturation events in that region.

The interior shelves of the Arctic Ocean (Beaufort, Kara, Laptev, East Siberian; Fig. SB5.5) have much lower rates of primary production due to nutrient limitation; however, high rates of riverine and terrestrial inputs of organic matter sustain similarly intense respiration rates and lead to a lower $\Omega$ (Fig. SB5.5). Broad areas of undersaturation have been observed over the Eurasian shelves due to this process (e.g., Anderson et al. 2010). It is likely that both primary production and terrestrial inputs of organic matter will increase in the coming decades as warming in the region continues (Lavoie et al. 2010; Arrigo and van Dijken 20II), which could lead to increased respiration and further reductions in $\Omega$. The Canadian Arctic Archipelago (Fig. SB5.5), an outflow shelf downstream from the Beaufort Sea, is already experiencing aragonite undersaturations for several months each year due to the impacts of ice melt, respiration, and upwelling (Shadwick et al. 20II; Yamamoto-Kawai et al. 20I3).

Finally, the upwelling of water that is undersaturated in aragonite from the halocline of the Arctic Ocean (Mathis et al. 2012) can also expose shelf regions to conditions that could be corrosive to calcifying organisms (Fig. SB5.5). The upwelling of high $\mathrm{CO}_{2}$, low $\Omega$ water can occur at any time during the year, but will likely increase in frequency as sea ice continues to decline, and particularly in fall months when storm conditions are at their peak (Pickart et al. 20II, 20I3).

Through continuing observations and synthesis activities, it is becoming more apparent that the Arctic Ocean is on a dangerous ocean acidification trajectory that could lead to direct impacts on calcifying organisms, many of which are keystone species such as clams and pteropods. The Arctic is facing multiple drivers for enhanced ocean acidification. The loss of sea ice in summer is allowing more $\mathrm{CO}_{2}$ to be taken up directly from the atmosphere as the ice melt reduces the buffer capacity of the waters and the continental shelves are being exposed to waters that are undersaturated in carbonate minerals due to organic matter respiration and upwelling. At a time when the Arctic Ocean and adjacent lands are undergoing rapid change, it will be critical to maintain observations of the extent of ocean acidification in this basin. content (calculated relative to freezing temperature in the upper $1000 \mathrm{~m}$ ) generally follow freshwater trends; there is $\sim 25 \%$ more heat on average in the summer now compared to the 1970 s.

\section{4) Pacific Water layer}

The Pacific Water layer in the Arctic Ocean originates from the Bering Strait inflow and resides in the Canada Basin at depths between about 50 and $150 \mathrm{~m}$. Pacific Water is a major source of heat, freshwater, and nutrients to the Arctic Ocean. As reported in Woodgate et al. (2012), 2011 was a high transport year for Pacific Water inflow through the Bering Strait, with transports being $\sim 1.1 \mathrm{~Sv}$, much higher than the accepted climatology (1991-2003) of $\sim 0.8$ Sv (Woodgate et al. 2005). In contrast, annual average transport in 2012 (the most recent year for which data are available) was close to average. The annual average temperature of the Pacific Water layer in 2012 was colder than the last decade and comparable to the annual averages of the 1991-2001 period. These two factors yield a heat flux in 2012 comparable to the record low in 2001. Freshwater transport was also reduced in 2012 compared to 2011.

Pacific Water enters the Canada Basin via different mechanisms and pathways. Moored measurements of the Pacific water boundary current in the Beaufort Sea north of Alaska (the Beaufort shelfbreak jet) show an $80 \%$ decrease in volume transport in the current between 2002 and 2011 (Brugler et al. 2014), where this decrease is predominantly in the summer months. Brugler et al. (2014) attribute the decrease in transport to an increase in easterly winds and propose that in recent years Pacific heat and freshwater are being advected directly north into the Canada Basin interior instead of progressing eastward in the Beaufort shelfbreak jet.

In the central Canada Basin, observations show heat and freshwater content in the Pacific Water layer increased by about $40 \%$ during 2003-13, with the 
largest increases in the southern Canada Basin before 2010. Freshwater content has been relatively stable since 2010. In 2013, maximum Pacific Water layer temperatures over the abyssal plain of the Canada Basin were $\sim 0.5^{\circ} \mathrm{C}$.

\section{5) Atlantic Water layer}

Warm water of North Atlantic origin, lying below the halocline at depths between about 200 and $900 \mathrm{~m}$ (but nearer the surface in the vicinity of the Barents Sea Opening and Fram Strait), is characterized by a warm core with temperatures $>0^{\circ} \mathrm{C}$ and salinities $>34.5$. The transport of ocean heat in the Atlantic Water layer potentially contributes to the surface ocean heat budget and affects the sea ice volume. Atlantic Water temperatures are generally around $1^{\circ}-2^{\circ} \mathrm{C}$ higher in the Eurasian Basin than in the Canadian Basin (see figure 5.22b in Proshutinsky et al. 2012). In 2013, the warmest Atlantic Water temperatures $\left(\sim 5^{\circ} \mathrm{C}\right)$ were observed in the Barents Sea. The coolest temperatures $\left(\sim 0^{\circ} \mathrm{C}\right)$ were observed off the north coast of Greenland. No significant changes were observed in 2013 in the Atlantic Water layer compared to 2012 conditions. Maximum temperatures of the Atlantic Water flowing into the southern Barents Sea in 2013 were about $0.5^{\circ} \mathrm{C}$ higher than the $1977-2006$ average (Trofimov and Ingvaldsen 2014). Relative to 1970s conditions, Atlantic Water temperature anomalies were $\sim 0.5^{\circ}-1^{\circ} \mathrm{C}$ warmer in the Eurasian Basin and $<0.5^{\circ} \mathrm{C}$ warmer in the Canadian Basin. There was little to no temperature anomaly $\left(<0.1^{\circ} \mathrm{C}\right)$ at the southeast boundary of the Canada Basin nor in the basin boundary regions adjacent to Greenland and the Canadian Archipelago.

\section{h. Terrestrial snow cover-C. Derksen, R. Brown, and K. Luojus}

I) SNOW COVER EXTENT

Northern Hemisphere spring snow cover extent (SCE) anomalies (relative to a 1981-2010 reference period) were computed from the weekly NOAA snow chart Climate Data Record [CDR; maintained at Rutgers University and described in Estilow et al. (2013)] for months when snow cover is confined largely to the Arctic. SCE showed a continued reduction from the historical mean during May and June 2013 (Fig. 5.18a). For Eurasia, a new record low May SCE was established (27\% below average), and June SCE tied for the second lowest since 1967. Across North America, April SCE was well above average (16\% above the 1981-2010 mean), May SCE was near average, and June SCE well below average (34\% below the 1981-2010 mean). The contrasting SCE anomalies between North America and Eurasia during May 2013 were consistent with continental differences in spring air temperature anomalies (warm over the Eurasian Arctic; cold over North American Arctic; see Fig. 5.2b).

The shift to increasingly negative SCE anomalies as the melt season progressed is consistent with observed trends over the past decade (Fig. 5.18a; Derksen and Brown 2012). The rate of snow cover loss over Northern Hemisphere land areas in June between 1979 and 2013 was $-19.9 \%$ decade $^{-1}$ (relative to the 1981-2010 average; updated from Derksen and Brown 2012). The rate of loss in the June SCE exceeds the rate of September sea ice loss over the same time period $\left(-13.7 \%\right.$ decade $\left.^{-1}\right)$, adding further compelling evidence of the observed rapid response of both the terrestrial and marine cryosphere to Arctic amplification in surface temperature trends. The rate of reduction in Arctic June SCE over the period of the NOAA data record continues to exceed the CMIP5 (Coupled Model Intercomparison Project Phase 5) model ensemble simulated and projected (historical + scenario rcp8.5) rate of decrease (Derksen and Brown 2012)

\section{2) SNOW COVER DURATION}

The timing of snow cover onset in fall is influenced by both temperature and precipitation. Snow cover duration (SCD) departures derived from the NOAA daily IMS snow cover product (Helfrich et al. 2007) identified earlier-than-normal snow cover onset over Scandinavia (Fig. 5.18b), with no notable departures over other Arctic regions (earlier-than-normal snow onset was observed for a midlatitude region of North America and southeastern Eurasia; see section 2c2 for more detail). The negative SCE anomalies for May and June (Fig. 5.18a) are reflected in earlierthan-normal snow melt across the Canadian tundra and eastern Siberia (Fig. 5.18c). Snow cover persisted longer than normal across northwestern Europe, which drove the positive Eurasian SCE anomalies for April. This region was snow free by May, so the longer-than-normal spring SCD departures in this region in April had no impact on the record setting low SCE across Eurasia in May.

\section{3) SNOW DEPTH}

April snow depth anomalies from the Canadian Meteorological Centre daily gridded global snow depth analysis (Brasnett 1999; Fig. 5.18d) were positive over most of Eurasia (average anomaly of $+16.9 \%$ relative to 1999-2010 average) and North America 
(a)

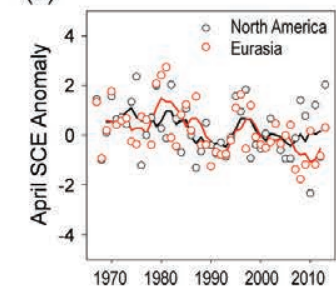

(b)

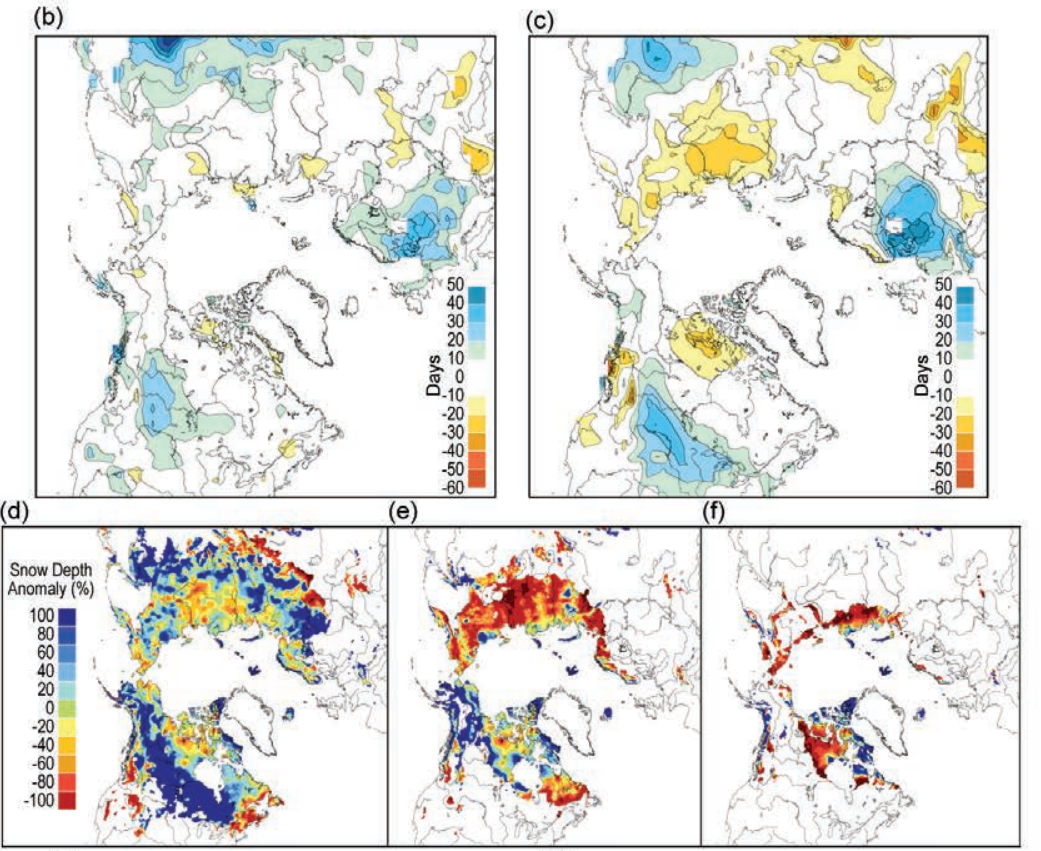

(g)

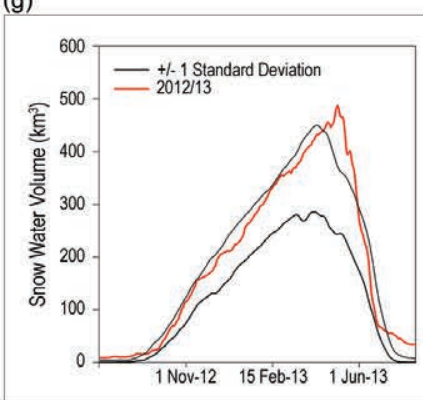

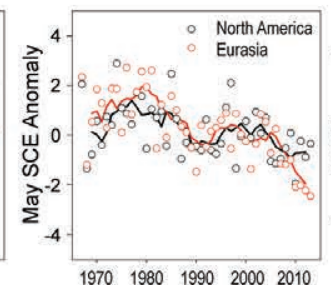

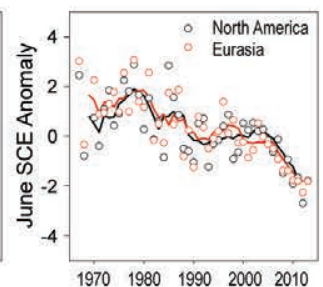

(c) (h)

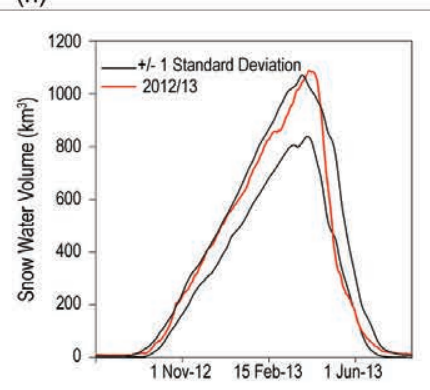

FIG. 5.I8. (a) Monthly Arctic snow cover extent standardized (unitless) anomaly time series (with respect to 1988-2007) from the NOAA snow chart CDR for Apr, May, and Jun 1967-2013 (solid lines denote 5 -yr moving average). Snow cover duration departures (with respect to 1998-2010) from the NOAA IMS (Interactive Multisensor Snow and Ice Mapping System) data record for the (b) 2012 fall season and (c) 2013 spring season. Snow depth anomaly (\% of 1999-2010 average) from the Canadian Meteorological Centre (CMC) snow depth analysis for (d) Apr, (e) May, and (f) Jun 2013. Daily 20I2/13 time series (red) of Arctic snow water volume for (g) North America and $(h)$ Eurasia derived from the CMC snow depth analysis. The solid black lines show the \pm I std. dev. range about the mean SWE over $1998 / 99$ to 20II/I 2 snow seasons. Note different $y$-axis ranges. (average anomaly of $+29.4 \%$ ). This is consistent with the negative winter season Arctic Oscillation (DJF average of -1.12; weaker Arctic jet favorable to cold air outbreaks), which produced below-average winter season temperatures over subarctic Eurasia and North America (see Fig. 5.2a). By May, however, the Eurasian snow depth anomalies were strongly negative (Fig. 5.18e; average anomaly of $-52.1 \%$ ), illustrating the rapid response of snow conditions to positive surface temperature anomalies over most of Eurasia (see Fig. 5.2) concurrent with belownormal cloud cover (as estimated by the ERA-Interim reanalysis; not shown).

\section{4) SNOW WATER EQUivalent}

The quick transition from abovenormal to below-normal snow depth was also captured by the daily time series of Arctic snow water equivalent (SWE; land areas north of $60^{\circ} \mathrm{N}$ ) derived from the Canadian Meteorological Centre analysis (Fig. $5.18 \mathrm{~g}, \mathrm{~h})$. Before melt onset, the total SWE was above the average for the data record (since 1998) over both Eurasia and North America. During a two-week period in mid-May, the record high SWE over Eurasia plummeted to well below average (Fig. 5.18h). The decline in SWE was less dramatic for North America because regionally extensive positive temperature anomalies (also concurrent with below-average cloud cover and above-average surface net radiation, see Figs. 5.5b, 5.6b) did not set in until June. As in 2012, rapid snowmelt (not anomalously low winter season snow accumulation) was the main process responsible for the record-setting loss of Eurasian spring snow cover in May 2013 and the below-normal June 2013 SCE in North America. 
i. Glaciers and ice caps (outside Greenland) -M. Sharp, G. Wolken, M-L. Geai, D. Burgess, A. Arendt, B. Wouters, J. Kohler, L. M Andreassen, and M. Pelto

Mountain glaciers and ice caps cover an area of over $400000 \mathrm{~km}^{2}$ in the Arctic and have been a major contributor to global sea level change in recent years (Gardner et al. 2011; Jacob et al. 2012). They gain mass by snow accumulation and lose mass by surface melt and runoff and by iceberg calving where they terminate in water (ocean or lake). The climatic mass balance $\left(B_{\text {clim }}\right.$, the difference between annual snow accumulation and annual runoff) is a widely used index of how glaciers respond to climate variability and change. Snow accumulation minus mass losses by iceberg calving and runoff gives the total mass balance $(\Delta \mathrm{M})$.

Since many $B_{\text {clim }}$ measurements for the 2012/13 mass balance year are not yet available, we begin by summarizing measurements from 24 Arctic glaciers in 2011/12 (World Glacier Monitoring Service 2014). These glaciers are located in Alaska (three), Arctic Canada (four), Iceland (six), Svalbard (four), Norway (two), and Sweden (five) (Fig. 5.19; Table 5.2). For the monitored Arctic glaciers as a whole, $B_{\text {clim }}$ in 2011/12 was negative (Fig. 5.20), although 2011/12 was the eighth least negative year since 1989.

All but seven of the glaciers (Wolverine and Lemon Creek in coastal southern Alaska, Kongsvegen in Svalbard, Engabreen in northern Norway, and Rabotsglaciären, Storglaciären, and Tarfalaglaciären in northern Sweden) had a negative $B_{\text {clim }}$, i.e., loss of ice mass. For the four Scandinavian glaciers with

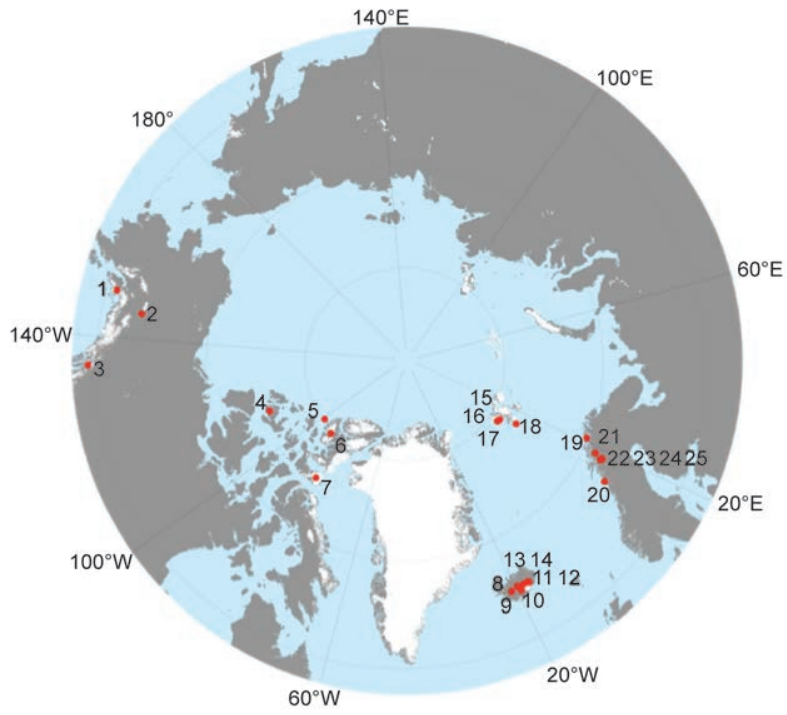

FIG. 5.19. Locations of 25 Arctic glaciers with long-term records of annual climatic mass balance $\left(B_{\text {clim }}\right)$. See Table $\mathbf{5 . 2}$ for glacier names.

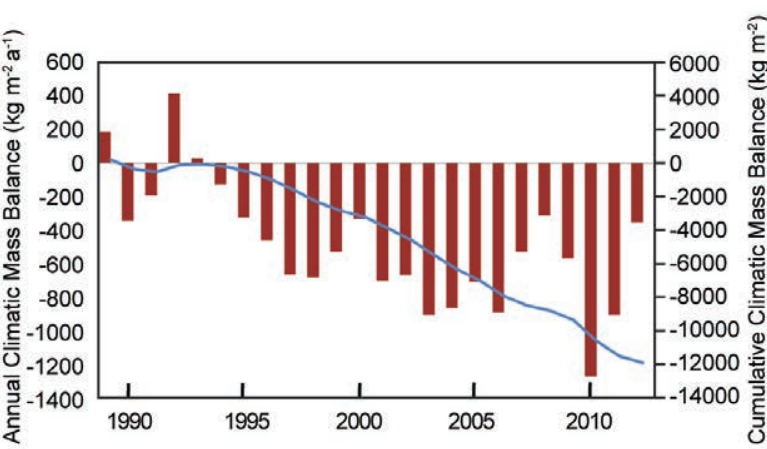

Fig. 5.20. Average annual (red bars) and cumulative (blue line) climatic mass balance $\left(B_{\text {clim }}\right)$ of 24 Arctic glaciers (see Fig. 5.19) monitored during the period 1988/89-20II//2.

positive $B_{\text {clim }}$ in 2011/12, the recorded values were among the 5-7 most positive in the period of record for each glacier. This is most likely a result of anomalously cool temperatures over the region in summer 2012 (see Figs. 5.2c, 5.4a). In the Canadian Arctic, however, the 2011/12 climatic balances were each among the four most negative in their 50-52-year records, extending the unusually high mass loss rates from that region since 2006/07 (Sharp et al. 2011). This is consistent with the extensive surface melting and mass loss recorded in Greenland in summer 2012, which was a result of advection of warm southerly air masses (Tedesco et al. 2013a). $\mathrm{B}_{\text {clim }}$ was negative in interior Alaska (Gulkana Glacier) and positive in coastal southern Alaska (Wolverine and Lemon Creek glaciers), where winter snowfall was unusually high. In coastal southern Alaska, the 2011/12 balances were among the 5-10 most positive ever recorded at the glaciers sampled. The mass balance of Hansbreen in southern Spitsbergen, Svalbard, was the second most negative in the 24-year record.

Trends of increasingly negative cumulative balances are evident in regional total mass balance estimates $(\Delta \mathrm{M})$ for Arctic Canada and Alaska derived using GRACE satellite gravimetry (Fig. 5.21). However, GRACE estimates of $\Delta \mathrm{M}$ for the 2012/13 mass balance year are incomplete at the time of writing. Nevertheless, available measurements of $\Delta \mathrm{M}$ for all the glaciers and ice caps in the Canadian Arctic Archipelago (CAA) suggest that the region gained mass between the ends of the summer 2012 and 2013 melt seasons, while mass accumulation in the Gulf of Alaska region over winter 2012/13 was significantly less than in winter 2011/12 (Fig. 5.21). It is not yet possible, however, to determine the sign of the mass balance in the Gulf of Alaska region in 2012/13 be- 
Table 5.2. Measured annual climatic mass balance $\left(B_{\text {clim }}\right)$ of 24 glaciers in Alaska, the Canadian Arctic, Iceland, Svalbard, and northern Scandinavia for 2009/10, 2010/11, and 2011/12 (data from the World Glacier Monitoring Service). Additional 2012/13 data for glaciers in Svalbard and Norway were provided by J. Kohler and L. Andreassen. Numbers in the far left column identify glacier locations in Fig. 5.19.

\begin{tabular}{|c|c|c|c|c|c|}
\hline \multirow{2}{*}{ Region } & \multirow{2}{*}{$\begin{array}{c}\text { Glacier } \\
\text { (Length of record in } \\
\text { years) }\end{array}$} & \multicolumn{4}{|c|}{$\begin{array}{c}\text { Climatic Balance } \\
\left(\mathrm{kg} \mathrm{m}^{-2} \mathrm{yr}^{-1}\right)\end{array}$} \\
\hline & & $2009 / 10$ & $2010 / 11$ & $2011 / 12$ & $2012 / 13$ \\
\hline \multicolumn{6}{|l|}{ Alaska } \\
\hline 1 & Wolverine (47) & -85 & -1070 & 510 & \\
\hline 3 & Lemon Creek (60) & -580 & -720 & 450 & \\
\hline 2 & Gulkana (47) & -1832 & -1290 & -790 & \\
\hline \multicolumn{6}{|c|}{ Arctic Canada } \\
\hline 7 & Devon Ice Cap (52) & -417 & -683 & -503 & \\
\hline 5 & Meighen Ice Cap (5I) & -387 & -1310 & -1118 & \\
\hline 4 & $\begin{array}{l}\text { Melville S. Ice Cap } \\
(50)\end{array}$ & -939 & -1339 & -1556 & \\
\hline 6 & White (50) & -188 & -983 & -951 & \\
\hline \multicolumn{6}{|l|}{ Iceland } \\
\hline 8 & Langjökull S. Dome (16) & -3800 & -1279 & -542 & \\
\hline 9 & Hofsjökull E & -2830 & & & \\
\hline 9 & Hofsjökull N & -2400 & & & \\
\hline 9 & Hofsjökull SW & -3490 & & & \\
\hline 14 & Köldukvislarjökull (20) & -2870 & -754 & -289 & \\
\hline 10 & Tungnaarjökull (2I) & $-355 I$ & -1380 & -1294 & \\
\hline 13 & Dyngjujökull (I5) & -1540 & +377 & -975 & \\
\hline 12 & Brúarjökull (20) & -1570 & +515 & -759 & \\
\hline 11 & Eyjabakkajökull (2I) & -1750 & +525 & -954 & \\
\hline \multicolumn{6}{|l|}{ Svalbard } \\
\hline 17 & Midre Lovenbreen (45) & -200 & -920 & -260 & -940 \\
\hline 16 & Austre Broggerbreen (46) & -390 & -1010 & -180 & -1090 \\
\hline 15 & Kongsvegen (26) & +130 & -440 & 210 & -610 \\
\hline 18 & Hansbreen (24) & -14 & -280 & -150 & \\
\hline \multicolumn{6}{|l|}{ Norway } \\
\hline 20 & Engabreen (43) & -520 & -910 & 1140 & -1780 \\
\hline 19 & LangfjordjØkulen (22) & -760 & -1257 & -760 & -2610 \\
\hline \multicolumn{6}{|l|}{ Sweden } \\
\hline 21 & Marmaglaciaren (23) & -500 & -1450 & -90 & \\
\hline 22 & Rabots Glaciar (3I) & -1080 & -2110 & 20 & \\
\hline 23 & Riukojietna (26) & -960 & -1080 & -90 & \\
\hline 24 & Storglaciaren (67) & -690 & -1060 & 680 & \\
\hline 25 & Tarfalaglaciaren (I8) & -1060 & -1820 & 830 & \\
\hline
\end{tabular}

cause the glaciers were still losing mass at the end of the available GRACE record.

In summer 2013, near-surface summer air temperatures over Greenland and Arctic Canada were up to $3.5^{\circ} \mathrm{C}$ cooler than in the period 2007-12 (see section 5 j, Figs. 5.2c, 5.4a). The relatively low mass loss measured in summer 2013 by GRACE in Arctic Canada (Fig. 5.21), and the lower melt extent and less negative surface mass balance on the Greenland ice sheet compared to 2012 (see section $5 \mathrm{j}$ ), are consistent with the air temperature observations for these cold, dry regions, where variability in average summer temperature accounts for much of the interannual variability in $\mathrm{B}_{\text {clim. }}$. This contrasts with more maritime regions, e.g., Iceland and the mountains adjacent to the Gulf of Alaska, where variability in winter precipitation is also a factor.

By contrast, summer 2013 was very warm over some glaciated regions of the Arctic, including southern Alaska, Novaya Zemlya, Svalbard, northern Scandinavia, and eastern Iceland (see Figs. $5.2 \mathrm{c}, 5.4 \mathrm{a})$. In northwest Svalbard and northern Norway, this warm summer followed a winter with unusually low snowfall. For northwest Svalbard, this resulted

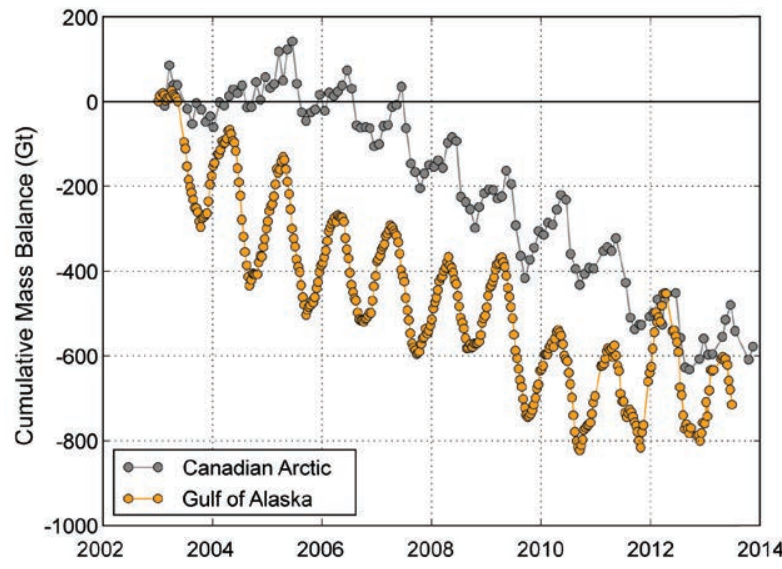

Fig. 5.2I. Cumulative total mass balance (Gt) of glaciers in the Canadian Arctic and the Gulf of Alaska region for the period 2003-13. Note that available measurements for the Gulf of Alaska do not cover the full 2012/13 mass balance year. The total uncertainty from 2003 to 2010 in the Gulf of Alaska and Canadian Arctic mass trends was \pm II Gt yr-1 $^{-1}$ (Luthcke et al. 2013) and $\pm 7 \mathrm{Gt}_{\mathrm{yr}^{-1}}$ (update of Gardner et al. 2013), respectively. Uncertainties in the GRACE time series result from different approaches used to process the raw Level IB satellite observations, signal leakage in and out of the solution domain, and different methods for modeling non-glacier sources of mass variability. 
in the second or third most negative annual climatic balances on record in 2012/13, while for northern Norway it resulted in the single and second most negative annual climatic balances (Table 5.1). In Alaska, final values for the annual climatic mass balance have not yet been determined, but measurements in late summer 2013 suggest that 2012/13 may have been the most negative balance year on record at coastal Wolverine Glacier and the fifth most negative at Gulkana Glacier in the Interior (preliminary data provided by the United States Geological Survey). In southeastern Alaska, both Lemon Creek and Taku Glaciers had above-average equilibrium line altitudes of 1050 and $1115 \mathrm{~m}$, respectively, at the end of summer 2013 , which suggests a moderately negative annual climatic balance $\left(\mathrm{B}_{\text {clim }}\right)$ in that region.

j. Greenland Ice Sheet-M. Tedesco, J. E. Box, J. Cappelen, X. Fettweis, T. S. Jensen, T. Mote, A. K. Rennermalm, L. C. Smith, R. S. W. van de Wal, and J. Wahr

I) Satellite observations of surface melting and ALBEDO

Melt estimates over the Greenland Ice Sheet obtained from passive microwave data (Mote and Anderson 1995; Mote 2007) indicate that melting during summer (June-August, JJA) 2013 was near the long-term average for the period 1981-2010. On 26 July, melt area reached a maximum, covering $44.1 \%$ of the ice sheet surface. This was much smaller than the record of 97\% set in 2012 (Nghiem et al. 2012; Tedesco et al. 2013b,c) and ranked 14th in the 35-year period of record (1979-2013). Moreover, the average melt area (the melting area averaged over the entire summer of 2013) of $16.7 \%$, ranked 16th in the period of record and was the lowest annual value since 2000 . For comparison, the average melt area during the record-setting summer of 2012 was 33.5\%. The frequency of melting was slightly above the 1981-2010 average along the western and northwestern ice sheet margins, but lower than average in the south and southeast. In terms of number of melting days, surface melting during 2013 occurred for more than 100 days in some southwestern ice sheet margin areas, consistent with the long-term trend (Fig. 5.22a).

The average ice sheet-wide albedo derived from the Moderate-resolution Imaging Spectroradiometer (MODIS; e.g., Box et al. 2012) during summer 2013 was the highest $(\sim 0.72)$ since 2008 , interrupting a period of increasingly negative and record albedo values since observations began (Fig. 5.23; Box et al. 2012; Tedesco et al. 2011, 2013b). Albedo for JJA 2013 was above the 2000-11 average along the southwest,
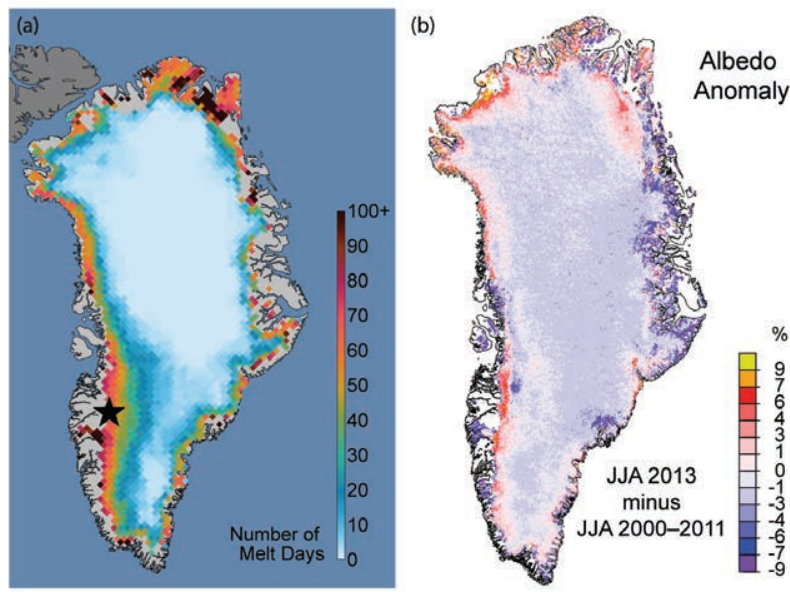

FIG. 5.22. (a) Cumulative number of melting days on the Greenland Ice Sheet between I Jan and 23 Sep 2013. (Source: National Snow and Ice Data Center) (b) Greenland Ice Sheet albedo anomalies in summer 2013 relative to the $2000-11$ average derived from MODIS (Moderate-resolution Imaging Spectroradiometer). The black star on the west coast of Greenland in (a) marks the location of Kangerlussuaq and the K-transect to its east.

northwest, and northeast regions and coasts of the ice sheet and below average for the east and southeast regions (Fig. 5.22b; Tedesco et al. 2013a). Areas of low albedo are generally associated with areas with prolonged melting.

\section{2) Surface mass balance AND RIVER DISCHARGE}

Surface mass balance measurements made $\sim 20 \mathrm{~km}$ east of Kangerlussuaq (Fig. 5.22a) between 340 and $1500 \mathrm{~m}$ above sea level (a.s.l.) along the 'K-transect' (van de Wal et al. 2005, 2012) indicate that melting along the transect in 2013 was below the 1990-2010 average, particularly near the ice margin (Fig. 5.24a).

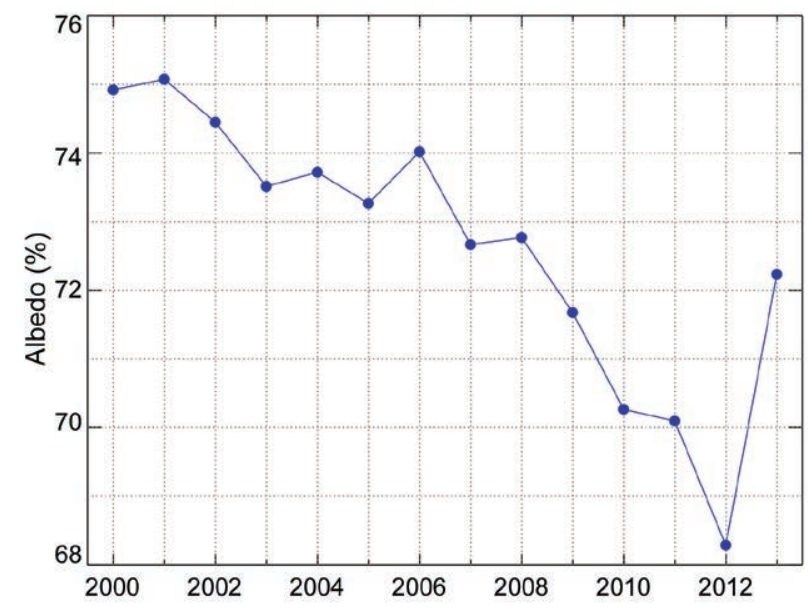

FIG. 5.23. Area-averaged albedo of the Greenland Ice Sheet in summer since 2000 derived from MODIS data. 


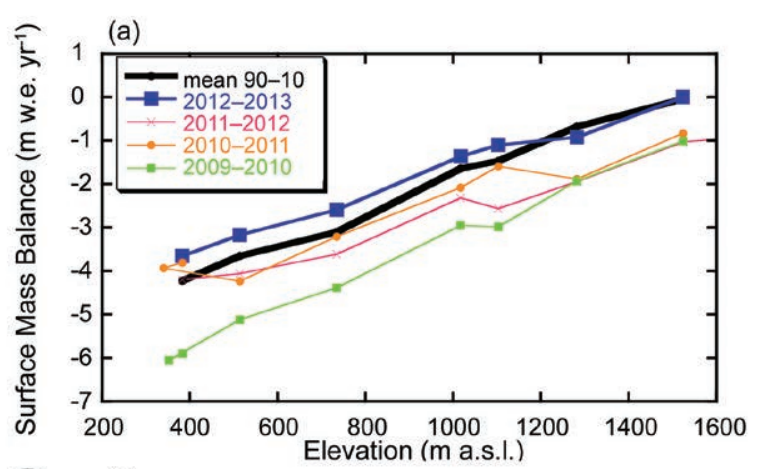

(b)

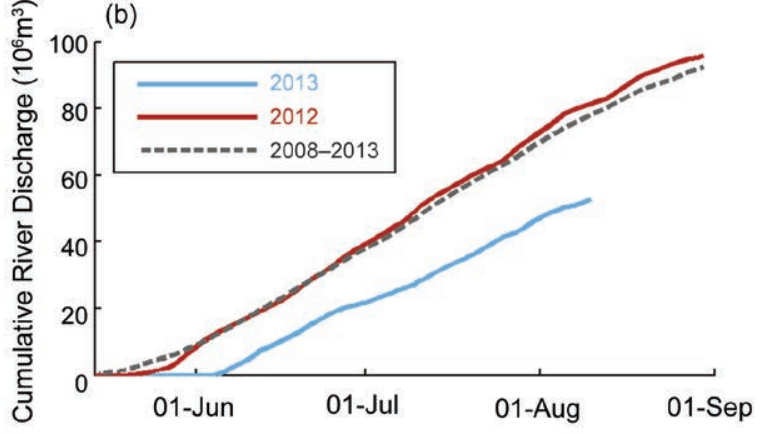

Fig. 5.24. (a) Surface mass balance (meters of water equivalent per year) as a function of elevation along the K-transect for four years since 2009/10, and the long-term average for 1990-2010. (b) Cumulative river discharge from the AK4 catchment $(\sim 20 \mathrm{~km}$ east of Kangerlussuaq) in southwest Greenland (see Fig. 5.22a) in 2013 compared with 2012 and the 2008-13 average.

The 2013 estimated equilibrium line altitude on the transect was near the long-term average position of $1500 \mathrm{~m}$ a.s.l., in strong contrast to its upslope migration to $\sim 2700 \mathrm{~m}$ during the very warm summer of 2012 (e.g., Tedesco et al. 2013c).

Consistent with surface mass balance estimates, river discharge observations of a small basin of the Kangerlussuaq catchment, which includes much of the K-transect (Rennermalm et al. 2012, 2013a,b), reveal a later melt season onset in 2013 and lower flow conditions compared to previous years. Cumulative river discharge in 2013 (Fig. 5.24b) was the lowest recorded during the instrumental record beginning in 2008, confirming that meltwater runoff from the ice margin in this area of southwestern Greenland was below previous years (Tedesco et al. 2013a).

\section{3) SURFACE AIR temperature obSeRVATIONS}

Near surface air temperature (NSAT) data recorded at long-term meteorological stations (Cappelen 2013; http://www.dmi.dk/fileadmin/Rapporter/TR /tr13-04.pdf) indicate that the outstanding surface temperature feature in 2013 was a consistent warm anomaly along the west Greenland coast during March (see Fig. 5.2a). A record warm March was recorded at Pituffik/Thule AFB, where the NSAT anomaly relative to $1981-2010$ baseline was $+7.7^{\circ} \mathrm{C}$, the warmest on record since 1948. Similarly, the Upernavik and Kangerlussuaq March NSAT anomalies were $+7.7^{\circ}$ and $+8.6^{\circ} \mathrm{C}$, respectively. In contrast, during the summer months (June-August) NSAT values were generally near or below one standard deviation of anomalies relative to the 1981-2010 average, indicating that summer 2013 NSATs were normal with respect to that period. Wide-area air temperature anomalies are broadly consistent with the data for individual stations (Tedesco et al. 2013a).

In contrast to the previous six summers, characterized by negative North Atlantic Oscillation (NAO) phases, summer 2013 was characterized by persistent positive NAO phases, inducing lower-than-normal 500-hPa geopotential heights over Greenland. Consequently, warm, southerly air masses were diverted eastward from Greenland and northerly airflow in west Greenland (see Fig. 5.4b) promoted cooler, wetter, and cloudier weather than normal, and less melting than in recent years, as reported above.

4) Satellite observations of ICE mass and marineTERMINATING GLACIERS

Based on GRACE satellite measurements, the cumulative ice sheet loss was $570 \pm 100 \mathrm{Gt}$ between the end of April 2012 and the end of April 2013, which corresponds to the period between the beginning of the 2012 and 2013 melt seasons. The mass loss was more than twice the average annual loss rate of 260 \pm 100 Gt during 2003-12 (Fig. 5.25). The 2012/13 mass loss is the largest annual loss rate for Greenland in the GRACE record, mostly reflecting the large mass loss during the summer of 2012 (Tedesco et al. 2013c).

LANDSAT and ASTER images of 41 of the widest marine-terminating glaciers in summer 2013 indicate a net cumulative area change of $-20 \mathrm{~km}^{2}$ since summer 2012 (after Box and Decker 2011). This is the second smallest area change on record and 118 $\mathrm{km}^{2}$ less than the average annual area change $(-138$ $\mathrm{km}^{2}$ ) since 2000. The largest local increases in area between 2012 and 2013 occurred at Petermann $(+16$ $\left.\mathrm{km}^{2}\right)$, Ryder $\left(+4 \mathrm{~km}^{2}\right)$, Nioghalvfjerdsbrae/79 (+3 $\mathrm{km}^{2}$ ) glaciers. The largest local area decreases occurred at Zachariae $\left(-16 \mathrm{~km}^{2}\right)$, Humboldt $\left(-10 \mathrm{~km}^{2}\right)$, and Helheim glaciers $\left(-4 \mathrm{~km}^{2}\right)$. 


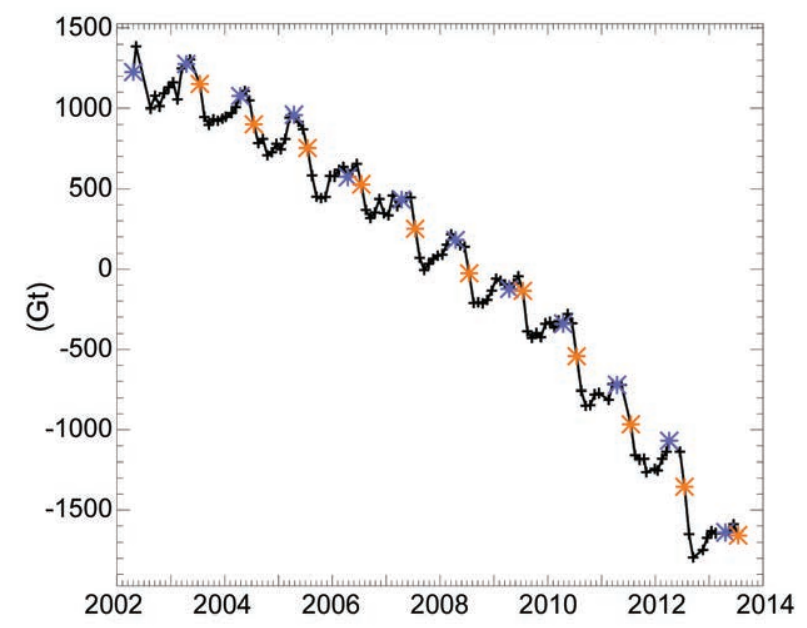

FIG. 5.25. Monthly changes in the total mass (Gt) of the Greenland Ice Sheet estimated from GRACE measurements since 2002. Blue and orange asterisks denote Apr and Jul values, respectively. Black asterisks denote all other months. Total ice mass change estimates from GRACE for summer 2013 are unavailable because the K-band ranging system was switched off during Aug and Sep to preserve battery life. The uncertainty in the mass loss estimate between Apr 2012 and Apr 2013, $\pm 100 \mathrm{Gt} \mathrm{rr}^{-1}$, is due to scatter in the data; estimates of leakage from imperfectly modeled signals external to the ice sheet; errors in the correction for glacial isostatic rebound; and uncertainty in the scaling factor used to correct for the limited horizontal resolution of GRACE. Velicogna and Wahr (2013) discuss uncertainties in GRACE estimates of polar ice sheet mass.

k. Lake ice-C. R. Duguay, L. C. Brown, K.-K. Kang, and H. Kheyrollah Pour

Lake ice is a sensitive indicator of climate variability and change. Lake ice phenology, which includes freeze-up (ice-on) and break-up (ice-off) dates, and ice cover duration, are largely influenced by air temperature changes and are, therefore, robust indicators of regional climate conditions (Duguay et al. 2006; Kouraev et al. 2007). Long-term trends in groundbased observational records reveal increasingly later freeze-up and earlier break-up dates, closely corresponding to increasing air temperature trends, but with greater sensitivity at the more temperate latitudes (Brown and Duguay 2010; Prowse et al. 2011). Broad spatial patterns in these trends are also related to major atmospheric circulation patterns originating from the Pacific and Atlantic Oceans, e.g., the El Niño-La Niña/Southern Oscillation, the Pacific North American pattern, the Pacific decadal oscillation, and the North Atlantic Oscillation/Arctic Oscillation (Bonsal et al. 2006; Prowse et al. 2011).

Despite the robustness of lake ice as an indicator of climate change, a dramatic reduction in ground- based observations has occurred globally since the 1980s (Lenormand et al. 2002; Duguay et al. 2006; IGOS 2007; Jeffries et al. 2012). Consequently, satellite remote sensing has assumed a greater role in observing lake ice phenology (Latifovic and Pouliot 2007; Brown and Duguay 2012; Kropáček et al. 2013; Surdu et al. 2014).

Freeze-up (FU) in 2012/13 occurred earlier than the 2004-12 average by $\sim 1-3$ weeks for most regions of the Arctic (Fig. 5.26a). Notable exceptions include Lakes Ladoga and Onega (western Russia) and lakes of smaller size in southern Norway and adjacent areas of Sweden ( 4-5 weeks earlier). Arctic-wide, few lakes experienced later FU than normal ( 1-2 weeks later); they were clustered mainly throughout northern Quebec, the northwest Canadian Arctic, northern Finland, and the adjacent areas of Russia, with lakes in a small, localized region of southern Sweden experiencing notably later FU than normal ( 2-5 weeks). This is in contrast to the 2011/12 ice season when FU occurred almost a full month later for most lakes located in the southern portion of northern Europe and part of the central portion of Arctic Canada (i.e., Great Slave Lake and Lake Athabasca regions; Duguay et al. 2013).

Break-up (BU) dates in 2013 occurred 1-3 weeks earlier than the 2004-12 average over much of the Arctic, with the exception of Baffin and Ellesmere Islands in Canada ( 1-4 weeks later), consistent with cooler-than-normal spring and summer temperatures in the high Canadian Arctic (see Figs. 5.2b,c), and the southern part of Scandinavia and western Russia ( 1-5 weeks later; Fig. 5.26b). Lakes showing the largest BU anomalies with earlier dates ( 3-4 weeks earlier) in 2013 are found in Siberia, consistent with spring-time positive air temperature anomalies and early snow cover loss (see sections $5 \mathrm{~b}$ and $5 \mathrm{~h}$ ). Breakup was also particularly early (by $\sim 2-3$ weeks) in the western Hudson Bay and Victoria Island regions of Canada. Earlier BU anomalies of the same magnitude were reported throughout Siberia in 2012 (Duguay et al. 2013). In general, the spatial pattern of ice cover duration (ICD; Fig. 5.26c) anomalies followed closely that of BU anomalies. ICD for 2012/13 was shorter by $~ 1-4$ weeks in regions adjacent to Hudson Bay, as well as in the western section of the Canadian Arctic Archipelago (CAA), northern Alaska, Siberia, and northern Scandinavia. ICD was longer by $\sim 1-4$ weeks for Baffin Island, most parts of central to western Arctic Canada, southern Alaska, western Russia, and southern Scandinavia. Exceptions included: (1) Canadian lakes Amadjuak and Nettilling (the largest 

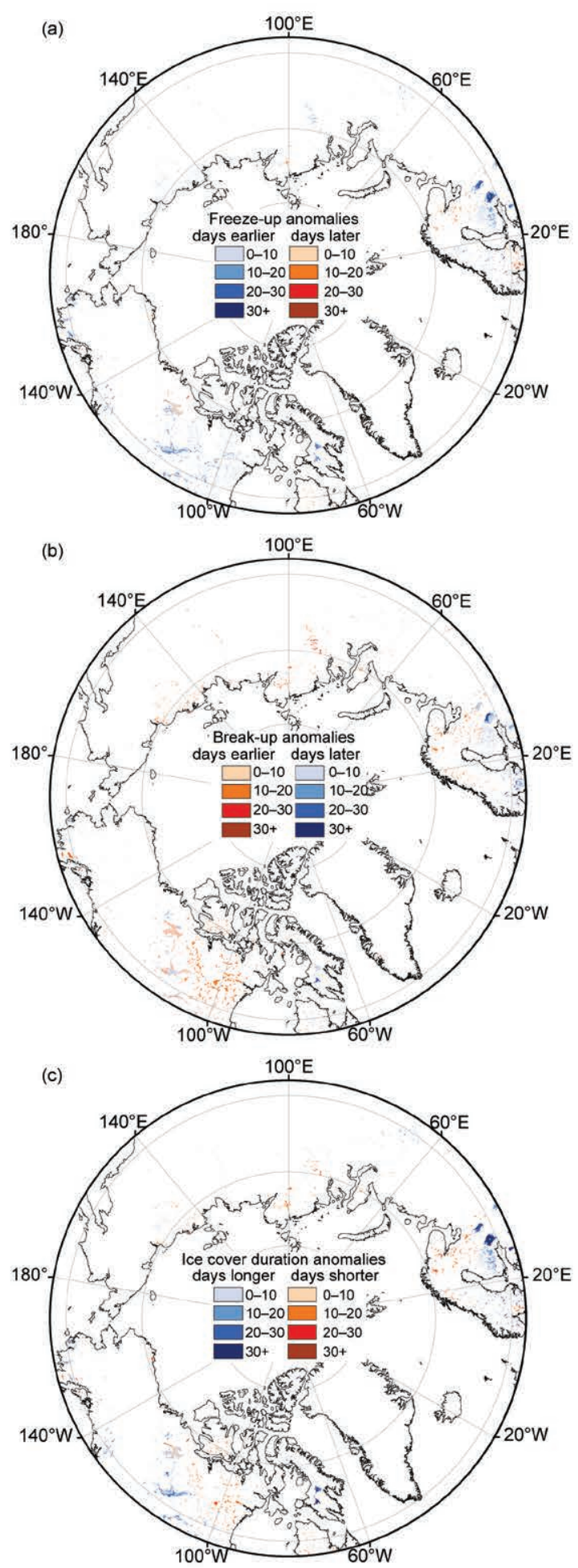

Fig. 5.26. (a) Freeze-up, (b) break-up, and (c) ice cover duration anomalies (in days) in the 2012/13 ice season relative to the 2004-12 average. Data are from the NOAA IMS (Helfrich et al. 2007) 4-km product, which incorporates a wide variety of satellite imagery, derived mapped products, and surface observations. Freeze-up and break-up dates, and ice duration were derived at the pixel level from this product. lakes of Baffin Island) and Lake Hazen on Ellesmere Island, which experienced longer ICD by $30-70$ days; and (2) north European Lakes Onega and Ladoga (western Russia) by $\sim 30-60$ days, as well as smaller lakes to their south, and lakes in southern Norway. ICD for these smaller Russian and Norwegian lakes was longer by $\sim 50-80$ days in $2012 / 13$ compared to the 2004-12 average.

I. Terrestrial permafrost—V. E. Romanovsky, S. L. Smith, H. H. Christiansen, N. I. Shiklomanov, D. A. Streletskiy, D. S. Drozdov, G. V. Malkova, N. G. Oberman, A. L. Kholodov, and S. S. Marchenko

Permafrost is defined as soil, rock, and any other subsurface earth material that exists at or below $0^{\circ} \mathrm{C}$ for two or more consecutive years. On top of the permafrost is the active layer, which thaws during the summer and freezes again the following winter. Average annual temperature of permafrost and the thickness of the active layer are good indicators of changing climate (Smith and Brown 2009). Increasing permafrost temperatures and active layer thickness caused by climate warming affect the stability of the northern ecosystems and infrastructure, and are predicted to cause the release of carbon into the atmosphere in the form of carbon dioxide $\left(\mathrm{CO}_{2}\right)$ and methane $\left(\mathrm{CH}_{4}\right.$; see section 5e). Here, permafrost temperatures and active layer thickness are reported for Alaska, Canada, Russia, and the Nordic region.

\section{I) Permafrost temperature}

In 2013, new record high temperatures at 20-m depth were measured at some permafrost observatories on the North Slope of Alaska (hereafter North Slope) and in the Brooks Range (Fig. 5.27a), where measurements began in the late 1970s and early 1980s (Fig. 5.27b). Changes in permafrost temperatures at 20-m depth typically lag about one year behind the changes in surface temperatures. The $20-\mathrm{m}$ temperatures in 2013 were $0.03^{\circ} \mathrm{C}$ higher than in 2012 at West Dock and Deadhorse (Fig. 5.27b) on the North Slope and $0.06^{\circ} \mathrm{C}$ higher at Coldfoot (Fig. 5.27c) in the southern foothills of the Brooks Range. Permafrost temperatures in 2013 at the other North Slope sites were similar to those in 2012, except at Happy Valley where they were $0.06^{\circ} \mathrm{C}$ lower. Temperature at $20-\mathrm{m}$ depth has increased between $0.28^{\circ}$ and $0.47^{\circ} \mathrm{C}$ decade $^{-1}$ since 2000 on the North Slope (Fig. 5.27b). Permafrost temperatures in Interior Alaska (Fig. 5.27a) continued to decrease in 2013 (Fig. 5.27c), a cooling that is due to a slight decrease in mean annual air temperature and lower than normal snow depth since 2007. Consequently, temperatures in 2013 at 
(a)

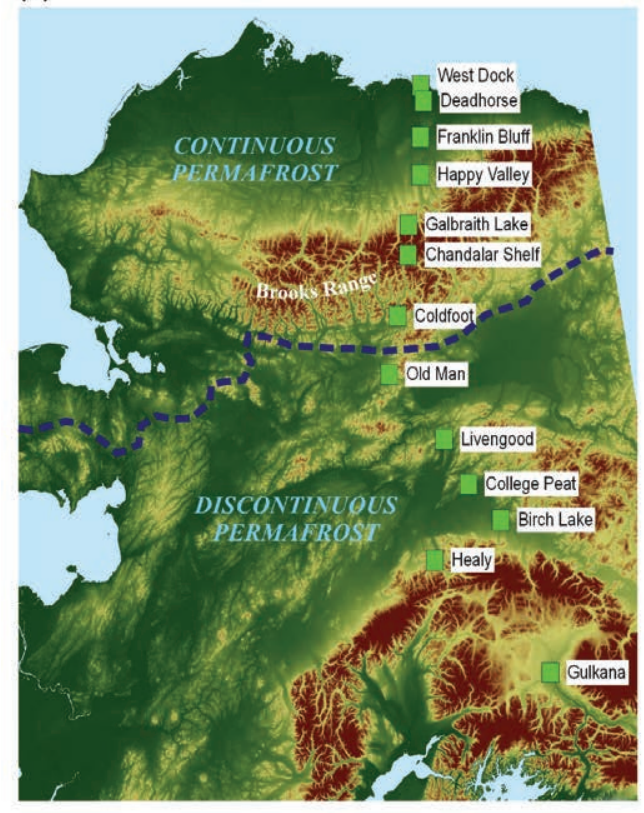

(b)

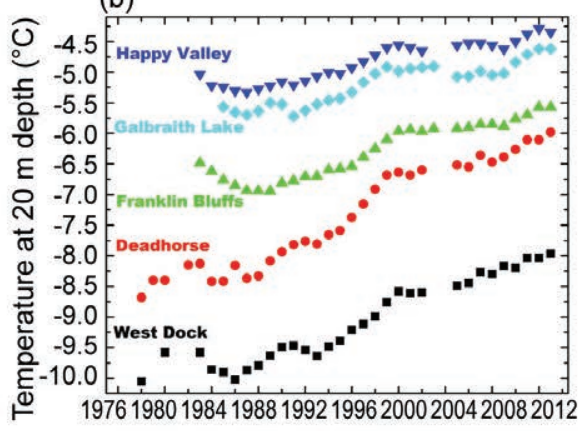

(c)

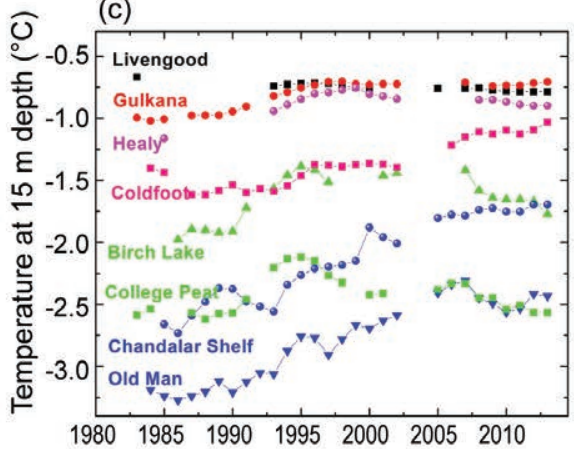

Fig. 5.27. (a) Map of Alaska showing the continuous and discontinuous permafrost zones (separated by the broken blue line) and locations of permafrost temperature measurement sites along a north-south transect. Time series of mean annual temperature $\left({ }^{\circ} \mathrm{C}\right)$ at depths of (b) $20 \mathrm{~m}$ and (c) $15 \mathrm{~m}$ below the surface at the measurement sites (updated from Romanovsky et al. 2012).

some sites in Interior Alaska were lower than those located farther north, e.g., temperatures at College Peat and Birch Lake are now lower than at Old Man and Chandalar Shelf in the Brooks Range (Fig. 5.27).

In 2012/13, temperatures in the upper $25 \mathrm{~m}$ of ground at Alert, northernmost Ellesmere Island, Canada, were among the highest recorded since measurements began in 1978 (Fig. 5.28). At a depth of $15 \mathrm{~m}$ in borehole $\mathrm{BH} 5$, temperature has increased by $\sim 1.4^{\circ} \mathrm{C}$ decade- since $^{-1000}$, which is almost $1^{\circ} \mathrm{C}$ higher than the rate for the entire record. Even at a depth of $24 \mathrm{~m}$, temperature has increased since 2000 at a rate approaching $1^{\circ} \mathrm{C}$ decade $^{-1}$. It should be noted, however, that over the last two years, the rate of temperature increase has slowed and there has been even a slight cooling at $15-\mathrm{m}$ depth; this is likely a response to a decrease in air temperatures between 2010 and 2012. Temperatures in the warm permafrost in the central Mackenzie River valley in northwestern Canada continue to increase, but at a much slower rate that has slowed further in the last decade (Fig. 5.28). At depths of 10-12 m, the permafrost temperature at Norman Wells and Wrigley has risen by $0.07^{\circ}-0.2^{\circ} \mathrm{C}$ per decade since 2000 . A recent study by James et al. (2013) found that significant degradation of permafrost has occurred since 1964 along the Al-

aska Highway corridor in the southern Yukon and northern British Columbia. As a result, the southern limit of permafrost appears to have shifted northward by at least $25 \mathrm{~km}$.

Permafrost temperature has increased by $1^{\circ}-2^{\circ} \mathrm{C}$ in northern Russia during the last 30-35 years (Romanovsky et al. 2010b), similar to that observed in northern Alaska and the Canadian high Arctic. In the Polar Ural, for example, temperatures at $15-m$ depth have increased by $\sim 0.5^{\circ} \mathrm{C}$ decade $^{-1}$ since the late 1980 s at colder permafrost sites (Fig. 5.29, sites ZS-124, R-92, and

R57). Less warming has been observed at warm permafrost sites and a slight cooling has occurred since 2009 (Fig. 5.29, sites ZS-124 and KT-16a).

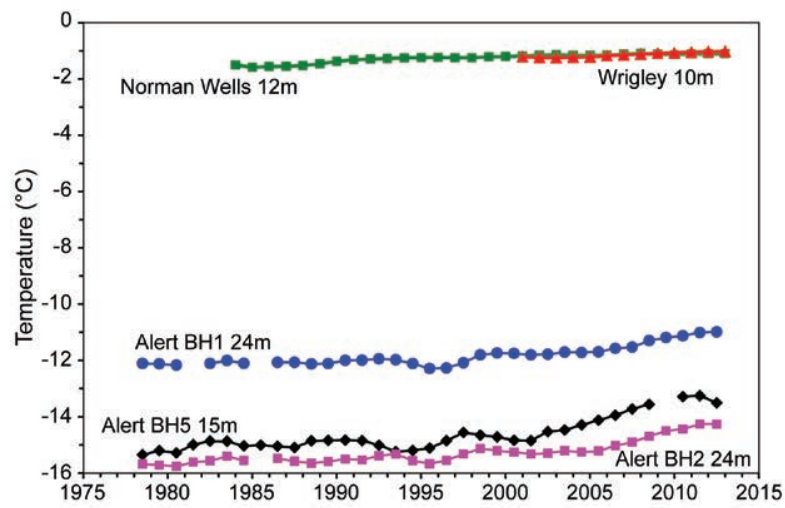

Fig. 5.28. Time series of mean annual permafrost temperatures $\left({ }^{\circ} \mathrm{C}\right)$ at $10-\mathrm{m}$ and $12-\mathrm{m}$ depth at Wrigley (red squares) and Norman Wells (green squares) in the discontinuous, warm permafrost of the central Mackenzie River Valley, Northwest Territories, Canada, and at 15-m (black diamonds) and 24-m (two boreholes: blue circles and pink squares) depth in continuous, cold permafrost at Alert, Nunavut, Canada (updated from Smith et al. 2010, 2012). The method described in Smith et al. (2012) was used to address gaps in the data and produce a standardized record of mean annual ground temperature. 


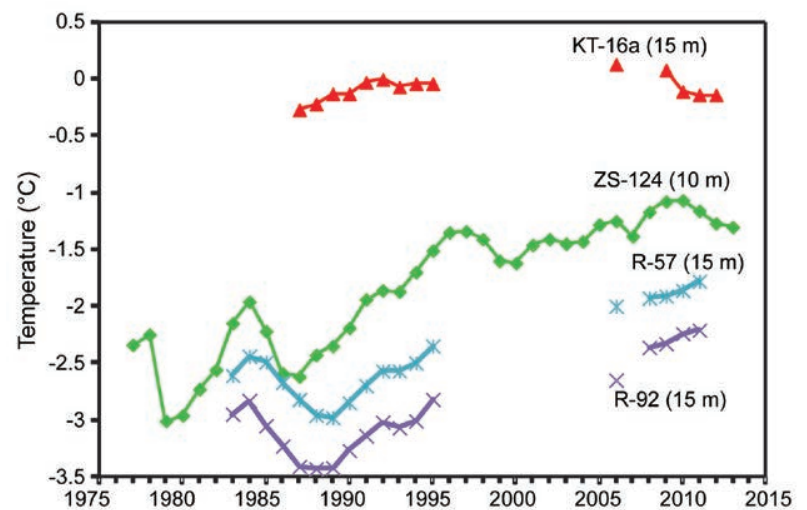

FIG. 5.29. Time series of annually-averaged permafrost temperatures $\left({ }^{\circ} \mathrm{C}\right)$ at $10-\mathrm{m}$ and $15-\mathrm{m}$ depth at four research sites in the polar Ural, Russia.

There are limited long-term permafrost temperature records for the Nordic area. A few of these were initiated at the end of the 1990s and since then temperature has increased at rates of $0.4^{\circ}-0.7^{\circ} \mathrm{C}$ decade $^{-1}$ in the highlands of southern Norway, northern Sweden, and Svalbard, with the largest warming in Svalbard and in northern Scandinavia (Isaksen et al. 2011; Christiansen et al. 2010). In western Greenland, permafrost temperatures are relatively warm, from $-1^{\circ}$ to $-3^{\circ} \mathrm{C}$ (Christiansen et al. 2010). In eastern Greenland, the first full year of permafrost temperatures in 10 recently established boreholes (depth range of 2-18 m) were obtained in summer 2013 , and the permafrost temperature was found to be $-6^{\circ}$ to $-7^{\circ} \mathrm{C}$.

\section{2) ACtIVE LAYER THICKNESS}

Decadal trends in the active layer thickness (ALT) vary by region (Shiklomanov et al. 2012). In 2013, a majority of sites in Alaska reported higher ALT values relative to the 1995-2013 average, consistent with an exceptionally warm summer (see section $5 b$ ). On the North Slope, for example, ALT in 2013 was, on average, $11 \%$ higher than the 1995-2013 average of $0.47 \mathrm{~m}$. The 2013 average ALT is 6\% higher than in 2012 and on par with the 20-year maximum recorded in 1998. In Interior Alaska, ALT has been relatively unchanged since the maximum value reached in 2007, and 2013 values were slightly lower than in 2012. ALT in 2013 was similar to 2012 at sites on the Seward Peninsula, westernmost Alaska mainland.

A slight decrease in ALT in 2013 was observed in west Siberia a year after the highest values in the observational record were observed in 2012. This does not alter an observed thickening trend in west Siberia over the last six years. The 2013 ALT values are 8\% higher than the 1995-2013 mean of 1.1 m. A more or less continuous thickening of the active layer has been reported at locations in the Russian European North, although ALT in 2013 was 6\% lower than the record maximum of 2012. Central Siberian locations also report slightly lower ALT values in 2013 than in 2012. ALT in eastern Siberia in 2013 was similar to 2012, $10 \%$ lower than in 2011, and all sites had lower ALT than the 1996-2013 average of $0.64 \mathrm{~m}$. In 2013, ALT values in Chukotka (Russian Far East) were about 2\% higher than in 2012, marking a slight increase in ALT during 2011-13 following a sharp decline in 2008-10. 
SI42 | BAMF JULY 2014 
6. ANTARCTICA - R. L. Fogt and T. A. Scambos, Eds.

\section{a. Introduction-R. L. Fogt and T. A. Scambos}

The calendar year 2013 was in many ways a recordbreaking year for Antarctic climate, especially during the late winter through early spring (August-October). Figure 6.1 presents the annually-averaged surface pressure and temperature anomalies based on the ERA-Interim reanalysis. Over the year, above-average pressure was observed over the Antarctic continent and below-average pressure over the Antarctic Peninsula. This pressure pattern led to weaker-thanaverage circumpolar winds and warmer conditions across much of the continent during late winter and early spring (reflected in Fig. 6.1b).

Significant events during 2013 across Antarctica include:

- Above-average temperature and pressure during August-October across nearly the entire Antarctic continent, with many of these anomalies exceeding three standard deviations from the climatological mean;

- Record-high temperatures set at many locations in the Antarctic interior in August and September. Amundsen-Scott South Pole Station had a record-high annually-averaged temperature of $-47.4^{\circ} \mathrm{C}$, and monthly average high temperature records in August and September, with a new record maximum temperature of $-27.7^{\circ} \mathrm{C}$ recorded during September, based on observations starting in 1957;

- The highest total surface melt across Antarctica during the austral summer of 2012/13 since 2004/05;

- An above-average sea ice extent throughout 2013, with 116 new daily record high extents,

(a)

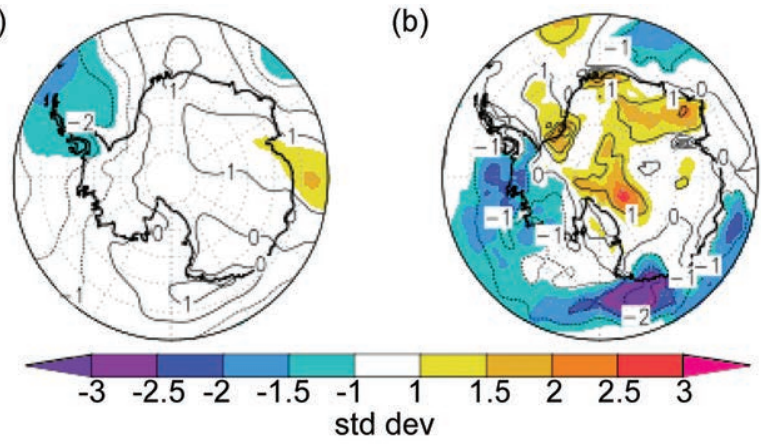

Fig. 6.I. 2013 Annually-averaged (a) surface pressure and (b) 2-m temperature anomalies based on the ERA-Interim reanalysis. The shading represents how many standard deviations the anomalies are from the 198I-2010 mean (color bar at bottom for scale). Contour interval is $\mathrm{I} \mathrm{hPa}$ for (a) and $\mathrm{I}^{\circ} \mathrm{C}$ for (b). especially during August-November. A new daily maximum sea ice area of 19.57 million $\mathrm{km}^{2}$ was reached on 1 October 2013;

- A smaller-than-average ozone hole area compared the last 20 years, due to a warmerthan-average spring stratosphere.

These features and other aspects of the 2013 Antarctic climate are described in more detail in the following sections.

\section{b. Atmospheric circulation - K. R. Clem, S. Barreira, R. L. Fogt, and T. A. Scambos}

The majority of 2013 was characterized by relatively short-lived anomalous atmospheric circulation patterns across Antarctica and the high southern latitudes. The year began with negative surface pressure and geopotential height anomalies over the polar cap (defined here as poleward of $60^{\circ} \mathrm{S}$ ) from late austral summer into the beginning of fall (January-March). A much stronger and opposite-sign circulation pattern emerged by late winter and spring ( $\mathrm{Au}-$ gust-October), where positive surface pressure and geopotential height anomalies dominated the polar cap, accompanied by well-above-average near-surface and tropospheric temperatures across continental Antarctica. The year ended (November-December) on a relatively quiet note with average pressure and near-average temperatures across the majority of continental Antarctica.

The circulation and temperature anomalies are examined in detail in Figs. 6.2 and 6.3. Figure 6.2 depicts a vertical cross section of monthly geopotential height anomalies (Fig. 6.2a) and temperature anomalies (Fig. $6.2 \mathrm{~b})$ over the polar cap $\left(60^{\circ}-90^{\circ} \mathrm{S}\right)$ extending from the troposphere into the stratosphere, and circumpolar $\left(50^{\circ}-70^{\circ} \mathrm{S}\right)$ averaged zonal wind anomalies (Fig. 6.2c). Based on Fig. 6.2, months of persistent, similar anomalies were combined, creating four periods within the year (Fig. 6.3).

January-March 2013 was characterized by increasingly negative surface pressure and tropospheric geopotential height anomalies over the polar cap (Figs. 6.2a and 6.3a). Farther equatorward, positive surface pressure anomalies were found in the middle southern latitudes (Fig. 6.3a). This atmospheric pattern was broadly characteristic of southern annular mode (SAM) positive conditions, and was reflected by positive SAM index values for January, February, and especially March. Above-average circumpolar zonal winds dominated the troposphere and stratosphere. In March, zonal wind anomalies were 1.5 standard deviations above the 1981-2010 monthly average 
(a)

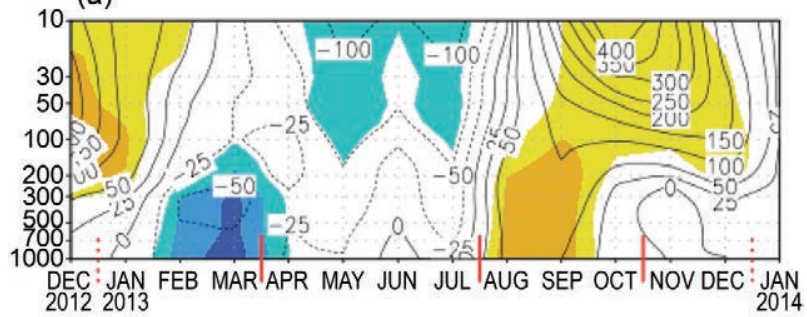

(b)

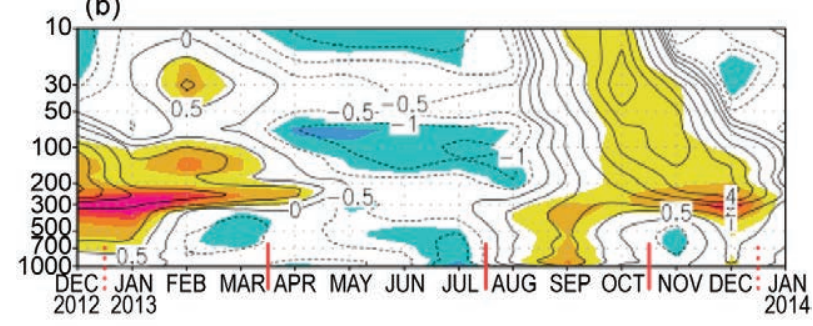

(c)

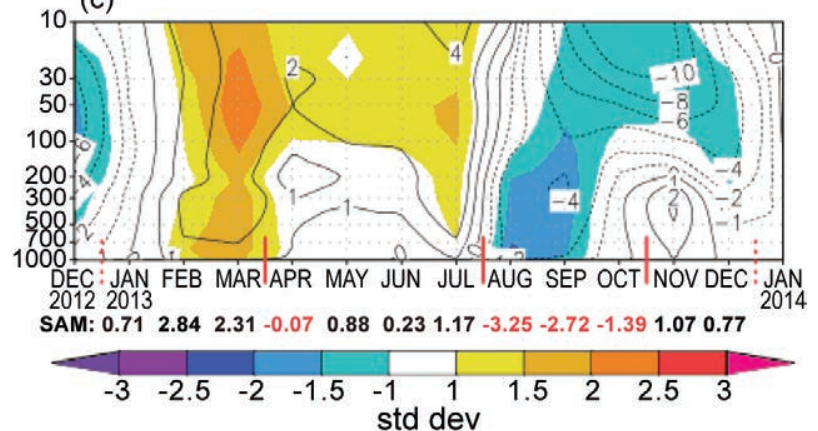

FIG. 6.2. Area-weighted averaged climate parameter anomalies for the southern polar region in 2013 relative to the $1981-2010$ period: (a) polar cap $\left(60^{\circ}-90^{\circ} \mathrm{S}\right)$ averaged geopotential height anomalies $(\mathrm{m})$; (b) polar cap averaged temperature anomalies $\left({ }^{\circ} \mathrm{C}\right)$; (c) circumpolar $\left(50^{\circ}-70^{\circ} \mathrm{S}\right)$ averaged zonal wind anomalies ( $\mathrm{m}$ $\left.s^{-1}\right)$. The shading represents standard deviations from the 198I-2010 mean. Red vertical bars indicate the four separate climate periods shown as spatial climate anomalies in Fig. 6.3; the dashed lines near Dec 2012 and Dec 2013 indicate circulation patterns wrapping around the calendar year. Primary contour interval is $50 \mathrm{~m}$ in (a), $1^{\circ} \mathrm{C}$ in (b), and $2 \mathrm{~m} \mathrm{~s}^{-1}$ in (c), respectively. Values for the SAM index are shown along the bottom in black and red. (Source: ERA-Interim reanalysis.)

in the entire atmospheric column (Fig. 6.2c). Nearsurface temperatures in the polar cap region were near average during January-March (Fig. 6.2b), due to offsetting regional surface temperature anomalies across Antarctica (warmer-than-average in West Antarctica and colder-than-average in East Antarctica; Fig. 6.3b). Above-average temperatures were found in the lower stratosphere and upper troposphere across the polar cap (Fig. 6.2b).

For April-July the stratosphere had higher zonal wind speeds ( $>1$ standard deviation above the 1981-2010 average) and relatively low temperatures
( $>1$ standard deviation below average at a few levels; Fig. 6.2b). In the South Pacific, a broad region of anomalous low surface pressure encompassed the Antarctic Peninsula and Bellingshausen Sea region, while a region of anomalous high surface pressure was present east of the Weddell Sea and centered along the Greenwich meridian (Fig. 6.3c). A narrow band of warm, onshore near-surface flow existed between these two features resulting in positive near-surface temperature anomalies over the Ronne Ice Shelf. Farther west, a cold, offshore near-surface flow dominated much of West Antarctica and the Amundsen and Ross Seas and resulted in below-average near- (a)

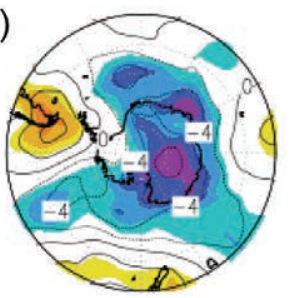

(c)

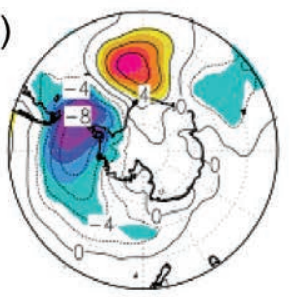

(e)

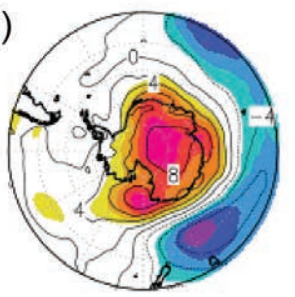

(g)

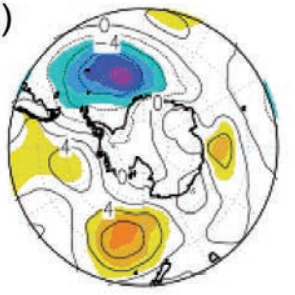

(b)

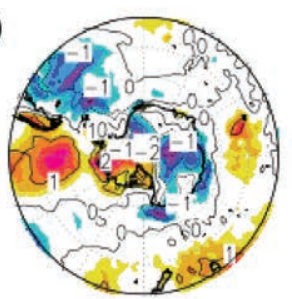

(d)

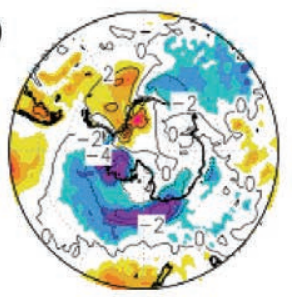

(f)

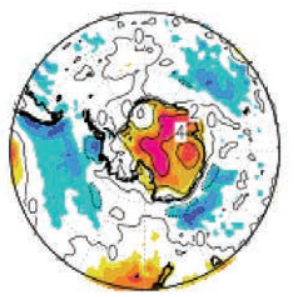

(h)

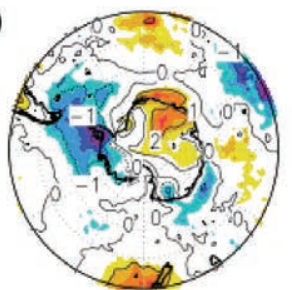

FIG. 6.3. (left) Surface pressure anomaly and (right) 2-m temperature anomaly contours [every $4 \mathrm{hPa}$ with an additional contour at $\pm 2 \mathrm{hPa}$ and every $2^{\circ} \mathrm{C}$, respectively, except for (b) and (h) at every $\left.1^{\circ} \mathrm{C}\right]$ relative to 198I-20I0 average for (a) and (b) Jan-Mar 2013; (c) and (d) Apr-Jul 2013; (e) and (f) Aug-Oct 2013; (g) and (h) Nov-Dec 2013. The shaded regions correspond to standard deviations from the 198I-2010 average. (Source: ERA-Interim reanalysis.) 
surface temperatures (Fig. 6.3d). Over the polar cap, negative geopotential height and temperature anomalies occurred in the upper stratosphere during April-July (Fig. 6.2a,b).

An abrupt shift in overall circulation occurred in late July-early August, ushering in a period of positive geopotential height anomalies over the polar cap and positive temperature anomalies throughout the troposphere that lasted through October (Figs. $6.2 \mathrm{a}, \mathrm{b}, 6.3 \mathrm{e}, \mathrm{f})$. Both anomalies were on the order of 1.5 standard deviations above the climatological mean (Fig. 6.2a,b). The SAM index shifted to below -2.5 in August and September, from mildly positive SAM patterns in July. Farther equatorward, the August-October average surface pressure was below average across the middle latitudes in the Eastern Hemisphere. The weakened pressure gradient between the polar cap and the middle latitudes resulted in negative circumpolar zonal wind anomalies, which were present throughout both the troposphere and the stratosphere (Fig. 6.2c). The 2013 August-October average surface pressure anomalies were $6-8 \mathrm{hPa}$ above average for nearly all of Antarctica (2-3 standard deviations above the climatological average; Fig. 6.3e). The pattern of negative surface pressure anomalies in the middle latitudes of the Eastern Hemisphere explains the strongly negative monthly SAM index values and the negative circumpolar zonal wind anomalies in Fig. 6.2c. The weaker circumpolar zonal winds (increased meridional flow) surrounding Antarctica at this time were associated with instances of poleward-propagating warm-air intrusions across Antarctica. As a result, the August-October average near-surface temperatures were $2^{\circ}$ to $4^{\circ} \mathrm{C}$ above average (more than 3 standard deviations above average in some locations), especially in interior East Antarctica and the South Pole, as discussed in section 6c. Elsewhere across Antarctica, temperatures were above average in all regions except portions of coastal West Antarctica and the Antarctic Peninsula (Fig. 6.3f).

Positive geopotential height and temperature anomalies persisted in the upper troposphere and stratosphere over the polar cap during November and December, as did lower-level negative circumpolar zonal wind anomalies (Fig. 6.2c). Near the surface, high pressure anomalies off the southeastern coast of New Zealand produced above-average temperatures along the east coast of the country (Fig. 6.3g,h). In contrast, a broad region of low pressure anomalies in the Weddell Sea region brought a cold, southerly flow onto the Antarctic Peninsula for November and December, resulting in below-average temperatures across the entire Antarctic Peninsula (that persisted into the new year). Lastly, anomalous high pressure was present off the coast of East Antarctica centered around $90^{\circ} \mathrm{E}$, which produced slightly-above-average temperatures on the western side of coastal and interior East Antarctica and below-average temperatures on the eastern side of coastal East Antarctica.

\section{c. Surface manned and automatic weather station} observations - S. Colwell, L. M. Keller, M. A. Lazzara, and A. Setzer The overall circulation anomalies outlined in section $6 \mathrm{~b}$ are reflected in observations at staffed and automatic weather stations (AWS). A map of key locations described in this section and throughout the chapter is displayed in Fig. 6.4. Climate data from four staffed stations (Rothera, Halley, Amundsen-Scott, and Casey) and two AWS (Ferrell and Byrd) that reflect regional conditions are displayed in Fig. 6.5.

Monthly average temperatures at Rothera station on the western side of the Antarctic Peninsula were warmer than average for the first half of the year and then colder than average for the second half compared to the 1981-2010 average (Fig. 6.5a). To the north of the Antarctic Peninsula, January and February were colder than average (reflected in Fig. 6.3a), but then followed a similar trend to Rothera. Temperatures at Marambio station on the eastern side of the Peninsula were warm in March and April (Fig. 6.3d), but about average for the rest of the year. The Antarctic Peninsula region did experience low pressures again during June (Fig. 6.5a), although the average values were not quite as low as the values in June 2011. Using a merged and adjusted record of stations across the northern Antarctic Peninsula (Base G, Bellingshausen, Deception Island, Ferraz, and the Polish station Arctowski),

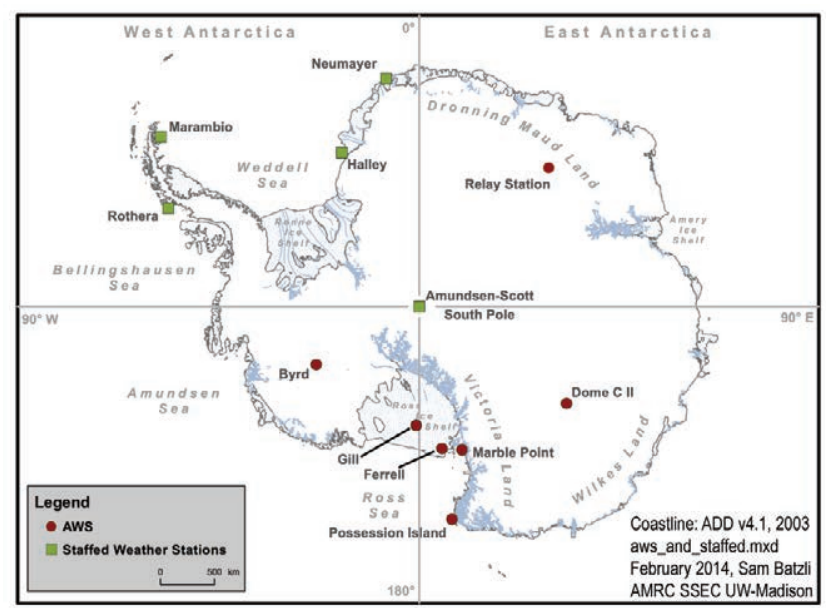

Fig. 6.4. Locations of automatic and staffed Antarctic weather stations described in Chapter 6. 
(a)

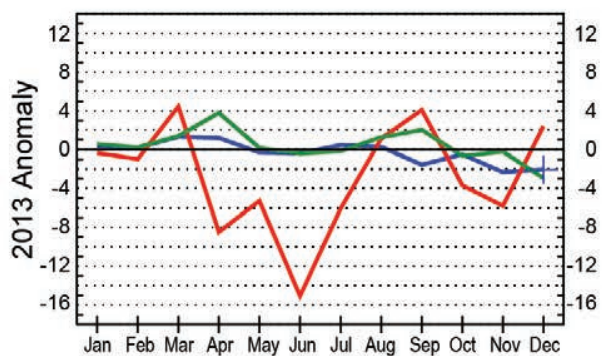

(c)

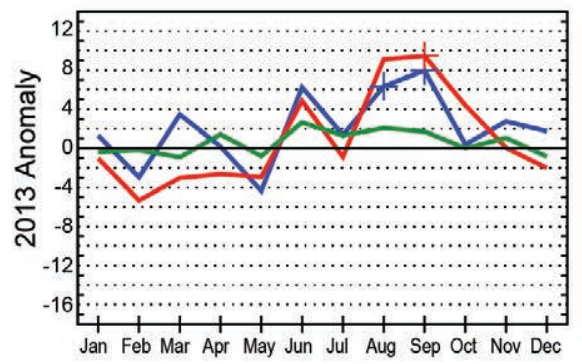

Ferrell

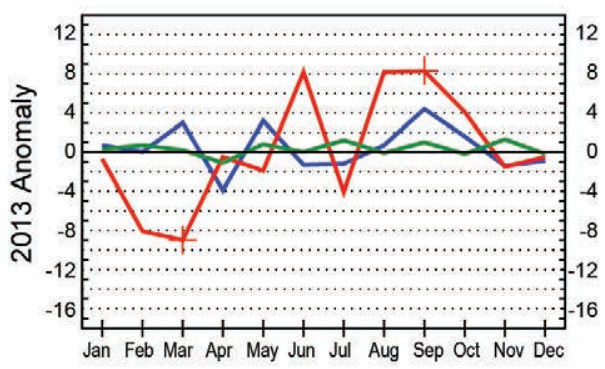

(b)

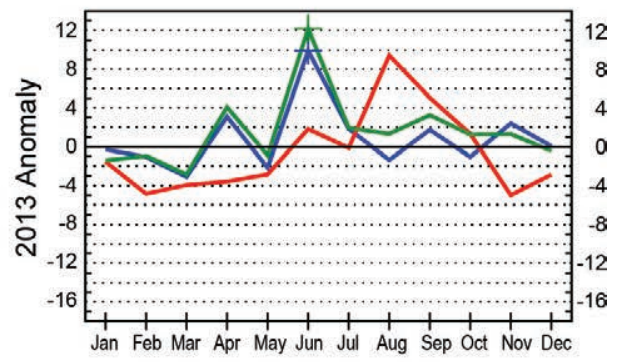

(d)

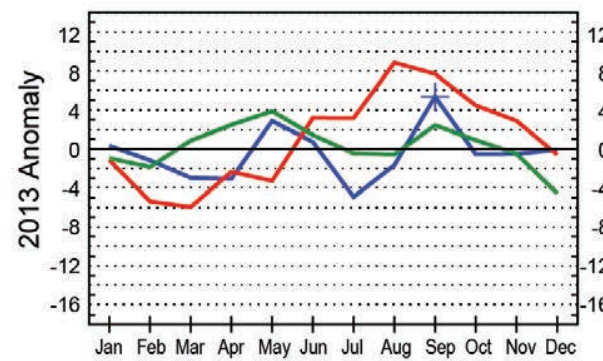

(f)

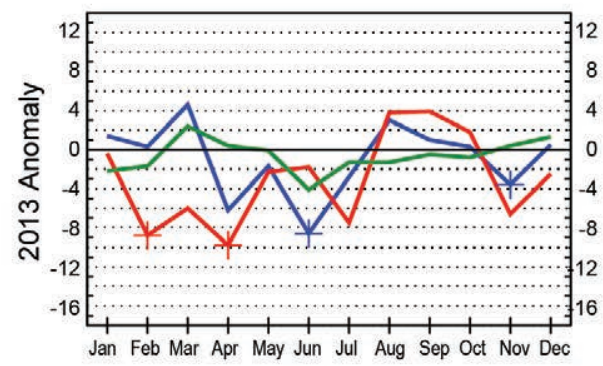

Wind Speed $\left(\mathrm{m} \mathrm{s}^{-1}\right)$

Byrd
Temperature $\left({ }^{\circ} \mathrm{C}\right)$

Pressure $(\mathrm{hPa})$

FIG. 6.5. (a)-(f) 2013 Antarctic climate anomalies at six representative stations [four staffed (a)-(d), and two automatic(e)-(f)]. Monthly mean anomalies for temperature $\left({ }^{\circ} \mathrm{C}\right), \mathrm{MSLP}(\mathrm{hPa})$, and wind speed $\left(\mathrm{m} \mathrm{s}^{-1}\right)$ are shown, + denoting record anomalies for a given month at each station in 2013. Climatological data start in 1957 for Halley and Amundsen-Scott, 1960 for Casey, 1976 for Rothera, and 198I for Ferrell and Byrd. All calculations based on 198 I-2010 averages.

2013 was another cool year, similar to 2007,2009 , 2011, and 2012, contributing to a trend of $-0.09^{\circ} \mathrm{C}$ decade $^{-1}$ over the past 30 years in this merged record. Considering the last 18 years (starting in 1996), this trend is $-0.6^{\circ} \mathrm{C}$ decade $^{-1}$, in contrast to the trend from 1944 to 2013 of $+0.19^{\circ} \mathrm{C}$ decade ${ }^{-1}$. The austral summer of 2012/13 (December-February) matched the previous low values of 1991 and 1967 as one of the coolest in the region; this tendency continued in December 2013. Only fall (March-May) 2013 had above-average air temperatures, similar to those of 2003, 2004, 2008 , and 2009. As suggested in section $6 \mathrm{~b}$, the low air temperatures resulted mainly from an increase in the winds from the northeast through southern sectors, accompanied by a reduction of the winds in the other sectors, particularly north and northwest. Sea level pressure was about 2 $\mathrm{hPa}$ below average for the region, maintaining a downward trend starting in 2005, with the exception of 2011. The combined stations at the far northern part of the Antarctic Peninsula had the record lowest annual-average pressure in 2013 of $988.4 \mathrm{hPa}$; the pressure in June 2013 was particularly low in these stations (12.6 hPa below average).

In the Weddell Sea region, the monthlyaveraged temperatures at Halley and Neumayer stations were about average with the exception of June at Halley where a recordhigh monthly temperature of $-17.4^{\circ} \mathrm{C}$ was reported, $9.9^{\circ} \mathrm{C}$ above the long-term average (Fig. 6.5b; reflected also in Fig. 6.3d). Halley also recorded a monthly mean wind speed of $13.1 \mathrm{~m} \mathrm{~s}^{-1}$ in June, which was $6.5 \mathrm{~m} \mathrm{~s}^{-1}$ above average. Record-high monthly mean pressure values were recorded at Neumayer in August and September. Around the coast of East Antarctica all of the Australian stations (Casey, Davis, and Mawson) experienced warm temperatures in September and high pressure in August (Fig. 6.5d), while over the rest of the year the stations showed different patterns of warm and cold months.

Amundsen-Scott South Pole Station recorded its highest annual average temperature ever of $-47.4^{\circ} \mathrm{C}$ based on observations starting in 1957; recordbreaking monthly average temperatures in August and September of $-53.3^{\circ} \mathrm{C}$ and $-51.2^{\circ} \mathrm{C}$, respectively (Fig. 6.5c; reflected in Fig. 6.3f), contributed to this annual record. The maximum temperature recorded 
in the month of September $\left(-27.7^{\circ} \mathrm{C}\right)$ also broke the long-term record. Monthly-averaged pressure values were close to the long-term averages except for high values recorded in August and September (Fig. 6.3e). For the high polar plateau, Dome C II had a colder July with average pressure being lower than average, especially in January and July, for all months except November. Relay Station had record-high monthly average temperatures for January, June, August, September, and November (from $+4.2^{\circ}$ to $+9.5^{\circ} \mathrm{C}$ above average) with all the other months except May warmer than average. Lower-than-average pressures were reported for late fall and early winter while late winter had higher-than-average pressures. Wind speeds were record low in February while the rest of the year was above average, with April and September reporting record high speeds $\left(8.6\right.$ and $9.7 \mathrm{~m} \mathrm{~s}^{-1}$, respectively).

On the Ross Ice Shelf, Ferrell's average temperature for September was $4.4^{\circ} \mathrm{C}$ above average (Fig. 6.5e). Lower-than-average monthly pressure in February and March (9.0 hPa below average) was replaced by higher-than-average pressure in June, August, and September, which had a record-high average pressure ( $8.3 \mathrm{hPa}$ above average). Marble Point, at the western edge of the ice shelf, also followed this distribution of temperature and pressure with the lower-than-average pressure in February tying the record for that month. Gill had warmer-than-average temperatures for late summer and fall while April and June were $6.8^{\circ}$ and $7.4^{\circ} \mathrm{C}$ below average, respectively. Record-low pressure was recorded in February and March (around $10 \mathrm{hPa}$ lower than average), with higher-than-average pressure in June, August, and September.

In West Antarctica, Byrd had a warmer-thanaverage March and colder-than-average April with record-cold monthly averages for June and November $\left(-8.6^{\circ}\right.$ and $-3.6^{\circ} \mathrm{C}$; Figs. $\left.6.5 \mathrm{f}, 6.3 \mathrm{~d}\right)$. Record-low average monthly pressure was reported for February and April (-8.8 and $-9.8 \mathrm{hPa}$ below average) with lower-than-average pressure for March, July, and November. Higher-than-average pressure occurred in August and September. February set a record for low wind speed.

Near the Ross Sea at Cape Adare, Possession Island had warmer-than-average winter temperatures, and a colder-than-average April. Record-low average pressure occurred in February and March, switching to higher-than-average pressure for winter and early spring (July had no data reported).
In general, most of the continent, with the exception of the Antarctic Peninsula, saw higher-thanaverage to record high temperatures and pressures for August and September (reflected in Figs. 6.3e,f). The area from West Antarctica across the Ross Ice Shelf experienced record to near-record low pressures for February and March (Fig. 6.3a).

\section{d. Net precipitation $(P-E)-D$. H. Bromwich and S.-H. Wang}

Precipitation minus evaporation/sublimation $(P-E)$ closely approximates the surface mass balance over Antarctica, except for the steep coastal slopes (e.g., Bromwich et al. 2011; Lenaerts and van den Broeke 2012). Precipitation variability is the dominant term for $P-E$ changes at regional and larger scales over the Antarctic continent. Precipitation and evaporation/sublimation fields from the Japanese Reanalysis (JRA; Onogi et al. 2007) were examined to assess Antarctic net precipitation $(P-E)$ behavior for 2013. The evaporation in JRA was calculated from the surface latent heat flux variable. In comparison to other long-term global reanalyses (e.g., NCEP1 and NCEP2), JRA has higher model resolution, both horizontally and vertically, greater observational usage, and a more advanced model configuration (Bromwich et al. 2007). Nicolas and Bromwich (2011) show that the reliability of JRA $P-E$ is highly ranked in relation to other global reanalyses.

Figure 6.6 shows the JRA 2013 and 2012 annual anomalies of $P-E$ and mean sea level pressure (MSLP) departures from the 1981-2010 average. In general, annual $P-E$ anomalies over the high interior of the continent are small (within $\pm 50 \mathrm{~mm} \mathrm{yr}^{-1}$ ) and larger anomalies can be observed along the coast, consistent with the low and high snow accumulation in these regions. The weak $P-E$ anomalies between $120^{\circ} \mathrm{W}$ and $170^{\circ} \mathrm{E}$ in 2012 changed to large negative anomalies in 2013. The annual $P-E$ anomaly triplet (negative-positive-negative) between Wilkes Land and Victoria Land (between $90^{\circ}$ and $170^{\circ} \mathrm{E}$ ) in 2012 was still present in 2013. However, both negative anomalies are slightly stronger and the positive anomaly over Adélie Land (near $140^{\circ} \mathrm{E}$ ) is much weaker. The $P-E$ anomalies over Dronning Maud Land (between $0^{\circ}$ and $50^{\circ} \mathrm{E}$; Fig. 6.4) in 2012 are slightly enhanced in 2013. The negative $P-E$ anomaly center over the Weddell Sea in 2012 was replaced by a positive anomaly center in 2013. Both sides of the Antarctic Peninsula had similar 2013 anomaly patterns to 2012, with positive (negative) anomalies along east (west) of the peninsula. However, the magnitudes of anomalies are increased but 

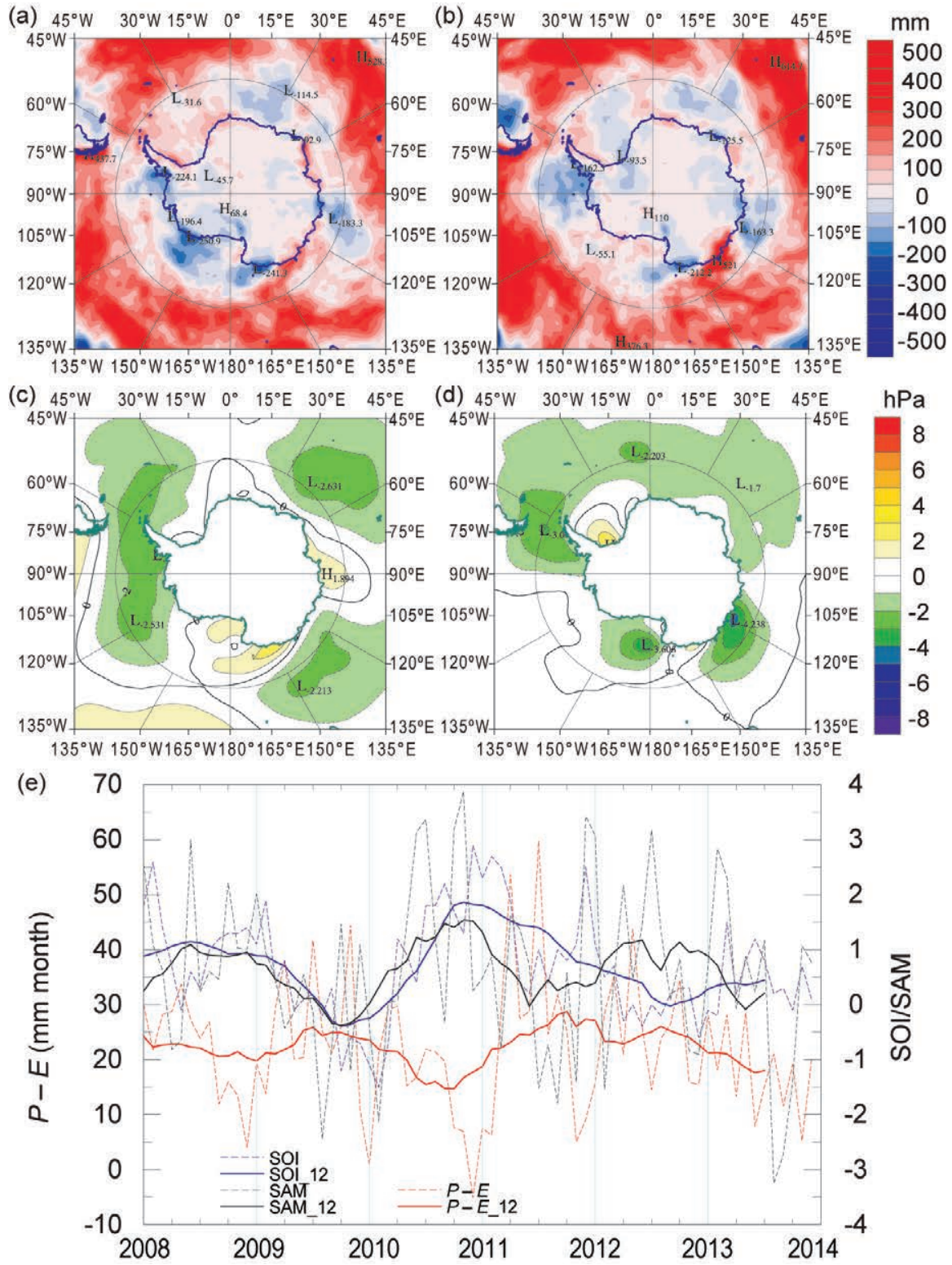

FIG. 6.6. Annually-averaged (a) $2013 P-E$ anomalies (mm); (b) $2012 P-E$ anomalies (mm); (c) 2013 MSLP anomalies (hPa); and (d) 2012 MSLP anomalies (hPa) with respect to the $198 \mathrm{I}-2010$ average. (e) Monthly total $P-E(\mathrm{~mm}$; red) for the West Antarctic sector bounded by $75^{\circ}-90^{\circ} \mathrm{S}, 120^{\circ} \mathrm{W}-180^{\circ}$, along with the SOl (blue, from NOAA Climate Prediction Center) and SAM [black, from Marshall (2003)] index since 2008. Centered annual running means are plotted as solid lines. along East Antarctic coast (between $150^{\circ} \mathrm{W}$ and $140^{\circ} \mathrm{E}$ ) during 2013 produced stronger offshore flow and less precipitation over the Ross Sea and the Ross Ice Shelf. The negative anomaly center near Casey $\left(\sim 120^{\circ} \mathrm{E}\right)$ shifted northward away from the coast. A positive anomaly center was observed near $90^{\circ} \mathrm{E}$. Both circulation patterns resulted in less precipitation in the coastal region between $140^{\circ}$ and $100^{\circ} \mathrm{E}$ than 2012. The positive MSLP anomaly over the Ronne Ice Shelf and the Weddell Sea was weaker in 2013. Less blocking results in higher inflow and produces greater precipitation anomalies in this area. The seasonal $P-E$ anomalies (not shown) also had a large influence on regional annual $P-E$ anomalies especially during austral winter (JJA) in 2013. The largest seasonal (JJA) impact of 2013 annual anomalies was found between the Antarctic Peninsula and the Ross Ice Shelf (between $60^{\circ} \mathrm{W}$ and $170^{\circ} \mathrm{E}$ ), where they contributed the extents were smaller compared to 2012, especially the negative anomalies over the Bellingshausen Sea (between $60^{\circ}$ and $110^{\circ} \mathrm{W}$ ).

These annual $P-E$ anomaly features are generally consistent with the average atmospheric circulation implied by the MSLP anomalies (Figs. 6.1a, 6.6c,d). In 2012, the MSLP anomalies surrounding Antarctica were more localized than 2013. The negative anomaly center in 2012 over the Drake Passage $\left(\sim 75^{\circ} \mathrm{W}\right)$ expanded to between $15^{\circ}$ and $140^{\circ} \mathrm{W}$. The combination of positive MSLP anomalies over the Ross Sea and more than $60 \%$ of the total annual $P-E$ anomalies in this region. This agrees with the strengthened circulation anomaly patterns over the Drake Passage (negative) and the Ross Sea (positive) during those winter months (Fig. 6.3c).

Earlier studies show that almost half of the moisture transport into Antarctica occurs in the West Antarctic sector and there is large interannual variability associated with extremes of ENSO (e.g., Bromwich et al. 2004) and SAM events (e.g., Fogt et al. 2011). Beginning in late 2012, the negative MSLP 
anomalies over the Ross Sea shifted away from the coast and became positive anomalies (not shown). These anomaly features are consistent with simultaneously weak La Niña and negative SAM index values. Figure 6.6e shows the time series of average monthly total $P-E$ over Marie Byrd Land-Ross Ice Shelf $\left(75^{\circ}-90^{\circ} \mathrm{S}, 120^{\circ} \mathrm{W}-180^{\circ}\right)$ and monthly Southern Oscillation index (SOI) and SAM index (with 12-month running means). It is clear that, as the SOI was near zero during 2013, the SAM became the dominant factor modulating precipitation in this region, especially during austral winter months.

\section{e. 20/2/13 Seasonal melt extent and duration-L. Wang,}

\section{H. Liu, S. Wang, and S. Shu}

Antarctic surface melt during the 2012/13 austral year was estimated using the daily microwave brightness temperature (TB) data acquired by Special Sensor Microwave-Imager/Sounder (SSMIS) onboard the Defense Meteorological Satellite Program (DMSP)-5D-3/F17 satellite. The National Snow and Ice Data Center (NSIDC) release the data in the level-3 Equal-Area Scalable Earth-Grid (EASE-Grid) format (Armstrong et al. 2013). To be consistent with previous work (Zwally and Fiegles 1994; Liu et al. 2005), the $19-\mathrm{GHz}$ horizontally polarized channel acquired in the ascending pass data were used in the analysis. The grid cell size used to measure melt extent is $25 \mathrm{~km}$. The time series of daily brightness temperature records of Antarctica were processed using the wavelet transformbased edge detection method (Liu et al. 2005). The algorithm delineates each melt event in the time series by tracking its onset and end date. The onset day of the first melt event is recorded as the start day of the melt season (Fig. 6.7a). Likewise, the end day of the last melt event is recorded as the end day of the melt season (Fig. 6.7b). The total number of melting days in the year was calculated as the accumulated number of days of all events (Fig. $6.7 \mathrm{c})$ in the melt season. Melt intensity is measured by two indices: melt extent and melt index
(Zwally and Fiegles 1994; Liu et al. 2006). Melt extent is the total area that experienced surface melt for at least one day. Melt index is the accumulated number of melt days over the study area, i.e., the Antarctica continent. In all cases, the instrumental records for Antarctic surface melt start in October 1978.

More extensive and intensive surface melt was observed in the 2012/13 austral summer across Antarctica than the last seven years. The measured melt extent is $1384375 \mathrm{~km}^{2}$, much larger than in 2011/12 (944375 km²; Wang and Liu 2013). The melt index value of 51335000 day $\mathrm{km}^{2}$ is almost double last year's figure. Both melt index and melt extent were the highest since austral summer 2004/05. The maps (Fig. 6.7) show that contiguous and lengthy $(\sim 1.5$ month) melt events in Dronning Maud Land, from mid-December 2012 to the end of January 2013, were major contributors to the overall high melt conditions for the continent. These melt events were associated with strong $2-\mathrm{m}$ temperature anomalies $\left(\sim+2.5^{\circ} \mathrm{C}\right)$ based on the ERA-Interim reanalysis (Wovrosh et al. 2013). Temperature records from the staffed station Neumayer at the coast of Dronning Maud Land, confirmed these model results, reporting a strong positive
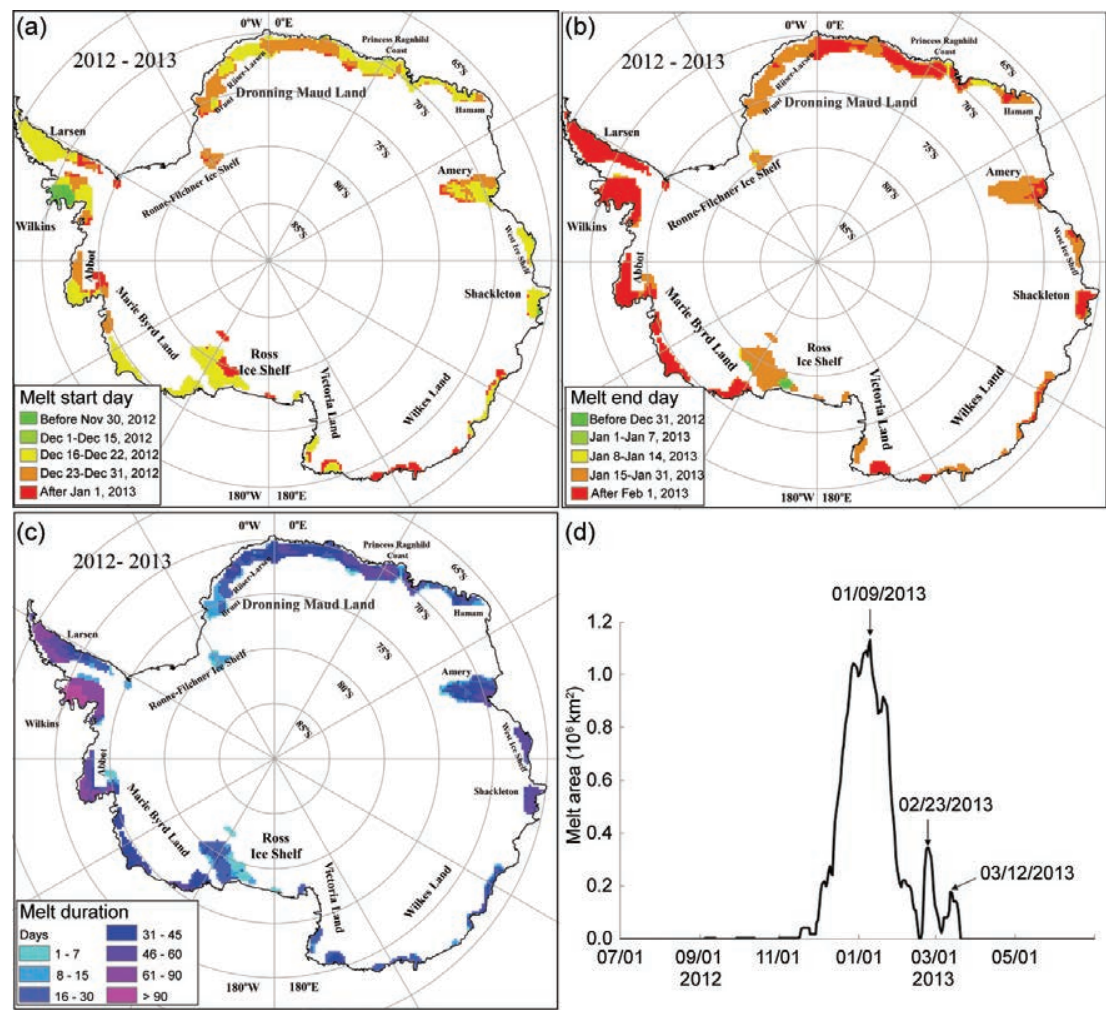

(d)

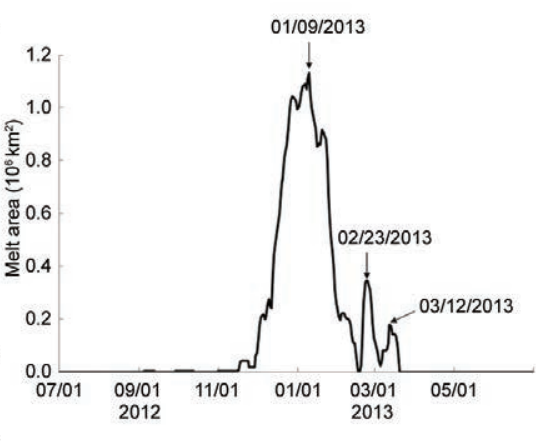

FIG. 6.7. (a) Melt start day, (b) melt end day, and (c) melt duration of Antarctic ice sheet during 20I2/13 austral summer. Daily melt area is plotted in (d) with three peak days labeled. (Source: DMSP-SSMIS daily brightness temperature observations.) 
anomaly from September 2012 onwards (Colwell et al. 2013). Air temperature anomalies were also observed around the Ross Sea embayment. At the same time, multiple short melt events occurred on the western Ross Ice Shelf. Unlike the sporadic pattern usually observed on the Ross Ice Shelf, the melt areas were spatially contiguous, forming large patches. Melt area extent across the Antarctic Peninsula is consistent with its cool summer conditions in 2012/13, driven in part by higher-than-average pressure in the Amundsen Sea at this time (Wovrosh et al. 2013). The melt index on the Peninsula was $15652500 \mathrm{~km}^{2}$, which is smaller than the 2011/12 austral summer (16036875 day. $\left.\mathrm{km}^{2}\right)$, but still greater than in 2010/11 (14215625 day. $\mathrm{km}^{2}$ ). The major melt season (Fig. 6.7d) over the continent started at the end of November 2012, reached its peak on 9 January 2013, and ended in early February. Two minor events peaked on 23 February and 12 March 2013 following the initial peak melt.

\section{f. Sea ice extent, concentration, and duration-R. A.} Massom, P. Reid, S. Stammerjohn, S. Barreira, T. Scambos, and J. Lieser In 2013, Antarctic sea ice was above average in overall area and extent throughout the year, compared to the 1981-2010 average. Following near-average conditions in December 2012, total circum-Antarctic ice extent became strongly positive in January 2013 and thereafter maintained aboveaverage to record conditions for the rest of the year (Fig. 6.8a). Numerous monthly and daily extent and area records were broken in 2013 (Reid et al. 2014, manuscript submitted to Ann. Glaciol.), with 116 days of record sea ice extent, including a near-continuous period between 19 August and 17 November, and a new daily annual maximum record of 19.57 million $\mathrm{km}^{2}$ set on 1 October (since records began in October 1978). 2013 continued the 1979-2012 positive trend in Antarctic-wide annual sea ice extent, but within the average trend are significant regional trends that are both positive and negative. Two regions exhibited sea ice extent anomalies most consistent with long-term regional trends: the Ross Sea sector (positive) and the western Weddell Sea (negative). These regional anomalies were consistent with large-scale atmospheric (section 6b) and oceanic interactions.

Negative pressure anomalies across the Antarctic and positive pressure anomalies at midlatitudes (positive SAM conditions) in January-May (Figs. 6.2 and $6.3 \mathrm{a}, \mathrm{c}$ ) led to a strengthening of westerly winds around the continent (Fig. 6.2c) and conditions suitable for wind-driven ice edge expansion, particularly in the Ross Sea (cf. figure 3 in Reid et al. 2014, manu- script submitted to Ann. Glaciol.). A deepening of low-pressure conditions between $\sim 170^{\circ} \mathrm{E}$ and $\sim 150^{\circ} \mathrm{W}$ during this period corresponded with enhanced sea ice extent in the western Ross Sea $\left(\sim 150^{\circ} \mathrm{E}\right.$ to $\left.\sim 175^{\circ} \mathrm{W}\right)$ and below-average ice extent in the Bellingshausen, Amundsen, and eastern Ross Seas. In the Weddell Sea from $30^{\circ}$ to $60^{\circ} \mathrm{W}$, a deepened polar trough along with colder-than-average sea surface temperatures (SSTs) coincided with above-average ice extent during these months. Across East Antarctica, regional variations in sea-ice extent were predominantly aligned with the positioning of low-pressure areas off the East Antarctic coast. This brought above-average extent in the western Pacific sector and near-average extent in the Indian Ocean sector, with the exception of the region north of the Amery Ice Shelf where ice extent was below average for January and February (but thereafter near-average).

June saw a change in large-scale atmospheric circulation, largely characterized by an increase in pressure over East Antarctica and deep lows centered in the Amundsen-Bellingshausen and southern Weddell Seas. The latter brought warm air into the Weddell Sea to limit northward ice advance there, while the presence of a well-developed Amundsen Sea low led to cold outflow across the eastern Ross Sea to enhance northward ice advance there (Fig. 6.8b). A prominent cold pool of SSTs north of the ice edge in the Ross Sea expanded eastwards (likely entrained in the Antarctic Circumpolar Current; Fig. 6.8d). In July, westerly winds strengthened again, particularly over the West Antarctic sector, to enhance ice-edge expansion into the expanding cold pool region in particular.

With a reduction in circumpolar wind strength in August and September (see Fig. 6.2c) and coolerthan-average SSTs to the north of the ice edge, sea ice expansion continued, appearing largely thermodynamically driven (the exception being the eastern Weddell and Haakon VII Seas, $\left.25^{\circ} \mathrm{W}-20^{\circ} \mathrm{E}\right)$. In October, sea ice anomalies remained positive around most of the continent, with the exception again of the eastern Weddell Sea $\left(25^{\circ} \mathrm{W}-0^{\circ}\right)$ and parts of the Haakon VII Sea, but now also the western Pacific Ocean and western Ross Sea sectors (Fig. 6.8c,e). New daily records for sea ice extent and area were set for every day in October, including a new daily annual maximum, set on 1 October. Only in three other years (since satellite records began) have daily annual maxima been set in October (usually September), i.e., 1988, 2011, and 2013.

Atmospheric conditions in November (Fig. 6.3g,h) were associated with stronger-than-average westerly 


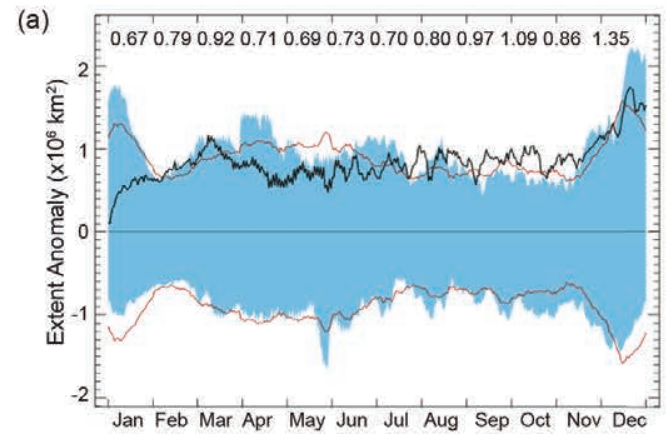

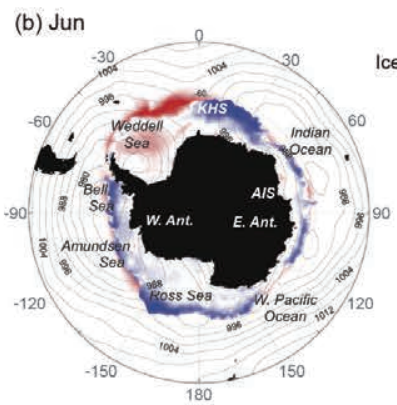

(d) Jun Extent \& SST Anomaly

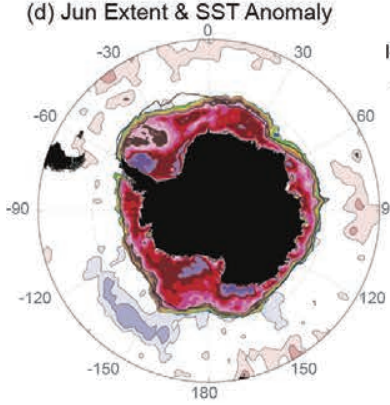

(f) Duration Anomaly

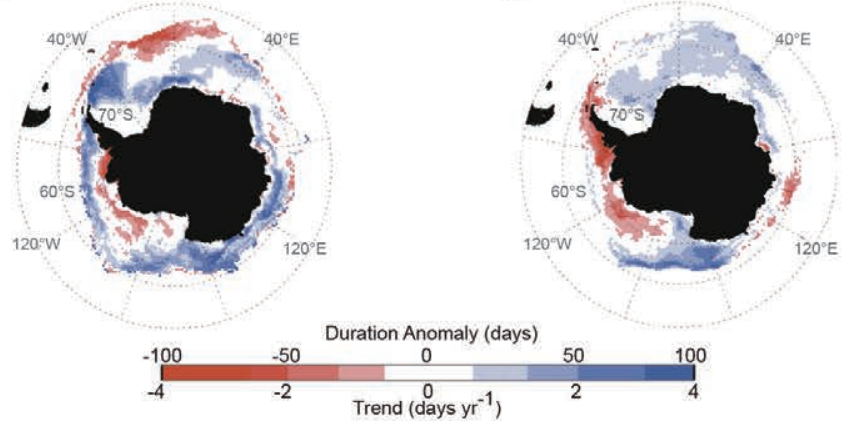

(c) Oct

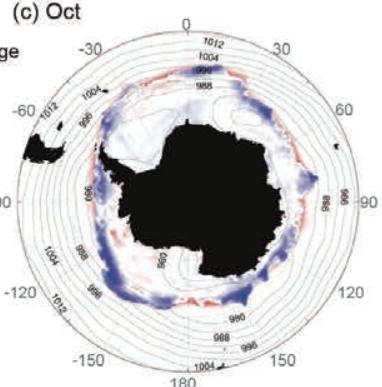

(e) Oct Extent \& SST Anomaly

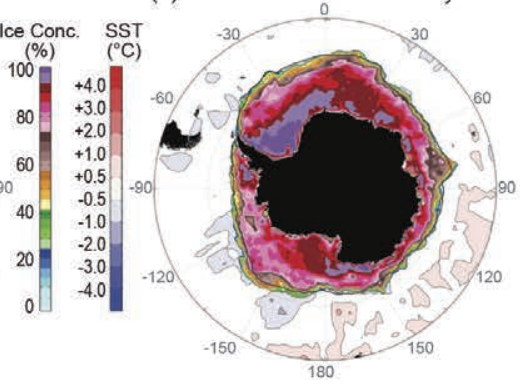

(g) Trend in Duration

FIG. 6.8. (a) Daily anomaly (black line) from the 198I-2010 mean of daily Southern Hemisphere sea-ice extent for 2013. Blue banding represents the range of daily values for $198 \mathrm{I}-2010$, while the red line represents \pm 2 std. devs. Numbers at the top are monthly-mean extent anomalies $\left(\times 10^{6} \mathrm{~km}^{2}\right)$. (b) and (c) Sea-ice concentration anomaly maps for Jun and Oct 2013, respectively, with respect to the 198I-2010 average, with monthly average contours of ACCESS MSLP. Bell is Bellingshausen Sea, KHS is King Haakon VII Sea, and AIS is Amery Ice Shelf. (d) and (e) Maps of monthly average sea ice concentration for Jun and Oct 2013, respectively, with mean ice edge (15\% extent) contours for 198I-20 I0 (black lines) and SST anomaly contours superimposed. The SST anomalies are with respect to the 198I-2010 average and are based on data from the Optimal Interpolation SST version 2 dataset (Reynolds et al. 2002; Smith et al. 2008). (f) Sea-ice duration anomaly for 2013/14, and (g) duration trend (see Stammerjohn et al. 2008). Both the climatology (for computing the anomaly) and trend are based on 198I/82 to 2010/II data (Cavalieri et al. 2012), while the 2013/14 duration-year data are from the NASA Team Near-Real-Time Sea Ice (NRTSI) dataset (Maslanik and Stroeve 1999). 
winds in the Bellingshausen and Amundsen Seas. This, along with the persistent cold pool of SSTs, continued to maintain strong positive ice edge anomalies there. Cold SSTs and a lack of transient cyclone activity in the East Antarctic and western Ross Sea sectors, which would normally encourage ice retreat (Kimura 2007; Kimura and Wakatsuchi 2011), were responsible for maintaining above-average ice coverage between $\sim 100^{\circ} \mathrm{E}$ and $180^{\circ}$ and through to the end of the year.

Consistent with the ice extent and area anomalies described above, the timing of annual ice-edge advance in fall was strongly negative (i.e., earlier than usual) in most regions, particularly for the inner pack ice region of the western Weddell $\left(30^{\circ}-60^{\circ} \mathrm{W}\right)$, East Antarctica $\left(100^{\circ}-170^{\circ} \mathrm{E}\right)$, and the western Ross Seas $\left(170^{\circ} \mathrm{E}-160^{\circ} \mathrm{W}\right)$. The exceptions showing later ice advance included the inner pack ice regions of the Amundsen and Bellingshausen Seas and the outer pack ice region of the Weddell and Haakon VII Seas.

With favorable wind and SST conditions prevailing during austral spring, the subsequent annual ice edge retreat anomalies were strongly positive (i.e., later than usual) almost everywhere. Exceptions included an earlier ice edge retreat along the outer pack ice in the eastern Weddell and King Haakon VII Seas, as well as small bands of earlier ice edge retreat along the outer pack ice between $\sim 100^{\circ}-115^{\circ} \mathrm{E}, \sim 160^{\circ} \mathrm{E}-180^{\circ}$, and $\sim 130^{\circ}-155^{\circ} \mathrm{W}$.
Given the earlier fall sea ice advance and later spring sea ice retreat observed almost everywhere, the resultant anomalies in ice season duration (Fig. 6.8f) were mostly positive. The exceptions were the inner pack ice region of the Bellingshausen and Amundsen Seas and outer pack ice of the Weddell and King Haakon VII Seas, where the 2013/14 ice season duration was shorter than usual (and of opposite sign to the trend shown in Fig. 6.8g). The longer ice season in the northern Bellingshausen Sea was also quite unusual and opposite in sign to the (decreasing) long-term trend observed there.

g. Ozone depletion-P. A. Newman, N. Kramarova, E. R. Nash, C. S. Long, M. C. Pitts, B. Johnson, M. L. Santee, M. Weber, and G. 0. Braathen

The Antarctic ozone hole reappeared in 2013, but was weaker than average compared to typical ozone holes over the last 20 years. Figure 6.9 displays October averages of total ozone derived from the Total Ozone Mapping Spectrometer (TOMS, 1979), the Aura Ozone Monitoring Instrument (OMI, 20062010) and the Ozone Mapping and Profiler Suite Total Column Nadir Mapper (OMPS TC-NM) aboard the Suomi National Polar-orbiting Partnership satellite (2012 and 2013). Prior to 1980, severe ozone depletion over Antarctica was not evident. After 1990, nearly every year has had a severe loss. The 2013 image (Fig. 6.9 , bottom right) shows that the hole was relatively
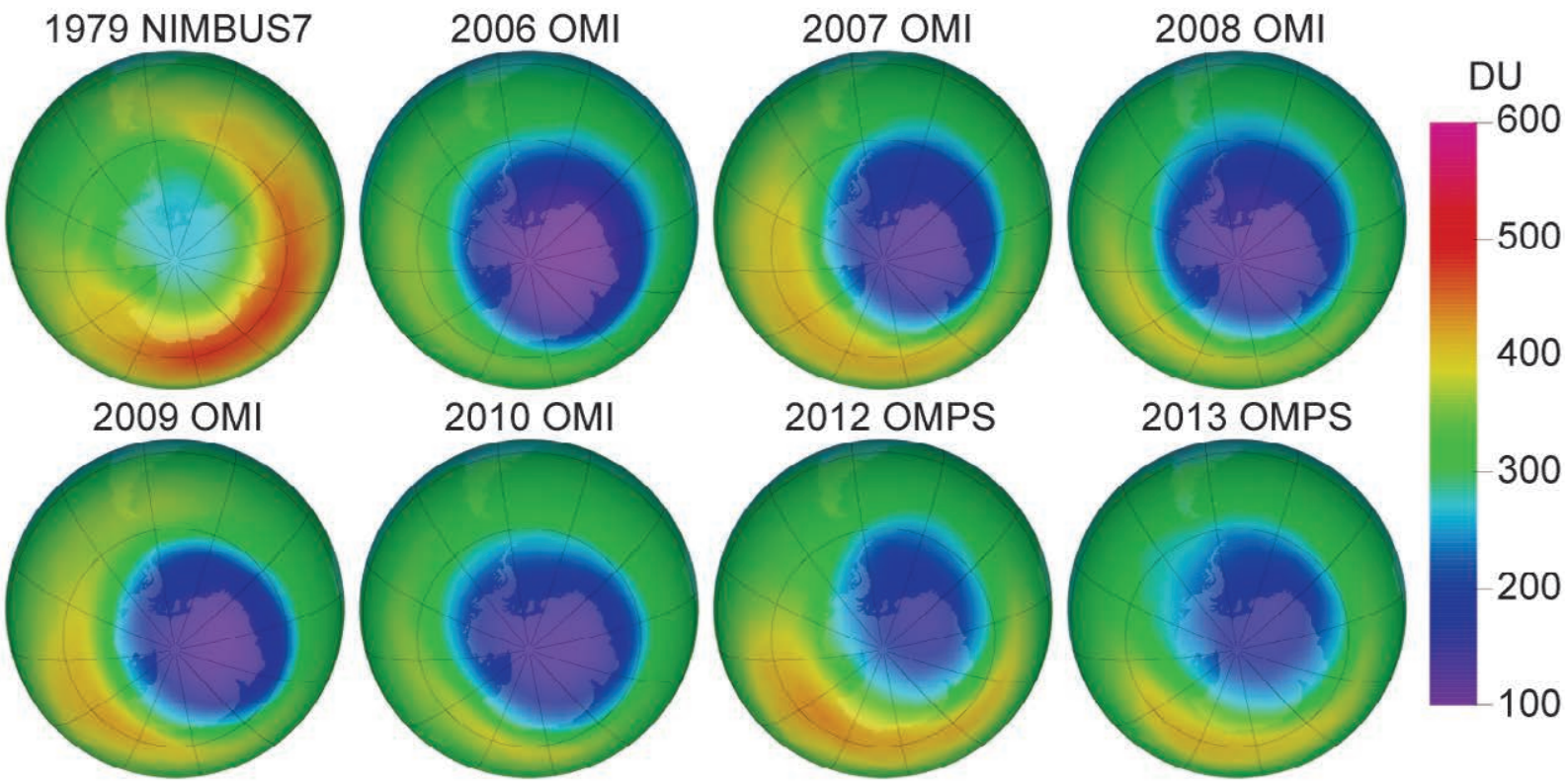

FiG. 6.9. Select Oct averages of total column ozone (Dobson units, DU) spanning the period 1979-2013. Both the 2012 and 2013 ozone holes were weaker than the period from 2006 to 2010. 
weak, but still deep in comparison to levels prior to 1985. Observations from the Global Ozone Monitoring Experiment 2 (GOME-2) aboard the MetOp-A satellites show a similar structure.

The Antarctic ozone hole's area and depth are typically used as severity metrics. The area usually peaks in mid-September to early-October. OMPS measured a single-day maximum area peak on 24.0 million $\mathrm{km}^{2}$ on 16 September 2013. The time-averaged area (7 September to 13 October) was 21.0 million $\mathrm{km}^{2}$. This made the 2013 ozone hole the 10th largest over the 2000-13 period. For comparison, the 2006 ozone hole was largest at 26.6 million $\mathrm{km}^{2}$. Ozone hole area fell to zero on 18 November 2013, the fourth earliest since 2000. The lowest OMPS value of 116 Dobson Units (DU) was on 29 September. The average depth (21 September to 16 October) of the 2013 hole was 132 DU, making 2013 the second highest over 2000-13.

South Pole balloon-borne ozonesondes (Fig. 6.10a) showed an above-average 2013 minimum. The August total column pre-ozone-loss average of $242 \mathrm{DU}$ (Fig. 6.10a, black line) dropped to a minimum of 124 DU on 29 September (Fig. 6.10a, red line), which ranked as the 20th lowest minimum measured in the 28-year South Pole record. Although this minimum was higher than average, a typical, rapid decline in ozone ( $>3 \mathrm{DU} \mathrm{day}^{-1}$ ) was observed in early September in the $12-20-\mathrm{km}$ layer. By 20 September stratospheric temperatures shifted to about $3^{\circ} \mathrm{C}$ above average, accompanied by an abrupt end to ozone depletion several days earlier than average over South Pole. The 12-20-km layer (averaged from the ozonesondes) dropped to 25 DU ( $\sim 80 \%$ depletion). This ranked 2013 as the 25th lowest minimum within this layer measured in the 28 -year record. The 22 October profile (Fig. 6.10a, blue line) shows high ozone levels above $23 \mathrm{~km}$ over the South Pole after the mid-stratospheric vortex breakup. Vertical profile information over the continent from the OMPS nadir profiler also confirmed this large September depletion with the strong mid-October increase above $25 \mathrm{~km}$.

The ozone hole is caused by the conversion of nonreactive forms of chlorine molecules into ozone-destroying forms on polar stratospheric clouds or PSCs surfaces (i.e., $\mathrm{HCl}+\mathrm{ClONO}_{2} \stackrel{P S C}{\rightarrow} \mathrm{Cl}_{2}+\mathrm{HNO}_{3}$ ). Molecular chlorine photolyzes as the sun rises in spring, and this chlorine (combined with bromine) causes catalytic ozone loss. Figure 6.10b shows Cloud-Aerosol Lidar and Infrared Pathfinder Satellite Observation (CALIPSO) observations of total PSC volume. The 2013 season was the third smallest in the 2006-13 record. The 2013 PSC season was generally below average for July-October. 


\section{SIDEBAR 6.I: ULTRA-LOW TEMPERATURES NEAR DOME A, ANTARCTICA-T. SCAMBOS, G. G. CAMPBELL, A. POPE, T. HARAN, AND M. LAZZARA}

A survey of satellite thermal infrared emission temperatures using 2003-13 data from NASA's Moderate Resolution Imaging Spectro-radiometer (MODIS: EOS dataset MYDII) aboard the Aqua multi-sensor satellite platform reveals a broad area of the East Antarctic Plateau where midwinter surface skin temperatures regularly drop below $-88^{\circ} \mathrm{C}$. In isolated areas, the reported surface temperatures reach $-93^{\circ} \mathrm{C}$. These are the lowest skin temperatures in the entire satellite record and likely identify the coldest areas on Earth. For reference, the record lowest $2-\mathrm{m}$ air temperature measurement, $-89.2^{\circ} \mathrm{C}$, occurred at Vostok Station, Antarctica, on 21 July 1983.

A precursor survey of satellite Advanced Very-High Resolution Radiometer (AVHRR) data from the 5-km gridded Polar Pathfinder Dataset (not shown; see Wang and Key 2005), and the I-km gridded MODIS MYDII datasets (Fig. SB6.Ia) revealed that above $\sim 3600$ m elevation, the spatial pattern of a map of lowest skin temperatures has a strong correlation with surface topography and is not perceptibly obscured or modified by cloud. The surface pattern is clear in both the AVHRR and MODIS thermal infrared datasets. This was confirmed by comparison with the MODIS Mosaic of Antarctica (MOA; Scambos et al. 2007), a digital elevation model (Bamber et al. 2009), and a laser elevation profile from airborne work in the Antarctic Gamburtsev Province (AGAP Project; R. E. Bell et al. 20II).

The coldest sites occur in local topographic lows of just a few meters closure near the ridge crest of the Dome A-Dome $F$ ridge (Fig. SB6.Ib). The majority of these sites are south of the ridge crest, and above $3750 \mathrm{~m}$. Ultra-low skin temperatures as low as $-93.2^{\circ} \mathrm{C}$ occur, and the same sites surpassed $-88^{\circ} \mathrm{C}$ on 10 to $60+$ occasions in the 2003-13 MYDII record (Fig. SB6.Ib; Campbell et al. 2013). A histogram of the record-cold occurrences in the II-year record peaks at 24 July. Record events for the MYDII dataset occurred on 10 August 2010 and 31 July 2013 , but several dates and locations were within $0.5^{\circ} \mathrm{C}$ of these records. Within the MYDII data, events of $<\sim-88^{\circ} \mathrm{C}$ are seen near Vostok, but no events at $<-91^{\circ} \mathrm{C}$.
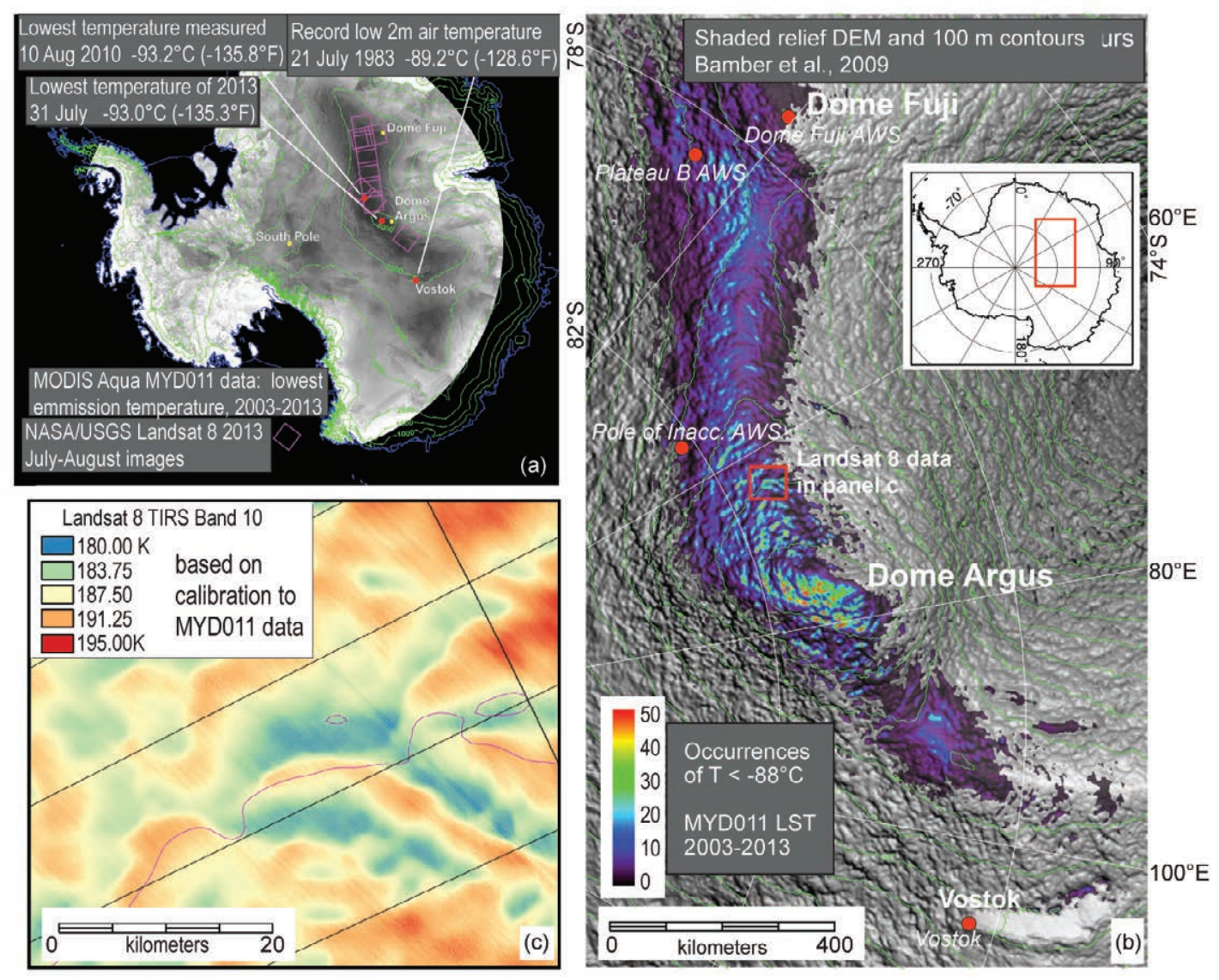

FIG. SB6.I. (a) Image map of lowest grid cell values for MODIS MYDII thermal emission temperatures for Antarctica south of $70^{\circ} \mathrm{S}, 2003-13$. Elevation contours shown in green, ice sheet coastline in blue. (b) Dome Fuji-Dome Argus region of the East Antarctic Plateau showing all areas of $<-88^{\circ} \mathrm{C}$ in the dataset (color), with color scale indicating the frequency of occurrence. (c) Landsat 8 thermal data from $31 \mathrm{Jul} 2013$ of one area during an ultra-cold event. 
Validation studies suggest that MYDII data are within $2^{\circ} \mathrm{C}$ of the in situ measured emission temperature (Wan et al. 2002; Scambos et al. 2006), although validation studies have not been conducted in this temperature range.

To verify and further examine the structure of the ultra-cold sites, a series of wintertime images from the newly-launched Landsat 8 Thermal Infra-Red Sensor (TIRS; Roy et al. 2014) were obtained. Calibration of the TIRS bands is still ongoing, and for this reason the reported thermal radiance values were adjusted to yield temperatures that regionally matched MODIS MYDII values (best fit of the data). Variation in skin temperatures between local lows and adjacent high-elevation or convex-upward areas are especially large (up to $10^{\circ} \mathrm{C}$ ) in the ultra-cold pocket areas under near-record conditions, and this is well shown in Landsat 8 data (Fig. SB6.Ic). No AWS stations appear to be sited in any of the coldest pocket areas.

Ultra-cold events in Antarctica occur at the end of prolonged periods of stagnant air with high $500 \mathrm{hPa}$ geopotential heights, producing long periods of clear sky and light winds. Radiative cooling of the snow surface under this extremely dry air column leads to a strong surface inversion (e.g., Turner et al. 2009). The conceptual model for the record-setting skin temperatures starts with this process, leading to drainage of a near-surface layer of air downhill (but modified by pressure gradients and the Coriolis effect). The cold air fills local topographic lows, allowing the surface snow in these low pockets to cool still further. Adjacent high areas are not able to cool as much because drainage of the near-surface air away from the high points exposes the surface to warmer air higher in the inversion layer. Because of the pooling of air in the near-ridge pockets, it is believed that the near-surface gradient of the inversion may be somewhat flatter in the pockets, making it likely that these record low skin temperatures underlie record cold air at $2 \mathrm{~m}$ of nearly the same value.
Aura's MLS measures nonreactive $\mathrm{HCl}$ (Fig. 6.11a), ozone-destroying $\mathrm{ClO}$ (Fig. 6.11b), and ozone (Fig. 6.11c). It therefore tracks chlorine activation and deactivation. In June and July, $\mathrm{HCl}$ decreases as temperatures drop and PSCs form. As noted in the equation above, $\mathrm{PSC}$ promote $\mathrm{HCl}$ and $\mathrm{ClONO}_{2}$ conversion into reactive chlorine (mainly $\mathrm{ClO}$ and $\mathrm{Cl}_{2} \mathrm{O}_{2}$ ). As a result, $\mathrm{ClO}$ increases from June through August. Low $\mathrm{HCl}$ and high $\mathrm{ClO}$ are confined within the polar vortex. $\mathrm{ClO}$ peaks in September from the continued PSC presence and the rising sun over Antarctica. In
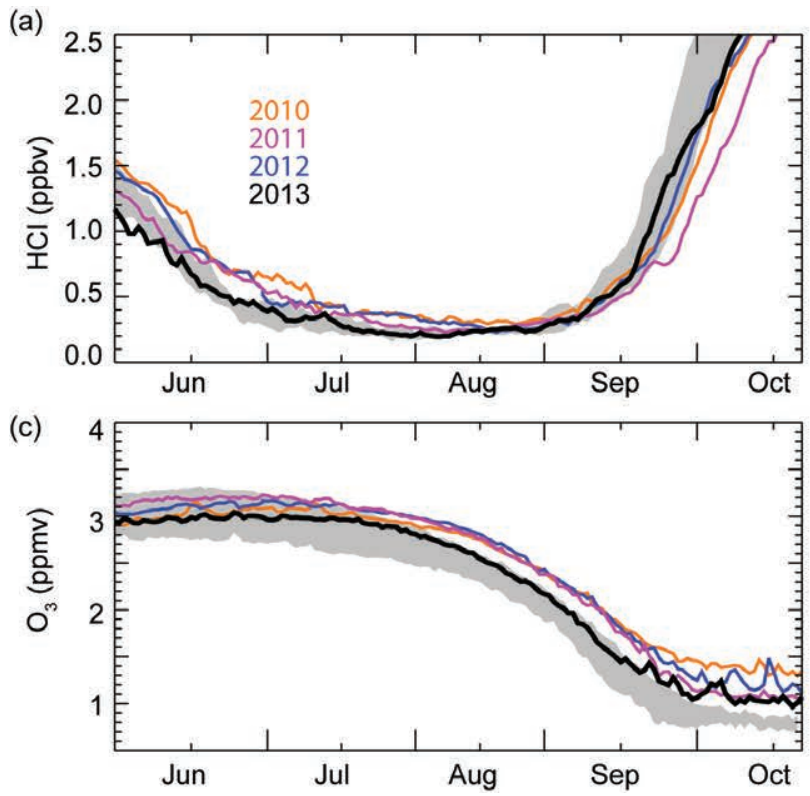

late-September, complete destruction of ozone and evaporation of PSCs causes $\mathrm{ClO}$ (rapid decrease) to be converted to $\mathrm{HCl}$ (rapid increase). Consistent with the ozone decrease (Fig. 611c), the degree of chlorine activation was slightly below average in 2013 .

Chlorine- and bromine-containing compounds cause the ozone hole. Ozone-depleting substances (ODSs) have only decreased by $0.27 \mathrm{ppb}$ to $3.78 \mathrm{ppb}$ (2000-02 peak of $4.05 \mathrm{ppb}$ ). This amounts to a $14.2 \%$ drop towards the 1980 level of $2.11 \mathrm{ppb}$.

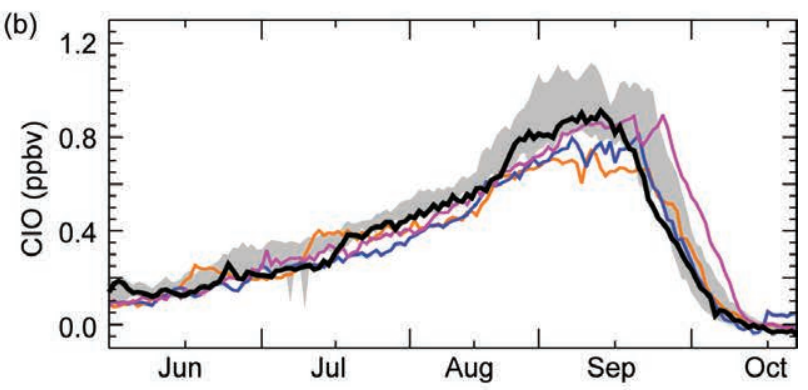

FIG. 6.II. Daily time series of (a) Antarctic vortex-averaged $\mathrm{HCl}$, in ppbv, (b) $\mathrm{ClO}$, in ppbv, and (c) ozone, in ppmv, from the Aura Microwave Limb Sounder (MLS). The averages are made inside the polar vortex on the $212 \mathrm{~K}$ potential temperature surface $(\sim 21 \mathrm{~km}$ altitude or $40 \mathrm{hPa}$ ). Grey shading shows the range of Antarctic values for 2004-10. Updated from Manney et al. (20II). 
Antarctic stratospheric temperature variability modulates the year-to-year ozone hole. NOAA/NCEP Antarctic monthly mean temperatures were $1^{\circ} \mathrm{C}$ above average $\left(65^{\circ}-90^{\circ} \mathrm{S}\right)$ for September 2013 , and $50-\mathrm{hPa}$ monthly averages were $1^{\circ} \mathrm{C}$ above average (reflected in Fig. 6.2b). This is consistent with smaller amounts of PSCs and less chlorine activation.

The Antarctic stratosphere is warmed by (1) shortwave radiation at the end of polar night, and (2) large-scale weather systems in the troposphere that propagate into the stratosphere. These waves deposit easterly momentum that decelerates the polar night jet and causes a poleward and downward circulation. This circulation adiabatically warms the Antarctic lower stratosphere. During 2013, this wave momentum deposition was higher than average, resulting in a warmer-than-average Antarctic vortex (see Fig. 6.2b), a weaker Antarctic ozone hole, and an early ozone hole breakup.

In summary, the 2013 Antarctic ozone hole was weaker than average in comparison to the typical ozone hole over the last decade. As in 2012, this weakness was primarily caused by dynamical effects that warmed the lower stratosphere and advected higher ozone into the polar region (Kramarova et al. 2014). High levels of activated chlorine and estimates of inorganic chlorine levels have yet to significantly decrease over Antarctica. Severe ozone depletion was again observed from ground, balloon, and satellite observations. Ozonesondes from Antarctic stations in August-November show ozone profiles with typical ozone depletions in the $15-20-\mathrm{km}$ altitude range and unusually high amounts of ozone around $25 \mathrm{~km}$. 
7. REGIONAL CLIMATES —A. Sánchez-Lugo, J. A. Renwick, W. M. Thiaw, and S. J. Weaver, Eds.

a. Overview-A. Sánchez-Lugo, J. A. Renwick, W. M. Thiaw, and S. J. Weaver

This chapter provides summaries of the 2013 temperature and precipitation conditions across North America, Central America and the Caribbean, South America, Africa, Europe, Asia, and Oceania; in most cases, summaries of notable weather events are also included. Local scientists provided an annual summary for their respective regions and, unless otherwise noted, the source of the data used is typically the agency affiliated with the authors.

Across North America, extreme events continued to dominate during 2013, even in the midst of weakerthan-average annual quantities. Canada endured significant flooding events in Calgary, southern Alberta, and Toronto, despite the country experiencing overall dry conditions for the year. Similarly, the United States had one of the lowest annual totals for tornadoes on record, notwithstanding the massive EF-5 tornado that devastated Moore, Oklahoma. Mexico had a wet year overall; it also experienced the simultaneous impact of two tropical systems, an occurrence not seen in over five decades. The Caribbean basin experienced a below-average year for tropical storms, recording only two named storms. Severe storms triggered heavy rains, landslides, and floods across parts of Central America during its rainy season. Annual temperatures were near average across the Caribbean. Near- to below-average precipitation was present across the Caribbean at the start of the year, shifting to wet conditions for the rest of the year. For a third consecutive year, parts of northeastern Brazil coped with one of the worst droughts on record. An intense heat wave affected central Argentina and Uruguay during mid-December, with several locations breaking historical records for heat wave duration. An active West African monsoon brought torrential rain across the Sahel band during August-September. Meanwhile, the worst drought conditions in eight decades plagued parts of South Africa. Europe and the Middle East were characterized by anomalous warmth during 2013. Copious rainfall in central Europe from late May through early June resulted in severe flooding. Large areas of the Eurasian continent experienced above-average annual temperatures, with parts of northeastern Asia and northern India experiencing below-average conditions. East Asia experienced episodes of severe heat, dry conditions, and heavy rainfall. Other events included a severe heat wave in Pakistan, a deadly heat wave and severe drought conditions in China during July-August, and anomalously warm and dry summers for Japan and South Korea. Across Oceania, Australia experienced persistent warmth throughout the year, contributing to its warmest year on record.

\section{b. North America}

I) CanAdA-L. A. Vincent, D. Phillips, and R. Whitewood

The year 2013 was another warm year in Canada although not as warm as recent years. The national temperature was above the 1961-90 base period during each season. The year was also characterized by drier-than-normal conditions, mainly in western Canada during winter and fall, and the national annual precipitation for 2013 was below average.

\section{(i) Temperature}

The annual nationally-averaged temperature for 2013 was $0.8^{\circ} \mathrm{C}$ above average, which was the 16 th warmest year since national records began in 1948 (Fig. 7.1). The warmest year remains $2010\left(3.0^{\circ} \mathrm{C}\right.$ above average) and the coldest year $1972\left(1.9^{\circ} \mathrm{C}\right.$ below average). Positive departures occurred across most of British Columbia, Yukon, Northwest Territories, Nunavut, northern Quebec, and Newfoundland (Fig. 7.2). Negative departures were recorded across southern Saskatchewan, Manitoba, and southwestern Ontario. The annual national temperature indicates a linear increase of $+1.6^{\circ} \mathrm{C}$ over the past 66 years.

Seasonally, winter (December-February) 2012/13 was $1.6^{\circ} \mathrm{C}$ above average and the 18 th warmest since 1948. Most of the country was at or slightly above average. A small area in northern Quebec and Labrador experienced above-average temperatures of more than $+3^{\circ} \mathrm{C}$ and a small portion of the northern

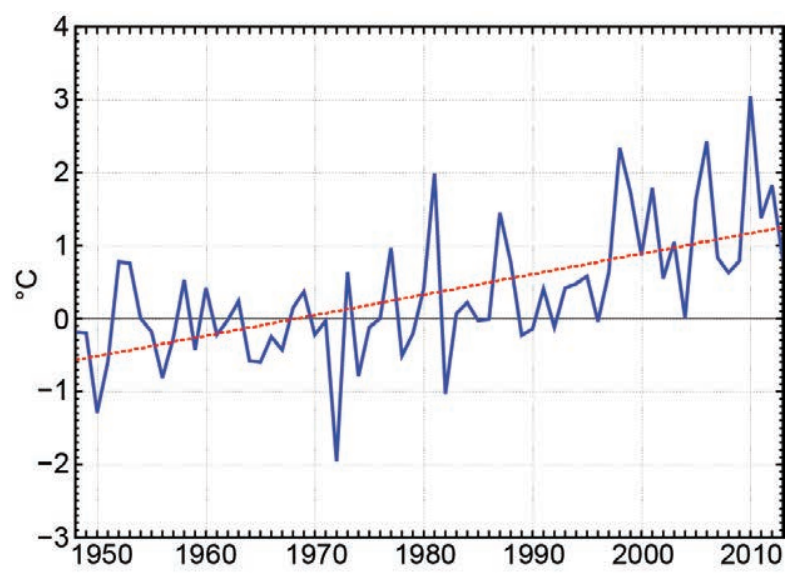

FIG. 7.I. Annual average temperature anomalies $\left({ }^{\circ} \mathrm{C}\right)$ for Canada based on 1961-90, for the period 19482013 . The red line indicates a linear increase of $1.6^{\circ} \mathrm{C}$ over the 66 years. (Source: Environment Canada.) 


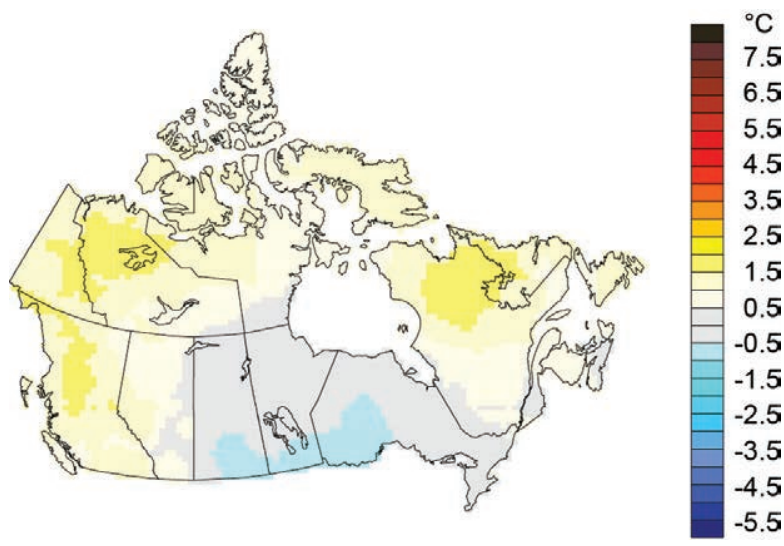

Fig. 7.2. Annual average temperature anomalies $\left({ }^{\circ} \mathrm{C}\right)$ in Canada for 2013 based on 196I-90. (Source: Environment Canada.)

Yukon and Northwest Territories had below-average temperatures.

During spring 2013, a strong pattern of negative temperature departures was found from the northwestern regions through to the south-central regions of the country while positive temperature departures occurred over the far north and northeastern Canada, mainly in northern Quebec and eastern Nunavut. The nationally-averaged temperature was $0.6^{\circ} \mathrm{C}$ above average, the 25th warmest spring since 1948 .

Summer was $0.9^{\circ} \mathrm{C}$ above average and the eighth warmest summer observed since 1948. Temperatures across much of south-central and eastern Canada were near average. Positive temperature departures occurred over British Columbia and the northwestern regions and negative departures were recorded for Ellesmere Island and the far north.

Fall 2013 was the 12th warmest on record with a nationally-averaged temperature of $1.4^{\circ} \mathrm{C}$ above the 1961-90 average. Near-average or slightly-above-average temperatures were experienced across much of the country. A small area over northwestern Canada recorded temperature departures of more than $+3^{\circ} \mathrm{C}$.

\section{(ii) Precipitation}

Dry conditions were observed in Canada in 2013. It was the 13th driest year since national records began in 1948, with annual precipitation $94 \%$ of the 1961-90 average. Drier-than-average conditions were observed for much of the Pacific, central British Columbia, northern Saskatchewan and Manitoba, southeastern Northwest Territories, and southern Nunavut. Nearaverage conditions were observed in the remaining portions of the country (Fig. 7.3).

Winter 2012/13 was characterized by drier-thannormal conditions (83\% of the 1961-1990 average),

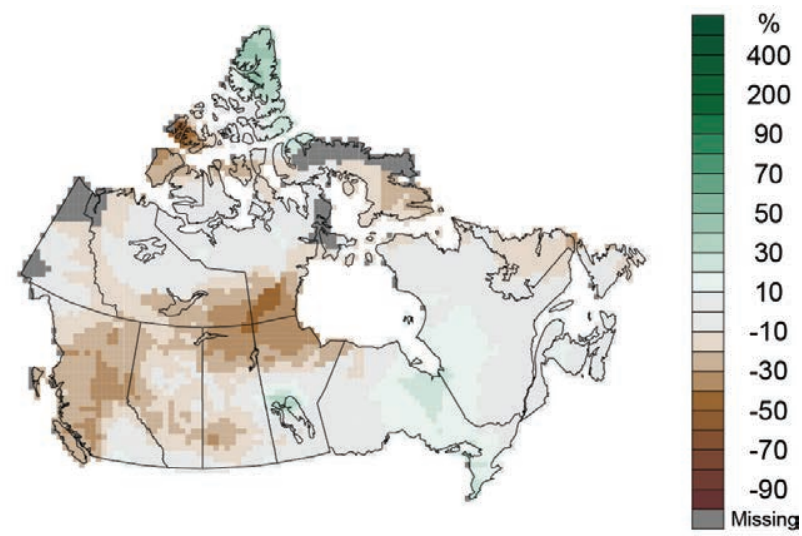

FIG. 7.3. Annual total precipitation anomalies in Canada for 2013 (\% departure from 196I-90). (Source: Environment Canada.)

the third driest in the 66-year period of record. Most of the western half of the country was $<70 \%$ of average, including British Columbia, Alberta, Saskatchewan, Yukon, Northwest Territories, and western Nunavut. Eastern Canada had precipitation values near the 1961-90 average.

Spring 2013 was the 21st driest since 1948, with nationally-averaged precipitation $94 \%$ of average. Drier-than-average conditions were observed for much of Saskatchewan and Manitoba, northern Alberta, the Northwest Territories, and part of western Nunavut. A wetter-than-average spring was experienced across much of Ontario, southern Quebec, Newfoundland, Ellesmere Island, and south-central British Columbia.

Summer was the 25 th wettest since 1948 and the national average precipitation was $103 \%$ of average. A wetter-than-average summer was observed in central Saskatchewan and Manitoba, eastern Ontario, the Maritimes, and the far north. Drier-than-average conditions were observed in central British Columbia and Alberta, northern Saskatchewan and Manitoba, southeastern Nunavut, southern Baffin Island, northwestern Quebec, and Newfoundland.

Fall was also characterized by drier-than-normal conditions (89\% of the 1961-90 average) and was the ninth driest on record. Similar to winter 2012/13, drier-than-average conditions were experienced in the western regions of the country, including British Columbia, Alberta, Saskatchewan, Yukon, Mackenzie, and Nunavut. Slightly-wetter-than-average conditions were observed in central Manitoba, northeastern Ontario, and western Quebec.

\section{(iii) Notable events}

Despite a dry year overall, flood and precipitation events dominated the list of major Canadian weather 
stories in 2013. The biggest flood of 2013 occurred in June when torrential downpours overwhelmed Calgary and vast areas of southern Alberta, forcing 100000 people from their homes and causing billions of dollars in damages. During 18-21 June, southern Alberta received more than $70 \mathrm{~mm}$ of rain. Rainfall west of Calgary, in the elevated areas of the Bow and Elbow Rivers, was exceptionally heavy and torrential, approaching $345 \mathrm{~mm}$. Warm air and rain also melted up to $60 \mathrm{~cm}$ of snowpack, which was about $25 \%$ above normal for that time of year, instantly engorging streams and rivulets.

On 8 July, large parts of Toronto's core were flooded by one of the heaviest single-day rainfalls in the city's history. Toronto Pearson International Airport received $126 \mathrm{~mm}$ in about two hours during afternoon rush hour, leaving millions of commuters in transit between work and home. With observations dating to November 1937, the $126 \mathrm{~mm}$ total was a new daily rainfall record (for any day) at the airport, breaking the previous record of $121.4 \mathrm{~mm}$, which fell during the Hurricane Hazel event on 15 October 1954.

Just before Christmas, a major ice storm occurred in eastern Canada, causing flight delays and highway accidents on one of the busiest travel weekends of the year. Blowing snow, ice pellets, freezing rain, and rain were reported almost continuously during 20-23 December. Toronto was at the epicenter of the ice storm, receiving nearly $30 \mathrm{~mm}$ of freezing rain over 43 hours, which damaged thousands of trees. This major ice storm affected five provinces across eastern Canada, causing long-lasting power outages for 500000 residents.

2) UNITED STATES-J. Crouch, R. R. Heim Jr., and C. Fenimore

Based on preliminary data, the annual average temperature in 2013 for the contiguous United States (CONUS) was $0.2^{\circ} \mathrm{C}$ above the long-term (1901-2000) average of $11.2^{\circ} \mathrm{C}$, ranking 2013 as one of the 40 warmest years in the 119-year period of record (Fig. 7.4). This temperature was $1.7^{\circ} \mathrm{C}$ cooler than 2012, which was the warmest year on record for the nation. The annual CONUS temperature is increasing at an average rate of $0.07^{\circ} \mathrm{C}$ decade $^{-1}$. The nationallyaveraged precipitation during 2013 was $791.5 \mathrm{~mm}$, $51.3 \mathrm{~mm}$ above average, and ranked in the wettest third of the historical record. The annual CONUS precipitation is increasing at an average rate of 4.3 $\mathrm{mm}$ decade $^{-1}$. This was the coolest and wettest year for the CONUS since 2009.

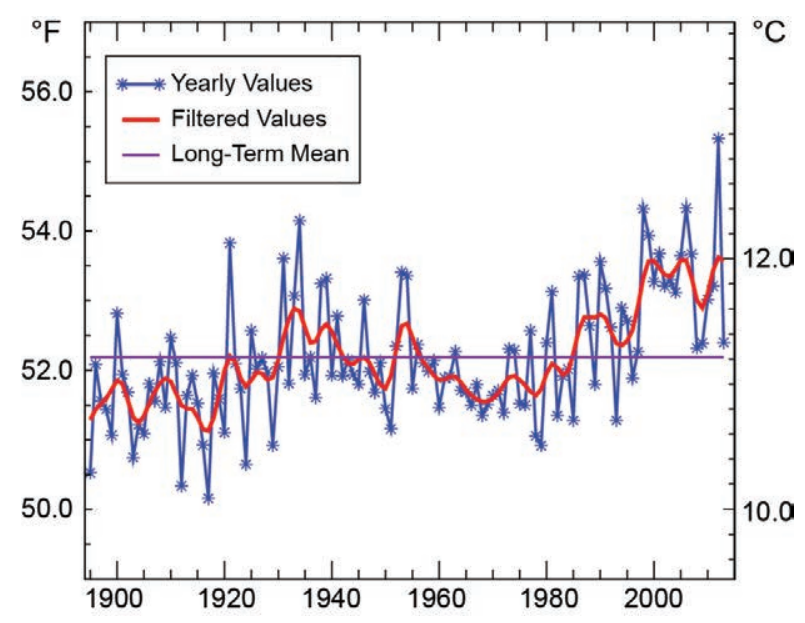

FIG. 7.4. Annual average temperature for the contiguous United States for the period 1895-2013. The filter is a weighted average used to smooth the year-to-year changes in the data values which may help identify the presence/absence of trends throughout the data record. (Source: NOAA/NCDC.)

\section{(i) Temperature}

Both above- and below-average temperatures dominated different seasons and regions of the CONUS during 2013. On the annual scale (Fig. 7.5a), above-average temperatures occurred for the Northeast, Florida, and parts of the West. Below-average temperatures were present across the Northern and Central Plains and parts of the Midwest and Southeast. No state had annual temperatures ranking among its ten warmest or coolest on record. The average winter (December-February) 2012/13 temperature was $1.1^{\circ} \mathrm{C}$ above the long-term average, with warmer-than-average temperatures occurring east of the Rockies. Spring (March-May) was $0.3^{\circ} \mathrm{C}$ below average, making this the coolest spring for the CONUS since 1996. Much-below-average temperatures were present in the Upper Midwest, Southeast, and parts of the Southern Plains, while New England and the West were warmer than average. The CONUS summer (June-August) temperature was $0.7^{\circ} \mathrm{C}$ warmer than average, ranking in the warmest third of the historical record. Parts of the Northeast and much of the West were much warmer than average, while parts of the Midwest and Southeast were cooler than average. Fall (September-November) brought nearaverage temperatures to much of the CONUS, at $0.3^{\circ} \mathrm{C}$ above average. The December CONUS temperature was $1.1^{\circ} \mathrm{C}$ below average with only the Southeast warmer than average. 
(a)
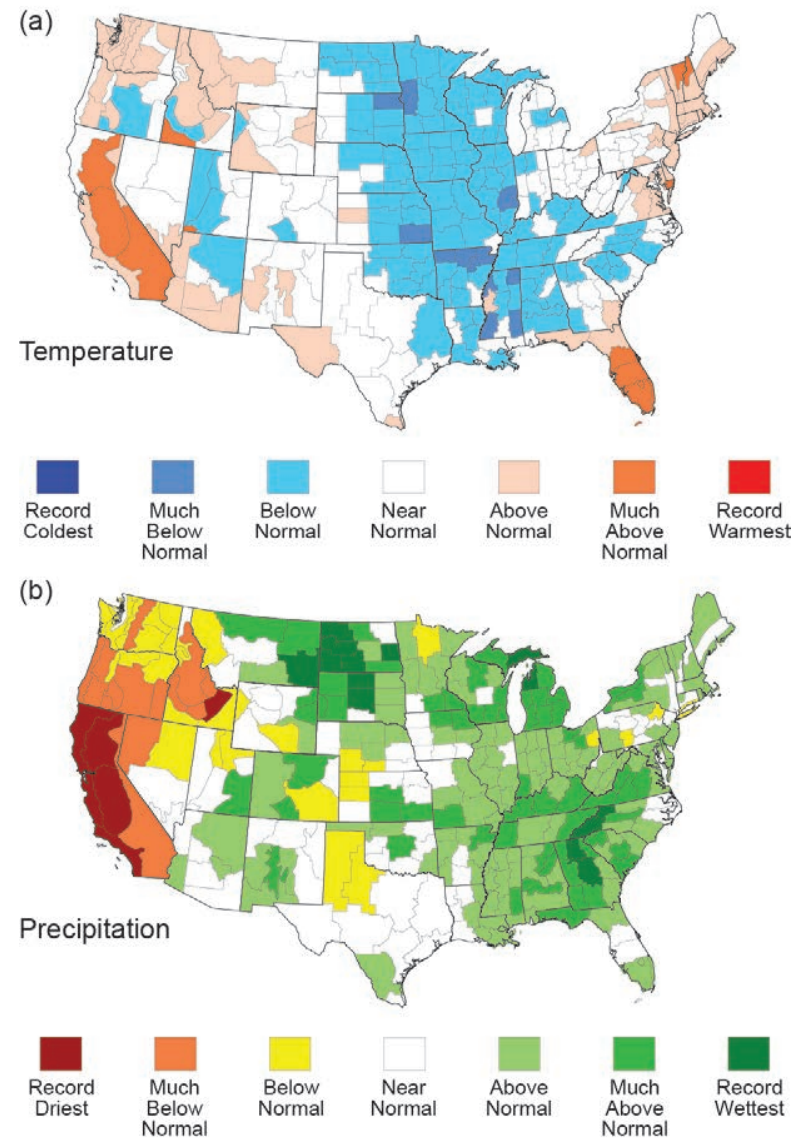

FIG. 7.5. Climate division percentiles of 2013 annual (a) temperature and (b) precipitation. Record coldest/ warmest or driest/wettest is defined as the smallest/ largest annual value for that climate division in the 1895-2013 period of record. Much-above-normal/ Much-below-normal values are defined as occurring in the top/bottom $10 \%$ of recorded years. Above-normal/ below-normal values are defined as occurring in the top/bottom third of recorded years. (Source: NOAA/ NCDC.)

\section{(ii) Precipitation}

As indicated by Fig. 7.5b, locations east of the Rockies were wetter than average for 2013 on balance, while the West Coast was drier than average. Michigan and North Dakota both had their wettest year on record, with $129 \%$ and $147 \%$ of average precipitation, respectively. California had its driest year on record, with $33 \%$ of average precipitation. The year began with about $61 \%$ of the CONUS in moderate to exceptional drought, based on the US Drought Monitor (Svoboda et al. 2002); this footprint shrank to 31\% of the CONUS by the end of December. Each season of 2013 was wetter than average for the CONUS, with both wet and dry regional extremes.

During winter 2012/13, much of the CONUS east of the Rockies was wetter than average, particularly the Midwest and Southeast. The above-average precipitation improved drought conditions in the Southeast, most notably in Georgia, which had dealt with drought since 2010. A lingering impact of the 2012 warmth and drought, Lakes Huron and Michigan reached new record-low water levels in January. The winter snow cover extent for the CONUS was the 15th largest in the 47-year period of record. However, by the end of winter, dry conditions in the West resulted in much-below-average snowpack across the Sierra Nevada Mountains, Great Basin, and Southern Rockies.

The CONUS spring precipitation was near average, masking regional wet and dry extremes. Aboveaverage precipitation was observed across much of the Midwest. Iowa had its wettest spring on record with $196 \%$ of average spring precipitation. The Southwest was drier than average, where New Mexico had its second driest spring and California had its eighth driest. By the end of May the area of the CONUS in drought shrank to $44.3 \%$. Several winter storms impacted the United States during spring, resulting in the eighth largest spring snow cover extent on record. Many locations received more snowfall during the spring than the preceding winter season.

Summer was wet for the CONUS, with a national precipitation total $116 \%$ of average. This was the eighth wettest summer on record and the wettest since 2004. Most locations in the East had muchabove-average summer precipitation. New York, South Carolina, Georgia, and Florida each had their wettest summer on record. This was the second consecutive summer that Florida broke its June-August precipitation record. Arizona had its ninth wettest summer on record, partially due to increased monsoonal precipitation. Tropical Storm Andrea, the only tropical cyclone to directly impact the CONUS during 2013, made landfall along Florida's Gulf Coast on 6 June, bringing heavy rain to parts of the Southeast. Below-average precipitation resulted in drought development across parts of the Upper Mississippi River Valley and Midwest.

The fall CONUS precipitation total was above average. Dryness along both coasts was counterbalanced by above-average precipitation across parts of the Rockies and Northern Plains, where five states had one of their ten wettest falls on record. Heavy precipitation, exceeding $455 \mathrm{~mm}$ in some locations, fell during September in Colorado. From 9-16 September a cut-off low pressure system pumped deep tropical moisture into the Colorado Front Range, resulting in record precipitation. Streams and rivers approached and exceeded record levels, causing 


\section{SIDEBAR 7.I: TRENDS IN SURFACE RADIATION OVER THE UNITED STATES SINCE THE MID-1990S—J. AUGUSTINE}

Surface net radiation is a key indicator of climate change because it represents the energetic response at the surface to atmospheric components that affect climate such as greenhouse gases, clouds, and aerosols. It is also consequential to weather, agriculture, and renewable energy.

Surface net radiation systematically increased by $13 \mathrm{~W} \mathrm{~m}^{-2}$ over the United States from 1996 to 20II, the most recent year for which final data are available (Augustine and Dutton 2013), as shown in Fig. SB7.I. That statistically significant trend was determined using data from NOAA's national surface radiation budget SURFRAD network, which makes accurate independent measurements of downwelling and upwelling broadband solar and thermal infrared irradiance. SURFRAD sites were chosen so that their measurements would represent large extended regions for satellite product and model validation. SURFRAD began reporting high temporal resolution surface radiation budget data in 1995 from four stations in Colorado, Illinois, Montana,

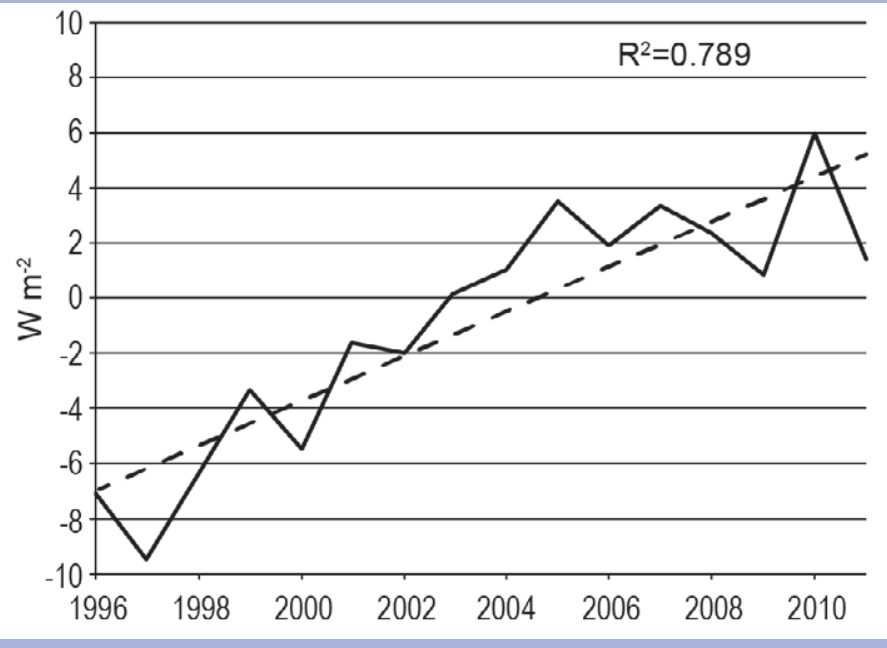

FIG. SB7.I. Time series of surface net radiation anomaly ( W m-2) over the United States for 1996-2011, as determined from the SURFRAD network. Surface net radiation is plotted as an anual anomaly, where $y=0$ represents the mean during the period. and Mississippi. Two stations were added in 1998 in Pennsylvania and Nevada, and the last station was installed in South Dakota in 2003. Collectively, annual averages of solar radiation from these sites have been shown to represent a large portion of the 48 contiguous states (Augustine et al. 2006).

Of its four components, a $10 \mathrm{~W} \mathrm{~m}^{-2}$ increase in downwelling solar (Fig. SB7.I) accounts for most of the escalation in surface net radiation over the US. This increase is significant because over just 16 years it represents three times the radiative effect expected from doubling preindustrial $\mathrm{CO}_{2}$. This documented increase in downwelling solar over the United States was part of a global-scale brightening observed during the 1990s and 2000s (Wild 2009a), although simultaneous dimming was also reported over parts of Asia during that period. That dimming was explained by a documented increase in aerosols over India and China, and speculation was that decreases in aerosols caused brightening elsewhere (Wild 20I2). Notably, general circulation models used to study climate change do not simulate the global brightening trend (Wild 2009b), thus demonstrating the importance of surface radiation measurements to climate research. With regard to the other three components of the surface net radiation, upwelling solar increased by about $2 \mathrm{~W} \mathrm{~m}^{-2}$ as a natural consequence of the increase in downwelling solar and a few years of anomalous snow cover in the eastern US, downwelling thermal infrared increased by about $3 \mathrm{~W} \mathrm{~m}^{-2}$, and upwelling thermal infrared decreased by about I W $\mathrm{m}^{-2}$. However, noted trends in these three components were not statistically significant because their year-to-year variability was quite high (Augustine and Dutton 2013).

Fortunately, quantitative measurements of aerosol optical depth (AOD) and cloud cover at SURFRAD sites were available to explain the observed brightening over the US Aerosol optical depth decreased by -0.025 over the 16 -year period. Such a change would contribute only $+0.82 \mathrm{~W} \mathrm{~m}^{-2}$ to the shortwave brightening. The remainder of the brightening was attributed to a documented decrease in cloud cover over the SURFRAD sites. That decrease was corroborated and extended to the entire US in a global study of Lambertian effective reflectivity (LER) using a 33-year time series of calibration-normalized SBUV satellite data (Herman et al. 2013).

Although upwelling thermal infrared over the US was well correlated with surface temperature, as expected, the variability of downwelling infrared was best correlated with the ENSO index, which systematically affects surface temperature, moisture, and cloud cover. That implies that ENSO strongly influences much of the weather and short-term climate variability over the US However, given that the mean surface air temperature did not change from 1996 to $201 \mathrm{I}$, it remains unclear what happened to the excess energy from the extraordinary brightening during that period. 
widespread flooding. Colorado had its wettest September on record with $312 \%$ of average precipitation. December CONUS precipitation was near average; however, California had its second driest December, punctuating the driest year in 119-years of record keeping in the state.

\section{(iii) Notable events}

Tornado activity during 2013 was much below average with 908 tornadoes confirmed for the year, compared to the 1991-2010 annual average of 1250 . This was the lowest number of tornadoes confirmed in the United States since 1989. There were 54 tornado-related fatalities in the CONUS, most of which occurred in Oklahoma during May. Twenty-four fatalities were reported on 20 May, when an EF-5 tornado hit the Oklahoma City metro area, with the most significant damage reported in the town of Moore. This tornado destroyed thousands of homes and businesses and was one of the costliest tornadoes in US history. On 31 May a 4.2-km-wide EF-3 tornado hit west of Oklahoma City-the widest tornado on record for the United States.

During 2013, approximately 46615 fires charred over 1.7 million hectares across the United States, both below average. Despite the below-average activity, there were several large and destructive wildfires. The Rim Fire in California burned over 103000 hectares, the third largest fire in California history. The Black Forest Fire destroyed over 500 homes near Colorado Springs, Colorado, making this the most destructive wildfire in Colorado history. And the Yarnell Hill Fire, near Prescott, Arizona, was responsible for 19 firefighter fatalities.

3) MeXıco-R. Pascual, A. Albanil, J. L. Vazquez, and R. Lobato

In 2013, a combination of dry spring months, nearnormal summer precipitation, and above-normal precipitation in the last quarter of the year was observed. The total annual rainfall of $920.6 \mathrm{~mm}$ (144 mm above the long-term mean) made 2013 the fourth wettest year since records began in 1941. Mexico also experienced its second warmest year since 1971, following the increasing temperature trend since the beginning of the 21 st century.

\section{(i) Temperature}

The 2013 national annual mean temperature of $21.9^{\circ} \mathrm{C}$ was $1.2^{\circ} \mathrm{C}$ above the $1971-2000$ normal, slightly cooler than the record-warm year of 2006 and just warmer than 2012 (Fig. 7.6). With the exception of January and December, each month

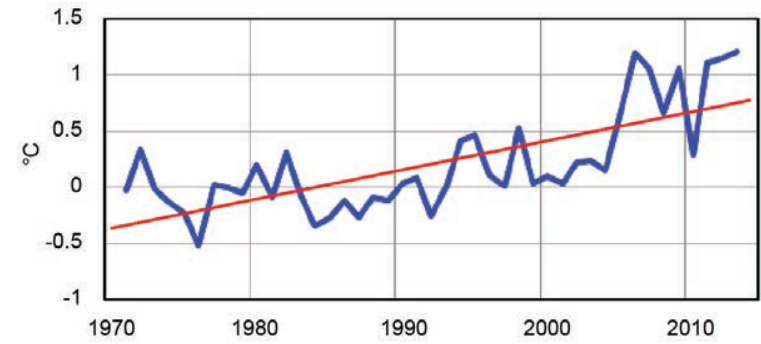

FIG. 7.6. Annual average temperature anomalies (blue line; ${ }^{\circ} \mathrm{C}$ ) for Mexico, for 197I-2012; red line represents the trend. (Source: National Meteorological Service of Mexico.)

had above-normal temperatures. Summer months (June-August) had the greatest positive anomalies, varying from $+2.6^{\circ}$ to $+3.0^{\circ} \mathrm{C}$, while December and January had $-0.5^{\circ} \mathrm{C}$ anomalies. Mean, maximum, and minimum temperatures were all warmer than two standard deviations above the average. The maximum temperature exceeded this threshold during spring (the dry season) and early August when the rainfall pattern decreased for several regions of the country, but remained slightly lower than earlier in the year as well as during the fall-to-winter transition. The minimum temperature was warmer than average from late May to October. Below-normal minimum temperatures occurred in March and December, when cold frontal systems resulted in strong and sudden decreases (Fig. 7.7).

During the year, $49 \%$ of the country had nearnormal temperatures (anomalies between $-1.0^{\circ}$ and $+1.0^{\circ} \mathrm{C}$ ), $36 \%$ between $+1.0^{\circ}$ and $+3.0^{\circ} \mathrm{C}$, and $8 \%$ with anomalies that exceeded $+3.0^{\circ} \mathrm{C}$. Only $6 \%$ recorded anomalies between $-1.0^{\circ}$ and $-3.0^{\circ} \mathrm{C}$ and $1 \%$ with anomalies less than $-3.0^{\circ} \mathrm{C}$ (Fig. 7.8a). Seven states were third warmest on record for the year (Baja California Sur, Chiapas, Durango, Morelos, Oaxaca,

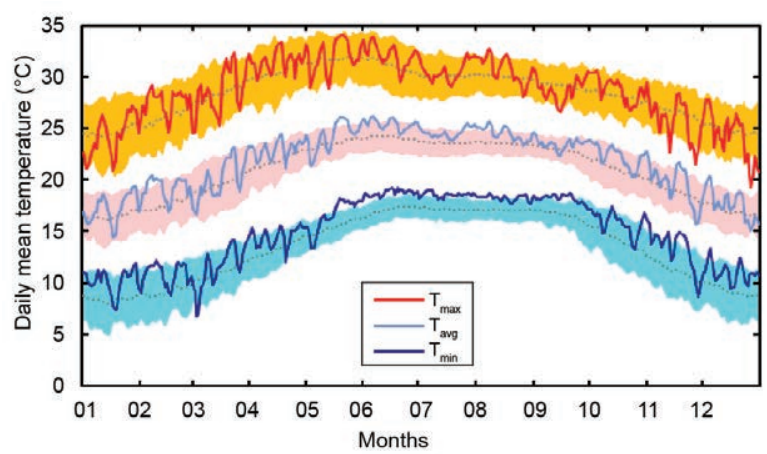

Fig. 7.7. Nationally-averaged annual maximum $\left(T_{\max }\right)$, average $\left(T_{\text {avg }}\right)$, and minimum $\left(T_{\text {min }}\right)$ temperature (solid lines; ${ }^{\circ} \mathrm{C}$ ) for 2013 . Shading represents \pm 2 std. dev. above or below the 197I-2000 period average. Dotted lines are the 197|-2000 average. (Source: National Meteorological Service of Mexico.) 
(a)

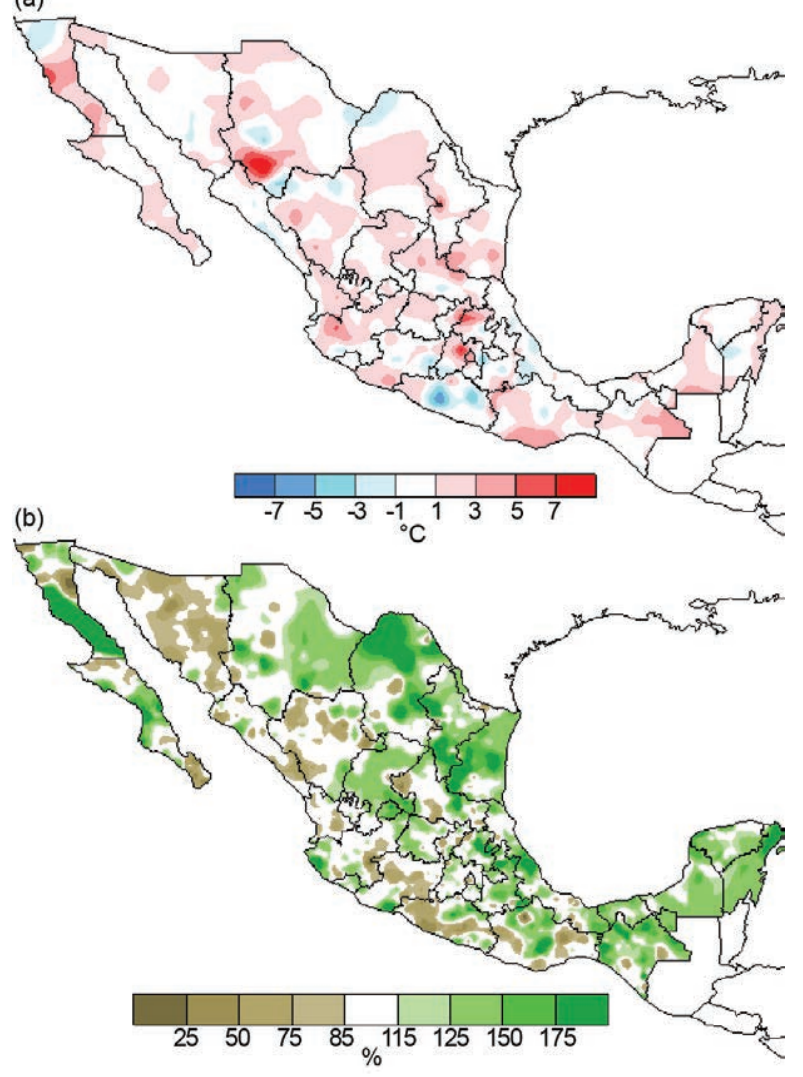

FIG. 7.8. (a) Annual average temperature anomalies $\left({ }^{\circ} \mathrm{C}\right)$ recorded in 2013 over Mexico (based on 197I2000 period) and (b) annual precipitation (\% of average), based on I97|-2000 period. (Source: National Meteorological Service of Mexico.)

Queretaro, and Yucatan); four states (Hidalgo, State of Mexico, Puebla, and San Luis Potosi) were second warmest, while Baja California, Campeche, and Federal District were warmest since records began in 1971.

During January-March, 38\% of the nation had at least five days with frost (when the daily minimum temperature was less than or equal to $0^{\circ} \mathrm{C}$ ), but some locations in Durango had more than 70 frost days. An isolated area in central Mexico had a lower number of frost days, where the Toluca synoptic station reported 37 frost days. During October-December, only 22\% of the nation recorded at least five frost days.

Hot days (daily maximum temperature $>40^{\circ} \mathrm{C}$ ) occurred in spring and summer. April-June was the warmest quarter for most of the country with temperatures exceeding $40^{\circ} \mathrm{C}$ over $35 \%$ of the country, most prominently in the northwest, west, north, south, and southeast but not the central region. Several locales on the Balsas River basin and between Jalisco and
Nayarit reported more than 60 hot days, with some even surpassing 70 .

The onset of the summer rainy season in central and southern Mexico contributed to a decrease in maximum temperature, such that the warmest regions were the northwest and northeast. Locations in Baja California, Sonora, and Coahuila reported more than 60 hot days during this period.

\section{(ii) Precipitation}

The year began with heavy rainfall in early January over the west-central region as a result of moist advection from the Pacific and a frontal passage. Nationally-averaged January precipitation was slightly above the 1971-2000 normal. From February to May, precipitation was intermittent and resulted in below-normal conditions. Although heavy rains were observed during late May and in the summer months, the rainfall deficit continued, then worsened between late July and the first half of August. In September moisture from four tropical cyclones (two occurring simultaneously) led to the wettest September in the last 70 years. While October rains were near normal, November was the wettest on record and December was fourth wettest for the month.

For the year, when defining "considerably above normal" as $>115 \%$ of normal, and "considerably below normal" as $<85 \%$ of normal, $47 \%$ of the country had considerably above normal and only $18 \%$ had considerably below normal, leaving 35\% with near-normal precipitation. However, excess rainfall occurred during September-December in many regions (Fig. $7.8 \mathrm{~b})$. The annual amount in the San Fernando-Soto La Marina River basin was above normal due to heavy rains observed in September, despite the precedent period to that month of near-normal precipitation. In contrast, in the Coatzacoalcos River basin, rainfall was below normal from January to October, but rains related to cold fronts in late October and early November provided enough moisture to overcome this deficit. The northern Yucatan Peninsula had beneficial rains throughout the summer, a slight decrease in July through the end of August, and continued rainfall for the rest of the year.

Precipitation during the first half of the year was below normal in northern Mexico, worsening drought conditions from April to June. In May, 58.2\% of Mexico was classified in drought or abnormal dryness, according to the North American Drought Monitor. Rainfall from July to December significantly reduced this drought area to only $6.8 \%$ by the end of the year. Hurricanes Barbara, Ingrid, and Manuel, 
Tropical Storms Barry and Lorena, and Tropical Depression Number Eight all brought heavy rainfall to various regions across Mexico.

\section{(iii) Notable events}

Two tropical cyclones arrived simultaneously on Mexico's coasts (Pacific and Atlantic) in September. Hurricane Ingrid (12-17 September) formed in the Gulf of Mexico, near northern Tabasco and made landfall between Tamaulipas and Veracruz. Southern Tamaulipas received half of its mean annual rainfall in just six days, while northern Veracruz received one-third of its mean annual during the same period. At the same time, Hurricane Manuel made landfall twice on the Pacific coast, with the rainfall contributing over $60 \%$ of the mean annual precipitation in parts of Guerrero; Michoacan, Colima, and Jalisco were also impacted. During 17-19 September, northern Sinaloa received $40 \%-60 \%$ of its mean annual rainfall. Manuel caused flooding and severe damage to infrastructure, but also helped to improve soil moisture and recharge aquifers and reservoirs. The last time two tropical cyclones impacted Mexico simultaneously was in 1958 when tropical storms Alma in the Atlantic and Number Two in the Pacific made landfall between 13 and 16 June.

Nine winter storms impacted the country this year, four of them between January and March and five from November to December. The mountains of Baja California, Sonora, Chihuahua, Coahuila, Durango, and Zacatecas were most affected by these with low temperature and snowfalls. The last winter storm in late December was the heaviest, causing sleet and snowfall over Chihuahua, Nuevo León, Durango, and Tamaulipas.

\section{c. Central America and the Caribbean}

I) Central America一J.A. Amador, E. J. Alfaro, H. G. Hidalgo, A. M. Durán-Quesada, B. Calderón, I. L. Rivera, and C. Vega

For this region, nine stations from five countries were examined. The stations located on the Caribbean slope are: Philip Goldson International Airport, Belize; Puerto Barrios, Guatemala; Puerto Lempira, Honduras; and Puerto Limón, Costa Rica. On the Pacific slope: Tocumen International Airport and David, Panamá; Liberia, Costa Rica; Choluteca, Honduras; and San José, Guatemala. Procedures follow Amador et al. (2011) for all variables, except that the base period used to compute anomalies was 1981-2010. Liberia showed abnormal precipitation values on 22 May, 30 May, and 7 June 2013; the corresponding corrections were made using precipitation observed at a nearby meteorological station from the Costa Rica National Meteorological Institute (CRNMI).

\section{(i) Temperature}

Mean temperature $\left(\mathrm{T}_{\mathrm{m}}\right)$ distributions for all stations are shown in Fig. 7.9. Most stations experienced a slightly warmer-than-average year. Similar to previous years, the negative skewness in $\mathrm{T}_{\mathrm{m}}$ at Philip Goldson and Puerto Barrios on the Caribbean slope, in both the climatology and for 2013, is most likely a result of frequent cold surges from the north during the winter months. The $\mathrm{T}_{\mathrm{m}}$ patterns suggest a near-normal year in northern Central America. The negative skewness in $\mathrm{T}_{\mathrm{m}}$ is rarely observed in Puerto Lempira and Puerto Limón, indicating that cold fronts reaching these station latitudes, in the mean, rapidly lose their thermal properties. On the Pacific slope, most stations recorded a higher frequency of warmer $\mathrm{T}_{\mathrm{m}}$ values during 2013 with less variability and lighter tails (indicating less frequent extremes).

\section{(ii) Precipitation}

For this section, "significant" probability (p) implies $0.05<\mathrm{p}<0.10$, and "very significant" probability implies $\mathrm{p}<0.05$. Tocumen was not considered in this analysis because of missing data during 2013. The start of the rainy season is identified as two consecutive days with at least $25 \mathrm{~mm}$ of precipitation followed by a third day with measurable precipitation. A similar approach was used to compute the end of the rainy season, but from the end of the year backwards.

Compared with the 1981-2010 period, 2013 was a near-normal year in terms of starting and ending dates of the rainy season for the Central American stations, with the exception of Liberia and Philip Goldson International Airport, which observed early starting dates of the rainy season. Liberia experienced a wet year during 2013, including significantly late ending dates of the rainy season. It was the only station with a very significantly above-normal maximum 5-day wet-period accumulation, and a significantly below-normal number of dry pentads. In addition, Liberia and Philip Goldson International Airport showed significantly above-normal precipitation interquartile ranges, indicating great variability in contrast to the climatology, and an above-normal number of extreme wet outliers (precipitation above the 90th percentile). Other stations with an abovenormal number of wet outliers were San José, Belize, and Puerto Barrios, Guatemala. Choluteca was the only station that showed above-normal maximum 


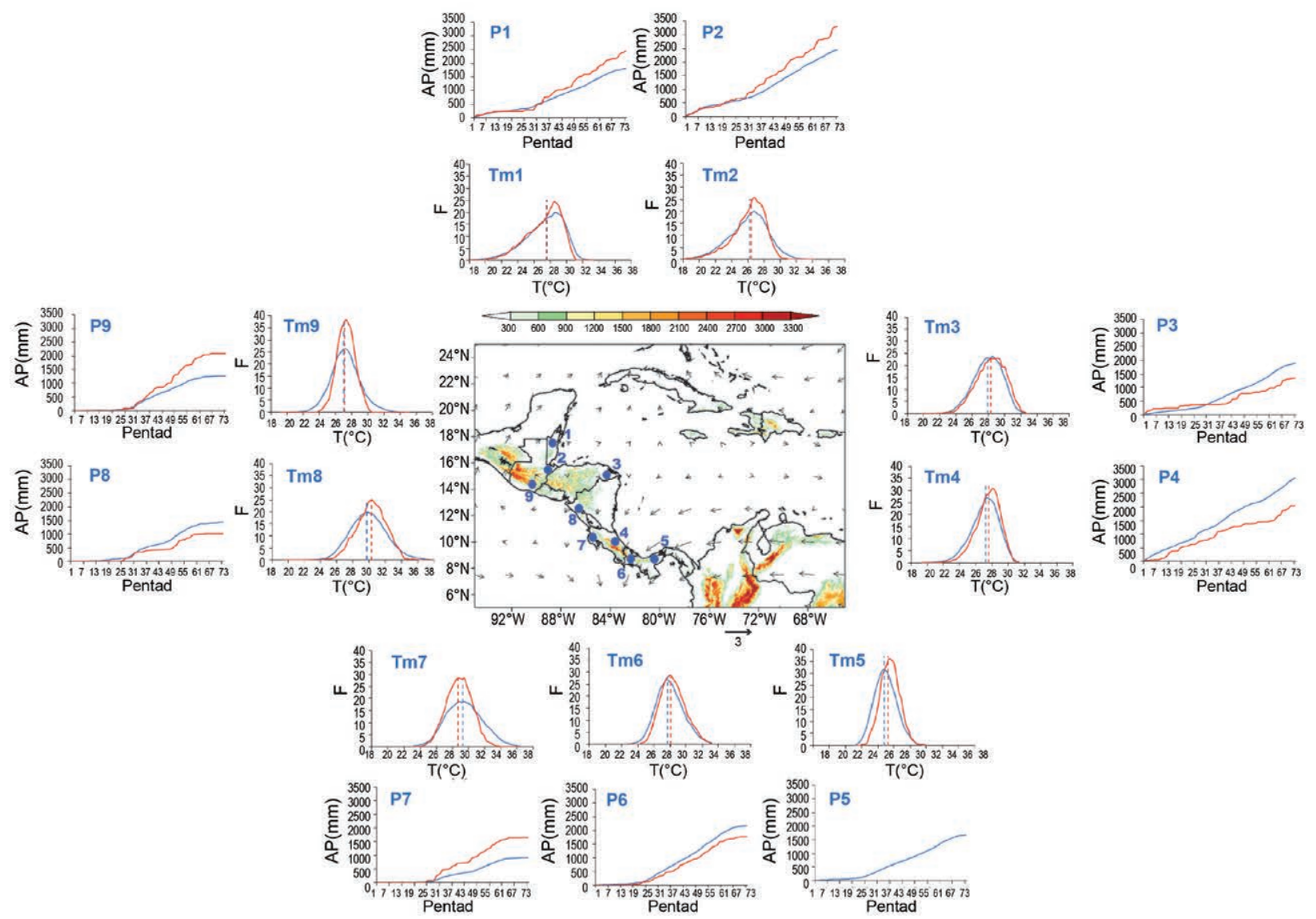

Fig. 7.9. Mean surface temperature $\left(T_{m},{ }^{\circ} \mathrm{C}\right)$ frequency $(F)$ and accumulated pentad precipitation (AP, mm) time series are shown for nine stations (blue dots) in Central America: (I) Philip Goldson International Airport, Belize; (2) Puerto Barrios, Guatemala; (3) Puerto Lempira, Honduras; (4) Puerto Limón, Costa Rica; (5) Tocumen International Airport, Panamá; (6) David, Panamá; (7) Liberia, Costa Rica; (8) Choluteca, Honduras; and (9) San José, Guatemala. The blue solid line represents the 1981-2010 average values and the red solid line shows 2013 values. Vertical dashed lines depict the mean temperature for 2013 (red) and the 1981-2010 period (blue). Tocumen (station 5) does not display 2013 precipitation due to missing data. Vectors indicate Jul wind anomalies at $925 \mathrm{hPa}$ (198I-20 I0 base period). Shading depicts regional elevation (m). (Source: NOAA/NCDC.)

number of dry-pentads, and Puerto Limón had significant above-normal number of extreme dry outliers.

Moisture transport from both the Caribbean and the eastern tropical Pacific followed the mean annual cycle with deviations in intensity from the 1980-2013 period. A decrease in moisture transport from the Caribbean was observed during January and February. This is likely related to a cooler-than-normal SST and associated reduction in evaporation. The start of the 2013 rainy season coincided with a marked increase in the transport of moisture from the Caribbean in April (of the order of $4 \mathrm{~mm} \mathrm{day}^{-1}$ ). A reduction of transport from the Caribbean is observed from reanalysis data during the second half of the year, which may be linked with a decrease of the cyclone activity in 2013. Moisture transport from the eastern tropical Pacific was greater than normal, indicating an intensification of evaporation (Leduc et al. 2007).

\section{(iii) Notable events}

The region was under the influence of neutral ENSO conditions (see section $4 \mathrm{~b}$ ) and strongerthan-average 925-hPa winds during July (vectors in Fig. 7.9), a condition unfavorable for tropical cyclone formation (Amador et al. 2006). Indeed, 2013 was a below-average year for tropical storms in the Caribbean basin $\left(6^{\circ}-24^{\circ} \mathrm{N}, 92^{\circ}-60^{\circ} \mathrm{W}\right)$. For the first time since 1986 there were only two named storms and no hurricanes in the region (Table 7.1).

During the first half of the rainy season (MayJune), strong convective storms brought heavy rains that triggered landslides, claiming two lives in Panamá and three in Guatemala. During 3-13 September, several intense rainfall events and flash floods affected the Pacific slope and the populated areas of the Costa Rica's Central Valley, according to the CRNMI. The second half of the rainy season 
Table 7.I. Number of named storms (NS) for years with zero, one, and two NS in the Caribbean ba$\sin \left(6^{\circ}-24^{\circ} \mathrm{N}, 92^{\circ}-60^{\circ} \mathrm{W}\right)$ for $1948-2013$. Named storms that reached hurricane $(\mathrm{H})$ or tropical storm (TS) strength are shown in parenthesis after the year with the maximum Saffir-Simpson category hurricane strength (Cat) also indicated. (Source: HURDAT 2, http://www.aoml.noaa.gov/hrd/hurdat IData_Storm.html.)

\begin{tabular}{|c|l|}
\hline Number of Named Storms (NS) & \multicolumn{1}{|c|}{ Years } \\
\hline 0 & 1983 \\
\hline 1 & $\begin{array}{l}1962 \text { (TS Daisy), 1965 (H Betsy Cat 3), 1972 (H Agnes Cat I), 1976 (TS } \\
\text { Emmy), I99I (TS Fabian), 1992 (TS Andre) }\end{array}$ \\
\hline 2 & $\begin{array}{l}1968 \text { (TS Abby, H Gladys Cat I), 1975 (H Eloise, H Gladys both Cat I), 1977 } \\
\text { (H Anita Cat 4, TS Freda), I 1986 (TS Danielle, TS Frances), 1987 (H Emily Cat }\end{array}$ \\
$\begin{array}{l}\text { 3, TS Floyd), 1997 (H Ericka Cat 3, TS Grace), 2002 (H Lili, H Isidore, both } \\
\text { Cat 3), 2013 (TS Chantal, TS Grabiele) }\end{array}$ \\
\hline
\end{tabular}

(August-November) wreaked havoc across Central America, claiming more than 41 lives (28 in Honduras and at least 13 in Nicaragua) due to intense rains, landslides, and river floods.

2) The Caribbean - T.S. Stephenson, M. A. Taylor, A. R. Trotman, A. 0. Porter, I. T. Gonzalez, J. M. Spence, N. Mclean, J. D. Campbell, G. Brown, M. Butler, R. C. Blenman, A. P. Aaron-Morrison, and V. Marcellin-Honore'

The Caribbeans climate was influenced by neutral ENSO conditions, an anomalously warm tropical North Atlantic in the latter half of the year, and below-normal hurricane activity. Annual temperatures were near normal (Fig. 7.10a). Normal to abovenormal annual rainfall occurred over most eastern Caribbean islands, Puerto Rico, eastern Jamaica, and eastern Cuba (Fig. 7.10b). Unless otherwise specified, comparisons are to the 1981-2010 base period. Records set for the following territories are with respect to the year in parenthesis: Dominica (1982), Puerto Rico (1898), St. Croix (1972), St. Thomas (1953), Trinidad and Tobago (1946 and 1969, respectively).

\section{(i) Temperature}

Annual temperatures over the Caribbean were generally normal relative to 1981-2010 (Fig. 7.10a). Barbados recorded monthly maximum temperatures near or below the climatological means, except in March. The Cayman Islands reported warmer- (cooler-) than-normal monthly maximum (minimum) temperatures throughout the year. Monthly average temperatures were above normal across Trinidad, Tobago, and Puerto Rico, with San Juan recording its second warmest December $\left(26.8^{\circ} \mathrm{C}\right)$. Other top 10 temperatures recorded for San Juan include the ninth warmest March $\left(26.4^{\circ} \mathrm{C}\right)$ and the fifth warmest April, $\left(27.1^{\circ} \mathrm{C}\right)$, fifth warmest April, September, and October $\left(29.1^{\circ}\right.$ and $28.8^{\circ} \mathrm{C}$, respectively). St. Croix experienced its tenth coolest March and May $\left(25.1^{\circ}\right.$ and $26.8^{\circ} \mathrm{C}$, respectively) and second warmest October $\left(28.6^{\circ} \mathrm{C}\right)$. Near-normal temperatures were recorded over Cuba, excluding March and October where above- and below-normal temperatures were
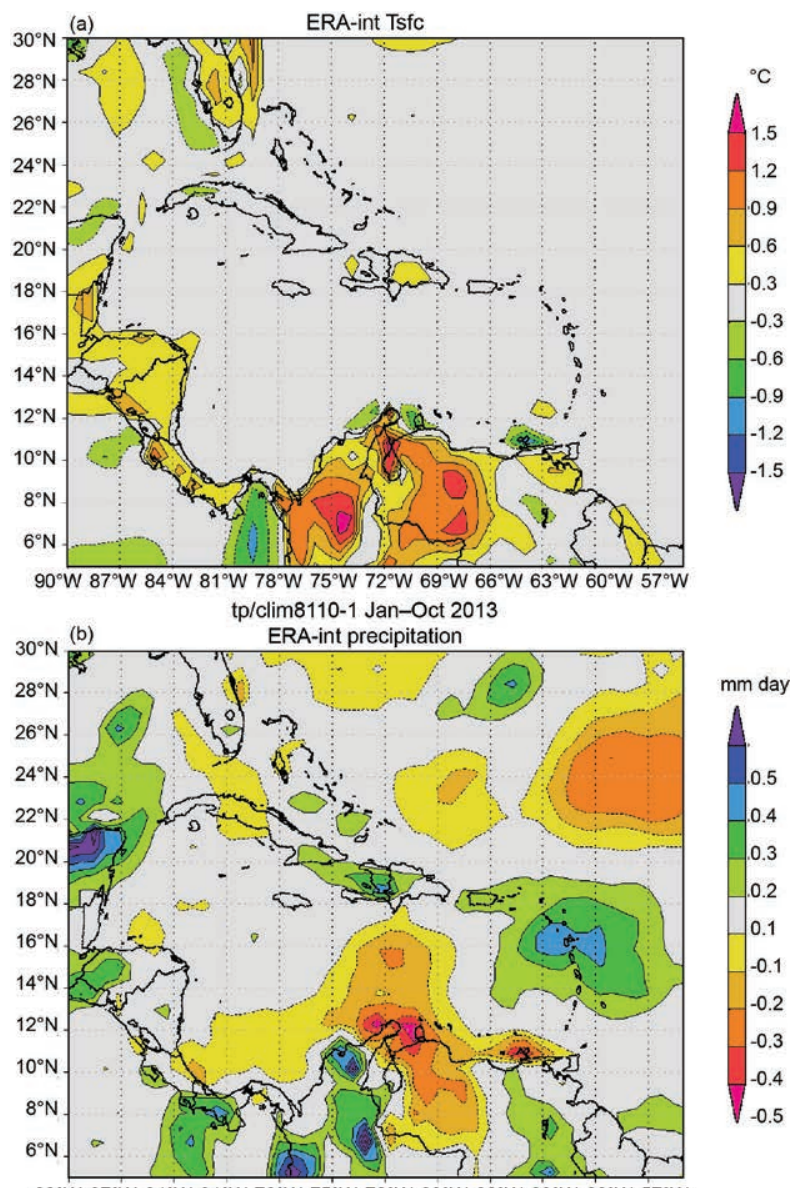

FIG. 7.I0. (a) Temperature $\left({ }^{\circ} \mathrm{C}\right)$ and (b) rainfall $(\mathrm{mm}$

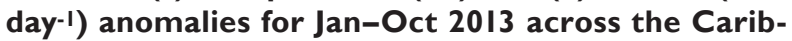
bean basin (with respect to the 198I-2010 mean). (Source: ERA-Interim.) 
Table 7.2. Values of climate indices calculated for 2013 and compared with the corresponding median value calculated over the $1981-2010$ period. CDD is the maximum number of consecutive dry days; $R \times I$ ( $R \times 5)$ is annual highest daily (5 consecutive days) precipitation ( $\mathrm{mm}$ ); TX90 (TN90) is the percentage of days when maximum (minimum) temperature is warmer than the 90 th percentile; TXI0 (TNI0) is the percentage of days when maximum (minimum) temperature is cooler than the 10 th percentile. Indices are a subset of indices of extremes defined by the WMO Commission for Climatology and the World Climate Research Programme Climate Variability and Predictability Expert Team on Climate Change Detection and Indices. A comprehensive analysis for the Caribbean is presented by Stephenson et al. (2014).

\begin{tabular}{|c|c|c|c|c|c|c|c|c|}
\hline \multirow{2}{*}{ Station } & \multicolumn{3}{|c|}{ CDD (days) } & \multicolumn{2}{|c|}{$\mathrm{RXI}(\mathrm{mm})$} & \multicolumn{3}{|c|}{$\mathrm{R} \times 5(\mathrm{~mm})$} \\
\hline & \multicolumn{2}{|l|}{2013} & Median & 2013 & Median & \multicolumn{2}{|c|}{2013} & Median \\
\hline Nassau, Bahamas & \multicolumn{2}{|l|}{18} & 25 & 162.6 & 92.1 & \multicolumn{2}{|c|}{238.5} & 163.8 \\
\hline $\begin{array}{c}\text { Grantley Adams } \\
\text { International, } \\
\text { Barbados }\end{array}$ & \multicolumn{2}{|l|}{33} & 33 & 73.0 & 72.6 & \multicolumn{2}{|c|}{ I0I.I } & 129.5 \\
\hline $\begin{array}{c}\text { Owen Robert } \\
\text { A Georgetown, } \\
\text { Cayman }\end{array}$ & \multicolumn{2}{|l|}{16} & 28 & 93.5 & 114.0 & \multicolumn{2}{|c|}{148.5} & 177.0 \\
\hline $\begin{array}{c}\text { Cabo de San } \\
\text { Antonio, Cuba }\end{array}$ & \multicolumn{2}{|l|}{26} & 31 & 114.8 & 111.7 & \multicolumn{2}{|c|}{346.0} & 178.3 \\
\hline Camagüey, Cuba & \multicolumn{2}{|l|}{24} & 29 & 220.0 & 83.2 & \multicolumn{2}{|c|}{431.0} & 134.0 \\
\hline $\begin{array}{c}\text { Casablanca, } \\
\text { Cuba }\end{array}$ & \multicolumn{2}{|l|}{39} & 28 & 228.3 & 106.1 & \multicolumn{2}{|c|}{314.7} & 166.9 \\
\hline $\begin{array}{c}\text { Punta de Maisi, } \\
\text { Cuba }\end{array}$ & 27 & & & 50.8 & 106.6 & 52. & & 156.0 \\
\hline $\begin{array}{c}\text { Melville Airport, } \\
\text { Dominica }\end{array}$ & 14 & & & 129.4 & 137.9 & 429 & & 241.5 \\
\hline $\begin{array}{c}\text { Worthy Park, } \\
\text { Jamaica }\end{array}$ & 22 & & & 73.0 & 119.0 & 101 & & 233.3 \\
\hline $\begin{array}{l}\text { Crown Point, } \\
\text { Tobago }\end{array}$ & 18 & & & 66.8 & 81.4 & 119 & & 140.8 \\
\hline Piarco, Trinidad & 33 & & & 74.7 & 88.0 & 113 & & 161.2 \\
\hline Station & TX90 & $\%$ days) & $\mathrm{TXIC}$ & $\%$ days) & TN90 & 6 days) & TNIC & (\% days) \\
\hline Station & 2013 & Median & 2013 & Median & 2013 & Median & 2013 & Median \\
\hline Nassau, Bahamas & 16 & 9 & 6 & 9 & 22 & 10 & 2 & 7 \\
\hline $\begin{array}{c}\text { Grantley Adams } \\
\text { International, } \\
\text { Barbados }\end{array}$ & 5 & 5 & 2 & 5 & 20 & 7 & 3 & 8 \\
\hline $\begin{array}{c}\text { Owen Robert } \\
\text { A Georgetown, } \\
\text { Cayman }\end{array}$ & 16 & 7 & 9 & 10 & 19 & 9 & 3 & 7 \\
\hline $\begin{array}{c}\text { Cabo de San } \\
\text { Antonio, Cuba }\end{array}$ & 17 & 9 & 12 & 10 & 14 & 8 & 13 & 9 \\
\hline Camagüey, Cuba & 10 & 9 & 10 & 9 & 10 & 8 & 10 & 9 \\
\hline $\begin{array}{c}\text { Casablanca, } \\
\text { Cuba }\end{array}$ & 14 & 9 & 14 & 9 & 19 & 9 & 9 & 10 \\
\hline $\begin{array}{c}\text { Punta de Maisi, } \\
\text { Cuba }\end{array}$ & - & 9 & - & - & 18 & 8 & 5 & 9 \\
\hline $\begin{array}{c}\text { Melville Airport, } \\
\text { Dominica }\end{array}$ & 13 & 5 & 8 & 9 & 9 & 10 & 4 & 8 \\
\hline $\begin{array}{l}\text { Worthy Park, } \\
\text { Jamaica }\end{array}$ & 16 & 9 & 0 & 9 & - & 9 & - & 6 \\
\hline $\begin{array}{l}\text { Crown Point, } \\
\text { Tobago }\end{array}$ & 13 & 7 & 9 & 9 & I & 7 & 10 & 7 \\
\hline Piarco, Trinidad & 11 & 5 & 6 & 8 & 16 & 7 & 2 & 6 \\
\hline
\end{tabular}

observed, respectively. Table 7.2 suggests that warm days and nights generally exceeded the 30 -year median. Cool days and nights were less than the 30 -year median for most stations evaluated.

\section{(ii) Precipitation}

From January through March, rainfall was normal to below normal over much of the Caribbean. Whereas Trinidad, Tobago, Grenada, St. Vincent, and Antigua experienced average rainfall, Puerto Rico, Jamaica, the U.S. Virgin Islands, and the Cayman Islands were dry, with Barbados and Dominica extremely dry. Records include the driest January $(12.2 \mathrm{~mm})$ for St. Thomas and the sixth driest February $(15.5 \mathrm{~mm})$ for St. Croix. Dominant influences were neutral ENSO conditions, nearnormal sea surface temperatures, and persistent subtropical high pressure.

During the second quarter of the year, with the exception of Haiti, southern Puerto Rico, Aruba, Bonaire, and Curaçao, the tendency changed to wet or very wet conditions, particularly in the eastern Caribbean. Dominica recorded its second wettest April $(684.4 \mathrm{~mm})$, receiving almost four times the monthly average. Puerto Rico (San Juan metro area) experienced its third wettest May (369.3 $\mathrm{mm}$ ) and fourth wettest June $(286.8 \mathrm{~mm})$, and St. Thomas recorded its fifth wettest June $(111.3 \mathrm{~mm})$. The wetter regime in the eastern Caribbean was facilitated by a northward shift of the subtropical high from mid-April and a persistent trough. Notably, eastern and southern Haiti 
were wet amidst generally dry conditions elsewhere in the country, giving rise to both water shortages and losses from floods.

Persistent ENSO neutral conditions, above-normal tropical Atlantic sea surface temperatures, unusually persistent inflow of dry air from the Sahara Desert, and a southwardly displaced subtropical high in July contributed to normal to below-normal rainfall over the eastern Caribbean between July and September. Barbados, St. Lucia, and Dominica reported normal rainfall totals while Trinidad, Tobago, Antigua, Grenada, and St. Vincent reported below-normal rainfall. Grenada recorded its lowest June-August rainfall total $(229.7 \mathrm{~mm})$; Trinidad had its third driest July (131 $\mathrm{mm}$ ) and second driest August (114 mm); Tobago had its driest July $(52.3 \mathrm{~mm})$; and St. Croix recorded its ninth driest July $(43.2 \mathrm{~mm})$. In contrast, Puerto Rico (San Juan metro area) had its wettest July (359.9 mm) and second wettest summer $(835.4 \mathrm{~mm}$ for June-August). San Juan recorded a one-day total of $234.4 \mathrm{~mm}$ due to a strong tropical wave on 18 July. This was its second wettest day on record, behind 15 August 1944, when $245.6 \mathrm{~mm}$ of rainfall was observed. St. Thomas experienced its ninth wettest July $(108.7 \mathrm{~mm})$, fourth wettest August $(195.3 \mathrm{~mm}$ ) and sixth wettest September $(249.4 \mathrm{~mm})$. Jamaica recorded normal amounts in the west to above normal in the east for the summer.

For the last quarter of 2013, the tendency was for normal to above-normal rainfall. Although St. Thomas recorded its sixth driest October $(57.9 \mathrm{~mm})$, it also recorded its third wettest November (278.1 $\mathrm{mm})$ and third wettest December (186.4 mm). St. Croix recorded the fifth highest December (168.7 $\mathrm{mm}$ ). Jamaica was moderately dry in the west and abnormally dry in the east.

The year 2013 ranks as the second wettest on record at Canefield Airport in Dominica $(2219.1 \mathrm{~mm}$, which represents $126 \%$ of normal). The year was the fourth wettest for San Juan, Puerto Rico (the Luis Muñoz Marin International Airport recorded 2162.0 $\mathrm{mm}$ which represents $151 \%$ of normal). Table 7.2 presents some extreme climate indices calculated annually for a number of Caribbean stations and how they compare with their counterpart median values.

\section{(iii) Notable events}

Above-normal rainfall in April led to two deaths in Dominica, and significant losses in Trinidad and Tobago. Tropical Storm Chantal in July affected up to $50 \%$ of banana production in some areas in Dominica and produced showers in St. Vincent and the Grenadines.
A surface trough affected the eastern Caribbean on 24 December. Dominica, St. Lucia, and St. Vincent and the Grenadines experienced heavy rainfall resulting in extensive flooding and landslides. St. Lucia and St. Vincent and the Grenadines reported six and nine fatalities, respectively, and all of the islands reported significant property losses and damaged infrastructure. St. Lucia's agricultural sector was significantly impacted. The same trough brought 76 and $127 \mathrm{~mm}$ of rainfall across eastern Puerto Rico and the US Virgin Islands, respectively.

Significant annual precipitation deficits were noted for the provinces of Pinar del Río, Matanzas, Las Tunas Santiago de Cuba, and Guantánamo in Cuba.

\section{d. South America}

The year 2013 was characterized by neutral ENSO conditions and persistent cold anomalies in the eastern Pacific Ocean (Fig. 7.11). This feature influenced the region's climate, especially across western South America.

The annual mean temperature was predominantly above normal in South America. However, the warmest and more persistent anomalies were observed over the Colombia-Venezuela border and eastern Brazil. Below-normal temperatures were observed in Bo-

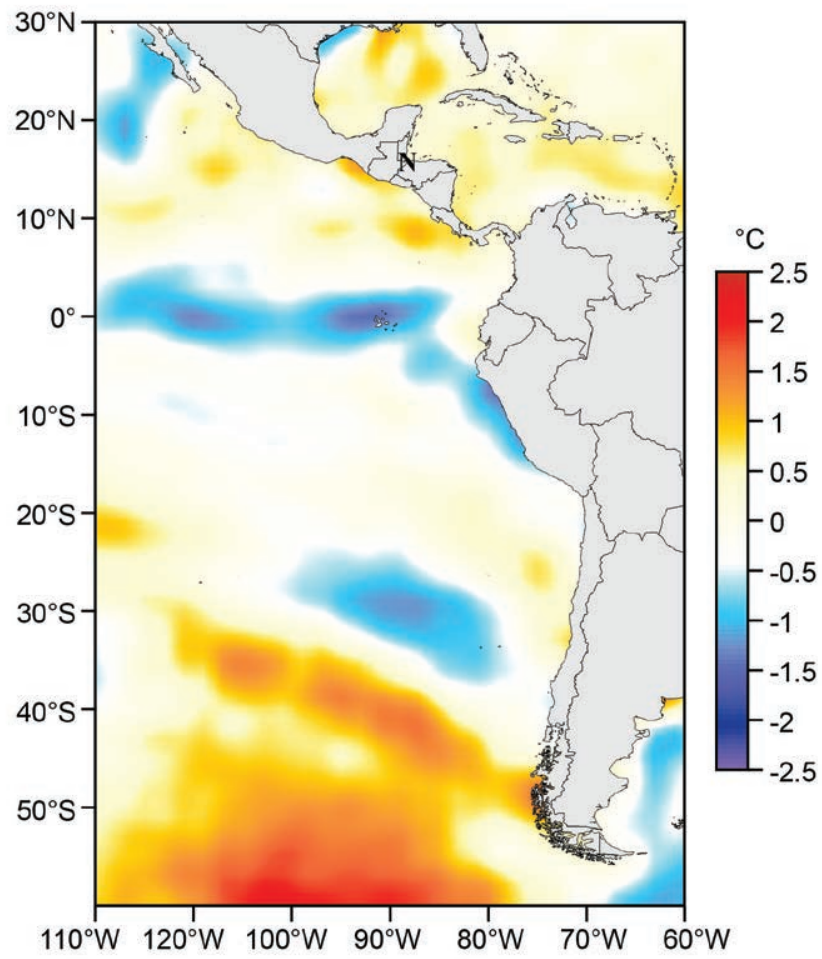

Fig. 7.II. Mean annual sea surface temperature anomalies $\left({ }^{\circ} \mathrm{C}\right)$ relative to $197 \mid-2000$. (Sources: NOAA/NCEP, processed by CIIFEN.) 

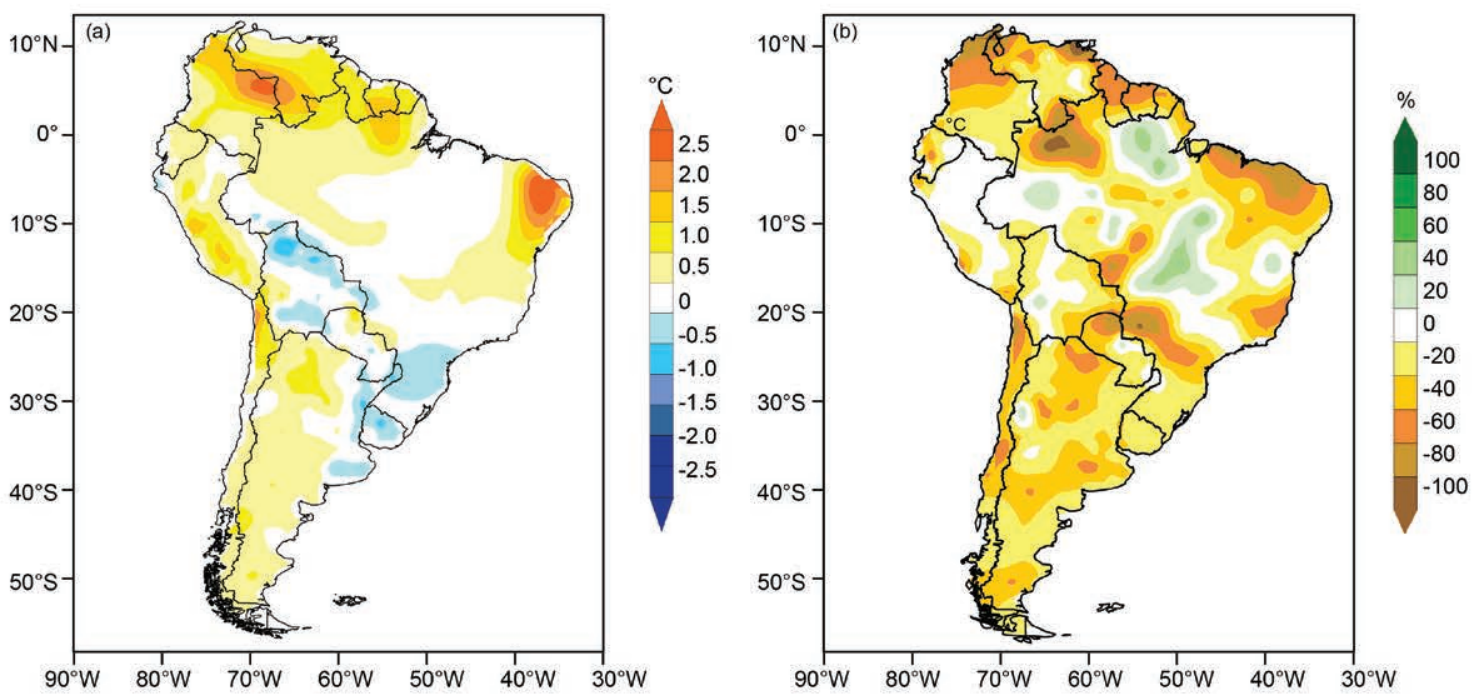

FiG. 7.12. South America 2013 annual (a) mean temperature anomalies ( ${ }^{\circ} \mathrm{C}$; $197 \mathrm{I}-2000$ base period) and (b) precipitation anomalies (\%; 197I-2000 base period). (Sources: National Meteorological Services of Argentina, Brazil, Bolivia, Chile, Colombia, Ecuador, Paraguay, Peru, Suriname, Uruguay, and Venezuela; processed by CIIFEN.)

livia, the Argentina-Brazil border, and Uruguay (Fig. 7.12a). Precipitation was below normal across most of the continent. Significant precipitation deficits were recorded in northeastern and southern Venezuela, northern Colombia, the northern coast of Ecuador, northern and central Chile, and several wide sectors in Argentina and Brazil (Fig. 7.12b).

I) Northern South America and the tropical ANDEs-R. Martínez, J. Arévalo, G. Carrasco, C. Euscátegui, J. Bazo, J. Nieto, and E. Zambrano

This section refers to Bolivia, Colombia, Ecuador, Peru, and Venezuela. Unless otherwise noted, anomalies are with respect to the 1971-2000 base period.

\section{(i) Temperature}

Above-normal temperatures were observed across most of Venezuela during January-March, with anomalies up to $+1.0^{\circ} \mathrm{C}$. During April-June, temperatures were near normal in the central and eastern zones and above normal in the west. Above-average temperatures prevailed the rest of the year, with temperatures up to $0.5^{\circ} \mathrm{C}$ above average across central and eastern Venezuela during the last three months of the year. In Colombia, maximum temperatures were above normal most of the year. Anomalies between $+2.0^{\circ}$ and $+5.0^{\circ} \mathrm{C}$ were observed during the first half of the year in large areas across the Caribbean coastal region and some areas of the northern and southern Andes. In Ecuador, the annual mean temperatures were below normal (about $-1.5^{\circ} \mathrm{C}$ ) across the coastal region. However, no record annual minimum temperatures were observed in 2013. In contrast, above- normal temperatures, up to $2.0^{\circ} \mathrm{C}$ above average, were predominantly observed in the highlands, where several records were set during 2013. Peru's Amazon region experienced below-average temperatures throughout the year, with the exception of positive anomalies at the end of the year.

In Peru's coastal region, temperatures were near normal during January-March and below normal during April-June. During July-September, subfreezing temperatures were observed in the southern highlands. but were higher than the records set in 2012.

\section{(ii) Precipitation}

Venezuela experienced below-average precipitation during January-March, especially across northern and southeastern parts of the country. During April-June, most of the country experienced slightly below-normal precipitation, again with the exception of northern and southeastern regions which had above-average precipitation. During June-September, the country experienced slightly below-normal precipitation. During October-December, Venezuela had near-normal precipitation. Colombia's total precipitation values were near-normal during 2013. However, during July-September 150\%-of-normal precipitation was reported in the Central and Southern Andean departments. Precipitation was $175 \%$ of normal over large areas of Cundinamarca, Tolima, Quindío, Valle, Cauca, Huila, and Nariño.

During the rainy season (January-March), Ecuador experienced above-average (140\% of normal) precipitation along the coastal zone, causing minor 
flooding in some areas but also favoring rice crops. During the same period, below-normal precipitation was recorded in the highlands. The dry conditions contributed to a higher frequency and intensity of bushfires. In the highlands of Ecuador, precipitation as high as $250 \%$ of normal fell during May-June.

In Peru, dry conditions were observed in the northwest region during the first months of 2013, while along the central and southern highlands and somewhat in the Amazonia region, precipitation was above normal. Several historical precipitation records were broken during the rainy season (January-March). During the second half of the year most of the country registered near-normal precipitation.

During 2013, Bolivia observed below-average precipitation, with the exception of the Altiplano (El Alto, Potosí, and Oruro) which had near-average precipitation. In Oruro, the total annual precipitation was $141 \%$ of normal in December. In Bolivia's valleys and low lands, precipitation was below normal most of the year with exception of December when precipitation was $116 \%$ (valleys) and 194\% (low lands) of normal. The northern region of the country showed below-normal precipitation during most of the year. However, monthly precipitation totals of up to $188 \%$ of normal were recorded in September.

\section{(iii) Notable events}

On 8 February, in Arequipa, Peru, a precipitation record of $125 \mathrm{~mm}, 500 \%$ of normal for the month, was registered. The heavy rain caused eight fatalities and losses of nearly $\$ 35$ million US dollars.

During 21-26 July, Peru's Madre de Dios region was affected by strong cold events with temperatures dropping between $10^{\circ}$ and $20^{\circ} \mathrm{C}$ in less than 24 hours. During August, a snow storm affected the Andes region which killed over 25300 animals, left over 5200 people homeless, and destroyed nearly 140 homes in Apurimac, Ayacucho, Cusco, Huancavelica, Puno, and Junín.

2) Tropical South America east of the Andes-J.A. Marengo, L. M. Alves, J. C. Espinoza, and J. Ronchail

Unless otherwise noted, normals and anomalies are based on the 1961-90 average.

\section{(i) Temperature}

Across most of the region, the monthly mean temperature was about $1^{\circ} \mathrm{C}$ warmer than average throughout most of 2013. In the northern Amazon, northern Paraguay, and southern Bolivia temperatures were about $2^{\circ} \mathrm{C}$ above normal from January-
July. Anomalously low temperatures $\left(1^{\circ} \mathrm{C}\right.$ below normal) were observed in southern Brazil and southern Paraguay in March.

Temperatures were warmer than normal during much of the winter (June and July), though August was colder than normal. From July to September, 19 cold surges affected southern Amazonia, southern Brazil, and western Amazonia. In Inacio Martins, in the highlands of the state of Parana, Brazil, air temperatures dropped to $-4.5^{\circ} \mathrm{C}$ and, for the first time in 38 years, it snowed in the capital city of Curitiba. In the southern part of the state of Sao Paulo on 24 July temperatures dropped to $4^{\circ} \mathrm{C}$, the lowest minimum temperature for that month since 2000. In the city of Rio Branco, in the state of Acre in western Brazilian Amazonia, temperatures dropped to $7.5^{\circ} \mathrm{C}$ on 25 July, $9.0^{\circ} \mathrm{C}$ below normal and the lowest July temperature in 15 years.

\section{(ii) Precipitation}

During summer and fall 2013, rainfall was well below average between January and May (50-200 mm below average) in northeastern Brazil, continuing the intense drought that started in 2012. Wet conditions prevailed in February ( $200 \mathrm{~mm}$ above normal) over southern Peru and Bolivia. Rainfall episodes in central Brazil were due to the presence of three episodes of the South Atlantic convergence zone (SACZ). Dry conditions (50 $\mathrm{mm}$ below normal) prevailed in southern Brazil almost all year long, intensifying during December. Wet conditions prevailed in June from southern Peru all the way to southern Brazil $(100 \mathrm{~mm}$ above normal) due to several cold fronts impacting the region. Wet conditions were also detected over Bolivia and south of Northeast Brazil in December (100-300 mm above normal). This was due to the presence of the SACZ, while precipitation deficits continued over the core region of the South American monsoon (200 $\mathrm{mm}$ below normal).

From March to June many areas of Bolivia had insufficient amounts of rainfall (50-100 mm below normal) and drought severely affected agriculture production. In August, wet conditions (100 mm above normal) left 50 districts of the states of Parana, Santa Catarina, and Rio Grande do Sul under a state of emergency, with 70000 people affected.

\section{(iii) Notable events}

In March, temperatures across the interior of the state of Pernambuco in Northeast Brazil reached $39.5^{\circ} \mathrm{C}$, the highest temperature in 2013. On $17 \mathrm{Sep}$ tember Brazil's capital, Brasilia, recorded tempera- 
tures as high as $32.6^{\circ} \mathrm{C}\left(4.1^{\circ} \mathrm{C}\right.$ above normal $)$ and on 23 September the city of Belo Horizonte experienced temperatures $34.5^{\circ} \mathrm{C}\left(7.2^{\circ} \mathrm{C}\right.$ above normal $)$ - the highest daily temperature recorded for each location in 2013. On 11 November temperatures were as high as $34.6^{\circ} \mathrm{C}\left(8.6^{\circ} \mathrm{C}\right.$ above normal), the highest daily temperature in 2013 in Sao Paulo, while in Rio de Janeiro the temperature soared to $41.8^{\circ} \mathrm{C}\left(14.8^{\circ} \mathrm{C}\right.$ above normal) on 12 November, its highest daily temperature in 2013. On 26 December temperatures reached $38.8^{\circ} \mathrm{C}$ $\left(9.8^{\circ} \mathrm{C}\right.$ above normal) in the city of Porto Alegre, surpassing the previous record of $37.7^{\circ} \mathrm{C}$ set in 2012 .

A remarkable cold air surge brought cold temperatures to parts of the tropical South America during 22-25 July. This event produced snow in southern Brazil, and on 24 July the city of Sao Paulo registered its coldest temperature since $1961\left(8.6^{\circ} \mathrm{C}\right)$.

The wet conditions in southern Peru and Bolivia in February produced floods and landslides that destroyed 3500 houses. By March, wet conditions in the Huallaga River basin (Peruvian Amazon), produced floods that affected 2700 people and the agriculture production in the region. Floods between March and May affected more than 50000 people in Colombia. On 20 March, heavy rains affected the highlands of Rio de Janeiro, causing damages estimated at $\$ 60$ million US dollars. In Petropolis, $300 \mathrm{~mm}$ of rainfall were registered during a 24-hour period, compared to just $270 \mathrm{~mm}$ typical for all March.

In the city of Salvador in the state of Bahia, on 10 December, torrential rains caused 16 fatalities and more than 800 people were forced to evacuate their houses. Torrential rains caused floods and landslides in southeastern Brazil during 16-23 December, leading to 50 deaths in the Brazilian states of Rio de Janeiro, Bahia, and Espiritu Santo.

A state of emergency was declared across parts of northeastern Brazil where residents coped with one of the worst droughts on record. Three consecutive years of drought have had a devastating effect in the region, considered one the country's poorest (Fig. 7.13). The causes of this drought are related to anomalies in the large scale circulation, where warm surface water in the tropical North Atlantic favored an anomalously northward migration of the ITCZ. This reduces the moisture transport from the tropical North Atlantic to the region (Marengo et al. 2013; Nobre and Shukla 1996).

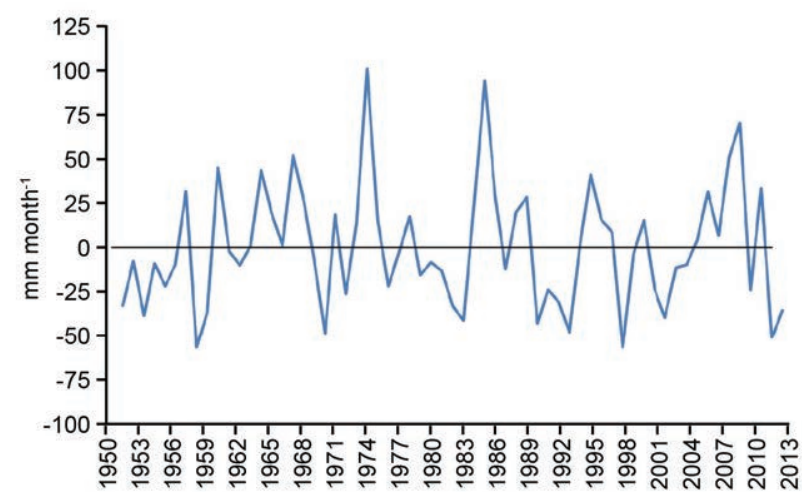

FIG. 7.13. Rainfall anomaly (mm month-1; 196I-90 base period) during the peak rainy season (Feb-May) in Northeast Brazil for 195I-2013. (Source: Global Precipitation Climatology Centre; Marengo et al. 20I3.)

Rainfall in Espirito Santo during December (Fig. 7.14) was the most intense during the last 90 years, according to INMET and INCAPER (Meteorological Center of the state of Espiritu Santo), affecting 70000 people. In the capital, Vitoria, a record-setting total of $669 \mathrm{~mm}$ of rain fell in 23 days-more than three times the monthly average of $180 \mathrm{~mm}$. The previous rainiest December in Vitoria was in 1948 with 522 $\mathrm{mm}$. At other stations, rainfall surpassed $700 \mathrm{~mm}$. Within the state, 46000 people were forced to leave their homes due to flooding. By 25 December, 21 deaths were reported, and floods and landslides affected more than $60 \%$ of the state. The cause of the intense rainfall was the very active SACZ over Minas Gerais, Espirito Santo, and Bahia. (a)

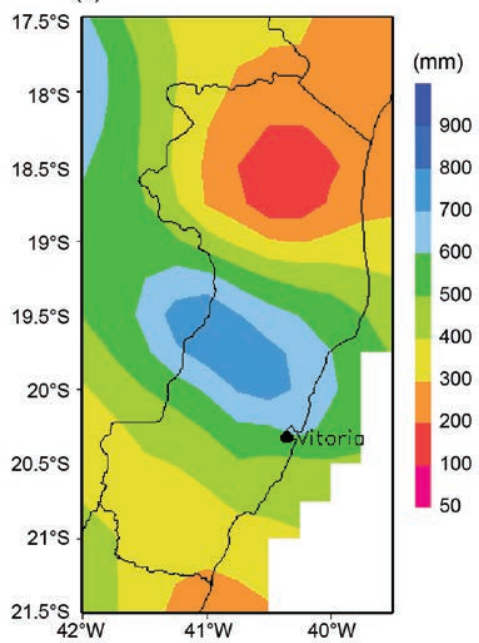

(b)

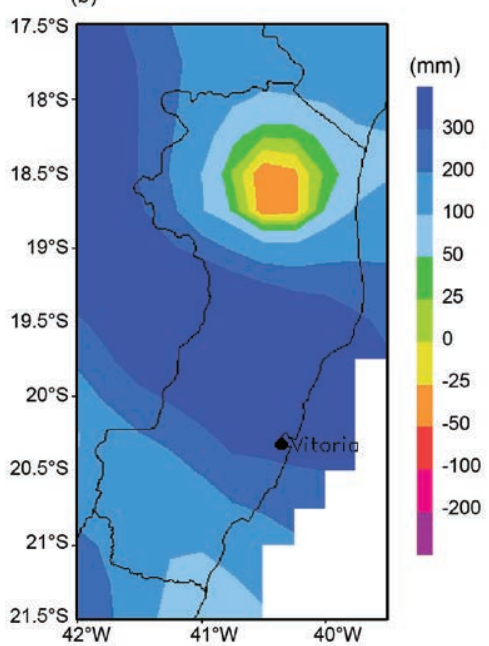

FIG. 7.14. (a) Accumulated rainfall $(\mathrm{mm})$ and (b) rainfall anomalies $(\mathrm{mm})$ in the state of Espirito Santo, Brazil, for Dec 2013. Anomalies are with respect to the 1961-90 base period. (Source: INCAPERMeteorological Center, state of Espiritu Santo.) 
3) Southern South America-M. Bidegain, J. L. Stella, and 0. C. Penalba

In this section, Argentina, Chile, Uruguay and adjacent areas of southeastern Brazil are part of the southern South America and the anomalies are based on the period 1961-90.

\section{(i) Temperature}

Above-normal temperatures were observed over most of southern South America (SSA) during 2013, with mean temperature anomalies between $+0.2^{\circ}$ and $+1.0^{\circ} \mathrm{C}$ (see Fig. 7.12a). The 2013 mean temperature anomaly for Argentina, as a whole, was estimated at $+0.57^{\circ} \mathrm{C}$, the second warmest year (behind 2012) since national records began in 1961.

The Southern Hemisphere summer (December 2012-February 2013) was particularly warm in southern and across parts of northwestern Argentina. During the Southern Hemisphere fall (March-May), mean temperatures were cooler than normal across Uruguay and eastern Argentina, with the most notable monthly temperature anomalies (between $-3^{\circ}$ and $-5^{\circ} \mathrm{C}$ ) in the Buenos Aires Province, Argentina and Uruguay. However, April was extremely warm, with several locations setting new monthly records.

The Southern Hemisphere winter (June-August) in SSA was extremely variable, with very warm and very cold periods. August was particularly cold, as two cold waves brought minimum temperatures below $-5^{\circ} \mathrm{C}$ across most of the region. However, an abrupt change in circulation at the end of the month brought warm temperatures to the same region, with several locations recording temperatures over $30^{\circ} \mathrm{C}$. In some cases new absolute minimum and maximum temperature monthly records were set only a few days apart (e.g., Bahia Blanca: $-7.9^{\circ} \mathrm{C}$ on 25 August and $32.6^{\circ} \mathrm{C}$ on 30 August).

The Southern Hemisphere spring (SeptemberNovember) brought more variability in extreme temperatures. The first eleven days of September were extremely hot across most of Argentina and Uruguay. Extreme high maximum monthly temperatures for September were recorded in several locations, breaking historical records (e.g., $41.8^{\circ} \mathrm{C}$ on 10 September in San Juan, Argentina; $35.3^{\circ} \mathrm{C}$ on 11 September in Buenos Aires, Argentina; $37.4^{\circ} \mathrm{C}$ on 11 September in Bella Unión, Uruguay). This situation changed when a strong cold outbreak reached central and northern Argentina and Uruguay. The mean temperatures decreased more than $20^{\circ} \mathrm{C}$ in just a few days and the rest of the month was characterized by cold outbreaks. Very low maximum temperatures dominated the rest of the month and some locations broke historical records. Within a span of days some locations set new September records for the highest maximum temperature and lowest maximum temperature (e.g., $34.4^{\circ} \mathrm{C}$ on 9 September and $4.6^{\circ} \mathrm{C}$ in 28 September in Santa Rosa).

From October onwards warmer-than-normal conditions prevailed over most parts of the country, with December being the hottest month of the year.

\section{(ii) Precipitation}

During 2013, rainfall was below normal across most of SSA (see Fig. 7.12b). The year was dry for the region, particularly across the wet Pampas region in Argentina. The annual rainfall as a whole was estimated at $88 \%$ of normal. Some locations in the north and central parts of Argentina experienced their driest year since records began in 1961.

The SSA experienced below-average precipitation during summer (December-February), with northern Argentina provinces having $~ 50 \%$ rainfall deficits. The lack of precipitation affected both agriculture and water supply. During March, an early cold outbreak produced very low temperatures in central and northern Argentina, with unusual snowfall in lower latitudes of Cordoba and San Luis provinces.

Due to a Pacific cold front and low pressure center at the end of September, the provinces of La Pampa, San Luis, and Mendoza in Argentina recorded moderate snowfall. This is a rare phenomenon in September and, according to historical data, the latest snowfall observed for this region.

\section{(iii) Notable events}

Extreme daily rainfall severely affected some areas during the year. The most significant event occurred on 2 April in the city of La Plata (near Buenos Aires). A powerful storm hit the city with extraordinarily heavy rainfall, producing flash floods and causing more than 60 fatalities. It was considered one of the worst weather disasters in Argentina's history. The official station recorded $181 \mathrm{~mm}$ in just a few hours, marking a daily record for that location (http://www .smn.gov.ar/htms/informe_tormenta_abril_2013 .pdf). The previous night, the city of Buenos Aires was also affected by heavy rainfall and flooding in some districts. The total rainfall amount ranged between 150 and $180 \mathrm{~mm}$ in just a few hours. Analysis of satellite and radar images showed that this storm had a very slow movement, affecting a small localized area.

During June, exceptional rainfall amounts were observed in Brazil's Upper Parana River and Iguazu 


\section{SIDEBAR 7.2: EXTREME HEAT WAVE OVER CENTRAL SOUTHERN SOUTH AMERICA DURING DECEMBER 2013-M. BIDEGAIN, J. L. STELLA, AND}

\section{C. PENALBA}

Central Argentina and Uruguay experienced an intense heat wave as a marked increase in temperatures began II December (Fig. S7.2), with most of the temperatures above the extreme threshold (>90th percentile; http:// www.smn.gov.ar/serviciosclimaticos/clima/archivo/informe _temperatura_dicl3.pdf; http://www.meteorologia.gub.uy/ $\mathrm{pdf} / \mathrm{rrpp} / 118$-77212.pdf). [When maximum and minimum temperatures simultaneously surpass the 90 th percentile thresholds for three or more consecutive days, the event is considered a heat wave (Beniston 2004).] The central part of the region was severely affected by the persistence of extremely high temperatures. By 19 December, the extreme warmth extended to the north and intensified over the central region. The heat persisted until the end of the month and several locations broke historical records for heat wave duration. Most of the affected region recorded its warmest December on record, with the length of this extreme heat wave ranging between 5 and 16 days at various locations. The persistence of extreme maximum and minimum temperatures, separately, ranged between 7 and 18 days. This extreme heat was mainly related to the persistence of high pressure in the middle and high levels of the atmosphere that prevented colder air masses from reaching central and northern Argentina. This type of circulation anomaly configures a blocking pattern and the longer its duration, the more extreme its effects on weather extremes.

The city of Buenos Aires recorded its warmest December on record in 2013 with a mean temperature of $26.6^{\circ} \mathrm{C}$, and equaled the warmest month (January 1989) recorded since records began in 1906.

Other significant heat waves have been previously observed in Argentina and Uruguay, particularly notable in December 1971, March 1980, and February 1987.

basin, eastern Paraguay, and northern Misiones province in Argentina. In this area, monthly rainfall anomalies were more than $200 \mathrm{~mm}$ (e.g., Puerto Iguazu: $+351.3 \mathrm{~mm}$ ), and totals of more than three times the normal were recorded for June.

A series of flood events in the Parana and Iguazu Rivers spread into the Argentine section on 1 July, with neighborhoods flooded, residents evacuated, and animals transferred to higher ground.

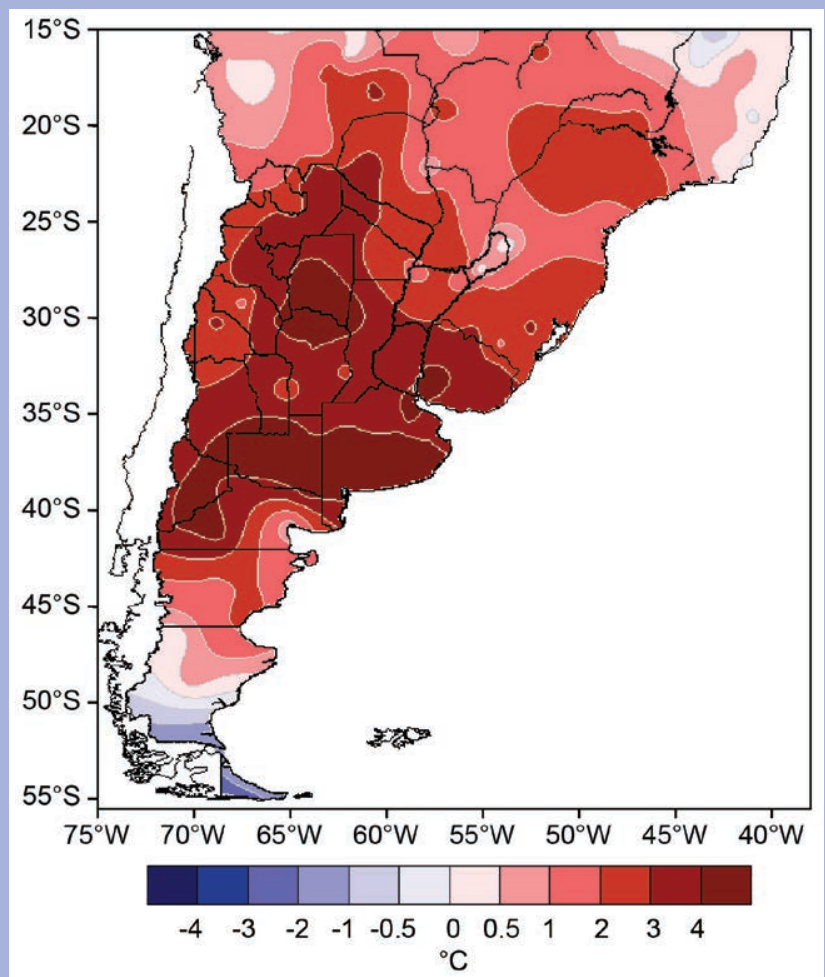

FIG. SB7.2. Monthly maximum mean temperature anomaly $\left({ }^{\circ} \mathrm{C}\right)$ for December 2013 relative to the 196I-90 base period. 


\section{e. Africa}

I) Northern Africa—K Kabidi, A. Sayouri, and A. Ebrahim

This analysis includes Morocco, Algeria, Tunisia, and Egypt. In the following, Morocco, Algeria, and Tunisia are referred to as Northwestern Sub-Region (NWSR). The base periods for NWSR and Egypt are 1981-2010 and 1978-2008, respectively.

\section{(i) Temperature}

Over Morocco, the annual mean temperature was near normal, with some exceptions. February brought a cold wave associated with heavy snowfall over NWSR (Fig. 7.15a). The North Atlantic circulation, featuring the strengthening of the Azores anticyclone, favored the penetration of deep cold air from central Europe through the western Mediterranean basin into northern Africa and parts of West Africa (Mali and Mauritania). The lowest temperatures were recorded on 2 February: $-10^{\circ} \mathrm{C}$ in Ainsefra, Algeria, and $-8.2^{\circ} \mathrm{C}$ in Ifrane, Morocco. Monthly minimum temperature anomalies were $-2.4^{\circ} \mathrm{C}$ in Tangier and $-4.0^{\circ} \mathrm{C}$ in Kef, Tunisia. In Egypt, temperatures were generally above normal from January to March. The lowest minimum temperature was $2.1^{\circ} \mathrm{C}$ on 10 January in El Arish, while mean monthly minimum temperature anomalies ranged between $-0.2^{\circ} \mathrm{C}$ in Alexandria and $-0.3^{\circ} \mathrm{C}$ in El Arish.

Similar to 2012, strong heat waves did not occur during the summer of 2013, except for the period

(a)

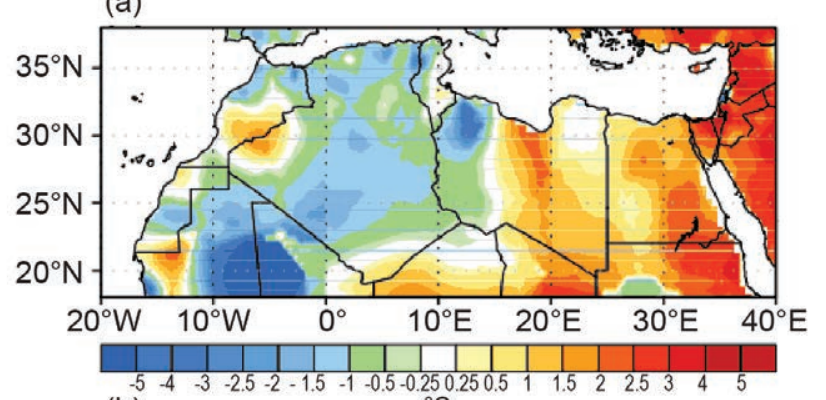

(b)

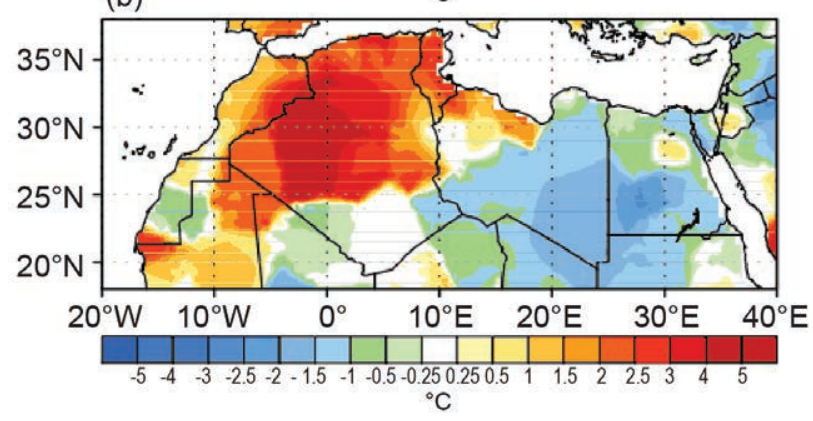

Fig. 7.15. Temperature anomaly $\left({ }^{\circ} \mathrm{C}\right)$ in northern Africa in (a) Feb 2013 and (b) Oct 2013, departure from the 198I-2010 mean. (Source: NOAA/NCEP.) from the end of July to the first half of August. In August, the daily maximum temperatures ranged from $41^{\circ} \mathrm{C}$ in coastal areas to $49^{\circ} \mathrm{C}$ in southern areas of the NWSR.

Over Morocco, the seasonal average maximum temperature was $4.5^{\circ} \mathrm{C}$ above normal in Taroudant. The nation's highest temperature for the year, $48.6^{\circ} \mathrm{C}$, was recorded on 8 August in Smara, located in southern Morocco. In Egypt, August average maximum temperatures reached $1.3^{\circ} \mathrm{C}$ above normal in Aswan and $2.8^{\circ} \mathrm{C}$ above normal in Hurguada. Temperatures in NWSR were above normal during fall, especially in October (Fig. 7.15b), when the monthly average maximum temperature anomaly over Morocco was $+2.8^{\circ} \mathrm{C}$. Temperatures were normal to below normal over Egypt.

\section{(ii) Precipitation}

Rainfall was generally below average across NWSR especially during January and February, except along the northern coastline from Morocco to Tunisia, where totals reached between 100 and $250 \mathrm{~mm}$ (Fig. 7.16a), indicating anomalies $20-50 \mathrm{~mm}$ above average for the two months (Fig. 7.16b). Rainfall deficits reached 50 to $100 \mathrm{~mm}$ below average along the west coast of Morocco. Nador, in northern NWSR, registered rainfall $292 \mathrm{~mm}$ below average. Locally, in north central and parts of southeastern Egypt the annual rainfall was $150 \%$ above average. Several localized

(a)
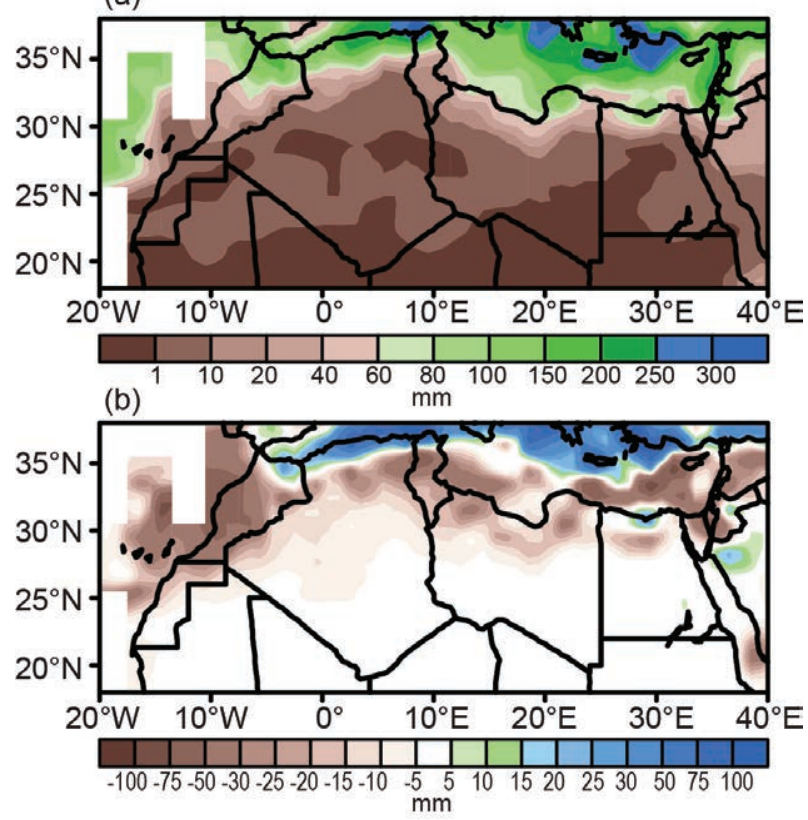

FIG. 7.16. Jan-Feb 2013 precipitation $(\mathrm{mm})$ for northern Africa, as (a) total precipitation and (b) departure from the 198I-2010 climatology. (Source: NOAA/NCEP.) 
extremely heavy rainfall events occurred in January. Hurguada, Egypt, received $250 \%$ of normal rainfall. Alexandria recorded $36.07 \mathrm{~mm}$ on 8 January, the highest 24-hour rainfall total in Egypt for the year.

Extremely heavy rains also fell during the spring season. In Chefchaouen, Morocco, the seasonal rainfall totals approached $160 \%$ of normal with a new 24-hour record of about $85 \mathrm{~mm}$ on $12 \mathrm{March}$. In Algeria, Oran recorded $97 \mathrm{~mm}$ in 24 hours in April, and Bouzaréah recorded a 24-hour rainfall total of $195 \mathrm{~mm}$ in May.

During summer, especially August, the presence and intensification of the Saharan heat low generated deep convective systems over the region. New seasonal record rainfall amounts were registered; Bousalem, Tunisia, recorded $118 \mathrm{~mm}$, while Asskrem, Algeria, received $75 \mathrm{~mm}$. Strong storms also occurred along the Mediterranean coast of Morocco. Fnideq registered $50 \mathrm{~mm}$ of rainfall on 29 August. There were regional differences in the NWSR rainfall during the fall season as Jijel, Algeria, recorded a monthly rainfall total of $367 \mathrm{~mm}$ (140\% of normal) in November, while Morocco, overall, received about $80 \%$ of average.

\section{(iii) Notable events}

Heavy rains associated with violent storms prevailed over the NWSR during the spring season and in August, causing serious property damage and casualties, with seven fatalities in Algeria. Freezing temperatures associated with heavy snowfall occurred in February over NWSR and resulted in the loss of lives. Heat waves associated with continental easterly winds and temperatures near $50^{\circ} \mathrm{C}$ favored several forest fires burning over 4300 ha land over Algeria.

2) West Africa一W. M. Thiaw, I. A. James, F. S. Dekaa, F. Sima, and K. A. Coulibaly

West Africa extends from the Guinea coast to about $20^{\circ} \mathrm{N}$ and from the eastern Atlantic coast to Chad. Climatologically, it consists of two distinct but inherently linked subregions: (1) the Sahel to the north from about $12^{\circ}$ to $17^{\circ} \mathrm{N}$, spanning countries from Senegal and Gambia in the west to Chad in the east; and (2) the Gulf of Guinea region to the south from about $4^{\circ}$ to $10^{\circ} \mathrm{N}$ encompassing the Guineas to the west along the east Atlantic coast and Nigeria and Cameroon to the east. Unless otherwise specified, the climatological base period for both temperature and precipitation is 1981-2010.

\section{(i) Temperature}

Annual temperature was near average across West Africa, except for the north central region including eastern Mali and northwestern Niger, where anomalies ranged between $+0.5^{\circ}$ and $+1^{\circ} \mathrm{C}$. Local areas, for example Dimbokre in east central Cote d'Ivoire, recorded more than $2^{\circ} \mathrm{C}$ above normal in February and in June, the highest in 53 years. Annual maximum temperatures were $0.5^{\circ}$ to $1^{\circ} \mathrm{C}$ above normal along the coast of Senegal and Mauritania, but $1^{\circ}$ to $3^{\circ} \mathrm{C}$ below normal over the Gulf of Guinea region from Cote d'Ivoire to western Nigeria. Annual minimum temperature was $0.5^{\circ}$ to $1^{\circ} \mathrm{C}$ above normal along coastal West Africa and over the central areas from the Gulf of Guinea region northward into the Sahel. Monthly air temperatures were generally near normal except for March and May. Anomalies in March ranged between $1^{\circ}$ and $3^{\circ} \mathrm{C}$ above the mean (Fig. 7.17). Northern Nigeria was extremely hot with maximum temperatures in March and April averaging $40^{\circ}$ to $42^{\circ} \mathrm{C}$, representing anomalies of $1^{\circ}$ to $2^{\circ} \mathrm{C}$ above normal. Temperatures in the lower Gulf of Guinea region were below normal during this time. The summer months exhibited below-normal temperatures in the central areas from Chad to Burkina Faso.

\section{(ii) Precipitation}

Consistent with the trend of the last decade and the prominence of the Atlantic multidecadal oscillation featuring a warm tropical north Atlantic, annual rainfall was once again above average across the Sahel. Slightly below-average rainfall was observed over the Gulf of Guinea region. The wetter-thannormal soils in the Sahel, especially during summer, which accounts for much of the annual precipitation, resulted in lower-than-normal temperatures during the season. Rainfall totals during June-September,

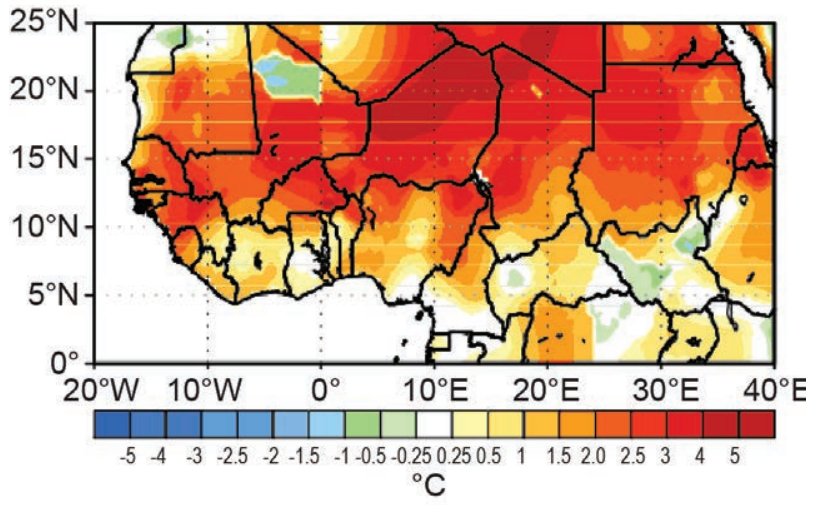

Fig. 7.I7. Temperature anomaly $\left({ }^{\circ} \mathrm{C}\right)$ for northern SubSaharan Africa in Mar 2013, departure from 1981-2010 climatology. (Source: NOAA/NCEP.) 
which accounts for much of the annual rainfall totals in the Sahel, ranged from 100 to $300 \mathrm{~mm}$ in the northern part of the Sahel (just north of $15^{\circ} \mathrm{N}$ ) and between 300 and $900 \mathrm{~mm}$ in the central areas $\left(12^{\circ}-5^{\circ} \mathrm{N}\right)$ to over $1200 \mathrm{~mm}$ in the areas of maximum precipitation, including the western Guinean coast and along the east coast of Nigeria and west coast of Cameroon (Fig. 7.18a). The 300-mm isohyet, defining the strength of the monsoon system, stretched from northern Senegal to central Chad along the $15^{\circ} \mathrm{N}$ latitude band. These amounts corresponded to aboveaverage rainfall across the Sahel and portions of the Gulf of Guinea region (Fig. 7.18b). Rainfall anomalies were $400 \mathrm{~mm}$ above normal along coastal Guinea. Surpluses approached $200 \mathrm{~mm}$ over the western part of the Sahel including Guinea Bissau, the southern half of Senegal, and Gambia. Elsewhere in the Sahel, rainfall anomalies ranged between 50 and $150 \mathrm{~mm}$ above average, in the areas stretching from northern Senegal to southern Mali and from eastern Nigeria to Chad, including northeastern Nigeria and northern Cameroon. In contrast, rainfall was 50-200 mm below average over the central sector of the Gulf of Guinea region from eastern Liberia to southwestern Nigeria. However, the spring season brought moderate moisture surpluses (50-100 $\mathrm{mm}$ ) across most areas in the Gulf of Guinea region. During fall, rainfall

(a)
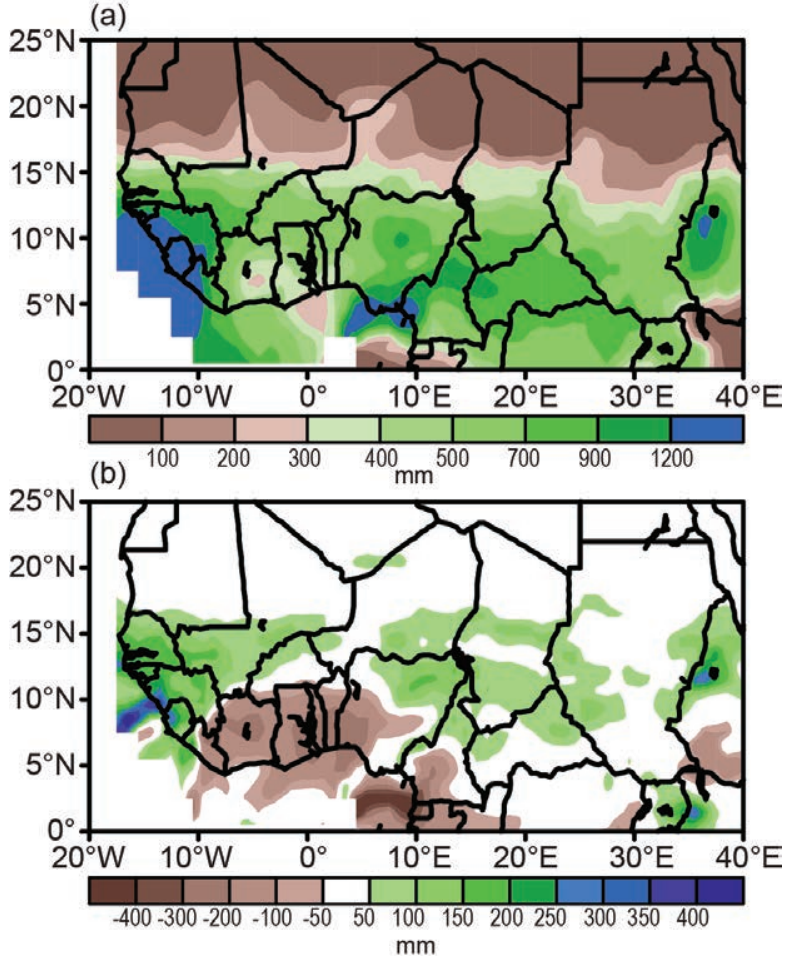

FIG. 7.I8. Jun-Sep 2013 precipitation $(\mathrm{mm})$ for northern Africa, as (a) total precipitation and (b) departure from the 198I-20 I0 climatology. (Source: NOAA/NCEP.) was above average in the eastern and western sectors. However, rainfall deficits prevailed along the central coastal areas from Liberia to southwestern Nigeria.

\section{(iii) Notable events}

The active West African monsoon (WAM) system in 2013 was once again associated with the prominence of the Atlantic multidecadal oscillation (AMO) featuring a warm tropical north Atlantic for much of January through October. In July, the Atlantic equatorial cold tongue intensified further, contributing to the enhancement of the WAM. Torrential rains fell along the Sahel band in August and September while below-average rainfall prevailed over the Gulf of Guinea region. This is a classic picture of the WAM decadal signal also linked to the AMO. According to the UN Office for the Coordination of Humanitarian Affairs, floods killed more than 80 people, displaced over 40000 , and otherwise affected more 300000 people in West Africa during 2013. Over 30000 hectares of agricultural land were damaged. Niger was the country most seriously affected in the region as nearly 100000 people needed humanitarian assistance. Gardeners and farmers along the Niger River lost their harvests as the river water rose very fast following episodic flood events that destroyed or submerged wells and irrigation ditches and dykes. In Nigeria, extremely heavy rains and flooding affected tens of thousands of people as high water levels prevailed at major dams. Camps were set up for the displaced people. In Mali, two severe flood events killed nearly 40 people, destroyed 300 homes and displaced 20000. Over 100000 homes were flooded in Senegal, mainly in the country's western sector.

While rainfall was above average across much of the region, insufficient and poorly-distributed rainfall led to large rainfall deficits across the Gulf of Guinea countries and resulted in reduced maize yields in Ghana, southern Togo, and to a lesser extent, southwestern Nigeria.

3) EAstern Africa—W. Gitau, L. Chang'a, C. Oludhe, L. Ogallo, Z. Atheru, P. Ambenje, A. Kijazi, H. Ng'ongolo, P. Luhunga, and P. Levira

The Greater Horn of Africa (GHA) can be divided into three sectors: (1) the Northern Sector, north of $5^{\circ} \mathrm{N}$, comprises Sudan, South Sudan, Ethiopia, Eritrea, Djibouti, and north and central Somalia; (2) the Equatorial Sector between $5^{\circ} \mathrm{N}$ and $5^{\circ} \mathrm{S}$, consists of southern Somalia, Kenya, northern Tanzania, Uganda, Rwanda, and Burundi; (3) the Southern Sector, south of $5^{\circ} \mathrm{S}$, encompasses central and southern Tanzania. This division applies to the analysis of 
rainfall only. Unless otherwise stated, the base period of 1981-2010 is used for climatology.

\section{(i) Temperature}

Annual temperatures were overall above normal across the region, consistent with anomalies registered over the last five years (2008-12; Fig. 7.19). Temperatures ranked between the 90th and the 99th percentile in Uganda, western Kenya, parts of northeastern Ethiopia and northern Somalia, and eastern Sudan. Maximum temperatures were average over the northern sector, and highest along the coastal equatorial sector and over the southern areas, especially in Tanzania, where they ranked between the 90th and the 99th percentile according to the NCEP reanalysis. Exceptions for Tanzania were a few local areas including Arusha in the northeastern highlands, where the maximum temperature was about average. Minimum temperature was highest in the northern sector with a 90 to 99 percentile ranking over northern Ethiopia and Somalia. Minimum temperature was average over the southern sector, except for portions of Tanzania, where Songea registered an annual minimum temperature $1.5^{\circ} \mathrm{C}$ below its $1961-90$ normal.

\section{(ii) Precipitation}

The GHA lies across the equator and receives rainfall year-round. December-February marks the main rainfall season over the southern sector of the GHA and the dry season in the northern sector. The equatorial sector receives rainfall in March-May (the "Long Rains" season) and in September-December (the "Short Rains" season). June-August is the main rainfall season over the northern sector. The western part of the equatorial sector also receives significant rainfall during this season. Precipitation anomalies for the main rainfall seasons are displayed in Fig. 7.20. Rainfall was below average over the southern sector during December-February. The western part of the equatorial sector received moderate rains indicated by anomalies of +10 to $+40 \mathrm{~mm}$. Rainfall was also abundant across this subregion in March-May. Anomalies exceeded $+150 \mathrm{~mm}$ locally over southern Somalia and ranged between +10 and $+70 \mathrm{~mm}$ in Kenya and northern Uganda. Precipitation was below average over Tanzania. The summer rains in June-August were characterized by moisture deficits in western Ethiopia, South Sudan, Uganda, Rwanda, and Burundi. Precipitation was above average over Sudan, northeastern Ethiopia, and Djibouti. The Short Rains season was characterized by moisture deficits across the equatorial sector and parts of eastern Tanzania.

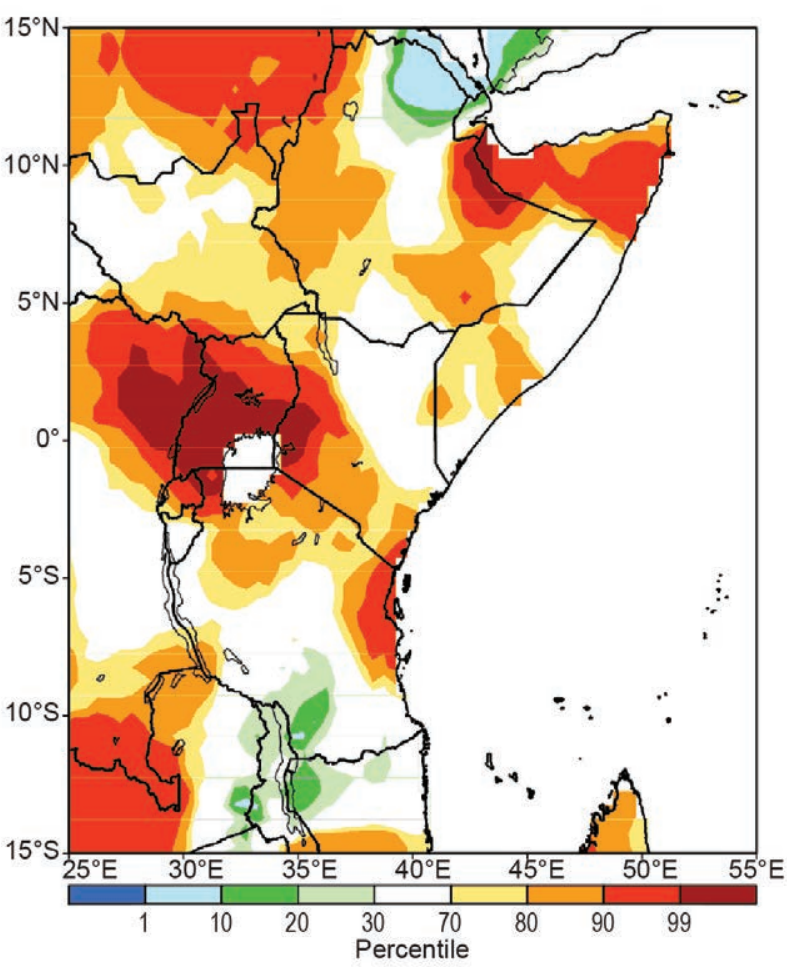

Fig. 7.19. Annual temperature anomaly $\left({ }^{\circ} \mathrm{C}\right)$ for the Greater Horn of Africa, departure from 198I-2010 climatology. (Source: NOAA/NCEP.)

The Indian Ocean dipole mode was slightly negative throughout the year. This, in combination with the suppressed phase of the MJO in September and October, contributed to below-average rains in eastern Africa, especially in Tanzania.

A more detailed analysis of the rainfall characteristics based on local station data and the 1961-90 climatology follows. During December-February 2012/13, Rwanda and Burundi, southern Kenya, and southern Uganda received between $75 \%$ and $125 \%$ of the long-term mean. The northern coast, central and western Kenya, and most areas in Uganda received between $125 \%$ and $175 \%$ of the long-term mean for the season. February brought an early cessation of the rains over the southern sector of the GHA. In March and April, average to above-average rains fell over much of the equatorial sector. Dry conditions prevailed over much of the northern sector. In June-August, areas in central Sudan received between $75 \%$ and $125 \%$ of the long-term mean. However, northeastern Sudan, parts of Somalia, eastern and southern Kenya, northern Tanzania, Rwanda, and Burundi received between $25 \%$ and $75 \%$ of the mean rainfall. The southern sector also received below-average rainfall. In September and October, most areas in the equatorial sector experienced a 


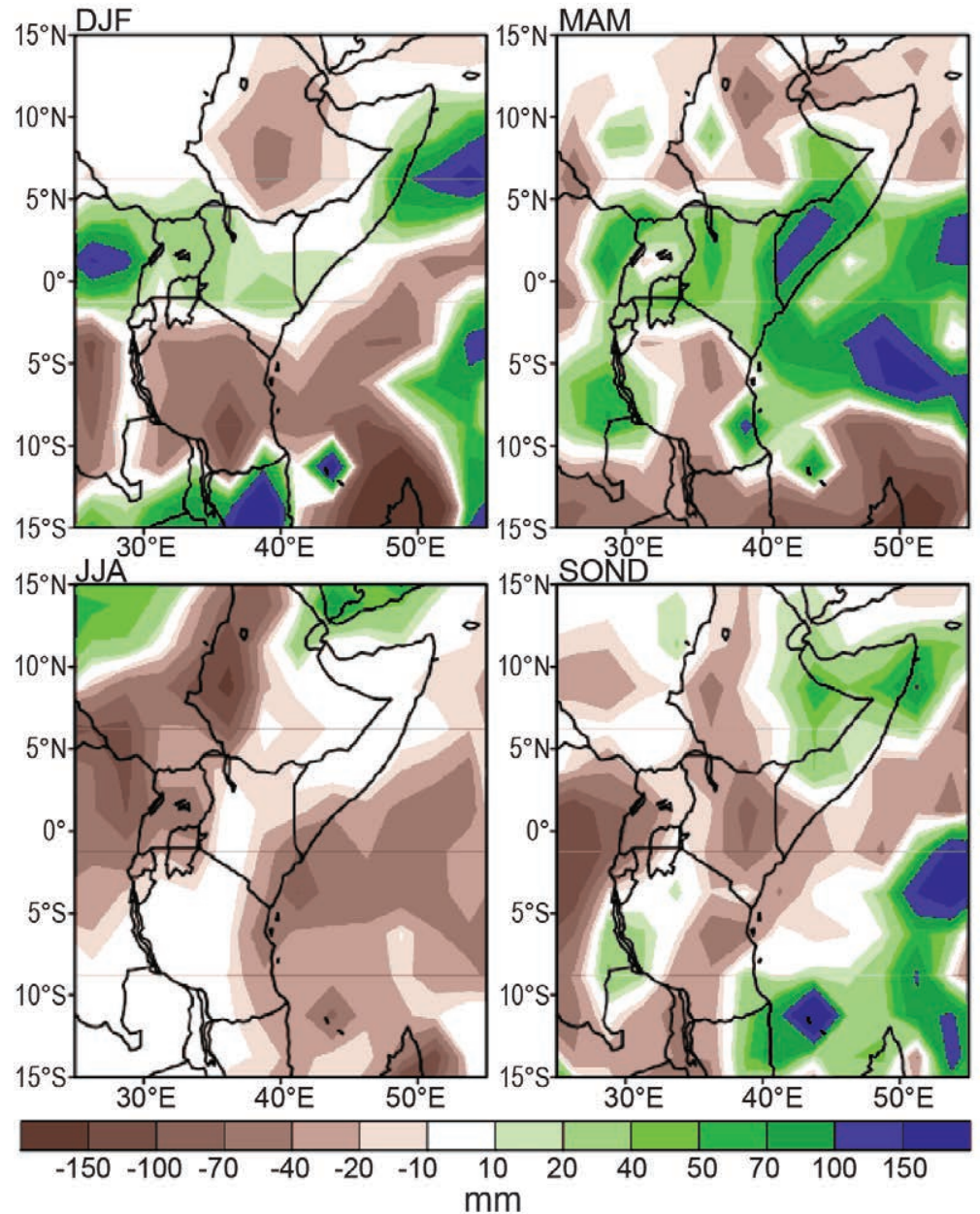

FIG. 7.20. Seasonal precipitation anomaly $(\mathrm{mm})$ for the Greater Horn of Africa, departure from the 198I-2010 climatology. (Source: NOAA/NCEP.)

delayed onset of the Short Rains season as moisture was mainly concentrated over the southwestern and central parts of the northern sector. The central and western parts of equatorial sector received abundant rains in November. Less than $75 \%$ of average rainfall in September-November fell over eastern Kenya and north central Tanzania. In December, average to above-average rainfall was observed over most areas in Tanzania, Rwanda, Burundi, and southwestern Kenya. Annual rainfall in Tanzania was overall about $75 \%-125 \%$ of the long-term average (1961-90). There were local exceptions: Singida received $>125 \%$ of normal rainfall, while Zanzibar, Morogoro, and Dar es Salaam received only $50 \%-75 \%$ of the mean rainfall.

4) Southern AfricA-A. Kruger, C. McBride, and W. Thiaw

This region includes the countries south of about $5^{\circ} \mathrm{S}$, with more detailed reporting on South Africa. Climatology is 1981-2010 unless otherwise indicated.

\section{(i) Temperature}

The mean annual air temperature from the NCEP reanalysis was generally near normal across southern Africa. However, maximum temperatures were $0.5^{\circ}$ to $2^{\circ} \mathrm{C}$ above normal over portions of Botswana, Democratic Republic of the Congo, and Tanzania (Fig. 7.21a). Minimum temperatures were $0.5^{\circ}$ to $2^{\circ} \mathrm{C}$ below normal over western South Africa, Namibia, and locally along coastal Tanzania (Fig. 7.21b). During the summer months of February and March, the monthly maximum temperature anomaly was $+1^{\circ}$ to $+4^{\circ} \mathrm{C}$ in the area encompassing South Africa, Botswana, and Namibia. Monthly mean maximum temperature anomaly was positive across much of the region from September to November. The monthly mean minimum temperature was below normal over most areas in the region in April, May, and the winter and spring seasons. In South Africa, the preliminary annual mean temperature anomaly from 21 climate stations was about $0.3^{\circ} \mathrm{C}$ above the 1961-90 reference period. A warming trend of $0.13^{\circ} \mathrm{C}$ decade $^{-1}$, statistically significant at the $5 \%$ level, is indicated by the data of these particular climate stations. The data also indicate that the mean temperature of the past 17 years was above normal.

\section{(ii) Precipitation}

Annual rainfall was generally near average across the region except slightly below average for areas in southeastern South Africa and the sector encompassing northern Namibia and southern Angola. Annual rainfall was above average over the southern half of Mozambique. Southern Africa receives the bulk of its annual rainfall during the Southern Hemisphere warm season of November through April, with a peak in December-February. Rainfall totals averaged less than $100 \mathrm{~mm}$ along west coast of South Africa and coastal Namibia with a northeastward increase to about $1000 \mathrm{~mm}$ over the northern sector encompassing Mozambique, Malawi, Zambia, Democratic Republic of the Congo, and Angola (Fig. 7.22a). Rainfall was significantly below average over northern Namibia, southern Angola, and southeastern South Africa with deficits between 100 and $200 \mathrm{~mm}$ (Fig. 
(a)

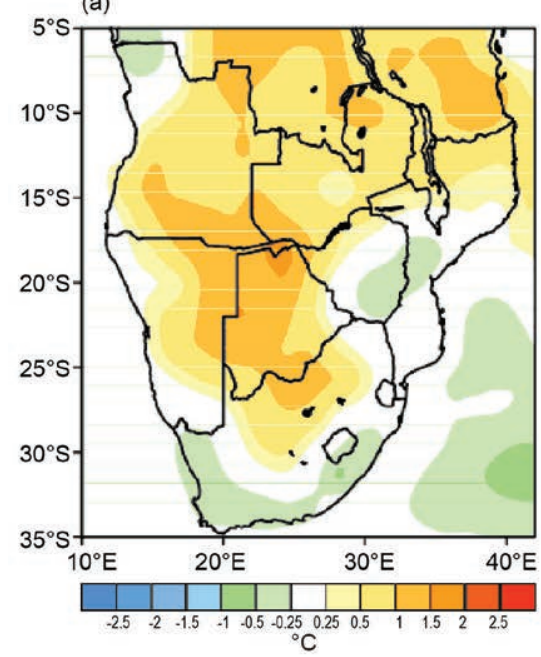

(b)

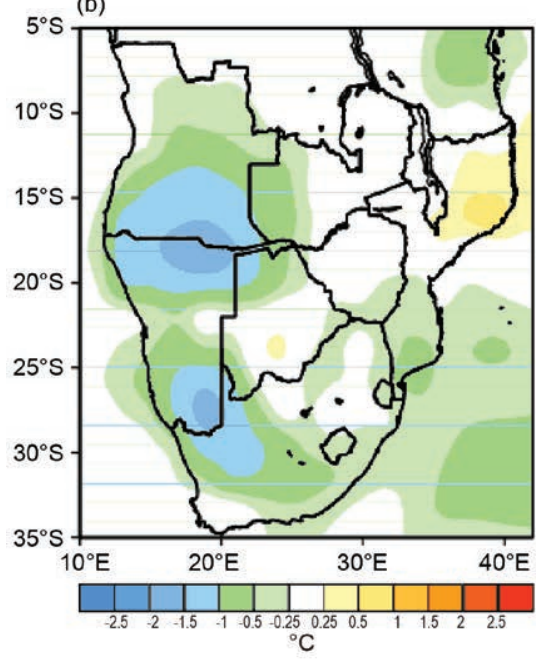

Fig. 7.2I. Annual (a) maximum and (b) minimum temperature anomalies $\left({ }^{\circ} \mathrm{C}\right)$ for southern Africa, departure from 198I-2010 climatology. (Source: NOAA/NCEP.) (a)

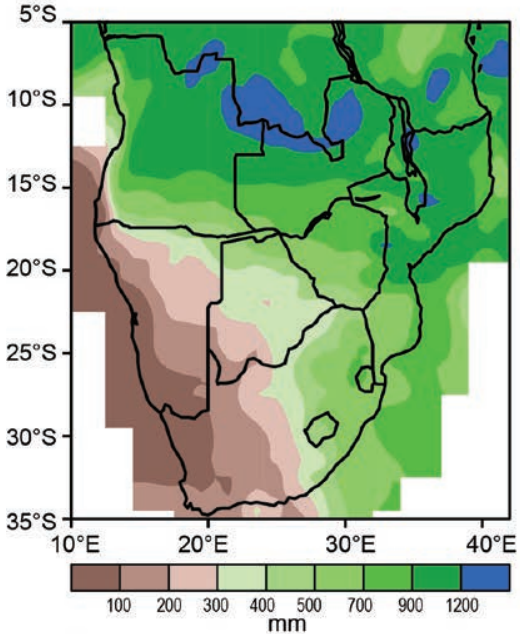

(b)

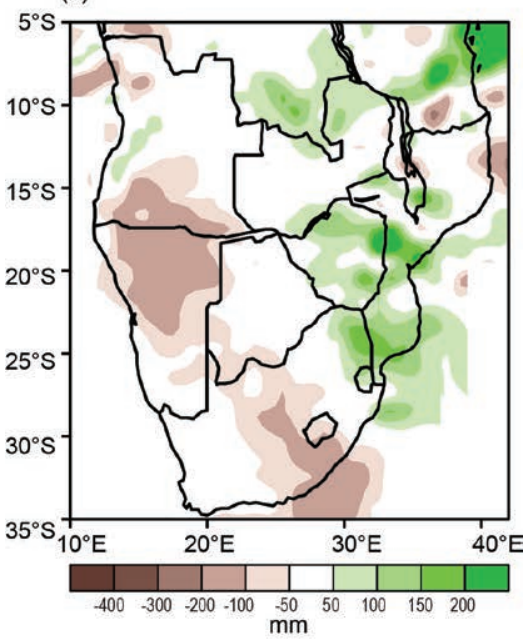

FIG. 7.22. Precipitation $(\mathrm{mm})$ for southern Africa during Nov-Apr $2012 / 13$, expressed as (a) total and (b) departure from the $198 \mid-2010$ climatology. (Source: NOAA/NCEP.) provinces. January and February were characterized by below-average rainfall over the western interior with wetter conditions in the south and east. While abundant rains fell over the western interior in March, the rainfall was below normal over this region from April, spreading eastward over the North-West and Limpopo provinces in May. These dry conditions persisted over the North-West Province and the southern areas of the Free State Province until November, with relief only in December. In the meantime, above-average rainfall was experienced over the southwestern part of the country. Strong persistent SST gradients between subtropical and tropical southwest Indian Ocean during the spring and early summer seasons contributed to enhanced rainfall in Mozambique and southern Madagascar, and suppressed rainfall in South Africa.

\section{(iii) Notable events}

Several flooding incidents caused loss of life and damage to infrastructure in South Africa, and resulted in the displacement of over 2200 7.22b). In contrast, rainfall was above average over northeastern South Africa, the southern half of Mozambique, and Zimbabwe. January was extremely dry along a diagonally oriented northwest-southeast transect from coastal Angola to southeastern South Africa with rainfall amounts below the 10th percentile over Namibia and Angola. However, heavy rains resulted in moisture surpluses in the eastern sector from northeastern South Africa to Mozambique. February was drier than normal across the region with totals indicating $0.5-2 \mathrm{~mm}$ day $^{-1}$ rainfall deficits.

Figure 7.23 presents South African rainfall anomalies for 2013 compared to the reference period of 1961-90. Dry conditions were the most significant rainfall feature of 2013 and persisted for most of the year over the North-West and southern Free State

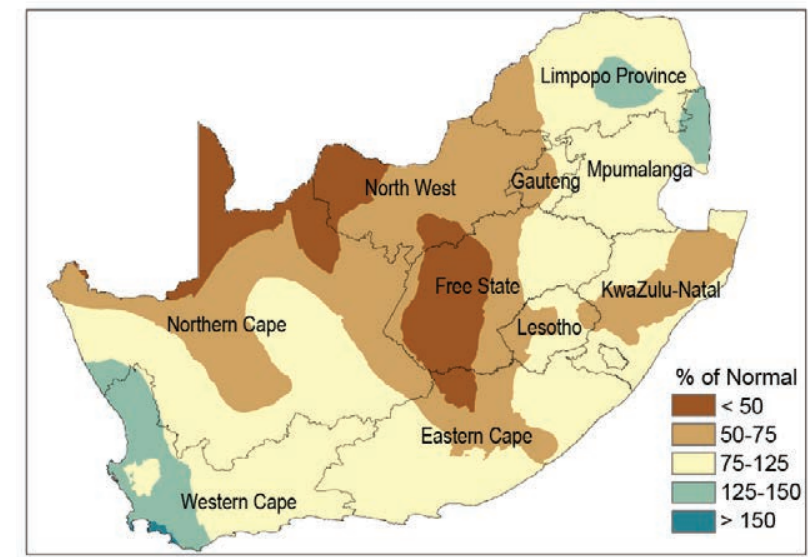

Fig. 7.23. Annual rainfall anomaly expressed as a percentage of the 1961-90 mean for South Africa. (Source: South African Weather Service.) 
people. A cold front that brought extremely heavy rains and unusually cold weather over the Western Cape Province on 27 August caused three fatalities, while scores were left homeless and in need of shelter. Flooding occurred in Cape Town on 17 April, with more than 200 houses affected. In contrast, extremely dry conditions prevailed in portions of the summer rainfall regions. The standardized precipitation index for South Africa indicates that several regions in the interior experienced prolonged dry conditions over a year or longer. The drought was considered the worst in 80 years. The North-West Province was declared a drought disaster area in September. More than 19000 applications for financial assistance from commercial and subsistence farmers were processed. The South African government approved over $\$ 30$ million US dollars in drought disaster relief. In September devastating wild fires destroyed large tracks of land in parts of the Limpopo Province and the Free State causing damage estimated in the millions of US dollars. Strong winds fanned the fires in very hot conditions making them extremely difficult to extinguish.

5) Western Indian OCEAN COUNTRIES - Z. Rakotomavo and $\mathrm{G}$. Jumaux

This region is made of many islands grouped into five countries, including Comoros, Madagascar, Mauritius, Seychelles, and Réunion (France). Here the focus is on Madagascar and Réunion. Climatology is $1971-2000$.

\section{(i) Temperature}

In Madagascar, 2013 was the third warmest year on record since 1971, after 2006 and 2010. The overall annual mean temperature was $23.5^{\circ} \mathrm{C}$, corresponding to an anomaly of about $0.5^{\circ} \mathrm{C}$ above the $1971-2000$ mean. The highest temperature anomalies, approximately between $+0.6^{\circ}$ and $+1^{\circ} \mathrm{C}$, were observed over the northern areas (Fig. 7.24). The northeastern station of Antsohihy and the eastern station of Sainte Marie recorded the highest temperature anomalies. During the summer months of January-March, the mean seasonal temperatures were above normal in the northern areas of the island with the highest positive anomalies observed in Sainte Marie $\left(1.3^{\circ} \mathrm{C}\right)$ and Antsohihy $\left(1.0^{\circ} \mathrm{C}\right)$. During the austral winter, June-August, the mean seasonal temperatures were near normal across most of Madagascar. However, the northeastern coast registered below-normal temperatures. The lowest anomaly $\left(-0.8^{\circ} \mathrm{C}\right)$ was recorded in Sambava. However, temperatures were above normal along the mid-Indian Ocean west coast, and Moron-

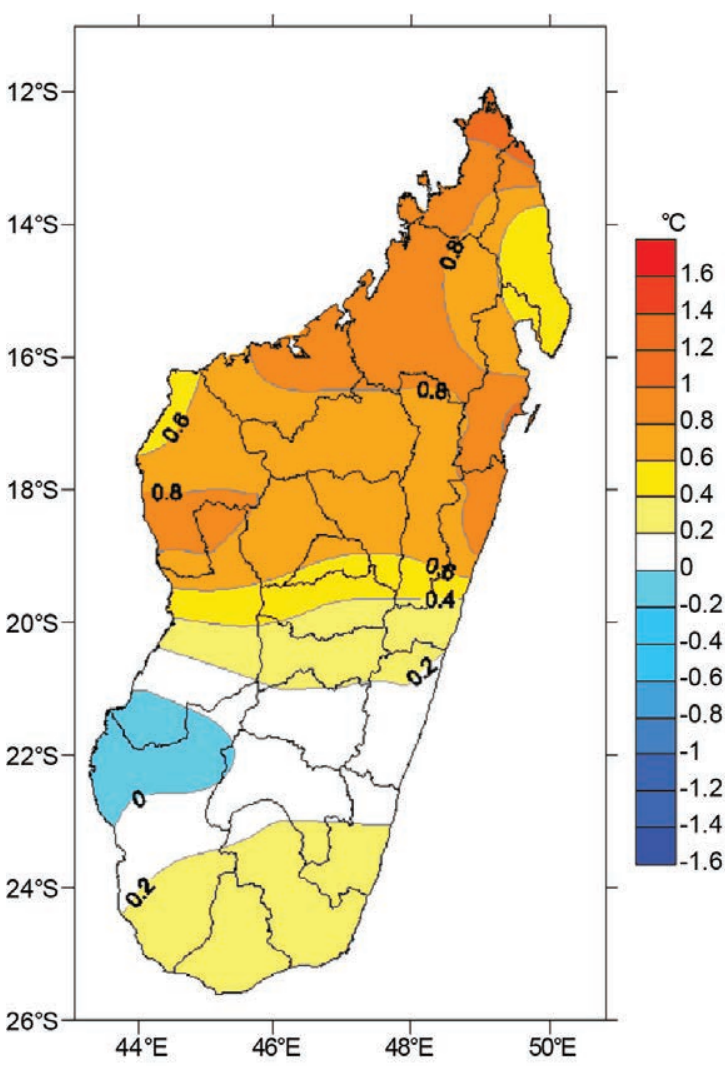

Fig. 7.24. Annual temperature anomaly $\left({ }^{\circ} \mathrm{C}\right)$ from the 1971-2000 mean for Madagascar. (Source: DGM Madagascar.)

dava recorded the highest temperature with $1.1^{\circ} \mathrm{C}$ above the mean. In November, the central highland stations of Antananarivo and Fianarantsoa recorded the highest temperatures of about $2^{\circ} \mathrm{C}$ above normal.

For Réunion Island, 2013 was the sixth warmest year on record since 1971, with an annual mean temperature anomaly of $+0.45^{\circ} \mathrm{C}$. Minimum and maximum temperature anomalies were respectively $0.1^{\circ}$ and $0.8^{\circ} \mathrm{C}$ above normal. However, minimum temperatures were lower than normal from May to August. Maximum temperatures were above normal from July to December. November was the warmest on record over the last 45 years.

\section{(ii) Precipitation}

The mean annual rainfall was near the 1971-2000 average in central Madagascar, but below average in the northeastern part. The southern tip of the island registered well-above-normal rainfall (Fig. 7.25). During the summer months, January-March, rainfall was about $60 \%$ of the 1971-2000 mean in the northern areas of the island, but $>175 \%$ of normal in the southern and southwestern areas. The winter months June-August were drier than normal across 


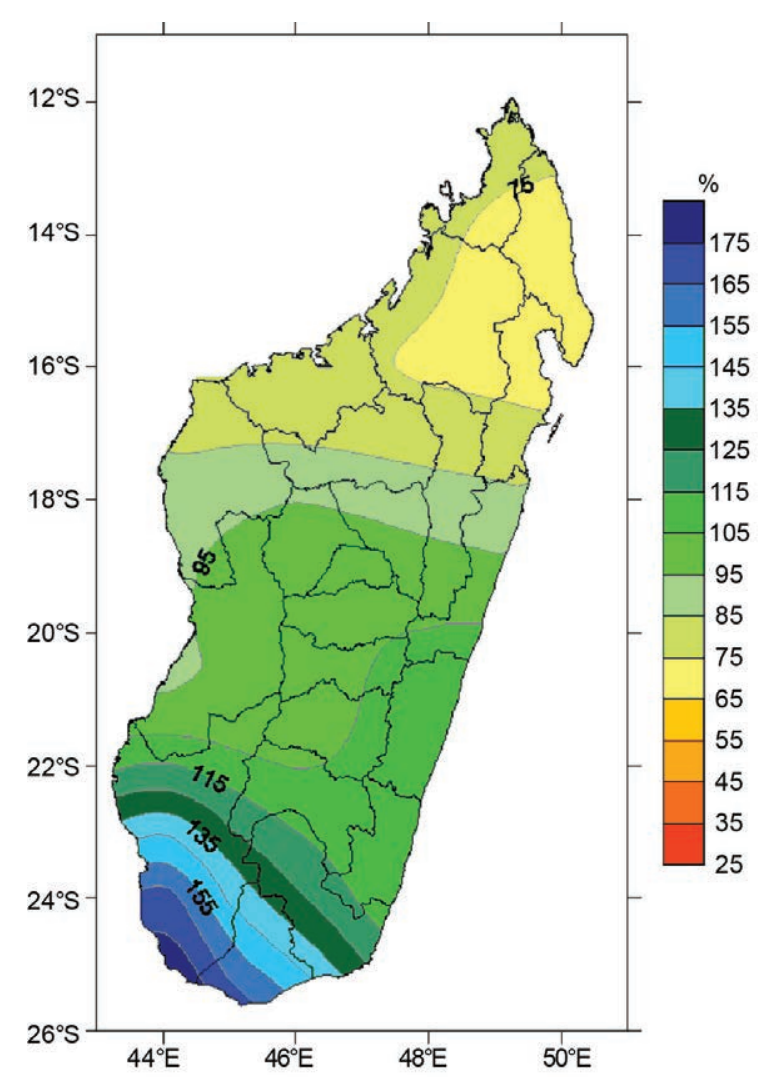

Fig. 7.25. Annual total precipitation for Madagascar expressed as percentage of 197I-2000 mean. (Source: DGM Madagascar.)

Madagascar. However, the onset of the summer season 2013/14 in November and December brought near-average rainfall across the island.

In Réunion, the mean annual rainfall was near average. January was the wettest month, owing to Tropical Cyclones Dumile and Felleng. However, a severe drought followed and affected the entire island from May to October. Rainfall amounts averaged only about $50 \%$ of the long-term mean.

\section{(iii) Notable events}

Category 3 Tropical Cyclone Haruna made landfall in the southwestern region of Madagascar at Cap Saint-Vincent on 22 February, dumping more than $160 \mathrm{~mm}$ of precipitation in 24 hours. The cyclone caused significant damage, killing 26 people with 16 others reported missing. The government declared a state of emergency as over 40000 people needed assistance due to floods and property damage.

Category 4 Tropical Cyclone Felleng cruised southward along the east coast of Madagascar and the west coast of Réunion between 30 January and 2 February and soaked Comerson (La Fournaise Volcano) with $928 \mathrm{~mm}$ of rain in 48 hours. A maximum gust of $133 \mathrm{~km} \mathrm{hr}^{-1}$ was recorded at Maido in the highlands of Réunion. The rains caused 12 fatalities (4 others remained missing) and nearly 5000 people were displaced.

Tropical Cyclone Dumile passed about $100 \mathrm{~km}$ from the western coast of Réunion on 3 January and brought $1187 \mathrm{~mm}$ of rain at Commerson in 48 hours. A maximum wind gust of $189 \mathrm{~km} \mathrm{hr}^{-1}$ was recorded at Maido. The impact in Réunion was mostly on agriculture.

f. Europe and the Middle East-K. Trachte, P. Bissolli, A. Obregón, H. Nitsche, D. Parker, J. Kennedy, M. Kendon, R. Trigo, D. Barriopedro, A. Ramos, S. Sensoy, and D. Hovhannisyan

Throughout this section, normal is defined as the 1961-90 average for both temperature and precipitation, unless otherwise specified. European countries conform to different standards applied by the national weather services. All seasons mentioned in this section refer to the Northern Hemisphere. Naming of midlatitude highs and lows is a common procedure in Europe; in every even year highs are designated with male names and lows are designated with female names and vice versa in odd years.

More detailed information can be found in the Monthly and Annual Bulletin on the Climate in RA VI - European and the Middle East, provided by WMO RA VI Pilot Regional Climate Centre on Climate Monitoring (RCC-CM; http://www.dwd .de/rcc-cm).

\section{I) OVERVIeW}

In 2013, Europe and the Middle East were affected by widespread anomalous warmth. Air temperature anomalies were up to $+2^{\circ} \mathrm{C}$ in eastern Europe and the Middle East and nearly $+1^{\circ} \mathrm{C}$ in the western half of Europe including the Arctic region (Fig. 7.26). According to the CRUTEM4 dataset (Jones et al. 2012), the temperature over land surfaces for the European region $\left(35^{\circ}-75^{\circ} \mathrm{N}, 10^{\circ} \mathrm{W}-30^{\circ} \mathrm{E}\right)$ was $0.88^{\circ} \mathrm{C}$ above average (Fig. 7.27). This was nominally the 12 th warmest year on record since 1850 .

Annual precipitation totals in 2013 were above normal across continental Europe (100\%-125\% of normal) and below average over parts of the British Isles, southern Scandinavia (80\%), and the Middle East (60\%-80\%; Fig. 7.28).

Temperatures for winter 2012/13 (DecemberFebruary) were near average across wide areas of continental Europe and the British Isles except southeastern France and southern Scandinavia where $-2^{\circ} \mathrm{C}$ anomalies were observed (Fig. 7.29). In accord with 


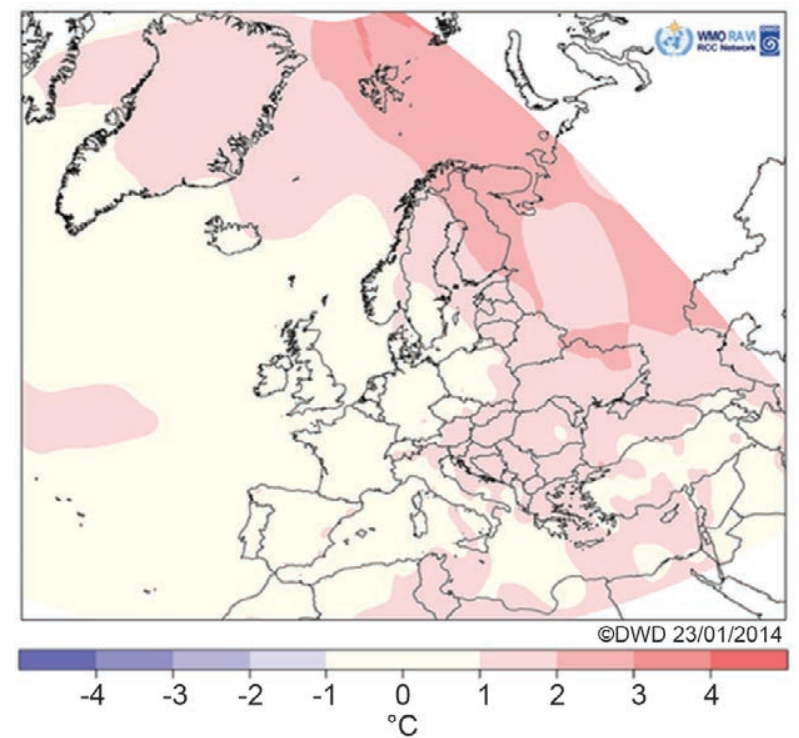

Fig. 7.26. Annual mean air temperature anomaly $\left({ }^{\circ} \mathrm{C}\right)$ for 2013, relative to the 196I-90 base period. (Source: Deutscher Wetterdienst.)

the 500-hPa geopotential heights, northern Scandinavia, eastern Europe, as well as the Middle East, were warmer than average (mostly around $+2^{\circ} \mathrm{C}$ ). Higher deviations were reported in Spitsbergen (more than $+4^{\circ} \mathrm{C}$ ), Iceland, and over the eastern Black Sea $\left(+3^{\circ} \mathrm{C}\right)$. While most of Europe was wetter than normal, southern Iberia and western Scandinavia had below-normal precipitation (Fig. 7.30).

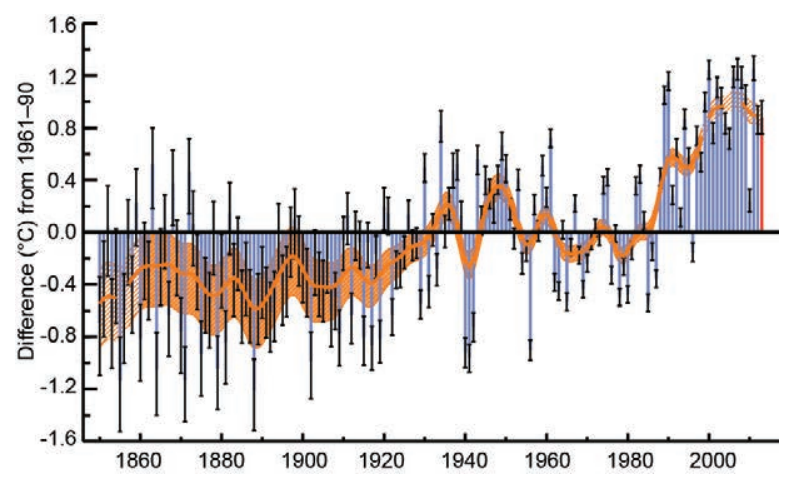

FIG. 7.27. Annual average land surface air temperature anomaly $\left({ }^{\circ} \mathrm{C}\right)$ for Europe $\left(35^{\circ}-75^{\circ} \mathrm{N}, 10^{\circ} \mathrm{W}-30^{\circ} \mathrm{E}\right)$ relative to the 1961-90 base period. Blue bars show the annual average values and the black error bars indicate the $95 \%$ confidence range of the uncertainties. The red bar is the annual value for 2013. The smooth orange line shows annual values after smoothing with a $2 \mathrm{I}$-point binomial filter. The dashed portion of the line indicates where the smoothed curve is affected by the choice of endpoint padding and is liable to change in future. The hatched orange area indicates the $95 \%$ confidence range on the smoothed values. (Source: CRUTEM4 dataset, Jones et al. 20I2.)

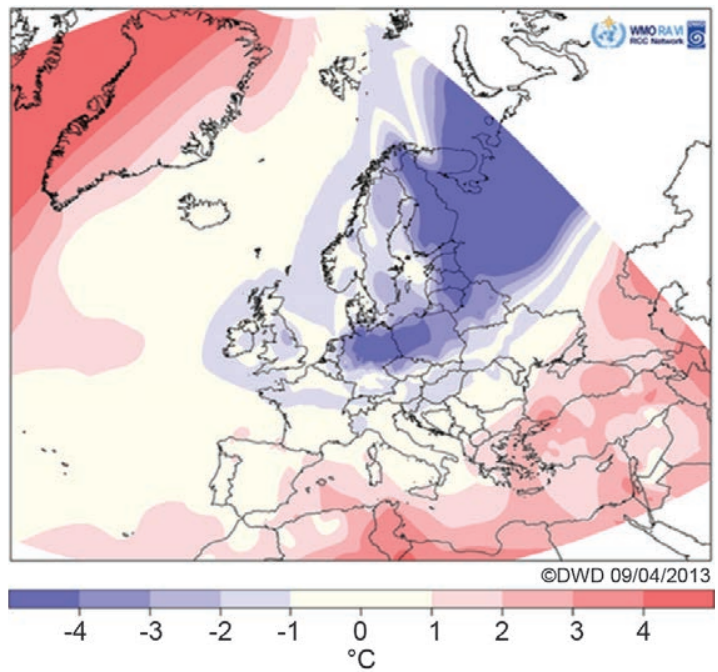

Fig. 7.28. Mar 2013 temperature anomalies in Europe ( ${ }^{\circ} \mathrm{C}, 196 \mathrm{I}-90$ base period). (Source: Deutscher Wetterdienst.)

February was dominated by a persistent omega block, which led to warmer-than-normal conditions over the North Atlantic region and western Russia. Much of western, southwestern, and central Europe on the other hand was much colder and drier than normal.

Spring was characterized by strong westerlies at times, but with contrasting surface climate conditions (Figs. 7.29, 7.30). During March, most areas experienced much colder-than-normal temperatures, except central and eastern Mediterranean regions

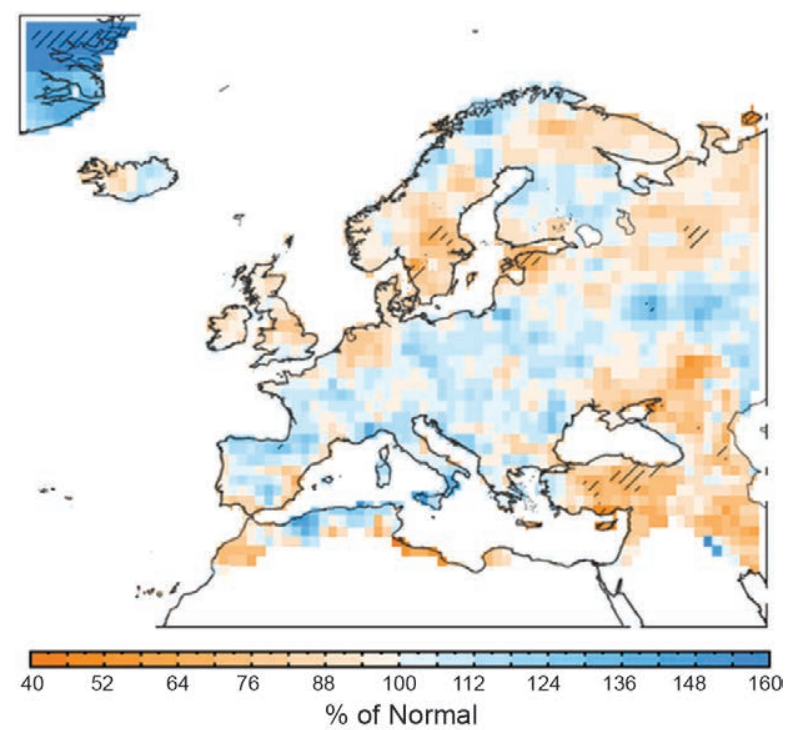

Fig. 7.29. European precipitation totals (\% of normal, 196I-90 base period) for Jan-Dec 2013. Hatching indicates regions where precipitation is higher (lower) than the 95th (5th) percentile of the 196I-90 distribution. Only grid points with annual normals above $15 \mathrm{~mm}$ month $^{-1}$ are represented. (Source: Global Precipitation Climatology Centre, Schneider et al. 2008.) 

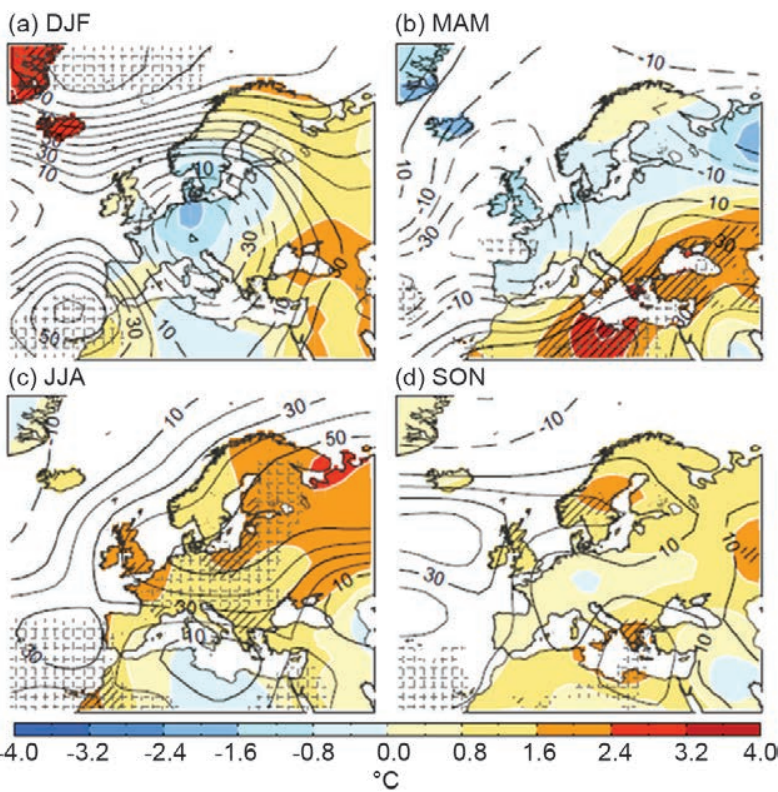

FIG. 7.30. Seasonal anomalies (196I-90 reference) of 500-hPa geopotential height (contour, gpm) and 850 hPa temperature (shading, ${ }^{\circ} \mathrm{C}$ ) using data from the NCEP/NCAR reanalysis. (a) Winter 2012/13 (DJF), (b) spring 2013 (MAM),(c) summer 2013 (JJA), and (d) fall 2013 (SON). Stippling indicates regions where 500-hPa geopotential is higher (lower) than 95th (5th) percentile of the 196I-90 distribution, while hatching represents the corresponding thresholds but for 850-hPa temperature. (Source: Global Precipitation Climatology Centre, Schneider et al. 2008.)

and the Middle East (Fig. 7.31). Both the North Atlantic Oscillation (NAO) and the Arctic Oscillation (AO) were in extremely strong negative phases. In mid-April the NAO changed to its positive phase, which persisted during May. This led to prevailing cyclonic conditions and a strong northwesterly flow of cold and moist air to much of Europe, while drier-than-average conditions were seen in northern Scandinavia, Iberia, and southeastern Europe due to the influence of high pressure.

Summer was warmer and drier than normal in most regions, except the Norwegian coast, which was wetter than average, associated with above-average 500-hPa geopotential heights over northern Europe and anomalous southwest flow off the Scandinavian coast (Figs. 7.29, 7.30). In June, intense cyclonic airflow from the Atlantic led to above-normal precipitation totals in Scandinavia, central Europe, and the western Black Sea region. High pressure prevailed during July and August over western, central, and eastern Europe (Figs. 7.29, 7.30). In August, the NAO became clearly positive when the Azores high extended far into western Russia. Very warm and dry conditions were observed over most parts of Europe.
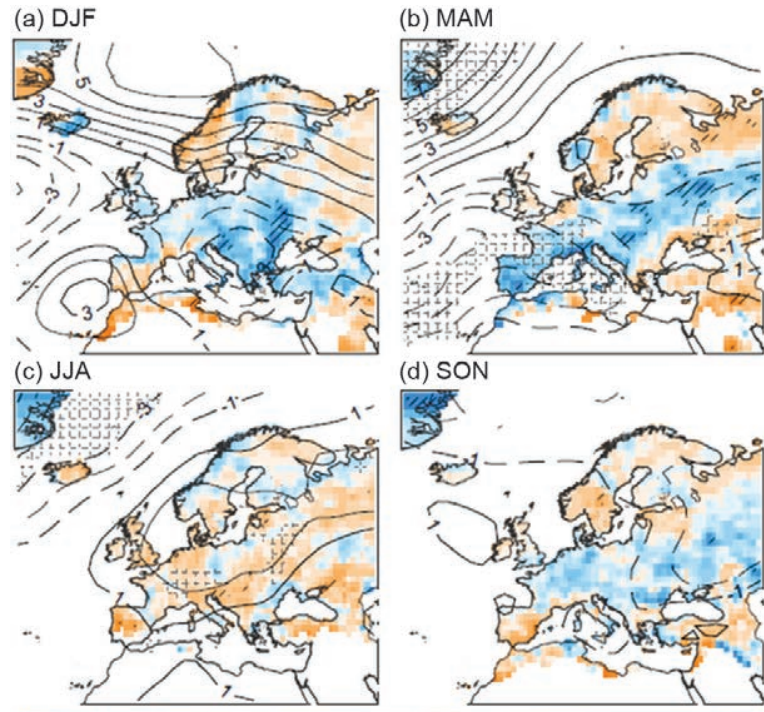

(d) SON

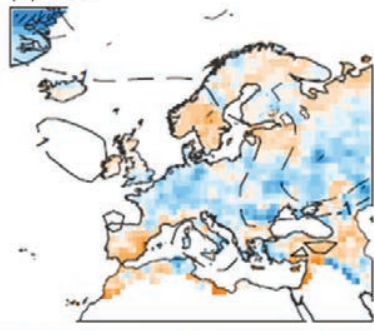

$\begin{array}{lllllllllll}0 & 20 & 40 & 60 & 80 & 100 & 120 & 140 & 160 & 180 & 200\end{array}$

FIG. 7.3I. Seasonal anomalies (I96I-90 reference) of sea level pressure (hPa) from NCEP/NCAR reanalysis (contours). Colored shading represents the percentage of seasonal mean precipitation compared with I96I-90 mean from the monthly GPCC precipitation dataset (only grid points with climatological mean seasonal precipitation above $15 \mathrm{~mm}$ month-1 are represented). Stippling indicate regions where SLP is higher (lower) than the 95th (5th) percentile of the 196I-90 distribution, while hatching represents the corresponding thresholds but for precipitation.

Fall continued to be warmer than normal, particularly over northeastern Europe (Fig. 7.29). Temperatures in September were below average in parts of central and eastern Europe due to cold cyclonic airflow from eastern Europe. October was exceptionally warm over much of the continent due to frequent warm airflow from the southwest (Fig. 7.30). The mild October, however, brought wet conditions to western, central, and northern Europe, except Greenland, the northern UK, and parts of Scandinavia, whereas drier conditions occurred in most of southern and eastern Europe due to high pressure influence. In November the warmer-than-normal temperatures continued in northeastern Europe, while the western part of Europe had slightly below- or near-normal temperatures. Along the Norwegian coast strong westerly flows (positive NAO and AO phases) led to significantly wetter conditions with heavy precipitation on the windward slopes of the Scandinavian mountains. Norway reported many new November daily precipitation records. In contrast, the British Isles, the Iberian Peninsula, the eastern Mediterranean coast, and the Black Sea region had drier-thannormal conditions. 
The year ended warmer than normal in most of the region, but was colder than normal in the southeast. Scandinavia experienced temperatures anomalies of more than $+4^{\circ} \mathrm{C}$. Denmark had its second warmest December since 1874 . Precipitation was above normal in Scandinavia and much of the British Isles (125\%-160\%, locally more), while much of central Europe and most of southern, eastern central, and southeastern Europe had drier conditions associated with the positive $\mathrm{NAO}$ and $\mathrm{AO}$, and a shift of the jet stream to the north. Norway recorded its second wettest December since 1900 and Denmark its second wettest since 1874 .

\section{2) Central and western Europe}

This region includes Ireland, the United Kingdom (UK), the Netherlands, Belgium, Luxembourg, France, Germany, Switzerland, Austria, Poland, Czech Republic, Slovakia, and Hungary.

\section{(i) Temperature}

Averaged over the year, mean temperatures in the region were $+0.2^{\circ} \mathrm{C}$ to $+1^{\circ} \mathrm{C}$ above normal.

In winter $2012 / 13$, temperature anomalies ranged between $-1^{\circ} \mathrm{C}$ and $+1^{\circ} \mathrm{C}$ in most areas, but were $-2^{\circ} \mathrm{C}$ in southeastern France. February was exceptionally cold in wide areas of France and southwestern Germany. Persistent upper-level troughs over the Alpine region ushered advection of arctic air into central Europe. Temperature anomalies locally fell below $-3^{\circ} \mathrm{C}$.

It remained cold in March. The negative NAO phase strengthened and polar air advanced into northwestern and central Europe. The lowest anomalies occurred in Germany and Poland with mean temperature anomalies down to $-4^{\circ} \mathrm{C}$. The UK recorded its second coldest March since 1910. Ireland locally reported its coldest March for 50-70 years and France had its coldest March in the past 25 years. May was colder than average as well, making spring as a whole colder than normal, particularly in the North Sea region.

Area-wide positive temperature anomalies were recorded during summer. July was particularly warm with temperature anomalies exceeding $+3^{\circ} \mathrm{C}$ in places. The UK and France reported their third warmest July since 1910. Ireland observed its warmest July in more than 60 years at several locations; at the Valentia Observatory (southwestern Ireland) the mean temperature $\left(17.3^{\circ} \mathrm{C},+2^{\circ} \mathrm{C}\right.$ above average) was the warmest since 1921. Austria tied its second warmest July since 1767; only 2006 was warmer.
In fall 2013, the warmer-than-normal conditions continued (up to $+2^{\circ} \mathrm{C}$ ), mainly due to an unusually warm October. All areas, except western Ireland $\left(-1^{\circ} \mathrm{C}\right.$ at the western coast), had above-average temperatures in October.

December was much warmer than normal. High alpine stations in Austria measured $3.6^{\circ} \mathrm{C}$ above the long-term mean, the second warmest December since 1851 in that region.

\section{(ii) Precipitation}

Annual precipitation was near normal except for some parts of the UK and Ireland, which were drier than normal.

Winter 2012/13 was mostly wetter than normal in western and central Europe mainly, due to a very wet December. January and February were drier than normal in western parts, but wetter than normal in the east. In January, parts of Austria received two to four times more precipitation than normal.

Spring was wetter than normal except for the British Isles (95\% of normal) and the Netherlands ( $80 \%$ of normal). May was particularly wet; in many areas rainfall exceeded the 90th percentile of occurrences and many records were broken. The wet conditions continued into June, especially in eastern central Europe due to an extreme event at the beginning of the month (see Sidebar 7.3 for more details).

The extremely wet spring was followed by a dry summer. July and August brought $60 \%-80 \%$ of normal precipitation to much of the area and locally even less. Hungary experienced its driest July since 1901. In Slovakia the lowest July precipitation in the last 50 years (26\% of average in places) contributed to drought conditions. August precipitation was $30 \%$ of normal in northwestern France. In Austria, southeastern Germany, northern Hungary, and adjacent areas of the Czech Republic drought conditions occurred in the first half of August.

Fall was wetter than normal in most areas except Ireland, northern UK, and the south of France. In September drier conditions were observed in the UK, Ireland, and northern and western France whereas areas of central Europe had above-average precipitation (up to $150 \%$ of normal). Eastern England and eastern Scotland received less than half of the long-term average. Milder tropical air advected to western and central Europe in October, leading to above-normal precipitation over western and most of central Europe whereas the eastern part remained dry ( $80 \%$ or less). The Alpine region continued to be wet in November. Austria experienced its wettest November since 2003. 


\section{SIDEBAR 7.3: INTENSE FLOODING IN CENTRAL EUROPE- \\ K. TRACHTE, P. BISSOLLI, A. OBREGÓN, H. NITSCHE, D. PARKER, J. KENNEDY, M. KENDON, R. TRIGO, \\ D. BARRIOPEDRO, A. RAMOS, S. SENSOY, AND D. HOVHANNISYAN}

Heavy precipitation from late May through early June resulted in intense flooding in mid-June in central Europe. Many places received more than their normal monthly precipitation totals within one or two days. The rivers Danube, Elbe, and Rhine in particular had high water levels due to several days of heavy precipitation over the area, saturated soils, and late snow melt.

An extensive depression over central Europe dominated the weather situation from 30 May to 2 June. The 500-hPa geopotential heights featured a large slow-moving loop in the jet stream over Europe (Fig. SB7.3). Additionally, a blocking high developed over northern Europe forcing the low pressure system to track over central Europe. The low pressure center shifted from the North Sea southward to the Alpine region, then migrated northeastward, affecting a wide area from the western Alps to Hungary. As it intensified, there was large-scale upward motion and intense precipitation. The depression brought large amounts of moisture from the Mediterranean and steered it over eastern Europe to the north side of the Alps. In the upper troposphere, the kink in the jet stream led moistureladen Mediterranean air masses over central Europe, where it met colder air from the north. Near the surface, an opposing northwesterly flow developed, which caused an enhancement of the rainfall through dynamic convergence and orographic uplift. At the northern flank of the trough the moist and unstably stratified air was led to Austria, Hungary,

(a)

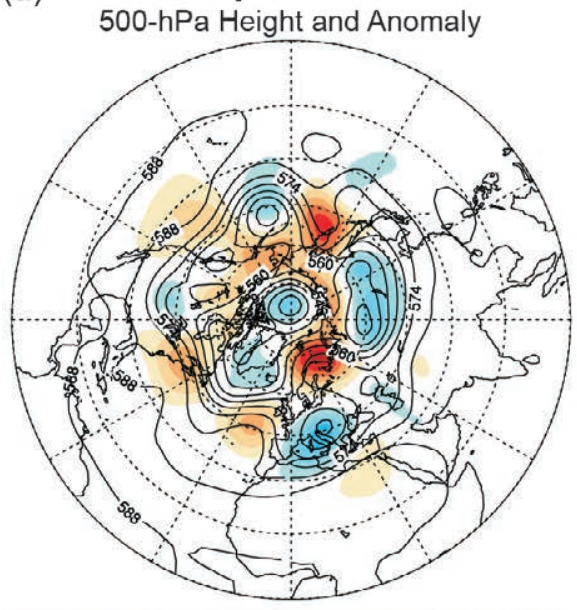

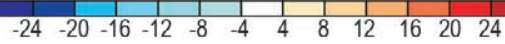

$\mathrm{m}$
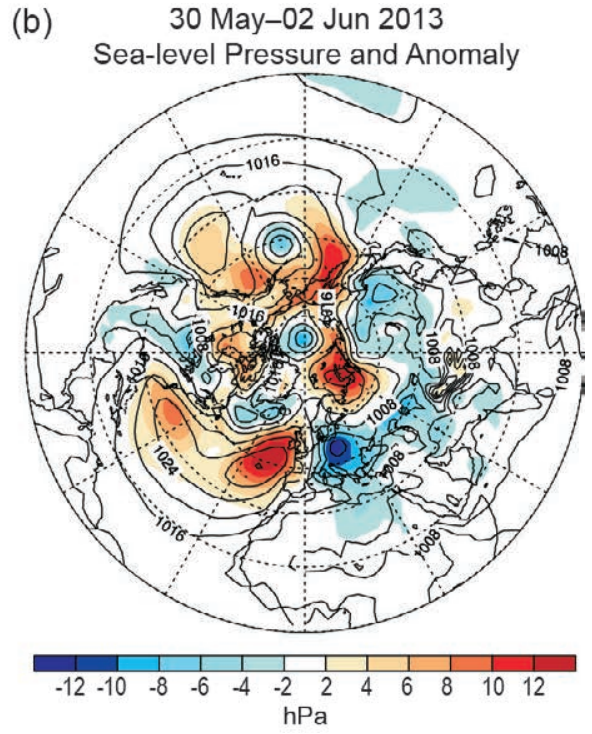

FIG. SB7.3. 30 May-2 Jun 2013 Northern Hemisphere mean and anomalous (a) 500-hPa geopotential height $(\mathrm{m})$ and $(\mathrm{b})$ sea level pressure $(\mathrm{hPa})$. The shading indicates anomalies relative to 198I-2010 base period. (Source: NCEP/NCAR Reanalysis.)

the Czech Republic, and

northeastern Germany.

Spring had been characterized by cold and wet conditions due to an unusually persistent trough over central Europe. Moist and cold polar air from the northern North Atlantic or North Sea repeatedly advanced to the continent. March was extremely cold in central Europe with temperature anomalies of $-4^{\circ} \mathrm{C}$. In May, temperatures remained colder than normal and $160 \%$ of normal precipitation was observed in Germany, parts of Poland, and the northern Alpine region. Snowfalls occurred in the lowlands and the Alpine region experienced persistent snow cover. These factors caused late snow melt and high water levels of the Danube, Elbe, and Rhine. Passau, Germany, experienced its highest river levels in more than 500 years, and Budapest, Hungary, had its highest in at least 100 years. The Elbe at Dresden was the highest since the flooding in 2002. Additionally, soils were saturated due to excessive rainfall and reservoirs filled. In Germany, $40 \%$ of soils had above-normal soil moisture and reached record-breaking values in wide areas. Another factor was that the low pressure system remained stationary at the peak of its development. In the Alpine region, where the highest precipitation amounts were measured, rainfall was further intensified by orographic lifting. 
CONT. SIDEBAR 7.3: INTENSE FLOODING IN CENTRAL EUROPE-

K. TRACHTE, P. BISSOLLI, A. OBREGÓN, H. NITSCHE, D. PARKER, J. KENNEDY, M. KENDON, R. TRIGO, D. BARRIOPEDRO, A. RAMOS, S. SENSOY, AND D. HOVHANNISYAN

The nations primarily affected by the intense precipitation were Switzerland, Austria, Germany, Hungary, Czech Republic, and Slovakia. Precipitation totals of more than $100 \mathrm{~mm}$ were recorded, particularly in the Alpine region. 24-hour rainfall amounts of 30-60 mm occurred with even more along the northern Alps (7I mm; Fig. SB7.4). Switzerland recorded precipitation amounts of $80-150$ $\mathrm{mm}$ on the north side of the Alps and record-breaking totals of $100-150 \mathrm{~mm}$ were measured at Teufen.

In eastern Austria, during 30-3I May, precipitation totals of $70 \mathrm{~mm}$ fell within 36 hours. On I June western Austria had $100-150 \mathrm{~mm}$ rainfall, which led to flooding along the Rhine valley. On I June the Danube breached its banks and from 2 June wide areas of Austria were under civil protection. In Germany, the highest rainfalls occurred on the northern side of the German Alps as well as in eastern areas. Many stations reported extremely high 96-hour totals of more than $160 \mathrm{~mm}$, with the highest such value of $400.4 \mathrm{~mm}$ measured in Aschau-Stein in the Alpine region.

The area-wide and intense flooding significantly affected people, traffic, and the economy in the respective regions because the Elbe, Danube, Saale, and other rivers rose well above their banks and breached flood defenses. In many regions, thousands of people had to leave their homes and at least 24 people died. In Germany alone, flooding of more than 150000 hectares of grassland and cropland caused damage to agriculture. Overall, this flooding event caused billions of Euros in damage to affected regions.

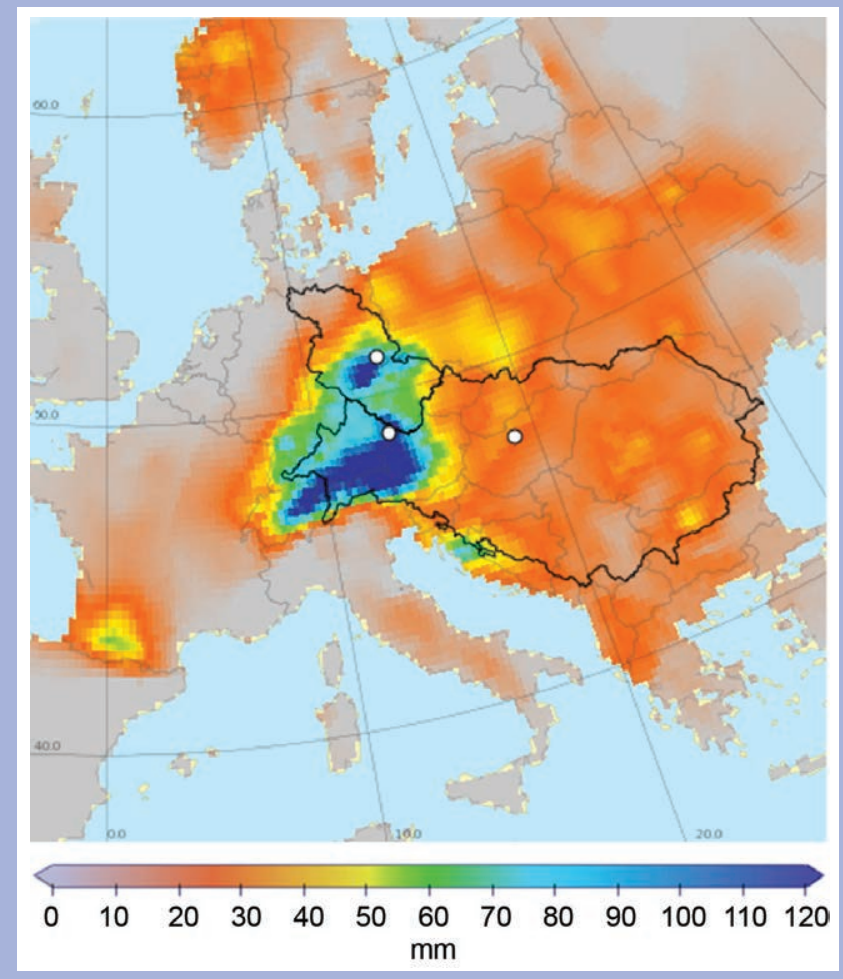

FIG. SB7.4. Total precipitation 30 May-2 Jun 2013 (mm). Black lines indicate the drainage basins of the rivers Elbe (top), and Danube (bottom). White dots indicate the cities Dresden (relatively north), Passau (central) and Budapest (southeast). (Source: E-OBS; Haylock et al. 2008.)
December was wetter than normal in the British Isles. Scotland had its wettest December since records began there in 1910. In contrast, most of continental Europe experienced drier conditions.

\section{(iii) Notable events}

In March, wide areas of central Europe were under the influence of an unusual cold spell. During 10-14 March a major snow storm hit western Europe.

On 21 May a tornado occurred in Austria and a heavy thunderstorm hit central Europe, causing damages of more than 1 million Euros (approx. \$1.4 million US dollars).

Tropical nights (minimum temperatures $>20^{\circ} \mathrm{C}$; Klein Tank et al. 2009) affected eastern Germany, Poland, and easternmost Austria and neighboring countries in July and August. The high temperatures contributed to damage to road surfaces in Austria and Germany. Together with the dry conditions, many forest fires occurred in Austria.
During a heat wave from 20 July to 10 August, a new Austrian national record high temperature of $40.5^{\circ} \mathrm{C}$ in lower German-Altenburg was recorded. This event occurred on 8 August and was the first time a temperature above $40^{\circ} \mathrm{C}$ had been observed in Austria. The July heat wave in the UK caused a number of wildfires across southern England.

Although July as a whole was drier than normal, there were extreme precipitation intensities of more than $50 \mathrm{~mm}$ within 1-2 hours in both France and the UK. The events were accompanied by hail up to $10 \mathrm{~cm}$ in diameter. On 27 July an extreme thunderstorm hit the Netherlands and Germany dropping hailstones $5-10 \mathrm{~cm}$ in diameter. Similar severe events also occurred in August.

On 28 October western Europe was hit by Storm Christian (referred to as the "St. Judes' Day Storm" in the UK); wind gusts of more than $40 \mathrm{~m} \mathrm{~s}^{-1}$ were observed at several stations. The UK reported wind gusts of $44.3 \mathrm{~m} \mathrm{~s}^{-1}$ and Germany had $47.8 \mathrm{~m} \mathrm{~s}^{-1}$. The 
Netherlands and France experienced highest values of $42.2 \mathrm{~m} \mathrm{~s}^{-1}$ and $40.8 \mathrm{~m} \mathrm{~s}^{-1}$, respectively.

During December 2013, central Europe was affected by a series of severe storms. During 4-7 December Storm Xaver hit northern Germany and Scotland; wind gusts between 41 and $44 \mathrm{~m} \mathrm{~s}^{-1}$ were measured in Germany (5-6 December). A surge in the North Sea was nearly as high as in the floods of 1953. Storm Dirk brought high waves and rain to the UK and northern France at Christmas. In association with Dirk a Foehn situation developed in the Alps with extremely strong winds (more than $35 \mathrm{~m} \mathrm{~s}^{-1}$ ). On 27 and 28 December Storm Erich affected the British Isles and France with wind gusts of $35 \mathrm{~m} \mathrm{~s}^{-1}$ and even more in the higher Alpine areas. The UK reported wind gusts up to $52.4 \mathrm{~m} \mathrm{~s}^{-1}$ in Aberdaron (southwest Wales). The storm depression was accompanied with daily rainfall totals between 20 and $40 \mathrm{~mm}$ in the UK.

\section{3) Nordic and Baltic COUNTRIes}

This region includes Iceland, Norway, Denmark, Sweden, Finland, Estonia, Latvia, and Lithuania.

\section{(i) Temperature}

The annual temperature anomalies in the Nordic and Baltic countries were above average with a clear west-east gradient. The west had anomalies of $+0.5^{\circ} \mathrm{C}$ and anomalies in the east were up to $+2^{\circ} \mathrm{C}$.

Temperatures in winter 2012/13 were well-below average in Denmark, Norway, Sweden, and the Baltic States, with anomalies down to $-2^{\circ} \mathrm{C}$ at the south Norwegian coast. In contrast, Iceland, Finland, and northern Norway recorded temperature anomalies of more than $+2^{\circ} \mathrm{C}$, mainly due to the very warm January and February. Lithuania experienced an exceptionally warm February $\left(+3^{\circ} \mathrm{C}\right.$ above average) and Iceland reported its second warmest February, behind 1964, since records began in 1871 .

March and May had strongly contrasting conditions but spring as a whole was colder than normal in all regions except northern Scandinavia. During March advection of arctic air brought unusually cold temperatures to Scandinavia and the Baltic States. The lowest anomalies (below $-4^{\circ} \mathrm{C}$ ) were recorded in Finland and the eastern Baltic countries. Across Scandinavia monthly temperatures fell below the 10th percentile of occurrences. In May, warm air masses from southeastern Europe extended far to the north, leading to well-above-average temperatures in the north. Local temperature anomalies exceeded $+4^{\circ} \mathrm{C}$ and a maximum temperature of more than $30^{\circ} \mathrm{C}$ was reported in Finland. In Latvia, the May 2013 average temperature was $14.4^{\circ} \mathrm{C}\left(3.4^{\circ} \mathrm{C}\right.$ above normal); for the first time since at least 1993 the country areal mean daily maximum air temperature exceeded $30^{\circ} \mathrm{C}$ during the first 10 days of May. In Iceland temperature anomalies ranged between $-1^{\circ} \mathrm{C}$ in the west and $+1^{\circ} \mathrm{C}$ in the east.

Summer temperatures remained above the longterm mean. Summer temperatures ranged from near normal in southern areas to $+3^{\circ} \mathrm{C}$ in the north. It was the warmest June for Finland since 1999 and northern Norway recorded its third warmest June on record. Northeastern Iceland experienced its warmest June since 1953 , including a monthly average of $11.4^{\circ} \mathrm{C}$ at Akureyri.

The warmer conditions continued during the fall. In November mild Atlantic air brought temperature anomalies of $+2^{\circ}$ to $+3^{\circ} \mathrm{C}$ to east Finland.

December was exceptionally warm. Temperature anomalies exceeded $+4^{\circ} \mathrm{C}$ in Scandinavia and the Baltic countries. Norway experienced its eighth warmest December since 1900 with temperature anomalies locally of $+6^{\circ} \mathrm{C}$ to $+8^{\circ} \mathrm{C}$.

\section{(ii) Precipitation}

Total precipitation was mostly below or close to average over the region. Some northern areas received well-above-normal precipitation (>125\% of normal).

Winter 2012/13 was remarkably dry in western Scandinavia and close to normal in Finland and the Baltic States. However, Lithuania reported $132 \%$ of its normal precipitation in February. Iceland had a north-south gradient with wetter-than-normal conditions in southern areas.

Spring was mostly drier than normal. High pressure in March led to significantly dry conditions. Much of the region except northwestern Norway received precipitation totals of $20 \%-40 \%$ of normal and some localized areas even less. During May, under the influence of a trough in central Europe, southern Norway, Denmark, and the Baltic countries received up to $200 \%$ of normal precipitation. At the trough's southeastern flank warm dry air was transported far to the north leading to below-average precipitation of $40 \%-60 \%$ in northern Norway and Finland.

In summer, precipitation totals were unevenly distributed. While southern Scandinavia, the northern regions of the Baltic States, and most of Iceland had $60 \%-80 \%$ of normal precipitation, the Norwegian coast received $150 \%$ of normal due to prevailing warm air advection from the Atlantic. June was unusually wet in Scandinavia, when more intense westerlies brought moist air to Scandinavia. It was the third wet- 
test June on record in eastern Norway, after 2011 and 1987. High pressure over central Europe during July brought dry conditions to southern Scandinavia (less than $20 \%$ of normal precipitation locally). Dry conditions, albeit less extreme, continued during August.

Fall precipitation was below normal in most areas, except northern Sweden, eastern Finland, and Lithuania. Southern Scandinavia experienced drier-thanaverage conditions. September was very dry. Precipitation totals less than $40 \%$ of normal were recorded in many places and in parts of southern Sweden less than $20 \%$ of normal was recorded. Iceland had wetter conditions (120\%-160\%). November was dry, especially in Sweden, where it was the fifth consecutive month with below-average precipitation. The dry fall was followed by a wetter-than-normal December for much of Scandinavia (120\%-160\%), when the Iceland low (mean SLP below $995 \mathrm{hPa}$ ) extended to northern Norway and brought mild moist air to Scandinavia.

\section{(iii) Notable events}

Unusually heavy snowfall occurred in March and April. Denmark reported $36 \mathrm{~cm}$ of snow on 19 March. During the first 10 days in April, Latvia experienced its thickest snow cover $(40 \mathrm{~cm})$ of the cold season. Later in the month, melting snow and ice caused high water levels in rivers and floodings in eastern Europe. In southern Lithuania, the River Ogre reached its locally highest water level in 240 years on 21 April. On the same day, Estonia reported record water levels of $246 \mathrm{~cm}$ at Tartu.

On 22 May hundreds of people were forced to evacuate their homes after heavy rain caused flooding in southeastern Norway. Denmark reported its highest daily precipitation total since 1874 .

In the last week of October, midlatitude Storm Christian crossed northern Europe with violent and damaging gusts. In southern Denmark record wind gusts of $53.3 \mathrm{~m} \mathrm{~s}^{-1}$ were measured. Sweden, where the storm was named "Simone", recorded storm winds of 28.5-32.6 $\mathrm{m} \mathrm{s}^{-1}$. The highest gust measured was $42.5 \mathrm{~m} \mathrm{~s}^{-1}$ in southern regions and was a local record. Short-term high water levels were reported on Sweden's southwestern coast. On 28 October Halmstad measured $169 \mathrm{~cm}$ above the mean coastal water levels, which is the second highest on record. The Baltic States observed wind gusts of up to $30 \mathrm{~m}$ $\mathrm{s}^{-1}$ in Estonia and $23.8 \mathrm{~m} \mathrm{~s}^{-1}$ in Lithuania.

A damaging storm hit Norway on 16 November. Daily precipitation totals of over $50 \mathrm{~mm}$ were recorded. The highest total was $104.9 \mathrm{~mm}$. At Christmas, Iceland was hit by a severe snowstorm, which caused traffic disruption and power outages in much of the country.

\section{4) Iberian Peninsula}

This region includes Spain and Portugal. Unless otherwise noted, anomalies refer to base period of 1971-2000.

\section{(i) Temperature}

In 2013, Spain and Portugal were both slightly warmer than normal, with mean anomalies of $+0.29^{\circ} \mathrm{C}$ and $+0.21^{\circ} \mathrm{C}$, respectively. The winter mean temperature was slightly above average in the Mediterranean sector of the Iberian Peninsula and slightly below average elsewhere. The mean temperature in February was below average in Portugal $\left(-1.2^{\circ} \mathrm{C}\right.$ anomaly) and in Spain $\left(-0.9^{\circ} \mathrm{C}\right)$ due to a blocking pattern in the $500-\mathrm{hPa}$ circulation.

Spring was cooler than normal across the Iberian Peninsula $\left(-0.3^{\circ} \mathrm{C}\right.$ in Spain and $-0.4^{\circ} \mathrm{C}$ in Portugal). These anomalies, although small, correspond to the coldest spring since 1993 in Portugal and the second coldest of the 21st century in Spain. May was the main contributor to the low spring average, with anomalies of $-0.8^{\circ} \mathrm{C}$ (Portugal) and $-1.3^{\circ} \mathrm{C}$ (Spain).

Summer was considerably hotter than usual in Spain $\left(+0.8^{\circ} \mathrm{C}\right)$ and Portugal $\left(+0.7^{\circ} \mathrm{C}\right)$, owing to high temperatures in July and August. It was the 10th warmest summer since 1931 in Portugal, with the seasonal mean daily maximum temperature being $1.4^{\circ} \mathrm{C}$ above normal.

During fall, mean temperatures in Iberia were significantly above the long-term average $\left(+1^{\circ} \mathrm{C}\right.$ in Spain and $+0.8^{\circ} \mathrm{C}$ in Portugal). These anomalies were due to large positive temperature departures in September $\left(+1.2^{\circ} \mathrm{C}\right.$ in Spain and $+1.6^{\circ} \mathrm{C}$ in Portugal $)$ and October $\left(+2.1^{\circ} \mathrm{C}\right.$ in Spain and $+1.4^{\circ} \mathrm{C}$ in Portugal). The warm October, influenced by a negative phase NAO, was followed by a cold November, when the NAO changed to its positive phase. December was colder than average $\left(-0.8^{\circ} \mathrm{C}\right.$ in Spain and $-0.3^{\circ} \mathrm{C}$ in Portugal).

\section{(ii) Precipitation}

The annual mean precipitation averaged over Iberia was slightly above normal. The mean annual rainfall was $717 \mathrm{~mm}$ in Spain (110\% of normal) and $937 \mathrm{~mm}$ in Portugal (106\% of normal).

Rainfall in the 2012/13 winter was close to normal in Spain: above normal in the north and below normal elsewhere. In Portugal the mean was $93 \%$ of normal. However, the season average masked contrasting periods within it. In January strong westerlies led 
to exceptionally wet conditions in northern areas, while eastern Iberia experienced drier conditions. An atmospheric blocking pattern in February brought below-average rainfall in Portugal and above-average totals in Spain.

Spring precipitation was above average by roughly $50 \%$ in Spain and Portugal, mainly due to an extremely wet March in Iberia (see notable events below). This corresponded to the fifth wettest spring in Spain since 1947 and the third wettest spring in Portugal since 1972. This wet spring is consistent with the synoptic pattern of negative SLP anomalies over western Europe and most of the Mediterranean basin.

Summer precipitation totals were below average on the Iberian Peninsula. The anomaly was larger in Portugal, with precipitation around $60 \%$ of normal, while in Spain it was around $80 \%$. However, it should be taken into consideration that the average summer precipitation in Iberia is relatively low.

Fall precipitation was below normal on the Iberian Peninsula (80\% of normal in Spain and $90 \%$ in Portugal), mainly due to an extremely dry November (65\% of normal in Spain and only $20 \%$ of normal in Portugal, the fourth driest in 83 years). December precipitation was below average in Spain $(83 \%$ of normal) while near-normal in Portugal.

\section{(iii) Notable events}

Portugal was seriously affected by extratropical Storm Gong on 19 January. Its explosive cyclogenesis during 18-19 January led to a SLP minimum of $968 \mathrm{hPa}$ during the early hours of 19 January over northern Portugal. Wind gusts exceeded $28 \mathrm{~m} \mathrm{~s}^{-1}$ on 19 January throughout Portugal, with a maximum of $39 \mathrm{~m} \mathrm{~s}^{-1}$ at Cabo Carvoeiro. Population centers Lisbon and Porto registered wind gusts of $29 \mathrm{~m} \mathrm{~s}^{-1}$ and 32.3 $\mathrm{m} \mathrm{s}^{-1}$, respectively. Widespread fallen trees and power cables left more than 1 million people without power.

Intense precipitation occurred on 27 and $28 \mathrm{Feb}$ ruary between Barcelona and Valencia, with some rain gauges registering 24-hr amounts in excess of $150 \mathrm{~mm}$. March was the wettest since 1947 in Spain (340\% of normal) and the second wettest in Portugal in the last 50 years (360\% of normal). Many stations across Iberia recorded their wettest March.

During summer, four heat waves struck much of Portugal. The first occurred in June, followed by another in July, and two more in August. The heatwaves contributed to 1600 deaths in Portugal and led to a large number of severe forest fires, which killed eight firefighters.
During 21-24 October, northwestern Iberia was affected by a deep low pressure system with some locations registering accumulated precipitation in excess of $250 \mathrm{~mm}$.

There were noteworthy low minimum temperatures at the end of November in Spain: $-12.5^{\circ} \mathrm{C}$ in Molina de Aragón on 28 November and $-8.5^{\circ} \mathrm{C}$ in Teruel and $-8.3^{\circ} \mathrm{C}$ at Salamanca Airport on 29 November.

\section{5) Mediterranean, Italy, and Balkan States}

This region includes Italy, Malta, Slovenia, Croatia, Serbia, Montenegro, Bosnia and Herzegovina, Albania, Macedonia, Greece, Bulgaria, and Turkey.

\section{(i) Temperature}

Annual temperature anomalies ranged from $+1^{\circ} \mathrm{C}$ in the Alps and eastern Turkey to $+2^{\circ} \mathrm{C}$ in the Mediterranean, Italy, and the Balkan States. In Bulgaria, 2013 tied 2007 as its warmest year on record $\left(+1.4^{\circ} \mathrm{C}\right.$ $\left.\pm 0.4^{\circ} \mathrm{C}\right)$.

Winter 2012/13 was colder than normal in Italy and warmer than normal in the Balkan countries and Turkey. Much of Turkey was more than $3^{\circ} \mathrm{C}$ above average. January was up to $4^{\circ} \mathrm{C}$ warmer than average, especially over the Balkans. In February, Italy was $1^{\circ}-$ $2^{\circ} \mathrm{C}$ colder than average and the Balkan States, while Turkey registered well-above-average temperatures with anomalies exceeding $+4^{\circ} \mathrm{C}$ locally in the east.

Spring was warmer than normal, especially in the Aegean Sea region (up to $+3^{\circ} \mathrm{C}$ ). A prevailing southerly flow brought tropical air to Greece, which experienced temperature anomalies of $+3^{\circ} \mathrm{C}$. In May, northern Italy was under the influence of westerly cold air and reported anomalies as low as $-2^{\circ} \mathrm{C}$. On the other hand, the eastern Balkan States and Turkey were dominated by tropical warm air masses $\left(+2^{\circ}\right.$ to $\left.+3^{\circ} \mathrm{C}\right)$.

Summer was warmer than normal due to high SLP which extended over western, central, and southeastern Europe. The highest temperature anomalies of $+2^{\circ}$ to $+3^{\circ} \mathrm{C}$ were measured in Croatia, Bosnia and Herzegovina, Montenegro, and northern Serbia. Croatia experienced area-wide temperatures above the 98th percentile. August was particularly warm with anomalies of up to $+3^{\circ} \mathrm{C}$ in the Balkan countries (Bulgaria $+2.8^{\circ} \mathrm{C}$, Slovenia more than $+3^{\circ} \mathrm{C}$ ).

Fall continued warmer than normal in southeastern Europe. The positive anomalies were $+1^{\circ}$ to $+2^{\circ} \mathrm{C}$ in most areas, except Turkey where near-normal conditions occurred. December was characterized by much colder-than-normal conditions in Turkey (negative anomalies below $-4^{\circ} \mathrm{C}$ ) and warmer con- 
ditions in the Balkan countries and Italy. Over the northern Adriatic Sea areas positive anomalies of $+2^{\circ}$ to $+3^{\circ} \mathrm{C}$ were recorded.

\section{(ii) Precipitation}

Italy, the western Mediterranean, the Balkan States, and western Turkey were wetter than average in 2013, whereas the eastern Mediterranean and eastern Turkey were drier than average.

Winter was wetter than normal, and February particularly so, in most regions except the western Mediterranean. With negative geopotential height anomalies present, the Balkan countries received $150 \%$ of normal precipitation with significantly wet conditions in Slovenia and Croatia. February SLP anomalies ranged between -4 and $-8 \mathrm{hPa}$ in the Tyrrhenian Sea region and up to $250 \%$ of the normal precipitation was recorded.

In spring, drier-than-normal southern areas contrasted with wetter-than-average northern regions. Greece registered precipitation totals only $40 \%$ of normal. Italy and the Balkan States experienced 150\% of normal rainfall widely and up to $250 \%$ locally.

Summer was rather dry in southeastern Europe, except Sicily, which received more than $250 \%$ of normal precipitation. In June it was very dry in the southern Alpine region with only $20 \%$ of normal rainfall. Drier conditions continued during July and August due to persistent high pressure. In August, Slovenia experienced very severe drought conditions, while Greece and Bulgaria registered locally less than $20 \%$ of normal precipitation. A surplus of summer precipitation in parts of the western Mediterranean was driven by extremely heavy precipitation events.

Fall was drier than normal in Italy, Greece, and eastern Turkey, whereas the Balkan countries and western Turkey were mostly close to normal overall. During September western Turkey recorded extremely dry conditions locally (20\%), whereas in October the Black Sea region had above-normal precipitation with more than $160 \%$ of normal in places. Dominant high pressure in December resulted in below-average precipitation totals in most areas, except northwestern Italy and southern Greece (125\% of normal). Precipitation totals less than $20 \%$ of normal were recorded over the Balkan countries and much of Turkey.

\section{(iii) Notable events}

In northern Italy a Fujita scale F3 tornado (estimated wind speed range 70-92 $\mathrm{m} \mathrm{s}^{-1}$ ) formed near Bologna on 3 May. During this 10-minute event, cars were swept into the air, trees were uprooted, and 13 people were injured. On $14 \mathrm{May}$, a tornado in the Çukurova airport construction area in Mersin, Turkey, killed two workers and 19 were injured.

In Ordu, Turkey, on 18 June, $89.6 \mathrm{~mm}$ rainfall fell in 18 hours, compared to June's normal monthly rainfall of $76.6 \mathrm{~mm}$. There was one fatality reported and 17 villages and 8 municipalities' roads were destroyed. Recovery and reconstruction projects totaling \$250 000 US dollars were allocated to Ordu Governorship.

Flooding occurred on 8 August at the Turkish Black Sea coast. Daily precipitation totals of 204.6 $\mathrm{mm}$ were reported. Extremely heavy precipitation was observed in the Black Sea region in October as well. Several stations measured daily totals of more than $50 \mathrm{~mm}$. The highest total of $153.5 \mathrm{~mm}$ on 3 October was reported by Hopa on the east coast.

During 15-18 November Cyclone Cleopatra formed over the western Mediterranean causing torrential rainfall and flooding in Sardinia. A total of $204 \mathrm{~mm}$ of rainfall was recorded at Olbia during 16-18 November. This amount is four times the normal for November and nearly one-third of the annual average. Deep convection intensified the rainfall locally.

\section{6) EAstern Europe}

This region includes the European part of Russia, Belarus, Ukraine, Moldova, and Romania.

\section{(i) Temperature}

Annual temperatures for eastern Europe were above normal with anomalies between $+1^{\circ}$ and $+2^{\circ} \mathrm{C}$.

Winter 2012/13 was warmer than normal in eastern Ukraine and southwestern Russia with anomalies of $+2^{\circ}$ to $+3^{\circ} \mathrm{C}$, reaching $+4^{\circ} \mathrm{C}$ in Russia. In February, anomalies exceeded $+4^{\circ} \mathrm{C}$ over wide areas of western Russia, when blocking caused a persistent southerly airflow.

During spring, eastern Europe was divided into a colder-than-average north and a warmer-thannormal south. This reflected negative 500-hPa geopotential height anomalies over western Europe, which extended to central Russia, with positive anomalies over southeastern Europe.

March was characterized by high pressure, which led to extremely cold temperatures in the north. Northern Russia experienced temperature anomalies below $-4^{\circ} \mathrm{C}$. Minsk, Belarus, observed its eighth coldest March since 1945. In contrast, Ukraine and western Russia experienced May temperature anomalies exceeding $+4^{\circ} \mathrm{C}$ due to a warm subtropical air 
flow. May temperatures in western Russia exceeded the 90 th percentile.

A warmer-than-normal summer was observed in eastern Europe. The highest anomalies were in eastern Ukraine as well as western and northern Russia, where anomalies of more than $+3^{\circ} \mathrm{C}$ occurred.

Fall continued to be warmer than normal, especially in northern Russia where anomalies of more than $+3^{\circ} \mathrm{C}$ were recorded. On the other hand, eastern Ukraine, Moldova, and Romania experienced near-normal conditions. September was colder than normal in Romania, Moldova, Ukraine, and southwestern Russia with anomalies of $-2^{\circ}$ to $-1^{\circ} \mathrm{C}$. Anomalies as low as $-3^{\circ} \mathrm{C}$ were observed in southeastern Ukraine. Milder air from the Atlantic advanced well into northern Russia in November (positive NAO phase) and caused above-average temperatures throughout eastern Europe. In most of European Russia, parts of Belarus, Ukraine, and Moldova, anomalies exceeded $+4^{\circ} \mathrm{C}$. December was warmer than normal, with anomalies of $+4^{\circ} \mathrm{C}$ in the northern part of European Russia.

\section{(ii) Precipitation}

Eastern Europe was generally wetter than average in 2013, except for northern and southern European Russia and eastern Ukraine. Western European Russia received up to $150 \%$ of normal precipitation; this was above the 95th percentile. Meanwhile northern European Russia was extremely dry (60\% of normal).

The winter season was near normal in most regions, except Romania, Moldova, Ukraine, and Belarus, which experienced more than $150 \%$ of normal precipitation. February was drier in southern Russia and adjacent areas; in the eastern Black Sea region only $20 \%$ of normal precipitation was registered.

Spring precipitation in eastern Europe was characterized by drier-than-normal conditions in northern and southern areas and wetter-than-normal in central areas. In March, negative SLP anomalies extended from the North Atlantic over continental Europe to southern Russia (negative NAO phase) and resulted in precipitation totals more than $250 \%$ in most areas except northern Russia. Ukraine experienced unusually high rainfall in western and northern areas due to a strong westerly flow. In May, warm and dry subtropical air advanced far into the north, resulting in drier-than-normal conditions in the Black Sea region (less than $20 \%$ of normal) and northern Russia (40\% of normal). Belarus was under cyclonic influence, which locally caused $250 \%$ of normal precipitation.
During the summer, above-average 500 -hPa geopotential height anomalies over the eastern North Atlantic extended from Europe to central Russia. Thus, the precipitation was mostly below normal in eastern Europe, locally only $40 \%$ of the seasonal normal. Only a few areas in Russia and areas near the Black Sea experienced some heavy precipitation.

Conditions in the fall were mostly wetter than normal. In September, above-average 500-hPa geopotential heights over northwestern Russia resulted in a continuation of exceptionally dry conditions across this region, while Romania, Moldova, Ukraine, and much of European Russia had up to 250\% of normal precipitation. Ukraine registered $265 \%-390 \%$ of normal precipitation due to a trough and an associated series of cyclones. In October, the middle latitudes of eastern Europe continued drier than normal ( $40 \%$ of normal). Eastern Ukraine received only $20 \%$ of normal rainfall, while some areas near the northern Black Sea recorded up to $250 \%$ of normal. Conditions changed in December. It was drier than normal in the southwest, while northeastern areas received aboveaverage totals (125\% of normal). Most Black Sea regions recorded less than $20 \%$ of normal precipitation.

\section{(iii) Notable events}

Moscow experienced unusually heavy snow (heaviest falls in 100 years) during winter 2012/13, especially during February. Following the remarkable snowfalls, melt water led to high water levels and flooding in April. Belarus reported flooding on 21 April.

A midtropospheric depression over Europe affected eastern Europe in March. Moscow recorded a remarkable snow depth of $75 \mathrm{~cm}$ on 26 March (the highest March snow depth in more than 20 years) and Ukraine experienced a severe snow storm with a recurrence time of once in a century. In Minsk, Belarus, snow depth rose to $55 \mathrm{~cm}$ on 16 March and stayed around $45 \mathrm{~cm}$ for several days.

In May, Russia experienced a short heat wave with daytime temperatures $+10^{\circ} \mathrm{C}$ higher than normal. On 14 May, the maximum temperature of $28.7^{\circ} \mathrm{C}$ broke a 27-year record for that day at Moscow.

During 12-18 September, rainfall totals of 200-300 mm caused severe flooding in Romania and southern Ukraine. On 13 September at Cardir-Lunga, Moldova, $34 \mathrm{~mm}$ of rain fell in 1 hour, $50-77 \mathrm{~mm}$ in 12 hours in the areas of Briceni Ribnitsa, Orhei, and Comrat, and up to $172 \mathrm{~mm}$ in 12 hours at Cahul. 
7) MIDDLE EAST

This region includes Israel, Cyprus, Jordan, Lebanon, Syria, West Kazakhstan, Armenia, Georgia, and Azerbaijan.

\section{(i) Temperature}

The Middle East in 2013 was $+1^{\circ}$ to $+2^{\circ} \mathrm{C}$ warmer than normal throughout the region. Cyprus recorded a departure of $+2.3^{\circ} \mathrm{C}$ from the long-term mean. The year 2013 ranked as the second warmest year for Armenia since 1935.

Winter $2012 / 13$ was above normal with $+1^{\circ}$ to $+2^{\circ} \mathrm{C}$ across the eastern Mediterranean and up to $+3^{\circ} \mathrm{C}$ in western Kazakhstan due to below-average SLP in January and again in February. February's highest monthly anomalies, which exceeded $+4^{\circ} \mathrm{C}$, were recorded in western Kazakhstan and the eastern South Caucasus region.

Spring remained warmer than normal. Due to more southwesterly flow May was significantly above average. These temperature anomalies were above the 90th percentile in the eastern Mediterranean area.

Persistent high pressure caused a warmer-thannormal summer in the Middle East $\left(+1^{\circ}\right.$ to $+2^{\circ} \mathrm{C}$ over the eastern Mediterranean). July and August had particularly high positive anomalies and days with maximum temperatures exceeding $40^{\circ} \mathrm{C}$. The highest daytime temperatures were measured in the eastern Mediterranean region (Israel, Jordan, Syria, and Cyprus).

In fall, the Middle East experienced abovenormal temperatures of $+1^{\circ}$ to $+2^{\circ} \mathrm{C}$. In November high pressure over Kazakhstan and southern Russia (1020-1025 hPa) led to positive anomalies in the entire Middle East. Locally, temperatures $2^{\circ}-4^{\circ} \mathrm{C}$ above average were recorded. December was colder than normal in the Middle East, except western Kazakhstan, where temperature anomalies up to $+3^{\circ} \mathrm{C}$ occurred. Armenia had an exceptionally long cold spell in December resulting in a monthly temperature anomaly of $-7.7^{\circ} \mathrm{C}$ in Yerevan, for its coldest December on record.

\section{(ii) Precipitation}

Annual precipitation in Middle East was mostly lower than normal (60\%-80\%), except western Kazakhstan, where up to $125 \%$ of normal precipitation fell. The western Caspian Sea region experienced particularly dry conditions, some locally less than $20 \%$ of normal. Cyprus received $59 \%$ of normal precipitation, the fourth lowest amount since records began in 1902.
Winter 2012/13 was mostly near normal, but with slightly drier conditions in the southwestern areas and wetter in northern Syria and the eastern South Caucasus region. January registered above-average precipitation in most of the area except Cyprus and northern Syria. February was dry in western parts. In some areas of the South Caucasus and the eastern Mediterranean less than $60 \%$ of normal precipitation was recorded.

Spring as a whole was drier than normal in most areas and near normal in parts of the South Caucasus, but with contrasting individual months. In March, the eastern Mediterranean countries received less than $20 \%$ of normal precipitation, while the eastern Black Sea region had wetter-than-normal conditions (160\%). In May conditions changed. Above-average precipitation, up to $250 \%$ of normal, was recorded in Syria, Lebanon, Jordan, Israel, and Cyprus while the northern part of Middle East had drier-than-normal conditions. Western Kazakhstan and the Black Sea region received only $\sim 20 \%$ of normal totals.

The drier-than-normal spring was followed by the usual dry summer season in the Mediterranean areas with little precipitation. In the South Caucasus and West Kazakhstan, precipitation was mostly close to normal, though with some heavy precipitation events.

Fall remained drier than normal in most areas of the Middle East (except West Kazakhstan) due to positive 500-hPa geopotential height anomalies in southeastern Europe. In September, Syria, which is normally dry, experienced unusually heavy precipitation. Along the eastern Black Sea coast extremely heavy rainfall caused flooding. In October, widespread drier conditions were recorded in the eastern Mediterranean area and the South Caucasus region where high pressure with subsidence dominated. December was characterized by high pressure with positive SLP anomalies of 6-10 hPa over the Black Sea, which led to drier-than-normal conditions in the South Caucasus and Cyprus. The Caucasus region received less than $20 \%$ of normal precipitation in places. On the other hand southeastern Mediterranean areas had above-normal totals (locally more than 250\%).

\section{(iii) Notable events}

In the first days of January, snow, frost, and thunderstorms seriously affected parts of Israel, Lebanon, Syria, and Jordan. The extreme weather affected Jordan during 5-11 January. The conditions resulted from a deep depression in the eastern Mediterranean region with a deep cold trough extending through the depth of the troposphere. The depression extended 
far to the east with its core over south Turkey and Cyprus. Due to the warm Mediterranean sea surface temperatures, deep convection with thunderstorms, heavy rainfall, and wind gusts occurred over northern and central Jordan.

In March, a heat wave hit the Middle East; maximum temperatures of $36^{\circ} \mathrm{C}$ were observed in Israel, Lebanon, and Jordan.

From 19 July until the end of the month there was flooding in western and northern Georgia. Eight Georgian stations reported precipitation totals of $16-84.4 \mathrm{~mm}$ between 19 and 30 July.

In August, extremely warm days occurred in Syria, Jordan, Lebanon, and Israel. More than 25 days were hot days (maximum temperature of $\geq 40^{\circ} \mathrm{C}$ ) with temperatures of $45^{\circ} \mathrm{C}$ measured in Jordan and $43^{\circ} \mathrm{C}$ in Syria.

During 10-14 December Israel, Jordan, and western Syria were hit by a severe storm, which brought low temperatures as well as high precipitation totals. In mountainous regions, significant snowfalls were recorded. An upper trough brought extremely cold air from northern Russia far into southern Europe and caused exceptional deviations from monthly mean temperatures. On 12 and 13 December daily maximum temperatures of $-5^{\circ} \mathrm{C}$ were recorded. In Zefat, Israel, temperatures remained below $0^{\circ} \mathrm{C}$. This was the third lowest value for any date since records began in 1939; lower temperatures were recorded only in February 1950 and January/February 1992. During this winter storm, the highest daily precipitation total of $122.3 \mathrm{~mm}$ was observed on 12 December in Israel. Nearly 400 Israeli stations recorded 5-day totals exceeding $50 \mathrm{~mm} ; 300$ of these received more than $100 \mathrm{~mm}$, and 100 recorded more than $200 \mathrm{~mm}$. Only during late November through early December 1991 was more significant rainfall measured since records began in the 1940s-1950s.

\section{g. Asia}

Throughout this section, normal is defined as the 1981-2010 average for both temperature and precipitation, unless otherwise specified. All seasons mentioned in this section refer to the Northern Hemisphere.

I) OVERVIEW-0. N. Bulygina, M. Khoshkam, N. N. Korshunova, Y. Liu, L. Oyunjargal, E-H. Park, F. Rahimzadeh, M. Rajeevan, V. N. Razuvaev, J. Revadekar, A. K. Srivastava, R. Yamada, and P. Zhang

Annual mean surface air temperatures during 2013 were above normal in large areas of the Eurasian continent and below normal in parts of northeastern Asia and northern India (Fig. 7.32). Annual precipitation amounts were above normal from eastern Siberia to northeastern China, from the south-central Siberia to central Asia and into India (Fig. 7.33).

Winter 2012/13 mean surface temperatures were below normal for much of the Eurasian continent and by more than $2^{\circ} \mathrm{C}$ in central Siberia and northern Asia (Fig. 7.34a). In contrast, values were above normal from western China to the Indochina Peninsula, southern India, and the Middle East. Winter precipitation was more than $140 \%$ of normal from southeastern Siberia to western Kazakhstan and from northern India to Pakistan (Fig. 7.34b). In contrast, total precipitation was less than $60 \%$ of normal around northern China, from southern China to northeastern India, on the eastern Indochina Peninsula, and the southern Arabian Peninsula.

Spring mean surface temperatures were above normal in central and eastern Siberia north of $60^{\circ} \mathrm{N}$ and across Asia south of $50^{\circ} \mathrm{N}$ except for China (Fig. 7.34c). Below-normal temperatures were observed from northern Japan to western Russia. Total precipitation amounts were more than $140 \%$ of normal in eastern Siberia, northeastern Mongolia, from the southern part of western Siberia to northern Kazakhstan, and from southern Pakistan to southern Saudi

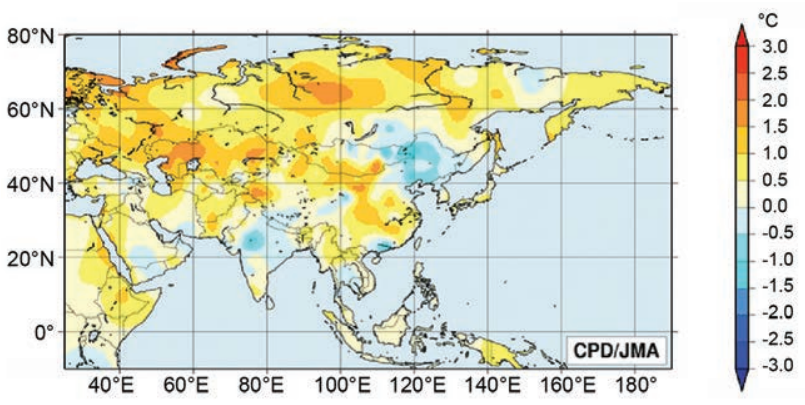

FIG. 7.32. Annual mean temperature anomalies $\left({ }^{\circ} \mathrm{C}\right.$; 1981-2010 base period) over Asia in 2013. (Source: Japan Meteorological Agency.)

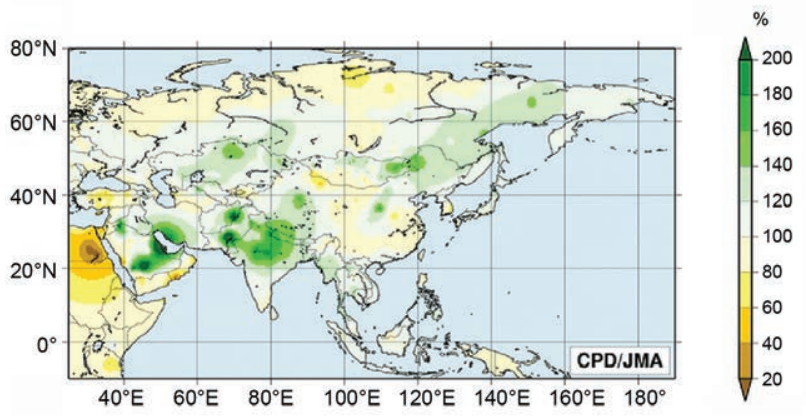

FIG. 7.33. Annual precipitation ratio as percentage of normal (1981-2010 base period) over Asia in 2013. (Source: Japan Meteorological Agency.) 
Arabia, but less than $60 \%$ of normal from western Mongolia to northern China (Fig. 7.34d).

Summer mean temperatures were above normal from Japan to the Middle East and in northern Siberia, and below normal in Mongolia, Kazakhstan, Thailand, and India (Fig. 7.34e). Total precipitation was more than $140 \%$ of normal around eastern Mongolia and Kazakhstan, from western China to central India, in the southern Philippines, and in central and southern Indochina (Fig. 7.34f). In contrast, total precipitation amounts were less than $60 \%$ of normal around the Middle East.

(a)

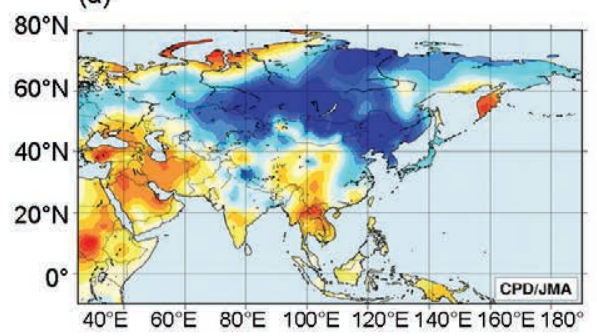

(c)

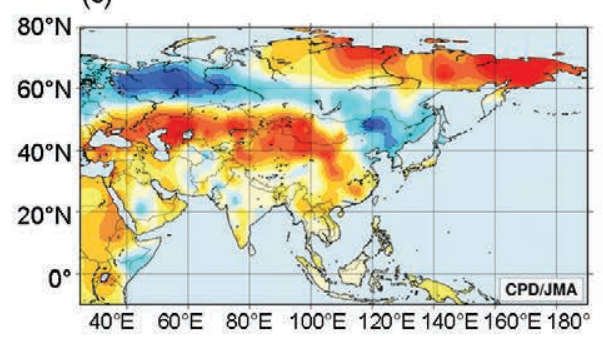

(e)

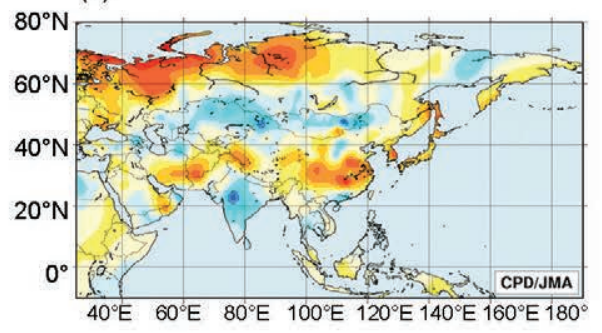

(g)

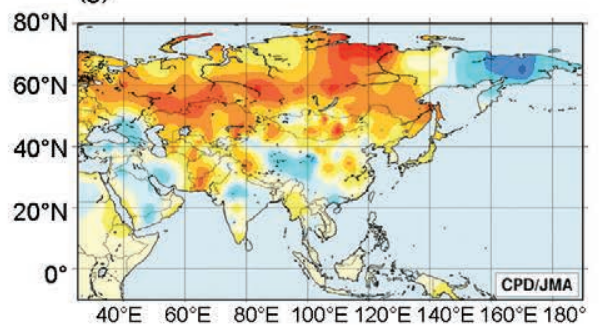

Mean surface temperatures in fall were above normal over much of Asia, but below normal in far eastern Siberia, from southern to western China, northern India, and the Middle East (Fig. 7.34g). Total precipitation amounts were more than $140 \%$ of normal around western Japan, northeastern China, eastern India, from western India to the eastern Arabian Peninsula, and the eastern Indochina Peninsula (Fig. 7.34h). Precipitation was less than $60 \%$ of normal from western China to eastern Kazakhstan and western Uzbekistan.

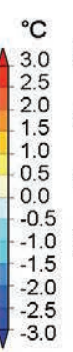

(b)

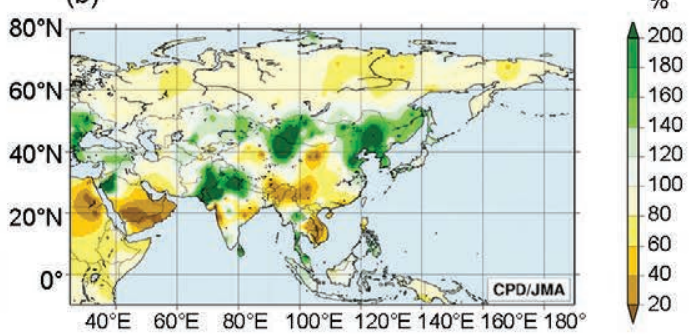

${ }^{\circ} \mathrm{C}$ 3.0
2.5
2.0
1.5
1.0
0.5
0.0
-0.5
-1.0
-1.5
-2.0
-2.5
-3.0

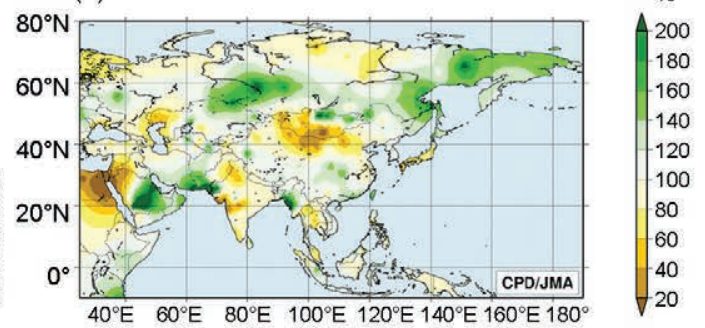
${ }^{\circ} \mathrm{C}$ 3.0
2.5
2.0
1.5
1.0
0.5
0.0
-0.5
-1.0
-1.5
-2.0
-2.5
-3.0 20\%

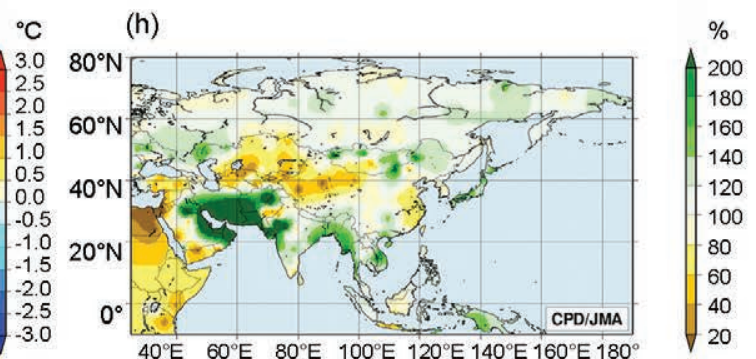

Fig. 7.34. (Left) Seasonal temperature anomalies $\left({ }^{\circ} \mathrm{C}\right)$ and (right) precipitation ratios (\%) over Asia in 2013: (a) and (b) winter (20/2/13), (c) and (d) spring, (e) and (f) summer, (g) and (h) fall. (Source: Japan Meteorological Agency.) 
Several surface climate anomalies were associated with distinct circulation features. In winter and early spring, cold arctic air tended to move into Russia and northern Asia in association with a negative Arctic Oscillation (AO). The Southwest monsoon was stronger than normal, enhancing convective activity was over much of south and Southeast Asia. The North Pacific high expanded westward into eastern China and western Japan. A positive AO prevailed in November, contributing to significantly above-normal temperatures in Russia.

2) RussiA-0. N. Bulygina, N. N. Korshunova, and V. N. Razuvaev

\section{(i) Temperature}

Overall, 2013 was warm; mean annual air temperature averaged over the Russian territory was $1.52^{\circ} \mathrm{C}$ higher than the 1961-90 normal and the sixth warmest year since 1939 (Fig. 7.35). Particularly warm were summer $\left(+1.29^{\circ} \mathrm{C}\right.$, fourth warmest since 1939) and fall $\left(+1.99^{\circ} \mathrm{C}\right.$, sixth warmest).

For all of Russia, the winter 2012/13 temperature was near normal, with the seasonal anomaly $-0.50^{\circ} \mathrm{C}$. Abnormally warm weather in February over European Russia was offset by severe December cold in Siberia, where winter was one of the coldest of the 21st century, at $2^{\circ}-3^{\circ} \mathrm{C}$ below normal. Record-breaking low temperatures repeatedly occurred in Siberia, Yakutia, Kolyma, Chukotka, and along the Arctic coast. Minimum temperatures dropped below $-55^{\circ} \mathrm{C}$.

A particularly warm January was recorded in far western Russia where the mean monthly temperature anomaly was $+4^{\circ}$ to $+6^{\circ} \mathrm{C}$. Meanwhile over Asian Russia, strong negative anomalies formed in western Siberia, southern Yakutia, and in southern Chukotka, where the mean monthly temperature anomaly was $-4^{\circ}$ to $-6^{\circ} \mathrm{C}$. In February, warm anomalies were observed over most of Russia, especially in the west. Severe frosts persisted in Asian Russia: morning temperatures in Evenkia and the Irkutsk Region were around $-50^{\circ} \mathrm{C}$. On the Arctic coast of the Laptev Sea, the temperature was $8^{\circ}-10^{\circ} \mathrm{C}$ below normal.

Spring was warm over most of Russia, with a seasonal temperature anomaly of $+0.85^{\circ} \mathrm{C}$. However, March was cold over most of Russia; it was the coldest in 50 years in northern European Russia, where, except for the southern regions,
March proved colder than February for the first time since 1957. April was abnormally warm, one of the ten warmest Aprils since regular meteorological observations started in Russia (from 1891 at some stations). The warmest anomalies formed over northwestern $\mathrm{Si}$ beria and the Arctic islands, where mean monthly air temperature anomalies were $+4^{\circ}$ to $+8^{\circ} \mathrm{C}$, and in the northeast of Russia, where temperatures were $6^{\circ}-10^{\circ} \mathrm{C}$ above normal. May was also warm over most of Russia. In mid-May, abnormally hot weather developed in European Russia with many meteorological stations recording record-breaking daily temperatures, repeatedly above $30^{\circ} \mathrm{C}$. The month was particularly hot in northeastern Siberia and northwestern Yakutia, where temperatures were $6^{\circ}-10^{\circ} \mathrm{C}$ above normal.

Summer mean air temperatures were the fourth highest on record, after 2010, 2011, and 2012. Over most of Russia, mean June temperatures were $2^{\circ}-4^{\circ} \mathrm{C}$ above normal, with the exception of southern Siberia, where negative anomalies were recorded. Late June was hot in European Russia, particularly in the north of the region, where daytime temperatures were above $30^{\circ} \mathrm{C}$. In July, mean monthly temperatures in northwestern Siberia and northeastern European Russia were up to $6^{\circ} \mathrm{C}$ above normal. Meteorological stations in Vorkuta, Salekhard, Dixon, Norilsk, Arkhangelsk,

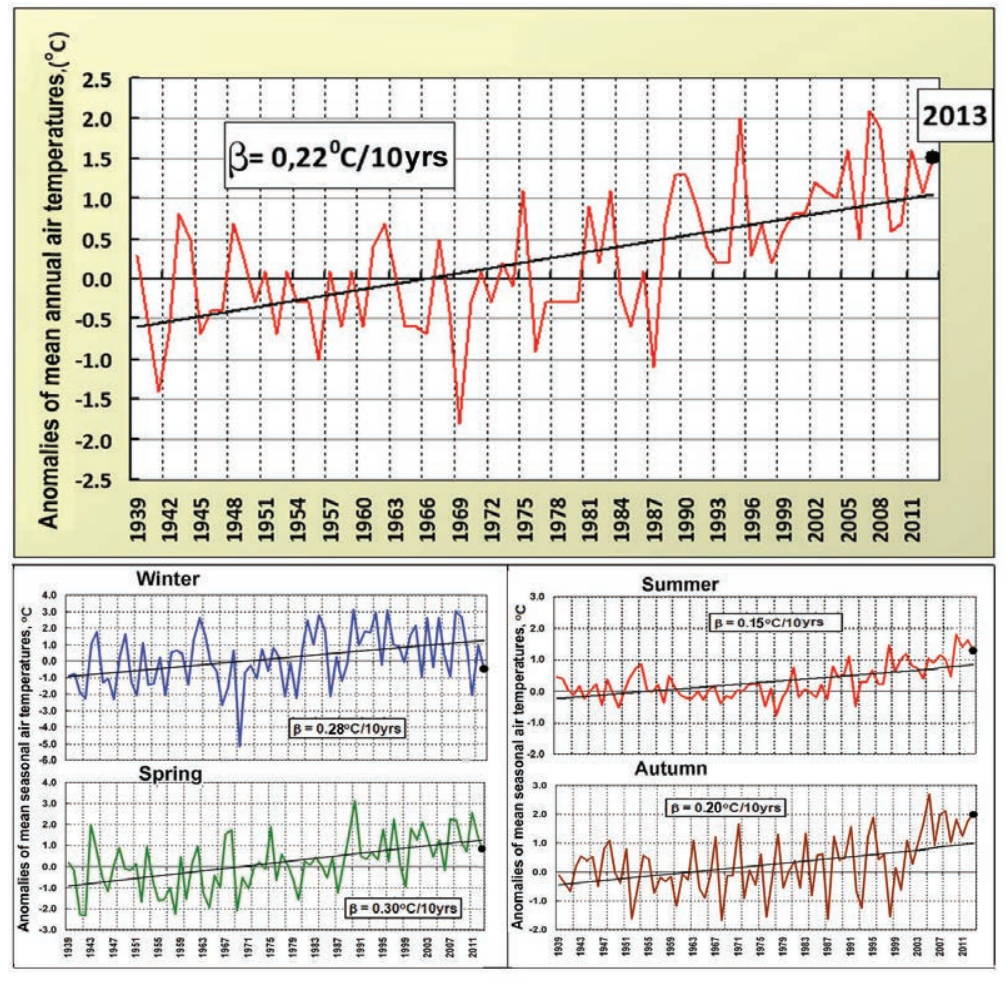

Fig. 7.35. Anomalies of mean annual and seasonal air temperatures $\left({ }^{\circ} \mathrm{C}\right)$ averaged over the Russian territory for 1939-2013 (relative to |96|-90). 
and many other cities registered record-breaking daily maximum temperatures.

Fall had a mean seasonal temperature anomaly of $+1.99^{\circ} \mathrm{C}$ (sixth highest on record) due to a recordbreaking warm November over nearly all of Russia. Fall began with cool weather in central and southern European Russia. October was warm for most of the Russian area. Over European Russia, late October was warmer than any recorded for more than a century. However, in northeastern Siberia, October was the coldest since 1976 and the third coldest since 1891. Russia experienced its warmest November on record in 2013, with a temperature anomaly of nearly $+5^{\circ} \mathrm{C}$, and up to $+10^{\circ} \mathrm{C}$ in Western Siberia. It was the warmest November on record in Hantymansijsk, Chelyabinsk, and several other cities (Fig. 7.36). Throughout the month, even minimum daily temperatures were higher than the 1961-90 normal mean air temperature.

December in Russia was also the warmest on record, with the mean monthly temperature $4^{\circ} \mathrm{C}$ above normal. Anomalies higher than $+10^{\circ} \mathrm{C}$ were recorded in the central Krasnoyarsk Territory and Chukotka Autonomous Area. The Siberian anticyclone, which typically prevails over the cooling continent at this time, could not develop due to an active westerly circulation. On 24-28 December, high temperature records were exceeded in many cities of western and central European Russia. On 25 December, Moscow's maximum air temperature of $3.5^{\circ} \mathrm{C}$ broke the previous record of $3.1^{\circ} \mathrm{C}$, set in 1910 .

\section{(ii) Precipitation}

Precipitation over Russia was generally near normal (80\%-120\%). During the year as a whole, excess precipitation was recorded in southeastern Western Siberia, Southern Urals, southern Yakutia, and the Amur and Magadan regions.

In January, monthly precipitation was above normal in southwestern and southern European Russia while a precipitation deficit was recorded in northern Caucasia and most of the Far East region. Heavy snowfalls occurred during February in central European Russia, while cold conditions in the northeast were associated with a large zone of below-normal precipitation (less than $40 \%$ of normal).

In March, above-normal precipitation was recorded in central and southern European Russia and in the Urals, with particularly heavy snowfalls in central European Russia in mid- and late March. Moscow recorded a new March record snow depth of $75 \mathrm{~cm}$ on 26 March. The previous record was $63 \mathrm{~cm}$, set
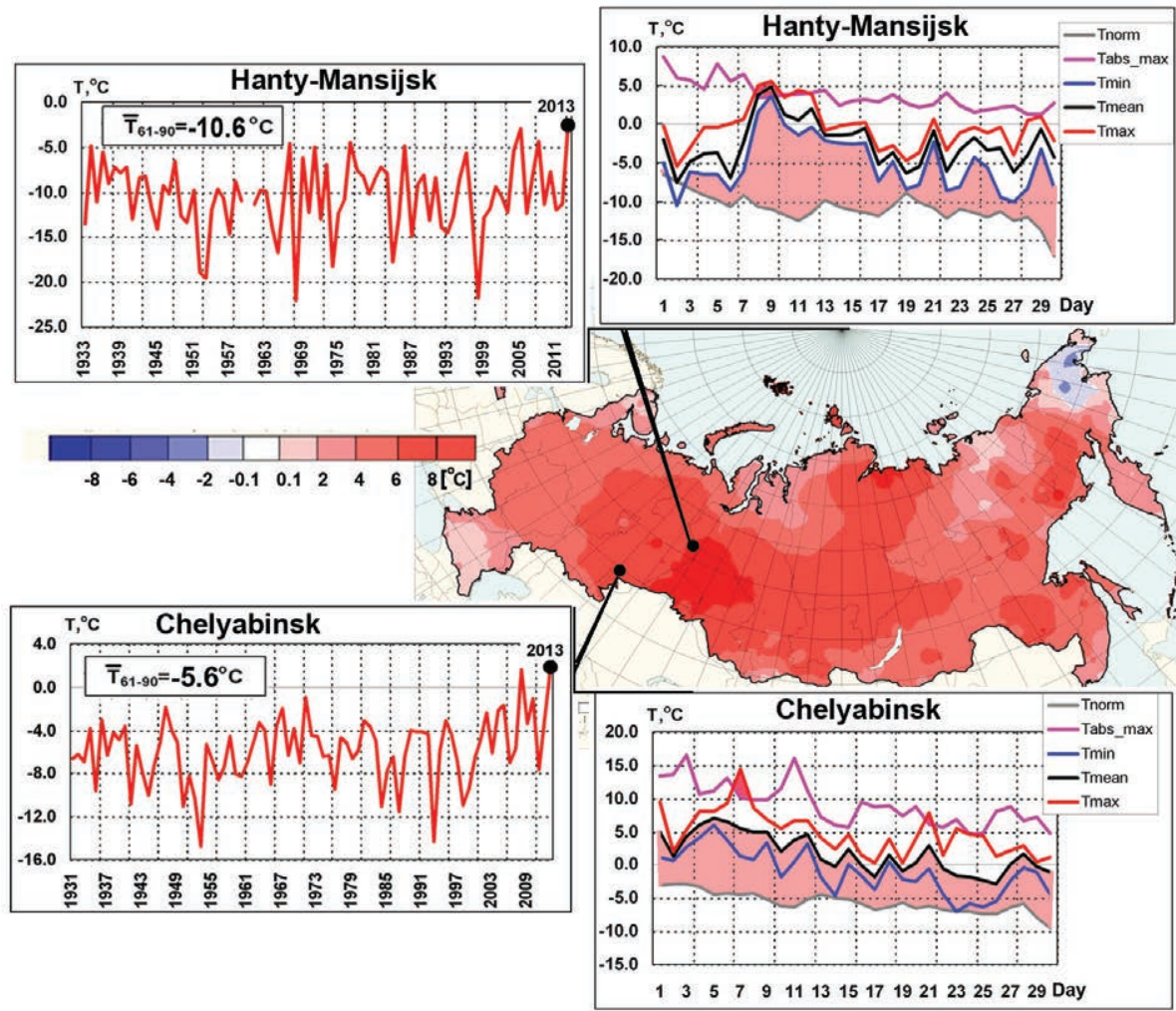

FIG. 7.36. Air temperature anomalies $\left({ }^{\circ} \mathrm{C}\right)$ in Nov 2013. Insets show the series of mean Nov temperatures (left) and Nov 2013 daily air temperatures (right) at meteorological stations Hanty-mansijsk and Chelyabinsk. in 1895. In April, European Russia experienced a substantial precipitation deficit (less than $40 \%$ of monthly normal), while the Far East region saw $240 \%-320 \%$ of normal precipitation. Much of European Russia received excess precipitation in May. On 17-18 May, the Chechen Republic received about $60 \mathrm{~mm}$ of precipitation in four hours and twenty minutes. Western Siberia experienced frequent snowfalls in May.

In June, monthly precipitation normals were exceeded in the far west and the south of European Russia. The Southern Urals and southern western Siberia experienced significant precipitation 
deficit $(6 \%-30 \%$ of monthly normal). Monthly precipitation normal was exceeded over most of the Far East. During July, almost all of European Russia experienced thunderstorm activity. On 9 July, Moscow received $30 \mathrm{~mm}$ of precipitation, nearly one-third of the July monthly normal $(94 \mathrm{~mm})$, and a new oneday record (since 1888). The main climatic event in July was the onset of disastrous flood in the southern Far East Federal District. The Amur Region and the southern Khabarovsk Territory received 2-2.5 times their monthly precipitation normals. Heavy rains in the southern Far East Federal District occurred again in August, two to three times the monthly normal.

In September, European Russia (except the north) was again wetter than normal, with two to four times the normal precipitation. In Moscow, $187.1 \mathrm{~mm}$ fell, breaking the previous September record of $171 \mathrm{~mm}$ recorded in 1885. Moscow saw its first snow on 25 September, the earliest recorded date of snow occurrence. European Russia again received above-normal precipitation in October, with Asian Russia recording much-above-normal precipitation. In November, northern and central European Russia received substantially above-normal precipitation, falling mainly as rain, totaling $160 \%-200 \%$ of normal. The entire southern region of European Russia was drier than normal with less than $40 \%$ of monthly normal in places.

A significant precipitation deficit was recorded in December in southwestern European Russia $(<40 \%$ of monthly normal). Monthly precipitation was well above normal in the central Krasnoyarsk Territory $(280 \%-360 \%$ of normal), parts of Siberia and in the Far East.

\section{(iii) Notable events}

On 2-3 March, a heavy snowstorm raged in southern Sakhalin with winds as strong as $32-40 \mathrm{~m} \mathrm{~s}^{-1}$ and poor visibility as low as $50-200 \mathrm{~m}$. Electric power and road traffic were interrupted. On $21 \mathrm{March}$, in southern Kamchatka, winds gusting to $45-50 \mathrm{~m} \mathrm{~s}^{-1}$ interrupted power supplies and most forms of communication.

On 23 April, a powerful mudslide $(1050 \mathrm{~m}$ in length and volume of $2 \mathrm{M} \mathrm{km}^{3}$ ) occurred in the Caucasus Mountains town of Tyrnauz. This resulted in casualties, destruction of houses, and the blockage of four federal highways.

On 22 May, the settlement of Efremov in the Tula Region was hit by a tornado that caused significant destruction. Roofs were destroyed, trees toppled, and power transmission lines broken. Twenty-two people, including five children, were injured. Damage was estimated to be 150 million rubles (approx. $\$ 4.2$ million US dollars).

On 17 August, large hail (up to $6 \mathrm{~cm}$ in diameter) fell in the Sverdlovsk Region, injuring people and damaging cars and roofs of houses.

The Amur River flooded several times during late summer and early fall. A stormy August in the Amur Region brought water levels to 7-11 m above normal. More than 74000 houses, 400 social facilities, 1200 roads, and 71 bridges were inundated. Property damage was more than 17 billion rubles (approx. $\$ 480$ million US dollars). The Amur crested 11-18 m above normal in the Jewish Autonomous District, causing property damage exceeding 3.2 billion rubles (approx. $\$ 90$ million US dollars). In September, the Amur River flooded again in the Khabarovsk Territory, with water levels 6-10 m above normal. Over 3000 properties were inundated with damage estimated at 14.6 billion rubles (approx. $\$ 410$ million US dollars).

3) EAST AsIA-P. Zhang, R. Yamada, Y. Liu, E-H. Park, and L. Oyunjargal

Countries considered in this section include: China, Japan, Korea, and Mongolia. Unless otherwise noted, anomalies refer to a normal period of 1981-2010.

\section{(i) Temperature}

Annual mean temperatures across East Asia are shown in Fig. 7.32. The annual mean temperature over China was $10.2^{\circ} \mathrm{C}, 0.6^{\circ} \mathrm{C}$ above normal, the fourth highest since 1961 , and $0.8^{\circ} \mathrm{C}$ higher than 2012 . The seasonal mean surface temperatures (anomalies) were $-3.7^{\circ} \mathrm{C}\left(-0.3^{\circ} \mathrm{C}\right), 11.4^{\circ} \mathrm{C}\left(+1.0^{\circ} \mathrm{C}\right) 21.7^{\circ} \mathrm{C}\left(+0.8^{\circ} \mathrm{C}\right)$, and $10.5^{\circ} \mathrm{C}\left(+0.6^{\circ} \mathrm{C}\right)$ and for winter, spring, summer, and fall, respectively.

The annual average surface temperature over Japan (averaged over 15 stations relatively unaffected by urbanization) was $0.34^{\circ} \mathrm{C}$ above normal, the eighth highest since 1898. High pressure systems with warm air frequently covered much of Japan and Okinawa/ Amami, bringing sunny and warm days from the latter half of spring to mid-fall. Consequently, annual mean temperatures were above normal except in northern Japan.

The annual mean surface temperature over South Korea was $12.9^{\circ} \mathrm{C}, 0.4^{\circ} \mathrm{C}$ above normal. The seasonal mean surface temperatures (anomalies) were $-1.0^{\circ} \mathrm{C}$ $\left(-1.6^{\circ} \mathrm{C}\right), 11.6^{\circ} \mathrm{C}\left(-0.1^{\circ} \mathrm{C}\right), 25.4^{\circ} \mathrm{C}\left(+1.8^{\circ} \mathrm{C}\right)$, and $14.6^{\circ} \mathrm{C}$ $\left(+0.5^{\circ} \mathrm{C}\right)$ for winter, spring, summer, and fall, respectively. South Korea experienced its hottest summer since 1973. 
The annual mean temperature over Mongolia was $1.0^{\circ} \mathrm{C}, 0.6^{\circ} \mathrm{C}$ above normal and $1.5^{\circ} \mathrm{C}$ higher than 2012. March was the warmest March since 1960 , with temperature anomalies of $+6.0^{\circ}$ to $+9.1^{\circ} \mathrm{C}$ over western Mongolia. Although the annual mean temperature was above normal, the summer was favorable with near-normal temperature.

\section{(ii) Precipitation}

Figure 7.33 shows 2013 annual precipitation as a percentage of normal over East Asia. The mean annual total precipitation in China was $653.5 \mathrm{~mm}, 104 \%$ of normal and slightly less than 2012 . The seasonal total precipitation was below normal in winter, but above normal in spring, summer, and fall. In 2013, the major rain belt of China lay much farther north than normal during the summer season due to a more active East Asian monsoon. The Mei-Yu started and ended earlier than normal and produced belownormal precipitation in many locations. However, the rainy season in North China began earlier and the total precipitation was above normal. The total annual precipitation was greater than normal in Northeast China (122\% of normal, including the most since 1951 in the Songhuajiang River basin), North China (112\% of normal), Northwest China, and South China.

In Japan, annual precipitation was above normal in northern Japan and eastern Japan along the Sea of Japan due to the frequent passage of cyclones and fronts. It was below normal in Okinawa/Amami where subtropical high pressure systems were dominant during summer and fall.

In South Korea, the annual precipitation was $1162.8 \mathrm{~mm}, 89 \%$ of normal. The seasonal precipitation was $139.3 \mathrm{~mm}$ (162\% of normal), $264.3 \mathrm{~mm}(111 \%)$, $567.5 \mathrm{~mm}(78 \%)$, and $231.1 \mathrm{~mm}$ (91\%) for the winter, spring, summer, and fall, respectively.

In Mongolia, above-normal or normal precipitation was observed over most areas of the country, except southern Mongolia. Seasonal precipitation amounts were near normal except winter. February was the wettest and December was the driest (156\% and $77 \%$ of normal, respectively). In October, monthly precipitation ratio was $146 \%$, a result of snow covering $60 \%-70 \%$ of the country.

\section{(iii) Notable events}

In South Korea, cold wave conditions prevailed across much of the country from 1 December 2012 to 10 January 2013 due to a significantly enhanced and expanded Siberian high. The mean surface temperature over the country for this period was $-2.7^{\circ} \mathrm{C}$, $3.7^{\circ} \mathrm{C}$ below normal. The minimum temperature for the first 10 days of January 2013 was $-11.1^{\circ} \mathrm{C}\left(5.8^{\circ} \mathrm{C}\right.$ below normal), the coldest such period since 1973 .

In Japan, winter mean temperatures were below normal in northern, eastern, and western Japan due to the strong winter monsoon. Total snowfall amounts were above normal and the highest snow depth record $(566 \mathrm{~cm})$ was observed at Sukayu in Aomori City.

In spring, China was affected by 6 dust and sand events, many fewer than the normal of 17 . There was an average of 0.3 dust days in northern China, 4.8 days fewer than normal and the fewest since 1961. While cold temperatures and floods affected spring ploughing and sowing in Northeast China, Yunnan Province and Northwest China suffered from spring drought.

There were 33 regional rainstorms over China concentrated from May to September, causing severe floods in Sichuan, Northwest China, and Northeast China successively.

In South Korea, the Changma (rainy season) started on 17 June. The rain belt was generally located over the central region and exhibited strong spatial gradients of precipitation in South Korea. For example, the Changma period precipitation over the central region and on Jeju Island was 144\% and 29\% of normal, respectively.

In Japan, from July to October, some regions experienced extremely heavy and significantly damaging rainfall due to the dominant moisture flow around the Pacific high, active fronts, and typhoons.

Mongolia was affected by 17 dust and sand storm events, higher than the past 10-year average. In summer, a hail event $(2.5 \mathrm{~cm}$ in diameter) occurred in Selenge Province, northern Mongolia.

In China, the strongest heat wave since 1951 occurred in the south, resulting in serious summer drought with direct economic losses of more than $\$ 8$ billion US dollars. East-central China suffered from 36 days with fog and haze events, many more than normal.

Japan experienced hot summer conditions across the country and western Japan recorded its highest summer mean temperature since 1946. In particular, eastern and western Japan experienced extremely hot weather in August. The country's all-time highest temperature of $41.0^{\circ} \mathrm{C}$ was observed at Ekawasaki in Kochi Prefecture on 12 August.

South Korea experienced an extremely hot summer. There were 52.5 tropical night days (daily minimum temperature $>25^{\circ} \mathrm{C}$ ) and 17 heat wave days (daily maximum temperature $>33^{\circ} \mathrm{C}$ ) recorded in Jeju 
Island, the most since 1973. Abnormally hot weather also was observed in the southern region.

Nine tropical cyclones made landfall in China (two more than normal). Five had landfall maximum wind speeds of more than $35 \mathrm{~m} \mathrm{~s}^{-1}$, bringing huge loss to southeastern coastal areas with direct losses of more than $\$ 20$ billion US dollars and 179 casualties.

South Korea was affected by three tropical cyclones (Leepi, Kong-Rey, and Danas) in summer and fall. Typhoon Danas brought heavy rainfall and strong winds to the southeastern part of South Korea.

\section{SIDEBAR 7.4: EXTREME CONDITIONS IN EAST ASIA IN SUMMER 2013 —S. TANAKA, K. YOSHIMATSU, H. OHNO, P. ZHANG, E-H. PARK, AND}

\section{BULYGINA}

East Asia experienced extremes such as severe heat, dry conditions, and heavy rainfall in summer (June-August) 2013 (Fig. SB7.5). One of the major factors contributing to these extreme conditions is the enhanced northwest Pacific high that distinctly expanded westward (Fig. SB7.6).

\section{Severe heat}

China saw its warmest August on record (tied with 2006). A persistent heat wave occurred from the beginning of July to the end of August across most of southern China. It was one of the most severe on record with respect to its geographical extent, duration, and intensity. More than 300 stations exceeded a daily maximum temperature of $40^{\circ} \mathrm{C}$ during the period. Forty-four people perished due to the heat.

Japan experienced hot summer conditions across the country. In particular, the mean summer temperature averaged over western Japan was $1.2^{\circ} \mathrm{C}$ above normal (i.e., the $1981-2010$ average), which is the highest on record for the season since
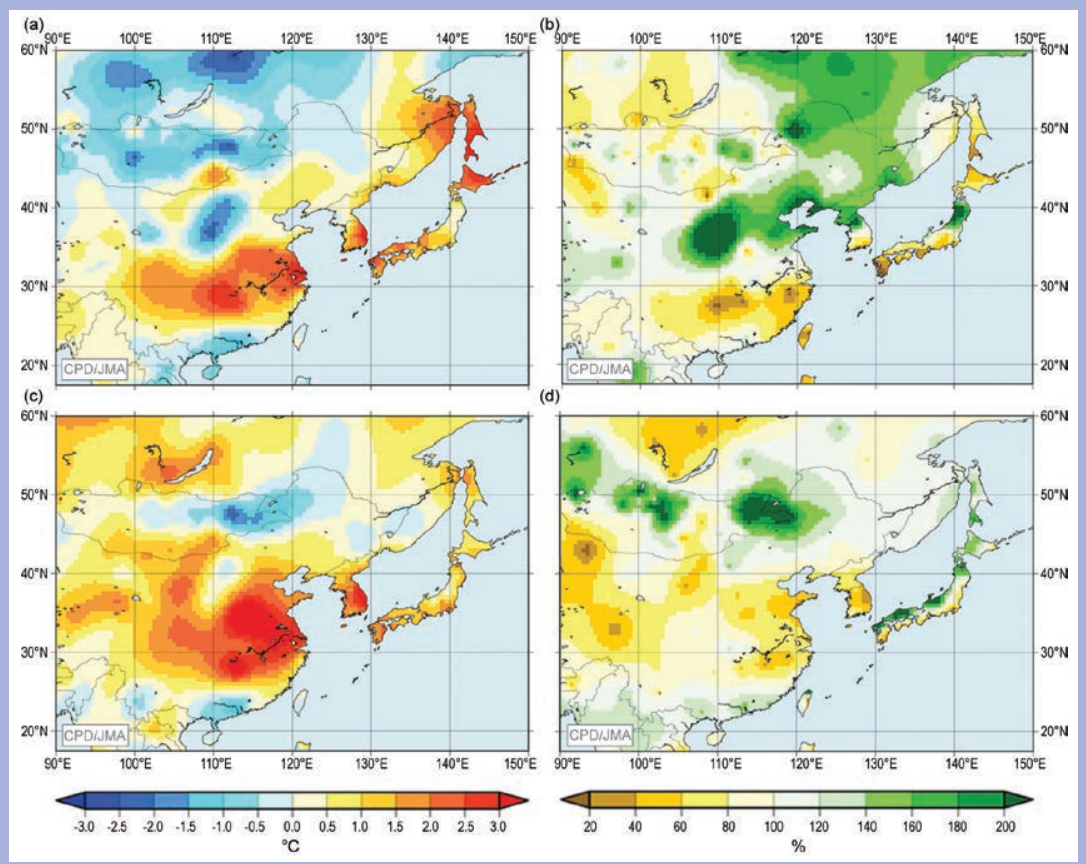

FIG. SB7.5. Monthly mean temperature anomalies $\left({ }^{\circ} \mathrm{C}\right)$ and monthly precipitation ratios (\%) for Jul and Aug 2013, departures from 1981-2010 base period. (Source: Japan Meteorological Agency CLIMAT reports.)

1946. On 12 August, Ekawasaki station in Shimanto-city, Kochi Prefecture, recorded a temperature of $41.0^{\circ} \mathrm{C}$, the highest temperature ever observed in Japan.

South Korea had its hottest summer since 1973. The heat wave and tropical nights (minimum temperatures greater than $20^{\circ} \mathrm{C}$ ) frequently affected South Korea, especially in July and August, resulting in a mean temperature I. $8^{\circ} \mathrm{C}$ above the normal of $23.6^{\circ} \mathrm{C}$.

\section{Dry conditions}

During July and August, southern China experienced severe drought conditions. Zhejiang, Jiangxi, Anhui, Hunan, Hubei, Guizhou, and Chongqing provinces received 135.2 $\mathrm{mm}$ during of precipitation I July-2I August, the lowest on record for the same period since 1951, and just $48 \%$ of average. An estimated 78 million people and more than 8 million ha of farm lands were impacted. Direct economic losses are estimated to be about $\$ 7.7$ billion US dollars.

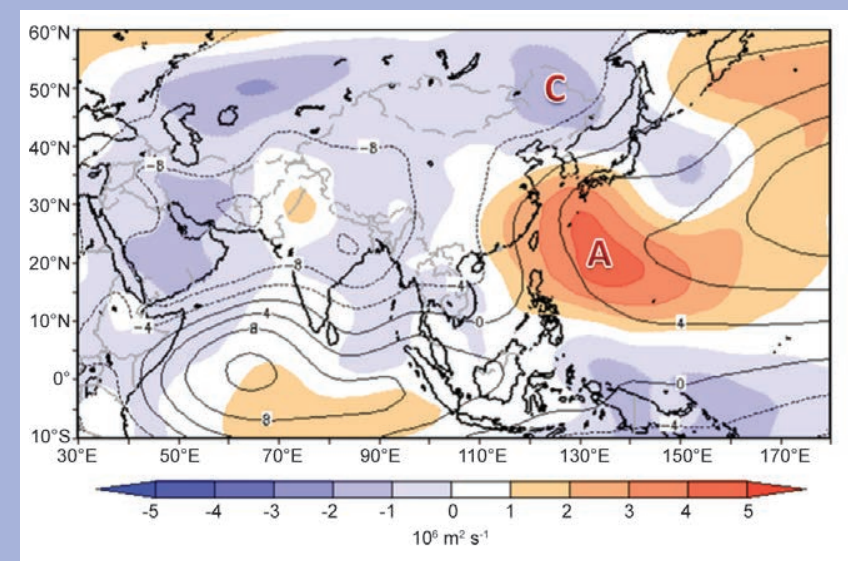

FIG. SB7.6.Two-month mean $850-\mathrm{hPa}$ stream function for Jul and Aug 2013. The contours indicate $850-\mathrm{hPa}$ stream function at intervals of $4 \times 10^{6} \mathrm{~m}^{2} \mathrm{~s}^{-1}$. The shading shows its anomalies at intervals of $I \times 10^{6} \mathrm{~m}^{2} \mathrm{~s}$-1. "A" and "C" mark the center of anticyclonic and cyclonic circulation anomalies. (Source: JRA/JCDAS reanalysis data, Onogi et al. 2007.) 


\section{CONT. SIDEBAR 7.4: EXTREME CONDITIONS IN EAST ASIA IN}

\section{SUMMER 2013 —S. TANAKA, K. YOSHIMATSU, H. OHNO, P. ZHANG, E-H. PARK,}

\section{AND 0. BULYGINA}

Some areas on the Pacific side of eastern and western Japan and parts of Okinawa/Amami experienced dry conditions. The monthly precipitation ratio to the normal averaged over southern Kyushu and Amami for July was II\% (the lowest on record for the month since 1946).

In South Korea, rainfall for the southern coast and Jeju Island was $30 \%-70 \%$ of normal precipitation from June to July, largely due to decreased influence of the monsoonal front.

\section{Heavy rainfall}

From the end of July to mid-August 2013, unusually heavy rain fell near the Amur River, which marks the border between China and Russia. The river reached a record $100.56 \mathrm{~m}$, surpassing the previous record set in 1984, as heavy flooding hit parts of the region. The Songhuajiang and Liaohe River basins in northeast China saw their heaviest floods since 1998. Nankouqian Township measured $449 \mathrm{~mm}$ of rain-half its average annual total-in a single day on 16 August. Heavy flooding was also reported in eastern Russia. More than 140 towns were affected by the worst flooding in 120 years. Over 74000 houses were flooded, 1200 roads were washed away, and 7I bridges were destroyed. In China there were direct economic losses of about $\$ 1.8$ billion US dollars and 102 casualties. In the Amur region of the Russian Federation, economic losses were estimated at $\$ 500$ million US dollars.

Tohoku and Japan's main island along the Sea of Japan experienced wet conditions. In particular, frequent heavy precipitation was observed in Tohoku, where the average monthly precipitation for July was $182 \%$ of normal, the highest on record for the month since 1946. The three-month precipitation ratio to the normal averaged over the region for summer was $151 \%$, the fourth highest on record for the season. Precipitation of unprecedented intensity was also observed in the prefectures of Yamaguchi, Shimane, Akita, and Iwate. The number of events with extreme precipitation (exceeding $80 \mathrm{~mm} \mathrm{~h}^{-1}$ ) observed during summer in Japan was the third highest since 1976.

In South Korea, the monsoonal front was frequently located over the central region, and as a result, the central region had $144 \%$ of normal precipitation from June to July.

\section{Atmospheric circulation contributing to the extreme conditions}

The northwestern Pacific high continued to expand westward and predominantly developed over southern China and western Japan during July and August 2013, contributing to severe heat and dry conditions. Enhanced warm moist air flowed over northeast China and the Sea of Japan coastal areas of Japan along the western and northern periphery of the Pacific high (Fig. SB7.7), contributing to heavy rain in these countries. In addition, upper cold air occasionally flowed over the areas in association with the southward meandering of westerly winds, contributing to heavy rain brought by unstable atmospheric conditions. Convective activity was significantly enhanced over large parts of the Asian summer monsoon region (south and Southeast Asia) in association with sea surface temperature anomaly patterns in the Pacific (above normal around Indonesia and the Philippines, and below normal in the equatorial central eastern Pacific). This heightened convective activity contributed to the enhancement of the northwestern Pacific high.

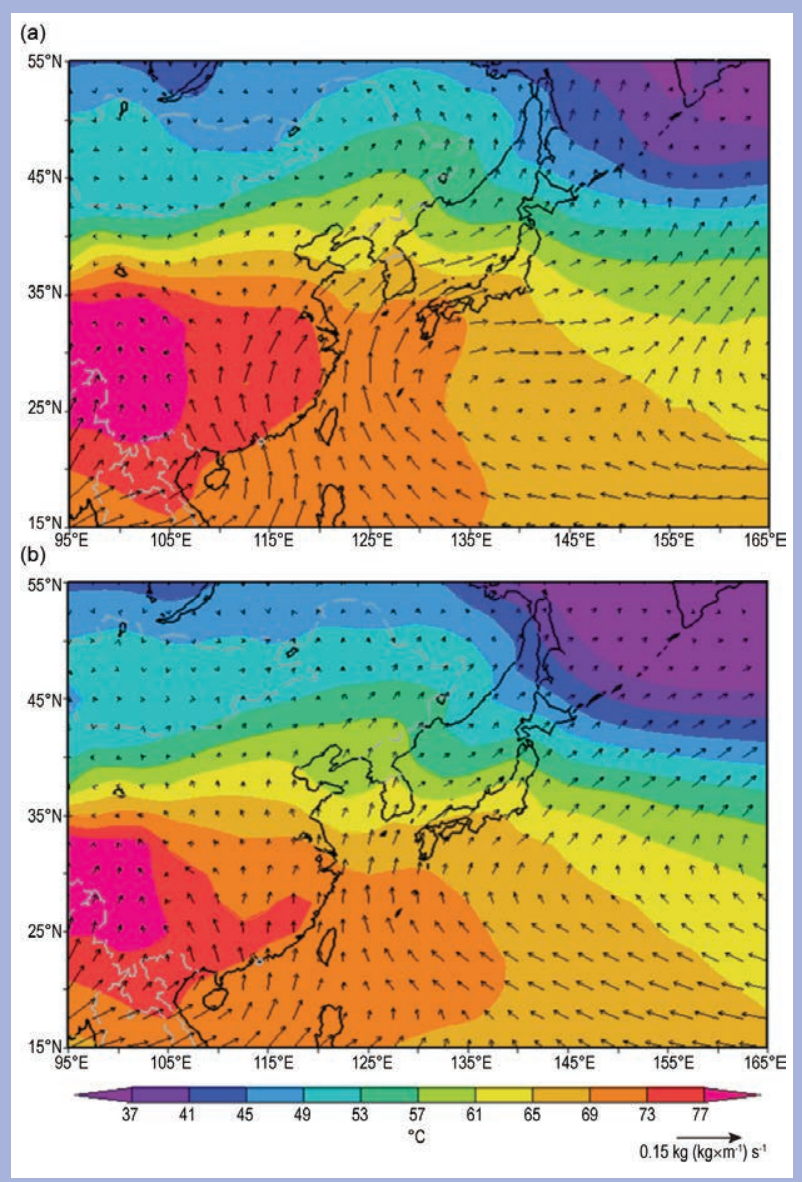

FIG. SB7.7. Two-month mean 925-hPa water vapor flux and equivalent potential temperature for Jul and Aug of (a) 2013 and (b) the $1981-2010$ average. The shading indicates $925-\mathrm{hPa}$ equivalent potential temperature at intervals of $4^{\circ} \mathrm{C}$. The arrows show 925-hPa water vapor flux. (Source: JRA/JCDAS reanalysis data, Onogi et al. 2007.) 
4) Soutr AsıA-A. K. Srivastava, J.V. Revadekar, and M. Rajeevan

Countries considered in this section include: Bangladesh, India, Pakistan, and Sri Lanka. Climate anomalies are taken relative to the 1961-90 normal, unless otherwise stated.

\section{(i) Temperature}

South Asia in general experienced moderately warm temperatures in 2013. The annual mean temperature for India in 2013 was $+0.35^{\circ} \mathrm{C}$ above the 1961-90 average, making it the 13th warmest year on record since nation-wide records commenced in 1901 (Fig. 7.37). Warmer temperatures during the winter season (January-February, $+0.65^{\circ} \mathrm{C}$ ) and the pre-monsoon season (March-May, $+0.57^{\circ} \mathrm{C}$ ) mainly contributed to the warmer annual temperatures. The pre-monsoon season this year, with daytime (maximum) temperature anomaly of $+0.68^{\circ} \mathrm{C}$, was the third warmest on record since 1901 after $2010\left(+1.4^{\circ} \mathrm{C}\right)$ and $2002\left(+0.71^{\circ} \mathrm{C}\right)$.

\section{(ii) Precipitation}

The most significant aspect of the monsoon onset phase was its rapid advancement. After the monsoon onset over Kerala (southern India) on the climatological onset date (1 June), it rapidly advanced and covered the entire south peninsula, northeastern states, and most of central India in stages during next 10 days. With the formation and westward movement of low pressure over the northwest Bay of Bengal, the monsoon rapidly covered the entire country on 16 June, nearly a month ahead of the normal date (15 July). The pace of advance of southwest monsoon this year was the fastest of the 1950-2013 period.

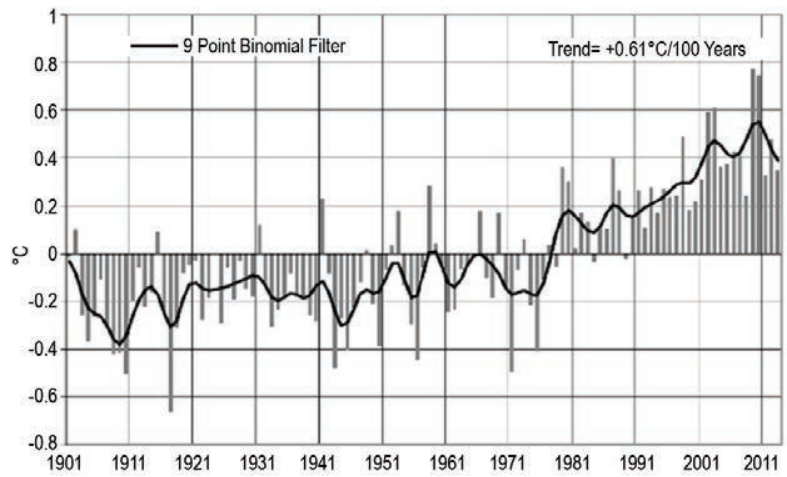

Fig. 7.37. Annual mean temperature anomalies $\left({ }^{\circ} \mathrm{C}\right)$, with respect to 1961-90 normal, averaged over India for the period 1901-2013. The smoothed time series (9-point binomial filter) is shown as a continuous line.

For India, the long-term average (1951-2000) or 'normal' value of the summer monsoon rainfall is $890 \mathrm{~mm}$. For 2013, the summer monsoon season rainfall averaged over the country was 106\% of normal. The rainfall for the season was above normal over central India and the south peninsula (123\% and $115 \%$ of normal, respectively), near normal over northwest India (109\% of normal), and below normal over the east and northeast of India (72\% of normal; Fig. 7.38). During the season, rainfall activity was not well distributed over time. During the first half of the season (1 June-31 July), the country received above-normal rainfall (117\% of normal), while during the second half of season (1 August to 30 September), rainfall activity was slightly suppressed ( $93 \%$ of normal).

During the monsoon season 14 of 36 meteorological subdivisions received excess rainfall, 16 received normal rainfall, and 6 received deficient rainfall. Out of a total of 617 districts, 100
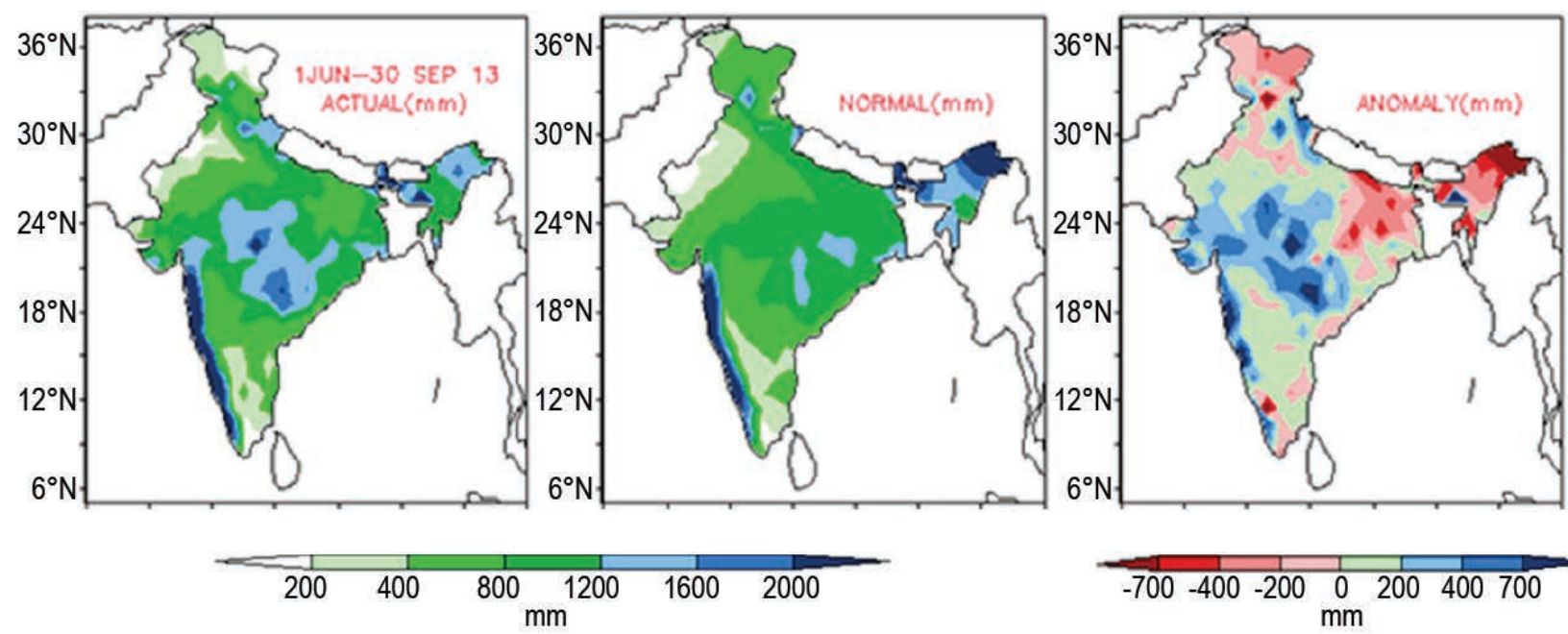

Fig. 7.38. Spatial distribution of (left) actual, (center) normal, and (right) anomaly monsoon seasonal (Jun-Sep) rainfall $(\mathrm{mm})$ over India in 2013. 
districts were affected by moderate meteorological drought (seasonal rainfall $50 \%-74 \%$ of the $1951-2000$ normal), while 39 were affected by severe meteorological drought ( $1 \%-49 \%$ of normal). On the daily time scale, rainfall averaged over the country as a whole was generally above or near normal on most of the days until the end of August and again during the last 10 days of September. Rainfall activity was substantially above normal at a stretch during the monsoon advancement stage, from 14 to 18 June. However, suppressed rainfall activity was observed during 25 August to 15 September (Fig. 7.39). In spite of a large number (16) of low pressure areas forming during the season, only two intensified into monsoon depressions. The large number of low pressure areas was primarily responsible for the above-normal rainfall activity during the season. During the winter (January-February) season, rainfall over the country was $126 \%$ of normal, it was $79 \%$ of normal during the pre-monsoon season (March-May) while during the post-monsoon season (October-December), it was $118 \%$ of normal.

The northeast monsoon (NEM) sets in over southern peninsular India during October and over Sri Lanka in late November. The NEM contributes $30 \%-50 \%$ of the annual rainfall over southern peninsular India and Sri Lanka as a whole. The 2013 NEM seasonal rainfall over south peninsular India was below normal ( $86 \%$ of normal).

Pakistan, at the western edge of the pluvial region of the south Asian monsoon, receives $60 \%-70 \%$ of its annual rainfall during the summer monsoon season (July-September). The summer monsoon sets over northeastern parts of the country around 1 July with a standard deviation of five days. In 2013, the summer monsoon was set on 27 June and generally subdued over the country. This year, monsoon was erratic with most of Pakistan receiving normal to below-normal rains while normal to above-normal rains occurred over the northern strip of the country

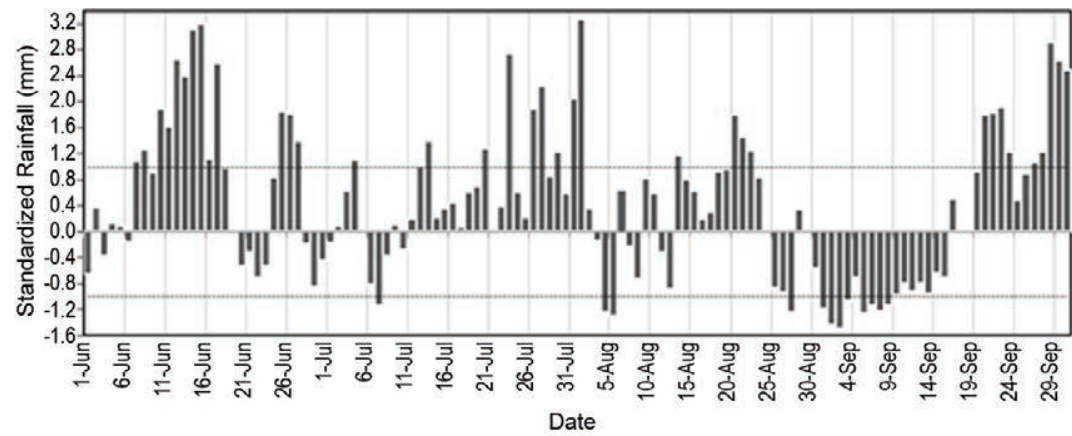

FIG. 7.39. Daily standardized rainfall time series $(\mathrm{mm})$ averaged over the monsoon core zone over India (I Jun-30 Sep 20I3). and Balochistan. However, some very heavy rainfall events in the second week of August over the northern areas of the country led to flooding. According to the Natural Disaster Management Agency of Pakistan, at least 178 people lost their lives and 855 were injured in the flood, which affected 1.5 million people across the country.

Bangladesh received below-normal to normal rainfall during the summer monsoon season. The country experienced seriously deficient rains during July almost uniformly over the country.

Overall, summer monsoon rainfall in Sri Lanka during May to September was above normal. However, northeast monsoon rainfall activity during October to December was subdued.

\section{(iii) Notable events}

During the year, five intense systems formed over the northern Indian Ocean. The post-monsoon season had above-normal storm activity with the formation of four intense tropical cyclones (with the intensity of cyclonic storm and above) during the season. Very Severe Cyclonic Storm Phailin, which crossed the east India (Odisha) coast on 12 October, was one of the most intense tropical cyclones formed over the north Indian Ocean. Thanks to coordinated evacuation efforts, only four casualties were reported, despite massive flood damage to infrastructure and crops.

Severe wintertime cold waves and dense foggy conditions prevailed over northern and central India, during January and again in December. Related incidents claimed more than 300 lives over the northern parts of the country, with over 170 casualties from Uttar Pradesh alone during January. Severe cold wave conditions also prevailed over Pakistan with some cities (e.g., Faisalabad and Sahiwal) reporting subfreezing temperatures, while Lahore reported temperatures of $0^{\circ} \mathrm{C}$. The 30 -year record minimum temperature for December was broken in parts of Balochistan as temperature dropped to $-15^{\circ} \mathrm{C}$ in Kalat.

Pakistan experienced one of its most severe heat wave events during the last half of May. Many towns in Sindh province reported maximum temperatures around $50^{\circ} \mathrm{C}$ on two occasions. Larkana reported $51.0^{\circ} \mathrm{C}$ on 19 May while Jacobabad and Mohenjo-Daro recorded $50^{\circ} \mathrm{C}$. Lahore recorded a 
maximum temperature of $47.4^{\circ} \mathrm{C}$ on 24 May. These events claimed about 100 lives.

Similarly, intense heat wave events prevailed over northeastern, central, and peninsular parts of India during May. Amritsar saw maximum temperatures reaching $48.0^{\circ} \mathrm{C}$ on 23 and 24 May. This was the hottest temperature ever recorded at Amritsar since temperature observations began in 1880. Another all-time heat record was broken at Nagpur Sonegaon Airport on 22 May when the maximum temperature soared to $47.9^{\circ} \mathrm{C}$. These events claimed over 1400 lives, with over 1300 from the state of Andhra Pradesh alone.

The most devastating events of the year were the massive floods and landslides that occurred in Uttarakhand, a hilly state in the western Himalayas, during mid-June. The disaster claimed over 5000 lives including a large number of religious pilgrims. The disaster was the cumulative effect of meteorological, hydrological, and geological causes. In association with an eastward moving midlatitude westerly trough and moisture incursion due to an early monsoon flow over northwest India, heavy rains were reported from 14 to 17 June. The accumulated rains and the snow melt across the hilly regions caused massive flooding and landslides. The holy town of Kedarnath was completely washed away due to flood water and debris from landslides.

There was severe flooding in the central and southern parts of Gujarat during the last week of September. Floods were triggered by exceptionally heavy rainfall during 23-25 September over different parts of the state. Three-day totals in central and southern Gujarat exceeded $500 \mathrm{~mm}$, with some stations observing more than $700 \mathrm{~mm}$. Floods and heavy rains during the monsoon season claimed over 800 lives over central and northern parts of India.

\section{5) SOUtHWESt AsIA-F. Rahimzadeh and M. Khoshkam}

This subsection covers only Iran. Turkey is incorporated in the Europe subsection. Climate anomalies are relative to the 1981-2010 normal, unless otherwise stated.

\section{(i) Temperature}

Winter was the only season warmer than the long-term average, with up to $+4^{\circ} \mathrm{C}$ anomalies (Fig. 7.40a). The other seasons experienced a mix of surface air temperature anomalies, but negative anomalies tended to dominate. Large areas of the country (up to $75 \%$ in spring) experienced temperatures cooler than average in spring, summer, and fall (Fig. 7.41). Temperatures in all regions of Iran have increased at (a)

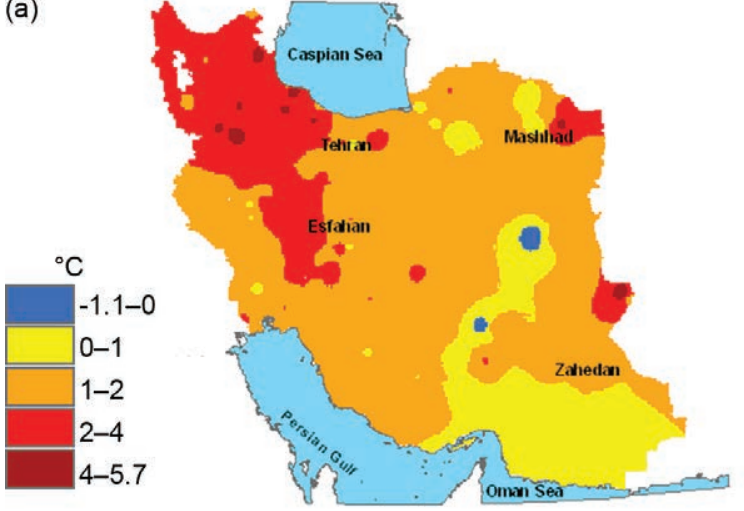

(b)

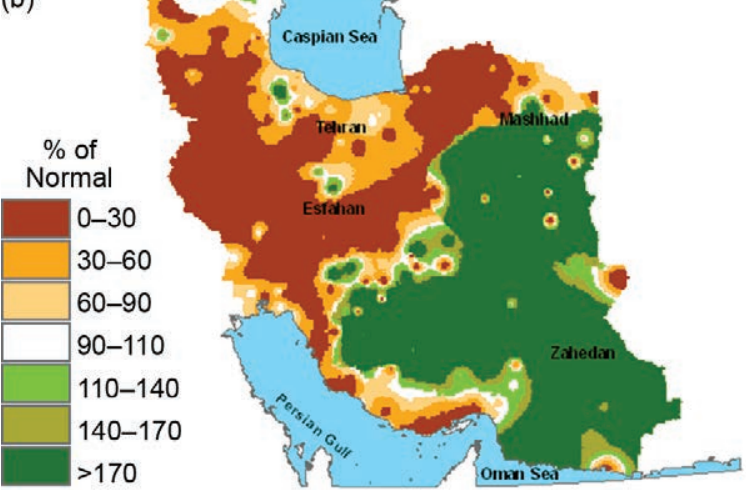

FIG. 7.40. Iran seasonal mean surface climate anomalies for (a) temperature $\left({ }^{\circ} \mathrm{C}\right.$ ) in winter $2012 / 13$, and (b) precipitation (\%) in summer 2013. (Source: I. R. of Iran Meteorological Organization.)

rates of $0.4^{\circ}-0.5^{\circ} \mathrm{C}$ decade ${ }^{-1}$ and $0.2^{\circ}-0.3^{\circ} \mathrm{C}$ decade $^{-1}$ for minima and maxima respectively for the period 1960-2010 (Rahimzadeh and Nasaji 2013, updated through 2013 in Fig. 7.41). Relative cooling can be seen for the years of 2011, 2012, and 2013 with respect to previous decades. Despite the recent relative cooling, large positive anomalies were still observed. Winter 2012/13 anomalies were $+5.7^{\circ} \mathrm{C}$ in Zabol (southeast) and $+4.8^{\circ} \mathrm{C}$ in Bijar (Zagross mountain area).

\section{(ii) Precipitation}

In general in 2013, Iran experienced drier-thannormal conditions in winter, spring, and summer, while fall experienced wetter-than-normal conditions.

During winter $2012 / 13,30 \%-90 \%$ of normal precipitation fell in most parts of the country. Areas with average or above-average rainfall (up to 170\%) were confined to a small part in the northwest of the county adjacent to the Turkish border. During spring, precipitation amounts were $90 \%-170 \%$ of normal in the southern part of the country as well as the west and northwest, while the rest of the country received 

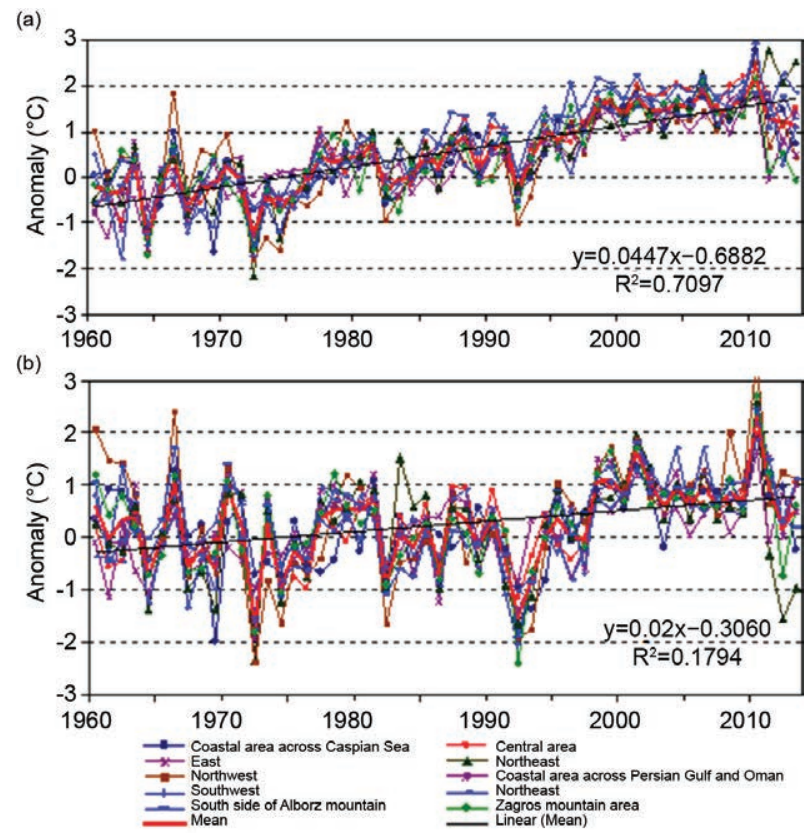

FIG. 7.4I. Regional annual (a) minimum and (b) maximum temperature anomalies $\left({ }^{\circ} \mathrm{C}\right)$ for the period 1960-2013, expressed as departures from 1961-90 average for different regions of Iran. The straight black lines are least squares trends of the country average for 1960-2010.

between $30 \%$ and $90 \%$ of normal precipitation. Unusually large precipitation anomalies were observed in spring, with extreme values such $239.9 \mathrm{~mm}$ in Chaldoran and $1.8 \mathrm{~mm}$ in Nehbandan.

A striking pattern of rainfall anomalies occurred in summer (Fig. 7.40b), with the northeast half of the country experiencing above-normal precipitation (90\%-170\% of normal) and the northwest half experiencing below-normal precipitation ( $<90 \%$ of normal). During fall, much of the eastern half of the country received less than $50 \mathrm{~mm}$ precipitation. Precipitation was between $30 \%$ and $90 \%$ of normal in northeast, central, and southwestern regions while the rest of country experienced up to $170 \%$ of normal.

\section{(iii) Notable events}

There were many strong wind events associated with high temperatures during winter and spring in the Caspian Sea region. Several air pollution events occurred in winter and fall in the largest cities in Iran, the result of frequent cold high-pressure systems and stable air masses.

Significant dust storms during spring and summer spread over many parts of Iran, especially southern and southwestern parts of the country. h. Oceania-P. R. Chappell, C. Ganter, C. P. Guard, M. A. Lander, G. Macara, S. McGree, and S. Tobin

This region includes the tropical northwest Pacific, southwest Pacific, Australia, and New Zealand.

\section{I) OVERVIEW}

ENSO-neutral conditions prevailed across the tropical Pacific for most of 2013. The Southern Oscillation index remained generally slightly positive while NINO3.4 SST anomalies remained slightly negative. Each value is indicative of neutral conditions, while leaning slightly toward La Niña. The tropical Pacific circulation exhibited some behavior typical of weak La Niña conditions, including enhanced low-level easterly winds in the western Pacific, a weak and/ or absent monsoon, and a westward shift of tropical cyclone activity. The southern annular mode (SAM) started the year in its positive polarity (up to +1.5 standard deviations) and changed midyear to a prolonged period in its negative polarity, peaking at around -2 standard deviations. Temperatures across the Oceania region were higher than normal in many places, especially in the west.

\section{2) Northwest Pacific and Micronesia-M. A. Lander and C. P. Guard}

This assessment covers the area from the dateline west to $130^{\circ} \mathrm{E}$, between the equator and $20^{\circ} \mathrm{N}$. It includes the US-affiliated islands of Micronesia, but excludes the western islands of Kiribati and nearby northeastern islands of Indonesia.

Conditions remained settled across much of the northwest Pacific through August 2013. For a brief period during mid-September through early November, there was a strong burst of tropical cyclone activity in the Western North Pacific Basin. Seven typhoons, a new monthly record, formed in the basin during October 2013 (see section $4 \mathrm{~d} 4$ for details). Some of these affected some western islands in Micronesia. During the first week of November, the final typhoon of 2013, Super Typhoon Haiyan, formed at low latitudes south of Pohnpei Island. After Haiyan, the tropical Pacific climate abruptly became quiet, with a return of low-latitude easterly wind anomalies, accompanied by the early onset of dry conditions at most islands. At the Guam Weather Forecast Office, two-thirds of the annual total rainfall for 2013 fell during August-October.

\section{(i) Temperature}

Temperatures across Micronesia in 2013 were mostly above normal, with the nighttime minimum 
temperature anomalies generally greater than those of daytime maxima. However, some locations on Guam and Saipan had persistent cooler-than-average maximum and minimum temperatures (see Table 7.3). Average monthly maximum and minimum temperatures across most of Micronesia have gradually increased for several decades with a total rise of average temperature on par with the global average increase of $+0.74^{\circ} \mathrm{C}$ in the last century (Guard and Lander 2012). At some stations, a recent pause in the rate of temperature rise is apparent (e.g., Fig. 7.42). In the years following the strong 1997/98 El Niño, the difference between the daytime high and the nighttime low has increased. This is seen directly in Fig. 7.43, and is manifested in Fig. 7.42 as a crossover of the blue trace of the minimum temperature anomalies from above to below the red trace of the maximum temperature anomalies.

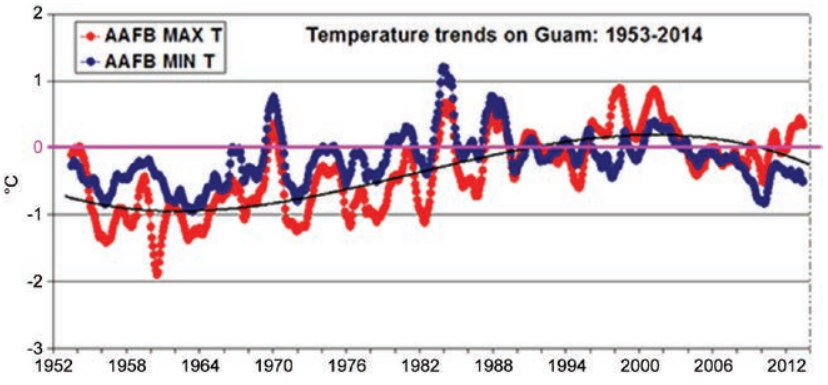

FIG. 7.42. Time series of maximum (red) and minimum (blue) temperature anomalies $\left({ }^{\circ} \mathrm{C}\right.$ ) at Andersen Air Force Base, Guam, for the period 1952-2013. Values are a 12-month moving average of the monthly anomalies, expressed as departures from the 198I-2010 base period (pink line). Third-order trend line is shown in black for the Max T.

\begin{tabular}{|c|c|c|c|c|c|c|c|c|c|c|}
\hline \multirow{3}{*}{ Location } & \multicolumn{2}{|c|}{$\begin{array}{l}\text { Max Temp } \\
\text { Min Temp }\end{array}$} & \multicolumn{8}{|c|}{ Rainfall } \\
\hline & Jan-Jun & Jul-Dec & $\begin{array}{c}\text { Avg. } \\
\text { Jan-Jun }\end{array}$ & $\begin{array}{c}2013 \\
\text { Jan-Jun }\end{array}$ & Jan-Jun & $\begin{array}{c}\text { Avg. } \\
\text { Jul-Dec }\end{array}$ & $\begin{array}{c}2013 \\
\text { Jul-Dec }\end{array}$ & Jul-Dec & Annual & Annual \\
\hline & ${ }^{\circ} \mathrm{C}$ & ${ }^{\circ} \mathrm{C}$ & $\mathrm{mm}$ & $\mathrm{mm}$ & $\%$ & $\mathrm{~mm}$ & $\mathrm{~mm}$ & $\%$ & $\mathrm{~mm}$ & $\%$ \\
\hline $\begin{array}{c}\text { Saipan } \\
15^{\circ} \mathrm{N}, 146^{\circ} \mathrm{E}\end{array}$ & $\begin{array}{l}-0.60 \\
-0.85\end{array}$ & $\begin{array}{r}0.0 \\
-0.63\end{array}$ & 514.4 & 501.4 & 97.5 & 1442.2 & 1020.8 & 78.2 & |739.| & 85.6 \\
\hline $\begin{array}{c}\text { Guam* } \\
13^{\circ} \mathrm{N}, 145^{\circ} \mathrm{E}\end{array}$ & $\begin{array}{r}+0.76 \\
-0.40\end{array}$ & $\begin{array}{l}+0.39 \\
-0.60\end{array}$ & 634.8 & 584.0 & 92.0 & 1549.2 & 1996.2 & 128.9 & $\begin{array}{l}2580.1 \\
2110.0\end{array}$ & $\begin{array}{l}118.2 \\
84.4\end{array}$ \\
\hline $\begin{array}{c}\text { Yap } \\
9^{\circ} \mathrm{N}, 138^{\circ} \mathrm{E}\end{array}$ & $\begin{array}{l}+1.05 \\
+1.73\end{array}$ & $\begin{array}{l}+1.00 \\
+1.75\end{array}$ & 1194.3 & 1046.0 & 87.6 & 1916.7 & 1916.2 & 100.0 & 2962.1 & 95.2 \\
\hline $\begin{array}{c}\text { Palau } \\
7^{\circ} \mathrm{N}, 134^{\circ} \mathrm{E}\end{array}$ & $\begin{array}{l}+0.27 \\
+0.65\end{array}$ & $\begin{array}{l}+0.07 \\
+0.23\end{array}$ & 1696.5 & 1307.3 & 77.1 & 2083.1 & 1608.1 & 77.2 & 2915.4 & 77.1 \\
\hline $\begin{array}{c}\text { Chuuk } \\
7^{\circ} \mathrm{N}, 152^{\circ} \mathrm{E}\end{array}$ & $\begin{array}{l}+0.03 \\
+0.85\end{array}$ & $\begin{array}{l}+0.27 \\
+0.77\end{array}$ & 1611.9 & 1562.4 & 96.9 & 1964.4 & 1749.0 & 89.0 & 3311.4 & 92.6 \\
\hline $\begin{array}{c}\text { Pohnpei } \\
7^{\circ} \mathrm{N}, 158^{\circ} \mathrm{E}\end{array}$ & $\begin{array}{l}-0.27 \\
+2.07\end{array}$ & $\begin{array}{l}+0.55 \\
+0.73\end{array}$ & 2298.7 & 1564.4 & 68.1 & 2429.8 & 1768.4 & 72.8 & 3332.7 & 70.5 \\
\hline $\begin{array}{l}\text { Kapinga } \\
1^{\circ} \mathrm{N}, 155^{\circ} \mathrm{E}\end{array}$ & N/A & N/A & 1761.2 & 1977.6 & 112.3 & 1511.6 & 1340.7 & 92.0 & 3368.3 & 102.9 \\
\hline $\begin{array}{c}\text { Kosrae } \\
5^{\circ} \mathrm{N}, 163^{\circ} \mathrm{E}\end{array}$ & $\begin{array}{l}-0.42 \\
+1.15\end{array}$ & $\begin{array}{l}+0.20 \\
+1.05\end{array}$ & 2427.2 & 2371.6 & 97.7 & 2139.4 & 2170.7 & 101.5 & 4542.3 & 99.5 \\
\hline $\begin{array}{c}\text { Majuro } \\
7^{\circ} \mathrm{N}, 171^{\circ} \mathrm{E}\end{array}$ & $\begin{array}{l}+0.42 \\
+1.63\end{array}$ & $\begin{array}{l}-0.20 \\
+1.43\end{array}$ & 1429.5 & 1056.6 & 73.9 & 1905.0 & 1472.2 & 77.3 & 2528.8 & 75.8 \\
\hline $\begin{array}{l}\text { Kwajalein } \\
9^{\circ} \mathrm{N}, 168^{\circ} \mathrm{E}\end{array}$ & $\begin{array}{l}+0.60 \\
+0.70\end{array}$ & $\begin{array}{l}+0.83 \\
+0.73\end{array}$ & 919.0 & 492.3 & 53.6 & 1587.3 & 1129.0 & 71.1 & 1621.3 & 64.7 \\
\hline
\end{tabular}

* Andersen Air Force Base (red); Guam WFO (black). The AAFB temperature record is more complete and stable than that of the Guam WFO. Most of the difference in annual rainfall at AAFB versus the WFO occurred during September's extreme two-day event. 


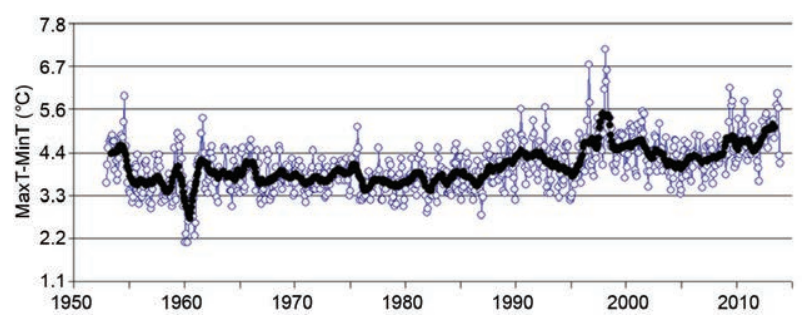

FIG. 7.43. Time series of the difference between maximum and minimum temperature $\left({ }^{\circ} \mathrm{C}\right)$ at Andersen Air Force Base, Guam. Black line is the I2-month moving average of the monthly averages (open blue dots). Note the extreme during the 1997-98 EI Niño and the elevated levels thereafter.

\section{(ii) Precipitation}

Most rainfall totals throughout Micronesia during 2013 were below normal, with some of the islands and atolls in the eastern portion of the region experiencing exceptional dryness for some or all of 2013. The 2013 annual rainfall of $1621.3 \mathrm{~mm}$ at Kwajalein was the second lowest annual total in its 66 -year record. Few locations had surplus rainfall during 2013. The annual rainfall at Peleliu in the Republic of Palau was 106\% of its annual average, although the other locations throughout Palau were below normal. At Kapingamarangi and Nukuoro (atolls near the equator south of Pohnpei Island), the annual surplus was greatest, with each receiving over $120 \%$ of average annual rainfall. During mid-September 2013, an extreme two-day rainfall event of $500 \mathrm{~mm}$ pushed many locations on Guam past their annual average. The six-month and annual rainfall values for selected locations across Micronesia are summarized in Table 7.3.

\section{(iii) Notable events}

The first half of 2013 was dry at northern atolls in the Republic of the Marshall Islands (RMI). Some atolls had extraordinarily dry conditions that are rarely seen anywhere within Micronesia. During a 7-month period from November 2012 through May 2013, Wotje and Utirik had rainfall totals of 189.7 and $191.8 \mathrm{~mm}$, respectively. These rainfall levels created an emergency drought situation. The RMI Cabinet declared a State of Disaster on 8 May, elevating the previous State of Emergency declared on 19 February, for their northern atolls. The Cabinet renewed the disaster declaration on 7 June. The severe drought affected over 6300 people (over 10\% of the total population). On 14 June, US President Barack Obama issued a Presidential Disaster Declaration for the RMI, authorizing additional US government funding for relief and reconstruction activities. Many of the remote atolls of the RMI depend on tree-based food staples like coconuts, pandanus, breadfruit, and bananas. These were severely depleted on the drought-impacted atolls of the northern RMI, and it will take several years until damaged trees can be replaced and start bearing fruit. Nearly all the islands of eastern Micronesia (and Hawaii) have long-term downward trending time series of annual rainfall. The atolls of the northern RMI have lost over 15\% of their annual rainfall over the course of the past three decades (Fig. 7.44).

During mid-September through early November, there was a surge in cyclone activity, with the Joint Typhoon Warning Center (JTWC) reporting 15 significant tropical cyclones. This burst included a record number of typhoons (seven) forming during October. The JTWC best track archive indicates an average of 2.8 typhoons during October, with the previous record high of six occurring in October 1989. Six Octobers during the previous 56 years produced five typhoons. The surge in cyclone activity was capped during the first week of November by the formation of the most intense and destructive typhoon of the year: Super Typhoon Haiyan (see also section $7 \mathrm{~h} 2$ and Sidebar 4.2 for details on the storm). Haiyan became a super typhoon to the east of Palau, just before it tracked directly over Palau's northernmost atoll of Kayangal causing much destruction, but no injuries or loss of life. It later made landfall close the city of Tacloban in the central Philippines, where the damage was catastrophic and the loss of life in the thousands. It was the second super typhoon in less than a year to directly affect and seriously impact the Republic of Palau. The prior cyclone was Super

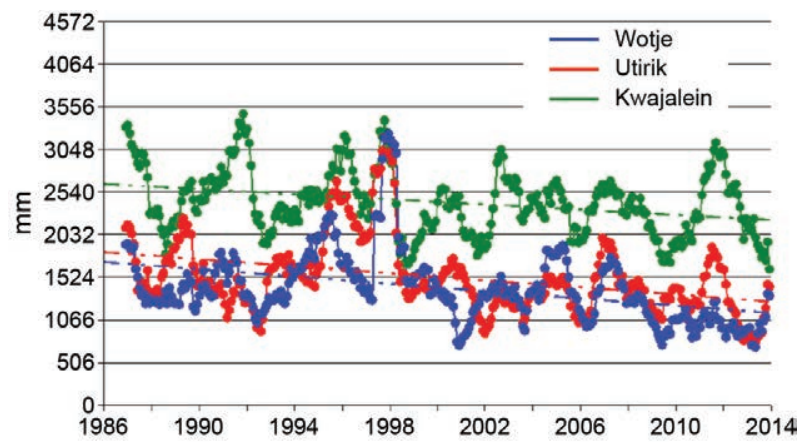

FIG. 7.44. Rainfall ( $\mathrm{mm}$ ) time series at Kwajalein, Wotje, and Utirik from 1986 to present. Values plotted are a I2-month moving sum of the monthly rainfall. Note the steady long-term decline and the pronounced fluctuations that are to a large extent related to ENSO. The recent dry conditions are the driest in this 27-year time series. High rainfall during 1997 was related to unusual typhoon and monsoonal activity during a very strong EI Niño. 
Typhoon Bopha, which passed near Palau in early December 2012, and sharing many similarities with Haiyan, Bopha also made landfall in the Philippines with catastrophic and deadly power.

\section{3) Southwest PACIFic—S. McGree}

Countries considered in this section include: American Samoa, the Cook Islands, Fiji, French Polynesia, Kiribati, Nauru, New Caledonia, Niue, Papua New Guinea (PNG), Samoa, Solomon Islands, Tokelau, Tonga, Tuvalu, and Vanuatu. Unless otherwise noted, anomalies are relative to the 1971-2000 period.

\section{(i) Temperature}

Mean air temperatures were near normal between January and March across most of the southwest Pacific. Positive anomalies between $0.5^{\circ}$ and $1.0^{\circ} \mathrm{C}$ were present across most of the Solomon Islands, Nauru, western Kiribati and eastern French Polynesia. Negative anomalies between $-0.5^{\circ}$ and $-1.0^{\circ} \mathrm{C}$ were observed east of New Caledonia and south of Vanuatu. The positive anomalies in the first quarter of the year expanded westward towards southern PNG and southeast towards Vanuatu, Fiji, and Samoa between April and June. This was associated with anomalously warm SSTs in this region. From southern Tonga to the southern Cook Islands, air temperature anomalies were greater than $+0.5^{\circ} \mathrm{C}$.

The positive anomalies east of Fiji continued into July through September, but to a lesser extent. Negative anomalies (around $-0.5^{\circ} \mathrm{C}$ ) were present around the southern French Polynesia islands, eastern Kiribati (associated with cool SST anomalies), and the northern PNG islands. The negative anomalies around the northern PNG islands continued into the final quarter of the year and those around eastern Kiribati strengthened further to almost $-2^{\circ} \mathrm{C}$. Positive anomalies between $+0.5^{\circ}$ and $+1^{\circ} \mathrm{C}$ were present east of the Solomon Islands and north to Nauru and near southern Tonga. Figure 7.45 shows annual mean air temperature anomalies for 2013.

\section{(ii) Precipitation}

Year-to-year rainfall variability in the southwest Pacific islands is strongly associated with ENSO as well as the position and intensity of the major modes of variability that are in close proximity. The west Pacific monsoon (WPM) lies over the warm pool, with the intertropical convergence zone (ITCZ) north

of the equator and the South Pacific convergence zone (SPCZ) positioned northwest-southeast south of the equator.

The year began with suppressed rainfall in the Nauru, western Kiribati, northern Solomon Islands, Vanuatu, and Fiji regions. In February, rainfall in New Caledonia was relatively scarce with a number of rain gauges recording some of their lowest monthly totals in almost 40 years. Suppressed rainfall continued in the Nauru and western Kiribati region in February and March. Several countries also reported wetter-than-normal conditions in the first quarter. In January, above-normal rainfall was associated with an enhanced WPM over PNG and SPCZ east of the dateline. The intense SPCZ activity resulted in significant flooding in Samoa. In February, abovenormal rainfall was recorded in the southern half of Fiji (Nausori Airport recorded its wettest February in 57 years), Tonga and parts of French Polynesia. In March, an active SPCZ west of the dateline resulted in Auki, in the Solomon Islands, recording its wettest March in 52 years and Henderson Airport its wettest in 39 years. In Fiji, high rainfall also resulted in flooding (see notable events).

Parts of Fiji, Niue, and northern Vanuatu received below-normal rainfall in April while the southern parts of French Polynesia received below-normal rainfall in May. The southern Cook Islands received below-normal rainfall for most of the second quarter, resulting in drought conditions in Rarotonga. Above-normal rainfall continued west of the dateline between eastern PNG and southern Vanuatu, with patches of above-normal rainfall in May between the southern Solomon Islands and Fiji. This pattern continued into June with the inclusion of above-normal rainfall over eastern PNG, the Gilbert Islands, and Samoa. Climatologically, the SPCZ is marginally 
present east of Samoa in July and August; however, in 2013 it extended as far east as French Polynesia. Rainfall was generally above normal from the Solomon Islands east to Samoa (see notable events), with the exception of Vanuatu and Fiji.

Convection was suppressed around Nauru and the Gilbert Islands between July and September and over PNG in September. There was enhanced SPCZ activity between the southern Solomon Islands and French Polynesia in October with the SPCZ close to its mean position for that time of year. The October total monthly rainfall was the highest recorded at Lata, Solomon Islands, in 39 years.

In November, there were two portions to the SPCZ. West of the dateline, the SPCZ lay over Vanuatu, New Caledonia, and Fiji resulting in above-normal rainfall in these countries and below-normal rainfall to the north. East of the dateline, the SPCZ was over Tokelau and the northernmost Cook and French Polynesia Islands. November was particularly dry in the southern half of the Solomon Islands. The year ended with enhanced WPM activity over PNG and the Solomon Islands and enhanced SPCZ activity over Fiji, Tuvalu, and the northern Cook and French Polynesia Islands. Below-normal rainfall was recorded in December at Nauru and the Gilbert Islands. Table 7.4 lists observed annual totals for national capitals where available.

\begin{tabular}{|c|c|c|}
\hline \multicolumn{3}{|c|}{$\begin{array}{c}\text { Table 7.4. Rainfall totals for } 2013 \text { and percent of } \\
\text { average for key sites in the southwest Pacific. }\end{array}$} \\
\hline Station & $\begin{array}{c}\text { Annual } \\
\text { Total } \\
\text { (mm) }\end{array}$ & $\begin{array}{c}\text { Percent } \\
\text { of } \\
\text { Average }\end{array}$ \\
\hline Port Moresby (PNG) & 1321 & 117 \\
\hline Honiara (Solomon Islands) & 2050 & 105 \\
\hline Port Vila (Vanuatu) & 2140 & 98 \\
\hline Noumea (New Caledonia) & 1139 & 106 \\
\hline Suva (Fiji) & 3001 & 99 \\
\hline Nuku'alofa (Tonga) & 2234 & 130 \\
\hline Hanan Airport (Alofi, Niue) & 1971 & 95 \\
\hline Apia (Samoa) & 3369 & 111 \\
\hline Rarotonga (Cook Islands) & 1421 & 77 \\
\hline Tahiti (French Polynesia) & 1240 & 73 \\
\hline Tarawa (Kiribati) & 1417 & 68 \\
\hline Funafuti (Tuvalu) & 4018 & 118 \\
\hline
\end{tabular}

\section{(iii) Notable events}

On 28 March, a slow-moving tropical depression (TD17F) with an associated active trough moved over Fiji from the north to lie just to the west of the country on 29 March. Overnight, the depression underwent rapid development, resulting in heavy rain with squally thunderstorms over the country. Prolonged rainfall led to flooding of low-lying areas in the western part of Fiji until the end of the month. Many stations received rainfall in excess of $200 \mathrm{~mm}$ on 29 March. Lautoka, on the western side of the main island of Viti Levu, received $362 \mathrm{~mm}$.

There were two notable events in New Caledonia. The first was associated with Tropical Cyclone Freda. Although only a tropical depression when it reached New Caledonia on 2 January, it produced an exceptional amount of rainfall ( $>10$-year return period) and high winds up to $150 \mathrm{~km} \mathrm{~h}^{-1}$ south of Grande Terre. The east coast of Grande Terre was the most affected, with roads and bridges destroyed as a consequence of flooding. Daily rainfall totals ranged from 300 to $500 \mathrm{~mm}$. On 2 July, torrential rainfall occurred on the eastern and the southern side of Grande Terre. This was associated with the convergence of westerly air from the extratropics and a warm tropical air mass flowing poleward. La Riviere Blanche received $520 \mathrm{~mm}$ in 12 hours and $714 \mathrm{~mm}$ in 24 hours. This rainfall event was one of the most significant in New Caledonia's history.

\section{4) Australia-C. Ganter and S. Tobin}

Australian temperature and precipitation anomalies refer to a 1961-90 base period.

\section{(i) Temperature}

The 2013 mean temperature anomaly of $+1.2^{\circ} \mathrm{C}$ was Australia's highest since its national record began in 1910; the previous record was $+1.0^{\circ} \mathrm{C}$ in 2005 . Both maximum temperatures (Fig. 7.46) and minimum temperatures (Fig. 7.47) were well-above average, with anomalies of $+1.5^{\circ} \mathrm{C}$ (warmest) and $+0.9^{\circ} \mathrm{C}$ (second warmest), respectively. Most states and territories had their warmest year for maximum temperatures, but Victoria and Tasmania were third and sixth warmest, respectively. Minimum annual temperatures for all states and territories were among their respective top five warmest, except for New South Wales, which was 12 th warmest.

Maximum temperatures were above average almost everywhere. Most coastal and adjacent inland areas experienced anomalies between $0.0^{\circ}$ and $+1.0^{\circ} \mathrm{C}$, except the coasts of western, southern, and southeast Australia, where anomalies were $+1.0^{\circ}$ to $+1.5^{\circ} \mathrm{C}$. The largest 

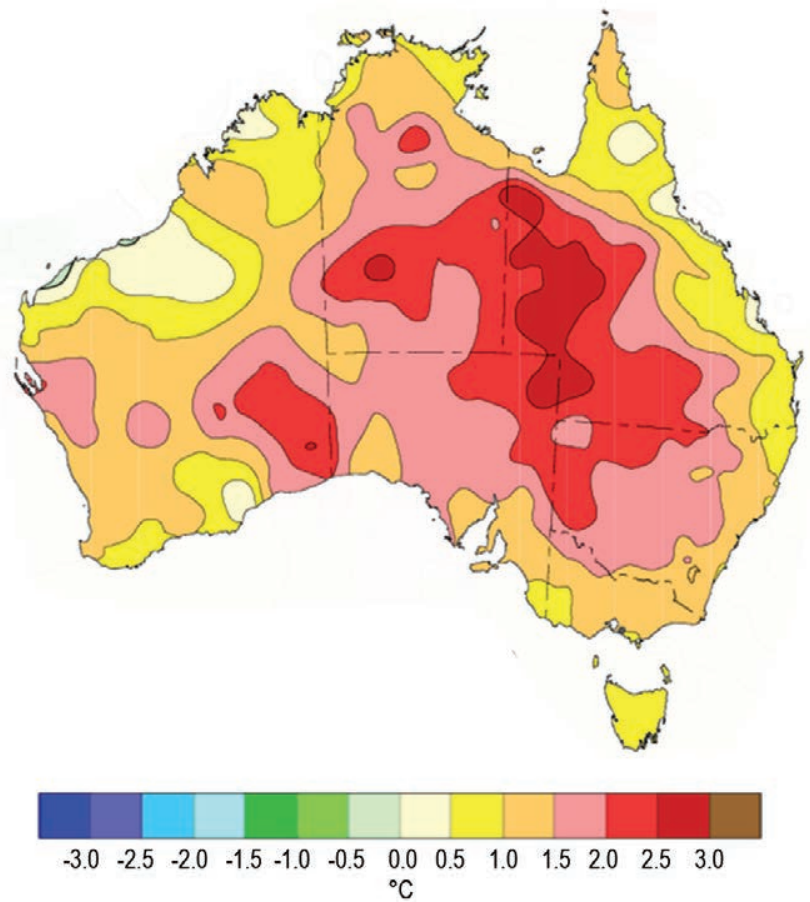

FIG. 7.46. Maximum temperature anomalies $\left({ }^{\circ} \mathrm{C}\right)$ for Australia, averaged over 2013, relative to the 196I-90 base period. (Source: Australia Bureau of Meteorology.)
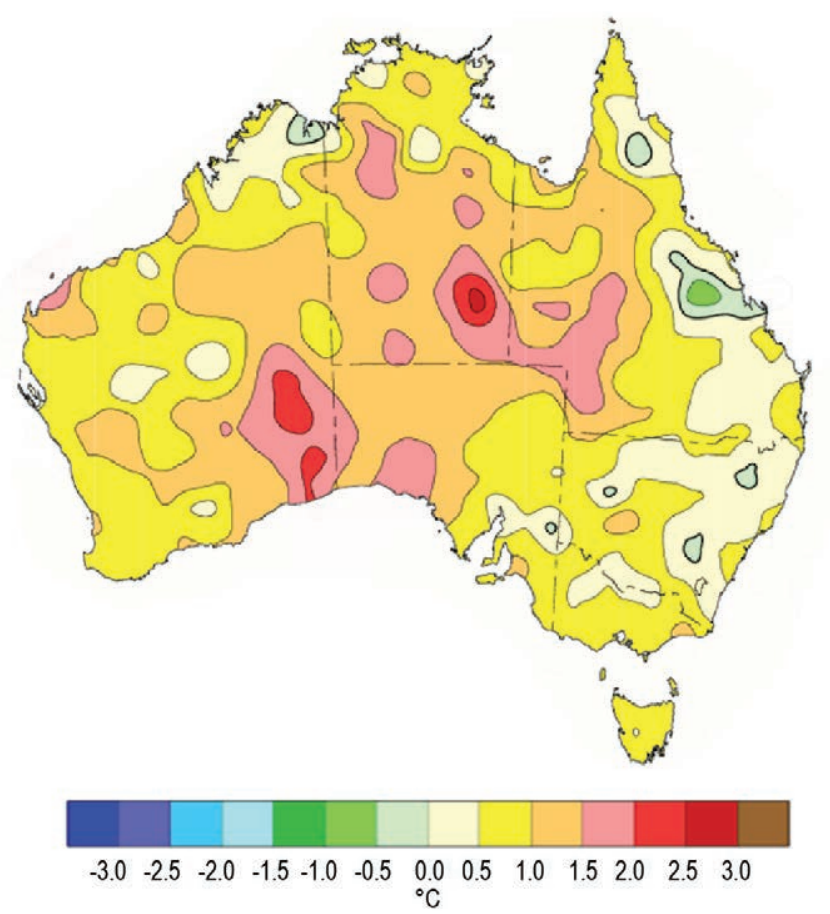

FIG. 7.47. Minimum temperature anomalies $\left({ }^{\circ} \mathrm{C}\right)$ for Australia, averaged over 2013, relative to the 196I-90 base period. (Source: Australia Bureau of Meteorology.) anomalies, up to $+3.0^{\circ} \mathrm{C}$, were recorded broadly across western Queensland, northeastern South Australia, and a small area northwest of Alice Springs in central Australia.

Nationally-averaged maximum temperatures were above average for each month of 2013 , and each month had a national average anomaly of more than $+0.5^{\circ} \mathrm{C}$. During January, April, August, and September, some parts of the country experienced anomalies of at least $+4.0^{\circ} \mathrm{C}$. July and October had more widespread warmth, but with weaker anomalies. These six months in 2013 all ranked in the top five warmest for their respective months, with record high values for January and September.

For September, the national-averaged maximum temperature anomaly was $+3.4^{\circ} \mathrm{C}$; this was the largest positive temperature anomaly observed for any month on record (previously $+3.2^{\circ} \mathrm{C}$ in August 2009). Large areas of central Australia had daytime temperatures more than $6.0^{\circ} \mathrm{C}$ above average for the month. In South Australia, the area-average of $+5.4^{\circ} \mathrm{C}$ for the state was the largest anomaly observed on record for any Australian state or territory.

Minimum temperatures for the year were marginally less significant than maximum temperatures, with the vast majority of the country experiencing above-average overnight temperatures. Only small areas inland of the east coast and a small part of northwest Australia were cooler than average. Overnight temperatures more than $1.0^{\circ} \mathrm{C}$ above average were observed across eastern Western Australia, the southern two-thirds of the Northern Territory, western South Australia, and western Queensland, with the remaining areas $0.0^{\circ}$ to $+1.0^{\circ} \mathrm{C}$. The highest anomalies surpassed $+2.0^{\circ} \mathrm{C}$ over southeast Western Australia and the southeast Northern Territory.

\section{(ii) Precipitation}

Australian rainfall for 2013 was $430 \mathrm{~mm}(35 \mathrm{~mm}$ below average), close to the median of observations since national records began in 1900. Much of the eastern interior experienced drought during the year. Rainfall was below average across much of the inland east and north, and in the lowest decile for much of western and inland southern Queensland. Rainfall was above average for parts of the east coast, northern Tasmania, the Pilbara, and south coast of Western Australia (Fig. 7.48).

Tasmania and Western Australia were the only states to record above-average annual totals, with the other states and the Northern Territory recording between $79 \%$ and $92 \%$ of average rainfall. Victoria was below average for the 14th year out of the past 17 . 


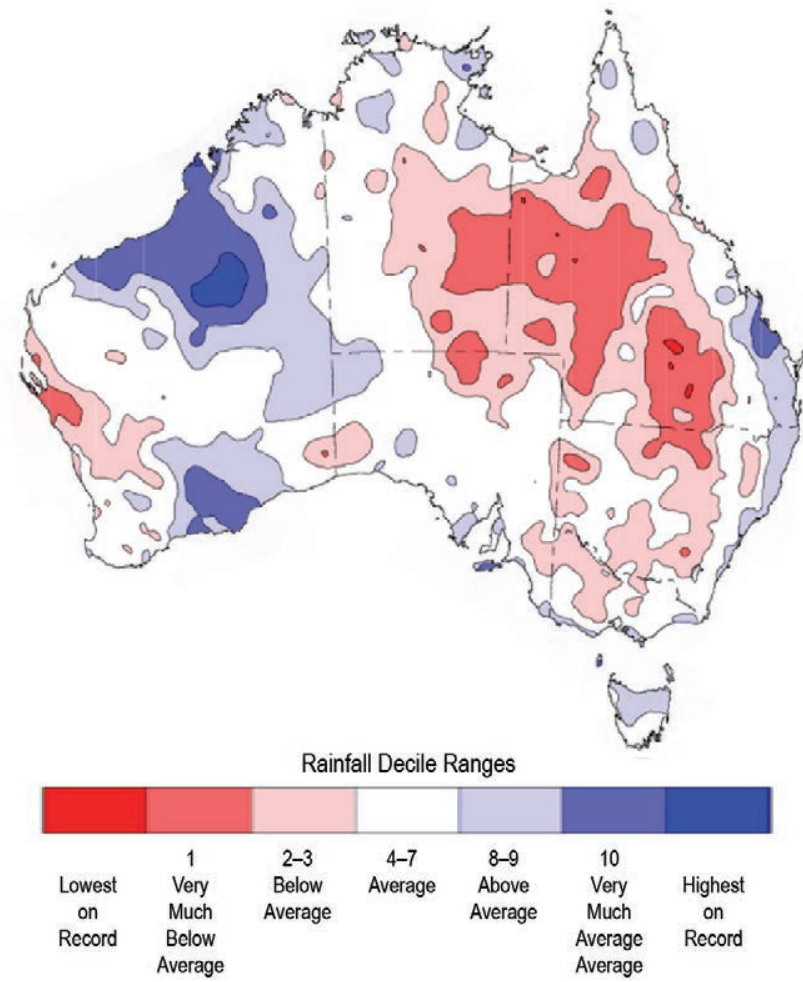

Fig. 7.48. Rainfall deciles for Australia for 2013, based on the 1900-2013 distribution. (Source: Australia Bureau of Meteorology.)

January and February were wet along the east coast, especially where ex-Tropical Cyclone Oswald brought heavy rain in late January. Western Australia was also wet with Tropical Cyclone Rusty bringing February rain to the northwest. Rain associated with Oswald led to Gladstone's ( $500 \mathrm{~km}$ north of Perth) second wettest first half of the year on record $(1341 \mathrm{~mm})$, a stark contrast to the second half of 2013 which was its driest on record (103 mm). Late wet season rainfall saw above-average March-April rain for the north while March rainfall was above average for the southern mainland; April was dry for the southeast.

Above-average rainfall over large parts of Australia between May and July was associated with a negative phase of the Indian Ocean dipole (IOD), with frequent northwest cloud bands extending across the continent from the northwest to the southeast.

A negative phase of the southern annular mode (SAM) between August and October drove the subtropical ridge farther north than usual, exposing southern Australia to strong westerlies. Rain resulted over coastal southwest Western Australia, southeast South Australia, southern Victoria, and western Tasmania, while New South Wales and Queensland experienced dry conditions.
Rainfall was above average for the south of Western Australia in September and along the northwest coast during October, with an early start to the wet season bringing a wet November to the north. November was also wet for the east coast and eastern Tasmania, while conditions turned dry for eastern Australia in December.

\section{(iii) Notable events}

Australia experienced significant heat events during January, March, September, and December (see Sidebar 7.5 for details).

While ENSO remained neutral for a second year running, a negative phase of the IOD brought rain to much of the south and west from mid-May to August. Northwest cloud bands, which originate over the Indian Ocean, brought significant rainfall to northwestern Western Australia: 202.0 mm fell on West Roebuck on 6 June; while a second event on 25 June saw Karratha triple its previous highest daily June rainfall, with $209.4 \mathrm{~mm}$. This was also its second wettest day on record for any month.

A number of low pressure systems hit the east coast of Australia during the first half of the year. On 23-26 February, one system caused storm damage and coastal erosion between central New South Wales and southeast Queensland, with heavy rain persisting into early March and causing localized flooding. Another occurred in the same region on 24-26 May and another system, farther south over southern coastal regions of New South Wales and eastern Victoria, occurred on 23-26 June; both caused localized flooding.

A significant tornado outbreak was associated with the passage of a cold front on 21 March. Supercell thunderstorms caused extensive damage in northern Victoria and adjacent southern New South Wales, with at least five confirmed tornadoes along and south of the border.

The SAM became strongly negative during late winter and early spring; this tends to increase frontal activity over far southern Australia. A number of systems, mostly strong fronts, produced damaging winds and storm damage across southern Australia during winter and spring. One system caused storm surges around Perth on 21-22 September, with coastal and estuarine flooding. On 1 October, Fawkner Beacon, in Melbourne's Port Phillip Bay, recorded a gust of $143 \mathrm{~km} \mathrm{~h}^{-1}$, the third-strongest gust ever recorded in the Melbourne region. 
Warm, dry weather combined with strong northerlies brought an early start to the New South Wales bushfire season in early September, including severe fires in the Blue Mountains, just west of Sydney. Most of October brought little relief, with hot, dry, windy conditions, furthering significant fires across the state during the month, including fires that destroyed about 200 properties in the Blue Mountains.
There were eleven tropical cyclones within the Australian region during 2013 (eight in the first half of 2013 and three in the following season), with five making landfall at cyclone strength and one as a remnant tropical low: Oswald, Peta, Rusty, Tim (as an ex-tropical cyclone), Alessia, and Christine. Alessia was the first of the 2013/14 season and helped kick off an early monsoon onset, in stark contrast to the late onset of 2012/13. Alessia was the first November cyclone to cross the Australian coast since Quenton in 1983.

\section{SIDEBAR 7.5: A YEAR OF PERSISTENT AND WIDESPREAD HEAT FOR AUSTRALIA-C. GANTER, S. TOBIN}

The year 2013 was characterized by persistent and widespread warmth (see Fig. SB7.8). The most significant events of the year are summarized below, with further detail available at http://www .bom.gov.au/climate/current/statements.

The heat wave spanning late December 2012 through January 2013 was easily Australia's longest continent-wide heat wave on record and the most significant heat event of 2013. Temperatures more than $10^{\circ} \mathrm{C}$ above average were widely recorded and numerous records were set when temperatures exceeded $48^{\circ} \mathrm{C}$ in inland regions of eastern Australia on 12-13 January. Records included both Australia's highest national daily average maximum temperature $\left(40.3^{\circ} \mathrm{C}\right.$ on 7 January) and Australia's warmest January (and warmest month on record, mean temperature anomaly $+1.8^{\circ} \mathrm{C}$ ) and contributed to Australia's warmest summer on record $\left(+\mathrm{I} .1^{\circ} \mathrm{C}\right)$. Hobart and Sydney also experienced their hottest days on record: $41.8^{\circ} \mathrm{C}$ on 4 January and $45.8^{\circ} \mathrm{C}$ on 18 January, respectively.

Persistent heat returned to the southeast during 2-13 March with southeast South Australia, southern Victoria, and Tasmania most strongly affected. Melbourne experienced nine consecutive days with temperatures at $32^{\circ} \mathrm{C}$ or above and seven consecutive nights at $20^{\circ} \mathrm{C}$ or above, both records for any time of year. Launceston also set a record with eight consecutive days of $30^{\circ} \mathrm{C}$ or above.

Unusual warmth was recorded across much of Australia, particularly away from the coast, from the last week of August through September. The period included Australia's warmest winter day on record (national daily average maximum temperature $29.9^{\circ} \mathrm{C}$ on 31 August) and contributed to both Australia's warmest spring on record $\left(+1.6^{\circ} \mathrm{C}\right)$ and largest positive mean temperature anomaly for any month since at least 1910 (September, $+2.8^{\circ} \mathrm{C}$ ). A number of records were set for the highest temperature recorded so early in the season, and $29 \%$ of Queensland had its hottest September day on record on the 26 th.

The year 2013 concluded with a final heat wave that continued into early 2014. Extreme heat was recorded over parts of Australia, particularly across the eastern interior. A number of locations in Queensland had their hottest recorded day on 29 or 30 December, with December monthly records set at several other sites. 
5) New Zealand-G. R. Macara and P. R. Chappell

In the following discussion, the base period is 1981-2010 for all variables, unless otherwise noted. The nationwide average temperature is based on NIWA's seven-station temperature series beginning in 1909 (see http://www.niwa .co.nz/our-science/climate/information -and-resources/nz-temp-record/seven -station-series-temperature-data). All statistics are based on data available as of 13 January 2014.

\section{(i) Temperature}

The nation-wide average temperature for 2013 was $13.4^{\circ} \mathrm{C}\left(0.8^{\circ} \mathrm{C}\right.$ above the 1971-2000 annual average), the third warmest year on record for New Zealand in the 105-year period of record. Annual mean temperatures were above average or near average across the entire country (Fig. 7.49a). Temperatures were at least $1.0^{\circ} \mathrm{C}$ above the annual average for parts of southern Northland, Hawke's Bay, Manawatu, Wairarapa, Banks Peninsula, and western Southland. Approximately $12 \%$ of the locations in New Zealand where long-term temperature measurements are recorded (17 of 146) experienced their warmest year on record, from as far north as Tauranga (Bay of Plenty, southeast of Auckland) to as far south as Gore (Southland, southwest of Dunedin). During the year, high temperature anomalies were observed throughout many regions of New Zealand in March, April, July, August, and November. In addition, New Zealand observed its warmest winter on record, with $39 \%$ of New Zealand locations (56 of 142) recording a winter 2013 mean temperature in the top four of their respective temperature records.

The highest mean annual temperature for 2013 was $16.5^{\circ} \mathrm{C}$, recorded at Dargaville (Northland). The lowest mean annual temperature for 2013 (excluding high altitude alpine sites, above $\sim 1500 \mathrm{~m}$ ) was $8.7^{\circ} \mathrm{C}$, recorded at Chateau Ruapehu (central North Island). The highest recorded air temperature for 2013 was $35.1^{\circ} \mathrm{C}$, recorded at Clyde (Central Otago) on 5 January, and at Gisborne on both 9 and 10 January. The lowest recorded air temperature for 2013 (excluding high altitude alpine sites) was $-12.1^{\circ} \mathrm{C}$, observed at Lake Tekapo (Canterbury) on 28 June.

\section{(ii) Precipitation}

Annual rainfall totals for 2013 were below normal (less than $80 \%$ of annual normal) for much of the northern half of the North Island and isolated areas of the West Coast of the South Island (Fig. 7.49b). It was the driest year on record for Dargaville, Toenepi, Taupo, and Turangi, with these locations each recording between just $67 \%$ and $72 \%$ of normal annual rainfall. January, February, and March were particularly dry months for the North Island and coincided with widespread drought conditions. In contrast, above-normal rainfall (more than $120 \%$ of annual normal) was recorded in parts of the eastern South Island. June was a relatively wet month for the eastern South Island, where some locations received more than $400 \%$ of their normal June rainfall.

Of the regularly reporting rainfall gauges, the wettest location in 2013 was Cropp River, in the Hokitika River catchment (West Coast, South Island), with an annual rainfall total of $10870 \mathrm{~mm}$. The driest of the regularly reporting rainfall sites in 2013 was Lauder (Central Otago), which recorded $453 \mathrm{~mm}$ of rainfall. Mount Cook Village experienced the highest 1-day rainfall total in $2013(346 \mathrm{~mm})$, recorded on 9 January.

\section{(iii) Notable events}

A significant drought event affected the North Island and Westland between January and April 2013 (Fig. 7.50). This drought was one of the most extreme on record in New Zealand, both in terms 
of intensity and geographical spread. It was driven by the persistence of slow-moving anticyclones over the Tasman Sea and New Zealand from the last 10 days of January to the first half of April. During this time, record or near-record low rainfall and record or near-record high sunshine hours were observed in many parts of the North Island. An adverse event due to drought was declared by the Ministry for Primary Industries (MPI) for the entire North Island on 15 March and for Buller and Grey districts (South Island) on 22 March. In June 2013, the MPI estimated the economic impact of the drought to be at least $\$ 1.12$ billion US dollars.

On 21 April, torrential rain caused flooding in the Nelson and Tasman regions, notably in Richmond and Stoke. This rainstorm was the most intense historical event recorded in these regions and was one of the most intense ever measured in New Zealand. The maximum 1-hour rainfall total during the storm was $101 \mathrm{~mm} \mathrm{~h}^{-1}$ in the Roding catchment near
Richmond-a total which has an estimated 500-year average recurrence interval in this area. The highest 24-hour rainfall total recorded during the storm was $216 \mathrm{~mm}$, recorded at the Tasman District Council office in Richmond.

Two significant wind events and one major snow event occurred in 2013. On 20-21 June, Wellington was hit by severe gales that caused widespread damage to infrastructure and vegetation. The maximum wind gust in the city was $140 \mathrm{~km} \mathrm{~h}^{-1}$ and $200 \mathrm{~km} \mathrm{~h}^{-1}$ on nearby hills. The same storm brought significant snowfall to the inland South Island, particularly northern Southland, eastern Central Otago, and inland Canterbury (600 $\mathrm{mm}$ at Tekapo). On 10-11 September, strong northwest winds affected much of the South Island, particularly the Canterbury region (133 $\mathrm{km} \mathrm{h}^{-1}$ gust recorded at Christchurch airport). About 28000 properties were without power and 800 irrigators were damaged, which cost millions of dollars to repair.

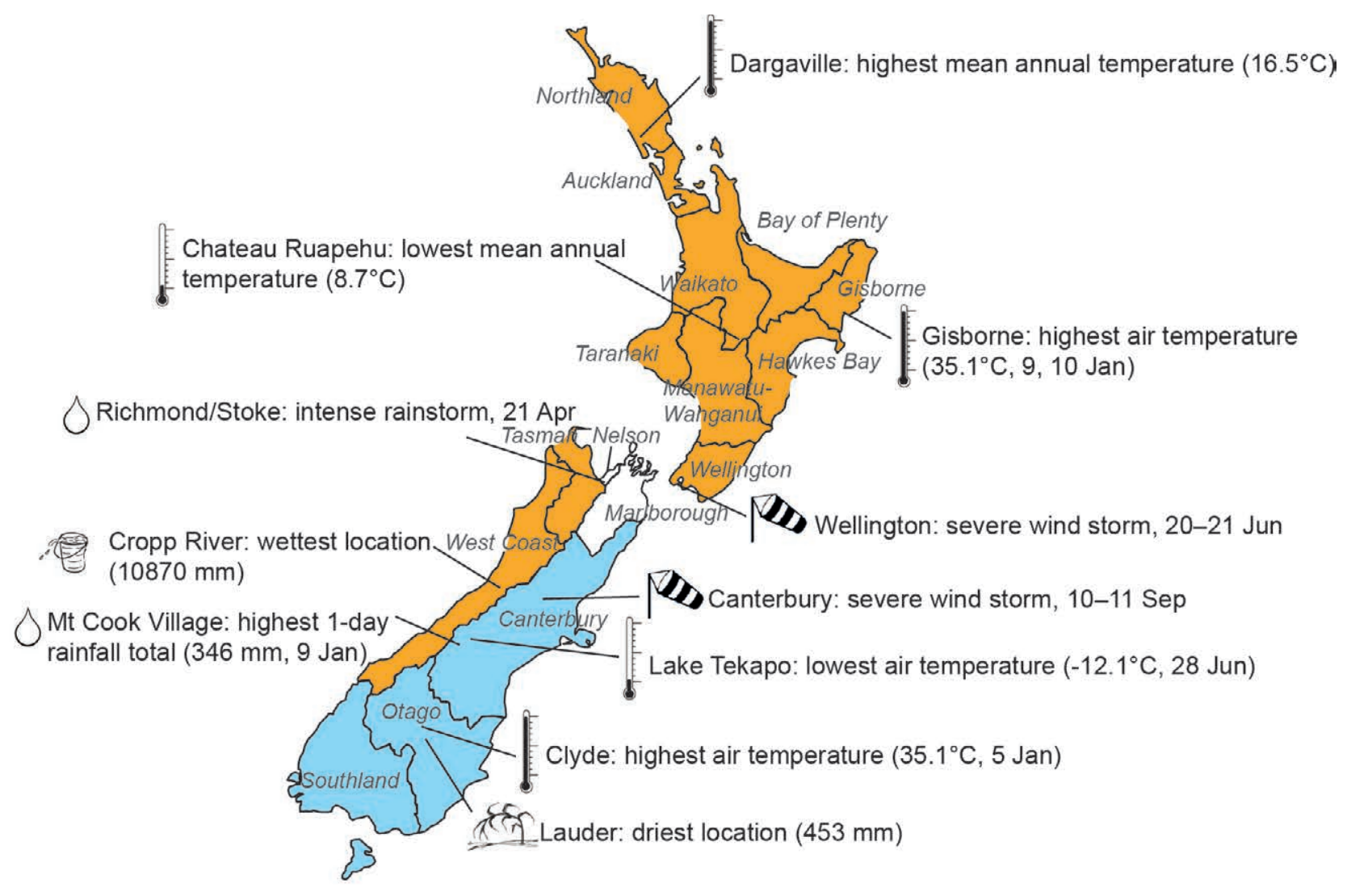

Regions affected by Jan-Apr drought

$\square$ Regions affected by $20-21$ Jun snow event

Fig. 7.50. Notable weather events and climate extremes for New Zealand in 2013. 
S2I4 | BAMF JULY 2014 

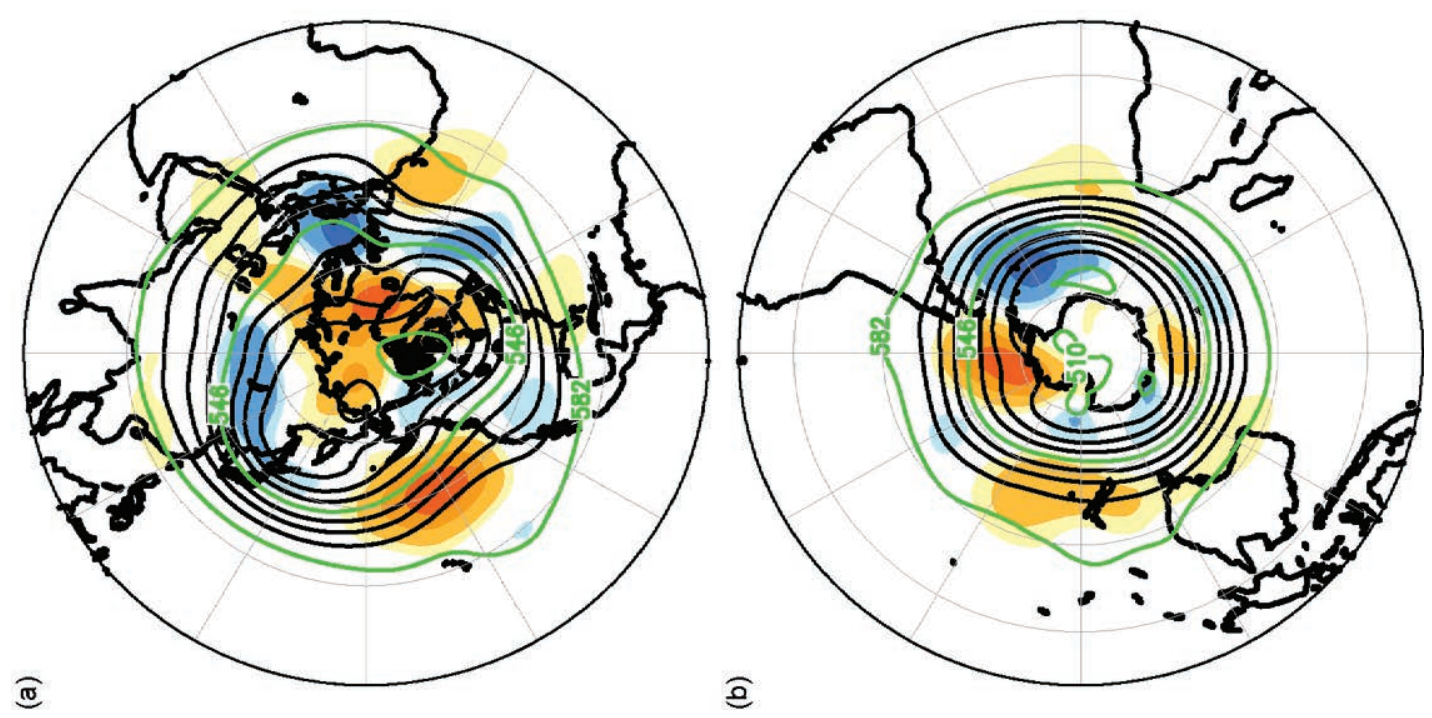

녿 웅

눙응

ำ $\varepsilon$ ㅇํㅇ

हो त्र $\frac{1}{\infty}$

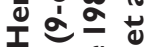

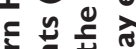

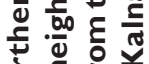

의

$\mathbf{Z}$

(당

m

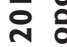

足品

นั่

돈

융ㅎํ : 든

บับ

i.

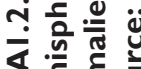

$\varangle$ है है

눈 돈

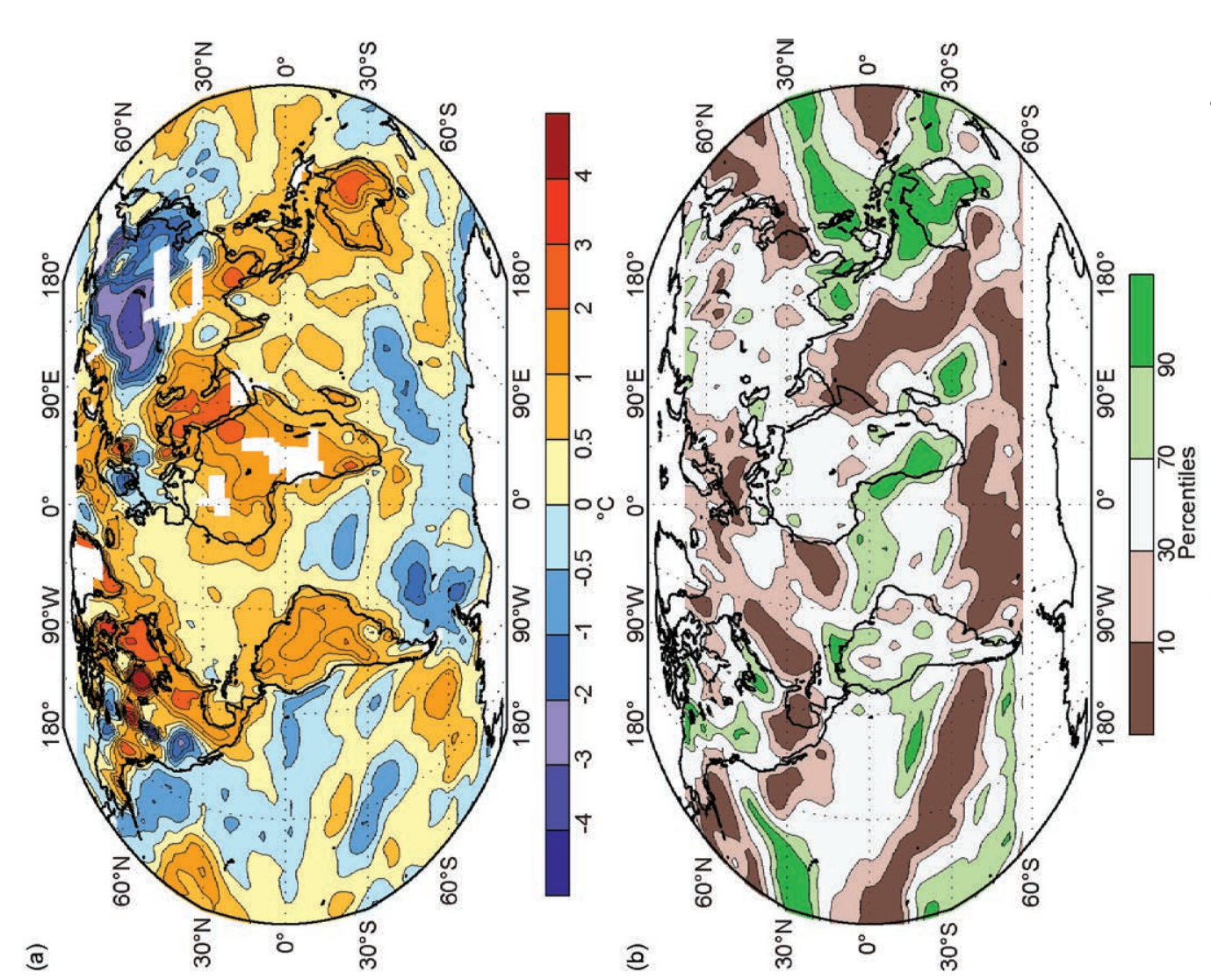

ฮั บิ웡 는

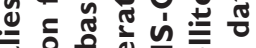

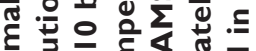

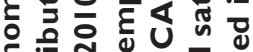
ल

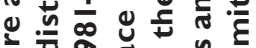

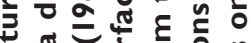
है है ติ

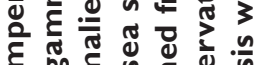
है ป ๘

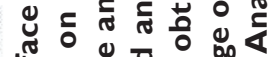

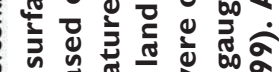
త

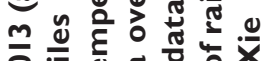

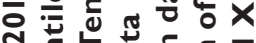
ใ แั

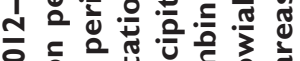

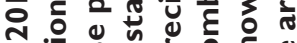
บั

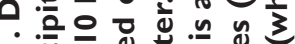
$\therefore \div$ 은

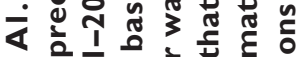

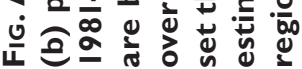




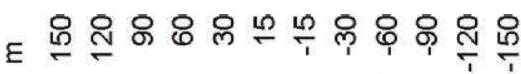

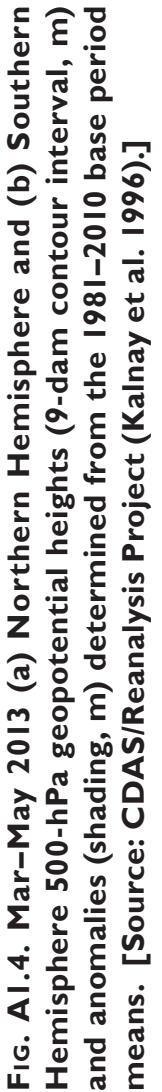
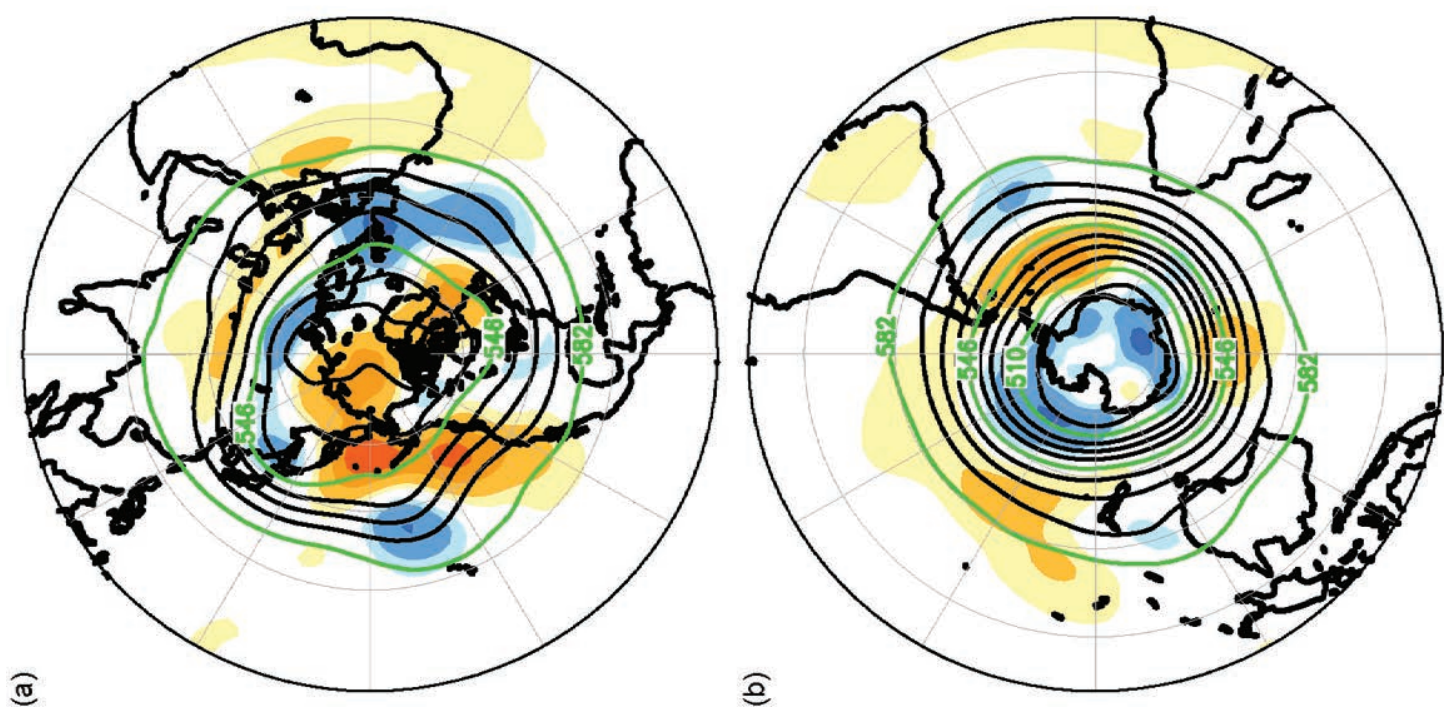

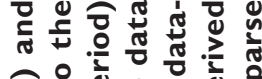

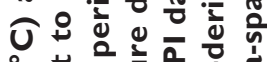
는

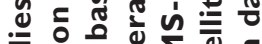

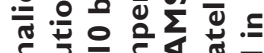

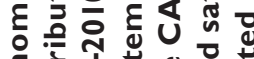
논

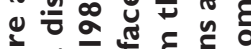

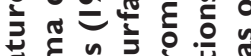
चै है जे む है ป ᄃ ปั0 ठ०

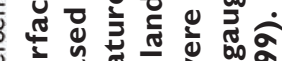

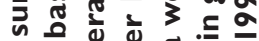
తิ m西近

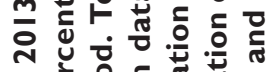

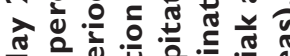

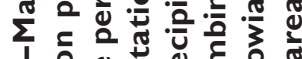
I

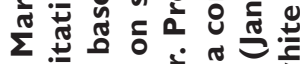

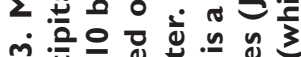

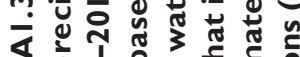
षํำ

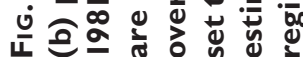

(3)

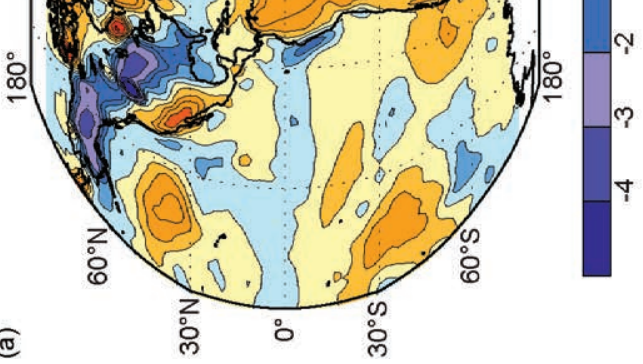

ลิ

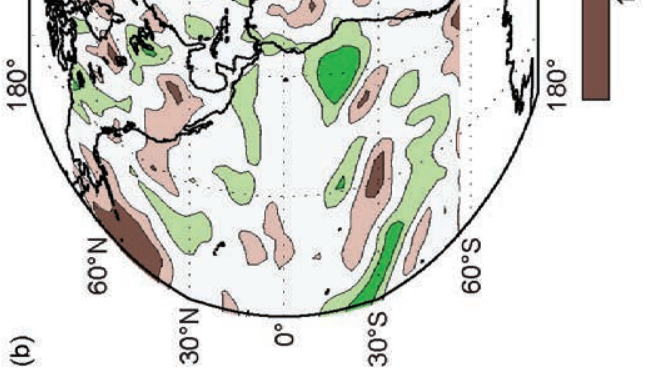

यूล 


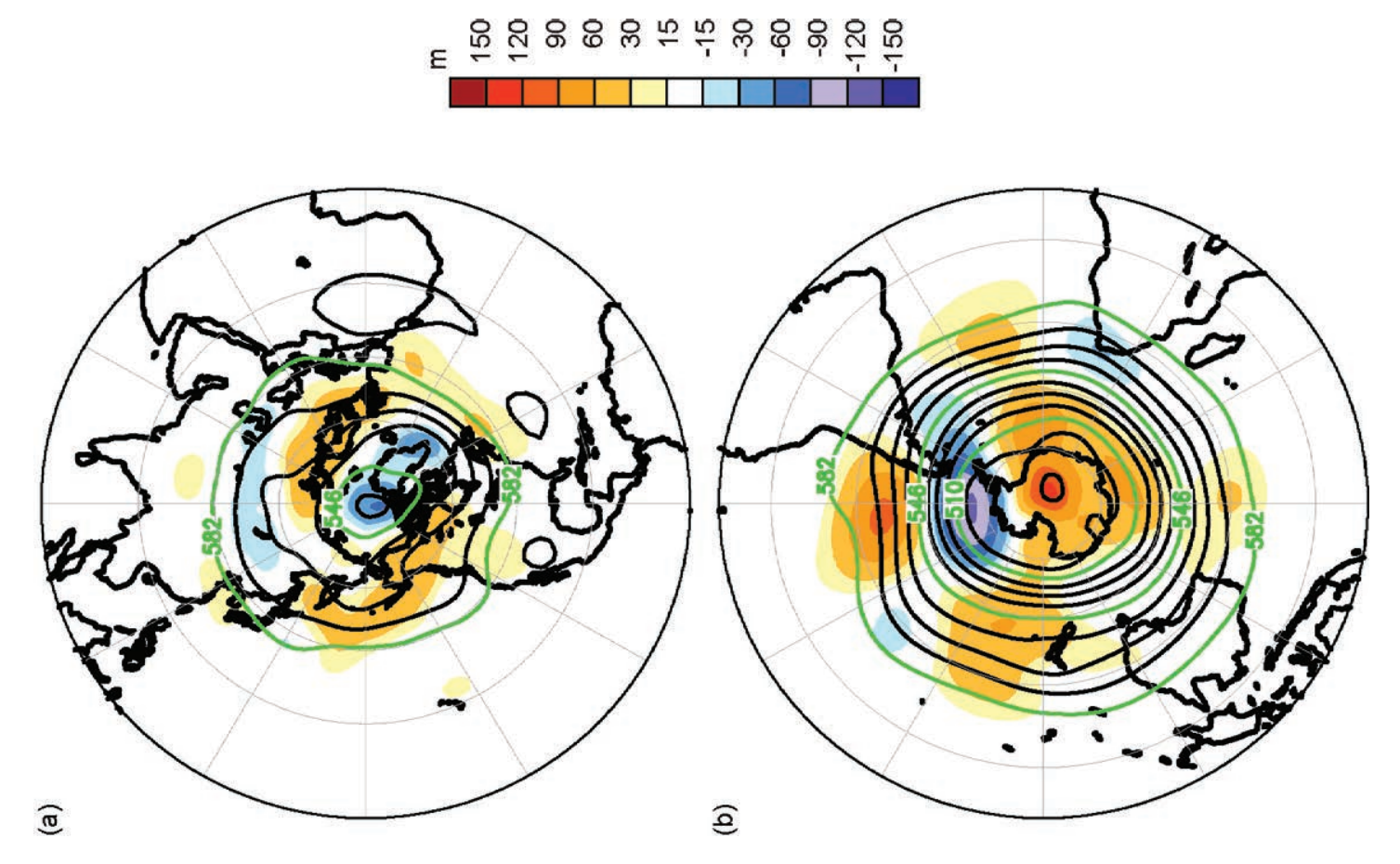

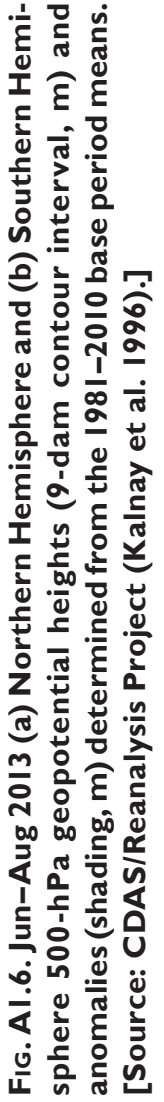

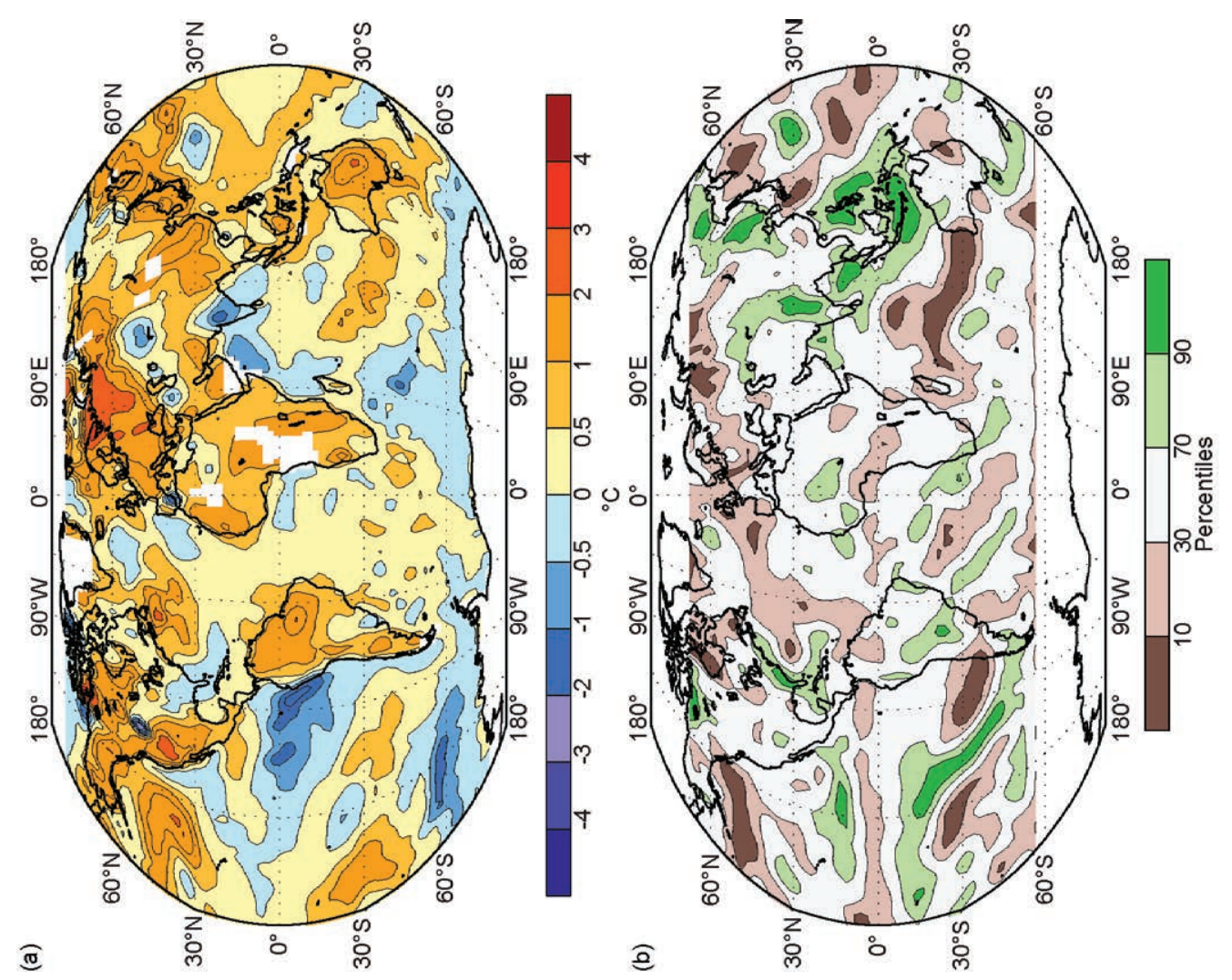

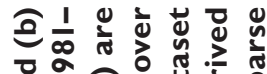

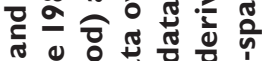

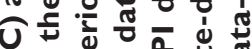

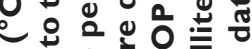

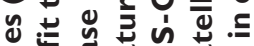

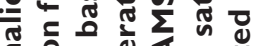
동은은 원 혼

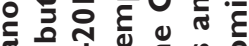

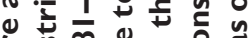

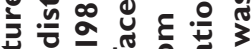
(⿻)

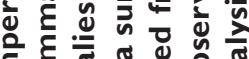

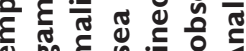

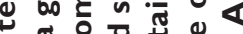

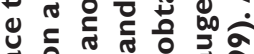

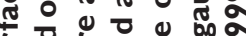

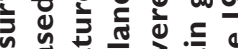
(1) ริ

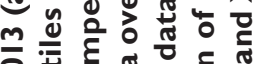

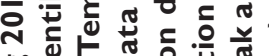
舟 㐘

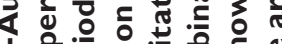

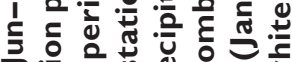
กิ

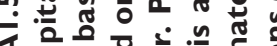

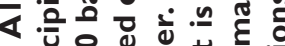

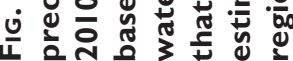




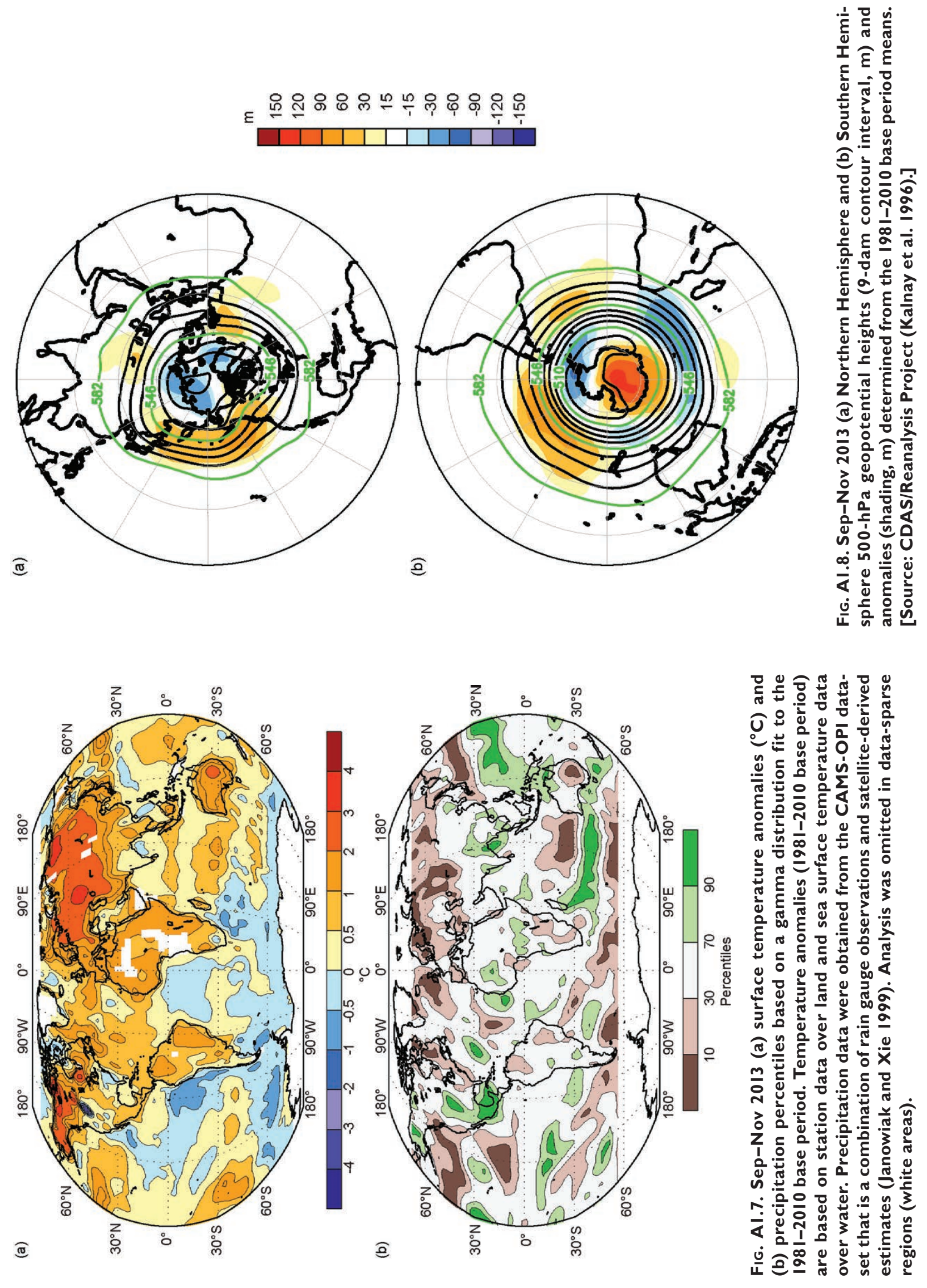


APPENDIX 2: RELEVANT DATASETS AND SOURCES

\begin{tabular}{|c|c|c|c|}
\hline $\begin{array}{l}\text { General Variable } \\
\text { or Phenomenon }\end{array}$ & $\begin{array}{l}\text { Specific Dataset } \\
\text { or Variable }\end{array}$ & Source & Section \\
\hline Aerosols & Aerosol products & http://www.copernicus-atmosphere.eu/data & $2 g 3$ \\
\hline Air-sea Fluxes & $\begin{array}{l}\text { Woods Hole } \\
\text { Oceanographic } \\
\text { Institute (WHOI) } \\
\text { OAFlux Project }\end{array}$ & http://oaflux.whoi.edu & $3 d$ \\
\hline \multirow{2}{*}{ Albedo } & MODIS & http://ladsweb.nascom.nasa.gov & $2 \mathrm{~h} 2,5 \mathrm{jl}$ \\
\hline & MODIS Cloud Mask & http://ladsweb.nascom.nasa.gov & $2 d 4,5 b$ \\
\hline Biomass Burning & Biomass Burning & http://www.globalfiredata.org & $2 \mathrm{~h} 4$ \\
\hline \multirow{8}{*}{ Clouds, Cloudiness } & HIRS & No known public portal & $2 \mathrm{~d} 4$ \\
\hline & ISCCP D2 & http://isccp.giss.nasa.gov & $2 \mathrm{~d} 4$ \\
\hline & MISR & $\begin{array}{l}\text { http://eosweb.larc.nasa.gov/PRODOCS/misr/level3 } \\
\text { loverview.html }\end{array}$ & $2 d 4$ \\
\hline & MODIS Cloud Mask & http://ladsweb.nascom.nasa.gov & $2 d 4,5 b 3$ \\
\hline & PATMOS-x & http://www.ncdc.noaa.gov/cdr/operationalcdrs.html & $2 \mathrm{~d} 4$ \\
\hline & CLARA_AI & $\begin{array}{l}\text { https://climatedataguide.ucar.edu/climate-data } \\
\text { /clara-al-cloud-properties-surface-albedo-and } \\
\text {-surface-radiation-products-based-avhrr }\end{array}$ & $2 \mathrm{~d} 4$ \\
\hline & ERA-Interim & http://www.ecmwf.int/research/era & $2 \mathrm{~d} 4$ \\
\hline & SOBS & $\begin{array}{l}\text { http://www.atmos.washington.edu/ ignatius } \\
\text { /CloudMap }\end{array}$ & $2 \mathrm{~d} 4$ \\
\hline Evaporation & JRA-25 & http://jra.kishou.go.jp & $6 d$ \\
\hline FAPAR & FAPAR & http://fapar.jrc.ec.europa.eu & $2 \mathrm{~h} 3$ \\
\hline \multirow[b]{2}{*}{ Geopotential Height } & ERA-Interim & http://www.ecmwf.int/research/era & $6 b$ \\
\hline & $\begin{array}{l}\text { NCE/MNAR } \\
\text { Reanalysis I: Pressure }\end{array}$ & $\begin{array}{l}\text { http://www.esrl.noaa.gov/psd/data/gridded } \\
\text { /data.ncep.reanalysis.pressure.html }\end{array}$ & $5 b 2,5 b 3$ \\
\hline \multirow{3}{*}{ Glacier Mass or Volume } & $\begin{array}{l}\text { World Glacier } \\
\text { Monitoring Service }\end{array}$ & http://www.wgms.ch/mbb/suml2.html & $5 i$ \\
\hline & GRACE & $\begin{array}{l}\text { http://podaac.jpl.nasa.gov } \\
\text { /datasetlist?ids=Platform\&values=GRACE }\end{array}$ & $5 i$ \\
\hline & GRACE & $\begin{array}{l}\text { http://isdc.gfz-potsdam.de/index.php?module } \\
=\text { pagesetter\&func=viewpub\&tid=I\&pid=35 }\end{array}$ & $5 i$ \\
\hline \multirow{7}{*}{$\begin{array}{l}\text { Humidity, } \\
\text { [Near] Surface }\end{array}$} & Dai & by email to adai@ucar.edu & $2 \mathrm{dl}$ \\
\hline & ERA-Interim & http://www.ecmwf.int/research/era & $2 \mathrm{dl}$ \\
\hline & HadCRUH & http://www.metoffice.gov.uk/hadobs/hadcruh & $2 \mathrm{dl}$ \\
\hline & HadISDH & http://www.metoffice.gov.uk/hadobs/hadisdh & $2 \mathrm{dl}$ \\
\hline & $\begin{array}{l}\text { JRA-25 Atmospheric } \\
\text { Reanalysis }\end{array}$ & http://jra.kishou.go.jp/JRA-25/index_en.html & $2 \mathrm{dl}$ \\
\hline & MERRA & http://gmao.gsfc.nasa.gov/merra & $2 \mathrm{dl}$ \\
\hline & NOCS 2.0 & http://www.noc.soton.ac.uk/noc_flux/noc2.php & $2 \mathrm{dl}$ \\
\hline \multirow{3}{*}{ Ice Sheet Characteristics } & DMSP-SSMIS & $\begin{array}{l}\text { http://nsidc.org/data/docs/daac/nsidc000I_ssmi_tbs } \\
\text { gd.html }\end{array}$ & $5 \mathrm{jl}, 6 \mathrm{e}$ \\
\hline & GRACE & $\begin{array}{l}\text { http://podaac.jpl.nasa.gov/datasetlist?ids=Platform } \\
\text { \&values=GRACE }\end{array}$ & $5 j 4$ \\
\hline & GRACE & $\begin{array}{l}\text { http://isdc.gfz-potsdam.de/index.php?module } \\
=\text { pagesetter\&func=viewpub\&tid=I\&pid=35 }\end{array}$ & $5 j 4$ \\
\hline Isotherm Depth & $\begin{array}{l}\text { NCEP Global Ocean } \\
\text { Data Assimilation } \\
\text { System }\end{array}$ & http://www.cpc.ncep.noaa.gov/products/GODAS & $4 i$ \\
\hline
\end{tabular}




\begin{tabular}{|c|c|c|c|}
\hline $\begin{array}{l}\text { General Variable } \\
\text { or Phenomenon }\end{array}$ & $\begin{array}{l}\text { Specific Dataset } \\
\text { or Variable }\end{array}$ & Source & Section \\
\hline Lake Ice & $\begin{array}{l}\text { NOAA IMS, } 4 \text { km } \\
\text { Daily }\end{array}$ & http://nsidc.org/data/g02156.html & $5 k$ \\
\hline \multirow{5}{*}{ Modes of Variability } & $\begin{array}{l}\text { Climate Prediction } \\
\text { Center: AAO, AO, } \\
\text { NAO, PNA, PDO }\end{array}$ & $\begin{array}{l}\text { http://www.cpc.ncep.noaa.gov/products/precip } \\
\text { /CWlink/daily_ao_index/teleconnections.shtml }\end{array}$ & $\begin{array}{l}\text { 2el, 3b, } \\
4 \mathrm{bl}, 4 \mathrm{~d} 2, \\
4 \mathrm{~h}, 5 \mathrm{bl}, \\
5 \mathrm{~h} 3,5 \mathrm{j} 3\end{array}$ \\
\hline & $\begin{array}{l}\text { Oceanic Niño Index } \\
\text { (ONI) }\end{array}$ & $\begin{array}{l}\text { http://www.cpc.ncep.noaa.gov/products } \\
\text { /analysis_monitoring/ensostuff/ensoyears.shtml }\end{array}$ & $4 \mathrm{~b}$ \\
\hline & $\begin{array}{l}\text { Quasi-bienniel } \\
\text { Oscillation (QBO) }\end{array}$ & $\begin{array}{l}\text { http://www.geo.fu-berlin.de/en/met/ag/strat/produkte } \\
\text { /qbo/index.html }\end{array}$ & $2 g 4$ \\
\hline & $\begin{array}{l}\text { Southern Annular } \\
\text { Mode Index (SAM) }\end{array}$ & http://www.antarctica.ac.uk/met/gjma/sam.html & $6 \mathrm{~b}, 6 \mathrm{~d}, 6 \mathrm{f}$ \\
\hline & $\begin{array}{l}\text { Southern Oscillation } \\
\text { Index (SOI) }\end{array}$ & http://www.cpc.ncep.noaa.gov/data/indices & $6 d$ \\
\hline Net Radiation & ERA-Interim & http://data-portal.ecmwf.int/data/d/interim_daily & $5 \mathrm{~b} 3$ \\
\hline \multirow{7}{*}{ Ocean Carbon } & $\begin{array}{l}\text { AOML Monthly Flux } \\
\text { Anomalies }\end{array}$ & $\begin{array}{l}\text { http://cwcgom.aoml.noaa.gov/erddap/griddap } \\
\text { /aomlcarbonfluxes.graph }\end{array}$ & $3 \mathrm{kl}$ \\
\hline & $\mathrm{pCO} 2$ & $\begin{array}{l}\text { http://www.ldeo.columbia.edu/res/pi/CO2 } \\
\text { /carbondioxide/global_ph_maps/pco2_maps.html }\end{array}$ & $3 \mathrm{kl}$ \\
\hline & $\begin{array}{l}\text { Hawaii Ocean Time- } \\
\text { series (HOT) }\end{array}$ & http://hahana.soest.hawaii.edu/hot/hot_jgofs.html & $3 \mathrm{k} 3$ \\
\hline & $\begin{array}{l}\text { U.S. CO2/Repeat } \\
\text { Hydrography Program }\end{array}$ & http://ushydro.ucsd.edu & $3 \mathrm{k} 2$ \\
\hline & $\begin{array}{l}\text { PACIFic ocean Interior } \\
\text { CArbon (PACIFICA) } \\
\text { Database } \\
\end{array}$ & http://cdiac.ornl.gov/oceans/PACIFICA & $3 \mathrm{k} 2$ \\
\hline & $\begin{array}{l}\text { Global Ocean Data } \\
\text { Analyis Project } \\
\text { (GLODAP) } \\
\end{array}$ & http://cdiac.ornl.gov/oceans/glodap & $3 \mathrm{k} 2$ \\
\hline & $\begin{array}{l}\text { Carbon Dioxide in } \\
\text { the Atlantic Ocean } \\
\text { (CARINA) }\end{array}$ & http://cdiac.ornl.gov/oceans/CARINA & $3 \mathrm{k} 2$ \\
\hline Ocean Circulation & \begin{tabular}{|l} 
Atlantic Meridional \\
Overturning \\
Circulation \\
\end{tabular} & http://www.noc.soton.ac.uk/rapidmoc & $3 \mathrm{~h}$ \\
\hline \multirow{4}{*}{ Ocean Heat Content } & $\begin{array}{l}\text { CSIRO/ACE CRC } \\
\text { estimate for global } \\
\text { ocean heat content }\end{array}$ & $\begin{array}{l}\text { http://www.cmar.csiro.au/sealevel } \\
\text { /thermal_expansion_ocean_heat_timeseries.html }\end{array}$ & $3 c$ \\
\hline & PMEL/JPL/JIMAR & http://oceans.pmel.noaa.gov & $3 c$ \\
\hline & NODC & http://www.nodc.noaa.gov/OC5/indprod.html & $3 c$ \\
\hline & $\begin{array}{l}\text { UK Met Office } \\
\text { EN4.0.2 }\end{array}$ & $\begin{array}{l}\text { http://www.metoffice.gov.uk/hadobs/en4 } \\
\text { /download-en4-0-2-109.html }\end{array}$ & $3 c$ \\
\hline
\end{tabular}




\begin{tabular}{|c|c|c|c|}
\hline $\begin{array}{l}\text { General Variable } \\
\text { or Phenomenon }\end{array}$ & $\begin{array}{c}\text { Specific Dataset } \\
\text { or Variable }\end{array}$ & Source & Section \\
\hline \multirow{8}{*}{ Ocean Salinity } & Aquarius V2.5.I & http://aquarius.nasa.gov/index.html & $3 e$ \\
\hline & Argo & http://www.argo.ucsd.edu/index.html & $3 e$ \\
\hline & $\begin{array}{l}\text { Beaufort Gyre } \\
\text { Observing System }\end{array}$ & http://www.whoi.edu/beaufortgyre & $5 g 3$ \\
\hline & $\begin{array}{l}\text { Global Ocean Heat } \\
\text { and Salt Content }\end{array}$ & $\begin{array}{l}\text { http://www.nodc.noaa.gov/OC5 } \\
\text { /3M_HEAT_CONTENT }\end{array}$ & $3 f$ \\
\hline & Ice-tethered Profilers & http://www.whoi.edu/itp & $5 g 2$ \\
\hline & $\begin{array}{l}\text { Beaufort Gyre } \\
\text { Observing System } \\
\text { (BGOS)/Joint Ocean } \\
\text { Ice Studies (JOIS) } \\
\text { project }\end{array}$ & http://www.whoi.edu/beaufortgyre & $5 g 3$ \\
\hline & $\begin{array}{l}\text { Tropical moored } \\
\text { buoys TAO/TRITON; } \\
\text { PIRATA; RAMA }\end{array}$ & http://www.pmel.noaa.gov/tao & $3 f$ \\
\hline & $\begin{array}{l}\text { World Ocean Atlas } \\
2009\end{array}$ & $\begin{array}{l}\text { http://www.nodc.noaa.gov/OC5/WOA09 } \\
\text { /pr_woa09.html }\end{array}$ & $3 f$ \\
\hline Ocean Temperature & $\begin{array}{l}\text { World Ocean } \\
\text { Database } 2009\end{array}$ & $\begin{array}{l}\text { http://www.nodc.noaa.gov/OC5/WOD09 } \\
\text { /pr_wod09.html }\end{array}$ & $3 c$ \\
\hline $\begin{array}{l}\text { Outgoing Longwave } \\
\text { Radiation }\end{array}$ & $\begin{array}{l}\text { CERES FLASHFlux } \\
\text { Project }\end{array}$ & http://flashflux.larc.nasa.gov & $3 d$ \\
\hline \multirow{6}{*}{ Permafrost } & Active Layer Thickness & http://www.udel.edu/Geography/calm/data/north.html & 512 \\
\hline & Active Layer Thickness & http://www.gwu.edu/ calm & $2 \mathrm{cl}$ \\
\hline & $\begin{array}{l}\text { GTN-P, Alaskan } \\
\text { Repository }\end{array}$ & http://www.permafrostwatch.org & $2 \mathrm{cl}$ \\
\hline & $\begin{array}{l}\text { GTN-P, Norwegian } \\
\text { Repository }\end{array}$ & http://www.ngu.no/kart/permafrost & $2 \mathrm{cl}$ \\
\hline & $\begin{array}{l}\text { Permafrost } \\
\text { Temperature } \\
\end{array}$ & http://permafrost.gi.alaska.edu/sites_map & 511 \\
\hline & Permafrost Data & http://nsidc.org/data/g02190.html & \\
\hline \multirow{3}{*}{$\begin{array}{l}\text { Phytoplankton, } \\
\text { Ocean Color }\end{array}$} & SeaWiFS v 2010.0 & $\begin{array}{l}\text { http://oceancolor.gsfc.nasa.gov/WIKI } \\
\text { /OCReproc20I00SW.html }\end{array}$ & $3 \mathrm{k} 4$ \\
\hline & VIIRS v 20I3.I & $\begin{array}{l}\text { http://oceancolor.gsfc.nasa.gov/WIKI } \\
\text { /OCReproc20I3IVN.html }\end{array}$ & $3 \mathrm{k} 4$ \\
\hline & $\begin{array}{l}\text { MODIS-Aqua } \\
\text { Reprocessing 2013.I }\end{array}$ & $\begin{array}{l}\text { http://oceancolor.gsfc.nasa.gov/WIKI } \\
\text { /OCReproc20I3(2e)IMA.html }\end{array}$ & $3 \mathrm{k} 4$ \\
\hline \multirow{7}{*}{ Precipitation } & CMAP & $\begin{array}{l}\text { http://www.esrl.noaa.gov/psd/data/gridded } \\
\text { /data.ncep.reanalysis.html }\end{array}$ & $2 \mathrm{~d} 3$ \\
\hline & GHCN & $\begin{array}{l}\text { http://www.ncdc.noaa.gov/temp-and-precip } \\
\text { /ghcn-gridded-products.php }\end{array}$ & $2 \mathrm{~d} 3$ \\
\hline & $\begin{array}{l}\text { Global Precipitation } \\
\text { Climatology Project } \\
\text { (GPCP) }\end{array}$ & http://precip.gsfc.nasa.gov & $4 f, 4 i$ \\
\hline & GPCC & http://www.gpcc.dwd.de & $2 \mathrm{~d} 3$ \\
\hline & GPCP & http://www.gewex.org/gpcpdata.htm & $2 \mathrm{~d} 3$ \\
\hline & $\begin{array}{l}\text { SSM/I, TMI, and } \\
\text { AMSR-E Data }\end{array}$ & http://www.remss.com & $2 \mathrm{~d} 3$ \\
\hline & TRMM 3B43 Rainfall & $\begin{array}{l}\text { http://trmm.gsfc.nasa.gov/trmm_rain/Events } \\
\text { /thirty_day.html }\end{array}$ & $4 g l, 4 g 2$ \\
\hline Precipitation (net) & $\begin{array}{l}\text { JRA-25 Atmospheric } \\
\text { Reanalysis }\end{array}$ & http://jra.kishou.go.jp/JRA-25/index_en.html & $6 d$ \\
\hline
\end{tabular}




\begin{tabular}{|c|c|c|c|}
\hline $\begin{array}{l}\text { General Variable } \\
\text { or Phenomenon }\end{array}$ & $\begin{array}{l}\text { Specific Dataset } \\
\text { or Variable }\end{array}$ & Source & Section \\
\hline \multirow{6}{*}{$\begin{array}{l}\text { Pressure, Sea Level or } \\
\text { Near-Surface }\end{array}$} & ACCESS & http://www.bom.gov.au/nwp/access/NWPData.shtml & $6 f$ \\
\hline & $\begin{array}{l}\text { AMRC (Antarctic } \\
\text { Meteorological } \\
\text { Research Center) } \\
\text { AWS }\end{array}$ & http://amrc.ssec.wisc.edu/data & $6 c$ \\
\hline & ERA-Interim & http://www.ecmwf.int/research/era & $\begin{array}{l}6 a, 6 b \\
6 c, 6 f\end{array}$ \\
\hline & HadSLP2r & http://www.metoffice.gov.uk/hadobs & $2 \mathrm{el}$ \\
\hline & $\begin{array}{l}\text { JRA-25 Atmospheric } \\
\text { Reanalysis }\end{array}$ & http://jra.kishou.go.jp/JRA-25/index_en.html & $6 d$ \\
\hline & READER & http://www.antarctica.ac.uk/met/READER & $6 c$ \\
\hline Sea Ice Age & NSIDC/CCAR & http://icdc.zmaw.de/seaiceage_arctic.html?\&L=I & $5 f 2$ \\
\hline Sea Ice Concentration & $\begin{array}{l}\text { Nimbus-7 SMMR } \\
\text { and DMSP SSM/I } \\
\text { (Bootstrap) }\end{array}$ & $\begin{array}{l}\text { http://nsidc.org/data/docs/daac } \\
\text { /nsidc0079_bootstrap_seaice.gd.html }\end{array}$ & $6 f$ \\
\hline Sea Ice Duration & $\begin{array}{l}\text { Near-Real-Time DMSP } \\
\text { SSM/I-SSMIS Daily } \\
\text { Polar Gridded }\end{array}$ & http://nsidc.org/data/nsidc-008I.html & $6 f$ \\
\hline Sea Ice Extent & $\begin{array}{l}\text { Nimbus-7 SMMR } \\
\text { and DMSP SSM/I } \\
\text { (Bootstrap) }\end{array}$ & $\begin{array}{l}\text { http://nsidc.org/data/docs/daac/nsidc0079 } \\
\text { _bootstrap_seaice.gd.html }\end{array}$ & $6 f$ \\
\hline $\begin{array}{l}\text { Sea Ice Freeboard/ } \\
\text { Thickness }\end{array}$ & CryoSat-2 & $\begin{array}{l}\text { https://earth.esa.int/web/guest/- } \\
\text { /how-to-access-cryosat-data- } 6842\end{array}$ & $5 f 3$ \\
\hline Sea Ice Index & $\begin{array}{l}\text { Sea Ice Concentration } \\
\text { from DMSP SSM/I- } \\
\text { SSMIS Passive } \\
\text { Microwave Data }\end{array}$ & http://nsidc.org/data/seaice_index/archives/index.html & $5 \mathrm{fl}$ \\
\hline \multirow[b]{2}{*}{ Sea Level } & NOAA/AOML & $\begin{array}{l}\text { http://www.aoml.noaa.gov/phod/altimetry/cvar } \\
\text { /agu/index.php }\end{array}$ & $3 g$ \\
\hline & $\begin{array}{l}\text { Ssalto/Duacs } \\
\text { Multimission Altimeter } \\
\text { Products }\end{array}$ & $\begin{array}{l}\text { http://www.aviso.oceanobs.com/en/data } \\
\text { /product-information/duacs/index.html }\end{array}$ & $3 j$ \\
\hline \multirow[b]{2}{*}{ Sea Surface Salinity } & Aquarius & http://aquarius.nasa.gov & $3 e$ \\
\hline & $\begin{array}{l}\text { World Ocean Atlas } \\
2009\end{array}$ & $\begin{array}{l}\text { http://www.nodc.noaa.gov/OC5/WOA09 } \\
\text { /pr_woa09.html }\end{array}$ & $3 e$ \\
\hline \multirow{5}{*}{ Sea Surface Temperature } & $\begin{array}{l}\text { Climate Prediction } \\
\text { Center's Monthly } \\
\text { Ocean Briefing }\end{array}$ & http://www.cpc.ncep.noaa.gov/products/GODAS & $3 b$ \\
\hline & ERSST-v3b & $\begin{array}{l}\text { http://www.esrl.noaa.gov/psd/data/gridded } \\
\text { /data.noaa.ersst.html }\end{array}$ & $\begin{array}{l}2 \mathrm{bl}, 3 \mathrm{~b}, \\
4 \mathrm{bl}, 4 \mathrm{~d} 2, \\
4 \mathrm{~h},\end{array}$ \\
\hline & HadSST3 & http://www.metoffice.gov.uk/hadobs/hadsst3 & $2 \mathrm{bl}$ \\
\hline & HadISSTI & http://www.metoffice.gov.uk/hadobs/hadisst & $3 b$ \\
\hline & $\begin{array}{l}\text { NOAA Optimum } \\
\text { Interpolation SST } \\
\text { (OISST) v2 }\end{array}$ & $\begin{array}{l}\text { http://www.esrl.noaa.gov/psd/data/gridded } \\
\text { /data.ncep.oisst.v2.html }\end{array}$ & $3 b, 5 g l$ \\
\hline
\end{tabular}




\begin{tabular}{|c|c|c|c|}
\hline $\begin{array}{l}\text { General Variable } \\
\text { or Phenomenon }\end{array}$ & $\begin{array}{l}\text { Specific Dataset } \\
\text { or Variable }\end{array}$ & Source & Section \\
\hline \multirow{5}{*}{ Snow Cover } & $\begin{array}{l}\text { Arctic Snow Cover } \\
\text { Extent }\end{array}$ & $\begin{array}{l}\text { http://climate.rutgers.edu/snowcover } \\
\text { http://nsidc.org/data/g02156 }\end{array}$ & $5 \mathrm{hl}$ \\
\hline & $\begin{array}{l}\text { Arctic Snow Cover } \\
\text { Duration }\end{array}$ & $\begin{array}{l}\text { http://nsidc.org/data/docs/noaa } \\
\text { lg02I56_ims_snow_ice_analysis/index.html }\end{array}$ & $5 \mathrm{~h} 2$ \\
\hline & $\begin{array}{l}\text { Canadian } \\
\text { Meteorological Centre } \\
\text { Daily Gridded }\end{array}$ & $\begin{array}{l}\text { http://nsidc.org/data/docs/daac } \\
\text { /nsidc0447_CMC_snow_depth/index.html }\end{array}$ & $5 \mathrm{hl}$ \\
\hline & $\begin{array}{l}\text { Snow Cover Extent } \\
\text { and Duration }\end{array}$ & http://climate.rutgers.edu/snowcover & $2 c 2$ \\
\hline & SSM/I & http://www.nsidc.org & $6 e$ \\
\hline $\begin{array}{l}\text { Snow Water } \\
\text { Equivalent }\end{array}$ & $\begin{array}{l}\text { Canadian } \\
\text { Meteorological Centre } \\
\text { Daily Gridded }\end{array}$ & $\begin{array}{l}\text { http://nsidc.org/data/docs/daac } \\
\text { /nsidc0447_CMC_snow_depth/index.html }\end{array}$ & $5 \mathrm{~h} 4$ \\
\hline Soil Moisture & GRACE & http://www.esa-soimoisture-cci.org & $2 \mathrm{~d} 6$ \\
\hline Solar Flux & FI0.7 solar flux & $\begin{array}{l}\text { ftp://ftp.ngdc.noaa.gov/STP/space weather/solar-data } \\
\text { /solar-features/solar-radio/noontime-flux/penticton } \\
\text { /penticton_adjusted/listings/listing_drao_noontime } \\
\text {-flux-adjusted_daily.txt }\end{array}$ & $2 g 4$ \\
\hline Solar Transmission & $\begin{array}{l}\text { Mauna Loa Solar } \\
\text { Transmission }\end{array}$ & http://www.esrl.noaa.gov/gmd/grad/mloapt.html & $2 f 2$ \\
\hline \multirow{3}{*}{$\begin{array}{l}\text { Stratospheric } \\
\text { Water Vapor }\end{array}$} & $\begin{array}{l}\text { Frost Point } \\
\text { Hygrometer Data } \\
\text { (Boulder, Hilo, Lauder) }\end{array}$ & ftp://aftp.cmdl.noaa.gov/data/ozwv/WaterVapor & $2 \mathrm{~g} 5$ \\
\hline & $\begin{array}{l}\text { Frost Point } \\
\text { Hygrometer Data } \\
\text { (San Jose) }\end{array}$ & http://physics.valpo.edu/ozone/ticosonde.html & $2 \mathrm{~g} 5$ \\
\hline & MLS Data & $\begin{array}{l}\text { http://disc.sci.gsfc.nasa.gov/Aura/data-holdings } \\
\text { /MLS/index.shtml }\end{array}$ & $2 \mathrm{~g} 5$ \\
\hline \multirow{5}{*}{ Surface Current } & $\begin{array}{l}\text { NOAA/AOML } \\
\text { Altimetry Products }\end{array}$ & http://www.aoml.noaa.gov/phod/altimetry/cvar/nbc & $3 g$ \\
\hline & $\begin{array}{l}\text { Long Term Time } \\
\text { Series of Surface } \\
\text { Currents: Agulhas } \\
\text { Current }\end{array}$ & $\begin{array}{l}\text { http://www.aoml.noaa.gov/phod/altimetry/cvar } \\
\text { lagu/index.php }\end{array}$ & $3 g 2$ \\
\hline & $\begin{array}{l}\text { Brazil-Malvina Region } \\
\text { Confluence Region }\end{array}$ & $\begin{array}{l}\text { http://www.aoml.noaa.gov/phod/altimetry/cvar/mal } \\
\text { /BM_anm.php }\end{array}$ & $3 g 3$ \\
\hline & $\begin{array}{l}\text { Ocean Surface } \\
\text { Current Analysis - } \\
\text { Real time (OSCAR) }\end{array}$ & http://www.oscar.noaa.gov & $3 g$ \\
\hline & $\begin{array}{l}\text { Ssalto/Duacs } \\
\text { Multimission Altimeter } \\
\text { Products }\end{array}$ & $\begin{array}{l}\text { http://www.aviso.oceanobs.com/en/data } \\
\text { /product-information/duacs/index.html }\end{array}$ & $3 i$ \\
\hline
\end{tabular}




\begin{tabular}{|c|c|c|c|}
\hline $\begin{array}{l}\text { General Variable } \\
\text { or Phenomenon }\end{array}$ & $\begin{array}{l}\text { Specific Dataset } \\
\text { or Variable }\end{array}$ & Source & Section \\
\hline \multirow{15}{*}{$\begin{array}{l}\text { Temperature, } \\
\text { [Near] Surface }\end{array}$} & $\begin{array}{l}\text { AMRC (Antarctic } \\
\text { Meteorological } \\
\text { Research Center) } \\
\text { AWS }\end{array}$ & http://amrc.ssec.wisc.edu/data & $6 c, 6 e$ \\
\hline & CRUTEM4 & http://www.metoffice.gov.uk/hadobs/crutem4 & $5 \mathrm{bl}$ \\
\hline & ERA-Interim & http://old.ecmwf.int/research/era/do/get/era-interim & $\begin{array}{l}2 \mathrm{bl}, 6 \mathrm{a}, \\
6 \mathrm{~b}, 6 \mathrm{c} \\
6 \mathrm{e}, 6 \mathrm{f}\end{array}$ \\
\hline & $\begin{array}{l}\text { HadCRUT4 Global } \\
\text { Temperature }\end{array}$ & http://www.metoffice.gov.uk/hadobs/hadcrut4 & $2 \mathrm{bl}$ \\
\hline & $\begin{array}{l}\text { JMA Global } \\
\text { Temperature }\end{array}$ & $\begin{array}{l}\text { http://ds.data.jma.go.jp/tcc/tcc/products/gwp/temp } \\
\text { /map/download.html }\end{array}$ & $2 \mathrm{bl}$ \\
\hline & $\begin{array}{l}\text { JRA-25 Atmospheric } \\
\text { Reanalysis }\end{array}$ & http://jra.kishou.go.jp/JRA-25/index_en.html & $2 \mathrm{bl}$ \\
\hline & $\begin{array}{l}\text { JRA-55 Atmospheric } \\
\text { Reanalysis }\end{array}$ & http://jra.kishou.go.jp/JRA-55/index_en.html & $2 \mathrm{bl}$ \\
\hline & MERRA & http://gmao.gsfc.nasa.gov/merra & $2 \mathrm{bl}$ \\
\hline & $\begin{array}{l}\text { MODIS: EOS data } \\
\text { set MYDII (skin } \\
\text { temperature) }\end{array}$ & $\begin{array}{l}\text { https://lpdaac.usgs.gov/products } \\
\text { /modis_products_table/mydllal }\end{array}$ & SB6.I \\
\hline & $\begin{array}{l}\text { NASA/GISS Global } \\
\text { Temperature }\end{array}$ & http://data.giss.nasa.gov/gistemp & $2 \mathrm{bl}$ \\
\hline & $\begin{array}{l}\text { NCEP/NCAR } \\
\text { Reanalysis }\end{array}$ & $\begin{array}{l}\text { http://www.esrl.noaa.gov/psd/data/gridded } \\
\text { /data.ncep.reanalysis.html }\end{array}$ & $\begin{array}{l}\text { 5b2, } \\
\text { SB5.I }\end{array}$ \\
\hline & CRUTEM4 & www.cru.uea.ac.uk/cru/data/temperature & $\begin{array}{ll}5 b l, \\
\text { SB5.I }\end{array}$ \\
\hline & NCEP-CFSR & http://cfs.ncep.noaa.gov & $6 c$ \\
\hline & $\begin{array}{l}\text { NOAA/NCDC Global } \\
\text { Temperature }\end{array}$ & $\begin{array}{l}\text { http://www.ncdc.noaa.gov/monitoring-references } \\
\text { /faq/anomalies.php }\end{array}$ & $2 \mathrm{bl}$ \\
\hline & READER & http://www.antarctica.ac.uk/met/READER & $6 c$ \\
\hline \multirow{11}{*}{$\begin{array}{l}\text { Temperature, } \\
\text { Upper Atmosphere }\end{array}$} & $\begin{array}{l}\text { 20th Century } \\
\text { Reanalysis }\end{array}$ & http://www.esrl.noaa.gov/psd/data/20thC_Rean & $2 \mathrm{bl}$ \\
\hline & ERA-Interim & http://old.ecmwf.int/research/era/do/get/era-interim & $\begin{array}{l}2 \mathrm{~b} 2,2 \mathrm{~b} 3, \\
6 \mathrm{~b}\end{array}$ \\
\hline & HadAT2 & http://hadobs.metoffice.com/hadat/hadat2.html & $\begin{array}{l}2 \mathrm{~b} 2,2 \mathrm{~b} 3 \\
6 \mathrm{~b}\end{array}$ \\
\hline & $\begin{array}{l}\text { JRA-25 Atmospheric } \\
\text { Reanalysis }\end{array}$ & http://jra.kishou.go.jp/JRA-25/index_en.html & $2 \mathrm{~b} 2$ \\
\hline & $\begin{array}{l}\text { JRA- } 55 \text { Atmospheric } \\
\text { Reanalysis }\end{array}$ & http://jra.kishou.go.jp/JRA-55/index_en.html & $2 b 2,2 b 3$ \\
\hline & MERRA & http://gmao.gsfc.nasa.gov/merra & $\begin{array}{l}2 b 2,2 b 3, \\
6 b\end{array}$ \\
\hline & $\begin{array}{l}\text { NCEP/DOE } \\
\text { Reanalysis } 2\end{array}$ & $\begin{array}{l}\text { http://www.esrl.noaa.gov/psd/data/gridded } \\
\text { /data.ncep.reanalysis2.html }\end{array}$ & SB5.I, $6 \mathrm{~g}$ \\
\hline & RAOBCORE, RICH & $\begin{array}{l}\text { http://www.univie.ac.at/theoret-met/research } \\
\text { /raobcore }\end{array}$ & $2 \mathrm{~b} 2,2 \mathrm{~b} 3$ \\
\hline & RATPAC & http://www.ncdc.noaa.gov/oa/climate/ratpac & $2 \mathrm{~b} 2,2 \mathrm{~b} 3$ \\
\hline & RSS & http://www.remss.com & $2 b 2,2 b 3$ \\
\hline & UAH MSU & http://vortex.nsstc.uah.edu/public/msu & $2 \mathrm{~b} 2,2 \mathrm{~b} 3$ \\
\hline
\end{tabular}




\begin{tabular}{|c|c|c|c|}
\hline $\begin{array}{l}\text { General Variable } \\
\text { or Phenomenon }\end{array}$ & $\begin{array}{c}\text { Specific Dataset } \\
\text { or Variable }\end{array}$ & Source & Section \\
\hline \multirow{3}{*}{$\begin{array}{l}\text { TOA Earth } \\
\text { Radiation Budget }\end{array}$} & $\begin{array}{l}\text { CERES EBAF Ed2.6r } \\
\text { IDeg }\end{array}$ & https://eosweb.larc.nasa.gov/project/ceres/ceres_table & $2 f$ \\
\hline & CERES FLASHFlux & https://eosweb.larc.nasa.gov/project/ceres/ceres_table & $2 f$ \\
\hline & $\begin{array}{l}\text { COSMIC Land and } \\
\text { Ocean Total Column } \\
\text { Water Vapor }\end{array}$ & http://cosmic-io.cosmic.ucar.edu/cdaac/index.html & $2 \mathrm{~d} 2$ \\
\hline \multirow{18}{*}{$\begin{array}{l}\text { Total Column \& } \\
\text { Stratospheric Ozone }\end{array}$} & Bodeker Scientific & $\begin{array}{l}\text { http://www.bodekerscientific.com/data } \\
\text { /total-column-ozone }\end{array}$ & $5 c$ \\
\hline & $\begin{array}{l}\text { Calipso (Polar } \\
\text { Stratospheric Clouds) }\end{array}$ & $\begin{array}{l}\text { http://eosweb.larc.nasa.gov/PRODOCS/calipso } \\
\text { /table_calipso.html }\end{array}$ & $6 g$ \\
\hline & CRUTEM4 & www.cru.uea.ac.uk/cru/data/temperature & $\begin{array}{l}\text { 5bl, } \\
\text { SB5.l }\end{array}$ \\
\hline & $\begin{array}{l}\text { ESA-CCI (HARMOZ) } \\
\text { datasets }\end{array}$ & $\begin{array}{l}\text { doi:I0.5270/esa ozone_ccilimb_occultation } \\
\text { _profiles-200I_2012 v_I } 201308\end{array}$ & $2 g 4$ \\
\hline & $\begin{array}{l}\text { GOME/SCIAMACHYI } \\
\text { GOME2 (GSG) } \\
\text { Merged Total Ozone }\end{array}$ & http://www.iup.uni-bremen.de/gome/wfdoas & $2 g 4$ \\
\hline & $\begin{array}{l}\text { GOZCARDS ozone } \\
\text { profiles }\end{array}$ & https://gozcards.jpl.nasa.gov & $2 g 4$ \\
\hline & $\begin{array}{l}\text { GOME/SCIAMACHYI } \\
\text { GOME2 (GTO) } \\
\text { Merged Total Ozone }\end{array}$ & $\begin{array}{l}\text { http://atmos.eoc.dlr.de/gome/gto-ecv.html } \\
\text { http://www.esa-ozone-cci.org }\end{array}$ & $2 g 4$ \\
\hline & KNMI OMI & http://ozoneaq.gsfc.nasa.gov & $6 g$ \\
\hline & $\begin{array}{l}\text { Microwave/Lidar } \\
\text { Ozone }\end{array}$ & http://www.ndsc.ncep.noaa.gov/data & $2 g 4$ \\
\hline & $\begin{array}{l}\text { Multi Sensor } \\
\text { Reanalysis (MSR) of } \\
\text { Total Ozone }\end{array}$ & http://www.temis.nl & $2 g 4$ \\
\hline & $\begin{array}{l}\text { NASA Aura } \\
\text { Microwave Limb } \\
\text { Sounder }\end{array}$ & http://aura.gsfc.nasa.gov/instruments/mls.html & $6 g$ \\
\hline & $\begin{array}{l}\text { NASA BUV/SBUV } \\
\text { V8.6 (MOD V8.6) } \\
\text { Merged Ozone } \\
\end{array}$ & http://acdb-ext.gsfc.nasa.gov/Data_services/merged & $2 g 4$ \\
\hline & $\begin{array}{l}\text { NCEP/NCAR } \\
\text { Reanalysis } \\
\end{array}$ & $\begin{array}{l}\text { http://www.esrl.noaa.gov/psd/data/gridded/data.ncep. } \\
\text { reanalysis.html }\end{array}$ & $\begin{array}{l}5 b 2 \\
\text { SB5.I }\end{array}$ \\
\hline & $\begin{array}{l}\text { NOAA SBUV V8.6 } \\
\text { (MOD V8.6) Merged } \\
\text { Ozone }\end{array}$ & ftp://ftp.cpc.ncep.noaa.gov/SBUV_CDR & $2 g 4$ \\
\hline & $\begin{array}{l}\text { Ozone Mapping and } \\
\text { Profiler Suite Total } \\
\text { Column Nadir Mapper } \\
\text { (OMPS TC-NM) } \\
\end{array}$ & http://ozoneaq.gsfc.nasa.gov/omps & $6 g$ \\
\hline & Ozonesonde & http://www.esrl.noaa.gov/gmd/dv/spo_oz & $6 g$ \\
\hline & $\begin{array}{l}\text { TOMS and OMI } \\
\text { Sensors }\end{array}$ & http://ozoneaq.gsfc.nasa.gov & $5 c$ \\
\hline & $\begin{array}{l}\text { WOUDC Ground- } \\
\text { based Ozone }\end{array}$ & ftp://ftp.tor.ec.gc.ca/Projects-Campaigns/ ZonalMeans & $2 g 4$ \\
\hline
\end{tabular}




\begin{tabular}{|c|c|c|c|}
\hline $\begin{array}{l}\text { General Variable } \\
\text { or Phenomenon }\end{array}$ & $\begin{array}{l}\text { Specific Dataset } \\
\text { or Variable }\end{array}$ & Source & Section \\
\hline \multirow{3}{*}{$\begin{array}{c}\text { Total Column Water } \\
\text { Vapor and Humidity, } \\
\text { Upper Air }\end{array}$} & $\begin{array}{l}\text { GPS Ground-Based } \\
\text { Total Column Water } \\
\text { Vapor }\end{array}$ & http://dss.ucar.edu/datasets/ds72I.I & $2 \mathrm{~d} 2$ \\
\hline & $\begin{array}{l}\text { SSM/I -AMSR-E Ocean } \\
\text { Total Column Water } \\
\text { Vapor }\end{array}$ & http://www.remss.com & $2 \mathrm{~d} 2$ \\
\hline & COSMIC-RO & http://www.cosmic.ucar.edu/ro.html & $2 \mathrm{~d} 2$ \\
\hline \multirow{11}{*}{ Trace Gases } & $\begin{array}{l}\text { Atmospheric } \\
\text { Greenhouse Gas Index } \\
\text { (AGGI) }\end{array}$ & http://www.esrl.noaa.gov/gmd/aggi & $2 g l, 5 e$ \\
\hline & Carbon Dioxide & http://www.esrl.noaa.gov/gmd/dv/iadv & $2 \mathrm{gl}$ \\
\hline & Carbon Monoxide & http://www.copernicus-atmosphere.eu/data & $2 g 7$ \\
\hline & EESC & $\begin{array}{l}\text { http://acdb ext.gsfc.nasa.gov/Data_services } \\
\text { /automailer/index.html }\end{array}$ & $2 g 4$ \\
\hline & JPL MLS ( $\mathrm{HCl}, \mathrm{ClO})$ & http://mls.jpl.nasa.gov/index.php & $6 g$ \\
\hline & Methane & http://www.esrl.noaa.gov/gmd/dv/iadv & $2 \mathrm{gl}$ \\
\hline & Nitrous Oxide & $\begin{array}{l}\text { http://www.esrl.noaa.gov/gmd/hats/combined } \\
\text { /N2O.html }\end{array}$ & $2 \mathrm{gl}$ \\
\hline & $\begin{array}{l}\text { Ozone-Depleting Gas } \\
\text { Index (ODGI) }\end{array}$ & http://www.esrl.noaa.gov/gmd/odgi & $2 \mathrm{~g} 2$ \\
\hline & Perfluorocarbons & http://agage.eas.gatech.edu & $2 \mathrm{gl}$ \\
\hline & Sulfur Hexafluoride & $\begin{array}{l}\text { http://www.esrl.noaa.gov/gmd/hats/combined } \\
\text { /SF6.html }\end{array}$ & $2 \mathrm{gl}$ \\
\hline & $\begin{array}{l}\text { SCIAMACHY (OCIO, } \\
\text { NO2) }\end{array}$ & http://www.sciamachy.org & $6 g$ \\
\hline \multirow{3}{*}{ Tropical Cyclone Data } & $\begin{array}{l}\text { International Best } \\
\text { Track Archive for } \\
\text { Climate Stewardship } \\
\text { (IBTrACS) }\end{array}$ & http://www.ncdc.noaa.gov/oa/ibtracs & $4 d$ \\
\hline & $\begin{array}{l}\text { JTWC Best-track } \\
\text { Dataset (20II } \\
\text { preliminary) }\end{array}$ & $\begin{array}{l}\text { http://www.usno.navy.mil/NOOC/nmfc-ph/RSS/jtwc } \\
\text { /best_tracks }\end{array}$ & $4 d 4$ \\
\hline & $\begin{array}{l}\text { Southwest Pacific } \\
\text { Enhanced Archive } \\
\text { of Tropical Cyclones } \\
\text { (SPEArTC) }\end{array}$ & http://apdrc.soest.hawaii.edu/projects/speartc & $4 d 8$ \\
\hline Tropospheric Ozone & $\begin{array}{l}\text { OMI/MLS } \\
\text { Tropospheric Column } \\
\text { Ozone }\end{array}$ & http://acd-ext.gsfc.nasa.gov/Data_services/cloud_slice & $2 g 6$ \\
\hline Ultraviolet Radiation & UV Index & $\begin{array}{l}\text { http://www.temis.nl/uvradiation/SCIA } \\
\text { /stations_uv.html }\end{array}$ & $5 d$ \\
\hline
\end{tabular}




\begin{tabular}{|c|c|c|c|}
\hline $\begin{array}{l}\text { General Variable } \\
\text { or Phenomenon }\end{array}$ & $\begin{array}{c}\text { Specific Dataset } \\
\text { or Variable }\end{array}$ & Source & Section \\
\hline \multirow{10}{*}{ Wind, [Near] Surface } & $\begin{array}{l}\text { 20th Century } \\
\text { Reanalysis }\end{array}$ & http://www.esrl.noaa.gov/psd/data/20thC_Rean & $2 \mathrm{e} 2$ \\
\hline & $\begin{array}{l}\text { AMRC (Antarctic } \\
\text { Meteorological } \\
\text { Research Center) } \\
\text { AWS }\end{array}$ & http://amrc.ssec.wisc.edu/data & $2 e 2$ \\
\hline & ERA-Interim & http://www.ecmwf.int/research/era & $2 \mathrm{e} 2$ \\
\hline & ISD-Lite wind data & $\begin{array}{l}\text { http://www.ncdc.noaa.gov/oa } \\
\text { /climate.isd.index.php?name=isdlite }\end{array}$ & $2 \mathrm{e} 2$ \\
\hline & $\begin{array}{l}\text { JRA-25 Atmospheric } \\
\text { Reanalysis }\end{array}$ & http://jra.kishou.go.jp/JRA-25/index_en.html & $2 e 2$ \\
\hline & MERRA & http://gmao.gsfc.nasa.gov/merra & $2 \mathrm{e} 2$ \\
\hline & NOCSv2.0 & $\begin{array}{l}\text { http://badc.nerc.ac.uk/view/badc.nerc.ac } \\
\text {.uk__ATOM_dataent_I22037/5926426308 }\end{array}$ & $2 \mathrm{el}$ \\
\hline & READER & http://www.antarctica.ac.uk/met/READER & $6 c$ \\
\hline & $\begin{array}{l}\text { Satellite Radiometer } \\
\text { Winds (SSM/I, } \\
\text { AMSR-E, WindSat, } \\
\text { SSMIS) }\end{array}$ & http://www.remss.com & $2 \mathrm{e} 2$ \\
\hline & WASWind & $\begin{array}{l}\text { http://www.dpac.dpri.kyoto-u.ac.jp/tokinaga } \\
\text { /waswind.html }\end{array}$ & $2 \mathrm{e} 2$ \\
\hline $\begin{array}{l}\text { Wind, Upper } \\
\text { Atmosphere }\end{array}$ & ERA-Interim & http://www.ecmwf.int/research/era & $6 b, 6 f$ \\
\hline
\end{tabular}




\section{ACKNOWLEDGMENTS}

The editors thank the staff of the Bulletin of the American Meteorological Society for their professionalism and assistance. Melissa Fernau provided valuable editorial advice and logistical support. As always, the guidance and leadership of Bryan Hanssen and Jeff Rosenfeld was essential. The chapter editors enthusiastically thank their respective internal reviewers, and anonymous external reviewers, for working on very tight timetables to improve the document.

Chapter 2:

- Various reanalysis datasets were provided by Paul Berrisford and Hitoshi Sato (ERA-Interim), Mike Bosilovich (MERRA), Muthuvel Chelliah (NCEP CFSR), Yayoi Harada (JRA-25/ JCDAS), and Cathy Smith (20CR).

- Kate Willett, Rob Allan, Chris Folland, Robert Dunn and John Kennedy were supported by the Joint UK DECC/Defra Met Office Hadley Centre Climate Programme (GA01101).

- The chapter editors thank David Parker of the Met Office for his thorough early review.

Chapter 3:

- Simon Good was supported by the Joint UK DECC/Defra Met Office Hadley Centre Climate Programme (GA01101).

- Jeff Dunn provided quality controlled Argo data.

- Neil White processed altimeter data for the CSIRO/ACE CRC OHCA estimates.

Chapter 4:

- Bill Ward, NOAA/NWS/Pacific Region Headquarters, Honolulu, Hawaii, is thanked for his detailed and very helpful internal review of the chapter.

Chapter 5:

- For support for co-editing the Arctic section, Martin Jeffries thanks the US Arctic Research Commission and the Office of Naval Research, and Jackie Richter-Menge thanks the NOAA Arctic Research Office.

- Chris Derksen and co-authors of the Terrestrial Snow Cover essay thank their data providers: Rutgers University Global Snow Laboratory; Canadian Meteorological Centre; and the U.S. National Ice Center.

- Marco Tedesco's work on the Greenland Ice Sheet section was supported by the U.S. National Science Foundation while he was working there as a program director under the auspices of the Inter-governmental Personnel Act (IPA).

- For research that contributed to Sidebar 5.3: Ocean Acidification in the Arctic, Jeremy Mathis acknowledges the U.S. National Science Foundation (grant PLR-1107997) and the NOAA Ocean Acidification Program.

- Jim Overland's contribution to the Lower Atmosphere essay was supported in part by the NOAA Arctic Research Project of the Climate Program Office and by the Office of Naval Research, Code 322.

- Germar Bernhard and co-authors of the Ozone and UV Radiation essays acknowledge the support of the U.S. National Science Foundation (grant ARC-1203250), a Research Council of Norway Centres of Excellence award (project number 223268/F50) to the Norwegian Radiation Protection Authority, and the Academy of Finland for UV measurements by the FARPOCC and SAARA projects in Finland.

- Vladimir Romanovsky and co-authors of the Terrestrial Permafrost essay acknowledge the support of the State of Alaska and U.S. National Science Foundation (NSF) grant ARC-0856864 to the University of Alaska Fairbanks; NSF grants OPP-0095088 and OPP-0352958 to the University of Delaware; NSF grants ARC-1002119 and ARC-1204110 to The George Washington University; the Geological Survey of Canada and Natural Resources Canada; and the Government of the Russian Federation.

- Lori Bruhwiler, Jessica Cross, Ed Dlugokencky, Wiley Evans, Jeff Key, Jeremy Mathis, Trish Quinn, Jim Overland and Robert Stone of NOAA note that the views, opinions, and findings contained in their contributions are those of the authors and should not be construed as an official National Oceanic and Atmospheric Administration or U.S. Government position, policy, or decision.

Chapter 6:

- For Rob Massom, Phil Reid, and Jan Lieser, this work was supported by the Australian Government's Cooperative Research Centre program through the Antarctic Climate and Ecosystems CRC, and contributes to AAS Project 4116.

- Phil Reid was also supported through the Centre for Australian Weather and Climate Research.

- Ted Scambos was supported under NASA grant NNX0oAM78G and NSF ANT 0944763, The Antarctic Glaciological Data Center.

- Sharon Stammerjohn was supported under NSF ANT0823101.

- The sidebar on extreme Antarctic surface temperatures acknowledges USGS Contract G12PC00066 for Cryospheric Applications of Landsat 8

Chapter 7:

- The editors acknowledge and thank the numerous National Hydrological and Hydrometeorological Services for collecting and providing data (and many authors) for this report.

- For South America: sources of data are the meteorological services of the countries in the region: Brazil (INMET), Bolivia (SENAMHI), Peru (SENAMHI) as well as CPTEC/ INPE, IRI, and CIIFEN, and for impacts we have INDECI (Instituto Nacional de Defensa Civil from Peru). 
ACRONYMS AND ABBREVIATIONS

$\mathrm{AAO}$

ACE

AGGI

ALT

AMO

AMSR-E

AMSU

$\mathrm{AO}$

AOD

ATSR

AVHRR

AVISO

CAMS

CDR

CERES

CPC

$\mathrm{CPHC}$

CRU

DU

E-P

ECMWF

ECV

$\mathrm{EECl}$

EESC

EOS

ERB

ERBE

ERSST

ESA

ESRL

FAPAR

FLASHflux

GCOS

GHCN

GHG

GISS

GOME
Antarctic Oscillation

NOAA's Accumulated Cyclone Energy

Index

NOAA's Annual Greenhouse Gas Index

active layer thickness

Atlantic Multidecadal Oscillation

Advanced Microwave Scanning

Radiometer for Earth Observing System

Advanced Microwave Sounding Unit

Arctic Oscillation

aerosol optical depth

Along-Track Scanning Radiometers

Advanced Very High Resolution

Radiometer

Archiving, Validating, and

Interpretation of Satellite

Oceanographic data

Climate Anomaly Monitoring System

climate data record

Clouds and the Earth's Radiant Energy

System

NOAA's Climate Prediction Center

NOAA's Central Pacific Hurricane

Center

Hadley Centre's Climate Research Unit

Dobson Unit

evaporation minus precipitation

European Centre for Medium-Range

Weather Forecasts

essential climate variable

effective equivalent chlorine

effective equivalent stratospheric

chlorine

Earth Observatory System

Earth radiation budget

Earth Radiation Budget Experiment

Extended Reconstructed Sea Surface

Temperature

European Space Agency

Earth System Research Laboratory

Fraction of Absorbed Photosynthetically

Active Radiation

Fast Longwave and Shortwave Radiative

Fluxes

Global Climate Observing System

Global Historical Climatology Network

greenhouse gas

NASA's Goddard Institute of Space

Studies

Global Ozone Monitoring Experiment
GPCC

GPCP

GRACE

GTN-P

HadAT

HadCRUT

HadISST

HIRS-W

IBTrACS

ICD

IOD

ISCCP

JMA

JPL

JRA

JTWC

LHF

LLGHG

MDR

MEI

MERIS

MISR

MLS

MOC

MOCHA

MODIS

MSLP

MSU

NAO

NASA

NCAR

NCDC

NCEP

NERC

NOAA
Global Precipitation Climatology

Centre

Global Precipitation Climatology

Project

Gravity Recovery and Climate

Experiment

Global Terrestrial Network on

Permafrost

Hadley Centre's radiosonde temperature product

Hadley Centre/CRU gridded monthly

temperatures dataset

Hadley Centre's sea ice and SST dataset

High Resolution Infrared Sounder

International Best Track Archive for

Climate Stewardship

ice cover duration

Indian Ocean dipole

International Satellite Cloud

Climatology Project

Japanese Meteorological Agency

Jet Propulsion Laboratory

Japanese Reanalysis

U.S. Navy's Joint Typhoon Warning

Center

latent heat flux

long-lived greenhouse gas

Main Development Region

multivariate ENSO index

Medium Resolution Imaging

Spectrometer

Multiangle Imaging SpectroRadiometer

Microwave Limb Sounder

meridional overturning current

Meridional Overturning Circulation

Heat Transport Array

Moderate Resolution Imaging

Spectroradiometer

mean sea level pressure

Microwave Sounding Unit

North Atlantic Oscillation

National Aeronautics and Space

Administration

National Center for Atmospheric

Research

NOAA's National Climatic Data Center

NOAA's National Center for

Environmental Prediction

National Environmental Research

Council

National Oceanic and Atmospheric

Administration 


\begin{tabular}{|c|c|}
\hline NSIDC & National Snow and Ice Data Center \\
\hline OAFlux & Objectively Analyzed Air-Sea Fluxes \\
\hline ODGI & Ozone Depleting Gas Index \\
\hline ODS & ozone depleting substance \\
\hline OHCA & ocean heat content anomaly \\
\hline OISST & Optimal Interpolation SST \\
\hline OLR & outgoing longwave radiation \\
\hline OMI & Ozone Monitoring Instrument \\
\hline ONI & NOAA’s Oceanic Niño Index \\
\hline OPI & OLR precipitation index \\
\hline P-E & precipitation minus evaporation \\
\hline PATMOS (-x) & $\begin{array}{l}\text { Pathfinder Atmospheres (Extended } \\
\text { Product) }\end{array}$ \\
\hline $\mathrm{PDO}$ & Pacific decadal oscillation \\
\hline PSC & polar stratospheric clouds \\
\hline PSS & practical salinity scale \\
\hline QBO & Quasi-biennial oscillation \\
\hline QuikSCAT & Quick Scatterometer \\
\hline RAOBCORE & Radiosonde Observation Correction \\
\hline RATPAC & $\begin{array}{l}\text { Radiosonde Atmospheric Temperature } \\
\text { Products for Assessing Climate }\end{array}$ \\
\hline $\mathrm{RICH}$ & $\begin{array}{l}\text { Radiosonde Innovation Composite } \\
\text { Homogenization }\end{array}$ \\
\hline RSS & Remote Sensing Systems \\
\hline SAM & Southern annular mode \\
\hline SCD & snow covered duration \\
\hline SCE & snow cover extent \\
\hline SCIAMACHY & $\begin{array}{l}\text { Scanning Imaging Absorption } \\
\text { Spectrometer for Atmospheric } \\
\text { Chartography }\end{array}$ \\
\hline SeaWiFS & Sea-viewing Wide Field of View \\
\hline SHF & Sensible heat flux \\
\hline SLP & Sea level pressure \\
\hline SOI & Southern Oscillation index \\
\hline SPCZ & South Pacific convergence zone \\
\hline $\mathrm{SSM} / \mathrm{I}$ & Special Sensor Microwave Imager \\
\hline $\mathrm{SSH}$ & Sea surface height \\
\hline SSS & Sea surface salinity \\
\hline SSTA & Sea surface temperature anomaly \\
\hline SWE & Snow water equivalent \\
\hline ТCHP & Tropical cyclone heat potential \\
\hline TCWV & Total column water vapor \\
\hline TOA & Top of atmosphere \\
\hline TOMS & Total Ozone Mapping Spectrometer \\
\hline TRMM & Tropical Rainfall Measuring Mission \\
\hline WBM & Water Balance Model \\
\hline w.e. & water equivalent \\
\hline WGMS & World Glacier Monitoring Service \\
\hline WMO & World Meteorological Organization \\
\hline WOA & World Ocean Atlas \\
\hline WOCE & World Ocean Circulation Experiment \\
\hline
\end{tabular}




\section{REFERENCES}

Abraham, J. P., and Coauthors, 2013: A review of global ocean temperature observations: Implications for ocean heat content estimates and climate change. Rev. Geophys., 51, 450-483, doi:10.1002/rog20022.

Ackerman, A. S., O. B. Toon, D. E. Stevens, A. J. Heymsfield, V. Ramanathan, and E. J. Welton, 2000: Reduction of tropical cloudiness by soot. Science, 288, 1042-1047.

Ackerman, S. A., R. E. Holz, R. Frey, E. W. Eloranta, B. C. Maddux, and M. McGill, 2008: Cloud detection with MODIS. Part II: Validation. J. Atmos. Oceanic Technol., 25, 1073-1086.

Adler, R. F., and Coauthors, 2003: The version 2 Global Precipitation Climatology Project (GPCP) monthly precipitation analysis (1979-present). J. Hydrometeor., 4, 1147-1167.

Aiyyer, A., and J. Molinari, 2008: MJO and tropical cyclogenesis in the Gulf of Mexico and eastern Pacific: Case study and idealized numerical modeling. J. Atmos. Sci., 65, 2691-2704.

Alaska Climate Research Center, 2013: May 2013 statewide summary. [Available online at http://climate.gi.alaska .edu/Summary/Statewide/2013/May.]

Alexander, L. V., and Coauthors, 2013: Summary for policymakers. Climate Change 2013: The Physical Science Basis, T. F. Stocker et al., Eds., Cambridge University Press, 3-29. [Available online at http://www.climatechange2013.org /images/report/WG1AR5_SPM_FINAL.pdf.]

Allan, R., and T. Ansell, 2006: A new globally complete monthly historical gridded mean sea level pressure dataset (HadSLP2): 1850-2004. J. Climate, 19, 5816-5842.

— J. A. Lindesay, and D. E. Parker, 1996: El Nino Southern Oscillation and Climatic Variability. CSIRO Publications, $405 \mathrm{pp}$.

Alley, W. M., R. W. Healy, J. W. LaBaugh, and T. E. Reilly, 2002: Flow and storage in groundwater systems. Science, 296, 1985-1990.

Amador, J. A., E. J. Alfaro, O. G. Lizano, and V. O. Magaña, 2006: Atmospheric forcing of the eastern tropical Pacific: A review. Progr. Oceanogr., 69, 101-142.

—, E. J. Alfaro, H. G. Hidalgo, and B. Calderón, 2011: [Regional climates] Central America [in "State of the Climate 2010"]. Bull. Amer. Meteor. Soc., 92 (6), S182-S183.

Anderberg, M. R., 1973: Cluster analysis for applications. Academic Press, 359 pp.

Anderson, L. G., and Coauthors, 2010: Arctic ocean shelf-basin interaction: An active continental shelf $\mathrm{CO}_{2}$ pump and its impact on the degree of calcium carbonate solubility. Deep Sea Res. I, 57, 869-879.

Andreassen, L., 2013: Climate indicator products. CryoClim/ Norwegian Water Resources and Energy Directorate (NVE). [Available online at http://glacier.nve.no/viewer $/ \mathrm{CI} / \mathrm{en} / \mathrm{cc} /$.
Antonov, J. I., and Coauthors, 2010: World Ocean Atlas 2009, Volume 2: Salinity. S. Levitus, Ed., NOAA Atlas NESDIS 69, US Government Printing Office, Washington, DC, $184 \mathrm{pp}$.

Aquila, V., L. D. Oman, R. S. Stolarski, A. R. Douglass, and P. A. Newman, 2013: The response of ozone and nitrogen dioxide to the eruption of Mt. Pinatubo at southern and northern midlatitudes. J. Atmos. Sci., 70, 894-900.

Arafiles, C. P., and C. P. Alcances, 1978: Storm Surge Potentials Of Selected Philippine Coastal Basins. Philippine Atmospheric, Geophysical and Astronomical Services Administration.

Armstrong, R. L., K. W. Knowles, M. J. Brodzik, and M. A. Hardman, 2013: DMSP SSM/I-SSMIS Pathfinder daily EASE-grid brightness temperatures. Version 2. Southern Hemisphere. National Snow and Ice Data Center, Boulder, $\mathrm{CO}$, digital media. [Available online at http://nsidc.org /data/nsidc-0032.]

Arrigo, K. R., and G. L. van Dijken, 2011: Secular trends in Arctic Ocean net primary production. J. Geophys. Res., 116, C09011, doi:10.1029/2011JC007151.

Askne, J. I. H., J. E. S. Fransson, M. Santoro, M. J. Soja and L. M. H. Ulander, 2013: Model-based biomass estimation of a hemi-boreal forest from multitemporal TanDEM-X acquisitions. Remote Sens., 5, 5574-5597, doi:10.3390 /rs5115574.

Atkinson, G. D., 1971: Forecasters' guide to tropical meteorology. U.S. Air Force Tech. Rep. 240, 360 pp.

Atlas, R., R. N. Hoffman, J. Ardizzone, S. M. Leidner, J. C. Jusem, D. K. Smith, and D. Gombos, 2011: A cross-calibrated multiplatform ocean surface wind velocity product for meteorological and oceanographic applications. Bull. Amer. Meteor. Soc., 92, 157-174.

Augustine, J. A., and E. G. Dutton, 2013: Variability of the surface radiation budget over the United States from 1996 through 2011 from high-quality measurements. J. Geophys. Res. Atmos., 118, 43-53, doi:10.1029/2012JD018551.

—, E. G. Dutton, T. Meyers, and J. Michalsky, 2006: Scientific rationale for the placement of sites to monitor the surface energy budget for climate applications. NOAA Tech. Memo. OAR GMD-17, 18 pp.

Azorin-Molina, C., and Coauthors, 2014: Homogenization and assessment of observed near-surface wind speed trends over Spain and Portugal, 1961-2011. J. Climate, 27, 3692-3712.

Baccini, A., and Coauthors, 2012: Estimated carbon dioxide emissions from tropical deforestation improved by carbon-density maps. Nature Climate Change, 2, 182-185, doi:110.1038/nclimate1354. 
Bamber, J. L., J. L. Gomez-Dans, and J. A. Griggs, 2009: A new $1 \mathrm{~km}$ digital elevation model of the Antarctic derived from combined satellite radar and laser data - Part 1: Data and methods. The Cryosphere, 3, 101-111, doi:10.5194 /tc-3-101-2009.

Baringer, M. O., and Coauthors, 2013: [Global oceans] Meridional overturning circulation and heat transport observations in the Atlantic [in "State of the Climate in 2012"]. Bull. Amer. Meteor. Soc., 94 (8), S65-S68.

Barnes, E. A., 2013: Revisiting the evidence linking Arctic amplification to extreme weather in mid-latitudes. Geophys. Res. Lett., 40, 4734-4739, doi:10.1002/grl.50880.

— , E. Dunn-Sigouin, G. Masato, and T. Woollings, 2014: Exploring recent trends in Northern Hemisphere blocking. Geophys. Res. Lett., 41, 648-644, doi:10.1002/2013GL058745.

Bastos, A., S. W. Running, C. Gouveia, and R. M. Trigo, 2013: The global NPP dependence on ENSO: La Niña and the extraordinary year of 2011. J. Geophys. Res. Biogeosci., 118, 1247-1255, doi:10.1002/jgrg.20100.

Bates, N. R., 2007: Interannual variability of the oceanic $\mathrm{CO}_{2}$ sink in the subtropical gyre of the North Atlantic Ocean over the last 2 decades. J. Geophys. Res., 112, C09013, doi:10.1029/2006JC003759.

— , 2012: Multi-decadal uptake of carbon dioxide into subtropical mode water of the North Atlantic Ocean. Biogeosciences, 9, 2649-2659.

— cycle: Evaluation of air-sea $\mathrm{CO}_{2}$ exchanges, ocean acidification impacts and potential feedbacks. Biogeosciences, 6, 2433-2459.

- , _ - and L. Cooper, 2009: The effect of ocean acidification on biologically induced seasonality of carbonate mineral saturation states in the Western Arctic Ocean. J. Geophys. Res., 114, C11007, doi:10.1029/2008JC004862.

Bauer-Marschallinger, B., W. A. Dorigo, W. Wagner, and A. I. J. M. van Dijk, 2013: How oceanic oscillation drives soil moisture variations over mainland Australia: An analysis of 32 years of satellite observations. J. Climate, 26, $10159-10173$.

Beal, L. M., V. Hormann, R. Lumpkin, and G. R. Foltz, 2013: The response of the surface circulation of the Arabian Sea to monsoonal forcing. J. Phys. Oceanogr., 43, 2008-2022.

Becker, A., P. Finger, A. Meyer-Christoffer, B. Rudolf, K. Schamm, U. Schneider, and M. Ziese, 2013: A description of the global land-surface precipitation data products of the Global Precipitation Climatology Centre with sample applications including centennial (trend) analysis from 1901-present. Earth Syst. Sci. Data, 5, 71-99, doi:10.5194/essd-5-71-2013.
Bednaršek, N., and Coauthors, 2012: Extensive dissolution of live pteropods in the Southern Ocean. Nature Geosci., 5, 881-885, doi:10.1038/ngeo1635.

Behrenfeld, M. J., and Coauthors, 2001: Biospheric primary production during an ENSO transition. Science, 291, 2594-2597.

- , and Coauthors, 2006: Climate-driven trends in contemporary ocean productivity. Nature, 444, 752-755.

$\longrightarrow$, K. Halsey, and A. Milligan, 2008: Evolved physiological responses of phytoplankton to their integrated growth environment. Phil. Trans. Royal Soc. B, 363, 2687-2703, doi:10.1098/rstb.2008.0019.

Behringer, D. W., M. Ji, and A. Leetmaa, 1998: An improved coupled model for ENSO prediction and implications for ocean initialization. Part I: The ocean data assimilation system. Mon. Wea. Rev., 126, 1013-1021.

Bell, G. D., and M. Chelliah, 2006: Leading tropical modes associated with interannual and multi-decadal fluctuations in North Atlantic hurricane activity. J. Climate, 19, $590-612$.

— - and Coauthors, 2000: The 1999 North Atlantic and eastern North Pacific hurricane season [in "Climate Assessment for 1999”]. Bull. Amer. Meteor. Soc., 81 (6), S19-S22.

_- and Coauthors, 2011: [The Tropics] Tropical cyclones; Atlantic basin [in "State of the Climate in 2010"]. Bull. Amer. Meteor. Soc., 92 (7), S115-S121.

_- and Coauthors, 2013: [The Tropics] Tropical cyclones: Atlantic basin [in "State of the Climate in 2012"]. Bull. Amer. Meteor. Soc., 94 (8), S85-S88.

Bell, R. E., and Coauthors, 2011: Widespread persistent thickening of the East Antarctic Ice Sheet by freezing from the base. Science, 331, 1592-1595.

Bellouin, N., J. Quaas, J-J. Morcrette, and O. Boucher, 2013: Estimates of aerosol radiative forcing from the MACC reanalysis. Atmos. Chem. Phys., 13, 2045-2062, doi:10.5194 /acp-13-2045-2013.

Beniston M., 2004: The 2003 heat wave in Europe: A shape of things to come? An analysis based on Swiss climatological data and model simulations. Geophys. Res. Lett., 31, L02202, doi:10.1029/2003GL018857.

Bergamaschi, P., and Coauthors, 2013: Atmospheric $\mathrm{CH}_{4}$ in the first decade of the $21^{\text {st }}$ century: Inverse modeling analysis using SCIAMACHY satellite retrievals and NOAA surface measurements. J. Geophys. Res. Atmos., 118, 7350-7369, doi:10.1002/jgrd.50480.

Bernhard, G., C. R. Booth, and J. C. Ehramjian, 2008: Comparison of UV irradiance measurements at Summit, Greenland; Barrow, Alaska; and South Pole, Antarctica. Atmos. Chem. Phys., 8, 4799-4810, doi:10.5194/acp-8 -4799-2008. 
_-, G. Manney, V. Fioletov, and J.-U. Grooß, and R. Müller, 2013a: Ozone. Arctic Report Card: Update for 2013, M. O. Jeffries et al., Eds., NOAA Rep., 20-25. [Available online at http://www.arctic.noaa.gov/reportcard/ozone.html.]

—, A. Dahlback, V. Fioletov, A. Heikkilä, B. Johnsen, T. Koskela, K. Lakkala, and T. M. Svendby, 2013b: High levels of ultraviolet radiation observed by ground-based instruments below the 2011 Arctic ozone hole. Atmos. Chem. Phys., 13, 10573-10590, doi:10.5194/acp-13-10573-2013.

Berry, D. I., and E. C. Kent, 2009: A new air-sea interaction gridded dataset from ICOADS with uncertainty estimates. Bull. Amer. Meteor. Soc., 90, 645-656.

— , and - 2011: Air-Sea fluxes from ICOADS: The construction of a new gridded dataset with uncertainty estimates. Int. J. Climatol., 31, 987-1001, doi:10.1002 /joc.2059.

Blake, E., and Coauthors, 2009: Tropical Cyclones of the Eastern North Pacific Basin, 1949-2006. Historical Climatology Series 6-5, NOAA/National Climatic Data Center, 162 pp.

Bodhaine, B. A., B. G. Mendonca, J. M. Harris, and J. M. Miller, 1981: Seasonal variations in aerosols and atmospheric transmission at Mauna Loa Observatory. J. Geophys. Res., 86 (C6), 7395-7398.

Boening, C., J. K. Willis, F. W. Landerer, R. S. Nerem, and J. Fasullo, 2012: The 2011 La Niña: So strong, the oceans fell. Geophys. Res. Lett., 39, L18607, doi:10.1029/2012GL052885.

BoM, 2013: Special Climate Statement 43: Extreme Heat in January 2014. Bureau of Meteorology (Australia), 19 pp. [Available online at http://www.bom.gov.au/climate /current/statements/scs43e.pdf.]

_ 2014: Annual Climate Report 2013. Bureau of Meteorology (Australia), 31 pp. [Available at http://www.bom.gov .au/climate/annual_sum/2013/.]

Bond, T. C., and Coauthors, 2013: Bounding the role of black carbon in the climate system: A scientific assessment. J. Geophys. Res. Atmos., 118, 5380-5552, doi:10.1002 /jgrd.50171.

Böning, C. W., A. Dispert, M. Visbeck, S. R. Rintoul, and F. U. Schwarzkopf, 2008: The response of the Antarctic Circumpolar Current to recent climate change. Nature Geosci., 1, 864-869.

Bonjean, F., and G. Lagerloef, 2002: Diagnostic model and analysis of the surface currents in the tropical Pacific Ocean. J. Phys. Oceanogr., 32, 2938-2954.

Bonsal, B. R., T. D. Prowse, C. R. Duguay, and M. P. Lacroix, 2006: Impacts of large-scale teleconnections on freshwater-ice duration over Canada. J. Hydrol., 330, 340-353.

Boucher, O., and Coauthors, 2013: Clouds and aerosols. Climate Change 2013: The Physical Science Basis. T. F. Stocker et al., Eds., Cambridge University Press, 571-657.
Bowerman, N. H. A., D. J. Frame, C. Huntingford, J. A. Lowe, S. M. Smith, and M. R. Allen, 2013: The role of short-lived climate pollutants in meeting temperature goals. Nature Climate Change, 3, 1021-1024, doi:10.1038/nclimate2034.

Box, J. E., and D. T. Decker, 2011: Greenland marine-terminating glacier area changes: 2000-2010. Ann. Glaciol., 52, 91-98, doi:10.3189/172756411799096312.

— , X. Fettweis, J. C. Stroeve, M. Tedesco, D. K. Hall, and K. Steffen, 2012: Greenland ice sheet albedo feedback: thermodynamics and atmospheric drivers. The Cryosphere, 6, 821-839, doi:10.5194/tc-6-821-2012.

Boyer, T. P., J. I. Antonov, S. Levitus, R. Locarnini, 2005: Linear trends of salinity for the world ocean, 1955-1998. Geophys. Res. Lett., 32, L01604, doi:1029/2004GL021791.

—, S. Levitus, J. Antonov, R. Locarnini, A. Mishonov, H. Garcia, and S. A. Josey, 2007: Changes in freshwater content in the North Atlantic Ocean 1955-2006. Geophys. Res. Lett., 34, L16603, doi:10.1029/2007GL030126.

— , and Coauthors, 2009: Introduction. World Ocean Database 2009, NOAA Atlas NESDIS 66, 216 pp.

—, S. Levitus, J. I. Antonov, J. R. Reagan, C. Schmid, and R. Locarnini, 2012: [Global oceans] Subsurface salinity [in "State of the Climate in 2011"]. Bull. Amer. Meteor. Soc., 93 (7), S72-S75.

— , and Coauthors, 2013a: World Ocean Database 2013. NOAA Atlas NESDIS 72, 209 pp.

—, S. Levitus, J. I. Antonov, J. R. Reagan, C. Schmid, and R. Locarnini, 2013b: [Global oceans] Subsurface salinity [in "State of the Climate in 2012"]. Bull. Amer. Meteor. Soc., 94 (8), S60-S62.

Brasnett, B., 1999: A global analysis of snow depth for numerical weather prediction. J. Appl. Meteor., 38, 726-740.

Broecker, W., and E. Clark, 2001: A dramatic Atlantic dissolution event at the onset of the last glaciation. Geochem. Geophys. Geosys., 2, 1065, doi:10.1029/2001GC000185.

Bromwich, D. H., A. J. Monaghan, and Z. Guo, 2004: Modeling the ENSO modulation of Antarctic climate in the late 1990s with Polar MM5. J. Climate, 17, 109-132.

—, R. L. Fogt, K. I. Hodges, and J. E. Walsh, 2007: A tropospheric assessment of the ERA-40, NCEP, and JRA-25 global reanalyses in the polar regions. J. Geophys. Res., 112, D10111, doi:10.1029/2006JD007859.

_ , J. P. Nicolas, and A. J. Monaghan, 2011: An assessment of precipitation changes over Antarctica and the Southern Ocean since 1989 in contemporary global reanalyses. J. Climate, 24, 4189-4209.

Brown, L. C., and C. R. Duguay, 2010: The response and role of ice cover in lake-climate interactions. Prog. Phys. Geogr., 34, 671-704. 
$\longrightarrow$, and — 2012: Modelling lake ice phenology with an examination of satellite detected sub-grid cell variability. Adv. Meteor., 2012, Article ID 529064, doi:10.1155/2012/529064.

Brugler, E. T., R. S. Pickart, G. W. K. Moore, S. Roberts, T. J. Weingartner, and H. Statscewich, 2014: Seasonal to interannual variability of the Pacific Water boundary current in the Beaufort Sea. Progr. Oceanogr., in press, doi:10.1016/j.pocean.2014.05.002.

Bruhwiler, L. M., and Coauthors, 2014: CarbonTracker$\mathrm{CH}_{4}$ : An assimilation system for estimating emissions of atmospheric methane. Atmos. Chem. Phys. Discuss., 14, 2175-2233, doi:10.5194/acpd-14-2175-2014.

Butchart, N., and E. E. Remsberg, 1986: The area of the stratospheric polar vortex as a diagnostic for tracer transport on an isentropic surface. J. Atmos. Sci., 43, 1319-1339.

Butler, A. H., and L. M. Polvani, 2011: El Niño, La Niña, and stratospheric sudden warmings: A reevaluation in light of the observational record. Geophys. Res. Lett., 38, L13807, doi:10.1029/2011GL048084.

Byrne, R. H., S. Mecking, R. A. Feely, and X. Liu, 2010: Direct observations of basin-wide acidifcation of the North Pacific. Geophys. Res. Lett., 37, L02601, doi:10.1029/2009GL040999.

Caldeira, K., and M. E. Wickett, 2003: Anthropogenic carbon and ocean $\mathrm{pH}$. Nature, 425, 365-365.

Camargo, S. J., K. A. Emanuel, and A. H. Sobel, 2007: Use of a genesis potential index to diagnose ENSO effects on tropical cyclone genesis. J. Climate, 20, 4819-4834.

Campbell, G. G., A. Pope, M. Lazzara, and T. A. Scambos, 2013: The coldest place on Earth: $-90^{\circ} \mathrm{C}$ and below in East Antarctica from Landsat 8 and other thermal sensors. 2013 Fall Meeting, San Francisco, CA, Amer. Geophys. Union, Abstract C21D-0678.

Campbell, J. W., J. M. Blaisdell, and M. Darzi, 1995: Level-3 SeaWiFS data products: Spatial and temporal binning algorithms. NASA Tech. Memo. 104566, Vol. 32, S. B. Hooker et al., Eds., NASA Goddard Space Flight Center, $73 \mathrm{pp}$.

Cappelen, J., 2013: Greenland - DMI Monthly Climate Data Collection 1768-2012, Denmark, The Faroe Islands and Greenland. Dansk Meteorol. Inst. Tech. Rap., 13-04, 75 pp.

Carmack, E., and P. Wassmann, 2006: Food webs and physical-biological coupling on pan-Arctic shelves: Unifying concepts and comprehensive perspectives. Progr. Oceanogr., 71, 446-477, doi:10.1016/j.pocean.2006.10.004.

Carturan, L., and Coauthors, 2013: Decay of a long-term monitored glacier: Careser Glacier (Ortles-Cevedale, European Alps). The Cryosphere, 7, 1819-1838, doi:10.5194 /tc-7-1819-2013.
Cassou, C., 2008: Intraseasonal interaction between the Madden Julian Oscillation and the North Atlantic Oscillation. Nature, 455, 523-527, doi:10.1038/nature07286.

Cavalieri, D. J., C. L. Parkinson, P. Gloersen, and H. Zwally, 2012: Sea ice concentrations from Nimbus-7 SMMR and DMSP SSM/I-SSMIS passive microwave data (19812011). National Snow and Ice Data Center, Boulder, CO, digital media. [Available online at http://nsidc.org/data /nsidc-0051.html].

Cess, R. D., 1983: Arctic aerosols: Model estimates of interactive influences upon the surface-atmosphere clear-sky radiation budget. Atmos. Environ., 17, 2555-2564.

Chehade, W., J. P. Burrows, and M. Weber, 2013: Total ozone trends and variability during 1979-2012 from merged datasets of various satellites. Atmos. Chem. Phys. Discuss., 13, 30407-30452, doi:10.5194/acpd-13-30407-2013.

Chiou, E. W., and Coauthors, 2013: Comparison of profile total ozone from SBUV(v8.6) with GOME-type and ground-based total ozone for 16-yr period (1996 to 2011). Atmos. Meas. Tech. Discuss., 6, 10081-10115, doi:10.5194 lamtd-6-10081-2013.

Christiansen, H. H., and Coauthors, 2010: The thermal state of permafrost in the Nordic area during the International Polar Year. Permafrost Periglacial Processes, 21, 156-181, doi:10.1002/ppp.687.

Christy, J., 2013: [Global climate] Lower tropospheric temperature [in "State of the Climate in 2012"]. Bull. Amer. Meteor. Soc., 94 (8), S13-S15.

- , R. W. Spencer, and W. B. Norris, 2011: The role of remote sensing in monitoring global bulk tropospheric temperatures. Int. J. Remote Sens., 32, 671-685, doi:10.1080 /01431161.2010.517803.

Church, J. A., and Coauthors, 2010: Ocean temperature and salinity contributions to global and regional sea-level change. Understanding Sea-Level Rise and Variability, J. A. Church et al., Eds., Blackwell, pp. 143-176.

_ - and Coauthors, 2011: Revisiting the Earth's sea-level and energy budgets from 1961 to 2008. Geophys. Res. Lett., 38, L18601, doi:10.1029/2011GL048794.

—, N. J. White, C. M. Domingues, D. P. Monselesan, and E. R. Miles, 2013: Sea-level and ocean heat-content change. Ocean Circulation and Climate: A 21st Century Perspective, G. Siedler et al. Eds., International Geophysics Series, Vol. 103, Academic Press, 697-725.

Ciais, P., and Coauthors, 2013: Carbon and other biogeochemical cycles. Climate Change 2013: The Physical Science Basis, T. R. Stocker et al., Eds., Cambridge University Press, 465-570.

Clarke, A. D., and K. J. Noone, 1985: Soot in the Arctic snowpack: A cause for perturbations in radiative transfer. Atmos. Environ., 19, 2045-2053. 
Clement, D., and N. Gruber, 2014: A C*-based extended multiple linear regression method to determine decadal changes in anthropogenic $\mathrm{CO}_{2}$ in the ocean. 2014 Ocean Sciences Meeting, Honolulu, HI, ALSO/AGU/TOS, Poster ID 2447. [Available online at http://www.sgmeet.com /osm2014/viewabstract.asp?abstractid=17196.]

Clerbaux, C., and Coauthors, 2009: Monitoring of atmospheric composition using the thermal infrared IASI/ MetOp sounder. Atmos. Chem. Phys., 9, 6041-6054, doi:10.5194/acp- 9-6041-2009.

Cohen, J., J. Jones, J. C. Furtado, and E. Tziperman, 2013: Warm Arctic, cold continents: A common pattern related to Arctic sea ice melt, snow advance, and extreme winter weather. Oceanography, 26 (4), 150-160, doi:10.5670 /oceanog.2013.70.

Colwell, S., L. M. Keller, and M. A. Lazzara, 2013: [Antarctica] Surface manned and automatic weather station observations [in "State of the Climate in 2012"]. Bull. Amer. Meteor. Soc., 94 (8), S135-S137.

Compo, G. P., and Coauthors, 2011: The Twentieth Century Reanalysis Project. Quart. J. Roy. Meteor. Soc., 137, 1-28, doi:10.1002/qj.776.

Cooley, S. R., and S. C. Doney, 2009: Anticipating ocean acidification's economic consequences for commercial fisheries. Environ. Res. Lett., 4, 024007, doi:10.1088/1748 $-9326 / 4 / 2 / 024007$.

Cooper, O., and J. Ziemke, 2013: [Global climate] Tropospheric ozone [in "State of the Climate in 2012"]. Bull. Amer. Meteor. Soc., 94 (8), S38-S39.

Cowtan, K., and R. G. Way, 2013: Coverage bias in the HadCRUT4 temperature series and its impact on recent temperature trends. Quart. J. Roy. Meteor. Soc., in press, doi:10.1002/qj.2297.

Cunningham, S. A., and Coauthors, 2013: Atlantic Meridional Overturning Circulation slowdown cooled the subtropical ocean. Geophys. Res. Lett., 40, 6202-6207, doi:10.1002/2013GL058464.

Curry, R., R. Dickson, and I. Yashayaev, 2003: A change in the freshwater balance of the Atlantic Ocean over the past four decades. Nature, 426, 826-829.

Curtis, S., and R. Adler, 2000: ENSO indexes based on patterns of satellite-derived precipitation. J. Climate, 13, 2786-2793.

Dadaser-Celik, F., and E. Cengiz, 2013: Wind speed trends over Turkey from 1975 to 2006. Int. J. Climatol., 34, 1913-1927, doi:10.1002/joc.3810.

Dai, A., 2006: Recent climatology, variability, and trends in global surface humidity. J. Climate, 19, 3589-3606.

— , J. Wang, P. W. Thorne, D. E. Parker, L. Haimberger, and X. L. Wang, 2011: A new approach to homogenize daily radiosonde humidity data. J. Climate, 24, 965-991.
Daniel, J. S., and Coauthors, 2011: A focus on information for policymakers. Scientific Assessment of Ozone Depletion: 2010. Global Ozone Research and Monitoring Project Rep. 52, World Meteorological Organization, 5.1-5.56.

Davidson, E. A., 2009: The contribution of manure and fertilizer nitrogen to atmospheric nitrous oxide since 1860 . Nature Geosci., 2, 659-662, doi:10.1038/NGEO608.

De Jeu, R., W. Dorigo, W. Wagner, and Y. Liu, 2011: [Global climate] Soil moisture [in "State of the Climate in 2010"]. Bull. Amer. Meteor. Soc., 92 (6), S52-S53.

_ - _ R. M. Parinussa, W. Wagner, and D. Chung, 2012a: [Global climate] Building a climate record of soil moisture from historical satellite observations [in "State of the Climate in 2011"]. Bull. Amer. Meteor. Soc., 93 (7), S32-S33.

$\ldots, \ldots, \ldots$, W. Wagner, and D. Chung, 2012b: [Global climate] Soil moisture [in "State of the Climate in 2011"]. Bull. Amer. Meteor. Soc., 93 (7), S30-S34.

Dee, D. P., and Coauthors, 2011: The ERA-Interim reanalysis: Configuration and performance of the data assimilation system. Quart. J. Roy. Meteor. Soc., 137, 553-597, doi:10.1002/qj.828.

Deeter, M. N., 2011: MOPITT (Measurements of Pollution in the Troposphere) Version 5 Product User's Guide. National Center for Atmospheric Research, 12 pp. [Available online at https://www2.acd.ucar.edu/sites/default/files /mopitt/v5_users_guide_beta.pdf.]

— product: Algorithm enhancements, validation, and long-term stability. J. Geophys. Res., 115, D07306, doi:10.1029/2009JD013005.

Delworth, T. L., and M. E. Mann, 2000: Observed and simulated multi-decadal variability in the Northern Hemisphere. Climate Dyn., 16, 661-676.

Derksen, C., and R. Brown, 2012: Spring snow cover extent reductions in the 2008-2012 period exceeding climate model projections. Geophys. Res. Lett., 39, L19504, doi:10.1029/2012GL053387.

Deser, M., A. Alexander, S. P. Xie, and A. S. Phillips, 2010: Sea surface temperature variability: Patterns and mechanisms. Ann. Rev. Mar. Sci., 2, 115-143.

Dewitte, S., D. Crommelynck, and A. Joukof, 2004: Total solar irradiance observations from DIARAD/VIRGO. J. Geophys. Res., 109, A02102, doi:10.1029/2002JA009694.

Di Girolamo, L., A. Menzies, G. Zhao, K. Mueller, C. Moroney, and D. J. Diner, 2010: Multi-angle imaging spectroradiometer level 3 cloud fraction by altitude algorithm theoretical basis document. JPL Publ. D-62358, Jet Propulsion Laboratory, 23 pp.

Diamond, H. J., Ed., 2012: Tropics [in "State of the Climate in 2011”]. Bull. Amer. Meteor. Soc., 93 (7), S93-S125. 
— Ed., 2013: Tropics [in "State of the Climate in 2012"]. Bull. Amer. Meteor. Soc., 94 (8), S79-S110.

—, A. M. Lorrey, K. R. Knapp, and D. H. Levinson, 2012: Development of an enhanced tropical cyclone tracks database for the southwest Pacific from 1840-2011. Int. J. Climatol., 32, 2240-2250, doi:10.1002/joc.2412.

Dlugokencky, E. J., E. G. Nisbet, R. Fisher, and D. Lowry, 2011: Global atmospheric methane: Budget, changes and dangers. Philos. Trans. Roy. Soc. London, Ser. A, 369 (1943), 2058-2072, doi:10.1098/rsta.2010.0341.

Doherty, R. M., D. S. Stevenson, C. E. Johnson, W. J. Collins, and M. G. Sanderson, 2006: Tropospheric ozone and El Niño-Southern Oscillation: Influence of atmospheric dynamics, biomass burning emissions, and future climate change. J. Geophys. Res., 111, D19304, doi:10.1029/2005JD006849.

Doherty, S. J., S. G. Warren, T. C. Grenfell, A. D. Clarke, and R. E. Brandt, 2010: Light absorption from impurities in Arctic snow. Atmos. Chem. Phys., 10, 11647-11680.

Domingues, C. M., J. A. Church, N. J. White, P. J. Gleckler, S. E. Wijffels, P. M. Barker, and J. R. Dunn, 2008: Improved estimates of upper-ocean warming and multi-decadal sea-level rise. Nature, 453, 1090-1093, doi:10.1038/nature07080.

Donat, M. G., and Coauthors, 2013a: Updated analyses of temperature and precipitation extreme indices since the beginning of the twentieth century: The HadEX2 dataset. J. Geophys. Res. Atmos., 118, doi:10.1002/jgrd.50150.

—, L. V. Alexander, H. Yang, I. Durre, R. Vose, and J. Caesar, 2013b: Global land-based datasets for monitoring climatic extremes. Bull. Amer. Meteor. Soc., 94, 997-1006, doi:10.1175/BAMS-D-12-00109.

Doney, S. C., V. J. Fabry, R. A. Feely, and J. A. Kleypas, 2009: Ocean acidification: The other $\mathrm{CO}_{2}$ problem. Ann. Rev. Mar. Sci., 1, 169-192.

Dong, S., S. L. Garzoli, M. O. Baringer, C. S. Meinen, and G. J. Goni, 2009: Interannual variation in the Atlantic meridional overturning circulation and its relationship with the net northward heat transport in the South Atlantic. Geophys. Res. Lett., 36, L20606, doi:10.1029/2009GL039356.

Dore, J. E., R. Lukas, D. W. Sadler, M. J. Church, and D. M. Karl, 2009: Physical and biogeochemical modulation of ocean acidification in the central North Pacific. Proc. Natl. Acad. Sci. USA, 106, 12235-12240.

Dorigo, W., R. De Jeu, D. Chung, R. Parinussa, Y. Liu, W. Wagner, D. Fernandez-Prieto, 2012: Evaluating global trends (1988-2010) in homogenized remotely sensed surface soil moisture. Geophys. Res. Lett., 39, L18405, doi:10.1029/2012GL052988.
Drumond, A., L. Gimeno, and R. Nieto, 2011: On the contribution of the tropical Western Hemisphere Warm Pool source of moisture to the Northern Hemisphere precipitation through a Lagrangian approach. J. Geophys. Res., 116, D00Q04, doi:10.1029/2010JD015397.

Duguay, C. R., T. D. Prowse, B. R. Bonsal, R. D. Brown, M. P. Lacroix, and P. Ménard, 2006: Recent trends in Canadian lake ice cover. Hydrol. Processes, 20, 781-801.

_- L. Brown, K.-K. Kang, and H. Kheyrollah Pour, 2013: [The Arctic] Lake ice [in "State of the Climate in 2012"]. Bull. Amer. Meteor. Soc., 94 (8), S124-S126.

Dunn, R. J. H., K. M. Willett, P. W. Thorne, E. V. Woolley, I. Durre, A. Dai, D. E. Parker, and R. S. Vose, 2012: HadISD: A quality-controlled global synoptic report database for selected variables at long-term stations from 1973-2011. Climate Past, 8, 1649-1679.

Durack, P. J., and S. E. Wijffels, 2010: Fifty-year trends in global ocean salinities and their relationship to broadscale warming. J. Climate, 23, 4342-4362.

$\longrightarrow$, _ strong global water cycle intensification during 1950 to 2000. Science, 336, 455-458.

Durre, I., M. J. Menne, B. E. Gleason, T. G. Houston, and R. S. Vose, 2010: Comprehensive automated quality assurance of daily surface observations. J. Appl. Meteor. Climatol., 49, 1615-1633.

Dutton, E. G., 1992: A coherence between the QBO and the amplitude of the Mauna Loa atmospheric transmission annual cycle. Int. J. Climatol., 12, 383-396.

_ , 2012: [Global climate] Long-term changes of atmospheric solar transmission [in "State of the Climate in 2011”]. Bull. Amer. Meteor. Soc., 93 (7), S50.

— , and B. A. Bodhaine, 2001: Solar irradiance anomalies caused by clear-sky transmission variations above Mauna Loa: 1958-1999. J. Climate, 14, 3255-3262.

_ J. J. Deluisi, and A. P. Austring, 1985: Interpretation of Mauna Loa atmospheric transmission relative to aerosols, using photometric precipitable water amounts. J. Atmos. Chem., 3, 53-68.

Dvorak, V. F., 1984: Tropical cyclone intensity analysis using satellite data. NOAA Tech. Rep. 11, 45 pp. [Available online at ftp://satepsanone.nesdis.noaa.gov/Publications /Tropical/Dvorak_1984.pdf.]

Ebita, A., and Coauthors, 2011: The Japanese 55-year Reanalysis "JRA-55": An interim report. SOLA, 7, 149-152, doi:10.2151/sola.2011-038.

ECMWF, cited 2013: Smoke affecting Singapore [Available online at http://gmes-atmosphere.eu/news /singapore_smoke/.]

Ellis, H. T., and R. F. Pueschel, 1971: Solar radiation: Absence of air pollution trends at Mauna Loa. Science, 172, 845-846. 
Elverhoi, H., 2013: 2013 Glacier length change table. Norwegian Water Resources and Energy Directorate. [Available online at http://www.nve.no/Global/Vann\%20og $\% 20$ vassdrag/Hydrologi/Bre/Nedlastinger/Length _Change_Table_2000-2013.pdf?epslanguage=en.]

Emanuel, K., and D. S. Nolan, 2004: Tropical cyclone activity and the global climate system. Proc. 26th Conf. on Hurricanes and Tropical Meteor., Amer. Meteor. Soc., 10A.2, 240-241.

Enfield, D. B., and A. M. Mestas-Nuñez, 1999: Multi-scale variabilities in global sea surface temperatures and their relationships with tropospheric climate patterns. J. Climate, 12, 2719-2733.

— _ _ , and P. J. Trimble, 2001: The Atlantic Multidecadal Oscillation and its relationship to rainfall and river flows in the continental US. Geophys. Res. Lett., 28, 2077-2080.

England, M. H., and F. Huang, 2005: On the interannual variability of the Indonesian Throughflow and its linkage with ENSO. J. Climate, 18, 1435-1444.

_ , and Coauthors, 2014: Recent intensification of winddriven circulation in the Pacific and the ongoing warming hiatus. Nature Climate Change, 4, 222-227, doi:10.1038 /nclimate2106.

Esaias, W. E., and Coauthors, 1998: An overview of MODIS capabilities for ocean science observations. IEEE Trans. Geosci. Remote Sens., 36, 1250-1265.

Estilow, T., and Coauthors, updated 2013: Snow cover extent (Northern Hemisphere) climate data record, by Rutgers. NCAR/UCAR, Boulder, CO, digital media. [Available online at https://climatedataguide.ucar.edu/climate-data /snow-cover-extent-northern-hemisphere-climate-data -record-rutgers.]

European Space Agency, 2012: Report for Mission Selection: Biomass. ESA SP 1324/1, 193 pp. [Available online at https://earth.esa.int/web/guest/document-library/browse -document-library/-/article/biomass-report-for-mission -selection-an-earth-explorer-to-observe-forest-biomass.]

Fabry, V. J., B. A. Seibel, R. A. Feely, and J. C. Orr, 2008: Impacts of ocean acidification on marine fauna and ecosystem processes. Ices J. Marine Sci., 65, 414-432.

_ , J. B. McClintock, J. T. Mathis, and J. M. Grebmeier, 2009: Ocean acidification at high latitudes: The bellwether. Oceanography, 22 (4), 160-171.

Farfán, L. M., R. Romero-Centeno, and G. B. Raga, 2012: Observations and forecast of landfall of tropical cyclones John, Lane and Paul (2006) on northwestern Mexico. Wea. Forecasting, 27, 1373-1393.

Fasullo, J. T., C. Boening, F. W. Landerer, and R. S. Nerem, 2013: Australia's unique influence on global sea level in 2010-2011. Geophys. Res. Lett., 40, 4368-4373, doi:10.1002/grl.50834.
Feely, R. A., S. C. Doney, and S. R. Cooley, 2009: Ocean acidification: Present conditions and future changes in a high- $\mathrm{CO}_{2}$ world. Oceanography, 22 (4), 36-47.

Fekete, B. M., U. Looser, and R. D. Robarts, 2012: Rationale for monitoring discharge on the ground. J. Hydrometeor., 13, 1977-1986.

Feng, W., M. Zhong, J.-M. Lemoine, R. Biancale, H.-T. Hsu, and J. Xia, 2013: Evaluation of groundwater depletion in North China using the Gravity Recovery and Climate Experiment (GRACE) data and ground-based measurements. Water Resour. Res., 49, 2110-2118, doi:10.1002 /wrcr.20192.

Fioletov, V. E., G. E. Bodeker, A. J. Miller, R. D. McPeters, and R. Stolarski, 2002: Global and zonal total ozone variations estimated from ground-based and satellite measurements: 1964-2000. J. Geophys. Res., 107 (D22), 4647, doi:10.1029/2001JD001350.

— , and Coauthors, 2008: The performance of the groundbased total ozone network assessed using satellite data. J. Geophys. Res., 113, D14313, doi:10.1029/2008JD009809.

Flanner, M. G., C. S. Zender, P. G. Hess, N. M. Mahowald, T. H. Painter, V. Ramanathan, and P. J. Rasch, 2009: Springtime warming and reduced snow cover from carbonaceous particles. Atmos. Chem. Phys., 9, 2481-2497, doi:10.5194/acp-9-2481-2009.

Fleming, E. L., C. H. Jackman, R. S. Stolarski, and A. R. Douglass, 2011: A model study of the impact of source gas changes on the stratosphere for 1850-2100. Atmos. Chem. Phys., 11, 8515-8541, doi:10.5194/acp-11-8515-2011.

Flemming, J., A. Inness, H. Flentje, V. Huijnen, P. Moinat, M. G. Schultz, and O. Stein, 2009: Coupling global chemistry transport models to ECMWF's integrated forecast system. Geosci. Model Dev., 2, 253-265, doi:10.5194 /gmd-2-253-2009.

Fofonoff, N. P., and E. L. Lewis, 1979: A practical salinity scale. J. Oceanogr. Soc. Japan, 35, 63-64, doi:10.1007 /BF02108283.

Fogt, R. L., D. H. Bromwich, and K. M. Hines, 2011: Understanding the SAM influence on the South Pacific ENSO teleconnection. Climate Dyn., 36, 1555-1576, doi:10.1007 /s00382-010-0905-0.

Folland, C. K., J. Knight, H. W. Linderholm, D. Fereday, S. Ineson, and J. W. Hurrell, 2009: The summer North Atlantic oscillation: Past, present and future. J. Climate, 22, 1082-1103.

Foster, M. J., and A. Heidinger, 2013: PATMOS-x: Results from a diurnally corrected 30 -yr satellite cloud climatology. J. Climate, 26, 414-425.

Francis, J. A., and S. J. Vavrus, 2012: Evidence linking Arctic amplification to extreme weather in mid-latitudes. Geophys. Res. Lett., 39, L06801, doi:10.1029/2012GL051000. 
Franz, B. A., M. J. Behrenfeld, D. A. Siegel, and P. J. Werdell, 2013: [Global oceans] Global ocean phytoplankton [in "State of the Climate in 2012"]. Bull. Amer. Meteor. Soc., 94 (8), S75-S78.

Free, M., D. J. Seidel, J. K. Angell, J. R. Lanzante, I. Durre, and T. C. Peterson, 2005: Radiosonde Atmospheric Temperature Products for Assessing Climate (RATPAC): A new dataset of large-area anomaly time series. J. Geophys. Res., 110, D22101, doi:10.1029/2005JD006169.

Friis, K., A. Körtzinger, J. Pätsch, and D. W. R. Wallace, 2005: On the temporal increase of anthropogenic $\mathrm{CO}_{2}$ in the subpolar North Atlantic. Deep-Sea Res. I, 52, 681-698.

Frossard, L., H. E. Rieder, M. Ribatet, J. Staehelin, J. A. Maeder, S. Di Rocco, A. C. Davison, and T. Peter, 2013: On the relationship between total ozone and atmospheric dynamics and chemistry at mid-latitudes - Part 1: Statistical models and spatial fingerprints of atmospheric dynamics and chemistry. Atmos. Chem. Phys., 13, 147-164, doi:10.5194/acp-13-147-2013.

Gardner, A. S., and Coauthors, 2011: Sharp acceleration of mass loss from Canadian Arctic Archipelago glaciers and ice caps. Nature, 473, 357-360.

— contributions to sea level rise: 2003 to 2009. Science, 340, 852-857.

Garrett, T. J., and C. Zhao, 2006: Increased Arctic cloud longwave emissivity associated with pollution from midlatitudes. Nature, 440, 787-789.

Garzoli, S. L., M. O. Baringer, S. Dong, R. C. Perez, and Q. Yao, 2012: South Atlantic meridional fluxes. Deep-Sea Res. II, 71, 21-32, doi:10.1016/j.dsr.2012.09.003.

Gattuso, J.-P., and L. Hansson, Eds., 2011: Ocean Acidification. Oxford University Press, $326 \mathrm{pp}$.

GCOS, 2003: The second report on the adequacy of the global observing systems for climate in support of the UNFCCC. GCOS-82 (WMO/TD no. 1143). World Meteorological Organization, $74 \mathrm{pp}$. [Available online at http://www .wmo.int/pages/prog/gcos/Publications/gcos-82_2AR .pdf.]

_ 2010: Implementation plan for the global observing system for climate in support of the UNFCCC (2010 Update). GCOS-138 (GOOS-184, GTOS-76, WMO-TD/ No. 1523). World Meteorological Organization, 180 pp. [Available online at http://www.wmo.int/pages/prog/gcos /Publications/gcos-138.pdf.]

George, M., and Coauthors, 2009: Carbon monoxide distributions from the IASI/METOP mission: Evaluation with other space-borne remote sensors. Atmos. Chem. Phys., 9, 8317-8330, doi:10.5194/acp-9-8317-2009.
Giglio, L., J. T. Randerson, G. R. van der Werf, P. S. Kasibhatla, G. J. Collatz, D. C. Morton, and R. S. DeFries, 2010: Assessing variability and long-term trends in burned area by merging multiple satellite fire products. Biogeosciences, 7, 1171-1186.

Gillett, N. P., and Coauthors, 2011: Attribution of observed changes in stratospheric ozone and temperature. Atmos. Chem. Phys., 11, 599-609, doi:10.5194/acp-11-599-2011.

Gobron, N., and M. Robustelli, 2013: Monitoring the state of the global terrestrial surfaces. Proc. 2013 ESA Living Planet Symposium, Edinburgh, UK, European Space Agency, SP-722.

—, A. S. Belward, B. Pinty, and W. Knorr, 2010: Monitoring biosphere vgetation 1998-2009. Geophys. Res. Lett., 37, L15402, doi:10.1029/2010GL043870.

Goldenberg, S. B., C. W. Landsea, A. M. Mestas-Nuñez, and W. M. Gray, 2001: The recent increase in Atlantic hurricane activity: Causes and implications. Science, 293, 474-479.

Goni, G., and I. Wainer, 2001: Investigation of the Brazil Current front dynamics from altimeter data. J. Geophys. Res., 106 (C12), 31 117-31 128.

— in the North Brazil Current retroflection region using satellite altimetry. Interhemispheric Water Exchange in the Atlantic Ocean, G. J. Goni and P. Malanotte-Rizzoli, Eds., Elsevier Oceanographic Series, Vol. 68, Elsevier, 335-356.

—, and J. A. Trinanes, 2003: Ocean thermal structure monitoring could aid in the intensity forecast of tropical cyclones. Eos, Trans. Amer. Geophys. Union, 84, 573-578.

—, S. Kamholz, S. Garzoli, and D. Olson, 1996: Dynamics of the Brazil-Malvinas confluence based on inverted echo sounders and altimetry. J. Geophys. Res., 101 (C7), 16273-16289.

—, S. L. Garzoli, A. J. Roubicek, D. B. Olson, and O. B. Brown, 1997: Agulhas ring dynamics from TOPEX/ POSEIDON satellite altimeter data. J. Mar. Res., 55, 861-883.

— - and Coauthors, 2009: Applications of satellite-derived ocean measurements to tropical cyclone intensity forecasting. Oceanography, 22 (3), 176-183.

— , F. Bringas, and P. N. Di Nezio, 2011: Observed low frequency variability of the Brazil Current front. J. Geophys. Res., 116, C10037, doi:10.1029/2011JC007198.

_, J. A. Knaff, and I-I Lin, 2013: [Tropics] Tropical cyclone heat potential [in "State of the Climate in 2012"]. Bull. Amer. Meteor. Soc., 94 (8), S99-S101.

González-Dávila, M., J. M. Santana-Casiano, M. J. Rueda, and O. Llinas, 2010: The water column distribution of carbonate system variables at the ESTOC site from 1995 to 2004. Biogeosciences, 7, 3067-3081. 
Good, S. A., M. J. Martin, and N. A. Rayner, 2013: EN4: Quality controlled ocean temperature and salinity profiles and monthly objective analyses with uncertainty estimates. J. Geophys. Res. Oceans, 118, 6704-6716, doi:10.1002/2013JC009067.

Gouretski, V., and F. Reseghetti, 2010: On depth and temperature biases in bathythermograph data: Development of a new correction scheme based on analysis of a global ocean database. Deep-Sea Res. I, 57, 812-833, doi:10.1016/j .dsr.2010.03.0111.

Granier, C., and Coauthors, 2011: Evolution of anthropogenic and biomass burning emissions of air pollutants at global and regional scales during the 1980-2010 period. Climatic Change, 109, 163-190, doi:10.1007/s10584-011-0154-1.

Guard, C., and M. A. Lander, 2012: [Regional climates: Oceania] Northwest Pacific, Micronesia [in "State of the Climate in 2011"]. Bull. Amer. Meteor. Soc., 93 (7), S215-S218.

Guglielmin, M., and N. Cannone, 2012: A permafrost warming in a cooling Antarctica? Climatic Change, 111, 177-195.

— , M. R. Worland, F. Baio, and P. Convey, 2014a: Permafrost and snow monitoring at Rothera Point (Adelaide Island, MaritimeAntarctica): Implications for rock weathering in cryotic conditions. Geomorphology, in press, doi:10.1016/j.geomorph.2014.03.051.

—, M. Dalle Fratte, and N. Cannone, 2014b: Permafrost warming and vegetation changes in continental Antarctica. Environ. Res. Lett., 9, 045001, doi:10.1088/17489326/9/4/045001.

Haeberli, W., J. Cihlar, and R. Barry, 2000: Glacier monitoring within the Global Climate Observing System. Ann. Glaciol, 31, 241-246.

— , and Coauthors, 2010: Mountain permafrost - development and challenges of a young research field. J. Glaciol., 56, 1043-1058.

Haimberger, L., C. Tavolato, and S. Sperka, 2012: Homogenization of the global radiosonde temperature dataset through combined comparison with reanalysis background series and neighboring stations. J. Climate, 25, 8108-8131.

Häkkinen, S., P. B. Rhines, and D. L. Worthen, 2013: Northern North Atlantic sea surface height and ocean heat content variability. J. Geophys. Res., 118, 3670-3678, doi:10.1002/jgrc.20268.

Hamlington, B. D., R. R. Leben, M. W. Strassburg, R. S. Nerem, and K.-Y. Kim, 2013: Contribution of the Pacific Decadal Oscillation to global mean sea level trends. Geophys. Res. Lett., 40, 5171-5175, doi:10.1002/grl.50950.

Hansen, J., and L. Nazarenko, 2004: Soot climate forcing via snow and ice albedos. Proc. Natl. Acad. Sci. USA, 101, 423-428.
_- and Coauthors, 2005: Efficacy of climate forcings. J. Geophys. Res., 110, D18104, doi:10.1029/2005JD005776.

—, R. Ruedy, M. Sato, and K. Lo, 2010: Global surface temperature change. Rev. Geophys., 48, RG4004, doi:10.1029/2010RG000345.

Hartmann, D. L., and Coauthors, 2013: Observations: Atmosphere and surface. Climate Change 2013: The Physical Science Basis, T. F. Stocker et al., Eds., Cambridge University Press, 159-254.

Haylock, M. R., N. Hofstra, A. M. G. Klein Tank, E. J. Klok, P. D. Jones, and M. New, 2008: A European daily high-resolution gridded dataset of surface temperature and precipitation. J. Geophys. Res., 113, D20119, doi:10.1029/2008JD10201.

Heidinger, A. K., M. J. Foster, A. Walther, and X. Zhao, 2013: The Pathfinder Atmospheres Extended (PATMOS-x) AVHRR climate data set. Bull. Amer. Meteor. Soc., 95, 909-922, doi:10.1175/BAMS-D-12-00246.1.

Held, I. M., and B. J. Soden, 2006: Robust response of the hydrological cycle to global warming. J. Climate, 19, 5686-5699.

Helfrich, S. R., D. McNamara, B. H. Ramsay, T. Baldwin, and T. Kasheta, 2007: Enhancements to, and forthcoming developments in the Interactive Multisensor Snow and Ice Mapping System (IMS). Hydrol. Processes, 21, 1576-1586.

Helm, K. P., N. L. Bindoff, and J. A. Church, 2010: Changes in the global hydrological-cycle inferred from ocean salinity. Geophys. Res. Lett., 37, L18701, doi:10.1029/2010GL044222.

Hendon, H., C. Zhang, and J. Glick, 1999: Interannual variation of the Madden-Julian Oscillation during austral summer. J. Climate, 12, 2538-2550.

Herman, J. R., and Coauthors, 2013: A net decrease in the Earth's cloud, aerosol, and surface $340 \mathrm{~nm}$ reflectivity during the past $33 \mathrm{yr}$ (1979-2011). Atmos. Chem. Phys., 13, 8505-8524, doi:10.5194/acp-13-8505-2013.

Hess, P. G., and R. Zbinden, 2013: Stratospheric impact on tropospheric ozone variability and trends: 1990-2009. Atmos. Chem. Phys., 13, 649-674.

Hilburn, K. A. and F. J. Wentz, 2008: Intercalibrated passive microwave rain products from the unified microwave ocean retrieval algorithm (UMORA). J. Appl. Meteor. Climatol., 47, 778-794.

Ho, S.-P., Y.-H. Kuo,W. Schreiner, and X. Zhou, 2010a: [Global climate] Using SI-traceable global positioning system radio occultation measurements for climate monitoring [in "State of the Climate in 2009"]. Bull. Amer. Meteor. Sci., 91 (7), S36-S37.

—, X. Zhou, Y.-H. Kuo, D. Hunt, and J.-H. Wang, 2010b: Global evaluation of radiosonde water vapor systematic biases using GPS radio occultation from COSMIC and ECMWF analysis. Remote Sens., 2, 1320-1330. 
Hobbs, W., and J. K. Willis, 2012: Estimates of North Atlantic heat transport from satellite and drifter data. J. Geophys. Res., 17, C01008, doi:10.1029/2011JC007039.

Hoeke, R. K., K. L. McInnes, J. Kruger, R. McNaught, J. Hunter, and S. Smithers, 2013: Widespread inundation of Pacific islands triggered by distant-source wind-waves. Global Planet. Change, 108, 128-138.

Hoerling, M. P., J. W. Hurrell, T. Xu, G. T. Bates, and A. S. Phillips, 2004: Twentieth century North Atlantic climate change. Part II: Understanding the effect of Indian Ocean warming. Climate Dyn., 23, 391-405.

Hofmann, D. J., and S. A. Montzka, 2009: Recovery of the ozone layer. Eos, Trans. Amer. Geophys. Union, 90, 1-2, doi:10.1029/2009EO010001.

— , J. H. Butler, E. J. Dlugokencky, J. W. Elkins, K. Masarie, S. A. Montzka, and P. Tans, 2006:. The role of carbon dioxide in climate forcing from 1979 to 2004: Introduction of the Annual Greenhouse Gas Index. Tellus, 58B, 614-619. [Updated annually at http://www.esrl.noaa.gov /gmd/aggi.]

Hosoda, S., T. Suga, N. Shikama, and K. Mizuno, 2009: Global surface layer salinity change detected by Argo and its implication for hydrological cycle intensification. J. Oceanogr., 65, 579-586, doi:10.1007/s10872-009-0049-1.

Hu, Z.-Z., A. Kumar, B. Huang, Y. Xue, W. Wang, and B. Jha, 2011: Persistent atmospheric and oceanic anomalies in the North Atlantic from summer 2009 to summer 2010. J. Climate, 24, 5812-5830.

,-- , H.-L. Ren, H. Wang, M. L'Heureux, and F.-F. Jin, 2013: Weakened interannual variability in the tropical Pacific Ocean since 2000. J. Climate, 26, 2601-2613.

Huang, C.-Y., W.-H. Teng, S.-P. Ho, Y. H. Kuo, 2013: Global variation of COSMIC precipitable water over land: Comparisons with ground-based GPS measurements and NCEP reanalyses. Geophys. Res. Lett., 40, 5327-5331, doi:10.1002/grl.50885.

Huffman, G. J., R. F. Adler, D. T. Bolvin, and G. Gu, 2009: Improving the global precipitation record: GPCP Version 2.1. Geophys. Res. Lett., 36, L17808, doi:10.1029/2009GL040000.

— , D. T. Bolvin, and R. F. Adler, updated 2012: GPCP version 2.2 SG combined precipitation data set. World Data Center for Meteorology, Asheville, NC, digital media. [Available online at http://www.ncdc.noaa.gov/oa/wmo /wdcamet-ncdc.html.]

Hurst, D. F., and K. H. Rosenlof, 2013: [Global climate] Stratospheric water vapor [in "State of the Climate in 2012”]. Bull. Amer. Meteor. Soc., 94 (8), S37-S41.
—, A. Lambert, W. G. Read, S. M. Davis, K. H. Rosenlof, E. G. Hall, A. F. Jordan, and S. J. Oltmans, 2014: Validation of Aura Microwave Limb Sounder stratospheric water vapor measurements by the NOAA frost point hygrometer. J. Geophys. Res. Atmos., 119, doi:10.1002/2013JD020757.

Ialongo, I., A. Arola, J. Kujanpää, and J. Tamminen, 2011: Use of satellite erythemal UV products in analysing the global UV changes. Atmos. Chem. Phys., 11, 9649-9658, doi:10.5194/acp-11-9649-2011.

ICIMOD, cited 2013: Students learn glacier mass balance measurement. International Centre for Integrated Mountain Development. [Available online at http://www .icimod.org/?q=12401.]

IGOS, 2007: Integrated Global Observing Strategy Cryosphere Theme Report - For the Monitoring of our Environment from Space and from Earth. World Meteorological Organization, WMO/TD-No. 1405, 100 pp.

Ingleby, B., and M. Huddleston, 2007: Quality control of ocean temperature and salinity profiles - historical and real-time data. J. Marine Sys., 65, 158-175, doi:10.1016/j .jmarsys.2005.11.019.

Inness, A., and Coauthors, 2013: The MACC reanalysis: An 8 -yr data set of atmospheric composition. Atmos. Chem. Phys., 13, 4073-4109, doi:10.5194/acp-13-4073-2013.

INPE, cited 2014: Projeto PRODES: Monitoramento da Floresta Amazônia Brasileira por Sátelite (in Portuguese). Instituto Nacional de Pesquisas Espaciais [Brazil]. [Available online at http://www.obt.inpe.br/prodes/index.php.]

Intrieri, J. M., C. W. Fairall, M. D. Shupe, P. O. G. Persson, E. L. Andreas, P. S. Guest, and R. E. Moritz, 2002: An annual cycle of Arctic surface cloud forcing at SHEBA. J. Geophys. Res., 107, 8039, doi:10.1029/2000JC000439.

Isaksen, K., J. L. Sollid, P. Holmlund, and C. Harris, 2007: Recent warming of mountain permafrost in Svalbard and Scandinavia. J. Geophys. Res., 112, F02S04, doi:10.1029/2006JF000522.

— in southern Norway: Spatial and temporal variability of mean ground temperatures, 1999-2009. Permafrost Periglacial Processes, 22, 361-377, doi:10.1002/ppp.728.

Ishidoya, S., S. Aoki, D. Goto, T. Nakazawa, S. Taguchi, and P. K. Patra, 2012: Time and space variations of $\mathrm{O}_{2} / \mathrm{N}_{2}$ ratio in the troposphere over Japan and estimation of the global $\mathrm{CO}_{2}$ budget for the period 2000-2010. Tellus, 64B, 18964, doi:10.3402/tellusb.v64i0.18964.

Ishihara, K., 2006: Calculation of global surface temperature anomalies with COBE-SST, (in Japanese). Sokkō-jihō [Weather Service Bull.], 73 Special Issue, S19-S25.

Ishii, M., and M. Kimoto, 2009: Revaluation of historical ocean heat content variations with time-varying XBT and MBT depth bias corrections. J. Oceanogr., 65, 287-299, doi:10.1007/s10872-009-0027-7. 
Jacob, T., J. Wahr, W. T. Pfeffer, and S. Swenson, 2012: Recent contributions of glaciers and ice caps to sea level rise. Nature, 482, 514-518.

Jacobson, M. Z., 2010: Short-term effects of controlling fossilfuel soot, biofuel soot and gases, and methane on climate, Arctic ice, and air pollution health. J. Geophys. Res., 115, D14209, doi:10.1029/2009JD013795.

James, M., A. G. Lewkowicz, S. L. Smith, and C. M. Miceli, 2013: Multi-decadal degradation and persistence of permafrost in the Alaska Highway corridor, northwest Canada. Environ. Res. Lett., 8, 045013, doi:10.1088/1748 $-9326 / 8 / 4 / 045013$.

Janowiak, J. E., and P. Xie, 1999: CAMS-OPI: A global satellite-rain gauge merged product for real-time precipitation monitoring applications. J. Climate, 12, 3335-3342.

Jeffries, M. O., K. Morris, and C. R. Duguay, 2012: Floating ice: Lake ice and river ice. Satellite Image Atlas of Glaciers of the World - State of the Earth's Cryosphere at the Beginning of the 21st Century: Glaciers, Global Snow Cover, Floating Ice, and Permafrost and Periglacial Environments, R. S. Williams, Jr. and J. G. Ferrigno, Eds., U.S. Geological Survey Professional Paper 1386-A, A381-A424.

Johns, W. E., and Coauthors, 2011: Continuous, array-based estimates of Atlantic Ocean heat transport at $26.5^{\circ} \mathrm{N}$. J. Climate, 24, 2429-2449.

Johnson, G. C., and J. M. Lyman, 2012: [Global oceans] Sea surface salinity [in "State of the Climate in 2011"]. Bull. Amer. Meteor. Soc., 93 (7), S68-S69, S72.

— - , J. K. Willis, S. Levitus, T. Boyer, J. Antonov, and S. A. Good, 2012a: [Global oceans] Ocean heat content [in "State of the Climate in 2011"]. Bull. Amer. Meteor. Soc., 93 (7), S62-S65.

—, S. Schmidtko, and J. M. Lyman, 2012b: Relative contributions of temperature and salinity to seasonal mixed layer density changes and horizontal density gradients, J. Geophys. Res., 117, C04015, doi:10.1029/2011JC007651.

__, and Coauthors, 2013a: [Global Oceans] Ocean heat content [in "State of the Climate in 2012"]. Bull. Amer. Meteor. Soc., 94 (8), S50-S53.

— J. M. Lyman, G. S. E. Lagerloef, and H.-Y. Kao, 2013b: [Global oceans] Sea surface salinity [in "State of the Climate in 2012”]. Bull. Amer. Meteor. Soc., 94 (8), S57-S61.

Jones, A., and Coauthors, 2009: Evolution of stratospheric ozone and water vapour time series studied with satellite measurements. Atmos. Chem. Phys., 9, 6055-6075, doi:10.5194/acp-9-6055-2009.

Jones, P. D., D. H. Lister, T. J. Osborn, C. Harpham, M. Salmon, and C. P. Morice, 2012: Hemispheric and largescale land surface air temperature variations: An extensive revision and an update to 2010. J. Geophys. Res., 117, D05127, doi:10.1029/2011JD017139.
Jutterström, S., and L. G. Anderson, 2005: The saturation of calcite and aragonite in the Arctic Ocean. Marine Chem., 94, 101-110.

Kaiser, J. W., and Coauthors, 2012: Biomass burning emissions estimated with a global fire assimilation system based on observed fire radiative power. Biogeosciences, 9, 527-554.

Kalnay, E., and Coauthors, 1996: The NCEP/NCAR 40-year reanalysis project. Bull. Amer. Meteor. Soc., 77, 437-471.

Kanamitsu, M., W. Ebisuzaki, J. Woollen, S.-K. Yang, J. J. Hnilo, M. Fiorino, and G. L. Potter, 2002: NCEP-DOE AMIP-II Reanalysis (R-2). Bull. Amer. Meteor. Soc., 83, 1631-1643.

Kanzow, T., and Coauthors, 2010: Seasonal variability of the Atlantic meridional overturning circulation at $26.5^{\circ} \mathrm{N}$. J. Climate, 23, 5678-5698.

Karion, A., and Coauthors, 2013: Methane emissions estimate from airborne measurements over a western United States natural gas field. Geophys. Res. Lett., 40, 4393-4397, doi:10.1002/grl.50811.

Karlsson, K.-G., and Coauthors, 2013: CLARA-A1: A cloud, albedo, and radiation dataset from $28 \mathrm{yr}$ of global AVHRR data. Atmos. Chem. Phys., 13, 5351-5367, doi:10.5194 lacp-13-5351-2013.

Kayano, M., and V. Kousky, 1999: Intra-seasonal (30-60 day) variability in the global tropics: Principal modes and their evolution. Tellus, 51A, 373-386.

Kennedy, J. J., and Coauthors, 2010: [Global climate] How do we know the world has warmed? [in "State of the Climate in 2009”]. Bull. Amer. Meteor. Soc., 91 (7), S26-S27.

—, N. A. Rayner, R. O. Smith, D. E. Parker, and M. Saunby, 2011a: Reassessing biases and other uncertainties in sea surface temperature observations since 1850: Part 1: Measurament and sampling uncertainties. J. Geophys. Res., 116, D14103, doi:10.1029/2010JD015218.

,,,---- , and,$- 2011 \mathrm{~b}$ : Reassessing biases and other uncertainties in sea surface temperature observations since 1850: Part 2: Biases and homogenisation. J. Geophys. Res., 116, D14104, doi:10.1029/2010JD015220.

Key, J., Y. Liu, R. Stone, C. Cox, and V. Walden, 2013: Cloud cover and surface radiation budget. Arctic Report Card: Update for 2013, M. O. Jeffries et al., Eds., NOAA Rep., 17-19. [ Available online at http://www.arctic.noaa.gov /reportcard/clouds_radiation.html.]

Key, R. M., and Coauthors, 2004: A global ocean carbon climatology: Results from Global Data Analysis Project (GLODAP). Global Biogeochem. Cycles, 19, GB4031, doi:10.1029/2004GB002247.

Khatiwala, S., F. Primeau, and T. Hall, 2009: Reconstruction of the history of anthropogenic $\mathrm{CO}_{2}$ concentrations in the ocean. Nature, 462, 346-349. 
_- and Coauthors, 2013: Global ocean storage of anthropogenic carbon. Biogeosciences, 10, 2169-2191.

Kiesewetter, G., B.-M. Sinnhuber, M. Weber, and J. P. Burrows, 2010: Attribution of stratospheric ozone trends to chemistry and transport: a modelling study. Atmos. Chem. Phys., 10, 12073-12089, doi:10.5194/acp-10-12073 -2010 .

Kiladis, G., and K. Weickmann, 1992: Circulation anomalies associated with tropical convection during northern winter. Mon. Wea. Rev., 120, 1900-1923.

$\longrightarrow$, K. H. Straub, and P. T. Haertel, 2005: Zonal and vertical structure of the Madden-Julian oscillation. J. Atmos. Sci., 62, 2790-2809.

—, M. C. Wheeler, P. T. Haertel, K. H. Straub, and P. E. Roundy, 2009: Convectively coupled equatorial waves. Rev. Geophys., 47, RG2003, doi:10.1029/2008RG000266.

Kim, H., P. J.-F. Yeh, T. Oki, and S. Kanae, 2009: Role of rivers in the seasonal variations of terrestrial water storage over global basins. Geophys. Res. Lett., 36, L17402, doi:10.1029/2009GL039006.

Kimura, N., 2007: Mechanisms controlling the temporal variation of the sea ice edge in the Southern Ocean. J. Oceanogr., 63, 685-694.

—_, and M. Wakatsuchi, 2011: Large-scale processes governing the seasonal variability of the Antarctic sea ice. Tellus, 63A, 828-840.

Kinnison, D. E., and Coauthors, 2007: Sensitivity of chemical tracers to meteorological parameters in the MOZART-3 chemical transport model. J. Geophys. Res., 112, D20302, doi:10.1029/2006JD007879.

Kirschke, S., and Coauthors, 2013: Three decades of global methane sources and sinks. Nature Geosci., 6, 813-823, doi:10.1038/ngeo1955.

Klein Tank, A. M. G., F. W. Zwiers, and X. Zhang, 2009: Guidelines on analysis of extremes in a changing climate in support of informed decisions for adaptation. Climate Data and Monitoring WCDMP-No. 72. WMO Technical Document 1500, 52 pp. [Available online at http://eca .knmi.nl/documents/WCDMP_72_TD_1500_en_1.pdf.]

Klotzbach, P. J., 2010: On the Madden-Julian oscillationAtlantic hurricane relationship. J. Climate, 23, 282-293.

—, 2011: A simplified Atlantic basin seasonal hurricane prediction scheme from 1 August. Geophys. Res. Lett., 38, L16710, doi:10.1029/2011GL048603.

— North Atlantic tropical cyclone activity. J. Climate, 21, 3929-3935.

Knapp, K. R., M. C. Kruk, D. H. Levinson, H. J. Diamond, and C. J. Neumann, 2010: The International Best Track Archive for Climate Stewardship (IBTrACS). Bull. Amer. Meteor. Soc., 91, 363-376.
Knutson, T., and K. Weickmann, 1987: 30-60 day atmospheric oscillations: Composite life cycles of convection and circulation anomalies. Mon. Wea. Rev., 115, 1407-1436.

Ko, M. K. W., P. A. Newman, S. Reimann, and S. E. Strahan, Eds., 2013: Lifetimes of stratospheric ozone-depleting substances, their replacements, and related species. SPARC Report No. 6, WCRP-15/2013, various paging. [Available online at http://www.sparc-climate.org/publications /sparc-reports/sparc-report-no6.]

Koch, D., S. Menon, A. D. Genio, R. Ruedy, I. Alienov, and G. A. Schmidt, 2009: Distinguishing aerosol impacts on climate over the past century. J. Climate, 22, 2659 - 2677.

Kopp, G., and J. L. Lean, 2011: A new, lower value of total solar irradiance: Evidence and climate significance. Geophys. Res. Lett., 38, L01706, doi:10.1029/2010GL045777.

Kosaka, Y., and S.-P. Xie, 2013: Recent global-warming hiatus tied to equatorial Pacific surface cooling. Nature, 501, 403-407, doi:10.1038/nature12534.

Koumoutsaris, S., I. Bey, S. Generoso, and V. Thouret, 2008: Influence of El Niño-Southern Oscillation on the interannual variability of tropospheric ozone in the northern midlatitudes. J. Geophys. Res., 113, D19301, doi:10.1029/2007JD009753.

Kouraev, A. V., S. V. Semovski, M. N. Shimaraev, N. M. Mognard, B. Légresy, and F. Remy, 2007: Observations of Lake Baikal ice from satellite altimetry and radiometry. Remote Sens. Environ., 108, 240-253.

Kousky, V., and M. Kayano, 1994: Principal modes of outgoing longwave radiation and $250-\mathrm{mb}$ circulation for the South American sector. J. Climate, 7, 1131-1143.

Kramarova, N. A., and Coauthors, 2014: Measuring the Antarctic ozone hole with the new Ozone Mapping and Profiler Suite (OMPS). Atmos. Chem. Phys., 14, 2353-2361, doi:10.5194/acp-14-2353-2014.

Kratz, D. P., S. K. Gupta, A. C. Wilber and V. E. Sothcott, 2010: Validation of the CERES edition 2B surface-only flux algorithms. J. Appl. Meteor. Climatol., 49, 164-180.

—, P. W. Stackhouse, Jr., S. K. Gupta, A. C. Wilber, P. Sawaengphokhai, and G. R. McGarragh, 2014: The Fast Longwave and Shortwave Flux (FLASHFlux) data product: Single scanner footprint fluxes. J. Appl. Meteor. Climatol., 53, 1059-1079.

Kroeker, K. J., R. L. Kordas, R. N. Crim, and G. G. Singh, 2010: Meta-analysis reveals negative yet variable effects of ocean acidification on marine organisms. Ecol. Lett., 13, 1419-1434.

Kropáček, J., F. Maussion, F. Chen, S. Hoerz, and V. Hochschild, 2013: Analysis of ice phenology of lakes on the Tibetan Plateau from MODIS data. The Cryosphere, 7, 287-301. 
Kuttippurath, J., F. Lefèvre, J.-P. Pommereau, H. K. Roscoe, F. Goutail, A. Pazmino, and J. D. Shanklin, 2013: Antarctic ozone loss in 1979-2010: First sign of ozone recovery. Atmos. Chem. Phys.,13, 1625-1635, doi:10.5194 lacp-13-1625-2013.

Lagerloef, G., R. Schmitt, J. Schanze, and H.-Y. Kao, 2010: The ocean and the global water cycle. Oceanography, 23 (4), 82-93, doi:10.5670/oceanog.2010.07.

Landsea, C. W., and J. L. Franklin, 2013: Atlantic hurricane database uncertainty and presentation of a new database format. Mon. Wea. Rev., 141, 3576-3592.

—, G. D. Bell, W. M. Gray, and S. B. Goldenberg, 1998: The extremely active 1995 Atlantic hurricane season: Environmental conditions and verication of seasonal forecasts. Mon. Wea. Rev., 126, 1174-1193.

Latifovic, R., and D. Pouliot, 2007: Analysis of climate change impacts on lake ice phenology in Canada using the historical satellite data record. Remote Sens. Environ., 16, 492-507.

Lavoie, D., K. L. Deman, and R. W. Macdonald, 2010: Effects of future climate change on primary productivity and export fluxes in the Beaufort Sea. J. Geophys. Res., 115, C04018, doi:10.1029/2009JC005493.

Laxon, S. W., and Coauthors, 2013: CryoSat-2 estimates of Arctic sea ice thickness and volume. Geophys. Res. Lett., 40, 732-737, doi:10.1002/grl50193.

Leduc, G., L. Vidal, K. Tachikawa, F. Rostek, C. Sonzogni, L. Beaufort, and E. Bard, 2007: Moisture transport across Central America as a positive feedback on abrupt climate changes. Nature, 445, 908-911.

Legates, D. R., and C. J. Willmott, 1990: Mean seasonal and spatial variability in gauge-corrected, global precipitation. Int. J. Climatol., 10, 111-127, doi:10.1002/joc.3370100202.

Lenaerts, J. T. M., and M. R. van den Broeke, 2012: Modeling drifting snow in Antarctica with a regional climate model: 2. Results. J. Geophys. Res., 117, D05109, doi:10.1029/2010JD015419.

Lenormand, F., C. R. Duguay, and R. Gauthier, 2002: Development of a historical ice database for the study of climate change in Canada. Hydrol. Processes, 16, 3707-3722.

Leuliette, E. W., and J. K. Willis, 2011: Balancing the sea level budget. Oceanography, 24 (2), 122-129, doi:10.5670 /oceanog.2011.32.

Leung, F.-Y. T., J. A. Logan, R. Park, E. Hyer, E. Kasischke, D. Streets, and L. Yurganov, 2007: Impacts of enhanced biomass burning in the boreal forests in 1998 on tropospheric chemistry and the sensitivity of model results to the injection height of emissions. J. Geophys. Res., 112, D10313, doi:10.1029/2006JD008132.

Levitus, S., and Coauthors, 2012: World ocean heat content and thermosteric sea level change (0-2000 m), 1955-2010. Geophys. Res. Lett., 39, L10603, doi:10.1029/2012GL051106.
Lewis, S. L., and Coauthors, 2013: Above-ground biomass and structure of 260 African tropical forests. Phil. Trans. R. Soc. London, Ser. B, 368, 20120295, doi:10.1098 /rstb.2012.0295.

Li, R., L. Zhao, Y.-J. Ding, T.-H. Wu, Y. Xiao, E.-J. Du, G.-Y. Liu, and Y.-P. Qiao, 2012: Temporal and spatial variations of the active layer along the Qinghai-Tibet Highway in a permafrost region. Chin. Sci. Bull., 57, 4609-4616, doi:10.1007/s11434-012-5323-8.

Lin, C., K. Yang, J. Qin, and R. Fu, 2013: Observed coherent trends of surface and upper-air wind speed over China since 1960. J. Climate, 26, 2891-2903.

Lin, H., G. Brunet, and J. Derome, 2009: An observed connection between the North Atlantic Oscillation and the Madden-Julian Oscillation. J. Climate, 22, 364-380.

Lin, I-I, C.-C. Wu, I.-F. Pun, and D.-S. Ko, 2008: Upper-ocean thermal structure and the western North Pacific category 5 typhoons. Part I: Ocean features and the category 5 typhoons' intensification. Mon. Wea. Rev., 136, 3288-3306.

—, C.-H. Chen, I.-F. Pun, W. T. Liu, and C.-Ch. Wu, 2009: Warm ocean anomaly, air sea fluxes, and the rapid intensification of tropical cyclone Nargis (2008). Geophys. Res. Let., 36, L03817, doi:10.1029/2008GL035815.

_, and Coauthors, 2013: An ocean coupling potential intensity index for tropical cyclones. Geophys. Res. Let., 40, 1878-1882, doi:10.1002/grl.50091.

Lin, M., L. W. Horowitz, S. J. Oltmans, A. M. Fiore, and S. Fan, 2014: Tropospheric ozone trends at Mauna Loa Observatory tied to decadal climate variability. Nature Geosci., 7, 136-143, doi:10.1038/ngeo2066.

Liu, H., L. Wang, and K. Jezek, 2005: Wavelet-based edge detection approach to derivation of snow-melt onset, duration and extent from satellite passive microwave measurements. Int. J. Remote Sens., 26, 4639-4660.

,$- \ldots$, and —_, 2006: Spatio-temporal variations of snow melt zones in Antarctic Ice Sheet derived from satellite SMMR and SSM/I data (1978-2004). J. Geophys. Res., 111, F01003, doi:10.1029/2005JF000318.

Liu, Y., and J. Key, 2014: Less winter cloud aids summer 2013 Arctic sea ice return from 2012 minimum. Environ. Res. Lett., 9, 044002, doi:10.1088/1748-9326/9/4/044002.

,-- J J. Francis, and X. Wang, 2007: Possible causes of decreasing cloud cover in the Arctic winter, 1982-2000. Geophys. Res. Lett., 34, L14705, doi:10.1029/2007GL030042.

Liu, Y. Y., W. A. Dorigo, R. M. Parinussa, R. A. M. De Jeu, W. Wagner, M. F. McCabe, J. P. Evans, and A. I. J. M. Van Dijk, 2012: Trend-preserving blending of passive and active microwave soil moisture retrievals. Remote Sens. Environ., 123, 280-297. 
Loeb, N. G., B. A. Wielicki, D. R. Doelling, G. L. Smith, D. F. Keyes, S. Kato, N. Manalo-Smith, and T. Wong, 2009: Toward optimal closure of the Earth's top-of-atmosphere radiation budget. J. Climate, 22, 748-766.

—, S. Kato, W. Su, T. Wong, F. Rose, D. R. Doelling, and J. Norris, 2012: Advances in understanding top-ofatmosphere radiation variability from satellite observations. Surv. Geophys., 33, 359-385, doi:10.1007/s10712-012 -9175-1.

Long, C. S., and J. R. Christy, 2013: [Global climate] Lower stratospheric temperature [in "State of the Climate in 2012”]. Bull. Amer. Meteor. Soc., 94 (8), S14-S15.

Loyola, D., and Coauthors, 2009: Global long-term monitoring of the ozone layer - a prerequisite for predictions Int. J. Remote Sens., 30, 4295-4318, doi:10.1080/01431160902825016.

Lozier, M. S., 2012: Overturning in the North Atlantic. Ann. Rev. Marine Sci., 4, 291-315.

Lumpkin, R., and S. Garzoli, 2010: Interannual to decadal changes in the southwestern Atlantic's surface circulation. J. Geophys. Res., 116, C01014, doi:10.1029/2010JC006285.

_-, G. Goni, and K. Dohan, 2013: [Oceans] Surface currents [in "State of the Climate in 2012"]. Bull. Amer. Meteor. Soc., 94 (7), S62-S64.

Luo, J.-J., 2011: [Tropics] Indian Ocean dipole [in "State of the climate in 2010”]. Bull. Amer. Meteor. Soc., 92, S138-S140.

_-, R. Zhang, S. K. Behera, Y. Masumoto, F.-F. Jin, R. Lukas, and T. Yamagata, 2010: Interaction between El Niño and extreme Indian Ocean dipole. J. Climate, 23, 726-742.

_- W. Sasaki, and Y. Masumoto, 2012: Indian Ocean warming modulates Pacific climate change. Proc. Natl. Acad. Sci. USA, 109, 18701-18 706, doi:10.1073 /pnas.1210239109.

Luthcke, S. B., T. J. Sabaka, B. D. Loomis, A. A. Arendt, J. J. McCarthy, and J. Camp, 2013: Antarctica, Greenland and Gulf of Alaska land ice evolution from an iterated GRACE global mascon solution. J. Glaciol., 59, 613-631.

Lyman, J. M., 2012: Estimating global energy flow from the global upper ocean. Surv. Geophys., 33, 387-393, doi:10.1007/s10712-011-9167-6.

— content changes in the upper $1800 \mathrm{~m}$ since 1950 and the influence of climatology choice. J. Climate, 27, 1945-1957.

—, S. A. Good, V. V. Gouretski, M. Ishii, G. C. Johnson, M. D. Palmer, D. A. Smith, and J. K. Willis, 2010: Robust warming of the global upper ocean. Nature, 465, 334-337, doi:10.1038/nature09043.

Lyon, B., A. G. Barnston, and D. G. DeWitt, 2013: Tropical Pacific forcing of a 1998-1999 climate shift: observational analysis and climate model results for the boreal spring season. Climate Dyn., Open Access, doi:10.1007/s00382 -013-1891-9.
Macdonald, A. M., and M. O. Baringer, 2013: Ocean heat transport. Ocean Circulation and Climate: A 21st Century Perspective, 2nd ed., G. Siedler et al., Eds., International Geophysics Series, Vol. 103, Elsevier, 759-785.

Madden, R., and P. Julian, 1971: Detection of a 40-50 day oscillation in the zonal wind in the tropical Pacific. J. Atmos. Sci., 28, 702-708.

- , and - 1972: Description of global-scale circulation cells in the tropics with a 40-50 day period. J. Atmos. Sci., 29, 1109-1123.

- , and —-, 1994: Observations of the 40-50 day tropical oscillation: A review. Mon. Wea. Rev., 122, 814-837.

Mäder, J. A., J. Staehelin, T. Peter, D. Brunner, H. E. Rieder, and W. A. Stahel, 2010: Evidence for the effectiveness of the Montreal Protocol to protect the ozone layer. Atmos. Chem. Phys., 10, 12 161-12 171, doi:10.5194/acp-10-12161 -2010 .

Mainelli, M., M. DeMaria, L. Shay, and G. Goni, 2008: Application of oceanic heat content estimation to operational forecasting of recent Atlantic category 5 hurricanes. Wea. Forecasting, 23, 3-16.

Maloney, E. D., and D. L. Hartmann, 2001: The Madden-Julian oscillation, barotropic dynamics, and North Pacific tropical cyclone formation. Part I: Observations. J. Atmos. Sci., 58, 2545-2558.

Manney, G., K. Kruger, J. L. Sabutis, S. A. Sena, and S. Pawson, 2005: the remarkable 2003-2004 winter and other recent warm winters in the Arctic stratosphere since the late 1990's. J. Geophys. Res., 110, D04107, doi:10.1029/2004JD005367.

_- and Coauthors, 2011: Unprecedented Arctic ozone loss in 2011. Nature, 478, 469-475.

Manning, A. C., and R. F. Keeling, 2006: Global oceanic and land biota sinks from the Scripps atmospheric oxygen flask sampling network. Tellus, 58B, 95-116.

Mantua, N. J., S. R. Hare, Y. Zhang, J. M. Wallace, and R. C. Francis, 1997: A Pacific interdecadal climate oscillation with impacts on salmon production. Bull. Amer. Meteor. Soc., 78, 1069-1079.

Marengo, J., L. Alves, W. Soares, D. A. Rodriguez, H. Camargo, M. P. Riveros, and A. Diaz Pabló, 2013: Two contrasting severe seasonal extremes in tropical South America in 2012: Flood in Amazonia and drought in Northeast Brazil. J. Climate, 26, 9137-9153.

Marshall, G. J., 2003: Trends in the southern annular mode from observations and reanalyses. J. Climate, 16, 4134-4143.

Maslanik, J., and J. Stroeve, 1999, updated daily: Near-realtime DMSP SSM/I daily polar gridded sea ice concentrations. National Snow and Ice Data Center, Boulder, CO, digital media. [Available online at http://nsidc.org/data /docs/daac/nsidc0081_ssmi_nrt_seaice.gd.html.] 
—, C. Fowler, J. Stroeve, S. Drobot, J. Zwally, D. Yi, and W. Emery, 2007: A younger, thinner Arctic ice cover: Increased potential for rapid, extensive sea ice loss. Geophys. Res. Lett., 34, L24501, doi:10.1029/2007GL032043.

—, J. Stroeve, C. Fowler, and W. Emery, 2011: Distribution and trends in Arctic sea ice age through spring 2011. Geophys. Res. Lett. 38, L13502, doi:10.1029/2011GL047735.

Mathis, J. T., and J. M. Questel, 2013: The impacts of primary production and respiration on the marine carbonate system in the western Arctic: Implications for $\mathrm{CO}_{2}$ fluxes and ocean acidification. Cont. Shelf Res., 67, 42-51, doi:10.1016/j.csr.2013.04.041.

_ , R. S. Pickart, D. A. Hansell, D. Kadko, and N. R. Bates, 2007: Eddy transport of organic carbon and nutrients from the Chukchi Shelf: Impact on the upper halocline of the western Arctic Ocean. J. Geophys. Res. 112, C05011, doi:10.1029/2006JC003899.

— , J. N. Cross, and N. R. Bates, 2011: The role of ocean acidification in systemic carbonate mineral suppression in the Bering Sea. Geophys. Res. Lett., 38, L19602, doi:10.1029/2011GL048884.

— high $p \mathrm{CO}_{2}$ waters onto the continental shelf of the western Arctic Ocean and implications for carbonate mineral saturation states. Geophys. Res. Lett., 39, L07606, doi:10.1029/2012GL051574.

McCarthy, G., and Coauthors, 2012: Observed interannual variability of the Atlantic Meridional Overturning Circulation at $26.5^{\circ}$ N. Geophys. Res. Lett., 39, L19609, doi:10.1029/2012GL052933.

McClain, C. R., 2009: A decade of satellite ocean color observations. Ann. Rev. Marine Sci., 1, 19-42.

McInnes, K. L., K. J. E. Walsh, J. G. O'Grady, R. K. Hoeke, F. Colberg, and G. D. Hubbert, 2014: Quantifying storm tide risk in Fiji due to climate variability and change. Global Planet. Change, 116, 115-129.

McKinlay, A. F., and B. L. Diffey, 1987: A reference action spectrum for ultraviolet induced erythema in human skin. CIE Res. Note, 6 (1), 17-22.

McPeters, R. D., P. K. Bhartia, D. Haffner, G. J. Labow, and L. Flynn, 2013: The version 8.6 SBUV ozone data record: An overview. J. Geophys. Res. Atmos., 118, 8032-8039, doi:10.1002/jgrd.50597.

McVicar, T. R., G. Van Niel, L. T. Li, M. L. Roderick, D. P. Rayner, L. Ricciardulli, and R. J. Donohue, 2008: Wind speed climatology and trends for Australia, 1975-2006: Capturing the stilling phenomenon and comparison with near-surface reanalysis output. Geophys. Res. Lett., 35, L20403, doi:10.1029/2008GL035627.

_- and Coauthors, 2012: Global review and synthesis of trends in observed terrestrial near-surface wind speeds: Implications for evaporation. J. Hydrol., 416/417, 182-205.
—, R. Vautard, J.-N. Thépaut, P. Berrisford, and R. J. H. Dunn, 2013: [Global climate] Land surface winds [in "State of the Climate in 2011"]. Bull. Amer. Meteor. Soc., 94 (8), S27-S29.

Mears, C. A., and F. J. Wentz, 2009: Construction of the RSS V3.2 lower-tropospheric temperature dataset from the MSU and AMSU microwave sounders. J. Atmos. Oceanic Technol., 26, 1493-1509.

Meijers, A. J. S., N. L. Bindoff, and S. R. Rintoul, 2011: Frontal movements and property fluxes: Contributions to heat and freshwater trends in the Southern Ocean. J. Geophys. Res., 116, C08024, doi:10.1029/2010JC006832.

Menemenlis, D., I. Fukumori, and T. Lee, 2005: Using Green's functions to calibrate an ocean general circulation model. Mon. Wea. Rev., 133, 1224-1240.

Merrifield, M. A., P. R. Thompson, and M. Lander, 2012: Multidecadal sea level anomalies and trends in the western tropical Pacific. Geophys. Res. Lett., 39, L13602, doi:10.1029/2012GL052032.

Midorikawa, T., and Coauthors, 2010: Decreasing $\mathrm{pH}$ trend estimated from 25-yr time series of carbonate parameters in the western North Pacific. Tellus, 62B, 649-659.

Miller, B. R., and Coauthors, 2010: HFC-23 (CHF3) emission trend response to HCFC-22 (CHClF2) production and recent HFC-23 emission abatement measures. Atmos. Chem. Phys., 10, 7875-7890.

Miralles, D. G., and Coauthors, 2014: El Niño-La Niña cycle and recent trends in continental evaporation. Nature Climate Change, 4, 122-126.

Misra, V., and S. M. DiNapoli, 2013: The observed teleconnection between the equatorial Amazon and the IntraAmericas Seas. Climate Dyn., 40, 2637-2649, doi:10.1007 /s00382-012-1474-1.

—, H. Li, and M. Kozar, 2014: The precursors in the Intra-Americas Seas to seasonal climate variations over North America. J. Geophys. Res., in press, doi:10.1002/2014JC009911.

Mitchard, E. T. A., and Coauthors, 2009: Using satellite radar backscatter to predict above-ground woody biomass: A consistent relationship across four different African landscapes. Geophys. Res. Lett., 36, L23401, doi:10.1029/2009GL040692.

— , S. S. Saatchi, A. Baccini, G. P. Asner, S. J. Goetz, N. L. Harris, and S. Brown, 2013: Uncertainty in the spatial distribution of tropical forest biomass: A comparison of pan-tropical maps. Carbon Balance Manage., 8 (10), doi:10.1186/1750-0680-8-10.

Mo, K. C., 2000: The association between intraseasonal oscillations and tropical storms in the Atlantic Basin. Mon. Wea. Rev., 128, 4097-4107. 
- and V. E. Kousky, 1993: Further analysis of the relationship between circulation anomaly patterns and tropical convection. J. Geophys. Res., 98 (D3), 5103-5113.

Montzka, S. A., B. D. Hall and J. W. Elkins, 2009: Accelerated increases observed for hydrochlorofluorocarbons since 2004 in the global atmosphere. Geophys. Res. Lett., 36, L03804, doi:10.1029/2008GL036475.

_ (ODSs) and related chemicals. Scientific Assessment of Ozone Depletion: 2010, Global Ozone Research and Monitoring Project Rep. 52, World Meteorological Organization, 1.1-1.108.

Moon, J.-H., Y. T. Song, P. D. Bromirski, and A. J. Miller, 2013: Multidecadal regional sea level shifts in the $\mathrm{Pa}$ cific over 1958-2008. J. Geophys. Res., 118, 7024-7035, doi:10.1002/2013JC009297.

Morcrette, J.-J., A. Benedetti, L. Jones, J. W. Kaiser, M. Razinger, and M. Suttie, 2011: Prognostic aerosols in the ECMWF IFS: MACC vs GEMS aerosols. ECMWF Tech. Memo. 659, 32 pp. [Available online at http://www.ecmwf .int/publications/library/do/references/list/14.]

Morice, C. P., J. J. Kennedy, N. A. Rayner, and P. D. Jones, 2012: Quantifying uncertainties in global and regional temperature change using an ensemble of observational estimates: The HadCRUT4 dataset. J. Geophys. Res., 117, D08101, doi:10.1029/2011JD017187.

Mote, T. L., 2007: Greenland surface melt trends 1973-2007: Evidence of a large increase in 2007. Geophys. Res. Lett., 34, L22507, doi:10.1029/2007GL031976.

— , and M. R. Anderson, 1995: Variations in melt on the Greenland Ice Sheet based on passive microwave measurements. J. Glaciol., 41, 51-60.

Mühle, J., and Coauthors, 2010: Perfluorocarbons in the global atmosphere: tetrafluoromethane, hexafluoroethane, and octafluoropropane. Atmos. Chem. Phys., 10, 5145-5164.

Müller, R., J.-U. Grooß, C. Lemmen, D. Heinze, M. Dameris, and G. Bodeker, 2008: Simple measures of ozone depletion in the polar stratosphere. Atmos. Chem. Phys., 8, 251-264, doi:10.5194/acp-8-251-2008.

Münnich, M., and J. D. Neelin, 2005: Seasonal influence of ENSO on the Atlantic ITCZ and equatorial South America. Geophys. Res. Lett., 32, L21709, doi:10.1029/2005GL023900.

Myhre, G., and Coauthors, 2013: Anthropogenic and natural radiative forcing. Climate Change 2013: The Physical Science Basis, T. F. Stocker et al., Eds., Cambridge University Press, 659-740.

Nair, P. J., and Coauthors, 2013: Ozone trends derived from the total column and vertical profiles at a northern midlatitude station. Atmos. Chem. Phys., 13, 10373-10384, doi:10.5194/acp-13-10373-2013.
Newchurch, M. J., E. S. Yang, D. M. Cunnold, G. C. Reinsel, J. M. Zawodny, J. M. Russell III, 2003: Evidence for slowdown in stratospheric ozone loss: First stage of ozone recovery. J. Geophys. Res., 108 (D16), 4507, doi:10.1029/2003JD003471.

Newman, P. A., J. S. Daniel, D. W. Waugh, and E. R. Nash, 2007: A new formulation of equivalent effective stratospheric chlorine (EESC). Atmos. Chem. Phys., 7, 4537-4552.

- - and Coauthors, 2013: [Antarctica] Ozone depletion [in "State of the Climate in 2012"]. Bull. Amer. Meteor. Soc., 94 (8), S142-S146.

Nghiem, S. V., and Coauthors, 2012: The extreme melt across the Greenland ice sheet in 2012. Geophys. Res. Lett., 39, doi:10.1029/2012GL053611.

Nicolas, J. P., and D. H. Bromwich, 2011 : Precipitation changes in high southern latitudes from global reanalyses: A cautionary tale. Surv. Geophys., 32, 475-494, doi:10.1007 /s10712-011-9114-6.

NIWA, 2013: State of the Climate 2013. National Institute of Water and Atmospheric Research (New Zealand), 109 pp. [Available online at http://www.niwa.co.nz/climate/ state-of-the-climate/state-of-the-climate-2013.]

Nobre, P., and J. Shukla, 1996: Variations of sea surface temperature, wind stress and rainfall over the tropical Atlantic and South America. J. Climate, 9, 2464-2479.

Noetzli, J., and S. Gruber, 2009: Transient thermal effects in Alpine permafrost. The Cryosphere, 3, 85-99.

OBPG, 2013: Ocean color data processing. [Available at http:// oceancolor.gsfc.nasa.gov/WIKI/OCReproc.html.]

Oki, T., and Y. C. Sud, 1998: Design of Total Runoff Integrating Pathways (TRIP) - A global river channel network. Earth Interact., 2, 1-36.

Olafsson, J., S. R. Olafsdottir, A. Benoit-Cattin, M. Danielsen, T. S. Arnarson, and T. Takahashi, 2009: Rate of Iceland Sea acidification from time series measurements. Biogeosciences, 6, 2661-2668.

O’Malley, R. T., M. J. Behrenfeld, D. A. Siegel, and S. Maritorena, 2010: [Global oceans] Global ocean phytoplankton [in "State of the Climate in 2009"]. Bull. Amer. Meteor. Soc., 91 (7), S75-S78.

Onogi, K., and Coauthors, 2007: The JRA-25 reanalysis. J. Meteor. Soc. Japan, 85, 369-432.

Ordóñez, C., D. Brunner, J. Staehelin, P. Hadjinicolaou, J. A. Pyle, M. Jonas, H. Wernli, and A. S. H. Prévôt, 2007: Strong influence of lowermost stratospheric ozone on lower tropospheric background ozone changes over Europe. Geophys. Res. Lett., 34, L07805, doi:10.1029/2006GL029113.

Orr, J. C., 2011: Recent and future changes in ocean carbonate chemistry. Ocean Acidification, J.-P. Gattuso and L. Hansson, Eds., Oxford University Press, 41-66. 
_- and Coauthors, 2005: Anthropogenic ocean acidification over the twenty-first century and its impact on calcifying organisms. Nature, 437, 681-686, doi:10.1038 /nature04095.

Otto, A., and Coauthors, 2013: Energy budget constraints on climate response. Nature Geosci., 6, 415-416, doi:10.1038 /ngeo1836.

Overland, J. E., 2009: The case for global warming in the Arctic. Influence of Climate Change on the Changing Arctic and Sub-Arctic Conditions, J. C. J. Nihoul and A. G. Kostianoy, Eds., Springer, 13-23.

—, K. R. Wood, and M. Wang, 2011: Warm Arctic-cold continents: Impacts of the newly open Arctic Sea. Polar Res., 30, 15787, doi:10.3402/polar.v30i0.15787.

Palmén, E., and C. W. Newton, 1969: Atmospheric Circulation Systems: Their Structure and Physical Interpretation. International Geophysical Series, Vol. 13, Academic Press, $603 \mathrm{pp}$.

Palmer, M. D., and P. Brohan, 2011: Estimating sampling uncertainty in fixed-depth and fixed-isotherm estimates of ocean warming. Int. J. Climatol., 31, 980-986, doi:10.1002/joc.2224.

— , K. Haines, S. F. B. Tett, and T. J. Ansell, 2007: Isolating the signal of ocean global warming. Geophys. Res. Lett., 34, L23610, doi:10.1029/2007GL031712.

Pardo, P. C., F. F. Perez, S. Khatiwala, and A. F. Rios, 2014: Anthropogenic CO2 estimates in the Southern Ocean: Storage partitioning in the different water masses. Progr. Oceanogr., 120, 230-242.

Parinussa, R. M., R. De Jeu, W. Wagner, W. Dorigo, F. Fang, W. Teng, and Y. Y. Liu, 2013: [Global climate] Soil moisture [in "State of the Climate in 2012"]. Bull. Amer. Meteor. Soc., 94 (8), S24-S25.

Park, G.-H., and R. Wanninkhof, 2012: A large increase of the $\mathrm{CO}_{2}$ sink in the western tropical North Atlantic from 2002 to 2009. J. Geophys. Res. 117, C08029, doi:10.1029/2011JC007803.

— K. Lee, R. Wanninkhof, and R. A. Feely, 2006: Empirical temperature-based estimates of variability in the oceanic uptake of $\mathrm{CO}_{2}$ over the past 2 decades. J Geophys. Res., 111, C07S07, doi:10.1029/2005JC003090.

— , and Coauthors, 2010a: Variability of global net sea-air $\mathrm{CO}_{2}$ fluxes over the last three decades using empirical relationships. Tellus, 62B, 352-368.

_- R. Wanninkhof, and J. Trinanes, 2010b: Procedures to create near real-time seasonal air-sea CO2 flux maps. NOAA Tech. Memo. OAR AOML-98, 21 pp.

Parrish, D. D., and Coauthors, 2014: Long-term changes in lower tropospheric baseline ozone concentrations: Comparing chemistry-climate models and observations at northern mid-latitudes. J. Geophys. Res., 119, 5719-5736, doi:10.1002/2013JD021435.
Pawson, S., and B. Naujokat, 1999: The cold winters of the middle 1990s in the northern lower stratosphere. J. Geophys. Res., 104, 14209-14222, doi:10.1029/1999JD900211.

Pelto, M., 2010: Forecasting temperate alpine glacier survival from accumulation zone observations. The Cryosphere, 4, 67-75.

— , 2013: Pacific Northwest 2013 glacier assessment. [Available online at http://glacierchange.wordpress .com/2014/02/20/pacific-northwest-glacier-mass -balance-2013/.]

Pérez-Hernández, M. D., and T. M. Joyce, 2014: Two modes of Gulf Stream variability revealed in the last two decades of satellite altimeter data. J. Phys. Oceanogr., 44, 149-163.

PERMOS, 2013: Permafrost in Switzerland: 2008/2009 and 2009/2010. Glaciological Report (Permafrost) No. 10/11, Cryospheric Commission of the Swiss Academy of Sciences, 80 pp. [Available online at http://www.permos.ch /downloads/permos08-10.pdf.]

Perovich, D. K., S. Gerland, S. Hendricks, W. Meier, M. Nicolaus, J. Richter-Menge, and M. Tschudi, 2013: Sea ice. Arctic Report Card: Update for 2013, M. O. Jeffries et al., Eds., NOAA Rep., 38 - 43. [Available online at http://www.arctic.noaa.gov/reportcard/sea_ice.html.]

Peterson, T. C., and R. S. Vose, 1997: An overview of the Global Historical Climatology Network temperature database. Bull. Amer. Meteor. Soc., 78, 2837-2849.

—, R. Vautard, T. R. McVicar, J. N. Thépaut, and P. Berrisford, 2011: [Global climate] Surface winds over land [in "State of the Climate in 2010"]. Bull. Amer. Meteor. Soc., 92 (6), S57.

Pickart, R. S., M. A. Spall, G. W. K. Moore, T. J. Weingartner, R. A. Woodgate, K. Aagaard, and K. Shimada, 2011: Upwelling in the Alaskan Beaufort Sea: Atmospheric forcing and local versus non-local response. Prog. Oceanogr., 88, 78-100.

—, L. M. Schulze, G. W. K. Moore, M. A. Charette, K. R. Arrigo, G. van Dijken, and S. L. Danielson, 2013: Long-term trends of upwelling and impacts on primary productivity in the Alaskan Beaufort Sea. Deep Sea Res. Part I., 79, 106-121.

Pinty, B., 2012: [Global climate] Land surface albedo [in "State of the Climate in 2011"]. Bull. Amer. Meteor. Soc., 93 (7), S52-S53.

- I. Andredakis, M. Clerici, T. Kaminski, M. Taberner, M. M. Verstraete, N. Gobron, and J.-L. Widlowski, 2011a: Exploiting the MODIS albedos with the Two-stream Inversion Package (JRC-TIP) Part I: Effective leaf area index, vegetation and soil properties. J. Geophys. Res., 116, D09105, doi:10.1029/2010JD015372. 
- - and Coauthors, 2011b: Exploiting the MODIS albedos with the Two-stream Inversion Package (JRC-TIP): 2. Fractions of transmitted and absorbed fluxes in the vegetation and soil layers. J. Geophys. Res., 116, D09106, doi:10.1029/2010JD015373.

Pitts, M. C., L. R. Poole, and L. W. Thomason, 2009: CALIPSO polar stratospheric cloud observations: Second-generation detection algorithm and composition discrimination. Atmos. Chem. Phys., 9, 7577-7589, doi:10.5194/acp-9-7577-2009.

Proshutinsky, A., and Coauthors, 2009: Beaufort Gyre freshwater reservoir: State and variability from observations. J. Geophys. Res., 114, C00A10, doi:10.1029/2008JC005104.

—-, and Coauthors, 2012: [The Arctic] Ocean [in "State of the Climate in 2011"]. Bull. Amer. Meteor. Soc., 93 (7), S142-S145.

Prowse, T., and Coauthors, 2011: Past and future changes in lake and river ice. Ambio, 40 (S1), 53-62.

Pryor, S. C., and Coauthors, 2009: Wind speed trends over the contiguous United States. J. Geophys. Res., 114, D14105, doi:10.1029/2008JD011416.

Pun, I.-F., I-I Lin, and M.-H. Lo, 2013: Recent increase in high tropical cyclone heat potential area in the Western North Pacific Ocean. Geophys. Res. Let., 40, 4680-4684, doi:10.1002/grl.50548.

— - — , and D.-S. Ko, 2014: New generation of satellitederived ocean thermal structure for the western North Pacific typhoon intensity forecasting. Prog. Oceanogr., 121, 109-124.

Purkey, S. G., and G. C. Johnson, 2013: Antarctic Bottom Water warming and freshening: Contributions to sea level rise, ocean freshwater budgets, and global heat gain. J. Climate, 26, 6105-6122.

Quinn, P. K., and Coauthors, 2008: Short-lived pollutants in the Arctic: their climate impact and possible mitigation strategies. Atmos. Chem. Phys., 8, 1723-1735.

Rabatel, A., A. Letréguilly, J.-P. Dedieu, and N. Eckert, 2013: Changes in glacier equilibrium-line altitude in the western Alps from 1984 to 2010: Evaluation by remote sensing and modeling of the morpho-topographic and climate controls. The Cryosphere, 7, 1455-1471, doi:10.5194 /tc-7-1455-2013.

Rabe, B., and Coauthors, 2014: Arctic Ocean basin liquid freshwater storage trend 1992-2012. Geophys. Res. Lett., 41, doi:10.1002/2013GL058121.

Raga, G. B., B. Bracamontes-Ceballos, L. Farfán, and R. Romero-Centeno, 2013: Landfalling tropical cyclones on the Pacific coast of Mexico: 1850-2010. Atmosfera, 26, 209-220.
Rahimzadeh, F., and M. Nasaji Zavareh, 2013: Effects of adjustment for non-climatic discontinuities on determination of temperature trends and variability over Iran. Int. J. Climatol., 34, 2079-2096, doi:10.1002/joc.3823.

Rayner, D., and Coauthors, 2010: Monitoring the Atlantic meridional overturning circulation. Deep-Sea Res. II, 58,1744-1753, doi:10.1016/j.dsr2.2010.10.056.

Rayner, N. A., D. E. Parker, E. B. Horton, C. K. Folland, L. V. Alexander, D. P. Rowell, E. C. Kent, and A. Kaplan, 2003: Global analyses of sea surface temperature, sea ice, and night marine air temperature since the late nineteenth century. J. Geophys. Res., 108 (D14), 4407, doi:10.1029/2002JD002670.

Reay, D. S., E. A. Davidson, K. A. Smith, P. Smith, J. M. Melillo, F. Dentener, and P. J. Crutzen, 2012: Global agriculture and nitrous oxide emissions. Nature Climate Change, 2, 410-416.

Ren, L., and S. Riser, 2010: Observations of decadal-scale salinity changes in the thermocline of the North Pacific Ocean. Deep-Sea Res. II, 57, 1161-1170.

Rennermalm, A. K., L. C. Smith, V. W. Chu, R. R. Forster, J. E. Box, and B. Hagedorn, 2012: Proglacial river stage, discharge, and temperature datasets from the Akuliarusiarsuup Kuua River northern tributary, Southwest Greenland, 2008-2011. Earth Sys. Sci. Data, 4, 1-12.

_- and Coauthors, 2013a: Understanding Greenland ice sheet hydrology using an integrated multi-scale approach. Environ. Res. Lett., 8, 015017.

—, L. C. Smith, V. W. Chu, J. E. Box, R. R. Forster, M. R. Van den Broeke, D. Van As, and S. E. Moustafa, 2013b: Evidence of meltwater retention within the Greenland ice sheet. The Cryosphere, 7, 1433-1445.

Reynolds, R. W., and D. B. Chelton, 2010: Comparisons of daily sea surface temperature analyses for 2007-08. J. Climate, 23, 3545-3562.

— N. N. A. Rayner, T. M. Smith, D. C. Stokes, and W. Wang, 2002: An improved in situ and satellite SST analysis for climate. J. Climate, 15, 1609-1625.

_- T. M. Smith, C. Liu, D. B. Chelton, K. S. Casey, and M. G. Schlax, 2007: Daily high-resolution-blended analyses for sea surface temperature. J. Climate, 20, 5473-5496. Rhein, M., and Coauthors, 2013: Observations: Ocean. Climate Change 2013: The Physical Science Basis, T. F. Stoker et al., Eds., Cambridge University Press, 255-315.

Richter-Menge, J. A., and S. L. Farrell, 2013: Arctic sea ice conditions in spring 2009-2013 prior to melt. Geophys. Res. Lett., 40, 5888-5893, doi:10.1002/2013GL058011.

Ricker, R., S. Hendricks, V. Helm, H. Skourup, and M. Davidson, 2014: Sensitivity of CryoSat-2 Arctic sea-ice volume trends on radar-waveform interpretation. Cryosphere Disc., 8, 1831-1871, doi:10.5194/tcd-8-1831-2014. 
Riddle, E., M. Stoner, N. Johnson, M. L'Heureux, D. Collins, and S. Feldstein, 2012: The impact of the MJO on clusters of wintertime circulation anomalies over the North American region. Climate Dyn., 40, 1749-1766, doi:10.1007/s00382-012-1493-y.

Rienecker, M. M., and Coauthors, 2011: MERRA: NASA's Modern-Era Retrospective Analysis for Research and Applications. J. Climate, 24, 3624-3648.

Rignot, E., S. Jacobs, J. Mouginot, and B. Scheuchl, 2013: Iceshelf melting around Antarctica. Science, 341, 266-270, doi:10.1126/science.1235798.

Robock, A., 1983: Ice and snow feedbacks and the latitudinal and seasonal distribution of climate sensitivity. J. Atmos. Sci., 40, 986-977.

Rodell, M., and J. S. Famiglietti, 2001: An analysis of terrestrial water storage variations in Illinois with implications for the Gravity Recovery and Climate Experiment (GRACE). Water Resour. Res., 37, 1327-1340.

_, I. Velicogna, and J. S. Famiglietti, 2009: Satellite-based estimates of groundwater depletion in India. Nature, 460, 999-1002, doi:10.1038/460789a.

Roemmich, D., and J. Gilson, 2009: The 2004-2008 mean and annual cycle of temperature, salinity, and steric height in the global ocean from the Argo Program. Progr. Oceanogr., 82, 81-100, doi:10.1016/j.pocean.2009.03.004. — , and - 2011: The global ocean imprint of ENSO. Geophys. Res. Lett., 38, L13606, doi:10.1029/2011GL047992.

— the global ocean with profiling floats. Oceanography, 22 (2), 34-43, doi:10.5670/oceanog.2009.36.

Romanovsky, V. E., S. L. Smith, and H. H. Christiansen, 2010a: Permafrost thermal state in the polar Northern Hemisphere during the International Polar Year 20072009: A synthesis. Permafrost Periglacial Processes, 21, 106-116.

— , and Coauthors, 2010b: Thermal state of permafrost in Russia. Permafrost Periglacial Processes, 21,136-155.

—, N. Oberman, D. Drozdov, G. Malkova , A. Kholodov, S. Marchenko, 2012: Permafrost [in "State of the Climate in 2010”]. Bull. Amer. Meteor. Soc., 93 (7), S137-S138.

—, S. L. Smith, H. H. Christiansen, N. I. Shiklomanov, D. S. Drozdov, N. G. Oberman, A. L. Kholodov, and S. S. Marchenko, 2013a: Permafrost. Arctic Report Card 2013, M. O. Jeffries et al., Eds., NOAA Rep., 132-136.

—, A. L. Kholodov, S. L. Smith, H. H. Christiansen, N. I. Shiklomanov, D. S. Drozdov, N. G. Oberman, and S. S. Marchenko, 2013b: [Arctic] Permafrost [in "State of the Climate in 2012”]. Bull. Amer. Meteor. Soc., 94 (8), S123S124.

Rossow, W. B., and R. A. Schiffer, 1999: Advances in understanding clouds from ISCCP. Bull. Amer. Meteor. Soc., 80, 2261-2288.
Roundy, P. E., 2012: Observed structure of convectively coupled waves as a function of equivalent depth: Kelvin waves and the Madden Julian oscillation. J. Atmos. Sci., 69, 2097-2106.

Roy, D. P., and Coauthors, 2014: Landsat-8: Science and product vision for terrestrial global change research. Remote Sens. Environ., 145, 154-172.

Rudolf, B., and F. Rubel, 2005: Global precipitation. Observed Global Climate, Landolt-Börnstein Numer. Data Funct. Relat. New Ser. Vol. 6, M. Hantel et al., Eds., Springer, 11.1- 11.53.

Saatchi, S. S., and Coauthors, 2011: Benchmark map of forest carbon stocks in tropical regions across three continents. Proc. Natl. Acad. Sci. USA, 108, 9899-9904.

Sabine, C. L., and R. A. Feely, 2007: The oceanic sink for carbon dioxide. Greenhouse Gas Sinks, D. Reay et al., Eds., CABI Publishing, 31-49.

— , and T. Tanhua, 2010: Estimation of anthropogenic CO2 inventories in the ocean. Ann. Rev. Marine Sci., 2, 175-198, doi:10.1146/annurev-marine-120308-080947.

Saha, S., and Coauthors, 2010: The NCEP climate forecast system reanalysis. Bull. Amer. Meteor. Soc., 91, 1015-1057. Santana-Casiano, J. M., M. González-Dávila, M. J. Rueda, O. Llinas, and E. F. González-Dávila, 2007: The interannual variability of oceanic $\mathrm{CO} 2$ parameters in the northeast Atlantic subtropical gyre at the ESTOC site. Global Biogeochem. Cycles, 21, GB1015, doi:10.1029/2006GB002788.

Santoro, M., C. Beer, O. Cartus, C. Schmullius, A. Shvidenko, I. McCallum, U. Wegmüller, and A. Wiesmann, 2011: Retrieval of growing stock volume in boreal forest using hyper-temporal series of Envisat ASAR ScanSAR backscatter measurements. Remote Sens. Environ., 115, 490-507.

_- and Coauthors, 2013: Estimates of forest growing stock volume for Sweden, Central Siberia and Québec using Envisat advanced synthetic aperture radar backscatter data. Remote Sens., 5, 4503-4532.

Sauvage, B., R. V. Martin, A. van Donkelaar, and J. R. Ziemke, 2007: Quantification of the factors controlling tropical tropospheric ozone and the South Atlantic maximum. J. Geophys. Res., 112, D11309, doi:10.1029/2006JD008008.

Scambos, T. A., T. M. Haran, and R. Massom, 2006: Validation of AVHRR and MODIS ice surface temperature products using in situ radiometers. Ann. Glaciol., 44, 345-351, doi:10.3189/172756406781811457.

_ - , M. Fahnestock, T. Painter, and J. Bohlander, 2007: MODIS-based Mosaic of Antarctica (MOA) data sets: continent-wide surface morphology and snow grain size. Remote Sens. Environ., 111, 242-257, doi:10.1016/j .rse/2006/12020. 
Schaaf, C. B., and Coauthors, 2002: First operational BRDF, albedo and nadir reflectance products from MODIS. Remote Sens. Environ., 83, 135-148.

Schanze, J. J., R. W. Schmitt, and L. L. Yu, 2010: The global oceanic freshwater cycle: A state-of-the-art quantification. J. Marine Res., 68, 569-595.

Schauffler, S. M., and Coauthors, 2003: Chlorine budget and partitioning during the Stratospheric Aerosol and Gas Experiment (SAGE) III Ozone Loss and Validation Experiment (SOLVE). J. Geophys. Res., 108 (D5), 4173, doi:10.1029/2001JD002040.

Schlesinger, M. E., and N. Ramankutty, 1994: An oscillation in the global climate system of period 65-70 years. Nature, 367, 723-726.

Schmidtko, S., G. C. Johnson, and J. M. Lyman, 2013: MIMOC: A global monthly isopycnal upper-ocean climatology with mixed layers. J. Geophys. Res. Oceans, 118, 1658-1672, doi:10.1002/jgrc.20122.

Schmitt, R., 2008: Salinity and the global water cycle. Oceanography, 21 (1), 12-19.

Schnadt Poberaj, C., J. Staehelin, and D. Brunner, 2011: Missing stratospheric ozone decrease at southern hemisphere middle latitudes after Mt. Pinatubo: A dynamical perspective. J. Atmos. Sci., 68, 1922-1945.

Schneider, U., T. Fuchs, A. Meyer-Christoffer, and B. Rudolf, 2008: Global precipitation analysis products of the GPCC. Deutscher Wetterdienst, 12 pp. [Available online at http:// gpcc.dwd.de.]

Schreck, C. J., and J. Molinari, 2011: Tropical cyclogenesis associated with Kelvin waves and the Madden-Julian oscillation. Mon. Wea. Rev., 139, 2723-2734.

Screen, J. A., 2013: Influence of Arctic sea ice on European summer precipitation. Environ. Res. Lett., 8, 044015, doi:10.1088/1748-9326/8/4/044015.

— , and I. Simmonds, 2010: The central role of diminishing sea ice in recent Arctic temperature amplification. Nature, 464, 1334-1337.

- , and - 2013: Exploring links between Arctic amplification and midlatitude weather. Geophys. Res. Lett., 40, 959-964, doi:10.1002/grl.50174.

Send, U., M. Lankhorst, and T. Kanzow, 2011: Observation of decadal change in the Atlantic meridional overturning circulation using 10 years of continuous transport data. Geophys. Res. Lett., 38, L24606, doi:10.1029/2011GL049801.

Seneviratne, S. I., T. Corti, E. L. Davin, M. Hirschi, E. B. Jaeger, I. Lehner, B. Orlowsky, and A. J. Teuling, 2010: Investigating soil moisture-climate interactions in a changing climate: A review. Earth-Sci. Rev., 99, 125-161.

Shadwick, E. H., H. Thomas, Y. Gratton, D. Leong, S. A. Moore, T. Papakyriakou, and A. E. F. Prowe, 2011: Export of Pacific carbon through the Arctic Archipelago to the North Atlantic. Cont. Shelf Res., 31, 806-816.
Sharkhuu, N., and A. Sharkhuu, 2012: Effects of climate warming and vegetation cover on permafrost of Mongolia. Eurasian Steppes: Ecological Problems and Livelihoods in a Changing World, M. J. A. Werger and M. A. van Staalduinen, Eds., Springer, 445-472.

Sharma, S., J. A. Ogren, A. Jefferson, K. Eleftheriadis, E. Chan, P. K. Quinn, and J. F. Burkhart, 2013: Black carbon. Arctic Report Card: Update for 2013, M. O. Jeffries et al., Eds., NOAA Rep., 30-36. [Available online at http:// www.arctic.noaa.gov/reportcard/black_carbon.html.]

Sharp, M., D. O. Burgess, J. G. Cogley, M. Ecclestone, C. Labine, and G. J. Wolken, 2011: Extreme melt on Canada's Arctic ice caps in the 21st century. Geophys. Res. Lett., 38, L11501, doi:10.1029/2011GL047381.

Shay, L. K., G. J. Goni, and P. G. Black, 2000: Effects of a warm oceanic feature on Hurricane Opal. Mon. Wea. Rev., 128, 1366-1383.

Shiklomanov, N. I., D. A. Streletskiy, and F. E. Nelson, 2012: Northern Hemisphere component of the global Circumpolar Active Layer Monitoring (CALM) program. Proc. 10th Int. Conf. on Permafrost, Vol. 1, Salekhard, Russia, 377-382.

Shindell, D., and G. Faluvegi, 2009: Climate response to regional radiative forcing during the twentieth century. Nature Geosci., 2, 294-300.

— near-term climate change and improving human health and food security. Science, 335, 183-189, doi:10.1126 /science.1210026.

Siegel, D. A., and B. A. Franz, 2010: Oceanography: A century of phytoplankton change. Nature, 466, 569-570.

_- and Coauthors, 2012: [Global oceans] Global ocean phytoplankton [in "State of the Climate in 2011"]. Bull. Amer. Meteor. Soc., 93 (7), S107-S110.

— , and Coauthors, 2013: Regional to global assessments of phytoplankton dynamics from the SeaWiFS mission. Remote Sens. Environ., 135, 77-91.

Sillmann, J., V. V. Kharin, F. W. Zwiers, X. Zhang, and D. Bronaugh, 2013: Climate extremes indices in the CMIP5 multimodel ensemble: Part 2. Future climate projections. J. Geophys. Res. Atmos., 118, 2473-2493, doi:10.1002/jgrd.50188.

Simmons, A., K. M. Willett, P. D. Jones, P. W. Thorne, and D. Dee, 2010: Low-frequency variations in surface atmospheric humidity, temperature and precipitation: Inferences from reanalyses and monthly gridded observational datasets. J. Geophys. Res., 115, D01110, doi:10.1029/2009JD012442.

Singh, O. P., T. M. Ali Khan, and S. Rahman, 2000: Changes in the frequency of tropical cyclones over the North Indian Ocean. Meteor. Atmos. Phys., 75, 11-20. 
Slade, S. A., and E. D. Maloney, 2013: An intraseasonal prediction model of Atlantic and East Pacific tropical cyclone genesis. Mon. Wea. Rev., 141, 1925-1942.

Smeed, D. A., and Coauthors, 2014: Observed decline of the Atlantic meridional overturning circulation 2004-2012. Ocean Sci., 10, 29-38, doi:10.5194/os-10-29-2014.

Smith, S., and J. Brown, 2009: Assessment of the status of the development of the standards for the Terrestrial Essential Climate Variables - T7 - Permafrost and seasonally frozen ground, Global Terrestrial Observing System, Rome, 24 pp. [Available online at http://library.arcticportal .org/668/1/T07.pdf.]

—, V. E. Romanovsky, A. G. Lewkowicz, C. R. Burn, M. Allard, G. D. Clow, K. Yoshikawa, and J. Throop, 2010: Thermal state of permafrost in North America - A contribution to the International Polar Year. Permafrost Periglacial Processes, 21,117-135.

_ , J. Throop, and A. G. Lewkowicz, 2012: Recent changes in climate and permafrost temperatures at forested and polar desert sites in northern Canada. Can. J. Earth Sci., 49, 914-924.

Smith, T. M., and R. W. Reynolds, 1998: A high-resolution global sea surface temperature climatology for the 1961-90 base period. J. Climate, 11, 3320-3323.

—, and —_, 2005: A global merged land air and sea surface temperature reconstruction based on historical observations (1880-1997). J. Climate, 18, 2021-2036.

,-- , T. C. Peterson, and J. Lawrimore, 2008: Improvements to NOAA's historical merged land-ocean surface temperature analysis (1880-2006). J. Climate, 21, 2283-2296.

Sobel, A. H., and D. Kim, 2012: The MJO-Kelvin wave transition. Geophys. Res. Lett., 39, L20808, doi:10.1029/2012GL053380.

Sofieva, V. F., and Coauthors, 2013: Harmonized dataset of ozone profiles from satellite limb and occultation measurements. Earth Syst. Sci. Data, 5, 349-363, doi:10.5194 lessd-5-349-2013.

Solberg, S., R. Astrup, J. Breidenbach, B. Nilsen, and D. Weydahl, 2013: Monitoring spruce volume and biomass with InSAR data from TanDEM-X. Remote Sens. Environ., 139, 60-67.

Solomon, S., J. S. Daniel, R. R. Neely III, J.-P. Vernier, E. G. Dutton, and L. W. Thomason, 2011: The persistently variable "background" stratospheric aerosol layer and global climate change. Science, 333, 866-870.

Srokosz, M., M. Baringer, H. Bryden, S. Cunningham, T. Delworth, S. Lozier, J. Marotzke, and R. Sutton, 2012: Past, present and future change in the Atlantic meridional overturning circulation. Bull. Amer. Meteor. Soc., 93, 1663-1676.
Stackhouse, P. W., Jr., D. P. Kratz, G. R. McGarragh, S. K. Gupta, and E. B. Geier, 2006: Fast Longwave and Shortwave Radiative Flux (FLASHFlux) products from CERES and MODIS measurements. Proc. 12th Conf. Atmospheric Radiation, Madison, WI, Amer. Meteor. Soc., P1.10. [Available online at http://ams.confex.com/ams /pdfpapers/113479.pdf.]

Stammerjohn, S. E., D. G. Martinson, R. C. Smith, X. Yuan, and D. Rind, 2008: Trends in Antarctic annual sea ice retreat and advance and their relation to El Niño-Southern Oscillation and Southern Annular Mode variability. J. Geophys. Res., 113, C03S90, doi:10.1029/2007JC004269.

Steinacher, M., F. Joos, T. L. Frölicher, G.-K. Plattner, and S. C. Doney, 2009: Imminent ocean acidification in the Arctic projected with the NCAR global coupled carbon cycle-climate model. Biogeosciences, 6, 515-533.

Steinbrecht, W., and Coauthors, 2009: Ozone and temperature trends in the upper stratosphere at five stations of the network for the detection of atmospheric composition change. Int. J. Remote Sens., 30, 3875-3886, doi:10.1080/01431160902821841.

— , U. Köhler, H. Claude, M. Weber, J. P. Burrows, and R. J. van der A, 2011: Very high ozone columns at northern mid-latitudes in 2010. Geophys. Res. Lett., 38, L06803, doi:10.1029/2010GL046634.

Stephenson, T. S., and Coauthors, 2014: Changes in extreme temperature and precipitation in the Caribbean region, 1961-2010. Int. J. Climatol., in press, doi:10.1002/joc.3889.

Stolarski, R. S., and S. M. Frith, 2006: Search for evidence of trend slow-down in the long-term TOMS/SBUV total ozone data record: The importance of instrument drift uncertainty and fingerprint detection. Atmos. Chem. Phys., 6, 4057-4065, doi:10.5194/acp-6-4057-2006.

Stone, R. S., 1997: Variations in western Arctic temperature in response to cloud radiative and synoptic-scale influences. J. Geophys. Res., 102 (D18), 21 769-21 776.

Straneo, F., and P. Heimbach, 2013: North Atlantic warming and the retreat of Greenland's outlet glaciers. Nature, 504, 36-43, doi:10.1038/nature12854.

Straub, K. H., G. N. Kiladis, and P. E. Ciesielski, 2006: The role of equatorial waves in the onset of theSouth China Sea summer monsoon and the demise of El Niño during 1998. Dyn. Atmos. Oceans, 42, 216-238, doi:10.1016/j .dynatmoce.2006.02.005.

Stroeve, J. C., M. C. Serreze, M. M. Holland, J. E. Kay, J. Maslanik, and A. P. Barrett, 2012: The Arctic's rapidly shrinking sea ice cover: A research synthesis. Climatic Change, 110, 1005-1027, doi:10.1007/s10584-011-0101-1. 
Surdu, C., C. R. Duguay, L. C. Brown, and D. Fernández Prieto, 2014: Response of ice cover on shallow lakes of the North Slope of Alaska to contemporary climate conditions (1950-2011): Radar remote sensing and numerical modeling data analysis. The Cryosphere, 8, 167-180.

Svoboda, M., and Coauthors, 2002: The U.S. Drought Monitor. Bull. Amer. Meteor. Soc., 83, 1181-1190.

Takahashi, T., and Coauthors, 2009: Climatological mean and decadal change in surface ocean $\mathrm{pCO}_{2}$, and net seaair $\mathrm{CO}_{2}$ flux over the global oceans. Deep-Sea Res. II, 56, 554-577.

—, S. C. Sutherland, and A. Kozyr, 2013: Global ocean surface water partial pressure of $\mathrm{CO}_{2}$ database: Measurements performed during 1957-2012 (Version 2012). ORNL/CDIAC-160, NDP-088(V2012), Carbon Dioxide Information Analysis Center, Oak Ridge, TN, digital media. [Available online at doi:10.3334/CDIAC/OTG .NDP088(V2012).]

Takata, K., S. Emori, and T. Watanabe, 2003: Development of the minimal advanced treatments of surface interaction and runoff. Global Planet. Change, 38, 209-222, doi:10.1016/S0921-8181(03)00030-4.

Tang, Q., X. Zhang, X. Yang, and J. A. Francis, 2013a: Cold winter extremes in northern continents linked to Arctic sea ice loss. Environ. Res. Lett., 8, 014036, doi:10.1088/1748-9326/8/1/014036.

— - , and J. A. Francis, 2013b: Extreme summer weather in northern mid-latitudes linked to a vanishing cryosphere. Nature Climate Change, 4, 45-50, doi:10.1038 /nclimate2065.

Tanskanen, A., and Coauthors, 2007: Validation of daily erythemal doses from Ozone Monitoring Instrument with ground-based UV measurement data. J. Geophys. Res., 112, D24S44, doi:10.1029/2007JD008830.

Tapley, B. D., S. Bettadpur, J. C. Ries, P. F. Thompson, and M. M. Watkins, 2004: GRACE measurements of mass variability in the Earth system. Science, 305, 503-505.

Taylor, C. M., R. A. M. De Jeu, F. Guichard, P. P. Harris, and W. A. Dorigo, 2012: Afternoon rain more likely over drier soils. Nature, 489, 282-286.

Tedesco, M., X. Fettweis, M. R. van den Broeke, R. S. W. van de Wal, C. J. P. P. Smeets, W. J. van de Berg, M. C. Serreze, and J. E. Box, 2011: The role of albedo and accumulation in the 2010 melting record in Greenland. Environ. Res. Lett., 6, 014005, doi:10.1088/1748-9326/6/1/014005.

— , and Coauthors, 2013a: Greenland ice sheet. Arctic Report Card: Update for 2013, M. O. Jeffries et al., Eds., NOAA Rep., 115-125. [Available online at http://www .arctic.noaa.gov/reportcard.]
—, X. Fettweis, T. Mote, J. Wahr, P. Alexander, J. E. Box, and B. Wouters, 2013b: Evidence and analysis of 2012 Greenland records from spaceborne observations, a regional climate model and reanalysis data. The Cryosphere, 7, 615-630, doi:10.5194/tc-7-615-2013.

- , and Coauthors, 2013c: [Arctic] Greenland ice sheet [in "State of the Climate in 2012"]. Bull. Amer. Meteor. Soc., 94 (8), S121-S123.

Teng, W.-H., C.-Y. Huang, S.-P. Ho, Y.-H. Kuo, and X.-J. Zhou, 2013: Characteristics of global precipitable water in ENSO events revealed by COSMIC measurements. J. Geophys. Res. Atmos., 118, 8411-8425, doi:10.1002/ jgrd.50371.

Thompson, D. W., and J. M. Wallace, 2001: Regional climate impacts of the Northern Hemisphere annular mode. Science, 293, 85-89, doi:10.1126/science.1058958.

Thorne, P. W., D. E. Parker, S. F. B. Tett, P. D. Jones, M. McCarthy, H. Coleman, and P. Brohan, 2005: Revisiting radiosonde upper-air temperatures from 1958 to 2002. J. Geophys. Res., 110, D18105, doi:10.1029/2004JD005753. Thurner, M., and Coauthors, 2014: Carbon stock and density of northern boreal and temperate forests. Global Ecol. Biogeogr., 23, 297-310, doi:10.1111/geb.12125.

Timmermans, M.-L., and Coauthors, 2013a: Ocean temperature and salinity. Arctic Report Card, Update for 2013, M. O. Jeffries et al., Eds., NOAA Rep., 44-49. [Available online at http://www.arctic.noaa.gov/reportcard /ocean_temperature_salinity.html.]

— , and Coauthors, 2013b: [The Arctic] Ocean temperature and salinity [in "State of the Climate in 2012"]. Bull. Amer. Meteor. Soc., 94 (8), S128-S130.

Tiwari, V. M., J. Wahr, and S. Swenson, 2009: Dwindling groundwater resources in northern India, from satellite gravity observations. Geophys. Res. Lett., 36, L18401, doi:10.1029/2009GL039401.

Tokinaga, H., and S.-P. Xie, 2011: Wave- and anemometerbased seas surface wind (WASWind) for climate change analysis. J. Climate, 24, 267-285.

Trenberth, K. E., and J. T. Fasullo, 2013: An apparent hiatus in global warming? Earth's Future, 1, 19-32, doi:10.1002/2013EF000165.

Troccoli, A., K. Muller, P. Coppin, R. Davy, C. Russell, and A. L. Hirsch, 2012: Long-term wind speed trends over Australia. J. Climate, 25, 170-183.

Trofimov, A., and R. Ingvaldsen, 2014: Hydrography. Survey report from the joint Norwegian/Russian ecosystem survey in the Barents Sea August-October 2013, E. Eriksen, Ed., IMR/PINRO Joint Rep. Ser. [Available online at https://www.imr.no/filarkiv/2014/02/3_1_hydrography_ survey_report_2013.pdf/nn-no.] 
Tschudi, M. A., C. Fowler, J. A. Maslanik, and J. A. Stroeve, 2010: Tracking the movement and changing surface characteristics of Arctic sea ice. IEEE J. Selected Topics in Earth Obs. Rem. Sens., 3, 536-540, doi:10.1109 /JSTARS.2010.2048305.

Turner, J., and Coauthors, 2009: Record low surface air temperature at Vostok station, Antarctica. J. Geophys. Res., 114, D24102, doi:10.1029/2009JD012104.

Twomey, S., 1977: The influence of pollution on the shortwave albedo of clouds. J. Atmos. Sci., 34, 1149-1152.

UNEP, 2013: Drawing Down $\mathrm{N}_{2} \mathrm{O}$ : To Protect Climate and the Ozone Layer. United Nations Environment Programme, 57 pp. [Available online at http://www.unep.org/pdf /UNEPN2Oreport.pdf.]

van de Wal, R. S. W., W. Greuell, M. R. van den Broeke, C.H. Reijmer, and J. Oerlemans, 2005: Surface mass-balance observations and automatic weather station data along a transect near Kangerlussuaq, West Greenland. Ann. Glaciol., 42, 311-316.

_ - W. Boot, C. J. P. P. Smeets, H. Snellen, M. R. van den Broeke, and J. Oerlemans, 2012: Twenty-one years of mass balance observations along the K-transect, West Greenland. Earth Sys. Sci. Data, 5, 351-363, doi:10.5194/ essdd-5-351-2012.

van der A, R. J., M. A. F. Allaart, and H. J. Eskes, 2010: Multi sensor reanalysis of total ozone. Atmos. Chem. Phys., 10, 11277-11294, doi:10.5194/acp-10-11277-2010.

van der Schrier, G., J. Barichivich, K. R. Briffa, and P. D. Jones, 2013: A scPDSI-based global dataset of dry and wet spells for 1901-2009. J. Geophys. Res. Atmos., 118, 4025-4048, doi:10.1002/jgrd.50355.

van der Werf, G. R., and Coauthors, 2010: Global fire emissions and the contribution of deforestation, savanna, forest, agricultural, and peat fires (1997-2009). Atmos. Chem. Phys., 10, 11707-11735, doi:10.5194/acp-10-11707-2010.

van Dijk, A. I. J. M., H. E. Beck, R. S. Crosbie, R. A. M. de Jeu, Y. Y. Liu, G. M. Podger, B. Timbal, and N. R. Viney, 2013: The Millennium Drought in southeast Australia (2001-2009): Natural and human causes and implications for water resources, ecosystems, economy, and society. Water Resour. Res., 49, 1040-1057.

Vautard, R., J. Cattiaux, P. Yiou, J.-N. Thépaut, and P. Ciais, 2010: Northern Hemisphere atmospheric stilling partly attributed to increased surface roughness. Nature Geosci., 3, 756-761.

— , T. R. McVicar, J. N. Thépaut, and M. L. Roderick, 2012: [Global climate] Land surface winds and atmospheric evaporative demand [in "State of the Climate in 2011"]. Bull. Amer. Meteor. Soc., 93 (7), S36-S38.
Velicogna, I., and J. Wahr, 2013: Time-variable gravity observations of ice sheet mass balance: Precision and limitations of the GRACE satellite data. Geophys. Res. Lett., 40, 3055-3063, doi:10.1002/grl.50527.

Ventrice, M. J., C. D. Thorncroft, and M. A. Janiga, 2012a: Atlantic tropical cyclogenesis: A three-way interaction between an African easterly wave, diurnally varying convection, and a convectively coupled atmospheric Kelvin wave. Mon. Wea. Rev., 140, 1108-1124.

- - — , and C. J. Schreck, 2012b: Impacts of convectively coupled Kelvin waves on environmental conditions for Atlantic tropical cyclogenesis. Mon. Wea. Rev., 140, 2198-2214.

Vernier, J.-P., and Coauthors, 2011: Major influence of tropical volcanic eruptions on the stratospheric aerosol layer during the last decade. Geophys. Res. Lett.. 38, L12807, doi:10.1029/2011GL047563.

Von Storch, H., and F. W. Zwiers, 1999: Statistical Analysis in Climate Research. Cambridge University Press, 484 pp. Voss, K. A., J. S. Famiglietti, M. Lo, C. de Linage, M. Rodell, and S. C. Swenson, 2013: Groundwater depletion in the Middle East from GRACE with implications for transboundary water management in the Tigris-EuphratesWestern Iran region. Water Resour. Res., 49, 904-914, doi:10.1002/wrcr.20078.

Voulgarakis, A., N. H. Savage, O. Wild, P. Braesicke, P. J. Young, G. D. Carver, and J. A. Pyle, 2010: Interannual variability of tropospheric composition: the influence of changes in emissions, meteorology and clouds. Atmos. Chem. Phys., 10, 2491-2506, doi:10.5194/acp-10-2491 -2010 .

—, P. Hadjinicolaou, and J. A. Pyle, 2011: Increases in global tropospheric ozone following an El Nino event: Examining stratospheric ozone variability as a potential driver. Atmos. Sci. Lett., 112, 228-232.

Waliser, D. E., and C. Gautier, 1993: A satellite-derived climatology of the ITCZ. J. Cimate, 6, 2162-2174.

Wan, Z., Y. L. Zhang, Q. C. Zhang, and Z. L. Li, 2002: Validation of the land-surface temperature products retrieved from Terra Moderate Resolution Spectroradiometer data. Remote Sens. Environ., 83, 163-180, doi:10.1016/S0034 -4257(02)00093-7.

Wang, B., and Q. Ding, 2008: Global monsoon: The dominant mode of the annual variations of the global tropical precipitation and circulation. Dyn. Atmos. Oceans, 44, 165-183, doi:10.1016/j.dynatmoce.2007.05.002.

—, J. Liu, H. J. Kim, P. J. Webster, and S. Y. Yim, 2012: Recent change of the global monsoon precipitation (1979-2008). Climate Dyn., 39, 1123-1135, doi:10.1007 /s00382-011-1266-z. 
Wang, C., and D. B. Enfield, 2001: The tropical Western Hemisphere warm pool. Geophys. Res. Lett., 28, 16351638.

—, and — 2003: A further study of the tropical Western Hemisphere warm pool. J. Climate, 16, 1476-1493.

_ _ _ - S.-K. Lee, and C. W. Landsea, 2006: Influences of the Atlantic warm pool on Western Hemisphere summer rainfall and Atlantic hurricanes. J. Climate, 19, 3011-3028.

—, S.-K. Lee, and D. B. Enfield, 2008a: Climate response to anomalously large and small Atlantic warm pools during the summer. J. Climate, 21, 2437-2450.

,$- \ldots$, and _- 2008b: Atlantic warm pool acting as a link between Atlantic multidecadal oscillation and Atlantic tropical cyclone activity. Geochem. Geophys. Geosyst., 9, Q05V03, doi:10.1029/2007GC001809.

—, S. Dong, and E. Munoz, 2010: Seawater density variations in the North Atlantic and the Atlantic meridional overturning circulation. Climate Dyn., 34, 953-968, doi:10.1007/s00382-009-0560-5.

_- H. Liu, S.-K. Lee, and R. Atlas, 2011: Impact of the Atlantic warm pool on United States landfalling hurricanes. Geophys. Res. Lett., 38, L19702, doi:10.1029/2011GL049265.

Wang, J., L. Zhang, A. Dai, T. Van Hove, and J. Van Baelen, 2007: A near-global, 8-year, 2-hourly atmospheric precipitable water dataset from ground-based GPS measurements. J. Geophys. Res., 112, D11107, doi:10.1029/2006JD007529.

Wang, L., and H. Liu, 2013: [Antarctica] 2011/2012 Seasonal melt extent and duration [in "State of the Climate in 2012”]. Bull. Amer. Meteor. Soc., 94 (8), S139-S141.

Wang, X., and J. R. Key, 2005: Arctic surface, cloud, and radiation properties based on the AVHRR Polar Pathfinder dataset. Part I: Spatial and temporal characteristics. J. Climate, 18, 2558-2574.

Wanninkhof, R., W. E. Asher, D. T. Ho, C. S. Sweeney, and W. R. McGillis, 2009: Advances in quantifying air-sea gas exchange and environmental forcing. Ann. Rev. Marine Sci., 1, 213-244, doi:10:1146/annurev.marine.010908.163742.

—, S. C. Doney, J. L. Bullister, N. M. Levine, M. Warner, and N. Gruber, 2010: Detecting anthropogenic CO2 changes in the interior Atlantic Ocean between 1989 and 2005. J. Geophys. Res., 115, C11028, doi:10.1029/2010JC006251.

— - and Coauthors, 2013: Global ocean carbon uptake: Magnitude, variability, and trends. Biogeosciences, 10, 1983-2000, doi:10.5194/bg-10-1983-2013.

Warren, S., and W. Wiscombe, 1980: A model for the spectral albedo of snow. II: Snow containing atmospheric aerosols. J. Atmos. Sci., 37, 2734-2745.
Watanabe, S., S. Kanae, S. Seto, P. J.-F. Yeh, Y. Hirabayashi, and T. Oki, 2012: Intercomparison of bias-correction methods for monthly temperature and precipitation simulated by multiple climate models. J. Geophys. Res., 117, D23114, doi:10.1029/2012JD018192.

Weatherhead, B., A. Tanskanen, and A. Stevermer, 2005: Ozone and ultraviolet radiation. Arctic Climate Impact Assessment, Cambridge University Press, 151-182. [Available online at http://www.acia.uaf.edu/PDFs/ACIA _Science_Chapters_Final/ACIA_Ch05_Final.pdf.]

Weber, M., S. Dikty, J. P. Burrows, H. Garny, M. Dameris, A. Kubin, J. Abalichin, and U. Langematz, 2011: The BrewerDobson circulation and total ozone from seasonal to decadal time scales. Atmos. Chem. Phys., 11, 11 221-11235, doi:10.5194/acp-11-11221-2011.

Wentz, F. J., 1997: A well calibrated ocean algorithm for special sensor microwave/imager. J. Geophys. Res., 102 (C4), 8703-8718.

—, L. Ricciardulli, K. A. Hilburn, and C. A. Mears, 2007: How much more rain will global warming bring? Science, 317, 233-235.

WGMS, 2013: Glacier Mass Balance Bulletin No. 12 (20102011). World Glacier Monitoring Service, 106 pp.

Wheeler, M., and G. N. Kiladis, 1999: Convectively coupled equatorial waves: Analysis of clouds and temperature in the wavenumber-frequency domain. J. Atmos. Sci., 56, 374-399.

_- and K. M. Weickmann, 2001: Real-time monitoring and prediction of modes of coherent synoptic to intraseasonal tropical variability. Mon. Wea. Rev., 129, 2677-2694.

WHO, 2002: Global Solar UV Index: A Practical Guide. World Health Organization, 28 pp. [Available online at http:// www.who.int/uv/publications/en/GlobalUVI.pdf.]

Wielicki, B. A., and Coauthors, 1998: Clouds and the Earth's Radiant Energy System (CERES): Algorithm overview. IEEE Trans. Geosci. Remote Sens., 36, 1127-1141.

Wild, J. D., C. S. Long, P. K. Barthia, and R. D. McPeters, 2012: Constructing a long-term ozone climate data set (1979-2010) from V8.6 SBUV/2 profiles. Quadrennial Ozone Symposium 2012, Toronto, Ontario, Canada, Abstract 6071. [Available online at http://larss.science.yorku .ca/QOS2012pdf/6071.pdf.]

Wild, M., 2009a: Global dimming and brightening: A review. J. Geophys. Res., 114, D00D16, doi:10.1029/2008JD011470. _ , 2009b: How well do IPCC-AR4/CMIP3 climate models simulate global dimming/brightening and twentiethcentury daytime and nighttime warming? J. Geophys. Res., 114, D00D11, doi:10.1029/2008JD011372.

_ 2012: Enlightening global dimming and brightening. Bull. Amer. Meteor. Soc., 93, 27-37. 
Willett, K. M., P. D. Jones, N. P. Gillett, and P. W. Thorne, 2008: Recent changes in surface humidity: Development of the HadCRUH dataset. J. Climate, 21, 5364-5383.

— D. I. Berry, and A. Simmons, 2013: [Global climate] Surface humidity [in "State of the Climate in 2012"] Bull. Amer. Meteor. Soc., 94 (8), S18-S19.

Willis, J. K., 2010: Can in situ floats and satellite altimeters detect long-term changes in Atlantic Ocean overturning? Geophys. Res. Lett., 37, L06602, doi:10.1029/2010GL042372. _ , and L.-L. Fu, 2008: Combining altimeter and subsurface float data to estimate the time-averaged circulation in the upper ocean. J. Geophys. Res., 113, C12017, doi:10.1029/2007JC004690.

_, D. Roemmich, and B. Cornuelle, 2004: Interannual variability in upper ocean heat content, temperature, and thermosteric expansion on global scales. J. Geophys. Res., 109, C12036, doi:10.1029/2003JC002260.

WMO, 1999: Scientific Assessment of Ozone Depletion: 1998. Global Ozone Research Monitoring Project-Rep. No. 44, World Meteorological Organization, various paging. [Available online at http://www.esrl.noaa.gov/csd /assessments/ozone/1998/.]

— 2012: Tropical cyclone operational plan for the south-west Indian Ocean. WMO/TD-No. 577, World Meteorological Organization, 58 pp. [Available online at http://www.wmo.int/pages/prog/www/tcp/documents /TCP-12-WMO-TD-577-rev-2012_121495_en.pdf.]

- , 2014: WMO statement on the status of the global climate in 2013. WMO-No. 1130, World Meteorological Organization, 24 pp. [Available online at http://library .wmo.int/opac/index.php?lvl=notice_display\&id=15957.]

Wolter, K., and M. S. Timlin, 1998: Measuring the strength of ENSO events - how does 1997/98 rank? Weather, 53, 315-324.

Woodgate, R. A., K. Aagaard, and T. J. Weingartner, 2005: Monthly temperature, salinity, and transport variability of the Bering Strait through flow. Geophys. Res. Lett., 32 , L04601, doi:10.1029/2004GL021880.

—, T. J. Weingartner, and R. Lindsay, 2012: Observed increases in Bering Strait oceanic fluxes from the Pacific to the Arctic from 2001 to 2011 and their impacts on the Arctic Ocean water column. Geophys. Res. Lett., 39, L24603, doi:10.1029/2012GL054092.

Worden, H. M., and Coauthors, 2013: Decadal record of satellite carbon monoxide observations. Atmos. Chem. Phys., 13, 837-850, doi:10.5194/acp-13-837-2013.

World Glacier Monitoring Service, cited 2014: Preliminary glacier mass balance data for 2011/2012. [Available online at http:/www.geo.uzh.ch/microsite/wgms/mbb/sum12 .html.]
Wovrosh, A. J., S. S. Barreira, R. L. Fogt, and T. Scambos, 2013: [Antarctica] Circulation [in "State of The Climate in 2012"]. Bull. Amer. Meteor. Soc., 94 (8), S133-S135.

Wylie, D. P., D. L. Jackson, W. P. Menzel, and J. J. Bates, 2005 : Global cloud cover trends inferred from two decades of HIRS observations. J. Climate, 18, 3021-3031.

Wyrtki, K., 1981: An estimate of equatorial upwelling in the Pacific. J. Phys. Oceanogr., 11, 1205-1214.

Xie, P., and P. A. Arkin, 1997: Global precipitation: A 17-Year monthly analysis based on gauge observations, satellite estimates and numerical model outputs. Bull. Amer. Meteor. Soc., 78, 2539-2558.

Yamamoto-Kawai, M., F. A. McLaughlin, E. C. Carmack, S. Nishino, and K. Shimada, 2009: Aragonite undersaturation in the Arctic Ocean: Effects of ocean acidification and sea ice melt. Science, 326, 1098-1100.

,-- , and $\_, 2013$ : Ocean acidification in the three oceans surrounding northern North America. J. Geophys. Res., 118, 6274-6284, doi:10.1002/2013JC009157.

Yim, S.-Y., B. Wang, J. Liu, and Z. W. Wu, 2013: A comparison of regional monsoon variability using monsoon indices. Climate Dyn., Open Access, doi:10.1007/s00382-013 -1956-9.

Young, P. J., and Coauthors, 2013: Pre-industrial to end 21st century projections of tropospheric ozone from the Atmospheric Chemistry and Climate Model Intercomparison Project (ACCMIP). Atmos. Chem. Phys., 13, 2063-2090, doi:10.5194/acp-13-2063-2013.

Yu, L., 2011: A global relationship between the ocean water cycle and near-surface salinity. J. Geophys. Res., 116, C10025, doi:10.1029/2010JC006937.

_ , and X. Jin, 2012: Buoy perspective of a high-resolution global ocean vector wind analysis constructed from passive radiometers and active scatterometers (1987-present). J. Geophys. Res., 117, C11013, doi:10.1029/2012JC008069. _ and R. A. Weller, 2007: Objectively Analyzed air-sea heat Fluxes (OAFlux) for the global ocean. Bull. Amer. Meteor. Soc., 88, 527-539.

_ - J. Xin, and R. A. Weller, 2008: Multidecade global flux datasets from the Objectively Analyzed Air-sea Fluxes (OAFlux) Project: Latent and sensible heat fluxes, ocean evaporation, and related surface meteorological variables. OAFlux Project Tech. Rep. OA-2008-01, 64 pp.

Zhang, C., 2005: Madden-Julian oscillation. Rev. Geophys., 43, 1-36.

— the Madden Julian oscillation in the equatorial Pacific. J. Climate, 15, 2429-2445.

Zhang, X., and J. A. Church, 2012: Sea level trends, interannual and decadal variability in the Pacific Ocean. Geophys. Res. Lett., 39, L21701, doi:10.1029/2012GL053240. 
—, L. Alexander, G. C. Hegerl, P. Jones, A. Klein Tank, T. C. Peterson, B. Trewin, and F. W. Zwiers, 2011: Indices for monitoring changes in extremes based on daily temperature and precipitation data. WIREs Climate Change, 2, 851-870, doi:10.1002/wcc.147.

Zhao, L., Q. Wu, S. S. Marchenko, and N. Sharkhuu, 2010: Thermal state of permafrost and active layer in Central Asia during the International Polar Year. Permafrost Periglacial Processes, 21, 198-207.

—, R. Li, Y. J. Ding, Y. Xiao, L. C. Sun, Y. Liu, 2011: Soil thermal regime in Qinghai-Tibet Plateau and its adjacent regions during 1977-2006. Adv. Climate Change Res., 7, 307-316.

Zhou, C.-Z., and W. Wang, 2010: Stability of the MSUderived atmospheric temperature trend. J. Atmos. Oceanic Technol., 27, 1960-1971.

Ziemke, J. R., S. Chandra, B. N. Duncan, L. Froidevaux, P. K. Bhartia, P. F. Levelt, and J. W. Waters, 2006: Tropospheric ozone determined from Aura OMI and MLS: Evaluation of measurements and comparison with the Global Modeling Initiative's chemical transport model. J. Geophys. Res., 111, D19303, doi:10.1029/2006JD007089.

_- S. Chandra, G. J. Labow, P. K. Bhartia, L. Froidevaux, and J. C. Witte, 2011: A global climatology of tropospheric and stratospheric ozone derived from Aura OMI and MLS measurements. Atmos. Chem. Phys., 11, 9237-9251.

Zwally, H. J., and S. Fiegles, 1994: Extent and duration of Antarctic surface melting. J. Glaciol., 40, 463-476. 


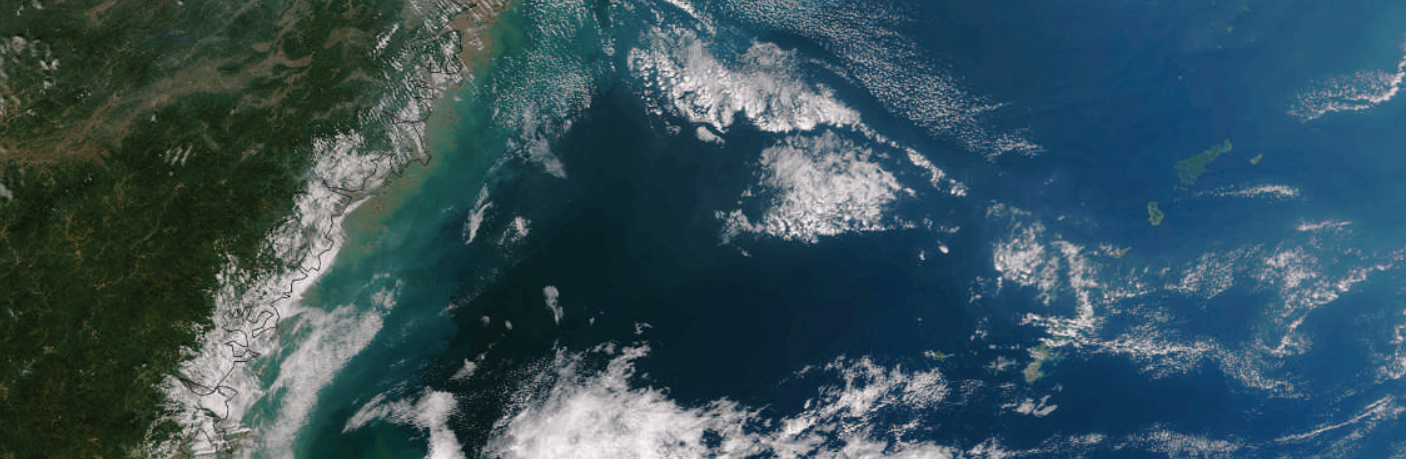

4ho (1)

(11)

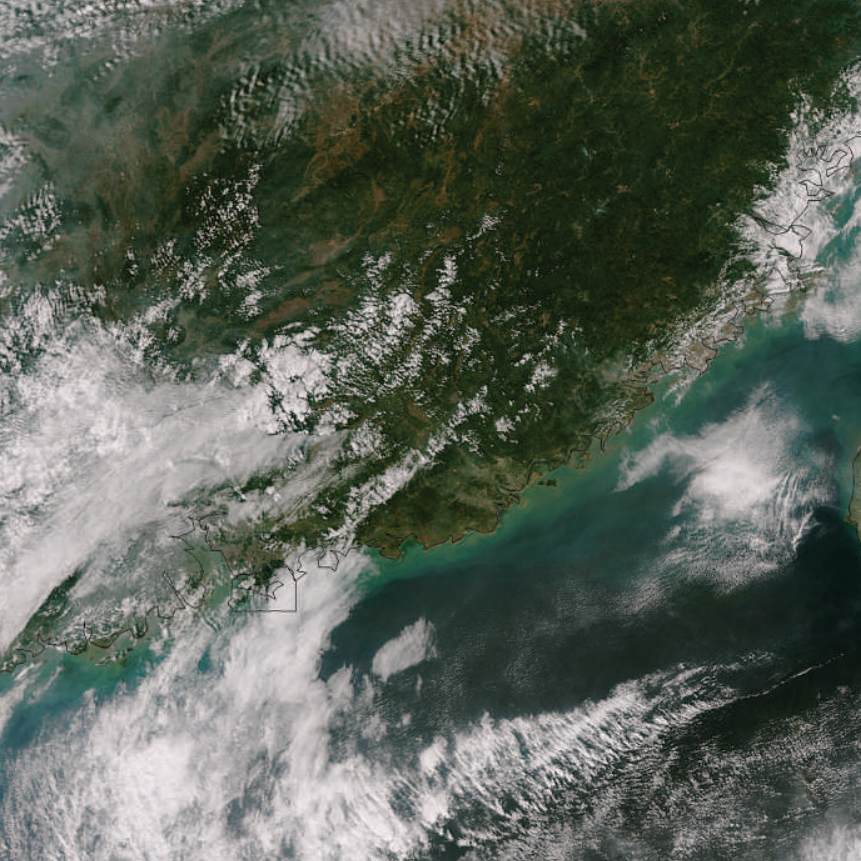

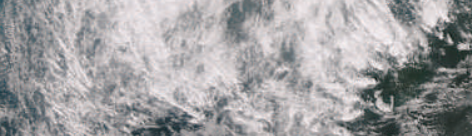
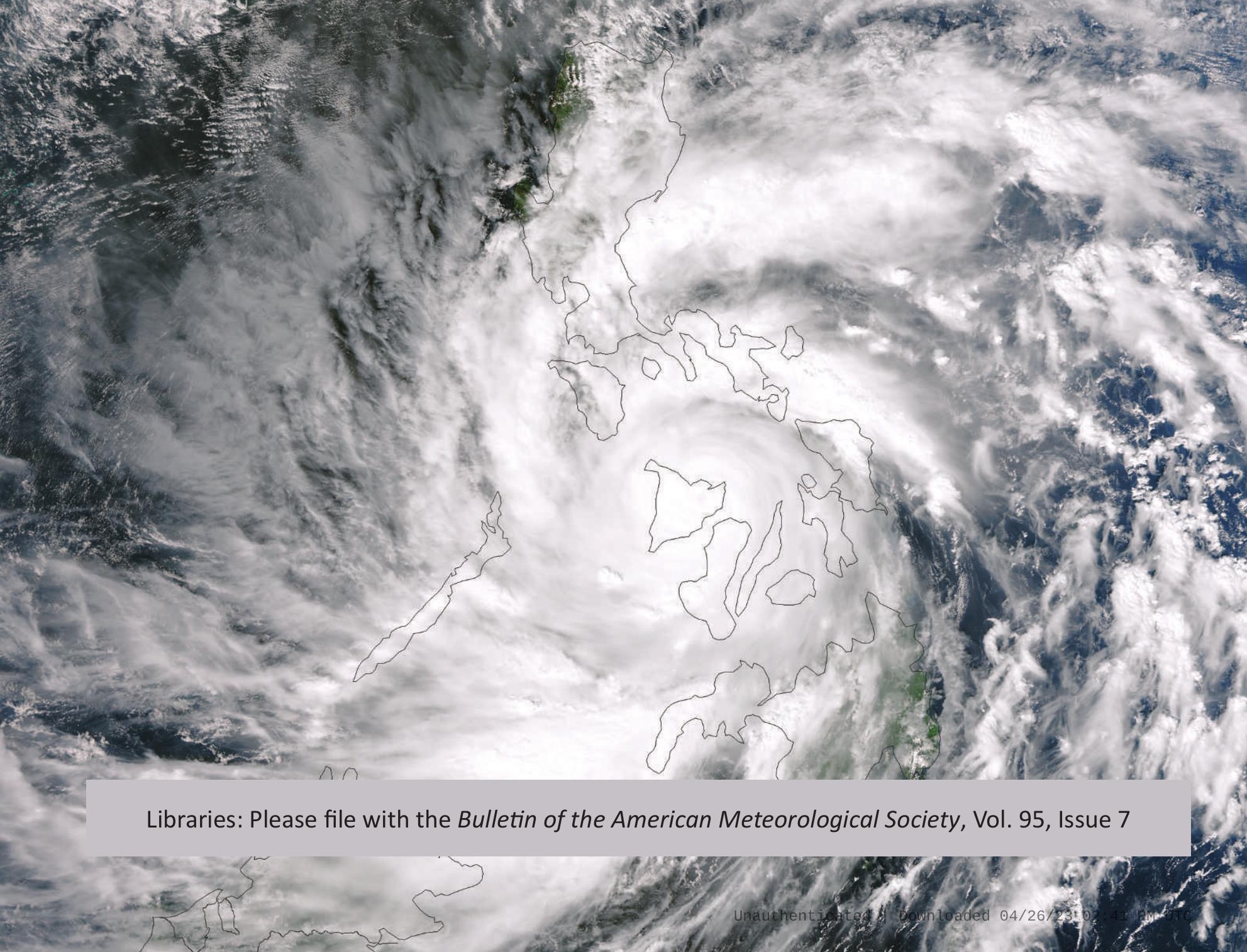